\title{
Extracorporeal membrane oxygenation support in complex clinical scenarios of refractory cardiogenic shock in adults
}

Citation for published version (APA):

Kowalewski, M. (2021). Extracorporeal membrane oxygenation support in complex clinical scenarios of refractory cardiogenic shock in adults. [Doctoral Thesis, Maastricht University]. Maastricht University. https://doi.org/10.26481/dis.20210920mk

Document status and date:

Published: 01/01/2021

DOI:

10.26481/dis.20210920mk

Document Version:

Publisher's PDF, also known as Version of record

Please check the document version of this publication:

- A submitted manuscript is the version of the article upon submission and before peer-review. There can be important differences between the submitted version and the official published version of record.

People interested in the research are advised to contact the author for the final version of the publication, or visit the DOI to the publisher's website.

- The final author version and the galley proof are versions of the publication after peer review.

- The final published version features the final layout of the paper including the volume, issue and page numbers.

Link to publication

\footnotetext{
General rights rights.

- You may freely distribute the URL identifying the publication in the public portal. please follow below link for the End User Agreement:

www.umlib.nl/taverne-license

Take down policy

If you believe that this document breaches copyright please contact us at:

repository@maastrichtuniversity.nl

providing details and we will investigate your claim.
}

Copyright and moral rights for the publications made accessible in the public portal are retained by the authors and/or other copyright owners and it is a condition of accessing publications that users recognise and abide by the legal requirements associated with these

- Users may download and print one copy of any publication from the public portal for the purpose of private study or research.

- You may not further distribute the material or use it for any profit-making activity or commercial gain

If the publication is distributed under the terms of Article $25 \mathrm{fa}$ of the Dutch Copyright Act, indicated by the "Taverne" license above, 


\section{Extracorporeal Membrane Oxygenation Support in Complex Clinical Scenarios of Refractory Cardiogenic Shock in Adults}

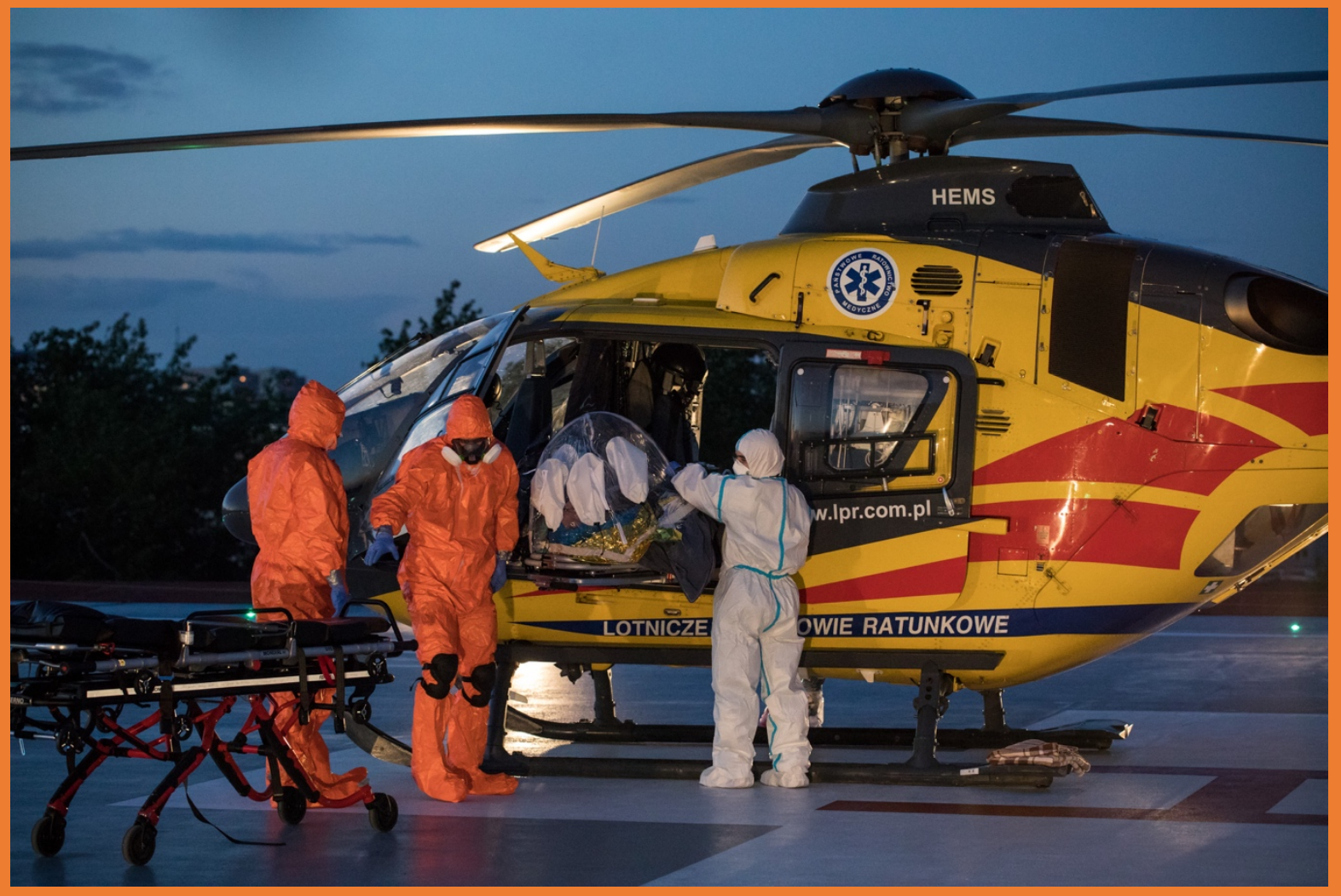

Mariusz Kowalewski, MD 
Extracorporeal Membrane Oxygenation Support in Complex Clinical Scenarios of Refractory Cardiogenic Shock in Adults

\section{Mariusz Kowalewski}

Maastricht University Medical Center 
๑) copyright Mariusz Kowalewski

Printing:

Lay-out: Mariusz Kowalewski

ISBN 


\title{
Extracorporeal Membrane Oxygenation Support
}

\author{
in Complex Clinical Scenarios
}

of Refractory Cardiogenic Shock

in Adults

\author{
DISSERTATION \\ to obtain the degree of Doctor at Maastricht University, \\ on the authority of the Rector Magnificus, Prof. Dr. Rianne M. Letschert \\ in accordance with the decision of the Board of Deans, \\ to be defended in public \\ on $20^{\text {th }}$ September 2021
}

10:00

by

Mariusz Kowalewski 


\section{Promotors}

Prof. dr. Roberto Lorusso

Prof. dr. Jos G. Maessen

Co-Promotor

Dr. Elham Bidar

Assessment committee

Prof. dr. Iwan C.C. van de Horst (Chair)

Prof. Dr. Filip De Somer (Gent, Belgium)

Prof. Dr. Udo Boeken (Dusseldorf, Germany)

Prof. Dr. Walther N.K.A. van Mook

Financial support by the Dutch Heart Foundation for the publication of this thesis is gratefully acknowledged 


\section{CONTENTS}

Page

Chapter 1. Introduction and Outline of the Thesis

List of Abbreviations

Chapter 2. Mortality Predictors in the Elderly with Cardiogenic Shock on Veno-

Arterial Extracorporeal Life Support

Chapter 3. Left Ventricle Unloading with Veno-Arterial Extracorporeal

Membrane Oxygenation for Cardiogenic Shock. Systematic Review and MetaAnalysis

Chapter 4. Baseline surgical status and short-term mortality after

extracorporeal membrane oxygenation for post-cardiotomy shock: A metaanalysis.

Chapter 5. Veno-Arterial Extracorporeal Membrane Oxygenation for PostCardiotomy Shock.

Chapter 6 . The impact of centre's heart transplant status and volume on inhospital outcomes following extracorporeal membrane oxygenation for refractory post-cardiotomy cardiogenic shock: a meta-analysis

Chapter 7. Cardiogenic shock and veno-arterial ECLS in heart transplantation/VAD centres as compared to non-transplant/vad units. metaanalysis.

Chapter 8. General Discussion

Valorization

Summary

294

Samenvatting

298

Acknowledgements

303

About the author

List of publications 


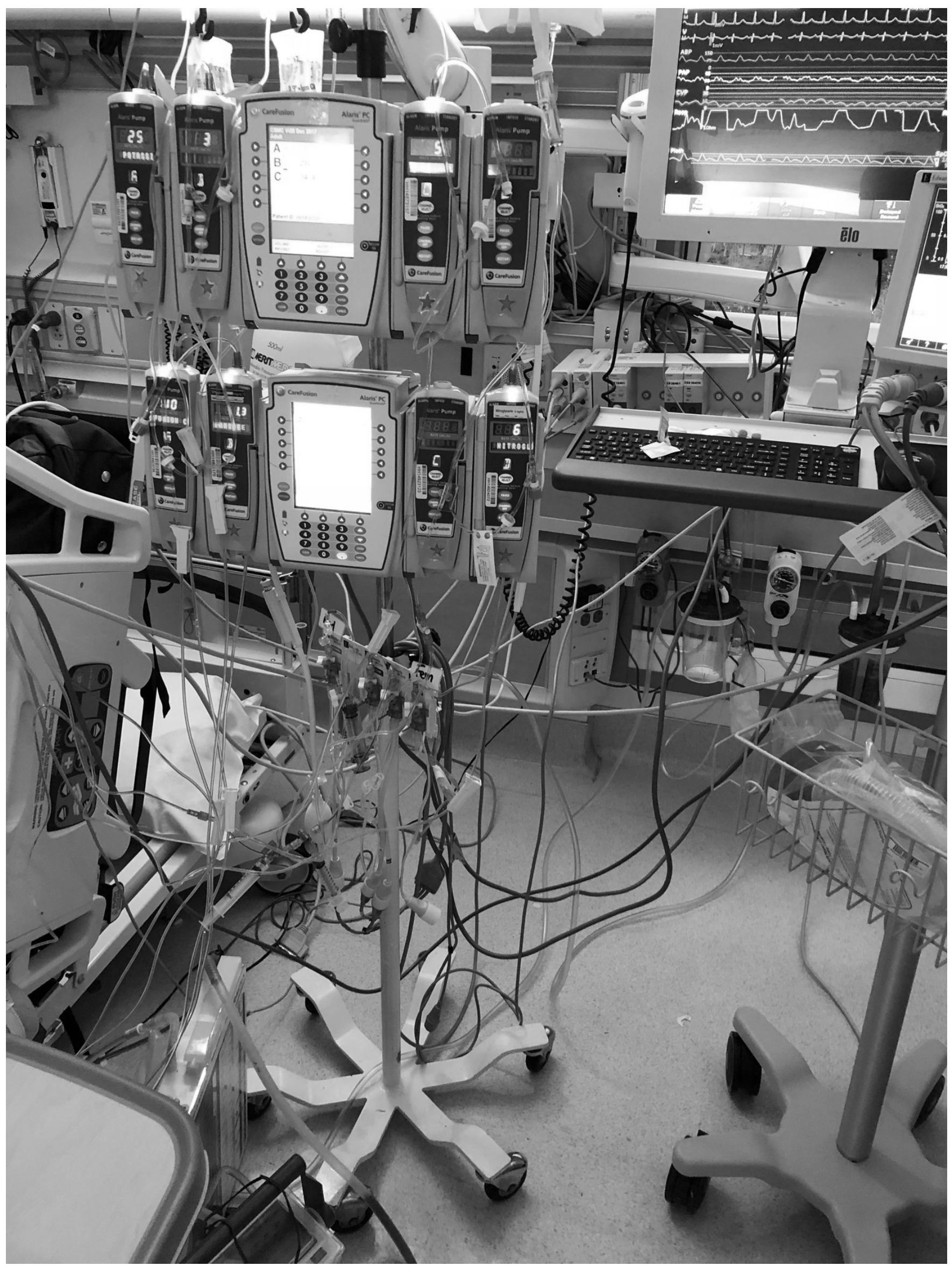


CHAPTER 1

GENERAL INTRODUCTION 


\section{List of Abbreviations}

$\mathrm{ECMO}=$ extracorporeal membrane oxygenation

$\mathrm{V}-\mathrm{V}=$ veno-venous

$\mathrm{V}-\mathrm{A}=$ veno-arterial

$\mathrm{PC}=$ post cardiotomy

$\mathrm{VAD}=$ ventricular assist device

ELSO $=$ Extracorporeal Life Support Organization

$\mathrm{AMI}=$ acute myocardial infarction

$\mathrm{LV}=$ left ventricle

$\mathrm{LA}=$ left atrium

$\mathrm{CABG}=$ coronary artery bypass grafting

$\mathrm{Htx}=$ heart transplantation

LVAD = left ventricle assist device

$\mathrm{RCS}=$ refractory cardiogenic shock

$\mathrm{RV}=$ right ventricle

RVAD = right ventricle assist device

$\mathrm{CPB}=$ cardiopulmonary bypass

LVEDP = left ventricle end-diastolic pressure

$\mathrm{IABP}=$ intra-aortic balloon pump

$I C U=$ intensive care unit

ECLS = extracorporeal life support

CNS = central nervous system

$E C P R=$ extracorporeal cardiopulmonary resuscitation

$\mathrm{TAVI}=$ transcatheter aortic valve implantation 


\section{Preface}

\section{Refractory cardiogenic shock}

Cardiogenic shock (CS) is the leading cause of mortality, and management remains challenging despite advances in therapeutic options. CS is a result of severe impairment of myocardial function that precedes lowered cardiac output, end-organ hypoperfusion, and global hypoxia [1]. Clinically, this presents as hypotension refractory to volume resuscitation with features of end-organ hypoperfusion requiring pharmacological or mechanical support [1]. Acute myocardial infarction (AMI) and its mechanical complications account for $81 \%$ of patients in CS [2]. Remaining causes may be cardiomyopathies, decompensated valvular heart diseases, cardiac tamponade, myocarditis and myocardial injury [3]. Heart surgery should be considered separately since postcardiotomy cardiogenic shock (PCS) may represent a combination of the above.

Exact definition of cardiogenic shock is not uniform neither in contemporary trials and guidelines, nor in clinical practice. In the SHOCK (Should We Emergently Revascularize Occluded Coronaries for Cardiogenic Shock) and IABP-SHOCK II trials, cardiogenic shock was defined as systolic blood pressure (SBP) measurements of $<90 \mathrm{~mm} \mathrm{Hg}$ for $\geq 30$ minutes or use of pharmacological and/or mechanical support to maintain an SBP $\geq 90 \mathrm{~mm} \mathrm{Hg}[4,5]$. Two large registries EHS-PCI (Euro Heart Survey Percutaneous Coronary Intervention Registry) [6] and KAMIR-NIH (Korean Acute Myocardial Infarction Registry-National Institutes of Health) [7] emphasized the role of collecting evidence of endorgan damage (altered mental status, urine output $<30 \mathrm{~mL} / \mathrm{h}$, or cool extremities) before the diagnosis is done. The SHOCK Trial included cardiac index $(\mathrm{Cl})$ of $\leq 2.2 \mathrm{~L} / \mathrm{min}$ per $\mathrm{m}^{2}$ and a pulmonary capillary 
wedge pressure (PCWP) of $\geq 15 \mathrm{~mm} \mathrm{Hg}$ [4] An SBP $<90 \mathrm{~mm} \mathrm{Hg}$ that is refractory to fluid resuscitation with clinical and laboratory evidence of end-organ dysfunction, in the setting of suspected cardiac dysfunction, is essential to the definition of CS. Latest European guidelines [8], in addition to the previous diagnostic criteria, look at clinical picture (cold extremities, oliguria, AMS, narrow pulse pressure) and laboratory tests (metabolic acidosis, elevated serum lactate, elevated serum creatinine) to define cardiogenic shock. Importantly, CS is a dynamic state extending from pre-shock to refractory shock states [9], which is influenced and potentially recolved by timely considerations of the required interventions.

Refractory cardiogenic shock (RCS) is a life-threatening condition often resulting from underlying cardiac or cardiopulmonary condition. Left untreated, it has an ominous prognosis. Since RCS is the leading cause of circulatory collapse, a circulatory support, and in particular, mechanical circulatory support (MCS), has been proposed as one modality of treatment. MCS encompasses a plethora of treatment approaches from short-term devices such as intra-aortic balloon-pump (IABP) or Impellaß to long-term assistance such as ventricle assist devices (VADs). Somewhere in between short- and longterm support lies extracorporeal membrane oxygenation (ECMO). Due to many possible configurations of ECMO circuit and also because it can be used in synergy with other MCSs, often allowing for resolving RCS regardless of underlying cause, ECMO is becoming used more frequently worldwide.

However, certain complications have been unbreakably associated with ECMO therapy such as bleeding, cerebrovascular accidents and, as consequence, multiorgan failure together leading to high mortality rates in ECMO patients. However, ECMO is characterized by several major complications 
such as bleeding, CVA, acidosis, vasoplegia and infection limiting its prolong use. On the other hand, patients with RCS and without MCS would inevitably die which puts ECMO therapy in an ethical dilemma context as well.

Refractory cardiogenic shock is a multilevel entity with heterogeneous etiology; therefore, varying mortality rates from report to report are not surprising. Due to a wide heterogeneity in the underlying pathology and comorbidity profile of the patients with RCS, the mortality and complciaitons rate are widely ranging in the literature. However, the indications for ECMO have changed over time, and so have the patients' risk profiles with high risk patients being candidate for ECMO therapy and referred more willingly and more promptly by the physicians. This has led to the fact that mortality rates vary even more.

The aim of the current series of studies in this PhD dissertation was to identify the predictors of mortality and factors associated with improved and worsened results in adult patients undergoing contemporary ECMO therapy in complex clinical scenarios of refractory cardiogenic shock.

\section{Mechanical circulatory support}

While inotropic agents are the mainstay of therapy for hypotension and, thus, are widely used in cardiogenic shock, the mortality is higher with an increased number of prescribed inotropes/vasopressors [10,11]. The use of catecholamines in CS is further limited in arrhythmias, increased myocardial oxygen consumption, and inadequate circulatory support [12]. MCS devices 
(Table 1) on the other hand offer significant advantages over vasopressor therapy, including substantial, often superior, cardiovascular support without increased risk of myocardial ischemia and possible decreased myocardial oxygen demand [13]. Some of them offer left ventricle (LV) unloading, lowering both the preload and afterload, particularly beneficial to impaired myocardium and reducing the risk of $L V$ distension and thrombosis. Accordingly, large registry data have clearly demonstrated an association between early MCS application and improved survival [11]. Thus, prompt use of support devices remains an important therapeutic modality.

\section{Types of MCS}

Acute percutaneous MCS include intraaortic baloonpumt (IABP), axial flow pumps (Impella®) left atrialto-femoral arterial ventricular assist devices (Tandem Heart) and veno-arterial extracorporeal membrane oxygenation (V-A ECMO). Table 1.

Table 1. Mechanical Circulatory Support Devices and characteristics.

\begin{tabular}{|c|c|c|c|c|}
\hline & $\begin{array}{l}\text { Intra-aortic Balloon } \\
\text { Pump }\end{array}$ & Impella ${ }^{\circledR}$ & TandemHeart@ & V-A ECMO \\
\hline Cardiac flow & $0.3-0.5 \mathrm{~L} / \mathrm{min}$ & 1-5L/min & $2.5-5 \mathrm{~L} / \mathrm{min}$ & 3-7L/min \\
\hline Flow direction & unchanged & LV->Ao & $L A->A_{0}$ & $\mathrm{RA}->\mathrm{A}_{0}$ \\
\hline $\begin{array}{l}\text { Synchronizatio } \\
\text { n with cardiac } \\
\text { rhythm }\end{array}$ & Yes & No & No & No \\
\hline Preload & unchanged & $\downarrow \downarrow$ & $\downarrow \downarrow$ & $\downarrow$ \\
\hline Afterload & $\downarrow$ & $\downarrow$ & $\uparrow$ & $\uparrow \uparrow \uparrow$ \\
\hline $\begin{array}{l}\text { Coronary } \\
\text { perfusion }\end{array}$ & $\uparrow$ & $\uparrow$ & unchanged & unchanged \\
\hline MAP & $\uparrow \uparrow$ & $\uparrow \uparrow$ & $\uparrow \uparrow$ & $\uparrow \uparrow$ \\
\hline
\end{tabular}




\begin{tabular}{|c|c|c|c|c|}
\hline Cardiac Flow & $\uparrow$ & $\uparrow \uparrow$ & $\uparrow \uparrow$ & $\uparrow \uparrow$ \\
\hline LVEDP & $\downarrow$ & $\downarrow \downarrow$ & $\downarrow \downarrow$ & unchanged \\
\hline $\begin{array}{l}\text { Oxygen } \\
\text { demand }\end{array}$ & $\downarrow$ & $\downarrow \downarrow$ & unchanged & unchanged \\
\hline PCWP & $\downarrow$ & $\downarrow \downarrow$ & $\downarrow \downarrow$ & unchanged \\
\hline \multicolumn{5}{|c|}{$\begin{array}{l}\text { V-A ECMO, veno-arterial extracorporeal membrane oxygenation; LV, left ventricle; Ao, aorta; MAP, mean arterial } \\
\text { pressure; LVEDP, left ventricle end-diastolic pressure; PCWP, pulmonary capillary wedge pressure. Reproduced from: } \\
\text { Atkinson TM, Ohman EM, O'Neill WW, Rab T, Cigarroa JE, Interventional Scientific Council of the American College of } \\
\text { C. A practical approach to mechanical circulatory support in patients undergoing percutaneous coronary intervention: } \\
\text { An interventional perspective. JACC Cardiovasc Interv. 2016;9:871-883. }\end{array}$} \\
\hline
\end{tabular}

There are 3 circuit configurations for MCS devices-pumping from the (1) right atrium/central vein to a systemic artery, (2) left atrium to a systemic artery or (3) left ventricle to a systemic artery. Peak flow rates of available devices range from 2.5 to $7 \mathrm{~L} / \mathrm{min}[14]$.

\section{IABP}

Intra-aortic balloon pump (or contrapulsation balloon) was introduced over 50 years ago and remains most commonly employed support device used for therapy of cardiogenic shock. The IABP acts with several "indirect" mechanisms reducing both the LV afterload (enhanced systolic ejection) and the LV end-diastolic pressure (enhanced left atrial and pulmonary venous unloading). The IABP induces the aortic valve opening [15], improves coronary and abdominal circulation [16], allows pulsatility in end organ capillary bed [17] and modestly increase cardiac output $(0.8-1 \mathrm{~L} / \mathrm{min})$.(ref) It is easy to implant and has contained costs. It is inserted via an 8Fr sheath in either the femoral or axillary artery [18]. The IABP Shock II Trial included 600 patients with CS from AMI undergoing early revascularization and randomized them to IABP or optimal medical therapy [5]. None of the assessed indices were anyhow altered with either approach; no mortality benefit was seen at 30 days, 6 and 12 months; neither the quality of life was improved [19]. The results were postulated to be driven by the fact that that the IABP plays no role in myocardium salvage $[19,20]$. Yet, certain limitations, among them a large proportion of 
non-protocol cross-overs, operator dependent strategy of multivessel revascularization and not unified, often too late timing of MCS insertion must be acknowledged before interpreting these findings.

\section{Impella}

There are a number of devices designed to redirect the blood flow from LV to the aorta, of which most often employed during CS are different generations of Impella® devices (Table 1). These are axial flow pumps that are inserted to the common femoral artery and passed across the aortic valve into the LV. An axial rotor than ejects blood into the ascending aorta. Depending on the type, they achieve and maintain a cardiac output of 2.5 to $4 \mathrm{~L} / \mathrm{min}$ for The Impella 2.5 and Impella CP. The Impella 5.0 is a larger device that can achieve a cardiac output of $5 \mathrm{~L} / \mathrm{min}$, however, unlike the smaller versions which can be inserted percutaneously, the latter often requires a surgical approach to the femoral artery for a 22-Fr sheath. Another device, Impella RP is a right-sided device introduced via an $11 \mathrm{Fr}$ catheter that pumps blood from the inferior vena cava to the pulmonary artery and delivers a flow rate $>4 \mathrm{~L} / \mathrm{min}$ for a right sided assist. Impella offers continuous, unsynchronized blood flow resulting in the loss of the normal isovolumic periods. With increasing the flow, it progressively unloads the LV. The LV stroke volume progressively decreases as pump flow increases, thereby increasing the systemic blood pressure and reducing the LA and pulmonary capillary wedge pressures. Despite the fact that the aortic valve does not open with the application of the Impella device, there is no risk of blood stasis in the LV and the aortic root. The uncoupling of LV and aortic pressure is a sign of an effective unloading of the ventricle. In this situation a flat systemic pressure line is a sign of maximal unloading. Secondary changes in myocardial contractility and peripheral resistance may further enhance the LV unloading 
[14,21]. The Impella can also reduce RV afterload and facilitate RV output and pulmonary blood flow with improvement in gas exchange $[23,24]$. Impella use is contraindicated in moderate-to-severe aortic valve disease, mechanical aortic valve and severe peripheral arterial disease [13].

In the randomized PROTECT II Trial that focused on high-risk percutaneous coronary intervention (PCl) instead of cardiogenic shock, 452 symptomatic patients with complex 3-vessel disease or unprotected left main coronary artery disease and severely depressed left ventricular function were assigned to IABP or Impella 2.5 support during the procedure. Impella provided superior hemodynamic support compared with IABP as measured by cardiac power output (CPO).(ref) Importantly, while the incidence of major adverse events at 30 days was not statistically different between the two groups, the use of Impella was associated with redced rates of composite endpoint (all-cause death, MI, transient ischemic attack (TIA) or stroke, repeat revascularization procedure, need for a cardiac or a vascular operation, acute kidney failure (AKI), severe intraprocedural hypotension requiring therapy, cardiopulmonary resuscitation (CPR), ventricular tachycardia requiring cardioversion, aortic insufficiency and angiographic failure of $\mathrm{PCl}$ ) at 90 days. Evidence on effectiveness of Impella devices in cardiogenic shock come from The IMPRESS in Severe Shock (IMPella versus IABP Reduces mortality in STEMI patients treated with primary $\mathrm{PCl}$ in Severe cardiogenic Shock) trial [24]. It randomized 48 patients suffering acute MI with CS to either Impella CP or IABP. Study was inconclusive due to relatively small sample and similar, close to $50 \%$, mortality in both groups.

Regardless of the increasing use of MCS devices, The SHOCK [4], IABP-SHOCK II [5] and IMPRESS in Severe Shock [24] trials all showed $50 \%$ constant mortality over 6 to 12 months over last 20 years 
of experience. On the contrary, one recent analysis of the cVAD (Catheter-based Ventricular Assist Device) Registry indicated that early implantation of a MCS device before PCI $(p=0.04)$ and before requiring inotropes and vasopressors $(p=0.05)$ was associated with increased survival in multivariate analysis. Indeed, survival was $66 \%$ when MCS was initiated $<1.25$ hours from shock onset, $37 \%$ when initiated within 1.25 to 4.25 hours, and $26 \%$ when initiated after 4.25 hours $(p=0.017)$ [11]. After the Detroit Cardiogenic Shock Initiative has proposed the use of standardized protocols emphasizing early Impella use, a pilot study by the same group reported $76 \%$ survival to discharge with this approach [25].

\section{Tandem heart}

The Tandem Heart is a device redirecting cardiac blood flow from LA to arterial system. Traditionally, a cannula is passed into LA through femoral vein, RA and atrial septal puncture; LA blood is aspirated and directed into one or both femoral arteries [13]. Because LA is drained directly, this unloads the LV, resulting in decreased pulmonary capillary wedge pressure (PCWP) and left ventricle end diastolic pressure (LVEDP) [14]. A previous randomized study, showed that as compared with IABP, the TandemHeart percutaneous VAD achieved significantly greater increases in cardiac index and mean arterial blood pressure and significantly greater decreases in pulmonary capillary wedge pressure. Overall 30-day survival and severe adverse events were not significantly different between the 2 groups [26]. However, the main limitation to the widespread use of the Tandem Heart is that it requires transseptal puncture whih often translates into prolonged time from "door-to-LV unloading".

Veno-arterial extracorporeal membrane oxygenation (V-A ECMO) 
Veno-arterial extracorporeal membrane oxygenation (V-A ECMO) in its original configuration involves drainage of venous blood, passing it through an oxygenator membrane and returning the oxygenated blood to systemic circulation using a centrifugal pump. Its institution is achieved with cannulation of the right atrium and aorta in case of central cannulation as in post-cardiotomy setting. Alternatively, femoral vessels are cannulated to constitute peripheral ECMO. While peripheral ECMO can reduce LV preload, it increases afterload and this can cause increased ventricular wall tension due to retrograde flow [13]. ECMO has a complex and variable hemodynamic response. ECMO institution seemingly increases the left ventricle afterload with a rise in LV end-systolic volume and reduction in LV stroke volume. If peripheral resistance and LV contractility are fixed, increase in LV end-diastolic volume is the only way to overcome the afterload via the Frank-Starling mechanism. In this case, higher levels of VA-ECMO flow cause a progressive rise in LV end-diastolic pressure, LA pressure, PCWP, that are associated with a further reduced LV stroke volume $[13,27,28]$. High afterload situations with inability of LV to manage the transpulmonary blood flow, inadequate response to inotropes, complete cardiac arrest with incomplete venous drainage and aortic valve incompetenc is the common path towards LV distension and failure. Patients with severely impaired LV function and/or right ventricular dysfunction are more prone to develop an ineffective LV unloading [29].

LV overload increases wall stress, myocardial oxygen consumption and induces sub-endocardial ischemia and ventricular arrhythmias, jeopardizing ventricular recovery after entering this vicious circle. The consequence of the pressure overload may ultimately result in pulmonary congestion and edema. 
Due its importance in the chain of support in the ardiogenic shock, ECMO runs have increased steadily in the past 5-10 years. Up till 2013, ECMO had been used in $\approx 13000$ patients and its rate of survivalto-discharge was $39 \%$ when used in cardiac support [30]. The counts are increasing each year; the latest report from the Extracorporeal Life Support Organization (ELSO) Registry (www.elso.org) points to nearly 26.000 ECMO runs in adult cardiac setting with $59 \%$ survival. However, the disturbing absence of large RCTs of ECMO in patients with CS limits its use to refractory CS cases as a bridging therapy [13]. The bridging offered by ECMO are the following (Figure 1).

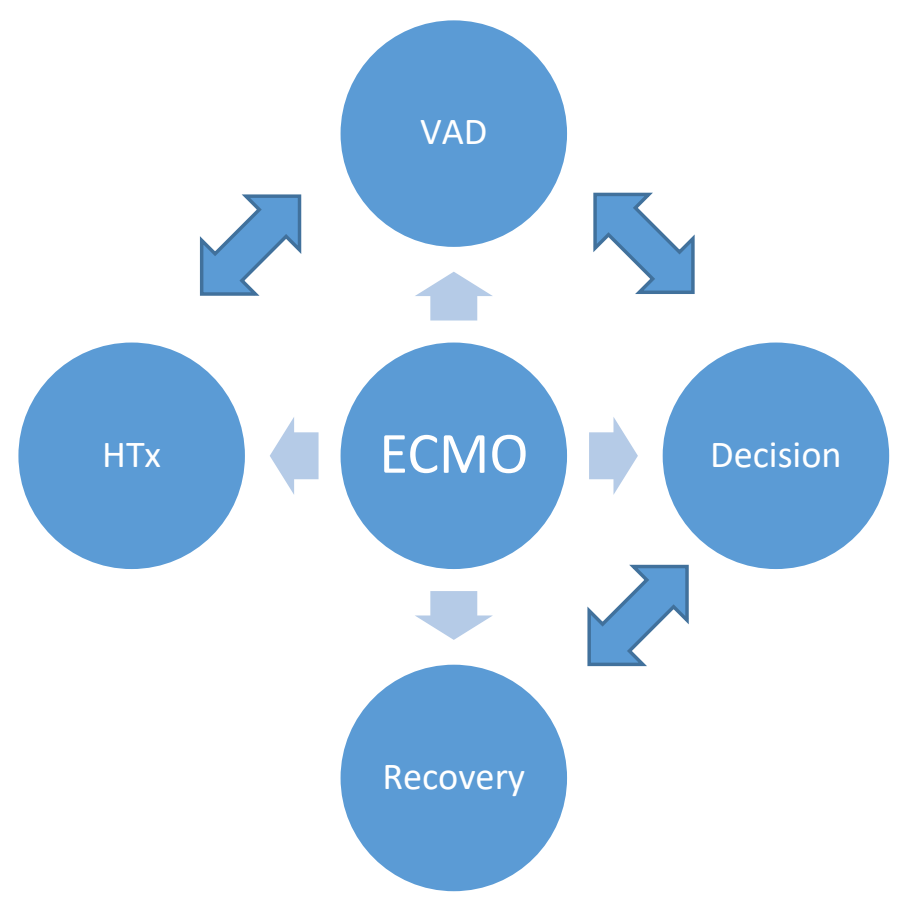

Figure 1. Decision flow diagram; ECMO, extracorporeal membrane oxygenation; $H T x$, heart transplantation; VAD, ventricle assist device.

Firstly, ECMO allows the vulnerable myocardium to recover in the setting of cardiogenic shock; if the time is enough, and the revascularization is performed either by $\mathrm{PCl}$ or coronary artery bypass grafting (CABG), ECMO may add to uneventful recovery. Even with limited resources and deteriorating patient, ECMO buys time to decision, whether to wait for recovery, bridge to more-durable support like VADs, 
bridge directly to heart transplantation, or quickly declaring the futility of ECMO in complex patients with limited or no indication for more advanced treatment in a timely manner and withdrawing the therapy. Transitioning to VAD support or heart transplantation listing from ECMO appears to improve in-hospital survival, as shown by Smedira and coworkers [31]. They found a $75 \%$ early survival rate in ECMO patients bridged to a VAD after a short ECMO run. Despite this apparent effectiveness, only $<20 \%$ of patients supported with ECMO transition to other support, that is, VAD or heart transplantation (range $0 \%-20 \%)$ totally dependent upon the suitability of the candidate for more durable therapies and the availability of hub-and-spoke networks allowing patient transfers to centers capable of these advanced heart failure options.

\section{Complications}

ECMO remains amongst most invasive and intensive therapies; occurrence of complications in ECMO patients is common and they frequently determine the final outcome [32]. The complications may occur already at the time of ECMO institution but their extent and gravidity depend highly on ECMO duration. ECMO as an accessory blood circuit deregulates the defense mechanisms in human body; the blood flow is continuous and retrograde instead of pulsatile and antegrade affecting brain-blood barrier and vasoactive properties of blood vessels. (ref) Exposure of blood to the artificial tubing system of ECMO circuit triggers a complex immune response affecting all metabolic pathways, and in particular, coagulation cascade. (ref) Therefore, to prevent clot formation in the tubing or oxygenator membrane, the ECMO necessitates systemic heparinization which adds to coagulopathies. Not surprising, bleeding represents the most frequent complication in ECMO, occurring in up to $90 \%$ of patients in some series 
$[33,34]$. The high risk of bleeding is further aggravated in cases of post-AMI and post-cardiotomy cardiogenic shock, resulting from antiplatelet therapy in the former and surgery-related bleeding in the latter. While some investigators advocate the avoidance of heparin infusion for the first 12-48 hours in ECMO $[35,36]$, heparin can be held for even longer periods $[37,38]$, or alternative anticoagulation e.g. bivalirudin [NCT03707418] used in high-risk patients. (ref)

Along with bleeding, there are additional adverse events whose rates are similar across ECMO settings with the exception of AMI and post-cardiotomy. Indeed, higher risk of complications in post-AMI and PC-ECMO often is a result of acute onset of cardiogenic shock, underlying comorbidities in these patients and the preceding cardiopulmonary bypass (CPB) run and the cardiac surgery.

Central nervous system (CNS) complications in V-A and V-V ECMO have recently been shown to occur in $15 \%$ and $7 \%$ of adult patients, respectively $[39,40]$. Since clearly associated with ominous prognosis, they are most feared. Indeed, in an analysis of 4,500 patients from the ELSO registry undergoing ECMO for several indications [39], hospital mortality in patients with CNS complications was $89 \%$, compared to $57 \%$ those without CNS $(p<0.001)$. In a multivariable model, age, pre-ECMO cardiac arrest, the use of inotropes on ECMO, and post-ECMO hypoglycemia were shown to be independently associated with CNS complications. In PC-ECMO, these rates appear to be much higher, accounting for up $30 \%$ of cases $[36,41-43]$ depending on pre-surgical condition, history of CNS accidents and surgical technique [44,45]. A high level of suspicion, appropriate and constant neuro-monitoring, and ECMO management modification [46] may influence the risk and rates of CNS complications. 
Acute kidney failure with or without the need for continuous renal replacement therapy (CRRT) poses a transient threat to most ECMO cases. One meta-analyses demonstrated a higher mortality and a longer ECMO duration corresponding with CRRT although the authors rightly pointed out that these findings were not based on RCTs[47] and therefor reflected, a relatively higher severity of illness in patients who received ECMO plus CRRT. For early initiation of CRRT to balance the fluid overload rather than evening the metabolic acidosis, the results are ambiguous [48].

Lastly, limb complications are strongly associated with circulation centralization in cardiogenic shock. The use of ECMO is exacerbating this problem, particularly in peripheral configuration. Although the use of ipsilateral additional DPC (distal perfusion cannula) reduces the risk for leg ischemia [49], delay in DPC placement, often triggers late signs of ischemia and may lead to a reperfusion injury and, ultimately, poor outcome [50]. To mitigate potential issues with cannula access site, femoral- but also axillary or carotid artery in case of femoral artery stenosis, can all be achieved by cannulating a Dacron or Hemashield prosthetic graft $(6-8 \mathrm{~mm})$, anastomosed end-to-side onto the artery of interest thus maintaining unobstructed arterial flow in both directions [36]. Figure 2.

\section{Configurations and hybrid cannulation}

Besides traditional ECMO cannulation approaches, including, certain changes in patients' conditions or the occurrence of particular complications (i.e., cerebral hypoxia or left ventricular dilation) may require alterations in cannulation strategies. Additionally a combination of ECMO with additional invasive or minimally invasive procedures, to improve organ function, distal perfusion and, thus, ECMO efficacy may be warranted. Prolonged ECMO support duration, in particular, for patients on transplant 
waiting lists but also those being bridged to long-term assist devices, has determined the need for technology development in order to ensure an adequate patient management and to reduce the risk of complications.

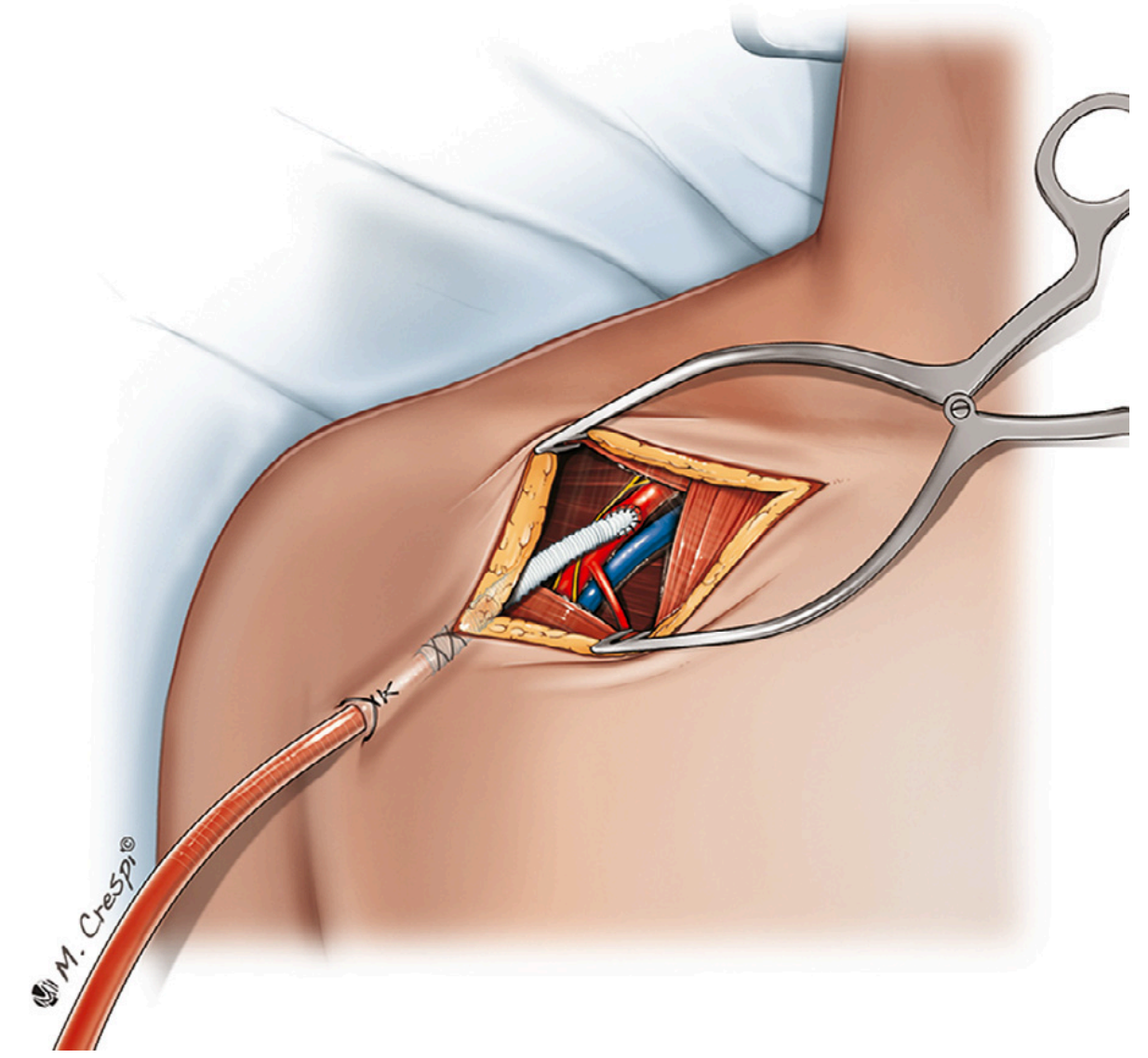

Figure 2. Cannulation of axillary artery for ECMO institution. Graft prosthesis is anastomosed end-to-side to the artery and cannulated to allow for unobstructed blood flow.

Notably, cannulation strategies evolved from original V-V and V-A configurations to so called "hybrid" ECMO configurations, employing third or fourth cannula to improve systemic oxygenation and/or cardiac unloading. ECMO configurations may further be expanded by adding percutaneous devices such as IABP, Impella or TandemHeart. 


\section{Epidemiology and outcomes}

Temporary mechanical circulatory support is increasingly used in patients affected by acute heart failure [51]. In the analysis of the Nationwide Inpatient Sample from 2011 to 2014 including almost 12,000 patients undergoing short-term cardiocirculatory assistance, use of percutaneous device increased by $1,511 \%$, whereas, non-percutaneous device by $101 \%$ [52]. More interestingly, the MCS implant moved from $39.6 \%$ to $47.2 \%$ of patients older than 65 years of age among the overall study population, underlining the higher consideration for MCS use also in this challenging patient population. Another recent analysis, this time including the 2004-2014 year-period, showed that among MCS types, ECMO had the highest growth $(1,421 \%)$, followed by other types of short-term MCS $(1,229.2 \%)$, percutaneous cardiocirculatory support (216.7\%), and intra-aortic balloon pump (140\%) [53]. The incidence of ECMO implementation in patients after open-heart surgery has been reported between $0.4 \%$ and $3.7 \%$ and has increased considerably over the past 2 decades [52] to the point that PC cardiogenic shock has become the most frequent indication for ECMO in the United States [54]. In fact, only between 2007 and 2011, non-percutaneous postcardiotomy ECMO cannulation increased 2-fold, while the use of percutaneous ECMO increased by more than 15-fold [52]. Maxwell et al. evaluated more than 9,000 ECMO patients from the Nationwide Inpatient Sample database in the United States from 1998 to 2009 and identified 4,493 (approx. 50\%) patients cannulated for cardiogenic shock in the postoperative period [55]. Recently, data from ELSO Registry also confirmed a substantial increase in PC-ECMO use over the last 10 years [56]. 
The European and American Societies of Cardiology guideline recommendations assigned ECMO the class Ilb recommendation, level of evidence $\mathrm{C}$, for the management of cardiogenic shock in STEMI [57]. Despite the above recommendation, and also growing worldwide utilization and experience, inhospital ECMO outcomes have not shown substantial improvement $[56,58]$. Little is still known of who benefits most from ECMO, or the cost-effectiveness of such a resource-intense therapy [52]. The inherent features of ECMO in terms of quick availability, relative ease of application in expert centers and reliability, have made it an attractive option, particularly in the post-cardiotomy setting $[59,60]$.

\section{Specific areas - PCS}

Due to its inherent features, ECMO represents a more appealing approach compared to other implantable or para-corporeal VAD [61-66], and particularly for PCS [52-56]. While indeed PC cardiogenic shock has become the most frequent indication for ECMO in the United States [54] its exponential increase did not parallel improved clinical outcomes [56,67]. Reports addressing PCECMO are limited, with only a few single-centre experiences available in the literature [68-86] commonly including adult and pediatric populations in the same series, or combining the PC-ECMO cases with the institutional global ECMO experience [87-104]. The characteristics of ECMO implantation (patient profiles, surgical access or location of implantation, timing of application, and duration of support), complications, and outcomes in the post-cardiotomy ECMO setting are different than in other applications of ECMO [105-110]. In the largest study to date assessing in-hospital and long-term survival after ECMO for PCS [56], overall successful weaning from ECMO was possible for $63 \%$ of patients but survival to hospital discharge was only $25 \%$. Figure 3. 


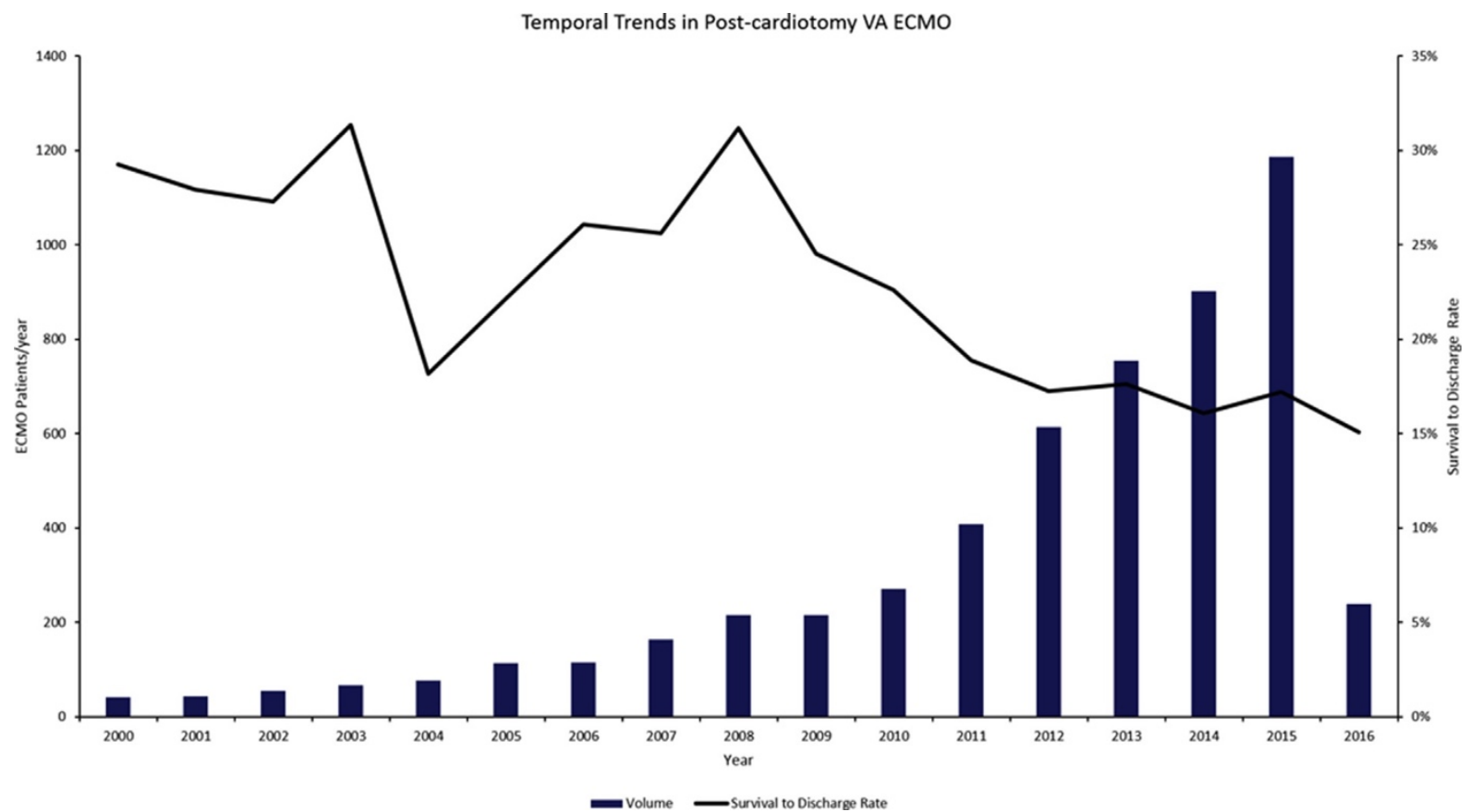

Figure 3. Data abstracted from the ELSO database show the exponential increase in extracorporeal membrane oxygenation (ECMO) for PCS. Figure copied from: 56. Whitman GJR. Extracorporeal membrane oxygenation for the treatment of postcardiotomy shock. J Thorac Cardiovasc Surg 2017;153:95-101.

These findings were comparable to results of smaller series of patients with PCS undergoing ECMO for which early survival rates of between $16 \%$ and $41 \%$ have been reported $[42,89]$.

\section{Specific areas - Elderly}

More advanced V-A ECMO technology, more experience in implant and management, as well as inclusion in resuscitation protocols, have been some of the factors which favored broader ECMO indications. Importantly, ECMO has now become a valid option also for patients previously not considered for temporary circulatory support, such as..., to promote organ recovery or transition to more advanced and durable therapies in case of failure to restore sufficient cardiac function. At the same time, however, V-A ECMO is well-known for being resource-intensive and often yielding a complicated post-implantation course. In older patients, in most scenarios, the only objective of V-A 
ECMO is 'bridge to recovery', since more advanced treatment modalities such as heart transplantation or use of durable LVADs are either contra-indicated or considered futile as well as inappropriate. Nonetheless, as the population ages, proper understanding of the use and impact of V-A ECMO specifically in patients with advanced age referred for RCS, will become increasingly relevant to elucidate actual patient outcome and whether this type of treatment may play a role and should be considered in this setting. Concerning the patients' characteristics, although PC-ECMO candidates are predominantly young and undergoing emergency operations [31], elderly patients are increasingly considered candidates for ECMO. Age of $>65$ years has not been regarded as an absolute contraindication to V-A or V-V ECMO candidacy [111,112] although long- term outcomes remain unreported. Other clinical characteristics of today's ECMO candidaytes include renal insufficiency, AMI, presence of left-main disease, LV dysfunction, prolonged history of coronary artery disease with previous AMI, prior open-heart surgery, and urgent or emergent status. Therefore, selection of elderly patients for ECMO dependent on multiple factors. Decision to implant or continue such a temporary MCS, therefore, is often difficult and several clinicians may avoid or limit the indications in the elderly to reduce resource consumption in limitedly successful procedures. From a clinical perspective, the majority of centers look at physical and neurological status prior to the event necessitating ECMO, the severity of insult, duration/degree of shock, presence of prior arrest, and associated medical comorbidities when selecting potential candidates for ECMO therapy. The availability, therefore, of indicators for more favorable outcome are required to guide clinical management, either prior or during ECMO support. High lactates at ECMO implant and renal failure, particularly requiring dialysis, have 
been shown to independently predict unfavorable results in all V-A ECMO patients, but particularly in the elderly.

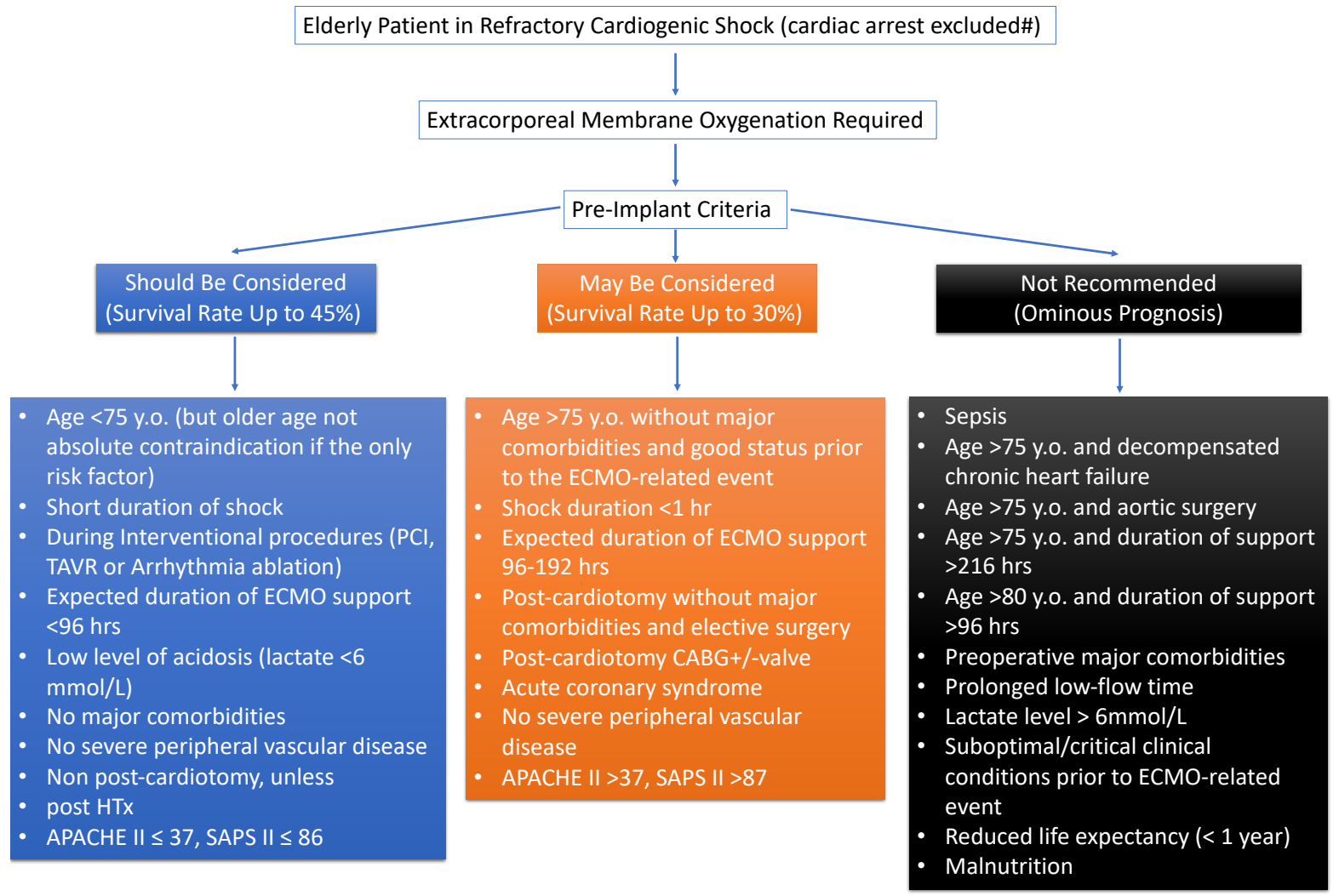

Figure 4. Summary of pre-implant criteria to be considered in the ECMO decision making in the elderly patients according to the survival probability. ECMO, extracorporeal membrane oxygenation; $\mathrm{PCI}$, percutaneous coronary intervention; TAVR, transcatheter aortic valve replacement; HTx, heart transplantation; APACHE I; acute physiology and chronic health evaluation II; SAPS II, simplified acute physiology score II; CABG, coronary artery bypass grafting.

As mentioned earlier, etiology of RCS may be also associated with more favorable conditions for recovery. For example, post-ACS patients have a considerable chance of surviving as compared to patients with acute decompensation of chronic heart failure as well as the presence of cardiac arrest or prolonged low-flow time during cardio-pulmonary resuscitation at ECMO implant, all of which are associated with almost no chance of survival $[37,113]$. Figure 4. 


\section{Specific areas - Bridge to VAD and bridge to HTx}

Despite evolution and recent advancements, V-A ECLS still represents a resource-consuming modality and mostly last resort of treatment. In most cases, centres' protocols and resources limit ECMO implementation to highest risk patients which are, in fact, least likely to benefit from such therapies $[52,56,58,114,115]$. Since CS arises from a plethora of underlying impaired cardiovascular .... and since conducting a randomized controlled trial in this peculiar setting would raise ethical questions, VA ECLS's optimal implementation and management in patients with CS has not been well studied or defined. Despite growing worldwide utilization and experience in MCS, outcomes of patients undergoing V-A ECLS, in particular in-hospital mortality, have not shown substantial progress $[55,56]$. Interestingly, outcomes are fairly different from centre to centre suggesting that variations in practice patterns in management of cardiogenic shock endure and may play a role in driving the above differences [116]. These might include different schemes of timing of cardiogenic shock recognition, tailored escalation to mechanical circulatory support, centralization of care and hemodynamic monitoring. Hypothetically, readability of well-experienced ECLS teams and potentially shorter bridging times in HTX/VAD units may contribute to improved results.

\section{Aim and outline of the thesis}

The purpose of this thesis was to analyze the in-hospital and remote outcomes of ECMO in the treatment of cardiogenic shock, including survival and complications. Additionally, complex clinical scenarios were addressed to evaluate and identify mortality predictors in these complex cases since these are most vulnerable to factors other than ECMO itself influencing the outcomes. For this purpose, 
several investigations were performed, by means of original studies, meta-analysis and reviews. Two large registry analyses were performed; one assessing the in-hospital outcomes in adults undergoing V-A ECMO for postcardiotomy cardiogenic shock from ELSO registry database; the other addressed elderly patients (>70 y.o.) undergoing V-A ECMO for cardiogenic shock. Notably, survival and complications were analyzed in a meta-analysis of LV-unloading techniques; by means of metaanalyses of the baseline surgical status as potentially influencing the outcome. Similarly, meta-analyses allowed for detailed investigation of the role of centre's status (VAD/HTx vs non-VAD/HTx) on patient sequelae both in postcardiotomy CS and in general CS setting.

\section{References}

1. van Diepen S, Katz JN, Albert NM, Henry TD, Jacobs AK, Kapur NK, Kilic A, Menon V, Ohman EM, Sweitzer NK, Thiele H, Washam JB, Cohen MG. Contemporary management of cardiogenic shock: a scientific statement from the American Heart Association. Circulation. 2017; 136:e232e268.

2. Harjola V-P, Lassus J, Sionis A, Køber L, Tarvasmäki T, Spinar J, Parissis J, Banaszewski M, Silva-Cardoso J, Carubelli V, Di Somma S, Tolppanen H, Zeymer U, Thiele H, Nieminen MS, Mebazaa A; for the CardShock study investigators and the GREAT network . Clinical picture and risk prediction of short-term mortality in cardiogenic shock: clinical picture and outcome of cardiogenic shock. Eur J Heart Fail. 2015; 17:501-509.

3. Gowda RM, Fox JT, Khan IA. Cardiogenic shock: basics and clinical considerations. Int J Cardiol. $2008 ; 123(3): 221-228$ 
4. Hochman JS, Sleeper LA, Webb JG, Sanborn TA, White HD, Talley JD, Buller CE, Jacobs AK, Slater JN, Col J, McKinlay SM, LeJemtel TH. Early revascularization in acute myocardial infarction complicated by cardiogenic shock. SHOCK Investigators. Should We Emergently Revascularize Occluded Coronaries for Cardiogenic Shock. N Engl J Med. 1999; 341:625-634.

5. Thiele H, Zeymer U, Neumann F-J, Ferenc M, Olbrich H-G, Hausleiter J, Richardt G, Hennersdorf M, Empen K, Fuernau G, Desch S, Eitel I, Hambrecht R, Fuhrmann J, Böhm M, Ebelt H, Schneider S, Schuler G, Werdan K. Intraaortic balloon support for myocardial infarction with cardiogenic shock. N Engl J Med. 2012; 367:1287-1296.

6. Bauer T, Zeymer U, Hochadel M, Möllmann H, Weidinger F, Zahn R, Nef HM, Hamm CW, Marco J, Gitt AK. Use and outcomes of multivessel percutaneous coronary intervention in patients with acute myocardial infarction complicated by cardiogenic shock (from the EHS-PCI Registry). Am J Cardiol. 2012; 109:941-946.

7. Lee JM, Rhee T-M, Hahn J-Y, Kim HK, Park J, Hwang D, Choi KH, Kim J, Park TK, Yang JH, Song YB, Choi J-H, Choi S-H, Koo B-K, Kim YJ, Chae SC, Cho MC, Kim CJ, Gwon H-C, Kim JH, Kim H-S, Jeong MH; KAMIR Investigators . Multivessel percutaneous coronary intervention in patients with ST-segment elevation myocardial infarction with cardiogenic shock. J Am Coll Cardiol. 2018; 71:844-856.

8. Ponikowski P, Voors AA, Anker SD, Bueno H, Cleland JGF, Coats AJS, Falk V, González-Juanatey JR, Harjola V-P, Jankowska EA, Jessup M, Linde C, Nihoyannopoulos P, Parissis JT, Pieske B, Riley JP, Rosano GMC, Ruilope LM, Ruschitzka F, Rutten FH, van der Meer P. 2016 ESC guidelines for the diagnosis and treatment of acute and chronic heart failure: the Task Force for 
the diagnosis and treatment of acute and chronic heart failure of the European Society of Cardiology (ESC). Developed with the special contribution of the Heart Failure Association (HFA) of the ESC. Eur Heart J. 2016; 37:2129-2200.

9. Kolte D, Khera S, Aronow WS, Mujib M, Palaniswamy C, Sule S, Jain D, Gotsis W, Ahmed A, Frishman WH, Fonarow GC. Trends in incidence, management, and outcomes of cardiogenic shock complicating ST-elevation myocardial infarction in the United States. J Am Heart Assoc. $2014 ; 3: \mathrm{e} 000590$.

10. Samuels LE, Kaufman MS, Thomas MP, Holmes EC, Brockman SK, Wechsler AS. Pharmacological criteria for ventricular assist device insertion following postcardiotomy shock: experience with the Abiomed BVS system. J Card Surg. 1999; 14:288293.CrossrefMedlineGoogle Scholar

11. Basir MB, Schreiber TL, Grines CL, Dixon SR, Moses JW, Maini BS, Khandelwal AK, Ohman EM, O'Neill WW. Effect of early initiation of mechanical circulatory support on survival in cardiogenic shock. Am J Cardiol. 2017; 119:845-851

12. Werdan K, Gielen S, Ebelt H, Hochman JS. Mechanical circulatory support in cardiogenic shock. Eur Heart J. 2014; 35:156-167.

13. Khan MH, Corbett BJ, Hollenberg SM. Mechanical circulatory support in acute cardiogenic shock. F1000Prime Rep. 2014; 6:91.

14. Burkhoff D, Sayer G, Doshi D, Uriel N. Hemodynamics of mechanical circulatory support. J Am Coll Cardiol. 2015; 66:2663-2674. 
15. Meani, P.; Delnoij, T.; Raffa, G.M.; Morici, N.; Viola, G.; Sacco, A.; Oliva, F.; Heuts, S.; Sels, J.W.; Driessen, R.; et al. Protracted aortic valve closure during peripheral veno-arterial extracorporeal life support: Is intra-aortic balloon pump an effective solution? Perfusion 2019, 34, 35-41, doi:10.1177/0267659118787426.

16. Williams, D.O.; Korr, K.S.; Gewirtz, H.; Most, A.S. The effect of intraaortic balloon counterpulsation on regional myocardial blood flow and oxygen consumption in the presence of coronary artery stenosis in patients with unstable angina. Circulation 1982, 66, 593-597, doi:10.1161/01.cir.66.3.593.

17. Werdan, K.; Gielen, S.; Ebelt, H.; Hochman, J.S. Mechanical circulatory support in cardiogenic shock. Eur. Heart J. 2014, 35, 156-167, doi:10.1093/eurheartj/eht248.

18. Ouweneel DM, Henriques JPS. Percutaneous cardiac support devices for cardiogenic shock: current indications and recommendations. Heart. 2012; 98:1246-1254.

19. Thiele H, Zeymer U, Neumann F-J, Ferenc M, Olbrich H-G, Hausleiter J, de Waha A, Richardt G, Hennersdorf M, Empen K, Fuernau G, Desch S, Eitel I, Hambrecht R, Lauer B, Böhm M, Ebelt H, Schneider S, Werdan K, Schuler G. Intra-aortic balloon counterpulsation in acute myocardial infarction complicated by cardiogenic shock (IABP-SHOCK II): final 12 month results of a randomised, open-label trial. Lancet. 2013; 382:1638-1645.

20. Patel MR, Smalling RW, Thiele H, Barnhart HX, Zhou Y, Chandra P, Chew D, Cohen M, French J, Perera D, Ohman EM. Intra-aortic balloon counterpulsation and infarct size in patients with acute anterior myocardial infarction without shock: the CRISP AMI randomized trial. JAMA. 2011; $306: 1329$ 
21. Schrage, B.; Burkhoff, D.; Rubsamen, N.; Becher, P.M.; Schwarzl, M.; Bernhardt, A.; Grahn, H.; Lubos, E.; Soffker, G.; Clemmensen, P.; et al. Unloading of the left ventricle during venoarterial extracorporeal membrane oxygenation therapy in cardiogenic shock. JACC. Heart Fail. 2018, 6, 1035-1043

22. Eliet, J.; Gaudard, P.; Zeroual, N.; Rouviere, P.; Albat, B.; Mourad, M.; Colson, P.H. Effect of impella during veno-arterial extracorporeal membrane oxygenation on pulmonary artery flow as assessed by end-tidal carbon dioxide. ASAIO J. 2018, 64, 502-507, doi:10.1097/MAT.0000000000000662.

23. Lim, H.S. The effect of impella $\mathrm{cp}$ on cardiopulmonary physiology during venoarterial extracorporeal membrane oxygenation support. Artif. Organs 2017, 41, 1109-1112, doi:10.1111/aor.12923.

24. Ouweneel DM, Eriksen E, Sjauw KD, van Dongen IM, Hirsch A, Packer EJS, Vis MM, Wykrzykowska JJ, Koch KT, Baan J, de Winter RJ, Piek JJ, Lagrand WK, de Mol BAJM, Tijssen JGP, Henriques JPS. Percutaneous mechanical circulatory support versus intra-aortic balloon pump in cardiogenic shock after acute myocardial infarction. J Am Coll Cardiol. 2017; 69:278-287.

25. Basir MB, Schreiber T, Dixon S, Alaswad K, Patel K, Almany S, Khandelwal A, Hanson I, George A, Ashbrook M, Blank N, Abdelsalam M, Sareen N, Timmis SBH, O'Neill Md WW. Feasibility of early mechanical circulatory support in acute myocardial infarction complicated by cardiogenic shock: the Detroit cardiogenic shock initiative. Catheter Cardiovasc Interv. 2018; 91:454-461.

26. Burkhoff D, Cohen H, Brunckhorst C, O'Neill WW, TandemHeart Investigators G. A randomized multicenter clinical study to evaluate the safety and efficacy of the tandemheart percutaneous 
ventricular assist device versus conventional therapy with intraaortic balloon pumping for treatment of cardiogenic shock. Am Heart J. 2006;152:469 e461-468

27. Ostadal, P.; Mlcek, M.; Kruger, A.; Hala, P.; Lacko, S.; Mates, M.; Vondrakova, D.; Svoboda, T.; Hrachovina, M.; Janotka, M.; et al. Increasing venoarterial extracorporeal membrane oxygenation flow negatively affects left ventricular performance in a porcine model of cardiogenic shock. J. Transl. Med. 2015, 13, 266,

28. Dickstein, M.L. The starling relationship and veno-arterial ecmo: Ventricular distension explained. ASAIO J. 2018, 64, 497-501,

29. Turner, D.A.; Cheifetz, I.M. Extracorporeal membrane oxygenation for adult respiratory failure. Respir. Care 2013, 58, 1038-1052,

30. Paden ML, Conrad SA, Rycus PT, Thiagarajan RR; ELSO Registry . Extracorporeal life support organization registry report 2012. ASAIO J. 2013; 59:202-210.

31. Smedira NG, Blackstone EH. Postcardiotomy mechanical support: risk factors and outcomes. Ann Thorac Surg 2001;71:S60-6. discussion S82.

32. Cheng R, Hachamovitch R, Kittleson M, et al. Complications of extracorporeal membrane oxygenation for treatment of cardiogenic shock and cardiac arrest: a meta-analysis of 1,866 adult patients. Ann Thorac Surg 2014;97:610-6

33. Chen SW, Tsai FC, Lin YS, et al. Long-term outcomes of extracorporeal membrane oxygenation support for postcardiotomy shock. J Thorac Cardiovasc Surg 2017;154:469-77 
34. Guihaire J, Dang Van S, Rouze S, et al. Clinical outcomes in patients after extracorporeal membrane oxygenation support for post-cardiotomy cardiogenic shock: a single-centre experience. Interact Cardiovasc Thorac Surg 2017

35. Ko WJ, Lin CY, Chen RJ, Wang SS, Lin FY, Chen YS. Extracorporeal membrane oxygenation support for adult postcardiotomy cardiogenic shock. Ann Thorac Surg 2002;73:538-45

36. Hsu PS, Chen JL, Hong GJ, et al. Extracorporeal membrane oxygenation for refractory cardiogenic shock after cardiac surgery: predictors of early mortality and outcome from 51 patients. Eur $\mathrm{J}$ Cardio-Thorac Surg 2010;37:328-33

37. Saxena P, Neal J, Joyce LD, et al. Extracorporeal membrane oxygenation support in postcardiotomy elderly patients: the Mayo Clinic experience. Ann Thorac Surg 2015;99:2053-60

38. Carroll BJ, Shah RV, Murthy V, et al. Clinical features and outcomes in adults with cardiogenic shock supported with extracorporeal membrane oxygenation. Am J Cardiol 2015;116:1624-30

39. Lorusso R, Barili F, Di Mauro M, et al. In-hospital neurologic complications in adult patients undergoing venoarterial extracorporeal membrane oxygenation: Results from the Extracorporeal Life Support Organization Registry. Crit Care Med 2016;44:e964-e972

40. Lorusso R, Gelsomino S, Parise O, et al. Neurologic injury in adults supported with veno-venous ECMO for respiratory failure: findings from the Extracorporeal Life Support Organization Registry. Crit Care Med 2017;45:1389-97

41. Magovern GJ Jr, Magovern JA, Benckart DH, et al. Extracorporeal membrane oxygenation: preliminary results in patients with postcardiotomy cardiogenic shock. Ann Thorac Surg 1994;57:71 
42. Fiser SM, Tribble CG, Kaza AK, et al. When to discontinue extracorporeal membrane oxygenation for postcardiotomy support. Ann Thorac Surg 2001;71:210-4

43. Smedira NG, Blackstone EH. Postcardiotomy mechanical support: risk factors and outcomes. Ann Thorac Surg 2001;71:S60-6

44. Kowalewski M, Suwalski P, Pawliszak W, Benetti F, Raffa GM, Malvindi PG, Carrel T, Paparella D, Anisimowicz L. Risk of stroke with "no-touch" - as compared to conventional off-pump coronary artery bypass grafting. An updated meta-analysis of observational studies. Int $\mathrm{J}$ Cardiol. 2016;222:769-771

45. Kowalewski M, Pawliszak W, Malvindi PG, Bokszanski MP, Perlinski D, Raffa GM, Kowalkowska ME, Zaborowska K, Navarese EP, Kolodziejczak M, Kowalewski J, Tarelli G, Taggart DP, Anisimowicz L. Off-pump coronary artery bypass grafting improves short-term outcomes in highrisk patients compared with on-pump coronary artery bypass grafting: Meta-analysis. J Thorac Cardiovasc Surg. 2016;151:60-77 e61-58

46. Wong JK, Smith TN, Pitcher HT, Hirose H, Cavarocchi NC. Cerebral and lower limb near infra-red spectroscopy in adults on extracorporeal membrane oxygenation. Artif Organs. 2012;36:659-67

47. Chen H, Yu RG, Yin NN, Zhou JX. Combination of extracorporeal membrane oxygenation and continuous renal replacement therapy in critically ill patients: A systematic review. Crit Care. 2014;18:675

48. Ostermann M, Connor M, Jr., Kashani K. Continuous renal replacement therapy during extracorporeal membrane oxygenation: Why, when and how? Curr Opin Crit Care. 2018;24:493-503 
49. Rastan AJ, Dege A, Mohr M, et al. Early and late outcome of 517 consecutive patients treated with extracorporeal membrane oxygenation for refractory postcardiotomy cardiogenic shock. J Thorac Cardiovasc Surg 2010;139:302-11

50. Ariyaratnam P, McLean LA, Cale ARJ, Loubani M. Extracorporeal membrane oxygenation for the post-cardiotomy patient. Heart Fail Rev 2014;19:717-25

51. Vallabhajosyula S, Patlolla SH, Dunlay SM et al. Regional variation in the management and outcomes of acute myocardial infarction with cardiogenic shock in the united states. Circ Heart Fail. 2020;13:e006661

52. Stretch R, Sauer CM, Yuh DD et al. National trends in the utilization of short-term mechanical circulatory support: Incidence, outcomes, and cost analysis. J Am Coll Cardiol. 2014;64:1407-1415

53. Strom JB, Zhao Y, Shen C et al. National trends, predictors of use, and in-hospital outcomes in mechanical circulatory support for cardiogenic shock. Eurolntervention. 2018;13:e2152e2159

54. Sauer CM, Yuh DD, Bonde P. Extracorporeal membrane oxygenation use increased $433 \%$ in adults in the United States from 2006 to 2011. ASAIO J 2015:61:31-36

55. Maxwell BG, Powers AJ, Sheikh AY, et al. Resource use trends in extracorporeal membrane oxygenation in adults: an analysis of the Nationwide Inpatient Sample 1998-2009. J Thorac Cardiovasc Surg 2014;148:416-21.

56. Whitman GJR. Extracorporeal membrane oxygenation for the treatment of postcardiotomy shock. J Thorac Cardiovasc Surg 2017;153:95-101.

57. Ibanez B, James S, Agewall S, Antunes MJ, Bucciarelli-Ducci C, Bueno H, Caforio ALP, Crea F, Goudevenos JA, Halvorsen S, Hindricks G, Kastrati A, Lenzen MJ, Prescott E, Roffi M, Valgimigli 
M, Varenhorst C, Vranckx P, Widimsky P, Group ESCSD. 2017 esc guidelines for the management of acute myocardial infarction in patients presenting with st-segment elevation: The task force for the management of acute myocardial infarction in patients presenting with st-segment elevation of the european society of cardiology (esc). Eur Heart J. 2018;39:119-177

58. McCarthy FH, McDermott KM, Kini V, Gutsche JT, Wald JW, Xie D, Szeto WY, Bermudez CA, Atluri P, Acker MA, Desai ND. Trends in u.S. Extracorporeal membrane oxygenation use and outcomes: 2002-2012. Semin Thorac Cardiovasc Surg. 2015;27:81-88

59. Abrams D, Combes A, Brodie D. Extracorporeal membrane oxygenation in cardiopulmonary disease in adults. J Am Coll Cardiol. 2014;63:2769-2778

60. Lorusso R, Raffa GM, Alenizy K, Sluijpers N, Makhoul M, Brodie D, McMullan M, Wang IW, Meani P, MacLaren G, Kowalewski M, Dalton H, Barbaro R, Hou X, Cavarocchi N, Chen YS, Thiagarajan R, Alexander P, Alsoufi B, Bermudez CA, Shah AS, Haft J, D'Alessandro DA, Boeken U, Whitman GJR. Structured review of post-cardiotomy extracorporeal membrane oxygenation: Part 1-adult patients. J Heart Lung Transplant. 2019;38:1125-1143

61. Goldstein DJ, Oz MC. Mechanical support for postcardiotomy cardiogenic shock. Sem Thorac Cardiovasc Surg 2000;12:220-8

62. Curtis JJ, McKenney-Knox CA, Wagner-Mann CC. Postcardiotomy centrifugal assist: a single surgeon's experience. Artif Organs 2002;26:994-7

63. Jurmann MJ, Siniawski H, Erb M, Drews T, Hetzer R. Initial experience with miniature axial flow ventricular assist devices for postcardiotomy heart failure. Ann Thorac Surg 2004;77:1642-7 
64. Hernandez AF, Grab JD, Gammie JS, et al. A decade of short-term outcomes in post-cardiac surgery ventricular assist device implantation. Circulation 2007;116:606-12

65. Akay MH, Gregoric ID, Radovancevic R, Cohn WE, Frazier OH. Timely use of a CentriMag heart assist device improves survival in postcardiotomy cardiogenic shock. J Card Surg 2011;26:548-52

66. Sylvin EA, Stern DR, Goldstein DJ. Mechanical support for postcardiotomy cardiogenic shock: has progress been made? J Card Surg 2010;25:442-54

67. Fukuhara S, Takeda K, Garan A, et al. Contemporary mechanical circulatory support therapy for postcardiotomy shock. Gen Thorac Cardiovasc Surg 2016;64:183-91

68. Magovern GJ Jr, Magovern JA, Benckart DH, et al. Extracorporeal membrane oxygenation: preliminary results in patients with postcardiotomy cardiogenic shock. Ann Thorac Surg 1994;57:71

69. Kodera K, Kitamura M, Hachida M, Endo M, Hashimoto A, Koyanagi H. Biventricular bypass with oxygenation for postcardiotomy ventricular failure. Artif Organs 1996;20:724-7

70. Ko WJ, Lin CY, Chen RJ, Wang SS, Lin FY, Chen YS. Extracorporeal membrane oxygenation support for adult postcardiotomy cardiogenic shock. Ann Thorac Surg 2002;73:538-45

71. Zhang R, Kofidis $\mathrm{T}$, Kamiya $\mathrm{H}$, et al. Creatine kinase isoenzyme MB relative index as predictor of mortality on extracorporeal membrane oxygenation support for postcardiotomy cardiogenic shock in adult patients. Eur J Cardio-Thorac Surg 2006;30:617-20

72. Bakhtiary F, Keller H, Dogan S, et al. Venoarterial extracorporeal membrane oxygenation for treatment of cardiogenic shock : clinical experiences in 45 adult patients. J Thorac Cardiovasc Surg $2008 ; 135: 382-8$ 
73. Elsharkawy HA, Li L, Skr Esa WA, Sessler D, Bashour CA. Outcome in patients who require venoarterial extracorporeal membrane oxygenation support after cardiac surgery. J Cardio-Thorac Vasc Anesth 2010;24:946-51

74. Pokersnik JA, Buda T, Bashour A, Gonzalez-Stawinski GV. Have changes in ECMO technology impacted outcomes in adult patients developing postcardiotomy cardiogenic shock? J Card Surg $2012 ; 27: 246-52$

75. Mikus E, Tripodi A, Calvi S, Del Giglio M, Cavallucci A, Lamarra M. CentriMag venoarterial extracorporeal membrane oxygenation supporta $s$ treatment for patients with refractory postcardiotomy cardiogenic shock. ASAIO J 2013:59:18-23

76. Slottosch I, Liakopoulos O, Kuhn E, et al. Outcomes after peripheral extracorporeal membrane oxygenation therapy for postcardiotomy cardiogenic shock: a single centre experience. J Surg Res $2013 ; 181: 47-55$

77. Unosawa S, Sezai A, Hata M, et al. Long-term outcomes of patients undergoing ECMO for refractory postcardiotomy cardiogenic shock. Surg Today 2013;43:264-70

78. Ariyaratnam P, McLean LA, Cale ARJ, Loubani M. Extracorporeal membrane oxygenation for the post-cardiotomy patient. Heart Fail Rev 2014;19:717-25

79. Li CL, Wang H, Jia M, Ma N, Meng X, Hou XT. The early dynamic behaviour of lactate is linked to mortality in postcardiotomy patients with extracorporeal membrane oxygenation support: a retrospective observational study. J Thorac Cardiovasc Surg 2015;149:1445-50 
80. Khorsandi M, Shaikhrezai K, Prasad S, et al. Advanced mechanical circulatory support for postcardiotomy cardiogenic shock: a 20 -year outcome analysis in a non-transplant unit. J CardioThorac Surg 2016;11:29-35

81. Dilstelmaier K, Schrutka L, Binder C, et al. Cardiac arrest does not affect survival in post-operative cardiovascular surgery patients undergoing extracorporeal membrane oxygenation. Resuscitation 2016;104:24-7

82. Mazzeffi MA, Sanchez PG, Herr D, et al. Outcomes of extracorporeal cardiopulmonary resuscitation for refractory cardiac arrest in adult cardiac surgery patients. J Thorac Cardiovasc Surg 2016;152:1133-9

83. Chen SW, Tsai FC, Lin YS, et al. Long-term outcomes of extracorporeal membrane oxygenation support for postcardiotomy shock. J Thorac Cardiovasc Surg 2017;154:469-77

84. Guihaire J, Dang Van S, Rouze S, et al. Clinical outcomes in patients after extracorporeal membrane oxygenation support for post-cardiotomy cardiogenic shock: a single-centre experience. Interact Cardiovasc Thorac Surg 2017, doi: 10.1093/icvts/ivx155.

85. Raffa GM, Gelsomino S, Sluijpers N, et al. In-hospital outcome of post-cardiotomy extracorporeal life support in adult patients: the 2007-2017 Maastricht experience. Crit Care Resusc. 2017;19:5361.

86. Fux, T, Holm M, Corbascio M, H. Lund LH, van der Linden J. Venoarterial Extracorporeal Membrane Oxygenation for Postcardiotomy Shock: Risk Factors for Mortality. J Thorac Cardiovasc Surg 156;5:1894-1902.e3, doi.org/10.1016/j.jtcvs.2018.05.061. 
87. Ranucci M, Ballotta A, Kandil H, et al. Bivalirudin-based versus heparin anticoagulation for postcardiotomy extracorporeal membrane oxygenation. Critical Care 2011;15:275-85

88. Ranucci M, Barushnikova E, Isgrò G, et al. Heparin-like effect in post-cardiotomy extracorporeal membrane oxygenation patients. Critical Care 2014;18:504-10

89. Smith C, Bellomo R, Raman JS, et al. An extracorporeal membrane oxygenation-based approach to cardiogenic shock in an older population. Ann Thorac Surg 2001;71:1421-7

90. Saito S, Nakatani T, Kobayashi J, et al. Is extracorporeal life support contraindicated in the elderly patients? Ann Thorac Surg 2007;83:140-5

91. Lan C, Tsai PR, Chen YS, Ko WJ. Prognostic factors for adult patients receiving extracorporeal membrane oxygenation as mechanical circulatory support - A 14-year experience at a medical center. Artif Organs 2010;34:59-64

92. Hei F, Lou S, Li J, et al. Five-year results of 121 consecutive patients treated with extracorporeal membrane oxygenation at Fu Wai hospital. Artif Organs 2011;35:572-8

93. Raffa GM, Kowalewski M, Brodie D, et al. Meta-Analysis of Peripheral or Central ECMO in Postcardiotomy and Non-Postcardiotomy Shock. Ann Thorac Surg. 2018, doi: 10.1016/j.athoracsur.2018.05.063.

94. LoforteA, Marinelli $G$, Musumeci $F$, et al. Extracorporeal membrane oxygenation support in refractory cardiogenic shock: treatment strategies and analysis of risk factors. Artif Organs 2014;38:129-41

95. Saed D, Stosik H, Islamovic M, et al. Femoro-femoral versus atrio-aortic ECMO: selecting the ideal cannulation technique. Artif Organ 2014;38:549-55 
96. Carroll BJ, Shah RV, Murthy V, et al. Clinical features and outcomes in adults with cardiogenic shock supported with extracorporeal membrane oxygenation. Am J Cardiol 2015;116:1624-30

97. Truby L, Mundy L, Kalesan B, et al. Contemporary outcomes of venoarterial extracorporeal membrane oxygenation for refractory cardiogenic shock at a large tertiary care center. ASAIO J $2015 ; 61: 403-9$

98. Brunet J, Valette X, Ivascau C, et al. Extracorporeal life support for refractory cardiac arrest or shock: a 10-year study. ASAIO J 2015;61:676-81

99. Tarzia V, Bertolussi G, Bianco R, et al. Extracorporeal life support in cardiogenic shock: impacts of acute versus chronic etiology on outcome. J Thorac Cardiovasc Surg 2015;150:333-40

100. Narotsky DL, Mosca MS, Mochari-Greenberger H, et al. Short-term and long-term survival of veno-arterial extracorporeal membrane oxygenation in an adult patient population: does older age matter? Perfusion 2016;31:366-75

101. Aso S, Matsui H, Fushimi K, Yasunaga H. In-hospital mortality and successful weaning from veno-arterial extracorporeal membrane oxygenation: analysis of 5,263 patients using a national inpatient database in Japan. Critical Care 2016;20-80

102. Demodion P, Fournel L, Golmard JL, Niculescu M, Pavie A, Leprince P. Predictors of 30-day mortality and outcome in cases of myocardial infarction with cardiogenic shock treated by extracorporeal membrane oxygenation. Eur J Cardio-Thorac Surg 2014;45:47-54

103. Takayama H, Truby L, Koekort M, et al. Clinical outcome of mechanical circulatory support for refractory cardiogenic shock in the current era. J Heart Lung Transplant 2013;32:106-11 
104. Xie A, Phan K, Tsai YC, Yan TD, Forrest P. venoarterial extracorporeal membrane oxygenation for cardiogenic shock and cardiac arrest: a metanalysis. J Cardio-Thorac Vasc Anesth 2015;29:637-45

105. Kowalewski M, Raffa G, Zielinski K et al. Baseline surgical status and short-term mortality after extracorporeal membrane oxygenation for post-cardiotomy shock: A meta-analysis. Perfusion. 2019:267659119865122

106. Meani P, Matteucci M, Jiritano F, Fina D, Panzeri F, Raffa GM, Kowalewski M, Morici N, Viola G, Sacco A, Oliva F, Alyousif A, Heuts S, Gilbers M, Schreurs R, Maessen J, Lorusso R. Longterm survival and major outcomes in post-cardiotomy extracorporeal membrane oxygenation for adult patients in cardiogenic shock. Ann Cardiothorac Surg. 2019;8:116-122

107. Lo Coco V, Lorusso R, Raffa GM, Malvindi PG, Pilato M, Martucci G, Arcadipane A, Zielinski K, Suwalski P, Kowalewski M. Clinical complications during veno-arterial extracorporeal membrane oxigenation in post-cardiotomy and non post-cardiotomy shock: Still the achille's heel. J Thorac Dis. 2018;10:6993-7004

108. Raffa GM, Kowalewski M, Meani P, Follis F, Martucci G, Arcadipane A, Pilato M, Maessen J, Lorusso R, Group EiTI. In-hospital outcomes after emergency or prophylactic veno-arterial extracorporeal membrane oxygenation during transcatheter aortic valve implantation: $A$ comprehensive review of the literature. Perfusion. 2019;34:354-363

109. Raffa GM, Kowalewski M, Brodie Det al. Meta-analysis of peripheral or central extracorporeal membrane oxygenation in postcardiotomy and non-postcardiotomy shock. Ann Thorac Surg. 2019;107:311-321 
110. Raffa GM, Gelsomino S, Sluijpers N, Meani P, Alenizy K, Natour E, Bidar E, Johnson DM, Makhoul M, Heuts S, Lozekoot P, Kats S, Schreurs R, Delnoij T, Montalti A, Sels JW, Poll MV, Roekaerts P, Maessen J, Lorusso R. In-hospital outcome of post-cardiotomy extracorporeal life support in adult patients: The 2007-2017 maastricht experience. Crit Care Resusc. 2017;19:53-61

111. Nakamura H, Yamaguchi H, Amano A, Nakao T. Veno-venous extracorporeal membrane oxygenation is effective against post-cardiotomy acute respiratory failure in adults. Gen Thorac Cardiovasc Surg 2013;61:402-8

112. Song JH, Woo WK, Song SH, et al. Outcome of veno-venous extracorporeal membrane oxygenation use in acute respiratory distress syndrome after cardiac surgery with cardiopulmonary bypass. J Thorac Dis 2016;8:1804-13

113. Sertic F, Diagne D, Rame E et al. Short-term outcomes and predictors of in-hospital mortality with the use of veno-arterial extracorporeal membrane oxygenation in the elderly patients with refractory cardiogenic shock. J Cardiovasc Surg (Torino). 2019

114. Lawler PR, Silver DA, Scirica BM, Couper GS, Weinhouse GL, Camp PC, Jr. Extracorporeal membrane oxygenation in adults with cardiogenic shock. Circulation 2015;131:676-680.

115. Karagiannidis C, Brodie D, Strassmann S, et al. Extracorporeal membrane oxygenation: evolving epidemiology and mortality. Intensive Care Med. 2016;42:889-896.

116. Barbaro RP, Odetola FO, Kidwell KM, et al. Association of hospital-level volume of extracorporeal membrane oxygenation cases and mortality. Analysis of the extracorporeal life support organization registry. Am J Respir Crit Care Med. 2015;191:894-901. 


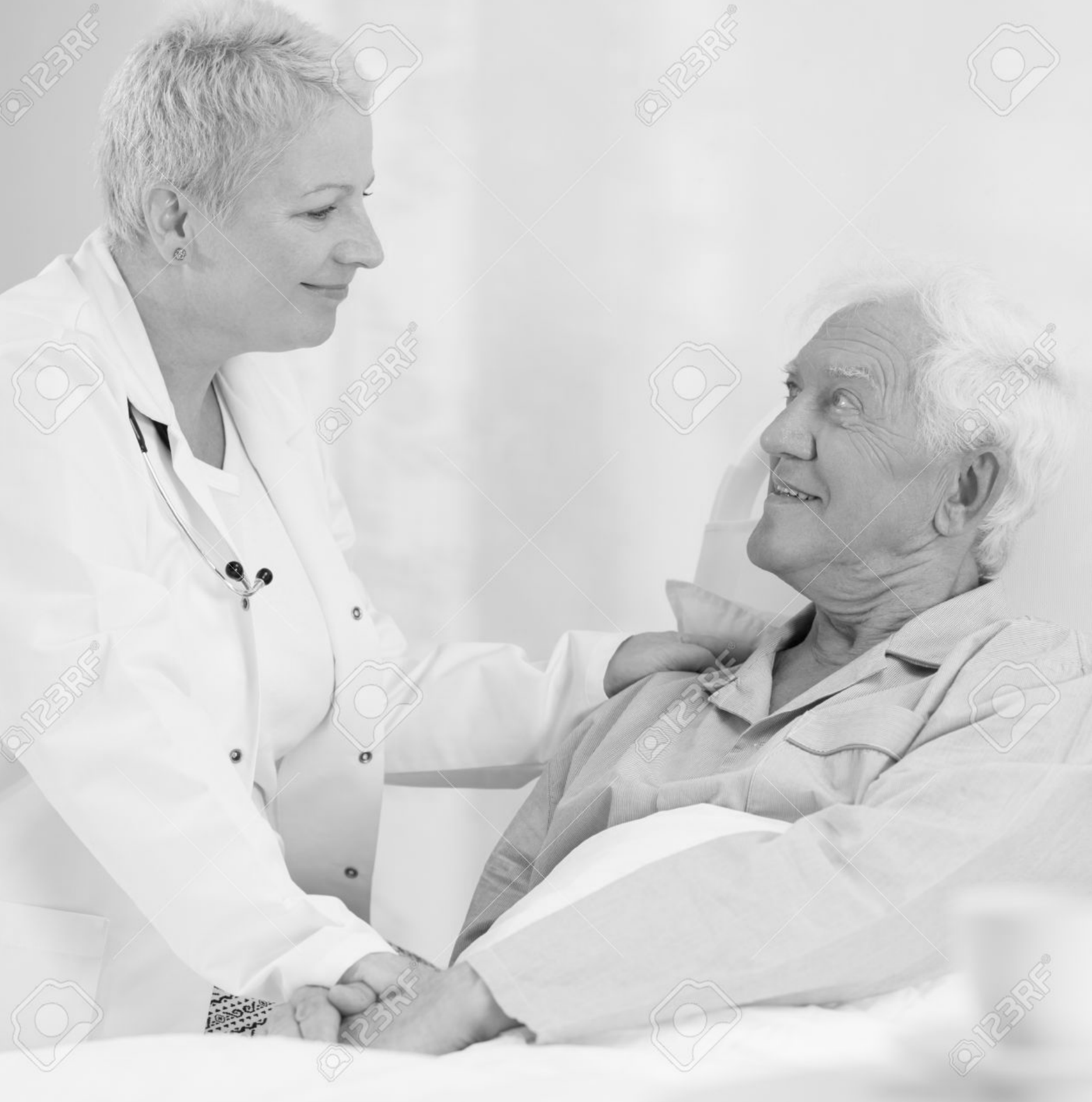




\section{CHAPTER 2}

MORTALITY PREDICTORS IN THE ELDERLY WITH CARDIOGENIC SHOCK ON VENOARTERIAL EXTRACORPOREAL LIFE SUPPORT

Kowalewski M, Zieliński K, Raffa GM, Meani P, Lo Coco V, Jiritano F, Fina D, Matteucci M, Chiarini G, Willers A, Simons J, Suwalski P, Gaudino M, Di Mauro M, Maessen J, Lorusso $R$

Critical Care Medicine 2020 (accepted, ahead of print), to be presented at EuroELSO London 6-8 May 2021 


\begin{abstract}
Objectives: Because significantly higher mortality is observed in the elderly patients undergoing venoarterial extracorporeal membrane oxygenation (V-A ECMO) for refractory cardiogenic shock (RCS), making decision-making in this setting challenging, we aimed to elucidate predictors of unfavorable outcomes in these elderly patients ( $\geq 70$ years).
\end{abstract}

Design: Multicentre registry.

Setting: Refractory cardiogenic shock due to various etiologies.

Patients: Elderly patients ( $\geq 70$ years).

Interventions: Veno-Arterial Extracorporeal Membrane Oxygenation

Measurements and Main Results: Three age groups (70-74, 75-79, $\geq 80$ years) were in-depth analyzed. Uni- and multi-variate analysis were performed. From 1998 to December 2018, 2,644 patients $\geq 70$ years $(1,395[52.8 \%] 70-74$ years of age, 858 [32.5\%] $75-79$ years, and $391[14.8 \%] \geq 80$ y.o.) were submitted to V-A ECMO for RCS. Peripheral access was applied in majority of patients. ECMO support duration was $4.3 \pm 5.5$ days, $(2.9 \pm 3.7$ days in patients $\geq 80$ years $)(P<0.001)$. Weaning from ECMO was possible in 1,236 pts (46.7\%). Overall in-hospital mortality was estimated at $68.3 \%$ $(1,807 / 2,644$ pts.) with highest crude mortality rates observed in $75-79$ y.o. subgroup $(70.1 \%)$. Complications were mostly cardiovascular and bleeding, without apparent differences between subgroups. Airway pressures, 24-hours pH after ECMO start, ECMO duration, and renal replacement therapy were associated with higher mortality. 
Conclusions: This study confirmed the remarkable increase of V-A ECMO use in the elderly affected by RCS. Despite in-hospital mortality remains high, V-A ECMO should still be considered in such a setting even in very elderly patients, since age itself was not linked to increased mortality, whereas several predictors may guide indication and management.

\section{Introduction}

Veno-arterial extracorporeal membrane oxygenation (V-A ECMO) is an effective therapy and is increasingly used in adults with refractory cardiogenic shock (RCS) [1-6]. During last 20 years, increase of the number of ECMO cases in the elderly patients was higher by half than among younger patients, with a rise of $280 \%$ between years $2005-2010$ and 2011-2015 [7]. More advanced V-A ECMO technology, more confidence in implant and management, as well as inclusion in resuscitation protocols, have been some of the factors which favored broader indications, also in patients previously not considered for such a type of temporary circulatory support, to promote organ recovery or transition to more advanced and durable therapies in case of failure to restore sufficient cardiac function. At the same time, however, V-A ECMO is well-known for being resource-intensive and often characterized by a complicated post-implantation course. In the very old patients, the only objective of V-A ECMO is 'bridge to recovery', since more advanced treatment modalities such as heart transplantation or use of durable left ventricular assist devices (LVAD) are either contra-indicated or considered futile as well as inappropriate. Nonetheless, as the population ages, proper understanding of the use and impact of VA ECMO specifically in patients with advanced age referred for RCS, will become increasingly more 
relevant to elucidate actual patient outcome and whether this type of treatment may play a role and should be considered in this setting.

Previous investigation comparing elderly versus younger patients undergoing V-A ECMO for RCS showed that in-hospital mortality is significantly higher in former group [7]. However, the overall outcome of elderly patient did not appear unacceptable, suggesting that V-A ECMO might be considered in RCS. Patient selection, however, may play an additional critical role in the light of optimizing resources and chances of favorable results. Paucity of data remains on involving the use of V-A ECMO in such a challenging setting and answering how the threshold of age among elderly patients (eg, $>75$ years or $>80$ years) affects the clinical outcome is crucial. Many programs entertain somewhat arbitrary upper age limits for ECMO use. Some investigators have even suggested that age $>75$ years should be a contraindication for ECMO support. As mentioned, however, growing number of elderly patients have been treated recently, and the trend seems to continue. It is becoming apparent that temporary cardiocirculatory support should not be denied solely only on the basis of patient age, but decision should be given to reversibility of cardiogenic shock with support and comorbid conditions likely to impact patient survival. Elderly patients in RCS often have significant and complex comorbidities that can affect outcomes. Defining better decision-making and optimal candidate selection of elderly patients eligible for V-A ECMO due to RCS, have been, till now, poorly investigated. The primary aim of the present analysis, therefore, was to analyze data from the international worldwide Extracorporeal Life Support Organization (ELSO) Registry to investigate ECMO outcomes among the 
elderly patients and hopefully define risk factors associated with in-hospital mortality specific to elderly patient group.

\section{Methods}

\section{Data source and study population.}

Patient data was extracted from the ELSO Registry which is a worldwide voluntary registry collecting data related to ECMO implant in all patient age and conditions, including cardiac, respiratory, or as part of cardio-pulmonary resuscitation [8]. Data are collected from the contributing centers with a standardized form containing patient demographics, diagnosis and procedure information, ECMO technique, complications during ECMO, and survival to hospital discharge. Currently, as for year 2018, 391 centers have provided adult and pediatric data to the registry with data on 19,627 V-A ECMO runs in adult (> 18 years of age) patients with cardiac etiology of RCS. Information from elderly patients alone ( $\geq 70$ years of age) supported with a single run of $\mathrm{V}-\mathrm{A}$ ECMO for RCS listed in the ELSO registry between 1997 and 2018 were extracted. Patients supported with ECMO for extracorporeal cardiopulmonary resuscitation (ECPR) or respiratory dysfunction, and those with multiple ECMO runs were excluded. No informed consent was obtained, because the data set was limited to non-identifiable elements of information. This study was approved by ELSO Registry Committee.

\section{Main goals and definitions.}

We aimed to describe the prevalence of complications following VA-ECMO in the elderly population and to identify factors associated with in-hospital mortality. To study the relation of more advanced age in the elderly population with outcomes, we examined 3 cohorts grouped according to the age at 
diagnosis: patients aged $70-74$ years, $75-79$ years, and $\geq 80$ years, respectively. The independent variables were grouped before analysis as follows: demographic data, International Classification of Diseases diagnosis codes (reviewed by two authors independently and disagreement resolved by consensus), pre-ECMO course variables, pre-ECMO therapies instituted, ECMO course data. Survival to hospital discharge was the primary end-point for the study. All complications were categorized using ELSO registry complication categorizations and included the following: 1) limb complications, 2) central nervous system complications, 3) bleeding complications, 4) kidney failure, 5) sepsis, and were further subdivided.

\section{Statistical analysis.}

Categorical data were compared with chi-square and presented were frequencies with proportions. Continuous variables were analyzed using the ANOVA analysis and were reported as means with standard deviations (SDs). To assess predictor variables and major morbidity, the chi2 was used for categorical variables. To address missing values for variables, we used fully conditional specification (Markov chain Monte Carlo) for missing data (1,000 iterations) [9]. Mortality, gender, primary diagnosis, pre-ECMO support, pre-ECMO cardiac arrest, age, $\mathrm{PCO} 2$, pH at 24 hours, and year were employed as predictors. Variables with missing data in more than $5 \%$ of the patients were excluded from analysis.

The pre-ECMO variables included CPR, chronic renal failure, time between intensive care unit (ICU) admission and cannulation, systolic and diastolic blood pressure values (DBP) within $6 \mathrm{~h}$ of cannulation, blood gases, pre-ECMO support and ventilator settings. 
The primary end-point was in-hospital mortality, and the primary predictor of interest was patient age at cannulation. A piecewise model was initially used to evaluate the association between age and inhospital mortality. An age cut-off was identified by calculating the probabilities of $2 \times 2$ tables formed by the outcome and dichotomized age for all possible thresholds of age and calculating the associated chi $^{2}$ statistic. The age with the maximum chi $^{2}$ statistic was identified as the cut-off point. Simulation study has shown that if a cut-off point exists, maximizing the chi2 statistic can recover a true threshold for a continuous random variable [10]. To evaluate independent risk factors of in-hospital mortality variables that achieved $\mathrm{P}<0.1$ in the univariate analysis were examined by using multivariate analysis with forward stepwise logistic regression. Previous studies suggested that factor which predominantly impact frequency of complication in the elderly population is shorter time of ECMO support we estimated odds ratios in multivariate model with duration of ECMO support. Complications occurring in both groups are reported as number (\%) with corresponding odds ratios (OR) and 95\% confidence intervals $(95 \% \mathrm{Cls})$.

\section{Results}

\section{Patient demographic characteristics.}

The number of elderly VA-ECMO cases in the ELSO registry increased over the study time period (Figure 1). 


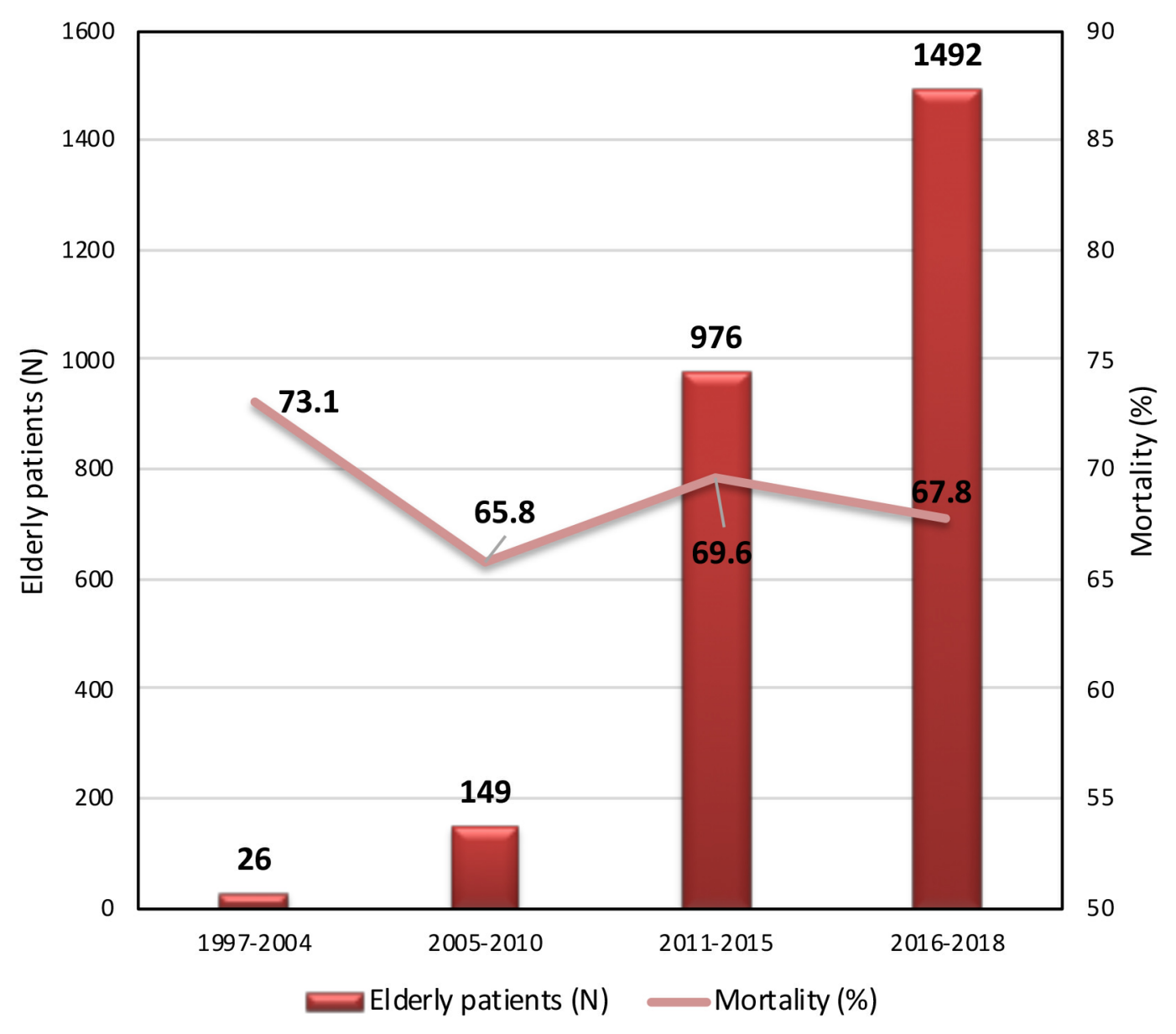

FIGURE 1. The in-hospital mortality rates in the elderly patients admitted to VA-ECMO for RCS enrolled in the ELSO registry in proceeding time periods.

There is a steady increase in number of ECMO cases in the elderly in analyzed time periods with steady mortality rates $(p=N S)$. A total of 2,644 elderly patients were included in this analysis. To establish an age cut-off, a distribution of the chi statistics was calculated for all possible cut-offs of age. The maximum chi was 4.834 ; with $52.8 \%(n=1,395)$ of these patients between 70 and 74 years of age, $32.5 \%(n=858)$ between 75 and 79 years, and $14.8 \%(n=391)$ of patients $\geq 80$ years of age. Pre-ECMO patient profiles stratified according to age are presented in Table 1. 
Table 1. Demographic and Clinical Characteristics along ECMO Support Details of Elderly Patients Stratified According to Age.

\begin{tabular}{|c|c|c|c|c|c|}
\hline Variable & $\begin{array}{l}\text { Overall } \\
(n=2,644)\end{array}$ & $\begin{array}{l}\text { Age Group } \\
70-74 \\
(n=1,395)\end{array}$ & $\begin{array}{l}\text { Age Group } \\
75-79 \\
(n=858)\end{array}$ & $\begin{array}{l}\text { Age Group } \\
\geq 80 \text { Years } \\
(n=391)\end{array}$ & p Value \\
\hline Male & $1684(63.7)$ & $896(64.2)$ & $539(62.8)$ & $249(63.7)$ & 0.796 \\
\hline Weight, kg & $81.0 \pm 19.8$ & $82.8 \pm 20.3$ & $80.6 \pm 19.0$ & $75.6 \pm 18.8$ & $<0.001$ \\
\hline \multicolumn{6}{|l|}{ Cause of cardiogenic shock } \\
\hline PCS & $1087(41.1)$ & $541(38.8)$ & $375(43.7)$ & $171(43.7)$ & 0.036 \\
\hline CABG & $340(12.9)$ & $170(12.2)$ & $134(15.6)$ & $36(9.2)$ & 0.004 \\
\hline Valve & $271(10.2)$ & $123(8.8)$ & $86(10.0)$ & $62(15.9)$ & $<0.001$ \\
\hline CABG+Valve & $212(8.0)$ & $99(7.1)$ & $73(8.5)$ & $40(10.2)$ & 0.107 \\
\hline AMI & $187(7.1)$ & $100(7.2)$ & $54(6.3)$ & $33(8.4)$ & 0.382 \\
\hline \multicolumn{6}{|c|}{ Hemodynamics before VA-ECMO } \\
\hline SBP & $85.5 \pm 29.5$ & $85.3 \pm 27.8$ & $85.6 \pm 30.6$ & $86.1 \pm 32.9$ & 0.928 \\
\hline DBP & $49.3 \pm 17.0$ & $49.9 \pm 15.9$ & $48.8 \pm 17.9$ & $48.4 \pm 19.0$ & 0.358 \\
\hline Mean & $61 \pm 18.5$ & $61.4 \pm 17.7$ & $60.2 \pm 18.7$ & $61.1 \pm 20.6$ & 0.476 \\
\hline Venous oxygen sat & $61.1 \pm 18.5$ & $61.4 \pm 18.3$ & $59.2 \pm 19.1$ & $64.1 \pm 18.0$ & 0.267 \\
\hline \multicolumn{6}{|l|}{ Pre-ECMO blood gases } \\
\hline Pre-ECMO pH & $7.28 \pm 0.15$ & $7.28 \pm 0.14$ & $7.28 \pm 0.15$ & $7.29 \pm 0.15$ & 0.478 \\
\hline Pre-ECMO HCO3 & $19.9 \pm 5.8$ & $19.9 \pm 5.9$ & $19.8 \pm 5.5$ & $20.3 \pm 6.1$ & 0.443 \\
\hline Pre-ECMO pO2 & $164.5 \pm 129.7$ & $153.9 \pm 121.2$ & $171.9 \pm 136.2$ & $187.5 \pm 141.1$ & $<0.001$ \\
\hline Pre-ECMO FiO2 & $83.1 \pm 22.9$ & $83.0 \pm 22.7$ & $82.5 \pm 23.5$ & $84.5 \pm 22.4$ & 0.552 \\
\hline Pre-ECMO SaO2 & 92.612 .5 & 92.611 .5 & 92.613 .8 & 92.913 .1 & 0.948 \\
\hline Pre-ECMO pCO2 & 41.817 .2 & 41.716 .2 & 42.619 .8 & 40.513 .7 & 0.232 \\
\hline \multicolumn{6}{|l|}{ Pre-ECMO support } \\
\hline IABP & $732(27.7)$ & $397(28.5)$ & $247(28.8)$ & $88(22.5)$ & 0.046 \\
\hline CPB & $746(28.2)$ & $359(25.7)$ & $259(30.2)$ & $128(32.7)$ & 0.007 \\
\hline Nitrix oxide & $149(5.6)$ & $83(5.9)$ & $56(6.5)$ & $10(2.6)$ & 0.014 \\
\hline Pacemaker & $223(8.4)$ & $113(8.1)$ & $77(9.0)$ & $33(8.4)$ & 0.769 \\
\hline Inotropes & $1538(58.2)$ & $821(58.9)$ & $503(58.6)$ & $214(54.7)$ & 0.326 \\
\hline LVAD & $96(3.6)$ & $58(4.2)$ & $33(3.8)$ & $5(1.3)$ & 0.025 \\
\hline \multicolumn{6}{|l|}{ ECMO Support Details } \\
\hline Peripheral cannulation & $1565(59.2)$ & $850(60.9)$ & $478(55.7)$ & $237(60.6)$ & 0.041 \\
\hline Days on ECMO & $4.3 \pm 5.5$ & $4.9 \pm 6.4$ & $4.0 \pm 4.3$ & $2.9 \pm 3.7$ & $<0.001$ \\
\hline
\end{tabular}

PCS, post-cardiotomy shock; $C A B G$, coronary artery bypass grafting; AMI, acute myocardial infarction; SBP, systolic blood pressure; DBP, diastolic blood pressure; ECMO, extracorporeal membrane oxygenation; FiO2, Fraction of inspired oxygen; IABP, intra-aortic balloon pump; CPB, cardiopulmonary bypass; LVAD, left ventricle assist device. Values are mean $\pm \mathrm{SD}$ or $\mathrm{n}(\%)$.

Most common origin of cardiogenic shock among elderly patients supported with ECMO remained undefined, post-cardiotomy shock was clearly mentioned in $41.1 \%$ of cases (among these post CABGPCS followed in $12.9 \%$ and valve in $10.2 \%, 28.2 \%$ could not be weaned from CPB), AMl was diagnosed in $7.1 \%$. 
Peripheral cannulation was preferred approach (59.2\%). Average ECMO support duration was $4.3 \pm$ 5.5 days in the overall population; with increasing age the ECMO support duration shortened from 4.9 \pm 6.4 days in the age range of $70-74$ years, $4.0 \pm 4.3$ in $75-79$ y.0., and $2.9 \pm 3.7$ in patients $\geq 80$ years $(\mathrm{P}<0.001)$. Weaning from ECMO was possible in 1,236 pts $(46.7 \%)$ with respective rates of 658 (47.2\%), 387 (45.1\%) and 191 (48.9\%) in subgroups 70-74 years, $75-79$ years, and $\geq 80$ years. Overall in-hospital mortality was estimated at $68.3 \%(1,807 / 2,644$ pts.) with highest crude mortality rates observed in $75-79$ y.o. subgroup (70.1\%); mortality in age groups $70-74$ years and $\geq 80$ years were $67.0 \%$ and $67.8 \%$ respectively. Figure 2.

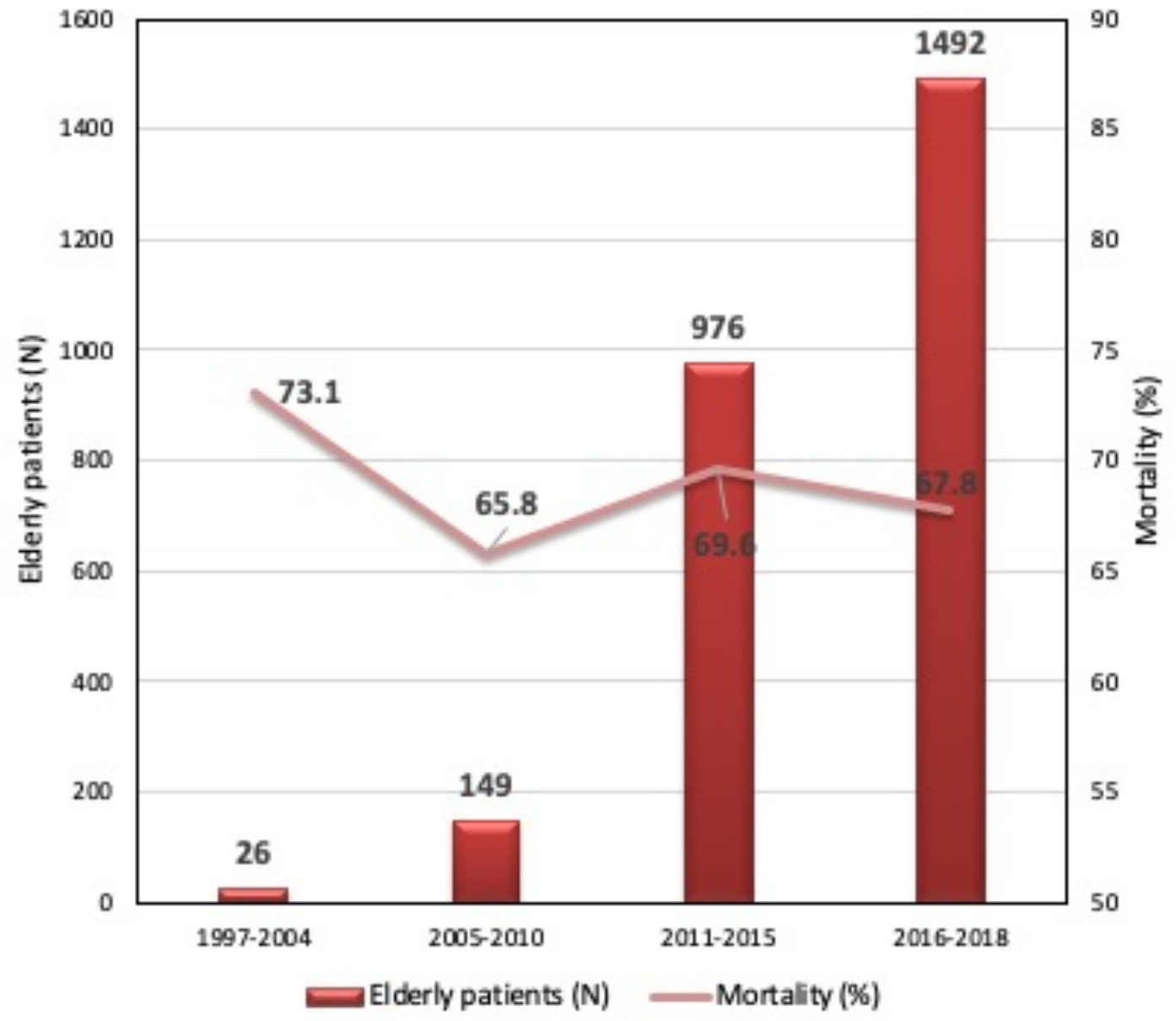

FIGURE 2. The in-hospital weaning from ECMO support and mortality rates according to predefined age subgroups. 
Table 2 lists univariate predictors of mortality in the elderly patients; among them, certain pre-ECMO

variables and outcomes predicted mortality in multivariate analyses as well and are listed in Table 3.

Table 2. Univariate Predictors $(p<0.1)$ of Mortality in the Elderly Patients

\begin{tabular}{|c|c|c|c|}
\hline \multirow{2}{*}{ Variable } & \multicolumn{3}{|c|}{ Univariate Analysis } \\
\hline & $\mathrm{HR}$ & $95 \% \mathrm{Cl}$ & p Value \\
\hline \multicolumn{4}{|l|}{ Age groups } \\
\hline 70-74 y (reference) & 1.00 & & \\
\hline $75-79$ y & 1.20 & $1.00-1.44$ & 0.06 \\
\hline$\geq 80 y$ & 1.01 & $0.79-1.28$ & 0.95 \\
\hline \multicolumn{4}{|l|}{ Other variables } \\
\hline Days on ECMO & 1.02 & $1.01-1.04$ & 0.01 \\
\hline Pre-ECMO PEEP & 1.03 & $1.00-1.06$ & 0.07 \\
\hline Pre-ECMO pH & 0.18 & $0.09-0.36$ & $<0.01$ \\
\hline Pre-ECMO HCO3 & 0.95 & $0.93-0.97$ & $<0.01$ \\
\hline $\mathrm{pH}$ at $24 \mathrm{~h}$ & 0.01 & $0.00-0.02$ & $<0.01$ \\
\hline $\mathrm{PaO} 2$ at $24 \mathrm{~h}$ per $10 \mathrm{mmHg}$ & 1.02 & $1.01-1.03$ & $<0.01$ \\
\hline $\mathrm{HCO} 3$ at $24 \mathrm{~h}$ & 0.94 & $0.92-0.96$ & $<0.01$ \\
\hline Rate (24 hours) & 1.02 & $1.00-1.05$ & 0.07 \\
\hline FiO2 (24 hours) & 1.00 & $1.00-1.01$ & 0.08 \\
\hline PIP (24 hours) & 1.06 & $1.04-1.08$ & $<0.01$ \\
\hline PEEP (24 hours) & 1.03 & $1.00-1.06$ & 0.05 \\
\hline Pre-ECMO SBP & 0.99 & $0.99-1.00$ & $<0.01$ \\
\hline Pre-ECMO DBP & 0.98 & $0.98-0.99$ & $<0.01$ \\
\hline Pre-ECMO mean BP & 0.99 & $0.98-0.99$ & $<0.01$ \\
\hline Percutaneous access & 0.78 & $0.66-0.93$ & $<0.01$ \\
\hline Post-CABG & 1.24 & $0.97-1.60$ & 0.09 \\
\hline Post-CABG+Valve & 1.32 & $0.96-1.81$ & 0.09 \\
\hline Post-HTx & 0.42 & $0.18-0.96$ & 0.04 \\
\hline Myocarditis & 0.28 & $0.07-1.16$ & 0.08 \\
\hline Pulmonary embolism & 0.21 & $0.09-0.52$ & $<0.01$ \\
\hline \multicolumn{4}{|l|}{ Complications } \\
\hline Cardiac arrhythmia & 2.10 & $1.59-2.79$ & $<0.01$ \\
\hline CPR required & 5.66 & $2.45-13.07$ & $<0.01$ \\
\hline Inotropes on ECLS & 1.68 & $1.40-2.01$ & $<0.01$ \\
\hline Myocardial stun & 3.39 & $1.84-6.24$ & $<0.01$ \\
\hline Tamponade (blood) & 2.19 & $1.40-3.44$ & $<0.01$ \\
\hline Cannulation site bleeding & 1.33 & $1.02-1.72$ & 0.03 \\
\hline DIC & 11.38 & $2.76-46.93$ & $<0.01$ \\
\hline GI hemorrhage & 4.02 & $2.14-7.56$ & $<0.01$ \\
\hline Hemolysis & 1.72 & $1.04-2.84$ & 0.03 \\
\hline Surgical site bleeding & 2.14 & $1.69-2.71$ & $<0.01$ \\
\hline Culture proven infection & 1.43 & $1.04-1.99$ & 0.03 \\
\hline WBC $<1500$ & 6.56 & $1.56-27.62$ & 0.01 \\
\hline Limb complication & 3.67 & $2.05-6.58$ & $<0.01$ \\
\hline $\begin{array}{l}\text { ECMO-related } \\
\text { complication }\end{array}$ & 1.92 & $1.45-2.54$ & $<0.01$ \\
\hline Glucose $<40$ & 19.87 & $2.73-144.61$ & $<0.01$ \\
\hline Hyperbilirubinemia & 2.90 & $1.95-4.31$ & $<0.01$ \\
\hline $\mathrm{pH}<7.2$ & 3.91 & $2.44-6.27$ & $<0.01$ \\
\hline Cerebral hemorrhage & 3.63 & $1.28-10.32$ & 0.02 \\
\hline Cerebral infarction & 4.23 & $2.03-8.83$ & $<0.01$ \\
\hline Seizures & 2.71 & $1.05-7.03$ & 0.04 \\
\hline
\end{tabular}




\begin{tabular}{llll} 
Pulmonary hemorrhage & 1.92 & $0.96-3.85$ & 0.07 \\
\hline Creatinine $>3.0$ & 2.24 & $1.56-3.23$ & $<0.01$ \\
\hline Creatinine 1.5-3.0 & 1.53 & $1.22-1.91$ & $<0.01$ \\
\hline RRT as a complication & 3.29 & $2.62-4.13$ & $<0.01$ \\
\hline Pre-ECMO support & & & \\
\hline Inotropes & 1.32 & $1.12-1.55$ & $<0.01$ \\
\hline Bicarbonates intravenous & 1.51 & $1.18-1.92$ & $<0.01$ \\
\hline Cardiac pacemaker & 1.35 & $0.99-1.84$ & 0.06 \\
\hline Cardiopulmonary bypass & 1.22 & $1.02-1.47$ & 0.03 \\
\hline Hyperventilation & 0.26 & $0.08-0.90$ & 0.03 \\
\hline IABP & 1.30 & $1.08-1.57$ & 0.01 \\
\hline RRT & 1.98 & $1.27-3.09$ & $<0.01$ \\
\hline RVAD & 3.49 & $0.80-15.30$ & 0.10
\end{tabular}

ECMO, extracorporeal membrane oxygenation; SBP, systolic blood pressure; DBP, diastolic blood pressure; CABG, coronary artery bypass grafting; HTx, heart transplantation; ECLS, extracorporeal life support; DIC, disseminated intravascular coagulation; GI, gastrointestinal; WBC, white blood cells; RRT, renal replacement therapy; IABP, intra-aortic balloon pump; RVAD, right ventricle assist device.

TABLE 3. Multivariate Predictors of Mortality in the Elderly Patients

\begin{tabular}{llll}
\hline \multirow{2}{*}{ Variable } & \multicolumn{3}{l}{ Multivariate Analysis } \\
\cline { 2 - 4 } & $\mathrm{HR}$ & $95 \% \mathrm{Cl}$ & $\mathrm{p}$ Value \\
\hline Pre-ECMO variables & & & \\
\hline $70-74 \mathrm{y}$ (reference) & 1.00 & & \\
\hline $75-79 \mathrm{y}$ & 1.37 & $1.05-1.80$ & 0.05 \\
\hline$\geq 80 \mathrm{y}$ & 1.72 & $1.18-2.52$ & $<0.01$ \\
\hline Pre-ECMO MAP & 0.99 & $0.98-1.00$ & $<0.01$ \\
\hline Pre-ECMO HCO3 & 0.94 & $0.92-0.97$ & $<0.01$ \\
\hline Pre-ECMO RRT & 1.96 & $1.05-3.66$ & 0.04 \\
\hline Pre-ECMO 24 hours variables & & & \\
\hline Pre-ECMO MAP & 0.96 & $0.93-0.99$ & 0.02 \\
\hline Pre-ECMO HCO3 & 0.99 & $0.98-1.00$ & 0.02 \\
\hline Pre-ECMO RRT & 3.25 & $1.56-6.78$ & $<0.01$ \\
\hline pH at 24h & 0.01 & $0.00-0.13$ & $<0.01$ \\
\hline PaO2 at 24h per 10 mmHg & 1.04 & $1.03-1.06$ & $<0.01$ \\
\hline HCO3 at 24h & 0.95 & $0.90-1.00$ & 0.03 \\
\hline PIP (24 hours) & 1.04 & $1.01-1.08$ & 0.01 \\
\hline 24 hours variables + complications & & \\
\hline pH at 24h & 0.02 & $0.00-0.18$ & $<0.01$ \\
\hline PaO2 at 24h per 10 mmHg & 1.04 & $1.03-1.06$ & $<0.01$ \\
\hline HCO3 at 24h & 0.94 & $0.90-0.98$ & $<0.01$ \\
\hline PIP (24 hours) & 1.03 & $1.00-1.06$ & 0.03 \\
\hline Myocardial stunning & 4.49 & $1.31-15.38$ & 0.02 \\
\hline Pulmonary hemorrhage & 4.76 & $1.06-21.47$ & 0.04 \\
\hline RRT as a complication & 2.49 & $1.71-3.63$ & $<0.01$ \\
\hline CNS infarction & 4.30 & $1.15-16.05$ & 0.03 \\
\hline Surgical site bleeding & 1.53 & $1.02-2.30$ & 0.04 \\
\hline Days on ECMO & 1.04 & $1.00-1.08$ & 0.04
\end{tabular}

MAP, mean airway pressure; RRT, renal replacement therapy; PIP, peak inspiratory pressure; CNS, central nervous system; ECMO, extracorporeal membrane oxygenation. 
Age of 75-79 years was found to be a mortality predictor in multivariate analysis with however borderline level of significance HR 1.37; $95 \%$ Cls: $1.05-1.80 ; P=0.05$, as compared to age $>80$ years: HR 1.72 ; 95\% Cls: 1.18-2.52; $\mathrm{P}<0.01$. Among remaining mortality predictors, pre-ECMO mean airway pressure, $\mathrm{pH}$ at 24 hours, ECMO duration, and renal replacement therapy both before and during ECMO support, were independently associated with higher mortality.

\section{Complications}

Figure 3 graphically represents the percentage extent of complication occurring while on ECMO for RCS.

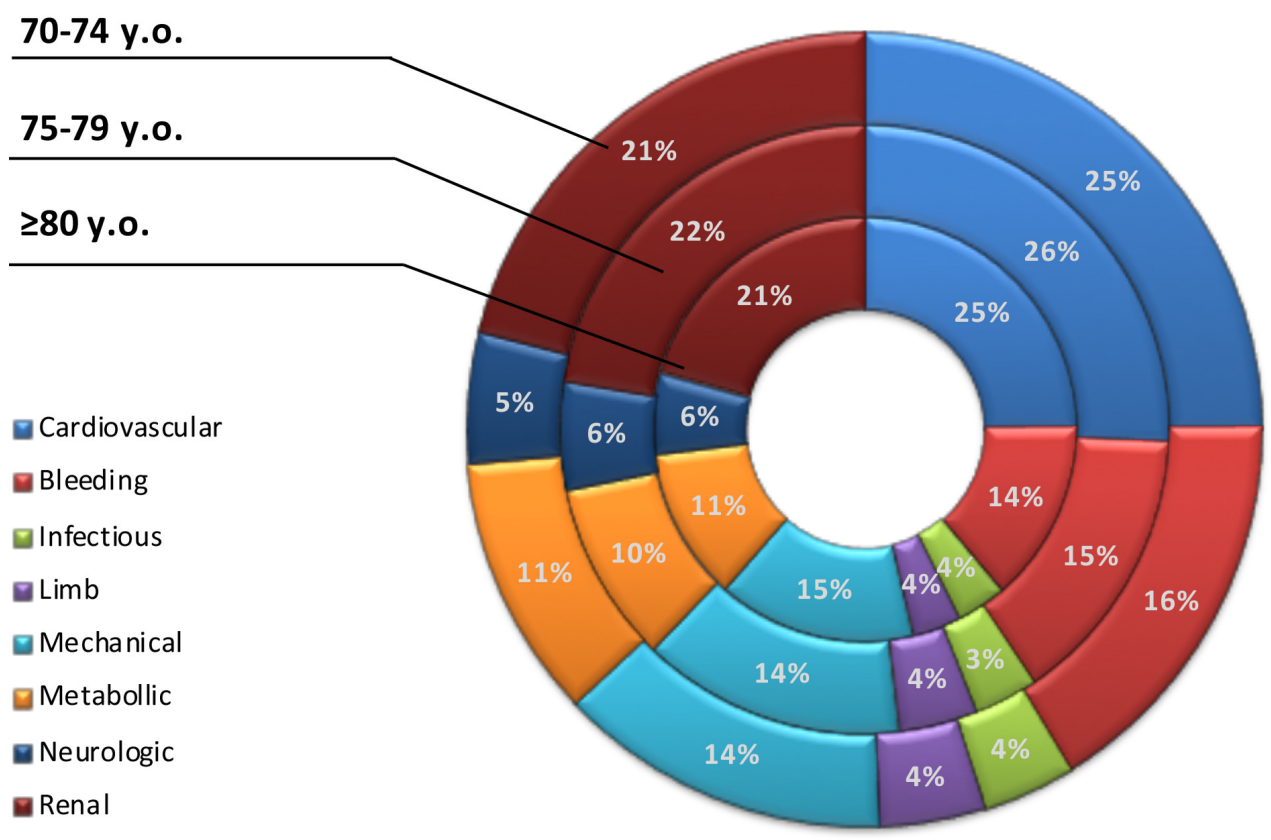

FIGURE 3. Overall complications rates in the ELSO registry analysis.

The most common complications were cardiovascular (25\%), followed by bleeding (15\%), renal $(22 \%)$, mechanical (14\%) and metabolic (11\%) complications. Limb complications along with neurologic and 
infectious sequeleae were observed in $13 \%$ of cases. There were no marked differences between age subgroups and incidence of clinically relevant complications Exact complications percentage rates according to age subgroup and complications' categories are delineated in Figures 4-11.

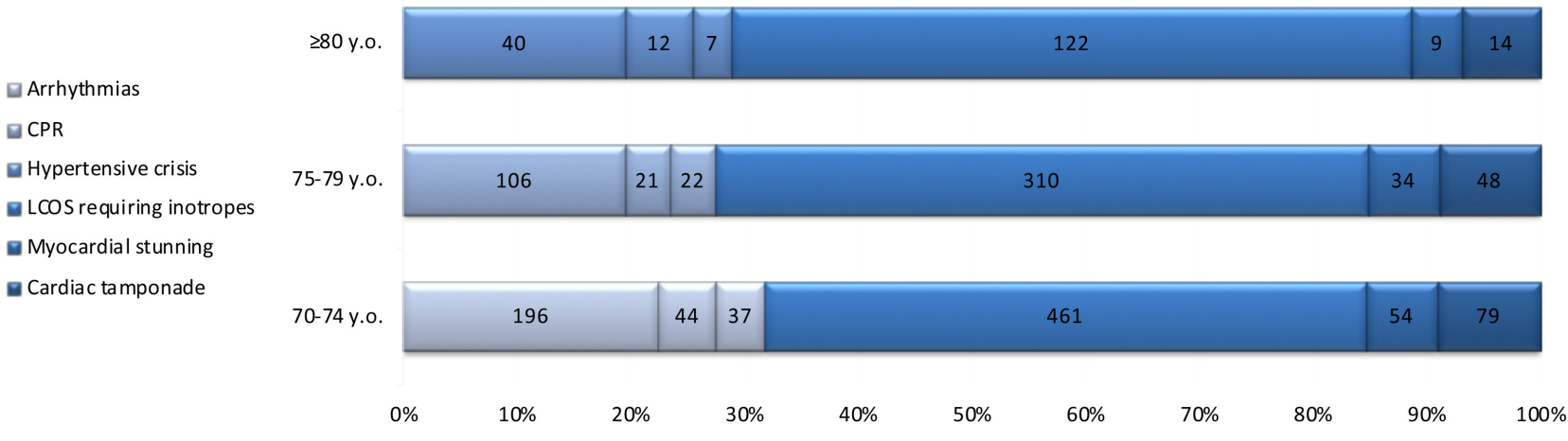

FIGURE 4. Cardiovascular complications rates.

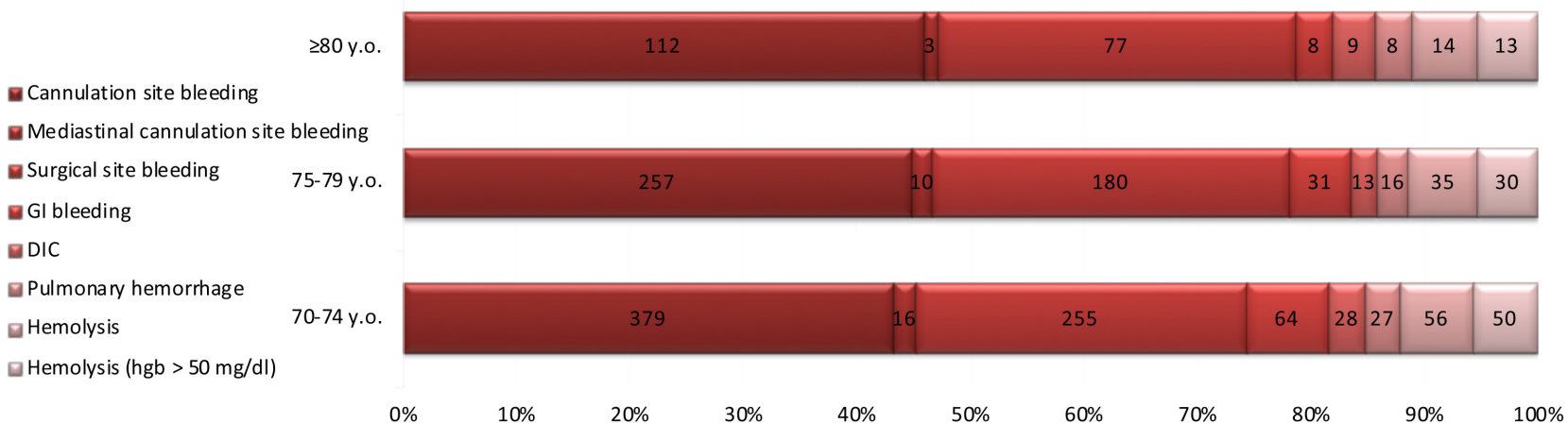

FIGURE 5. Bleeding complications rates.

$\geq 80$ y.o.

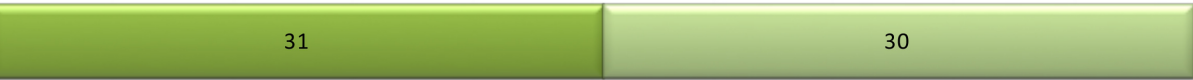

Elevated WBC (>15k/mm3) 75-79 y.o

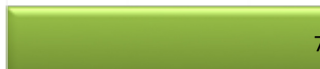

73

64

$\square$ Culture proven infection 70-74 y.o.

FIGURE 6. Infectious complications rates. 


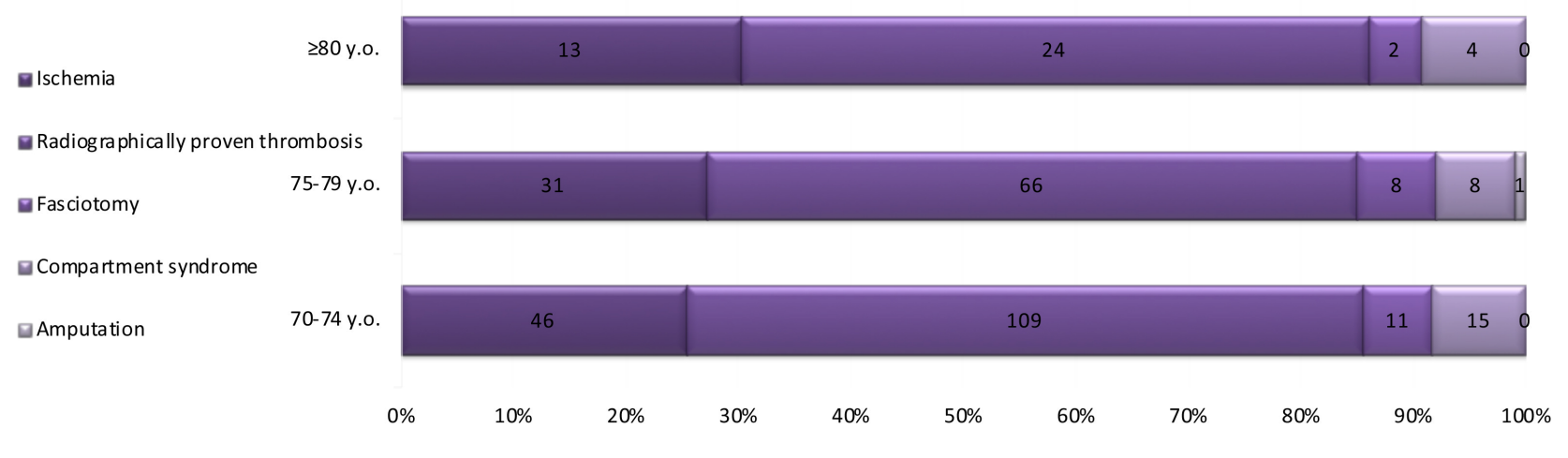

FIGURE 7. Limb complications rates.

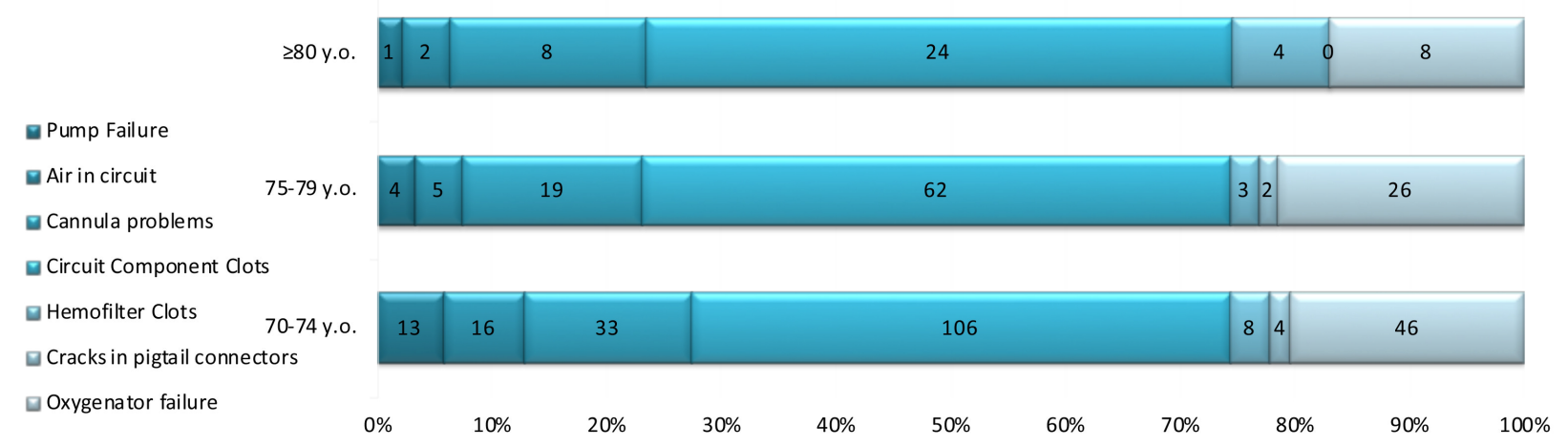

FIGURE 8. Mechanical complications rates.

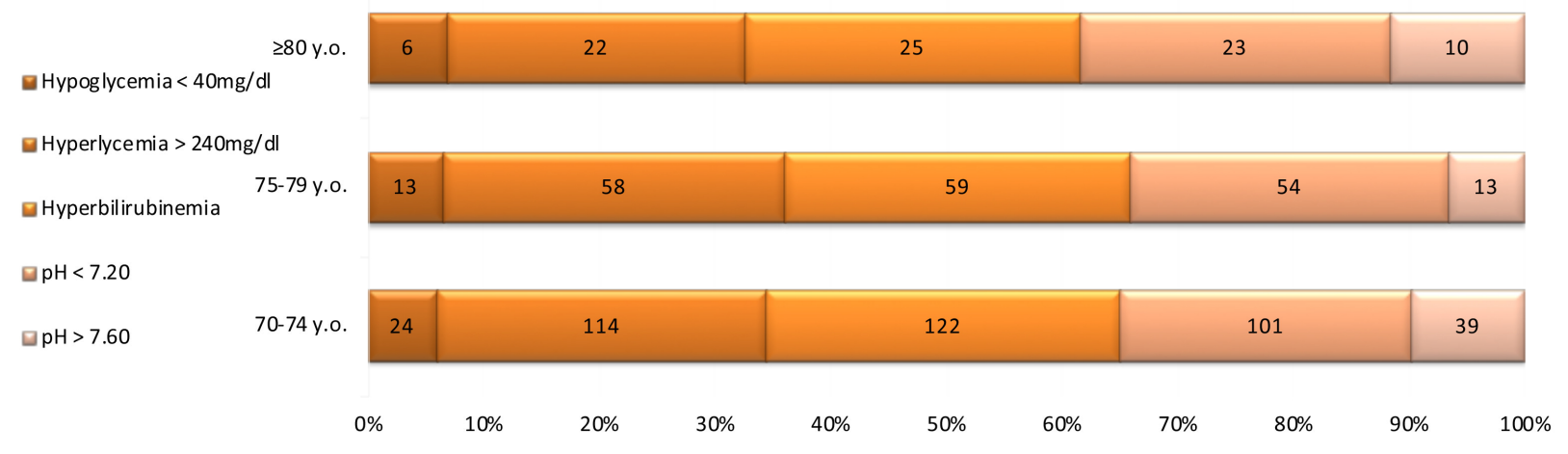

FIGURE 9. Metabolic complications rates. 


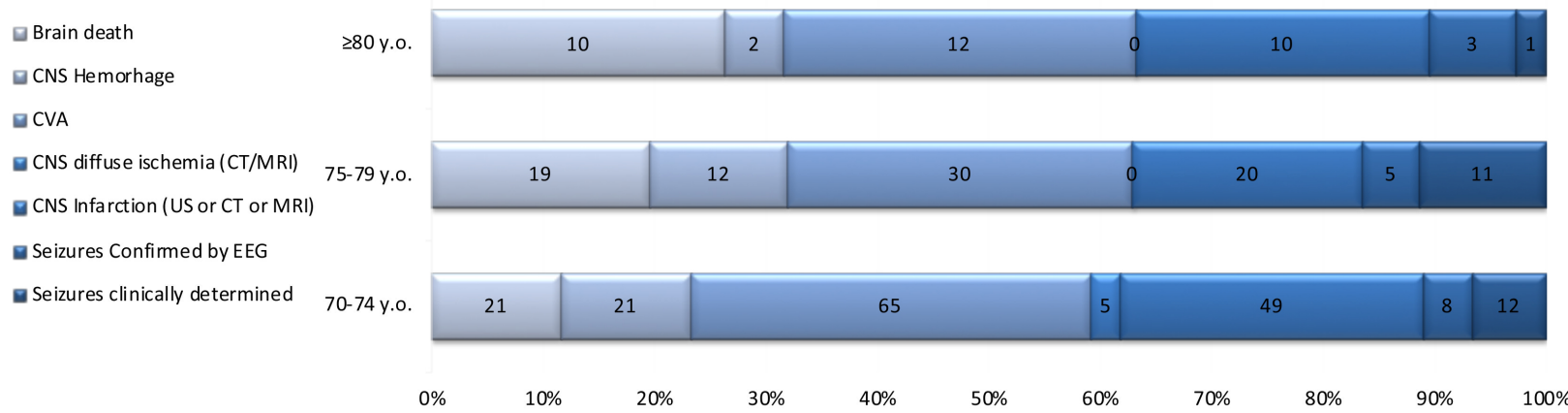

FIGURE 10. Neurologic complications rates.

$\square$ sCreatinine $1.5-3.0$ $\geq 80$ y.o.

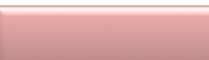

\section{8}
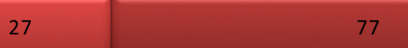

ascreatinine $>3.0$

75- 79 y.o.

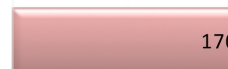

170

\section{0}

घenal Replacement Therapy 70-74 y.o.

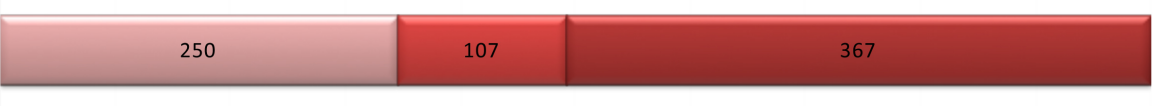

$0 \%$ $10 \%$

$20 \%$

$30 \% \quad 40 \%$

$60 \%$

FIGURE 11. Renal complications rates.

\section{Sensitivity analysis}

To corroborate the results on mortality beyond the multivariate analysis, subgroups comparison was performed opposing age subgroups $75-79$ years and $\geq 80$ years against $70-74$ years (reference subgroup) and calculating again the odds ratio for in-hospital mortality in 3 different scenarios: male vs female, post-cardiotomy- vs non-post-cardiotomy shock and peripheral vs central cannulation. Figure 12. Again, there were no statistical differences in the subgroup analyses. 


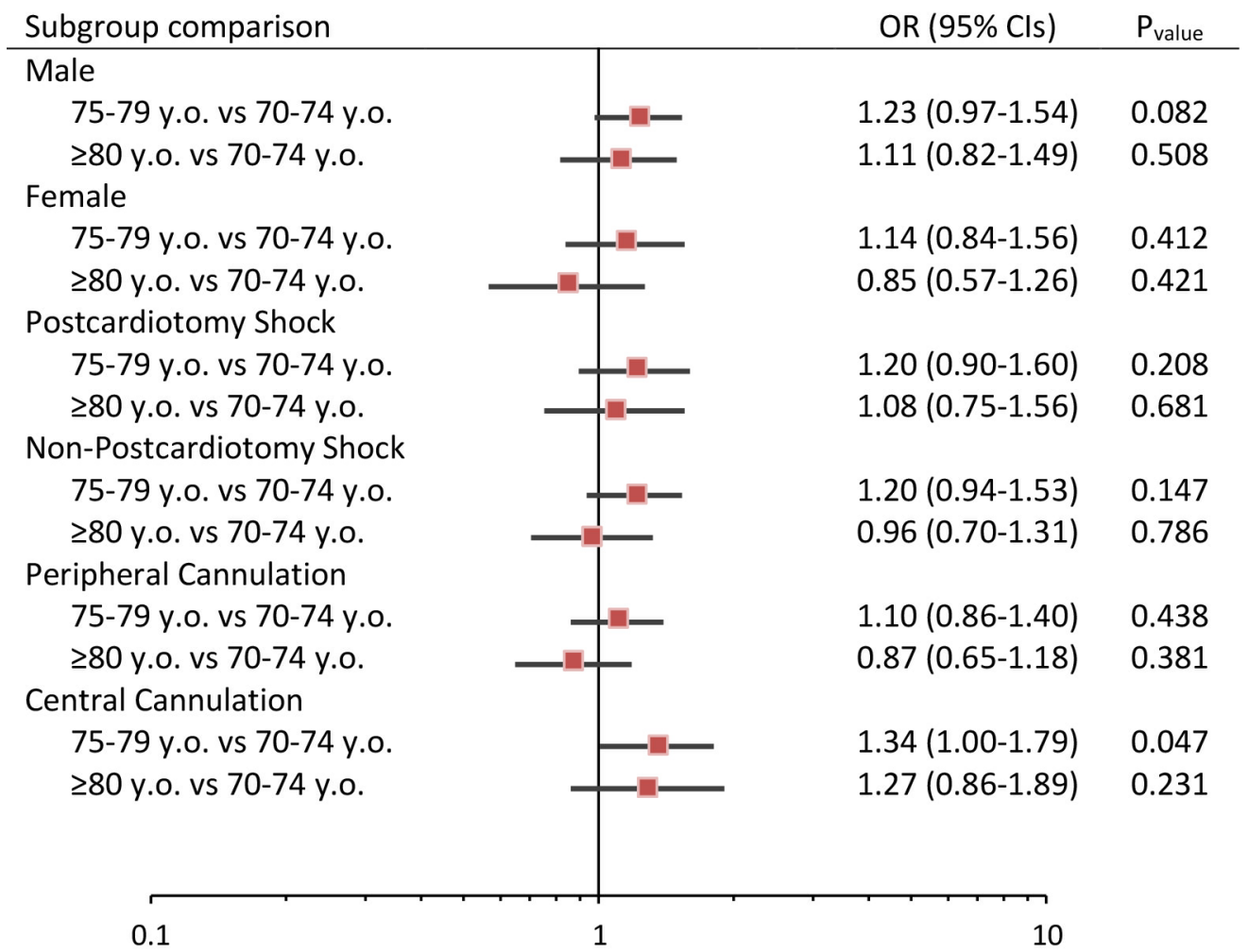

FIGURE 4. Subgroup analysis of in-hospital mortality among the age groups. Relative risks and 95\% confidence intervals

(Cl) are presented for the cumulative 30-day mortality in patients 75 to 79 y.o. and $\geq 80$ y.o. as compared to $70-74$ y.o. (reference). OR, odds ratio.

\section{Comment}

\section{Main Study Findings}

1. Our study showed that, as already shown in the trend of the general use of temporary mechanical circulatory support in RCS, V-A ECMO use in the elderly patients is exponentially increasing,

2. A relevant number of patients undergo $\mathrm{V}-\mathrm{A}$ ECMO placement because of post-cardiotomy RCS,

3. Overall in-hospital mortality in this challenging setting is not prohibitive and the trend is rather stable in the last years, 
4. Most likely due to already careful patient selection, even observing the age-adjusted outcome, even the more advanced ages (> 80 y.o.) have in-hospital results which do not discourage or contraindicate the use of ECMO in these age categories for RCS,

5. ECMO duration is significantly shorter in the more advanced age most likely due to earlier death or ECMO withdrawal because of futility (complications incompatible with recovery and life, like neurologic, family request, or attending personnel decision),

6. Cardiovascular-related complications represented the most frequent adverse event, followed by bleeding and renal complications. Neurologic complications (as shown by previous studies on this issue from ELSO Registry on CNS adverse events and V-A ECMO [7]) confirm high morbidity burden and strong association between neurologic complications and death.

7. Pre-ECMO factors ( $\mathrm{pH}$ at 24 hours), indication, and renal complication with dialysis, and ECMO duration were found as negative predictor regarding in-hospital survival.

Temporary mechanical circulatory support (MCS) is increasingly used in patients affected by acute heart failure. Stretch and associated have shown, through an analysis of the Nationwide Inpatient Sample from 2011 to 2014 including almost 12,000 patients undergoing short-term cardiocirculatory assistance, that the use of percutaneous device increased by $1,511 \%$, whereas, non-percutaneous device by $101 \%$ [2]. More interestingly, this study has shown that the MCS implant moved from $39.6 \%$ to $47.2 \%$ of patients older than 65 years of age among the overall study population, underlining the higher consideration for MCS use also in this challenging patient setting. Another recent analysis, from the Nationwide Inpatient Sample including the 2004-2014 year-period, showed that, among MCS types, 
ECMO had the highest growth $(1,421.4 \%)$, followed by other types of short-term MCS $(1,229.2 \%)$, percutaneous. Cardiocirculatory support (216.7\%), and intra-aortic balloon pump (140\%) [11] Despite increasing use and expertise, V-A ECMO represents an aggressive treatment in complex patients, thereby associated with high complication and mortality rates [7]. The search for predictors for unfavorable patient outcome is, therefore, critical in an attempt to improve results, resource utilization, and decision-making in challenging conditions [12]. Among several well-known factors, age has been accounted for less satisfactory in-hospital outcome [7,13-19]. Table 4.

Table 4. Summary of Favorable and Unfavorable Predictors for 30-Day/ln-Hospital Mortality after Veno-Arterial Extracorporeal Membrane Oxygenation in the Elderly Patients Based on the Presented Study (text underlined) and Other Published Investigations [references].

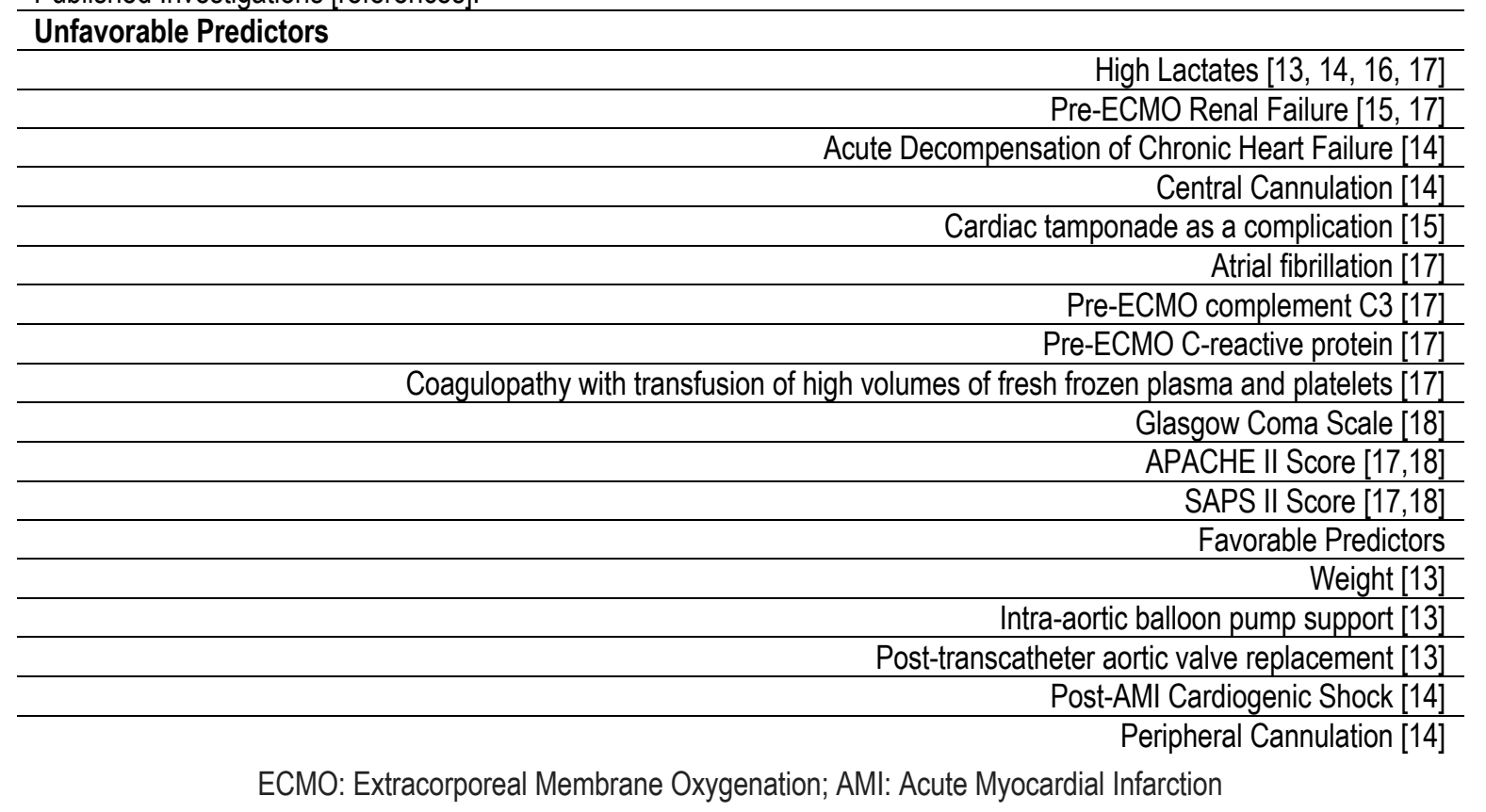

Indeed, a recent ELSO Registry analysis comparing younger versus older ( $\geq 70$ years of age) groups confirmed that elderly patients are exposed to higher rate of adverse results, either for complications or for in-hospital mortality [7]. However, in-hospital mortality rate was not discouraging, indicating that age per se' should not be considered an absolute contraindication for short-term use of V-A ECMO in RCS [7]. Our findings are relevant since, as mentioned above, indicate that although old age is linked 
to limited success rate, age was not directly related to ominous prognosis. Indeed, the 75-79 age group had somehow a worse outcome than patients with more advanced age, suggesting that careful selection, although not standardized by evidence-based data, may provide still ultimate favorable results.

Elderly patients have somehow peculiar features with respect to ECMO indications. Indeed, the most frequent condition for ECMO implant is post-cardiotomy, as shown by several invesitagors $[13,14,20]$. Post-cardiotomy indication for V-A ECMO placement is indeed common in older patients as compared to younger subjects [7]. This aspect may indicate that clinicians are more incline to consider and accept the use of temporary support due to RCS in the elderly patients than in non-surgical environment.

Peripheral cannulation was used more frequently in our patient population. This is in accordance with the findings of Sertic et al. [14] who also showed that central cannulation is associated with worse outcome in older patients. This aspect, however, may be related to worse clinical conditions usually pertained by post-cardiotomy situation. The use of $\mathrm{V}-\mathrm{A}$ ECMO for post-cardiotomy indication has been recently associated with poor results more likely because of pre-ECMO comorbidities, impact of preoperative cardiac illnesses and complicated surgical procedures, as well as type of complications more frequently observed in such a setting (bleeding) [6]. Other etiologies might have better results, as recently shown by Sertic et al who showed that post-acute myocardial infarction ECMO placement has better outcome, which is confirmed also at post-discharge assessment [14].

Complications rate is high in V-A ECM [21-23]. Our study confirms the high incidence of major complications in the elderly patients. Cardiovascular and end-organ perfusion adverse events are the 
most adverse events, followed by bleeding and renal complications, as shown by other investigators $[13,14]$. The shorter ECMO duration may derive from these dreadful complications which may impede acceptable cardio-circulatory support, or indicate extremely low chance of recovery, prompting the attending personnel to early interruption of ongoing mechanical assistance [14]. This attitude is also related to the almost unique bridge-to-recovery path which characterizes V-A ECMO in such patient category, being more advanced forms of therapy (left ventricular assist devices and heart transplant) almost unaccessible.

Decision to implant or continue such a temporary MCS, therefore, is often difficult and several clinicians may avoid or limit the indications in the elderly to reduce resource consumption in limitedly successful procedures. The availability, therefore, of indicators for more favorable outcome might be precious and guiding clinical management, either prior or during ECMO support. High lactates at ECMO implant and renal failure, particularly requiring dialysis, have been shown to independently predict unfavorable results in all V-A ECMO patients, but particularly in the elderly. Our data confirms such negative predictors, adding pre-ECMO circulatory state and ECMO duration as additional factors to consider. As mentioned, etiology of RCS may be also associated with more favorable conditions for recovery, being post-AMI as benign condition for positive outcome, whereas acute decompensation of chronic heart failure as well as the presence of cardiac arrest or prolonged low-flow time during cardiopulmonary resuscitation at ECMO implant, are associated with almost no chance of survival $[14,17]$. Our analysis of the ELSO Registry addressed only RCS cases, and therefore, we could not confirm this aspect. However, previous investigation using the same database to assess the results of ECMO in patient older than 75 years and undergoing V-A ECMO for refractory cardiac arrest, did show a 
reduced survival as compared to younger subjects ( $27 \%$ versus $40 \%$ of in-hospital survival), but, again, not so negative to contraindicates this kind of treatment, provided that underlying etiology and low-flow time are in accordance with the positive predictors of such variables $[14,24]$

\section{Limitations}

Data in the ELSO registry are submitted voluntarily and limited to in-hospital course with no follow-up information. Retrospectively collected data are subject to incomplete or missing reporting of events or patients. There were complete data for the outcome variable of death, but weight; arterial systolic, diastolic, and mean blood pressures; arterial oxygen saturation; pulmonary artery systolic, diastolic, and mean blood pressures; peak inflation pressure at $24 \mathrm{~h}$ on ECMO; and mean airway pressure at 24 $\mathrm{h}$ on ECMO all had some missing data. The size of the database and our use of multiple conditional specification method helped us to mitigate potential bias related to missing data. Nevertheless, it is possible that missing data might have biased the study findings. In addition, our data must be read with caution because the distribution of ages in the older cohort was narrow so there are few patients at the extreme ages. Indeed, limited access to elderly patients to ECMO should be taken into account, as many clinicians do not consider ECMO as an option in such patient settings also in the presence of RCS of various etiologies. Finally, patient survival and outcome are limited to in-hospital course because the ELSO registry does not include follow-up data collection after hospital discharge. Further clinical research about this aspect is therefore warranted.

\section{Conclusions}


The use of V-A ECMO for the treatment of RCS in the elderly patients is remarkably growing. In-hospital complication and mortality remain high, but not prohibitive to discourage ECMO use in such a challenging setting. Patient status at implant and etiology, complication type, ECMO duration, but not more advanced age, represent critical factor to take into consideration for V-A ECMO implant decisionmaking.

\section{REFERENCES}

1. Bellumkonda L, Gul B, Masri SC. Evolving concepts in diagnosis and management of cardiogenic shock. Am J Cardiol. 2018;122:1104-111

2. Stretch R, Sauer CM, Yuh DD et al. National trends in the utilization of short-term mechanical circulatory support: Incidence, outcomes, and cost analysis. J Am Coll Cardiol. $2014 ; 64: 1407-1415$

3. McCarthy FH, McDermott KM, Kini $\mathrm{V}$ et al.Trends in u.S. Extracorporeal membrane oxygenation use and outcomes: 2002-2012. Semin Thorac Cardiovasc Surg. 2015;27:8188

4. Sauer CM, Yuh DD, Bonde P. Extracorporeal membrane oxygenation use has increased by $433 \%$ in adults in the united states from 2006 to 2011 . ASAIO J. 2015;61:31-36

5. Maxwell BG, Powers AJ, Sheikh AY et al. Resource use trends in extracorporeal membrane oxygenation in adults: An analysis of the nationwide inpatient sample 1998-2009. J Thorac Cardiovasc Surg. 2014;148:416-421 e411 
6. Whitman GJ. Extracorporeal membrane oxygenation for the treatment of postcardiotomy shock. J Thorac Cardiovasc Surg. 2017;153:95-101

7. Lorusso R, Gelsomino S, Parise $\mathrm{O}$ et al. Venoarterial extracorporeal membrane oxygenation for refractory cardiogenic shock in the elderly patients: Trends in application and outcome from the extracorporeal life support organization (elso) registry. Ann Thorac Surg. 2017;104:62-69

8. Broman LM, Taccone FS, Lorusso $\mathrm{R}$ et al. The elso maastricht treaty for ecls nomenclature: Abbreviations for cannulation configuration in extracorporeal life support - a position paper of the extracorporeal life support organization. Crit Care. 2019;23:36

9. van Buuren S. Multiple imputation of discrete and continuous data by fully conditional specification. Stat Methods Med Res. 2007;16:219-242

10. Prince Nelson SL, Ramakrishnan V, Nietert PJ et al. An evaluation of common methods for dichotomization of continuous variables to discriminate disease status. Commun Stat Theory Methods. 2017;46:10823-10834

11. Strom JB, Zhao Y, Shen C et al. National trends, predictors of use, and in-hospital outcomes in mechanical circulatory support for cardiogenic shock. Eurolntervention. 2018;13:e2152e2159

12. Pagani FD. Extracorporeal membrane oxygenation for septic shock: Heroic futility? J Thorac Cardiovasc Surg 156:1110-1111. 
13. Pontailler M, Demondion P, Lebreton $G$ et al. Experience with Extracorporeal Life Support for Cardiogenic Shock in the Older Population more than 70 Years of Age. ASAIO J. 2017;63:279-284.

14. Sertic F, Diagne D, Rame E et al. Short-term outcomes and predictors of in-hospital mortality with the use of veno-arterial extracorporeal membrane oxygenation in the elderly patients with refractory cardiogenic shock. J Cardiovasc Surg (Torino). 2019

15. Mendiratta P, Tang X, Collins RT 2nd et al. Extracorporeal membrane oxygenation for respiratory failure in the elderly: a review of the Extracorporeal Life Support Organization registry. ASAIO J. 2014;60:385-90.

16. Biancari F, Saeed D, Fiore A et al. Postcardiotomy veno-arterial extracorporeal membrane oxygenation in patients aged >/=70 years. Ann Thorac Surg. 2019

17. Saxena P, Neal J, Joyce LD et al. Extracorporeal membrane oxygenation support in postcardiotomy elderly patients: The mayo clinic experience. Ann Thorac Surg. 2015;99:2053-2060

18. Lee SN, Jo MS, Yoo KD. Impact of age on extracorporeal membrane oxygenation survival of patients with cardiac failure. Clin Interv Aging. 2017;12:1347-1353.

19. Yeh TC, Chang HH, Ger LP et al. Clinical risk factors of extracorporeal membrane oxygenation support in older adults. PLoS One. 2018;13:e0195445

20. Salna M, Takeda K, Kurlansky P et al. The influence of advanced age on venous-arterial extracorporeal membrane oxygenation outcomes. Eur J Cardiothorac Surg. 2018;53:11511157 
21. Rastan AJ, Lachmann N, Walther T et al. Autopsy findings in patients on postcardiotomy extracorporeal membrane oxygenation (ecmo). Int J Artif Organs. 2006;29:1121-1131

22. Zangrillo A, Landoni G, Biondi-Zoccai G et al. A meta-analysis of complications and mortality of extracorporeal membrane oxygenation. Crit Care Resusc. 2013;15:172-178

23. Truby L, Mundy L, Kalesan B et al. Contemporary outcomes of venoarterial extracorporeal membrane oxygenation for refractory cardiogenic shock at a large tertiary care center. ASAIO J. 2015;61:403-409

24. Kim HS, Ha SO, Yu KH et al. Cerebral oxygenation as a monitoring parameter for mortality during venoarterial extracorporeal membrane oxygenation. ASAIO J. 2019;65:342-348 


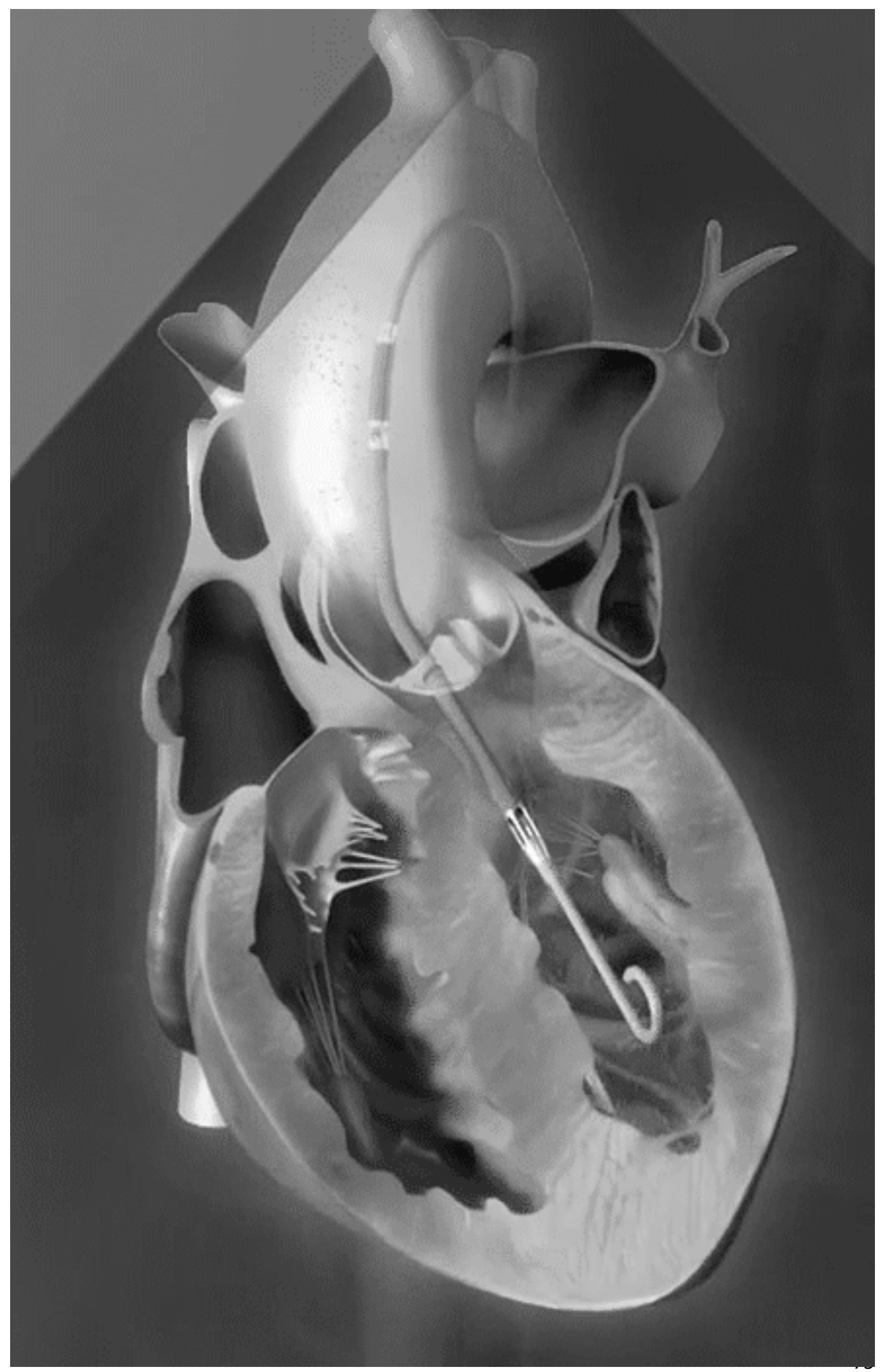




\section{CHAPTER 3}

LEFT VENTRICLE UNLOADING WITH VENO-ARTERIAL EXTRACORPOREAL MEMBRANE OXYGENATION FOR CARDIOGENIC SHOCK. SYSTEMATIC REVIEW AND META-ANALYSIS

Kowalewski M, Malvindi PG, Zielinski K, Martucci G, Slomka A, Suwalski P, Lorusso R, Meani P, Arcadipane A, Pilato M, Raffa GM. J Clin Med. 2020;9 
Abstract: During veno-arterial extracorporeal membrane oxygenation (VA-ECMO), the increase of left ventricular (LV) afterload can potentially increase the LV stress, exacerbate myocardial ischemia and delay recovery from cardiogenic shock (CS). Several strategies of LV unloading have been proposed. Systematic review and meta-analysis in accordance with the Preferred Reporting Items for Systematic Reviews and Meta-Analyses (PRISMA) statement included adult patients from studies published between January 2000 and March 2019. The search was conducted through numerous databases. Overall, from 62 papers, 7581 patients were included, among whom 3337 (44.0\%) received LV unloading concomitant to VA-ECMO. Overall, in-hospital mortality was $58.9 \%$ (4466/7581). A concomitant strategy of LV unloading as compared to ECMO alone was associated with $12 \%$ lower mortality risk (RR 0.88; 95\% Cl 0.82-0.93; $p<0.0001 ; I^{2}=40 \%$ ) and $35 \%$ higher probability of weaning from ECMO (RR 1.35; 95\% Cl 1.21-1.51; $\left.p<0.00001 ;\left.\right|^{2}=38 \%\right)$. In an analysis stratified by setting, the highest mortality risk benefit was observed in case of acute myocardial infarction: RR $0.75 ; 95 \% \mathrm{Cl} 0.68-0.83 ; p<0.0001 ; \mathrm{I}^{2}=0 \%$. There were no apparent differences between two techniques in terms of complications. In heterogeneous populations of critically ill adults in CS and supported with VA-ECMO, the adjunct of LV unloading is associated with lower early mortality and higher rate of weaning.

\section{Introduction}

Veno-arterial extracorporeal membrane oxygenation (VA-ECMO) provides life support for patients with refractory cardiogenic shock and significantly improves their survival working as a bridge to either recovery or other long-term treatments [1-7].

A well recognized limitation of the retrograde aortic flow while on VA-ECMO is the increase of left ventricular (LV) afterload [8], which can potentially lead to high LV stress and may exacerbate myocardial ischemia thus delaying recovery from cardiogenic shock [9]. Elevated LV pressure can also promote LV dilatation and trigger ventricular arrhythmias, or, secondarily, increase left atrial pressure 
causing pulmonary edema [10]. Ultimately, a reduced flow across the aortic valve can induce formation of thrombus in the LV or the aortic root [11].

Several LV unloading strategies have been described and proposed in order to minimize the risk of these complications [12], however, the available evidences are still conflicting whether these techniques are safe and useful adjuncts to VA-ECMO in patients with cardiogenic shock [13-15].

The aim of this study was to comprehensively assess the impact on early outcomes of different strategies of LV unloading in patients undergoing VA-ECMO and sustaining advanced cardiogenic shock by various etiologies.

\section{Experimental Section}

\subsection{Data Sources and Search Strategy}

This systematic review and meta-analysis was performed in accordance with the Preferred Reporting Items for Systematic Reviews and Meta-Analyses (PRISMA) [16]. Research of relevant studies was limited to the period January 2000-March 2019, through PubMed, EMBASE, CINAHL, the Cochrane Register of Controlled Clinical Trials (CENTRAL) and Google Scholar. Abstracts were eligible for detailed assessment if available online and reporting outcomes of interest. The search terms were: "extracorporeal membrane oxygenation" and "extracorporeal life support". No language restrictions were imposed. References of original articles were reviewed manually and cross-checked for other relevant reports. Authors of individual studies were contacted for missing data.

\subsection{Selection Criteria and Quality Assessment}

Human studies were included if they assessed survival after VA-ECMO or weaning from VA-ECMO support instituted for refractory cardiogenic shock. Research centers were checked to avoid potential overlapping patients and those reporting on smaller samples of patients were excluded. Reviews and case reports were not considered. Two independent reviewers (M.K. and K.Z.) selected the studies for 
inclusion, extracted studies, as well as patient characteristics of interest and relevant outcomes. Two authors (M.K. and K.Z.) independently assessed the trials' eligibility and risk of bias. Risk of bias at the individual study level was assessed using the Risk of Bias in Not-randomized Studies-of Interventions (ROBINS-I) tool [17]. Any divergences were resolved by a third reviewer (G.R.) and quantified using the approach of Cohen's kappa [18].

\subsection{Endpoint Selection}

The primary endpoints were in-hospital/30-day survival and weaning from VA-ECMO. Secondary endpoints were in-hospital cerebrovascular events (CVE), brain death, limb complications, reoperation for bleeding, sepsis and acute kidney failure w/wo continuous veno-venous hemofiltration (CVVH). Outcome definitions were the ones adopted by the investigators of the included studies.

\subsection{Statistical Analysis}

Statistical analyses were performed in Comprehensive Meta-Analysis, v. 2.0 (Biostat, Englewood, NJ, USA) and Review Manager 5.3 (The Nordic Cochrane Centre, Copenhagen, Denmark). The results are expressed as pooled untransformed proportion risk ratios (RR) with their $95 \%$ confidence intervals (Cl). Heterogeneity across studies was evaluated using the $\mathrm{I}^{2}$ test. To control for the anticipated heterogeneity among observational studies, absolute values and means were pooled using inverse variance random effects models. The primary endpoints were assessed in relation to the specific setting according to etiology of cardiogenic shock which included: (1) postcardiotomy shock (PCS), (2) acute myocardial infarction (AMI), (3) myocarditis and (4) mixed cohort of different etiologies including both postcardiotomy shock and AMI and other etiologies. Number needed to treat (NNT) was calculated for these subgroups. Secondary analysis focused on specific left ventricular unloading strategy: (1) intraaortic balloon pump (IABP), (2) LV venting with cannula in left atrium or ventricle or (3) percutaneous ventricular assist device (Impella, Abiomed, Danvers, MA, USA). We performed separate analysis of studies with propensity score matching or presenting propensity score adjusted odds ratio (OR) of 
primary endpoints. We investigated if use of different unloading strategies had influence on complication rates, ECMO duration and weaning rates by means of meta-regression analyses [19]. Similarly, we addressed the impact of hypertension, diabetes, age and gender on mortality outcome. Sensitivity analyses were performed by excluding from analyses single studies, one at a time, and repeating the calculations. Publication bias was assessed (1) by visual approach plotting log event rate against standard error in the funnel plot; and (2) by linear regression approach [20].

\section{Results}

\subsection{Study Selection}

The study selection process and reasons for exclusion of some studies are described in Figure 1.

A systematic search of the online databases allowed us to screen based on title and collect 271 potentially eligible records that were retrieved for scrutiny. Of those, 204 were further excluded because they were not pertinent to the design of the meta-analysis or did not meet the explicit inclusion criteria based on their content. To avoid potential double inclusion of patients' populations, 5 studies were excluded (A1-A5) since they were conducted in the same institution in overlapping time frames. Sixtythree series of patients from 62 observational studies (Appendix [6-67]) that enrolled 7581 patients eventually were included in the analysis. Patients were divided into 2 groups: those undergoing LV unloading concomitant to VA-ECMO and those undergoing VA-ECMO alone; (3337; 44.0\%) vs. (4244; $56.0 \%)$.

Patients undergoing VA-ECMO had a mean age of 57.8 years and $71.0 \%$ were male. Follow-up across the studies varied between 30-day and in-hospital survival. Table 1 details about studies and Table 2 about patients' characteristics. Risk of bias for each study across each of the seven risk of bias domains is presented in Table 3. Overall, the studies reported either moderate or serious risk of bias. 


\section{PRISMA 2009 Flow Diagram}

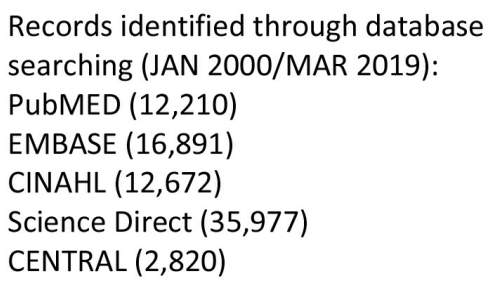

Additional records identified through other sources

$$
(n=45)
$$

Records after duplicates removed

$$
(n=271)
$$
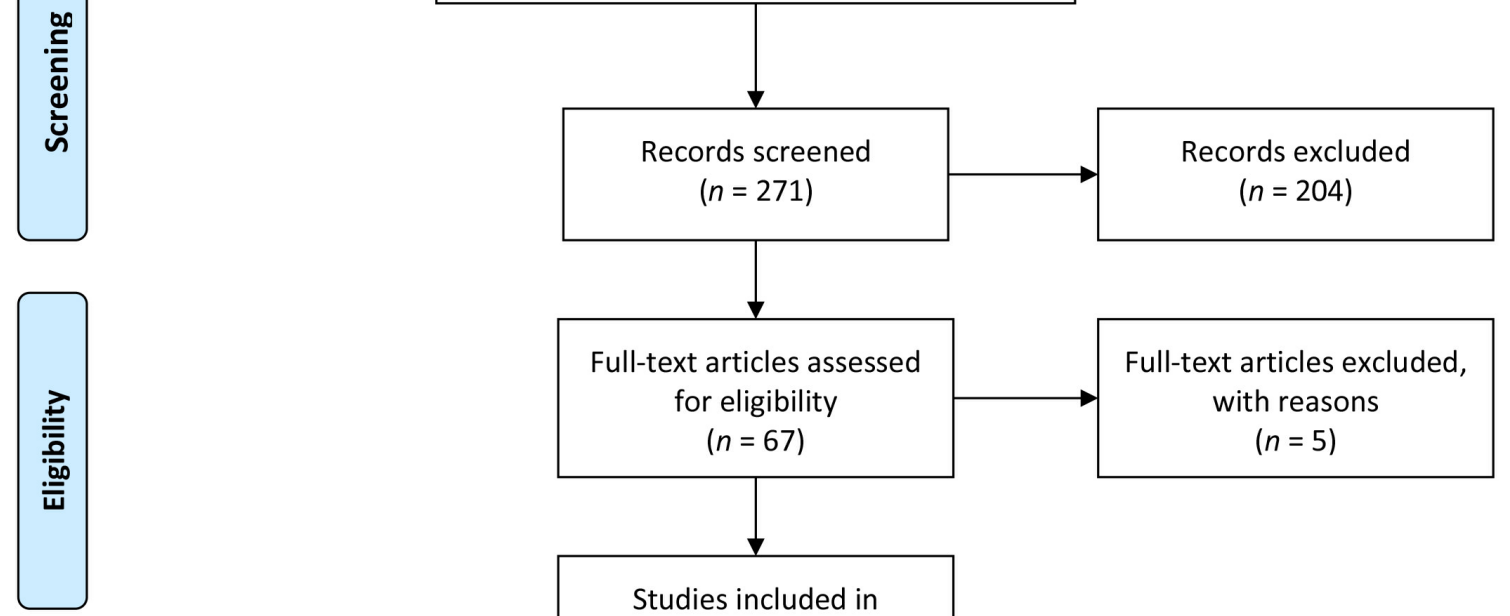

Studies included in qualitative synthesis $(n=62)$

Series included in quantitative synthesis (meta-analysis) $(n=63 ; \mathrm{N}=7,581)$

Figure 1. Preferred Reporting Items for Systematic Reviews and Meta-Analyses (PRISMA) flow diagram of study selection process. References of included and excluded studies are listed in the supplementary material.

Given the overall high risk of bias along with the limited number of studies, all articles were retained for the purposes of this review. Most commonly, biases arose from (1) selection of participants for the study, and (2) subjective distribution of the participants within the study arms. 
Populations included patients on VA-ECMO support for cardiogenic shock secondary to mixed etiologies (23 series, 4204 patients), PCS (22 series, 2324 patients) and AMI (14 series, 950 patients); VA-ECMO was employed for myocarditis in 4 series enrolling 103 patients.

\subsection{Primary Endpoints}

\subsubsection{Mortality}

All 63 included series (7581) contributed to the analysis of overall mortality; constructed funnel plot did not reveal any signs of publication bias or big study effect (Figure 2).

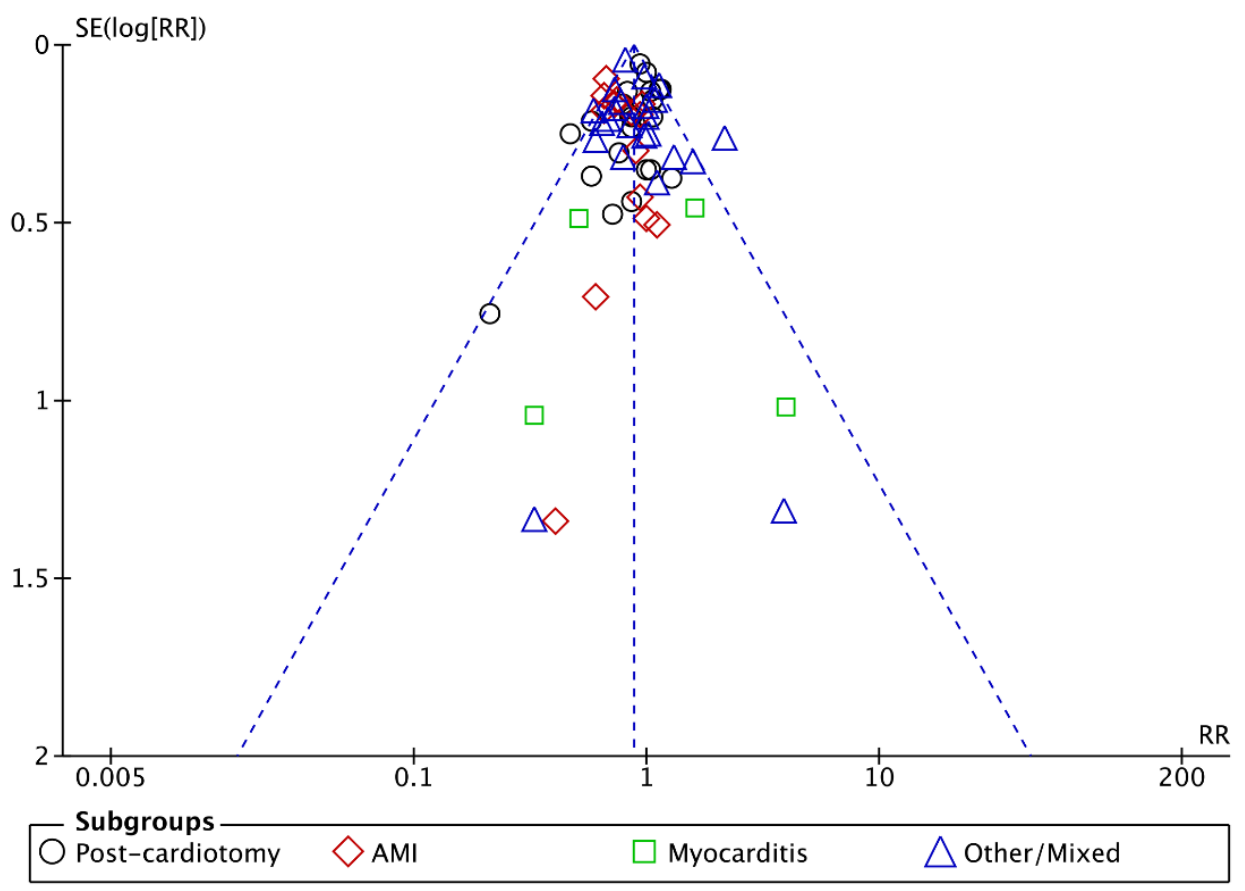

Figure 2. Publication bias analysis (SE: standard error).

Overall in-hospital mortality was $58.9 \%$ (4466/7581). LV unloading as adjunct to ECMO support was associated with $12 \%$ lower risk of mortality compared to ECMO alone therapy: risk ratio (RR); $95 \%$ confidence intervals (Cls): $0.88(0.82-0.93) ; p<0.0001 ;\left.\right|^{2}=40 \%$; Figure 3. 
Table 1. Characteristics of included studies.

\begin{tabular}{|c|c|c|c|c|c|c|c|c|c|c|c|}
\hline Study & Setting & Unloading Strategy & $\begin{array}{c}\text { Unloading } \\
\text { Strategy Usage } \\
(\%)\end{array}$ & N. of pts & $\begin{array}{l}\text { Peripheral } \\
\text { ECMO (\%) }\end{array}$ & $\begin{array}{c}\text { Distal } \\
\text { Perfusion (n) }\end{array}$ & ECMO Duration & Flow Rate & $\begin{array}{c}\text { Total } \\
\text { Weaning } \\
\text { Rate }(\%)\end{array}$ & $\begin{array}{l}\text { Bridge to } \\
\operatorname{VAD}(\mathrm{n})\end{array}$ & $\begin{array}{l}\text { Bridge to } \\
\text { HTx (n) }\end{array}$ \\
\hline Acheampong 2016 & PCS & IABP & 58.3 & 24 & $\mathrm{NR}$ & NR & $8.4(0.8-35.4) d$ & $\mathrm{NR}$ & 75 & 1 & 0 \\
\hline Akanni 2018 & mix & Impella & 12.9 & 225 & NR & NR & $3.54(1.64-5.97) d$ & $\mathrm{NR}$ & NR & 63 & NR \\
\hline Aoyama 2013 & AMI & IABP & 92.1 & 38 & 100 & NR & $126.5 \pm 146.4 \mathrm{~h}$ & NR & NR & NR & $\mathrm{NR}$ \\
\hline Asaumi 2005 & Other & IABP & 42.9 & 14 & 100 & $\mathrm{NR}$ & $130(42-171) \mathrm{h}$ & NR & 71.4 & 1 & 0 \\
\hline Aso 2016 & mix & IABP & 36.6 & 1650 & 100 & NR & $2.31 \mathrm{~d}$ & NR & 65.5 & NR & $\mathrm{NR}$ \\
\hline Aziz 2010 & $\operatorname{mix}$ & IABP & 20 & 10 & 100 & 10 & $5.8 \mathrm{~d}$ & 3.5 to $5.0 \mathrm{~L} / \mathrm{min}$ & 60 & 1 & 1 \\
\hline $\begin{array}{l}\text { Beiras-Fernandez } \\
2011\end{array}$ & PCS & IABP & 49.3 & 73 & NR & NR & $4.4 \pm 4.0 \mathrm{~d}$ & NR & NR & NR & $N R$ \\
\hline Beurtheret 2013 & $\operatorname{mix}$ & IABP & 31 & 87 & 100 & NR & NR & NR & 44.8 & 4 & 5 \\
\hline Biancari 2017 & PCS & IABP (47); vent (5) & 25.7 & 148 & 60.1 & 66 & $6.4 \pm 5.6 \mathrm{~d}$ & $\mathrm{NR}$ & 48.6 & 6 & 0 \\
\hline Brechot 2018 & $\operatorname{mix}$ & IABP & 40.2 & 259 & 100 & 259 & $2.2 \pm 4.3 \mathrm{~d}$ & $\begin{array}{l}3.5 \text { to } 4.5 \\
\mathrm{~L} / \mathrm{min}\end{array}$ & 55.2 & 34 & 21 \\
\hline Carroll 2015 & mix & IABP+Impella & 15.4 & 123 & 75 & NR & NR & $\mathrm{NR}$ & 56.1 & 2 & 29 \\
\hline Chen 2005 & Other & IABP & 60 & 10 & 100 & NR & $126.2 \pm 56.3 \mathrm{~h}$ & NR & 100 & 1 & 0 \\
\hline Chen 2006 & $\mathrm{AMI}$ & IABP & 86.1 & 36 & 100 & $\mathrm{NR}$ & $108.5 \pm 77.5 \mathrm{~h}$ & NR & 69.4 & $\mathrm{NR}$ & $\mathrm{NR}$ \\
\hline Chen 2018 & PCS & IABP & 63.3 & 60 & 100 & 100 & $5.3 \pm 2.8 \mathrm{~d}$ & NR & 48 & NR & $\mathrm{NR}$ \\
\hline Cho 2018 & AMI & IABP & 4.8 & 42 & 100 & NR & NR & $\begin{array}{c}\text { initial of } 2.2 \\
\mathrm{~L} / \mathrm{min} / \mathrm{m}^{2} \text {, which } \\
\text { was } \\
\text { subsequently } \\
\text { regulated to } \\
\text { maintain a mean } \\
\text { arterial pressure } \\
\text { of } 65 \mathrm{mmHg}\end{array}$ & 29.3 & NR & NR \\
\hline Choi 2018 & AMI & IABP & 35.2 & 145 & $\mathrm{NR}$ & 21 & $2.0 \mathrm{~d}$ [IQR: $1.0-4.0]$ & $3.3 \mathrm{~L} / \mathrm{min}$ & 62.8 & NR & 1 \\
\hline Chung 2011 & AMI & IABP & 70 & 20 & NR & $\mathrm{NR}$ & $3.8 \pm 4.3 \mathrm{~d}$ & NR & 70 & NR & NR \\
\hline Czobor 2016 & $\operatorname{mix}$ & IABP (10); Impella (1) & 44 & 25 & 100 & 25 & NR & $\begin{array}{l}\text { initiated at up to } \\
4.5 \mathrm{~L} / \mathrm{min} \text { and } \\
\text { adjusted }\end{array}$ & NR & NR & NR \\
\hline Elsharkawy 2010 & PCS & IABP & 9.4 & 233 & 33 & NR & NR & NR & NR & 28 & 25 \\
\hline Formica 2010 & PCS & IABP & 69 & 42 & 64.3 & 10 & $7.9 \pm 5.3 d$ & $\begin{array}{c}\text { to maintain a } \\
\text { cardiac index of } \\
2.5 \mathrm{l} / \mathrm{min} / \mathrm{m}^{2}\end{array}$ & 69 & NR & NR \\
\hline Gass 2014 & mix & IABP & 41.5 & 135 & 100 & $\mathrm{NR}$ & $8.5 \pm 7.1 \mathrm{~d}$ & 2.5 to $4.0 \mathrm{~L} / \mathrm{min}$ & 40.7 & 20 & 0 \\
\hline Guihaire 2017 & PCS & IABP (25); vent (13) & 27.2 & 92 & 84.8 & NR & $6 d$ & NR & 48 & 2 & 2 \\
\hline Hei 2011 & PCS & IABP & 16.2 & 68 & 100 & 68 & $4.75 d$ & $\begin{array}{c}40-220 \\
\mathrm{~mL} / \mathrm{kg} / \mathrm{min}\end{array}$ & 76.5 & 8 & NR \\
\hline Kagawa 2012 & AMI & IABP & 82.6 & 86 & 100 & NR & $24(8-65) \mathrm{h}$ & $\begin{array}{c}\text { minimum } \\
\text { flow of } 2.0 \mathrm{~L} / \mathrm{min}\end{array}$ & 50 & NR & NR \\
\hline Kim 2014 & AMI & IABP & 75.9 & 58 & $\mathrm{NR}$ & $\mathrm{NR}$ & $68.7 \pm 17.4 \mathrm{~h}$ & NR & 41.4 & NR & NR \\
\hline
\end{tabular}




\begin{tabular}{|c|c|c|c|c|c|c|c|c|c|c|c|}
\hline Lee 2016 & mix & IABP & 8.7 & 23 & 100 & NR & $98(60-192) \mathrm{h}$ & 3.0 to $4.0 \mathrm{~L} / \mathrm{min}$ & NR & NR & $\mathrm{NR}$ \\
\hline Lee 2017 & $\mathrm{mx}$ & IABP & 16.3 & 135 & 100 & NR & $99.6 \pm 103.23 \mathrm{~h}$ & $\begin{array}{c}\text { adjusted to } \\
\text { maintain a } \\
\text { cardiac index of } \\
2.4 \mathrm{~L} / \mathrm{min} / \mathrm{m}^{2}\end{array}$ & 39.3 & NR & NR \\
\hline Li 2015 & PCS & IABP & 59.3 & 123 & 100 & 123 & $4.3 \mathrm{~d}$ & $3.0 \mathrm{~L} / \mathrm{min}$ & 56.1 & NR & $\mathrm{NR}$ \\
\hline Lin 2016 & mix & IABP & 57.1 & 529 & 100 & 256 & NR & NR & $\mathrm{NR}$ & 2 & 29 \\
\hline Lorusso 2016 & other & IABP (34); vent (13) & 59.6 & 57 & 82.5 & 63.1 & $9.9 \pm 19 \mathrm{~d}$ & NR & 75.5 & 2 & 3 \\
\hline Luo 2009 & mix & IABP & 24.4 & 45 & 88.9 & NR & $5.48 d$ & $\begin{array}{l}\text { Initially, } 2.5 \\
\text { I/min/m2 with the } \\
\text { condition } \\
\text { improved, } 40 \\
\mathrm{~mL} / \mathrm{kg} / \mathrm{min} . \\
\text { adjusted the } \\
\text { ECMO blood flow } \\
\text { rate in time to } \\
\text { maintain LVEF } \\
\end{array}$ & 60 & 5 & NR \\
\hline Mikus 2013 & PCS & IABP & 92.9 & 14 & 42.9 & 14 & $5 d$ & $\begin{array}{c}\text { to maintain } \\
\text { cardiac index of } \\
2.6 \mathrm{l} / \mathrm{min} / \mathrm{m}^{2}\end{array}$ & 50 & 0 & 0 \\
\hline Muller 2016 & AMI & IABP (96); Impella (3) & 69.6 & 138 & NR & 132 & $7 \mathrm{~d}$ & NR & 35.5 & 13 & 18 \\
\hline Nakamura 2015 & other & IABP & 95.5 & 22 & 100 & 22 & $179 \pm 25 \mathrm{~h}$ & $\begin{array}{l}\text { initial flow rate } \\
\text { was 3.0-3.5 } \\
\text { L/min; According } \\
\text { to the indicators } \\
\text { of peripheral } \\
\text { circulatory failure } \\
\text { (e.g., arterial } \\
\text { blood gas } \\
\text { analysis, mixed } \\
\text { venous oxygen } \\
\text { saturation, lactic } \\
\text { acid and urinary } \\
\text { output), the flow } \\
\text { rate of ECMO } \\
\text { was decreased }\end{array}$ & NR & 1 & 0 \\
\hline Negi 2016 & AMI & IABP & 60 & 15 & 100 & NR & $1.875 \mathrm{~d}$ & NR & 53.3 & NR & 1 \\
\hline Overtchouk 2018 & AMI & IABP & 59.4 & 106 & NR & 106 & NR & NR & NR & 10 & 2 \\
\hline Papadopoulos 2015 & PCS & IABP & 21.9 & 360 & 90 & NR & $7 \pm 1 \mathrm{~d}$ & $50-70 \mathrm{~mL} / \mathrm{kg} / \mathrm{min}$ & 58.1 & 6 & 2 \\
\hline Pappalardo 2016 & mix & Impella & 21.7 & 157 & 100 & 39 & $167(72-286) h^{*}$ & Maximal speed & $36.3^{*}$ & $8^{*}$ & 0 * \\
\hline Park 2014 & AMI & IABP & 42.7 & 96 & 100 & NR & NR & $\begin{array}{c}\text { initial of } 2.2 \\
\mathrm{~L} / \mathrm{min} / \\
\mathrm{m} 2 \\
\text { and adjusted to } \\
\text { maintain a mean } \\
\text { arterial } \\
\end{array}$ & 60.4 & NR & NR \\
\hline
\end{tabular}




\begin{tabular}{|c|c|c|c|c|c|c|c|c|c|c|c|}
\hline & & & & & & & & $\begin{array}{c}\text { pressure of } 65 \\
\mathrm{~mm} \mathrm{Hg}\end{array}$ & & & \\
\hline Patel 2018 & mix & Impella & 45.5 & 66 & 100 & $\mathrm{NR}$ & $\mathrm{NR}$ & NR & 56.1 & 5 & $\mathrm{NR}$ \\
\hline Pokersnik 2012 & PCS & IABP & 59.2 & 49 & 65.3 & 32 & $3.8 \pm 3.4 d$ & $\begin{array}{c}\text { gradually } \\
\text { increased to } \\
2.0 \mathrm{~L} / \mathrm{min} / \mathrm{m}^{2} \text { and } \\
\text { adjusted as } \\
\text { necessary to } \\
\text { maintain } \\
\text { adequate } \\
\text { hemodynamics } \\
\text { and oxygen } \\
\text { delivery. }\end{array}$ & 55.1 & 2 & 0 \\
\hline Poptsov 2014 & PCS & vent & 60.9 & 46 & 100 & 100 & $\mathrm{NR}$ & NR & NR & $\mathrm{NR}$ & $\mathrm{NR}$ \\
\hline Raffa 2017 & PCS & IABP & 26.7 & 86 & 34.9 & NR & $5 d$ & NR & 49 & NR & $\mathrm{NR}$ \\
\hline Rastan 2010 & PCS & IABP & 74.1 & 517 & 39.3 & 121 & $3.28 \pm 2.85 d$ & NR & 63.3 & 15 & 5 \\
\hline Ro 2013 & mix & IABP & 23.7 & 253 & 96.4 & NR & $71.0 \mathrm{~h}$ & $\mathrm{NR}$ & 46.6 & $\mathrm{NR}$ & 3 \\
\hline Russo 2010 & mix & IABP & 85.7 & 14 & 57.1 & 253 & $10.2 \mathrm{~d}$ & NR & 78.6 & 2 & 6 \\
\hline Sakamoto 2012 & AMI & IABP & 95.9 & 98 & 100 & NR & $68.9 \pm 62.7 \mathrm{~h}$ & NR & 55.1 & 0 & 0 \\
\hline Santise 2014 & PCS & IABP & 72.2 & 18 & 17 & NR & $6.7 \pm 3.2 \mathrm{~d}$ & $\begin{array}{c}4164 \pm 679 \\
\mathrm{~mL} / \mathrm{min}\end{array}$ & 72.2 & NR & NR \\
\hline Shinn 2009 & mix & IABP & 33.7 & 92 & 100 & 24 & $90.9 \pm 126.0 \mathrm{~h}$ & NR & 64.1 & $\mathrm{NR}$ & $\mathrm{NR}$ \\
\hline Shmack 2017 & mix & vent & 41.7 & 48 & 20.1 & $\mathrm{NR}$ & $6.10 \pm 3.81 \mathrm{~d}$ & $2.6 \mathrm{~L} / \mathrm{min} / \mathrm{m}^{2}$ & NR & 14 & 5 \\
\hline Slottosch 2012 & PCS & IABP & 93.5 & 77 & 100 & 77 & $79 \pm 57 \mathrm{~h}$ & 4-7 L/min & 62.3 & $\mathrm{NR}$ & $\mathrm{NR}$ \\
\hline Slottosch 2017 & mix & IABP & 74.8 & 139 & 79.1 & $\mathrm{NR}$ & $4.9 \mathrm{~d}$ & $4-7 \mathrm{~L} / \mathrm{min}$ & 43.2 & $\mathrm{NR}$ & 15 \\
\hline Smedira 2001 & mix & IABP & 54.5 & 202 & 75.7 & NR & NR & NR & 58.9 & 6 & 42 \\
\hline Tepper 2018 & mix & IABP & 50 & 60 & 0 & $\mathrm{NR}$ & NR & $5.2 \mathrm{~L} / \mathrm{min}$ & 60 & 10 & $\mathrm{NR}$ \\
\hline Unosawa 2012 & PCS & IABP & 83 & 47 & 68.1 & NR & $63.5 \pm 61.5 \mathrm{~h}$ & $2.34 \mathrm{~L} / \mathrm{min}$ & 61.7 & 0 & 0 \\
\hline van den Brink 2017 & AMI & IABP & 16.7 & 12 & 100 & $\mathrm{NR}$ & $5(1-10) d$ & NR & 66.7 & 1 & $\mathrm{NR}$ \\
\hline Wang 2013 & PCS & IABP & 47.1 & 87 & NR & 37 & $61 \pm 37 \mathrm{~h}$ & $\begin{array}{l}\text { calculated to } \\
\text { supply at least } \\
\text { adequate total } \\
\text { systemic } \\
\text { circulatory } \\
\text { support (2.2 } \\
\mathrm{L} / \mathrm{min} \text { ) and to } \\
\text { achieve a SvO } \\
\text { of } 70 \%\end{array}$ & 58.6 & NR & $\mathrm{NR}$ \\
\hline Weber 2017 & mix & IABP & 27.3 & 11 & 100 & 11 & $123.8 \pm 120.9 \mathrm{~h}$ & NR & 0 & NR & NR \\
\hline Wu 2012 & mix & IABP & 73.3 & 60 & NR & NR & NR & NR & 63.3 & $\mathrm{NR}$ & $\mathrm{NR}$ \\
\hline Xu 2016 & mix & IABP & 68.8 & 16 & NR & NR & $119.3 \pm 114.8 \mathrm{~h}$ & NR & NR & NR & NR \\
\hline Zhao 2015 & PCS & IABP & 66.7 & 24 & 95.8 & NR & $115.23 \pm 70.17 \mathrm{~h}$ & $\begin{array}{l}49 \mathrm{~mL} / \\
\mathrm{min} / \mathrm{kg}\end{array}$ & 66.7 & $1^{*}$ & $N R$ \\
\hline Zhong 2017 & PCS & $\operatorname{IABP}(9)$; vent (3) & 33.3 & 36 & 80.6 & $\mathrm{NR}$ & $77.5 \pm 34.5 \mathrm{~h}$ & NR & 66.7 & $\mathrm{NR}$ & $\mathrm{NR}$ \\
\hline
\end{tabular}

* concurrent use of LVAD and ECMO. 
Table 2. Characteristics of patients.

\begin{tabular}{|c|c|c|c|c|c|c|c|c|c|c|}
\hline Study & Setting & Unloading Strategy & $\begin{array}{c}\text { Unloading Strategy } \\
\text { Usage }(\%)\end{array}$ & N. of pts & $\begin{array}{c}\text { Age } \\
\text { (Years) } \\
\end{array}$ & $\begin{array}{l}\text { Male } \\
(\%)\end{array}$ & $\begin{array}{c}\text { Diabetes } \\
(\%)\end{array}$ & $\begin{array}{l}\text { Hypertension } \\
(\%)\end{array}$ & $\begin{array}{l}\mathrm{PCl}^{*} \\
(\%)\end{array}$ & $\begin{array}{c}\text { CABG ** } \\
(\%)\end{array}$ \\
\hline Acheampong 2016 & PCS & IABP & 58.3 & 24 & 41 (IQR: 22-75) & 58.3 & NR & NR & NA & NA \\
\hline Akanni 2018 & $\operatorname{mix}$ & Impella & 12.9 & 225 & $57(46-67)$ & 69.3 & 29 & 57 & NR & NR \\
\hline Aoyama 2013 & AMI & IABP & 92.1 & 38 & $59.9 \pm 13.5$ & 92.1 & NR & NR & 89 & 11 \\
\hline Asaumi 2005 & Other & IABP & 42.9 & 14 & $38.4 \pm 15.8$ & 50 & NR & NR & NA & NA \\
\hline Aso 2016 & $\operatorname{mix}$ & IABP & 36.6 & 1650 & $\mathrm{NR}$ & 69.4 & $\mathrm{NR}$ & $\mathrm{NR}$ & $\mathrm{NR}$ & $\mathrm{NR}$ \\
\hline Aziz 2010 & mix & IABP & 20 & 10 & $45.3 \pm 18.9$ & 50 & 10 & 40 & NR & NR \\
\hline Beiras-Fernandez 2011 & PCS & IABP & 49.3 & 73 & $49.3 \pm 18.0$ & 64.4 & NR & NR & NA & NA \\
\hline Beurtheret 2013 & $\operatorname{mix}$ & IABP & 31 & 87 & $46 \pm 15$ & 67.8 & 15 & 24 & NR & NR \\
\hline Biancari 2017 & PCS & IABP (47); vent (5) & 25.7 & 148 & $65.4 \pm 9.4$ & 78.4 & 40 & NR & NA & NA \\
\hline Brechot 2018 & $\operatorname{mix}$ & IABP & 40.2 & 259 & 50.2 & 69.9 & NR & NR & NR & NR \\
\hline Carroll 2015 & $\operatorname{mix}$ & IABP+Impella & 15.4 & 123 & $56(41-65)$ & 69 & 20 & 42 & 6 & 4 \\
\hline Chen 2005 & Other & $\mathrm{IABP}$ & 60 & 10 & $37.4 \pm 14.7$ & NR & NR & NR & NA & NA \\
\hline Chen 2006 & AMI & IABP & 86.1 & 36 & $57 \pm 10$ & 91.7 & 39 & NR & 19 & 78 \\
\hline Chen 2018 & PCS & IABP & 63.3 & 60 & $51.4 \pm 12.7$ & 75 & 17 & 33 & NA & NA \\
\hline Cho 2018 & AMI & IABP & 4.8 & 42 & $63.48 \pm 11.46$ & 66.7 & 41 & 48 & $100[74]$ & 0 \\
\hline Choi 2018 & AMI & IABP & 35.2 & 145 & $64.6 \pm 11.7$ & 75.9 & 54 & 53 & $90[83]$ & NR \\
\hline Chung 2011 & AMI & IABP & 70 & 20 & $67.7 \pm 11.7$ & 30 & 35 & 45 & 35 & 55 \\
\hline Czobor 2016 & $\operatorname{mix}$ & IABP (10); Impella (1) & 44 & 25 & NR & 80 & 44 & 52 & NR & NR \\
\hline Elsharkawy 2010 & PCS & IABP & 9.4 & 233 & NR & 67.4 & 21 & NR & NA & NA \\
\hline Formica 2010 & PCS & IABP & 69 & 42 & $64.3 \pm 11.3$ & 66.7 & 33 & 67 & NA & NA \\
\hline Gass 2014 & $\operatorname{mix}$ & IABP & 41.5 & 135 & $57.3 \pm 15.3$ & 64.4 & 31 & 48 & NR & NR \\
\hline Guihaire 2017 & PCS & IABP (25); vent (13) & 27.2 & 92 & $64.5(18-83)$ & 59 & NR & NR & NA & NA \\
\hline Hei 2011 & PCS & IABP & 16.2 & 68 & $49.2 \pm 13.3$ & 76.5 & NR & NR & NA & NA \\
\hline Kagawa 2012 & AMI & IABP & 82.6 & 86 & $63(56-72)$ & 81 & 31 & 63 & 71 & 0 \\
\hline Kim 2014 & AMI & IABP & 75.9 & 58 & $61.2 \pm 11.3$ & 82.8 & NR & NR & NR & NR \\
\hline Lee 2016 & $\operatorname{mix}$ & IABP & 8.7 & 23 & $55(40,68)$ & 90 & 52 & 52 & 65 & NR \\
\hline Lee 2017 & $m x$ & IABP & 16.3 & 135 & $59.44 \pm 16.55$ & 69.6 & 38 & 42 & NR & NR \\
\hline Li 2015 & PCS & IABP & 59.3 & 123 & $56.2 \pm 11.8$ & 65.9 & NR & NR & NA & NA \\
\hline Lin 2016 & $\operatorname{mix}$ & IABP & 57.1 & 529 & $55.1 \pm 15.3$ & 75.4 & 32 & 35 & NR & NR \\
\hline Lorusso 2016 & other & IABP (34); vent (13) & 59.6 & 57 & $37.6 \pm 11.8$ & 35.1 & NR & NR & NR & NR \\
\hline Luo 2009 & $\operatorname{mix}$ & IABP & 24.4 & 45 & $49.0 \pm 14.1$ & 76 & NR & NR & NA & NA \\
\hline Mikus 2013 & PCS & IABP & 92.9 & 14 & $53.1 \pm 14.3$ & 64.3 & 29 & 64 & NA & NA \\
\hline Muller 2016 & AMI & IABP (96); Impella (3) & 69.6 & 138 & $55(46-63)$ & 80 & NR & NR & $81[72]$ & NR \\
\hline Nakamura 2015 & other & IABP & 95.5 & 22 & $46.2 \pm 18.7$ & 45.5 & NR & NR & NA & NA \\
\hline Negi 2016 & AMI & IABP & 60 & 15 & $57 \pm 13$ & 60 & 20 & 87 & NR & NR \\
\hline
\end{tabular}




\begin{tabular}{|c|c|c|c|c|c|c|c|c|c|c|}
\hline Overtchouk 2018 & AMI & IABP & 59.4 & 106 & $52.7 \pm 10.4$ & 84 & 21 & 37 & $75[72]$ & 4 \\
\hline Papadopoulos 2015 & PCS & IABP & 21.9 & 360 & $62 \pm 17$ & 76.1 & 42 & 63 & NA & NA \\
\hline Pappalardo 2016 & mix & Impella & 21.7 & 157 & $53(46-65)$ & 83 & NR & $\mathrm{NR}$ & 36 & NR \\
\hline Park 2014 & AMI & IABP & 42.7 & 96 & NR & 77.1 & 61 & 48 & 81 [63] & 10 \\
\hline Patel 2018 & $\operatorname{mix}$ & Impella & 45.5 & 66 & NR & 68.2 & NR & NR & 15 & 29 \\
\hline Pokersnik 2012 & PCS & IABP & 59.2 & 49 & $65 \pm 13$ & 67.3 & 39 & 90 & NA & $\mathrm{NA}$ \\
\hline Poptsov 2014 & PCS & vent & 60.9 & 46 & $42.1 \pm 4.1$ & 76.1 & NR & NR & NA & NA \\
\hline Raffa 2017 & PCS & IABP & 26.7 & 86 & $65 \pm 11.2$ & 65.1 & 17 & 94 & NA & $\mathrm{NA}$ \\
\hline Rastan 2010 & PCS & IABP & 74.1 & 517 & $63.5 \pm 11.2$ & 71.5 & 33 & 70 & $\mathrm{NA}$ & $\mathrm{NA}$ \\
\hline Ro 2013 & mix & IABP & 23.7 & 253 & $58.8 \pm 15.3$ & 60.9 & 23 & 39 & $\mathrm{NR}$ & NR \\
\hline Russo 2010 & mix & IABP & 85.7 & 14 & $47.8 \pm 16.8$ & 71.4 & NR & NR & NR & $\mathrm{NR}$ \\
\hline Sakamoto 2012 & AMI & IABP & 95.9 & 98 & $72 \pm 12$ & 66.3 & 35 & 45 & $94[66]$ & 2 \\
\hline Santise 2014 & PCS & IABP & 72.2 & 18 & $49 \pm 11$ & 77.8 & 17 & 22 & NA & $\mathrm{NA}$ \\
\hline Shinn 2009 & $\operatorname{mix}$ & IABP & 33.7 & 92 & $56 \pm 18$ & 64.1 & 24 & 29 & NR & NR \\
\hline Shmack 2017 & mix & vent & 41.7 & 48 & $49.7 \pm 19.5$ & 47.9 & NR & NR & NR & NR \\
\hline Slottosch 2012 & PCS & IABP & 93.5 & 77 & $60 \pm 13$ & 76.6 & 18 & 50 & NA & NA \\
\hline Slottosch 2017 & mix & IABP & 74.8 & 139 & $58 \pm 15$ & 76.3 & 27 & NR & NR & NR \\
\hline Smedira 2001 & $\operatorname{mix}$ & IABP & 54.5 & 202 & $55 \pm 14$ & 72 & 21 & NR & NR & NR \\
\hline Tepper 2018 & mix & IABP & 50 & 60 & $53.9 \pm 14.9$ & 53.3 & 38 & 53 & NR & NR \\
\hline Unosawa 2012 & PCS & IABP & 83 & 47 & $64.4 \pm 12.5$ & 74.4 & 38 & 43 & $\mathrm{NA}$ & $\mathrm{NA}$ \\
\hline van den Brink 2017 & AMI & IABP & 16.7 & 12 & $63(47-75)$ & 83 & 17 & 42 & 100 & 0 \\
\hline Wang 2013 & PCS & IABP & 47.1 & 87 & $65 \pm 7$ & 58.6 & 11 & 19 & $\mathrm{NA}$ & NA \\
\hline Weber 2017 & mix & IABP & 27.3 & 11 & $52.5 \pm 16.4$ & 81.8 & $\mathrm{NR}$ & NR & NR & NR \\
\hline Wu 2012 & $\operatorname{mix}$ & IABP & 73.3 & 60 & 49 & 66.7 & $43^{* * *}$ & NR & $48^{* * *}$ & $48^{* * *}$ \\
\hline Xu 2016 & mix & IABP & 68.8 & 16 & $62.3 \pm 11.1$ & 62.5 & 38 & NR & $\mathrm{NR}$ & NR \\
\hline Zhao 2015 & PCS & IABP & 66.7 & 24 & $59.3 \pm 11.9$ & 79.2 & 25 & 42 & NA & NA \\
\hline Zhong 2017 & PCS & IABP (9); vent (3) & 33.3 & 36 & $50.4 \pm 12.2$ & 91.7 & 25 & 81 & NA & NA \\
\hline
\end{tabular}

* $\mathrm{PCl}$ as a part of managing strategy of cardiogenic shock; data presented for studies with population with acute myocardial infarction etiology; in square brackets reported is the rate of successful angioplasty. ${ }^{*} \mathrm{CABG}$ as a part of managing strategy of cardiogenic shock; data presented for studies with population with acute myocardial infarction etiology. ${ }^{* * *}$ data for AMl patients only. 
Table 3. ROBINS-I tool bias assessment.

\begin{tabular}{|c|c|c|c|c|c|c|c|c|c|}
\hline Study & $\begin{array}{l}\text { Bias Due to } \\
\text { Confounding }\end{array}$ & $\begin{array}{l}\text { Bias in Selection of } \\
\text { Participants into the } \\
\text { Study }\end{array}$ & $\begin{array}{l}\text { Bias in Measurement of } \\
\text { Interventions }\end{array}$ & $\begin{array}{l}\text { Bias Due to Departures } \\
\text { from Intended Interventions }\end{array}$ & $\begin{array}{l}\text { Bias Due to } \\
\text { Missing Data * }\end{array}$ & $\begin{array}{l}\text { Bias in Measurement } \\
\text { of Outcomes * }\end{array}$ & $\begin{array}{l}\text { Bias in Selection of } \\
\text { Reported Result * }\end{array}$ & Overall Bias & $\begin{array}{l}\text { Cohen's } \\
\text { Kappa }\end{array}$ \\
\hline Acheampong 2016 & Serious & Critical & Serious & NA & Moderate & Moderate & Low & Serious & 0.83 \\
\hline Akanni 2018 & Moderate & Low & Low & NA & Low & Moderate & Moderate & Moderate & 1 \\
\hline Aoyama 2013 & Serious & Low & Moderate & NA & Moderate & Serious & Serious & Serious & 1 \\
\hline Asaumi 2005 & Serious & Moderate & Serious & NA & Low & Critical & Critical & Critical & 0.67 \\
\hline Aso 2016 & Moderate & Low & Critical & $\mathrm{NA}$ & Low & Serious & Moderate & Moderate & 0.83 \\
\hline Aziz 2010 & Serious & Low & Low & NA & Low & Moderate & Moderate & Low & 0.83 \\
\hline $\begin{array}{l}\text { Beiras-Fernandez } \\
2011\end{array}$ & Moderate & Low & Low & NA & Moderate & Critical & Critical & Critical & 0.83 \\
\hline Beurtheret 2013 & Serious & Moderate & Low & $\mathrm{NA}$ & Moderate & Low & Low & Low & 1 \\
\hline Biancari 2017 & Low & Low & Serious & NA & Moderate & Low & Low & Low & 0.83 \\
\hline Brechot 2018 & Moderate & Low & Critical & NA & Low & Critical & Critical & Critical & 1 \\
\hline Carroll 2015 & Moderate & Low & Moderate & NA & Moderate & Moderate & Moderate & Moderate & 1 \\
\hline Chen 2005 & Moderate & Moderate & Low & NA & Low & Serious & Serious & Serious & 0.83 \\
\hline Chen 2006 & Serious & Low & Low & NA & Moderate & Serious & Serious & Serious & 0.83 \\
\hline Chen 2018 & Moderate & Low & Critical & NA & Moderate & Serious & Serious & Serious & 0.67 \\
\hline Cho 2018 & Serious & Moderate & Moderate & NA & Moderate & Serious & Serious & Serious & 1 \\
\hline Choi 2018 & Serious & Low & Serious & NA & Moderate & Serious & Serious & Serious & 0.83 \\
\hline Chung 2011 & Moderate & Low & Low & NA & Moderate & Moderate & Moderate & Moderate & 1 \\
\hline Czobor 2016 & Serious & Low & Moderate & NA & Moderate & Serious & Serious & Serious & 1 \\
\hline Elsharkawy 2010 & Serious & Low & Low & NA & Moderate & Moderate & Moderate & Moderate & 0.83 \\
\hline Formica 2010 & Moderate & Moderate & Serious & NA & Moderate & Moderate & Moderate & Moderate & 0.67 \\
\hline Gass 2014 & Moderate & Low & Critical & NA & Low & Moderate & Moderate & Moderate & 1 \\
\hline Guihaire 2017 & Low & Serious & Low & NA & Moderate & Moderate & Moderate & Moderate & 1 \\
\hline Hei 2011 & Serious & Low & Low & NA & Moderate & Moderate & Low & Low & 0.83 \\
\hline Kagawa 2012 & Moderate & Serious & Serious & NA & Moderate & Serious & Serious & Serious & 0.83 \\
\hline Kim 2014 & Moderate & Moderate & Critical & $\mathrm{NA}$ & Moderate & Critical & Critical & Critical & 0.50 \\
\hline Lee 2016 & Serious & Moderate & Serious & NA & Moderate & Moderate & Moderate & Moderate & 1 \\
\hline Lee 2017 & Moderate & Low & Moderate & NA & Moderate & Serious & Serious & Serious & 1 \\
\hline Li 2015 & Moderate & Low & Low & NA & Moderate & Moderate & Low & Moderate & 0.83 \\
\hline Lin 2016 & Moderate & Low & Critical & NA & Low & Serious & Serious & Serious & 0.831 \\
\hline Lorusso 2016 & Low & Moderate & Critical & NA & Moderate & Moderate & Low & Moderate & 0.83 \\
\hline Luo 2009 & Moderate & Low & Low & NA & Moderate & Moderate & Low & Moderate & 0.67 \\
\hline Mikus 2013 & Serious & Low & Low & $\mathrm{NA}$ & Low & Moderate & Moderate & Low & 0.67 \\
\hline Muller 2016 & Serious & Low & Low & NA & Moderate & Moderate & Moderate & Moderate & 0.83 \\
\hline Nakamura 2015 & Serious & Moderate & Serious & $\mathrm{NA}$ & Moderate & Moderate & Moderate & Moderate & 1 \\
\hline Negi 2016 & Moderate & Low & Low & NA & Low & Moderate & Moderate & Moderate & 0.83 \\
\hline Overtchouk 2018 & Moderate & Serious & Low & NA & Moderate & Critical & Critical & Critical & 1 \\
\hline $\begin{array}{l}\text { Papadopoulos } \\
2015\end{array}$ & Serious & Low & Low & NA & Moderate & Moderate & Moderate & Moderate & 1 \\
\hline Pappalardo 2016 & Moderate & Low & Critical & NA & Low & Serious & Serious & Serious & 0.83 \\
\hline Park 2014 & Moderate & Moderate & Low & NA & Moderate & Moderate & Moderate & Moderate & 1 \\
\hline Patel 2018 & Serious & Low & Low & NA & Low & Moderate & Moderate & Low & 0.83 \\
\hline Pokersnik 2012 & Serious & Serious & Critical & NA & Moderate & Moderate & Moderate & Moderate & 1 \\
\hline
\end{tabular}




\begin{tabular}{|c|c|c|c|c|c|c|c|c|c|}
\hline Poptsov 2014 & Moderate & Serious & Critical & NA & Moderate & Critical & Critical & Critical & 1 \\
\hline Raffa 2017 & Moderate & Low & Serious & NA & Moderate & Moderate & Low & Moderate & 0.50 \\
\hline Rastan 2010 & Moderate & Low & Low & NA & Moderate & Moderate & Moderate & Moderate & 0.83 \\
\hline Ro 2013 & Serious & Low & Critical & NA & Low & Critical & Critical & Critical & 0.83 \\
\hline Russo 2010 & Serious & Low & Low & NA & Low & Critical & Serious & Low & 0.83 \\
\hline Sakamoto 2012 & Moderate & Low & Moderate & NA & Moderate & Serious & Serious & Moderate & 0.67 \\
\hline Santise 2014 & Moderate & Serious & Serious & NA & Moderate & Moderate & Moderate & Moderate & 0.83 \\
\hline Shinn 2009 & Moderate & Low & Critical & NA & Moderate & Serious & Serious & Serious & 0.83 \\
\hline Shmack 2017 & Serious & Low & Serious & NA & Low & Critical & Critical & Critical & 1 \\
\hline Slottosch 2012 & Low & Low & Low & NA & Moderate & Low & Low & Low & 1 \\
\hline Slottosch 2017 & Low & Low & Low & NA & Moderate & Moderate & Low & Low & 0.67 \\
\hline Smedira 2001 & Moderate & Low & Serious & $\mathrm{NA}$ & Moderate & Serious & Moderate & Moderate & 0.83 \\
\hline Tepper 2018 & Moderate & Low & Critical & NA & Low & Moderate & Moderate & Moderate & 1 \\
\hline Unosawa 2012 & Serious & Low & Low & NA & Moderate & Moderate & Low & Low & 1 \\
\hline van den Brink 2017 & Moderate & Low & Critical & $\mathrm{NA}$ & Moderate & Serious & Serious & Serious & 1 \\
\hline Wang 2013 & Moderate & Critical & Low & NA & Moderate & Low & Low & Low & 0.67 \\
\hline Weber 2017 & Low & Critical & Critical & NA & Low & Critical & Critical & Critical & 0.83 \\
\hline Wu 2012 & Serious & Low & Moderate & $\mathrm{NA}$ & Moderate & Moderate & Moderate & Moderate & 1 \\
\hline Xu 2016 & Moderate & Low & Critical & $\mathrm{NA}$ & Moderate & Serious & Serious & Serious & 0.83 \\
\hline Zhao 2015 & Serious & Critical & Critical & NA & Moderate & Moderate & Moderate & Moderate & 0.83 \\
\hline Zhong 2017 & Low & Critical & Low & NA & Moderate & Serious & Low & Low & 0.50 \\
\hline
\end{tabular}

* When multiple outcomes were reported for a study, the highest level of bias at the outcome level is reported in the table. Bias reported for comparison of peripheral vs. central extracorporeal circulation and not for a study in general. 


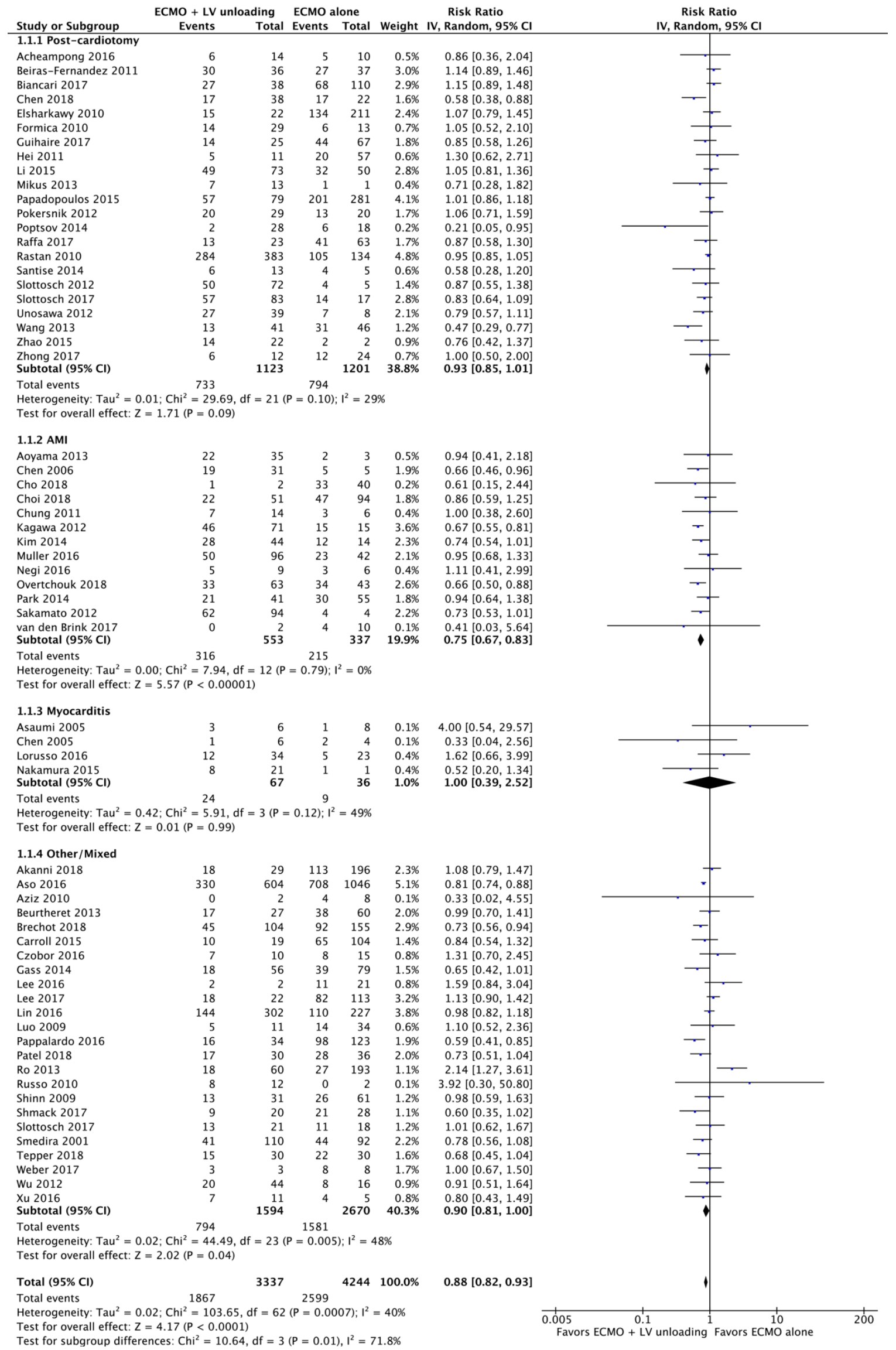

Figure 3. All-cause in-hospital mortality rate for patients receiving extracorporeal membrane oxygenation (ECMO) + left ventricular (LV) unloading versus ECMO alone treatment according to cardiogenic shock etiology. 
The highest mortality risk benefit (25\%) was observed in the subgroup of patients undergoing LV unloading + ECMO for AMl: RR (95\%Cls): $0.75(0.67-0.83) ; p<0.00001 ; I^{2}=0 \%$; NTT $=15$. A mortality risk benefit of $11 \%$ was demonstrated in studies including mixed indication for LV unloading + ECMO: RR $(95 \% \mathrm{Cls}): 0.90(0.81-$ 1.00); $p=0.04 ; I^{2}=48 \% ;$ NNT = 11; In patients with postcardiotomy cardiogenic shock, LV unloading on top of ECMO was associated with 7\% non-significantly lower mortality risk; $R R(95 \% \mathrm{Cls}): 0.93(0.85-1.01) ; p=0.09$; $I^{2}=29 \% ;$ NNT $=125$. No differences were seen between LV-unloading + ECMO as compared to ECMO alone in patients with myocarditis; $\mathrm{NNt}=9$. Significant statistical differences as of extent of benefit were demonstrated between subgroups ( $p_{\text {interaction }}=0.01$ ). No impact on early mortality was found according to the type of cannulation, peripheral and central, in a meta-regression analysis, Figure 4. Similarly, these were unaffected by age, gender, diabetes and hypertension status (Figures 5-8).

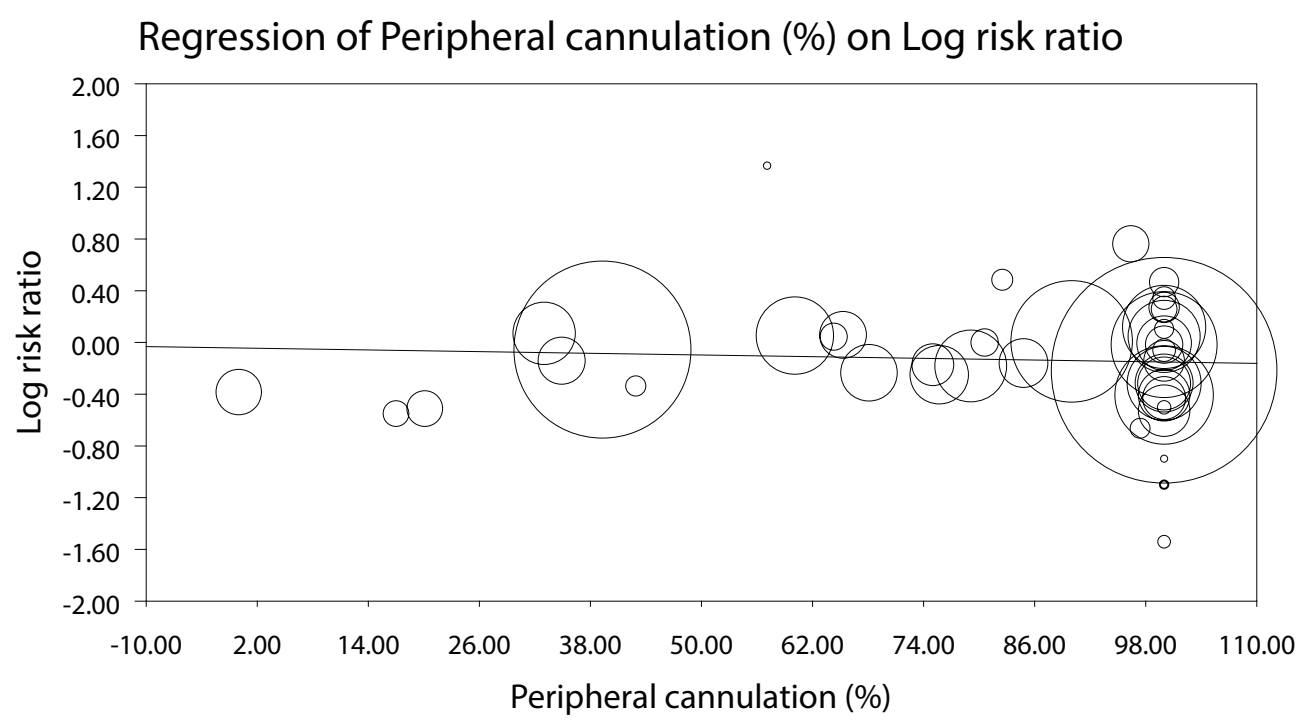

Figure 4. Meta-regression: the impact of the rate of peripheral cannulation on Log odds ratio.

\subsubsection{Weaning}

Seventeen studies with nearly 3000 patients reported on weaning rates in subsets receiving LV unloading + ECMO as compared to ECMO therapy alone. In the overall analysis, LV unloading was associated with $35 \%$ higher probability of weaning from ECMO: RR (95\%Cls): $1.35(1.21-1.51) ; p<0.00001 ;\left.\right|^{2}=38 \%$ : weaning was possible in $60.4 \%(1789 / 2964)$ of included patients with corresponding rates of $75.3 \%(821 / 1090)$ and $51.7 \%$ (968/1874) for LV unloading + ECMO and ECMO alone; Figure 9. 


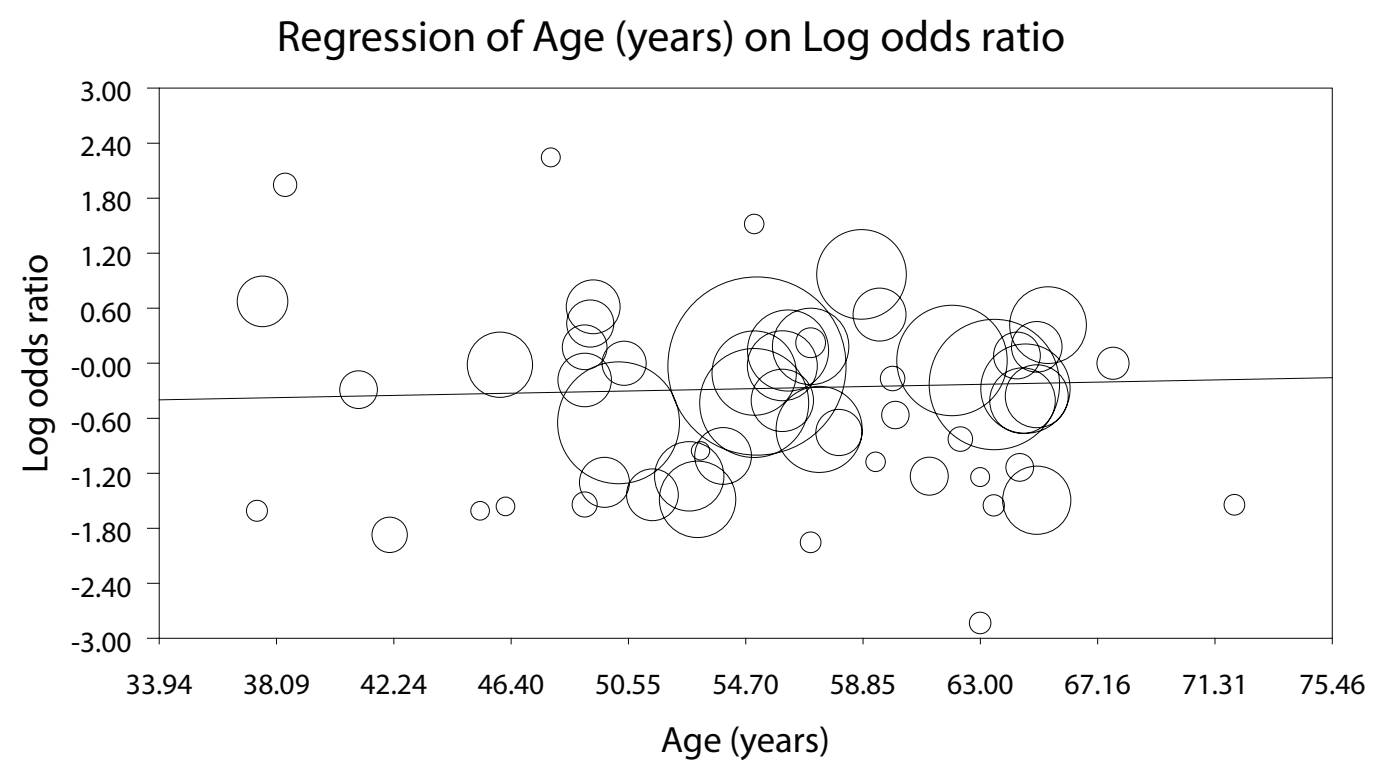

Figure 5. Meta-regression showing the impact of age distribution on Log odds ratio.

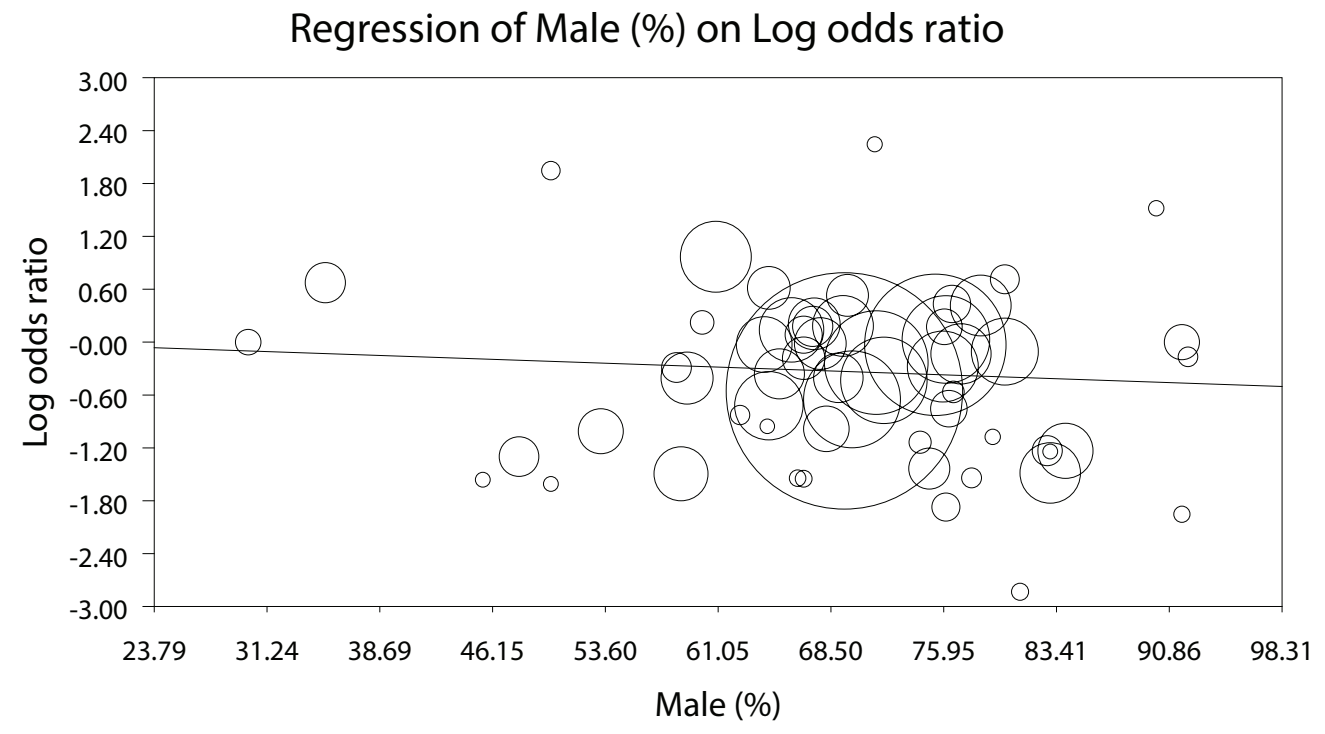

Figure 6. Meta-regression showing the impact of gender distribution on Log odds ratio. 


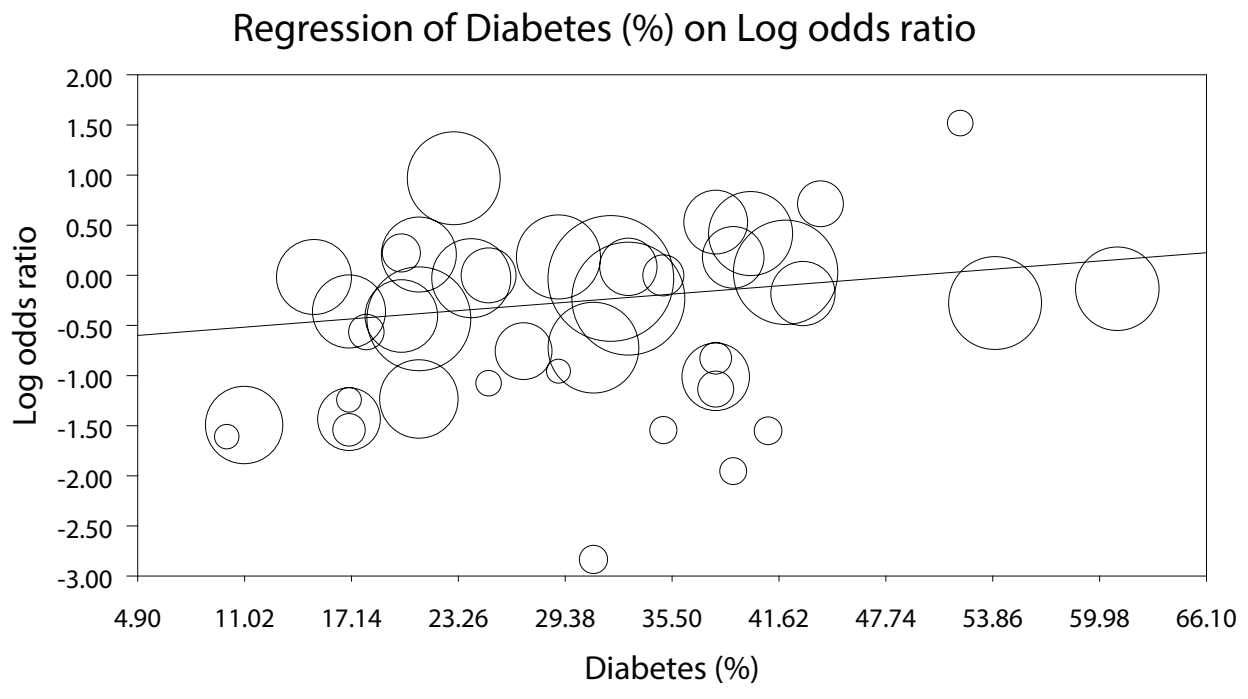

Figure 7. Meta-regression showing the impact of diabetes percentage distribution on Log odds ratio.

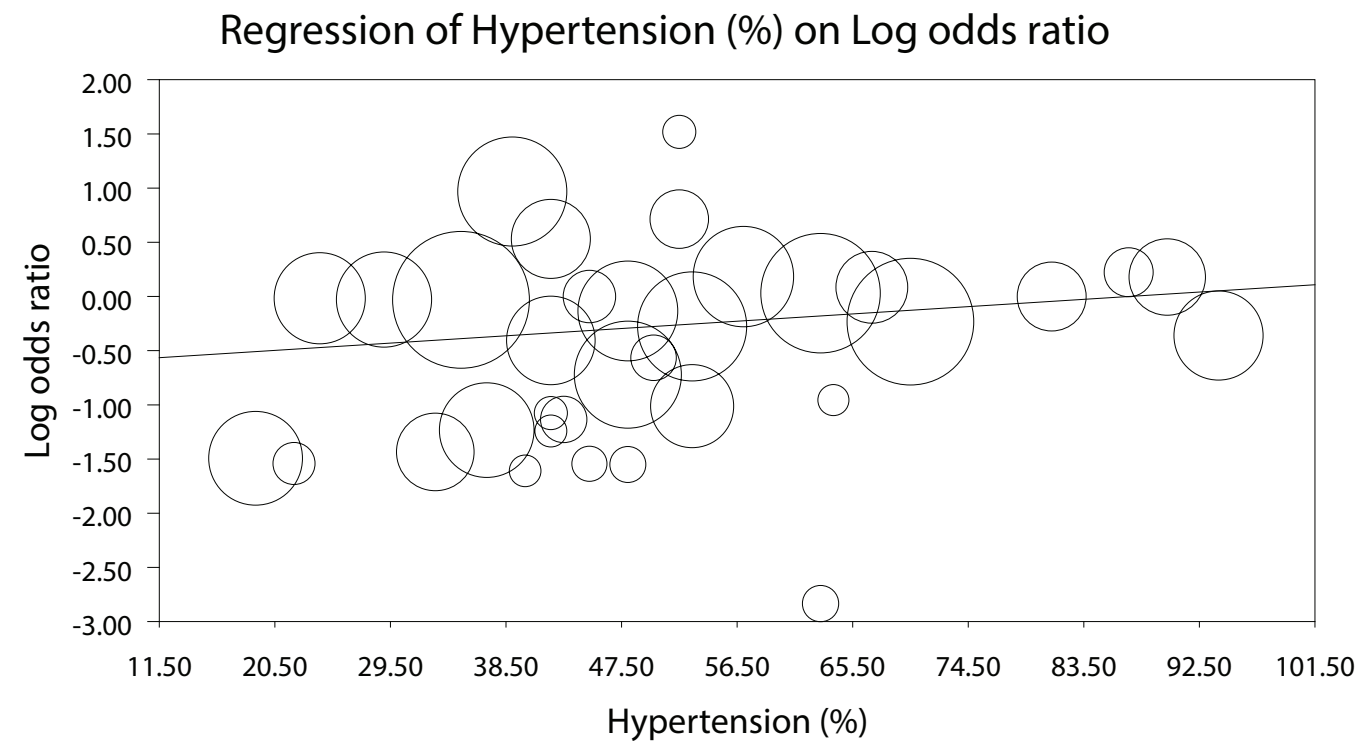

Figure 8. Meta-regression showing the impact of hypertension distribution on Log odds ratio 


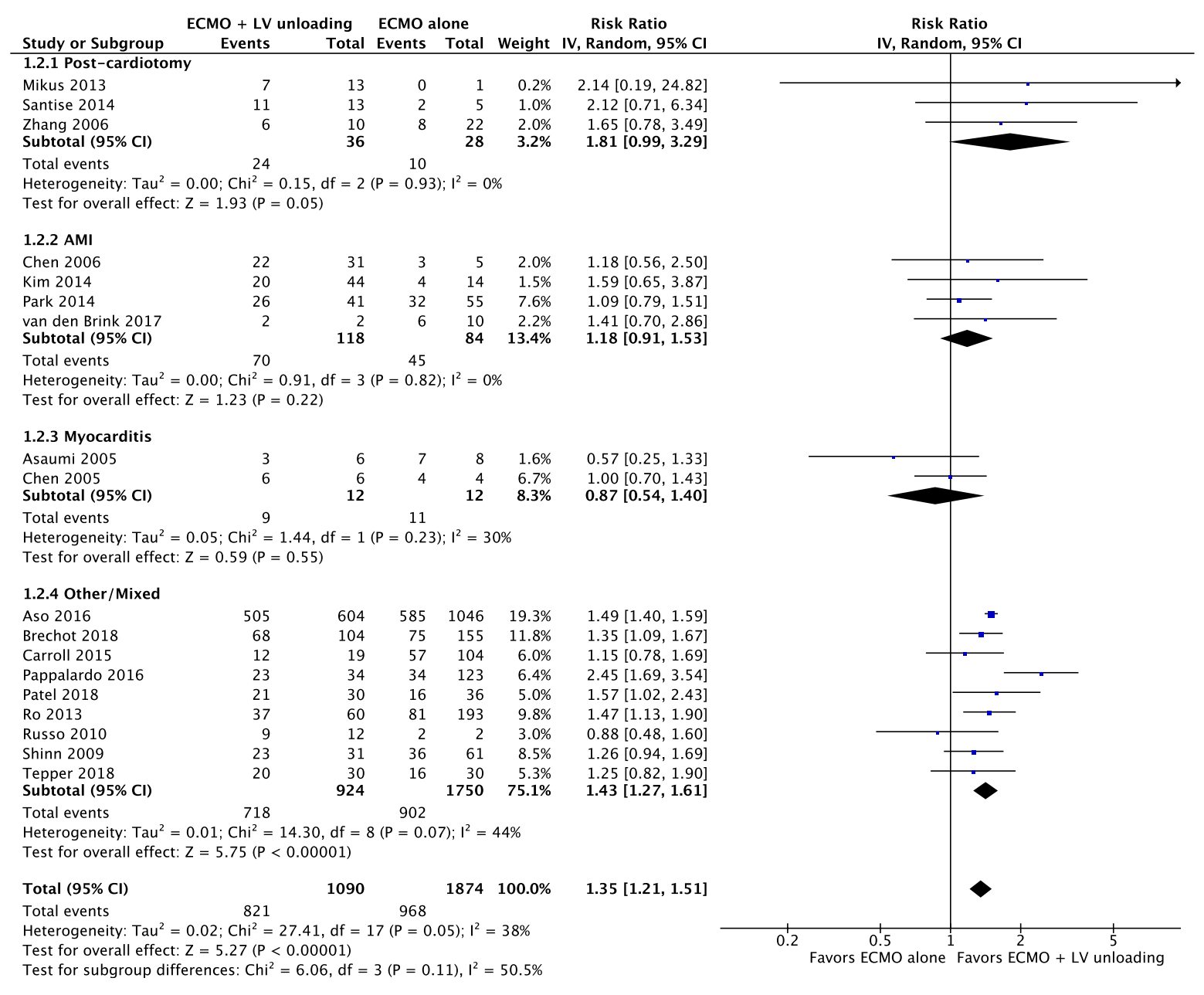

Figure 9. Weaning rate for patients receiving ECMO + LV unloading vs. ECMO alone treatment according to cardiogenic shock etiology.

LV unloading on top of ECMO was associated with a higher chance of weaning in postcardiotomy cardiogenic shock: RR (95\%Cls): $1.81(0.99-3.29) ; p=0.05 ; l^{2}=0 \%$. Differences between subgroups were not statistically significant.

\subsection{Secondary Endpoints}

There were no apparent differences between LV unloading + ECMO vs. ECMO alone treatment regarding the secondary endpoints (Figures 10-15). Neurologic complications incidence was reported in 6 studies (596 patients) with respective $8.5 \%$ (17/199) vs. $6.0 \%$ (24/397) for ECMO + LV unloading vs. ECMO alone (RR (95\%Cls): $\left.1.03(0.55-1.94) ; p=0.92 ;\left.\right|^{2}=0 \%\right)$; Figure 10. Similarly, non-significant differences in terms of brain death was seen: (RR $(95 \% \mathrm{Cls}): 0.82(0.34-1.97) ; p=0.66 ;\left.\right|^{2}=7 \%$; Figure 11. ECMO + LV unloading was not 
associated with any benefit nor harm in analysis of: limb complications ( 6 studies; 2695 patients): RR (95\%Cls):

$1.06(0.89-1.26) ; p=0.50 ; l^{2}=0 \%$ (Figure 12); acute kidney injury (10 studies; 3178 patients): RR (95\%Cls):

$1.03(0.87-1.26) ; p=0.64 ;\left.\right|^{2}=49 \%$ (Figure 13); revision for bleeding: $\operatorname{RR}(95 \% \mathrm{Cls}): 0.81(0.44-1.47) ; p=0.48$;

$1^{2}=0 \%$ (Figure 14); sepsis: RR (95\%Cls): $0.70(0.31-1.57) ; p=0.38 ; 1^{2}=0 \%$ (Figure 15).

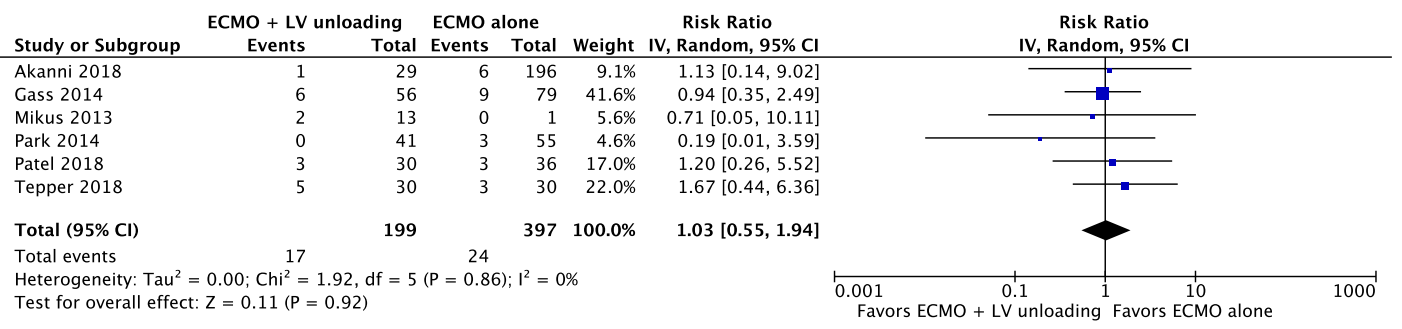

Figure 10. Neurologic complications.

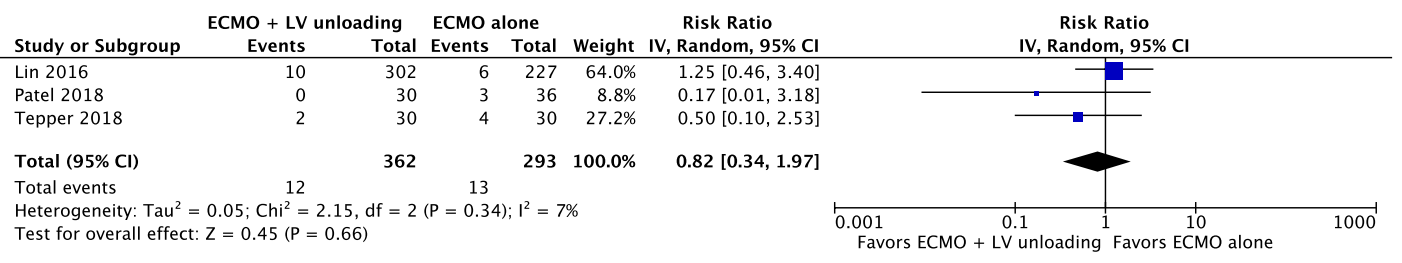

Figure 11. Brain death.

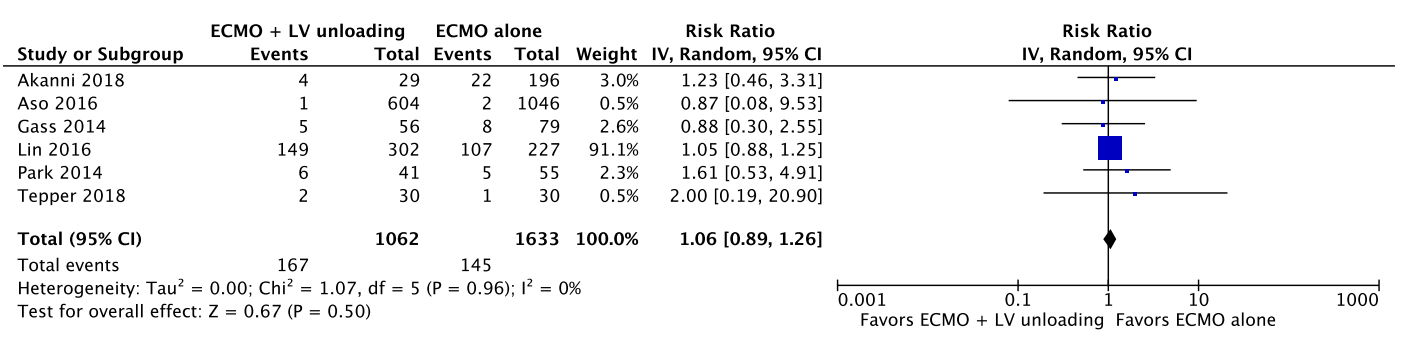

Figure 12. Limb complications.

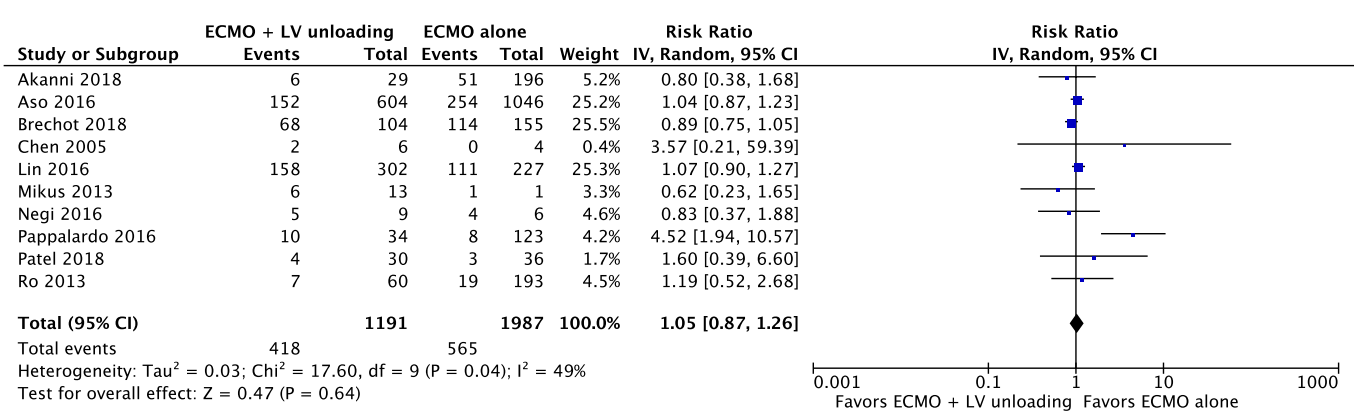

Figure 13. Acute kidney injury (AKI). 


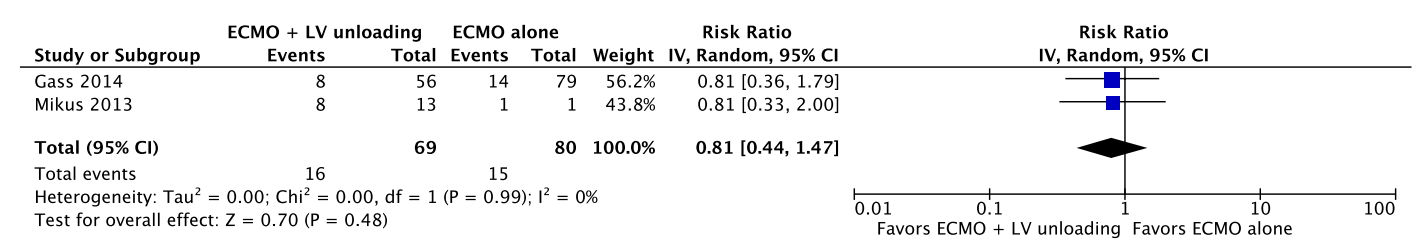

Figure 14. Revision for bleeding.

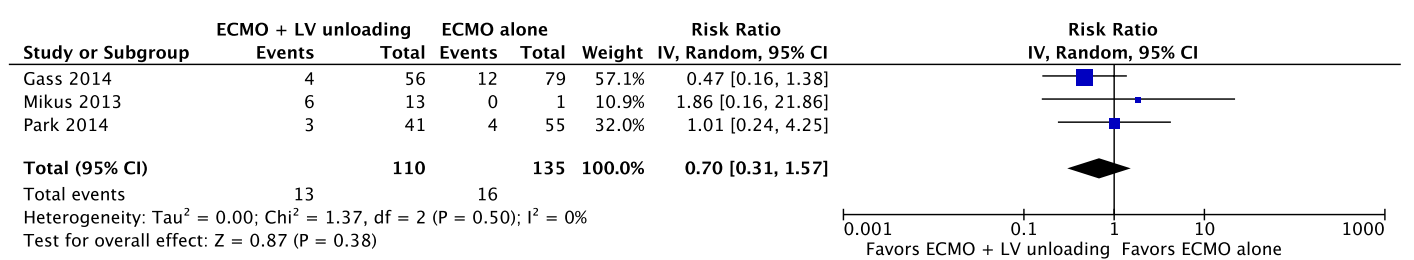

Figure 15. Sepsis.

\subsubsection{Analysis Stratified by LV Unloading Technique}

As secondary analysis, we assessed the impact of the different unloading techniques on mortality and weaning: 5 studies (382 patients) reported on LV unloading by direct LV venting catheters: a statistical trend of $32 \%$ reduced mortality risk was demonstrated for ECMO + LV venting as compared to ECMO alone: RR $(95 \% \mathrm{Cls})$ : $0.68(0.45-1.03) ; p=0.07 ;\left.\right|^{2}=28 \%$; Figure 16 and Table 4 . Respective mortality rates were $30.4 \%(24 / 79)$ vs. $60.7 \%$ (184/303) for LV unloading + ECMO and ECMO alone. No data was available about the rate of weaning in the groups receiving an LV venting. Use of IABP as an adjunct to ECMO was assessed in 56 studies (7015 patients): mortality rates were $56.4 \%$ (1791/3174) and 60.7\% (2331/3841) for ECMO + IABP vs. ECMO alone; RR $(95 \% \mathrm{Cls}): 0.89(0.84-0.95) ; p=0.0004 ; 1^{2}=39 \%$. Intra-aortic balloon pump was further associated with significant increased chance of weaning from ECMO: RR (95\%Cls): $\left.1.27(0.14-1.42) ; p<0.0001 ; l^{2}=32 \%\right)$. Figure 16.

Table 4. LV unloading strategy.

\begin{tabular}{|c|c|c|c|c|c|}
\hline & LA & RSPV & Direct LV Apex & LV by RSPV & $\mathrm{PA}$ \\
\hline Guihaire 2017 & 13 patients & & & & \\
\hline Biancari 2017 & & 3 patients & 1 patient & & 1 patient \\
\hline Poptsov 2014 & 19 patients (percutaneous) & & & & \\
\hline Shmack 2017 & & & & 29 patients & \\
\hline Lorusso 2016 & & 4 patients & 4 patients & & 2 patients \\
\hline
\end{tabular}


Lower, yet statistically non-significant mortality risk was found for ECMO + Impella as compared to ECMO alone (6 studies; 734 patients): RR (95\%Cls): $0.85(0.67-1.09) ; p=0.20 ; l^{2}=41 \%$. Additionally, Impella device was independently associated with higher chance of weaning from ECMO: RR $(95 \% \mathrm{Cls}): 1.65(1.05-2.59) ; p=0.03$; $I^{2}=74 \%$ (Figure 17).

\subsubsection{Sensitivity Analyses}

Analyses were repeated as sensitivity for primary endpoints mortality and weaning from ECMO this time included only studies that reported effect estimates for propensity matched cohorts only: 5 studies (Appendix References $[10,15,34,43,50])$ provided propensity adjusted estimates of mortality; pooled together, LV unloading on top of ECMO was associated with over $25 \%$ statistically significant reduction in the odds of mortality as compared to ECMO alone: OR (95\%Cls): $0.74(0.60-0.91) ; p=0.004 ; l^{2}=42 \%$; Figure $18 \mathrm{~A}$.

Weaning rates for comparison LV unloading + ECMO and ECMO alone adjusted for propensity were reported in 4 studies (Appendix references [10,15,43,50]); again, LV unloading on top of ECMO was associated with over $75 \%$ significantly higher odds to wean from ECMO: OR (95\%Cls): $1.78(1.40-2.28) ; p<0.001 ; l^{2}=0 \%$; Figure 18B.

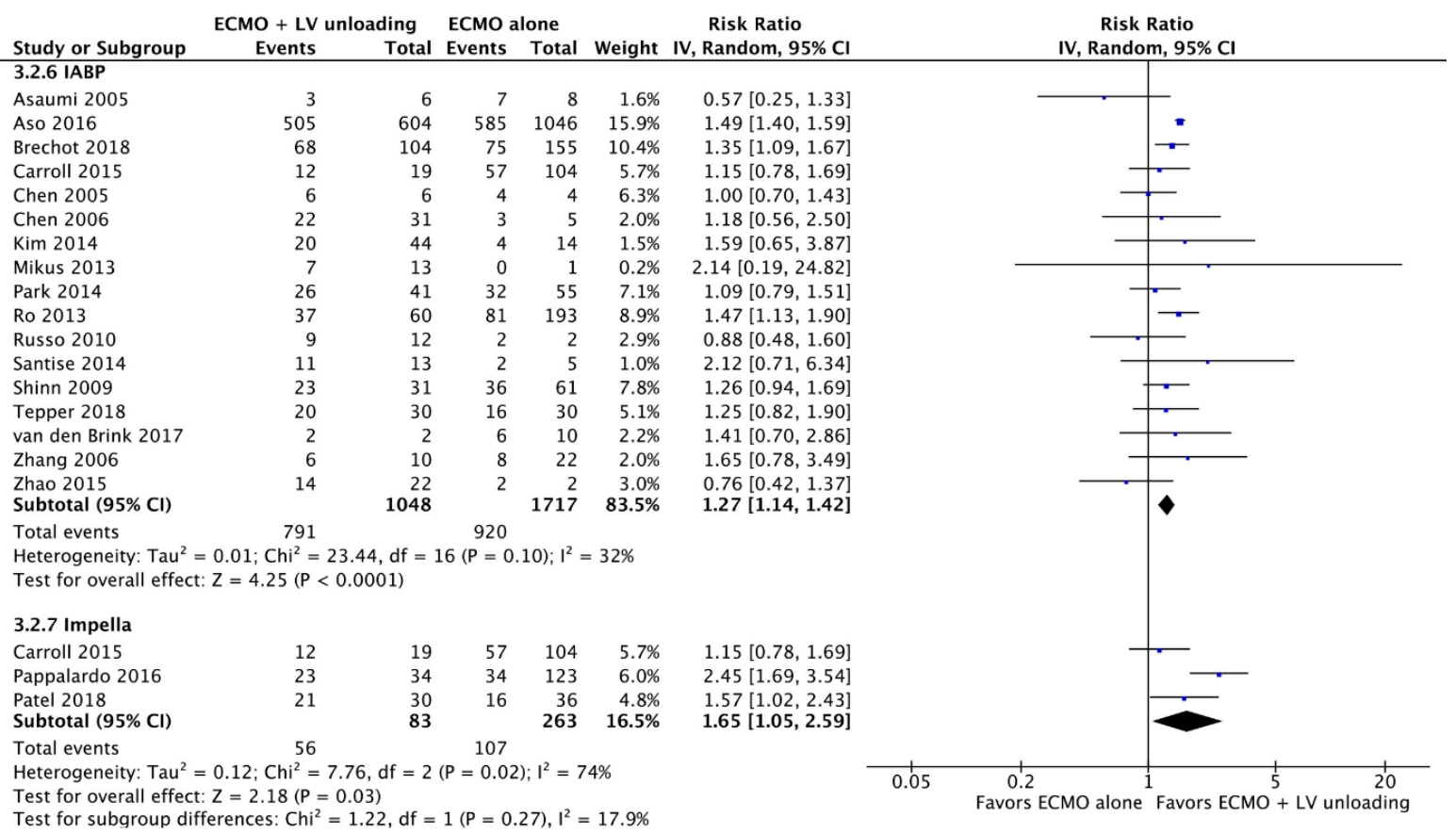

Figure 17. Weaning by device. 
ECMO + LV unloading ECMO alone

Risk Ratio

Risk Ratio

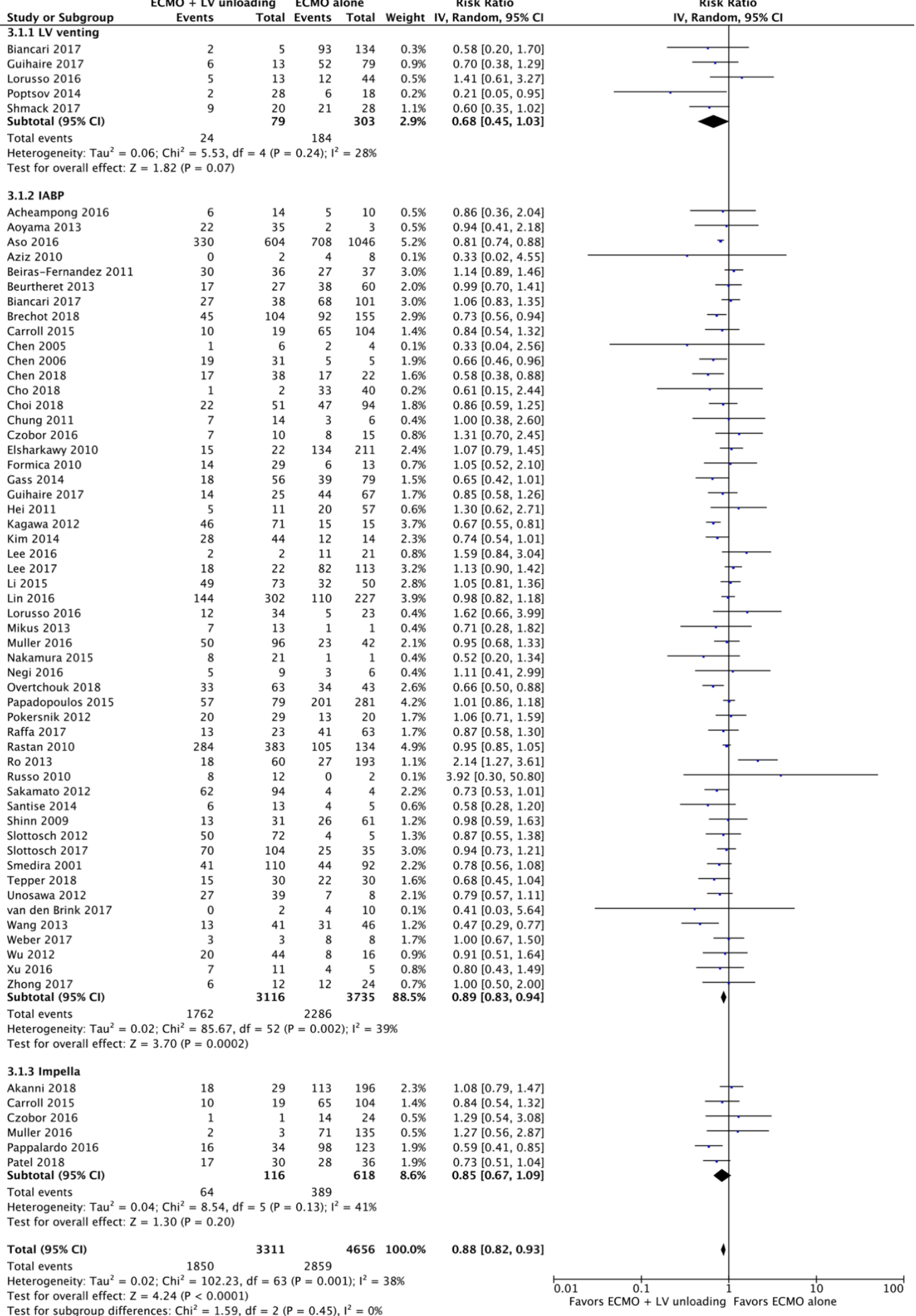

Figure 16. Mortality by device. 


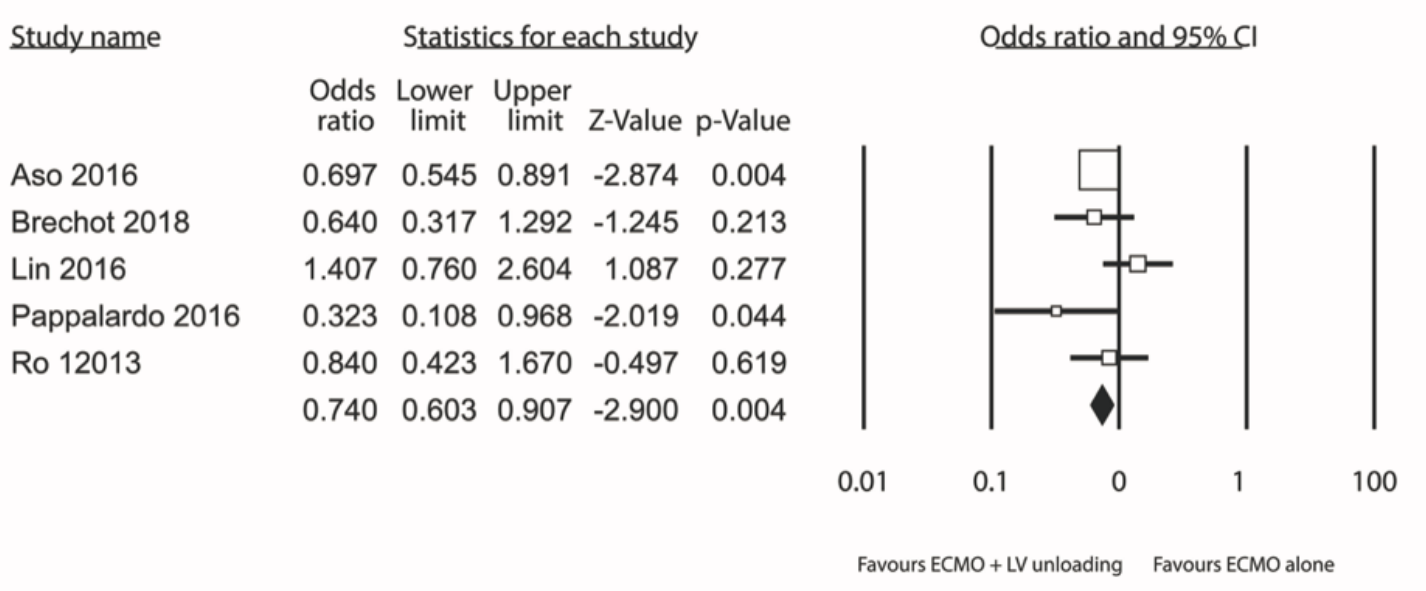

(A)

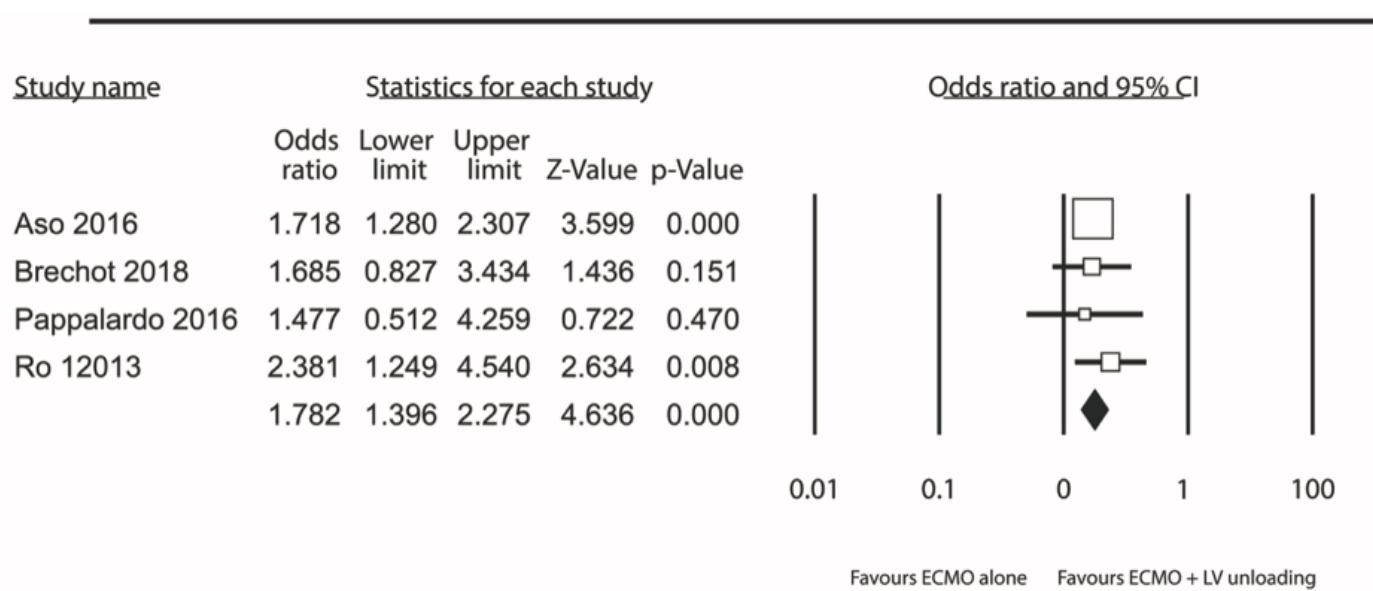

(B)

Figure 18. All-cause in-hospital mortality rate $(\mathrm{A})$ and weaning rate $(\mathrm{B})$ from studies reporting propensity adjusted results.

Sensitivity analyses performed by deleting each study, one at a time, and repeating the calculations did not change the direction nor magnitude of the treatment effect, suggesting absence of big-study effect.

\section{Discussion}

VA-ECMO is an established treatment able to provide a mechanical circulatory support for patients in cardiogenic shock, aiming a bridge to decision or to myocardial recovery [1-6]. Improvements in technology have mitigated the interaction between artificial surfaces of ECMO circuits and blood. However, other adverse 
effects, known as "flow-related dynamic", are strictly associated, both in central and peripheral ECMO configuration, with the retrograde direction of the flow towards a dysfunctioning left ventricle. Two major issues have been longer debated by the scientific community: the first is the difference in outcomes and hemodynamic support between the central and peripheral cannulation; the second is the clinical impact of the left ventricle unloading and the strategy to achieve a safe and effective ventricular decompression. The first issue has been already addressed by our group [21]; aim of the current meta-analysis is to address the question whether myocardial unloading is beneficial or, by raising the complexity of ECMO management, futile or potentially detrimental to patients' outcomes.

ECLS institution increases the left ventricle afterload with a rise in LV end-systolic volume and reduction in LV stroke volume. If peripheral resistance and LV contractility are fixed, increase in LV end-diastolic volume is the only way to overcome the afterload via the Frank-Starling mechanism. In this case, higher levels of VA-ECMO flow cause a progressive rise in LV end-diastolic pressure, LA pressure, pulmonary capillary wedge pressure, that are associated with a further reduced LV stroke volume [22-24]. High afterload situations with inability of LV to manage the transpulmonary blood flow, inadequate response to inotropes, complete cardiac arrest with incomplete venous drainage and aortic valve incompetence are the commonest risk factors for LV distension. Patients with severely impaired LV function and/or right ventricular dysfunction are more prone to develop an ineffective LV unloading [25]. LV overload increases wall stress, myocardial oxygen consumption and induce sub-endocardial ischemia and ventricular arrhythmias, jeopardizing ventricular recovery particularly in the presence of ischemia-induced myocardial impairment. The consequence of the pressure overload may ultimately account for pulmonary congestion and edema.

If the overload is extreme and LV contractile impairment significant, the LV is unable to provide a sufficient flow against the increased afterload and the aortic valve may remain closed even during systole, causing blood stasis in the left ventricle, left atrium and aorta, and accounting for intracardiac thrombosis which has been reported in up to $6 \%$ of the cases $[26,27]$. The LV dilatation may further induce annular dilatation and mitral valve leaflet tethering with severe functional regurgitation, thus, particularly in in patients with a history of chronic heart failure and LV dysfunction with a dilated LV, worsening the pulmonary congestion [28]. 
Definition of LV distension during VA-ECMO is lacking in the literature. Truby et al. [29] attempt to classify and grade the LVD according to the evidence of pulmonary edema on chest radiography and increased pulmonary artery diastolic blood pressure (> $25 \mathrm{mmHg}$ ). The latter was a surrogate of the wedge pressure evaluated in the "Should we emergently revascularize occluded coronaries for cardiogenic shock" (SHOCK) trial [30]. Clinical evidence of LV distension requiring immediate decompression was inversely related to the chance of myocardial recovery. Meani et al. [28] defined and graded the severity of LV loading during VA-ECMO according to hemodynamic parameters, chest X-ray and echocardiogram findings.

These differences in definitions and assessments may account for the high variability of LV distension rate in the literature. Camboni et al. [31] reported need for LV decompression in $2 \%$ of the cases in more than 600 patients. A strict and longer afterload reduction (> 24 hours), targeted lower ECMO flow and a restrictive fluid management were the strategy adopted in this large series. In Truby et al. [29] the clinical and subclinical (not warranting immediate decompression) LV distension occurred in $7 \%$ and $22 \%$ of patients, respectively. Among 184 peripheral VA ECMO in the series of Meani et al. [32], 5.4\% required IABP placement because of a protracted closure of the aortic valve.

Drugs administration is the first line treatment of left ventricle distension. Inotropes can be administered to increase LV contractility while vasodilators may reduce the peripheral resistances and decrease left ventricle afterload. A careful fluid balance (diuretics/fluid restriction) avoiding fluid overload can reduce the risk of pulmonary edema. Ventilatory optimization, including higher PEEP, prolonged expiration time and lower tidal volume, may further improve the venous drainage.

When medical treatment is not successful, the non-pharmacological management of LV distension, acting with a "direct" or indirect" mechanism, can be obtained through a surgical or percutaneous strategy (Figure 19).

\subsection{IABP}

IABP has been the most used technique to unload the left ventricle during ECMO support [33]. The IABP acts with several "indirect" mechanisms reducing both the LV afterload (enhanced systolic ejection) and the LV enddiastolic pressure (enhanced left atrial and pulmonary venous unloading). 


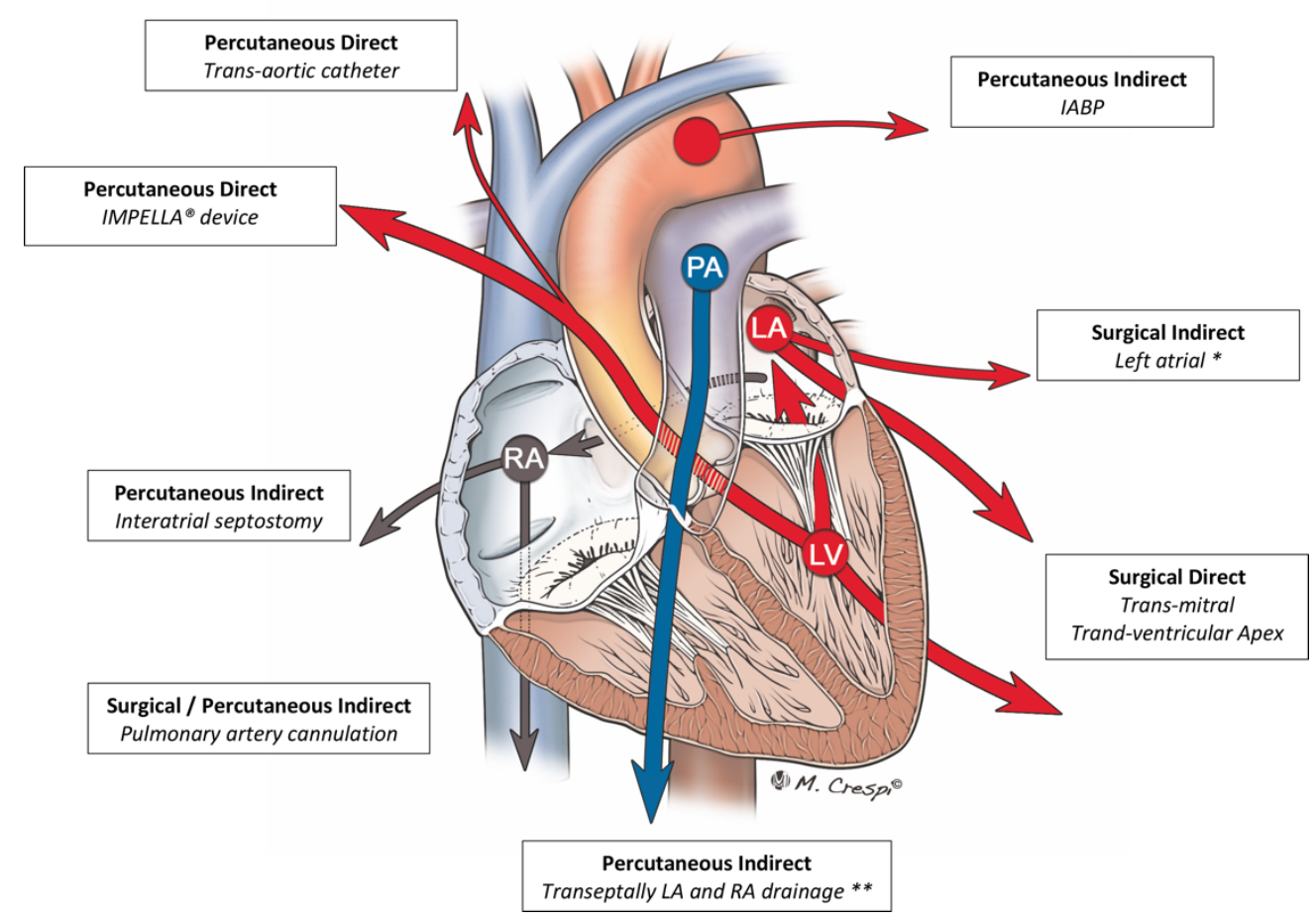

Figure 19. Left ventricle unloading strategies classified according to the direct or indirect, percutaneous or surgical strategies. The differences in arrows' width is intended suggesting the efficacy of left ventricle unloading (greater for direct surgical approach and Impella device). The color of the dash is intended suggesting blood oxygenation. Further techniques, not included in the picture, are the direct LV transaortic device by PulseCath device, percutaneous indirect

LA drainage with TandemHeart transeptal cannula. PA: pulmonary artery; LA: left atrium; LV: left ventricle; RA: right atrium; * achieved through right superior pulmonary vein, left atrial roof, interatrial groove; ${ }^{* *}$ simultaneous left and right atrial drainage with the multistage cannula coming from the femoral vein and positioned transeptally.

The IABP induces the aortic valve opening [32], improves coronary and abdominal circulation [34], allows pulsatility in end organ capillary bed [35], it is easy to implant and has contained costs. In animal studies the role of counterpulsation in VA-ECMO support seems controversial. Zobel [36] and Sauren [37] showed that IABP has beneficial effects on LV performance. Instead, Belohlávek et al. [38] showed that the combination of femoral VA-ECMO and IABP could impair coronary perfusion. In clinical practice the combination ECMO/IABP was associated with improvement in hemodynamics parameters [39,40], weaning rate $[39,41]$ and survival $[41,42]$.

\subsection{ECPELLA}

The use of Impella in combination with VA-ECMO (also known as ECPELLA/ECMELLA) has been shown to provide improved weaning and survival rates compared to ECMO alone strategy and to established risks scores [43-46]. The addition of a continuous flow vent reduces LV volumes and pressures. The LV stroke volume 
progressively decreases as pump flow increases, with the raise of systemic blood pressure and reduction of LA and pulmonary capillary wedge pressures. Despite the aortic valve does not open, there is no risk of blood stasis in the LV and the aortic root. The uncoupling of LV and aortic pressure is a sign of an effective unloading of the ventricle. In this situation a flat systemic pressure line is a sign of maximal unloading. Secondary changes in myocardial contractility and peripheral resistance may further enhance the LV unloading $[22,46]$. The Impella can also reduce RV afterload and facilitate RV output and pulmonary blood flow with improvement in gas exchange $[47,48]$. Alongside these hemodynamic features, the use of an axial flow pump may provide a circulatory support while weaning from VA-ECMO. The possibility of reducing the duration of ECLS has been reported by Scharge et al. [46], however, in the experience of Pappalardo et al. [44], the association of Impella and VA-ECMO prolonged the time of support but provided a successful recovery of patients who might not have survived under VA-ECMO treatment alone. The use of Impella has been associated with a significant risk of severe bleeding, vascular complications and cerebral stroke $[49,50]$. In patients receiving the dual treatment with VA-ECMO, a higher occurrence of hemolysis has been reported [44], however, no difference was generally found in terms of risk of major and minor bleeding, and cerebral stroke compared to VA-ECMO alone $[43,45]$. These initial results seem to support an expanding use of Impella for LV unloading. Despite the evidences are still limited and coming from retrospective studies, most of the patients who underwent ECPELLA therapy were in cardiogenic shock with severely impaired LV function, were upgraded to VA-ECMO while on axial flow pump due to a progressive deterioration, or needed the implantation of Impella following significant and complicated LV distension.

\subsection{Other Techniques}

Other unloading strategies have been reported in the literature and address the endpoints of this meta-analysis (Table 4). Briefly, the left atrium can be drained surgically by a cannula in the left atrial roof or in the right superior pulmonary vein or percutaneously $[28,51]$ by an interatrial septostomy (septostomy usually with ballooning or stent) or a cannula attached to the ECMO venous return or to device like TamdemHeart ${ }^{\circledR}$ ). Direct left ventricle unloading can be also achieved or by a surgical cannulation of the ventricle apex [52,53] and through the mitral 
valve from the left atrium $[52,54]$ or percutaneously by a catheter across the aortic valve. The surgical or percutaneous pulmonary artery cannulation [52,53], increasing the right-side blood drainage, will indirectly reduce the pulmonary venous return and left cardiac chamber loading. The experiences with these last unloading strategies include small populations, however, these studies found a positive impact of these adjuncts on patients' survival.

Hemodynamic responses to ECMO are different among patients and are affected by clinical presentation, associated comorbidities and the cardiovascular system coupling. This high variability may explain the difficulties in driving robust conclusions in terms of efficacy and safety of LV unloading during VA-ECMO.

Up to date and to the best of our knowledge other two meta-analysis have been published on LV unloading strategy [26,33]. In 2015, Cheng et al. [26] reported the impact of IABP on survival among 1517 patients (16 studies). The cumulative survival rate for patients on ECMO was 256/683 (37.5\%) compared with 294/834 (35.3\%) for patients with adjunctive IABP. Concomitant IABP was not associated with improved survival (RR: 1.143; $95 \% \mathrm{Cl}: 0.973$ to $1.343 ; \mathrm{p}=0.10)$. IABP was not associated with improved survival in AMl patients (RR, 1.120; 95\% Cl, 0.772-1.624; $p=0.55), \operatorname{PCS}(\mathrm{RR}, 1.121 ; 95 \% \mathrm{Cl}, 0.826-1.520 ; \mathrm{p}=0.46)$ when placed prior to ECMO initiation (RR, 0.948; $95 \% \mathrm{Cl}, 0.718-1.252 ; \mathrm{p}=0.71)$, or when routinely inserted $(\mathrm{RR}, 1.102 ; 95 \% \mathrm{Cl}$, 0.806-1.506; $p=0.54)$. Recently, Russo et al. [33] reviewed 17 observational studies including 3997 patients. A total of 1696 (42\%) patients received a concomitant left ventricular unloading strategy while on VA-ECMO (IABP 91.7\%, percutaneous ventricular assist device 5.5\%, pulmonary vein or transseptal left atrial cannulation 2.8\%). Mortality was lower in patients with (54\%) versus without (65\%) left ventricular unloading while on VAECMO (RR: $0.79 ; 95 \%$ confidence interval $(\mathrm{Cl}): 0.72$ to $0.87 ; p<0.00001)$. Bleeding, limb ischemia, renal replacement therapy, multiorgan failure and stroke or transient ischemic attack were not demonstrably different in patients treated with VA-ECMO with versus without left ventricular unloading. Hemolysis was the only secondary outcome higher in patients who underwent VA-ECMO with left ventricular unloading (RR: 2.15; 95\% Cl: 1.49 to $3.11 ; p<0.0001)$.

\subsection{Limitations}


As analysis of only non-randomized studies, our analysis shared similar limitations with these reports which included experiences with small populations and lacked some critical information about the timing of ECMO institution, the timing of LV unloading adjunct, or the weaning protocols. Most importantly, none of the studies report exact criteria for therapy escalation e.g., addition of IABP or Impella device to ECMO. In addition, observational nature of these studies promotes selection bias. However, compared to previous meta-analyses, that present certain methodological flaws (e.g., Russo by applying the very same search strategy included 17 studies and 3997 patients), the current study, including 62 studies and more than 7500 patients, represents the first comprehensive approach addressing LV unloading strategies during ECMO support.

We found that, regardless the strategy (IABP, Impella, others) and the etiology (PCS, AMI, other), LV unloading has a positive impact in patients' weaning, without adding any further risk of CVE, sepsis, acute renal injury requiring dialysis, limb complications and reoperation for bleeding. We have also provided a separate analysis of propensity-score matched and adjusted studies, trying, in the absence of prospective randomized data, to address the high heterogeneity of the included experiences due to different baseline populations' characteristics. This further analysis confirmed these findings favoring LV unloading techniques during VA-ECMO.

Despite the expected different flow patterns and afterload increase by central and peripheral cannulation, these two strategies were not significantly associated with a higher odds ratio risk of mortality considering the adjunct or the absence of LV unloading. However, we found a tendency in the association of higher odd ratio risk and progressively higher percentage of patients receiving peripheral cannulation, this finding couples the nonsignificant difference in outcomes in the PCS populations that have received a central VA-ECMO in almost $30 \%$ of the cases (less than $10 \%$ in the mixed populations, $0 \%$ in AMI patients), and suggests, within the limitations of this analysis, a more pronounced positive impact of LV unloading in the peripheral VA-ECMO setting.

The analysis of weaning, additionally included as a sensitivity analysis, might give presumptive underlying evidence of true reasons for improved survival after VA-ECMO support. The possibility of providing an adequate oxygen delivery associated with the reduction of myocardial injury and the relief of pulmonary congestion, thus enhancing arterial oxygenation and reducing pulmonary complications, may explain the higher rate of survival 
in patients who received an adjunct treatment able to prevent or solve left ventricular distension during VAECMO support.

\section{Conclusions}

During veno-arterial extracorporeal membrane oxygenation, the increase of left ventricular afterload can negatively impact the recovery from cardiogenic shock. In this meta-analysis including 7581 patients on VAECMO support, the adjunct of left ventricular unloading was associated with $35 \%$ higher probability of weaning and $12 \%$ lower risk of mortality.

\section{References}

1. Bellumkonda, L.; Gul, B.; Masri, S.C. Evolving concepts in diagnosis and management of cardiogenic shock. Am. J. Cardiol. 2018, 122, 1104-1110, doi:10.1016/j.amjcard.2018.05.040.

2. Stretch, R.; Sauer, C.M.; Yuh, D.D.; Bonde, P. National trends in the utilization of short-term mechanical circulatory support: Incidence, outcomes, and cost analysis. J. Am. Coll. Cardiol. 2014, 64, 1407-1415, doi:10.1016/j.jacc.2014.07.958.

3. McCarthy, F.H.; McDermott, K.M.; Kini, V.; Gutsche, J.T.; Wald, J.W.; Xie, D.; Szeto, W.Y.; Bermudez, C.A.; Atluri, P.; Acker, M.A.; et al. Trends in U.S. Extracorporeal Membrane Oxygenation Use and Outcomes: 2002-2012. Semin. Thorac. Cardiovasc. Surg. 2015, 27, 81-88, doi:10.1053/j.semtcvs.2015.07.005.

4. Sauer, C.M.; Yuh, D.D.; Bonde, P. Extracorporeal membrane oxygenation use has increased by $433 \%$ in adults in the United States from 2006 to 2011. ASAIO J. 2015, 61, 31-36, doi:10.1097/MAT.0000000000000160.

5. Maxwell, B.G.; Powers, A.J.; Sheikh, A.Y.; Lee, P.H.; Lobato, R.L.; Wong, J.K. Resource use trends in extracorporeal membrane oxygenation in adults: An analysis of the Nationwide Inpatient Sample 19982009. J. Thorac. Cardiovasc. Surg. 2014, 148, 416-421, doi:10.1016/j.jtcvs.2013.09.033.

6. Whitman, G.J. Extracorporeal membrane oxygenation for the treatment of postcardiotomy shock. J. Thorac. Cardiovasc. Surg. 2017, 153, 95-101, doi:10.1016/j.jtcvs.2016.08.024. 
7. Peek, G.J.; Mugford, M.; Tiruvoipati, R.; Wilson, A.; Allen, E.; Thalanany, M.M.; Hibbert, C.L.; Truesdale, A.; Clemens, F.; Cooper, N.; et al. Efficacy and economic assessment of conventional ventilatory support versus extracorporeal membrane oxygenation for severe adult respiratory failure (CESAR): A multicentre randomised controlled trial. Lancet 2009, 374, 1351-1363, doi:10.1016/S0140-6736(09)61069-2.

8. Chung, M.; Shiloh, A.L.; Carlese, A. Monitoring of the adult patient on venoarterial extracorporeal membrane oxygenation. Sci. World J. 2014, 2014, 393258, doi:10.1155/2014/393258.

9. Curran, J.; Burkhoff, D.; Kloner, R.A. Beyond Reperfusion: Acute Ventricular Unloading and Cardioprotection During Myocardial Infarction. J. Cardiovasc. Transl. Res. 2019, 12, 95-106, doi:10.1007/s12265-019-9863-z.

10. Drake, R.E.; Doursout, M.F. Pulmonary edema and elevated left atrial pressure: Four hours and beyond. Physiology 2002, 17, 223-226, doi:10.1152/nips.01399.2002.

11. Xie, A.; Forrest, P.; Loforte, A. Left ventricular decompression in veno-arterial extracorporeal membrane oxygenation. Ann. Cardiothorac. Surg. 2019, 8, 9-18, doi:10.21037/acs.2018.11.07.

12. Cevasco, M.; Takayama, H.; Ando, M.; Garan, A.R.; Naka, Y.; Takeda, K. Left ventricular distension and venting strategies for patients on venoarterial extracorporeal membrane oxygenation. J. Thorac. Dis. 2019, 11, 1676-1683, doi:10.21037/jtd.2019.03.29.

13. Garan, A.R.; Takeda, K.; Salna, M.; Vandenberge, J.; Doshi, D.; Karmpaliotis, D.; Kirtane, A.J.; Takayama, H.; Kurlansky, P. Prospective comparison of a percutaneous ventricular assist device and venoarterial extracorporeal membrane oxygenation for patients with cardiogenic shock following acute myocardial infarction. J. Am. Heart Assoc. 2019, 8, e012171, doi:10.1161/JAHA.119.012171.

14. Wilson-Smith, A.R.; Bogdanova, Y.; Roydhouse, S.; Phan, K.; Tian, D.H.; Yan, T.D.; Loforte, A. Outcomes of venoarterial extracorporeal membrane oxygenation for refractory cardiogenic shock: Systematic review and meta-analysis. Ann. Cardiothorac. Surg. 2019, 8, 1-8, doi:10.21037/acs.2018.11.09.

15. Romeo, F.; Acconcia, M.C.; Sergi, D.; Romeo, A.; Francioni, S.; Chiarotti, F.; Caretta, Q. Percutaneous assist devices in acute myocardial infarction with cardiogenic shock: Review, meta-analysis. World J. Cardiol. 2016, 8, 98-111, doi:10.4330/wjc.v8.i1.98. 
16. Tricco, A.C.; Lillie, E.; Zarin, W.; O'Brien, K.K.; Colquhoun, H.; Levac, D.; Moher, D.; Peters, M.D.J.; Horsley, T.; Weeks, L.; et al. PRISMA Extension for Scoping Reviews (PRISMA-ScR): Checklist and Explanation. Ann. Intern. Med. 2018, 169, 467-473, doi:10.7326/M18-0850.

17. Sterne, J.A.; Hernan, M.A.; Reeves, B.C.; Savovic, J.; Berkman, N.D.; Viswanathan, M.; Henry, D.; Altman, D.G.; Ansari, M.T.; Boutron, I.; et al. ROBINS-I: A tool for assessing risk of bias in non-randomised studies of interventions. Bmj 2016, 355, i4919, doi:10.1136/bmj.i4919.

18. Wongpakaran, N.; Wongpakaran, T.; Wedding, D.; Gwet, K.L. A comparison of Cohen's Kappa and Gwet's AC1 when calculating inter-rater reliability coefficients: A study conducted with personality disorder samples. BMC Med. Res. Methodol. 2013, 13, 61, doi:10.1186/1471-2288-13-61.

19. Stijnen, T.; Hamza, T.H.; Ozdemir, P. Random effects meta-analysis of event outcome in the framework of the generalized linear mixed model with applications in sparse data. Stat. Med. 2010, 29, 3046-3067, doi:10.1002/sim.4040.

20. Egger, M.; Davey Smith, G.; Schneider, M.; Minder, C. Bias in meta-analysis detected by a simple, graphical test. Bmj 1997, 315, 629-634, doi:10.1136/bmj.315.7109.629.

21. Raffa, G.M.; Kowalewski, M.; Brodie, D.; Ogino, M.; Whitman, G.; Meani, P.; Pilato, M.; Arcadipane, A.; Delnoij, T.; Natour, E.; et al. Meta-analysis of peripheral or central extracorporeal membrane oxygenation in postcardiotomy and non-postcardiotomy shock. Ann. Thorac. Surg. 2019, 107, 311-321, doi:10.1016/j.athoracsur.2018.05.063.

22. Burkhoff, D.; Sayer, G.; Doshi, D.; Uriel, N. Hemodynamics of mechanical circulatory support. J. Am. Coll. Cardiol. 2015, 66, 2663-2674, doi:10.1016/j.jacc.2015.10.017.

23. Ostadal, P.; Mlcek, M.; Kruger, A.; Hala, P.; Lacko, S.; Mates, M.; Vondrakova, D.; Svoboda, T.; Hrachovina, M.; Janotka, M.; et al. Increasing venoarterial extracorporeal membrane oxygenation flow negatively affects left ventricular performance in a porcine model of cardiogenic shock. J. Transl. Med. 2015, 13, 266, doi:10.1186/s12967-015-0634-6.

24. Dickstein, M.L. The starling relationship and veno-arterial ecmo: Ventricular distension explained. ASAIO J. 2018, 64, 497-501, doi:10.1097/MAT.0000000000000660. 
25. Turner, D.A.; Cheifetz, I.M. Extracorporeal membrane oxygenation for adult respiratory failure. Respir. Care 2013, 58, 1038-1052, doi:10.4187/respcare.02255.

26. Cheng, R.; Hachamovitch, R.; Makkar, R.; Ramzy, D.; Moriguchi, J.D.; Arabia, F.A.; Esmailian, F.; Azarbal, B. Lack of survival benefit found with use of intraaortic balloon pump in extracorporeal membrane oxygenation: A pooled experience of 1517 patients. J. Invasive Cardiol. 2015, 27, 453-458.

27. Weber, C.; Deppe, A.C.; Sabashnikov, A.; Slottosch, I.; Kuhn, E.; Eghbalzadeh, K.; Scherner, M.; Choi, Y.H.; Madershahian, N.; Wahlers, T. Left ventricular thrombus formation in patients undergoing femoral veno-arterial extracorporeal membrane oxygenation. Perfusion 2018, 33, 283-288, doi:10.1177/0267659117745369.

28. Meani, P.; Gelsomino, S.; Natour, E.; Johnson, D.M.; Rocca, H.B.; Pappalardo, F.; Bidar, E.; Makhoul, M.; Raffa, G.; Heuts, S.; et al. Modalities and effects of left ventricle unloading on extracorporeal life support: A review of the current literature. Eur. J. Heart Fail. 2017, 19, 84-91, doi:10.1002/ejhf.850.

29. Truby, L.K.; Takeda, K.; Mauro, C.; Yuzefpolskaya, M.; Garan, A.R.; Kirtane, A.J.; Topkara, V.K.; Abrams, D.; Brodie, D.; Colombo, P.C.; et al. Incidence and implications of left ventricular distention during venoarterial extracorporeal membrane oxygenation support. ASAIO J. 2017, 63, 257-265, doi:10.1097/MAT.0000000000000553.

30. Hochman, J.S.; Sleeper, L.A.; Webb, J.G.; Sanborn, T.A.; White, H.D.; Talley, J.D.; Buller, C.E.; Jacobs, A.K.; Slater, J.N.; Col, J.; et al. Early revascularization in acute myocardial infarction complicated by cardiogenic shock. shock investigators. Should we emergently revascularize occluded coronaries for cardiogenic shock. N. Engl. J. Med. 1999, 341, 625-634, doi:10.1056/NEJM199908263410901.

31. Camboni, D.; Schmid, C. To vent or not on veno-arterial extracorporeal membrane oxygenation, does it improve myocardial recovery and outcome? J. Thorac. Dis. 2017, 9, 4915-4918, doi:10.21037/jtd.2017.11.98.

32. Meani, P.; Delnoij, T.; Raffa, G.M.; Morici, N.; Viola, G.; Sacco, A.; Oliva, F.; Heuts, S.; Sels, J.W.; Driessen, R.; et al. Protracted aortic valve closure during peripheral veno-arterial extracorporeal life support: Is intraaortic balloon pump an effective solution? Perfusion 2019, 34, 35-41, doi:10.1177/0267659118787426. 
33. Russo, J.J.; Aleksova, N.; Pitcher, I.; Couture, E.; Parlow, S.; Faraz, M.; Visintini, S.; Simard, T.; Di Santo, P.; Mathew, R.; et al. Left Ventricular Unloading During Extracorporeal Membrane Oxygenation in Patients With Cardiogenic Shock. J. Am. Coll. Cardiol. 2019, 73, 654-662, doi:10.1016/j.jacc.2018.10.085.

34. Williams, D.O.; Korr, K.S.; Gewirtz, H.; Most, A.S. The effect of intraaortic balloon counterpulsation on regional myocardial blood flow and oxygen consumption in the presence of coronary artery stenosis in patients with unstable angina. Circulation 1982, 66, 593-597, doi:10.1161/01.cir.66.3.593.

35. Werdan, K.; Gielen, S.; Ebelt, H.; Hochman, J.S. Mechanical circulatory support in cardiogenic shock. Eur. Heart J. 2014, 35, 156-167, doi:10.1093/eurheartj/eht248.

36. Zobel, G.; Dacar, D.; Kuttnig, M.; Rodl, S.; Rigler, B. Mechanical support of the left ventricle in ischemia induced left ventricular failure: An experimental study. Int. J. Artif. Organs 1992, 15, 114-119.

37. Sauren, L.D.; Reesink, K.D.; Selder, J.L.; Beghi, C.; van der Veen, F.H.; Maessen, J.G. The acute effect of intra-aortic balloon counterpulsation during extracorporeal life support: An experimental study. Artif. Organs 2007, 31, 31-38, doi:10.1111/j.1525-1594.2007.00337.x.

38. Belohlavek, J.; Mlcek, M.; Huptych, M.; Svoboda, T.; Havranek, S.; Ost'adal, P.; Boucek, T.; Kovarnik, T.; Mlejnsky, F.; Mrazek, V.; et al. Coronary versus carotid blood flow and coronary perfusion pressure in a pig model of prolonged cardiac arrest treated by different modes of venoarterial ECMO and intraaortic balloon counterpulsation. Crit. Care 2012, 16, R50, doi:10.1186/cc11254.

39. Ma, P.; Zhang, Z.; Song, T.; Yang, Y.; Meng, G.; Zhao, J.; Wang, C.; Gu, K.; Peng, J.; Jiang, B.; et al. Combining ECMO with IABP for the treatment of critically III adult heart failure patients. Heart Lung Circ. 2014, 23, 363-368, doi:10.1016/j.hlc.2013.10.081.

40. Brechot, N.; Mastroianni, C.; Schmidt, M.; Santi, F.; Lebreton, G.; Hoareau, A.M.; Luyt, C.E.; Chommeloux, J.; Rigolet, M.; Lebbah, S.; et al. Retrieval of severe acute respiratory failure patients on extracorporeal membrane oxygenation: Any impact on their outcomes? J. Thorac. Cardiovasc. Surg. 2018, 155, $1621-$ 1629, doi:10.1016/j.jtcvs.2017.10.084. 
41. Santise, G.; Panarello, G.; Ruperto, C.; Turrisi, M.; Pilato, G.; Giunta, A.; Sciacca, S.; Pilato, M. Extracorporeal membrane oxygenation for graft failure after heart transplantation: A multidisciplinary approach to maximize weaning rate. Int. J. Artif. Organs 2014, 37, 706-714, doi:10.5301/ijao.5000353.

42. Doll, J.A.; Sketch, M.H., Jr. ECMO and the intraaortic balloon pump: In search of the ideal mechanical circulatory support device. J. Invasive Cardiol. 2015, 27, 459-460.

43. Patel, S.M.; Lipinski, J.; Al-Kindi, S.G.; Patel, T.; Saric, P.; Li, J.; Nadeem, F.; Ladas, T.; Alaiti, A.; Phillips, A.; et al. Simultaneous venoarterial extracorporeal membrane oxygenation and percutaneous left ventricular decompression therapy with impella is associated with improved outcomes in refractory cardiogenic shock. ASAIO J. 2019, 65, 21-28, doi:10.1097/MAT.0000000000000767.

44. Pappalardo, F.; Schulte, C.; Pieri, M.; Schrage, B.; Contri, R.; Soeffker, G.; Greco, T.; Lembo, R.; Mullerleile, K.; Colombo, A.; et al. Concomitant implantation of Impella $((\mathrm{R}))$ on top of veno-arterial extracorporeal membrane oxygenation may improve survival of patients with cardiogenic shock. Eur. J. Heart Fail. 2017, 19, 404-412, doi:10.1002/ejhf.668.

45. Fiedler, A.G.; Dalia, A.; Axtell, A.L.; Ortoleva, J.; Thomas, S.M.; Roy, N.; Villavicencio, M.A.; D’Alessandro, D.A.; Cudemus, G. Impella placement guided by echocardiography can be used as a strategy to unload the left ventricle during peripheral venoarterial extracorporeal membrane oxygenation. J. Cardiothorac. Vasc. Anesth. 2018, 32, 2585-2591, doi:10.1053/j.jvca.2018.05.019.

46. Schrage, B.; Burkhoff, D.; Rubsamen, N.; Becher, P.M.; Schwarzl, M.; Bernhardt, A.; Grahn, H.; Lubos, E.; Soffker, G.; Clemmensen, P.; et al. Unloading of the left ventricle during venoarterial extracorporeal membrane oxygenation therapy in cardiogenic shock. JACC. Heart Fail. 2018, 6, 1035-1043, doi:10.1016/j.jchf.2018.09.009.

47. Eliet, J.; Gaudard, P.; Zeroual, N.; Rouviere, P.; Albat, B.; Mourad, M.; Colson, P.H. Effect of impella during veno-arterial extracorporeal membrane oxygenation on pulmonary artery flow as assessed by end-tidal carbon dioxide. ASAIO J. 2018, 64, 502-507, doi:10.1097/MAT.0000000000000662.

48. Lim, H.S. The effect of impella $\mathrm{cp}$ on cardiopulmonary physiology during venoarterial extracorporeal membrane oxygenation support. Artif. Organs 2017, 41, 1109-1112, doi:10.1111/aor.12923. 
49. Ouweneel, D.M.; de Brabander, J.; Karami, M.; Sjauw, K.D.; Engstrom, A.E.; Vis, M.M.; Wykrzykowska, J.J.; Beijk, M.A.; Koch, K.T.; Baan, J.; et al. Real-life use of left ventricular circulatory support with Impella in cardiogenic shock after acute myocardial infarction: 12 years AMC experience. Eur. Heart J. Acute Cardiovasc. Care 2019, 8, 338-349, doi:10.1177/2048872618805486.

50. Schrage, B.; Ibrahim, K.; Loehn, T.; Werner, N.; Sinning, J.M.; Pappalardo, F.; Pieri, M.; Skurk, C.; Lauten, A.; Landmesser, U.; et al. Impella support for acute myocardial infarction complicated by cardiogenic shock. Circulation 2019, 139, 1249-1258, doi:10.1161/CIRCULATIONAHA.118.036614.

51. Poptsov, V.; Spirina, E.; Dogonasheva, A.; Zolotova, E. Five years' experience with a peripheral venoarterial ECMO for mechanical bridge to heart transplantation. J. Thorac. Dis. 2019, 11, S889-S901, doi:10.21037/jtd.2019.02.55.

52. Biancari, F.; Dalen, M.; Perrotti, A.; Fiore, A.; Reichart, D.; Khodabandeh, S.; Gulbins, H.; Zipfel, S.; Al Shakaki, M.; Welp, H.; et al. Venoarterial extracorporeal membrane oxygenation after coronary artery bypass grafting: Results of a multicenter study. Int. J. Cardiol. 2017, 241, 109-114, doi:10.1016/j.jjcard.2017.03.120.

53. Lorusso, R.; Centofanti, P.; Gelsomino, S.; Barili, F.; Di Mauro, M.; Orlando, P.; Botta, L.; Milazzo, F.; Actis Dato, G.; Casabona, R.; et al. Venoarterial extracorporeal membrane oxygenation for acute fulminant myocarditis in adult patients: A 5-year multi-institutional experience. Ann. Thorac. Surg. 2016, 101, 919926, doi:10.1016/j.athoracsur.2015.08.014.

54. Schmack, B.; Seppelt, P.; Weymann, A.; Alt, C.; Farag, M.; Arif, R.; Doesch, A.O.; Raake, P.W.; Kallenbach, K.; Mansur, A.; et al. Extracorporeal life support with left ventricular decompression-improved survival in severe cardiogenic shock: Results from a retrospective study. PeerJ 2017, 5, e3813, doi:10.7717/peerj.381.

\section{A.1. References to Excluded Studies}

A1. Doll, J.A.; Sketch, M.H., Jr. ECMO and the Intraaortic Balloon Pump: In Search of the Ideal Mechanical Circulatory Support Device. The Journal of invasive cardiology 2015, 27, 459-460. 
A2. Dangers, L.; Brechot, N.; Schmidt, M.; Lebreton, G.; Hekimian, G.; Nieszkowska, A.; Besset, S.; Trouillet, J.L.; Chastre, J.; Leprince, P., et al. Extracorporeal Membrane Oxygenation for Acute Decompensated Heart Failure. Critical care medicine 2017, 45, 1359-1366, doi:10.1097/CCM.0000000000002485.

A3. Zhao, Y.; Xing, J.; Du, Z.; Liu, F.; Jia, M.; Hou, X. Extracorporeal cardiopulmonary resuscitation for adult patients who underwent post-cardiac surgery. European journal of medical research 2015, 20, 83, doi:10.1186/s40001-015-0179-4.

A4. Luo, X.J.; Wang, W.; Hu, S.S.; Sun, H.S.; Gao, H.W.; Long, C.; Song, Y.H.; Xu, J.P. Extracorporeal membrane oxygenation for treatment of cardiac failure in adult patients. Interactive cardiovascular and thoracic surgery 2009, 9, 296-300, doi:10.1510/icvts.2008.197681.

A5. Park, S.J.; Kim, S.P.; Kim, J.B.; Jung, S.H.; Choo, S.J.; Chung, C.H.; Lee, J.W. Blood lactate level during extracorporeal life support as a surrogate marker for survival. The Journal of thoracic and cardiovascular surgery 2014, 148, 714-720, doi:10.1016/j.jtcvs.2014.02.078.

\section{A.2. References to Included Studies}

A6. Acheampong, B.; Johnson, J.N.; Stulak, J.M.; Dearani, J.A.; Kushwaha, S.S.; Daly, R.C.; Haile, D.T.; Schears, G.J. Postcardiotomy ECMO Support after High-risk Operations in Adult Congenital Heart Disease. Congenital heart disease 2016, 11, 751-755, doi:10.1111/chd.12396.

A7. Akanni, O.J.; Takeda, K.; Truby, L.K.; Kurlansky, P.A.; Chiuzan, C.; Han, J.; Topkara, V.K.; Yuzefpolskaya, M.; Colombo, P.C.; Karmpaliotis, D., et al. EC-VAD: Combined Use of Extracorporeal Membrane Oxygenation and Percutaneous Microaxial Pump Left Ventricular Assist Device. ASAIO journal 2019, 65, 219-226, doi:10.1097/MAT.0000000000000804.

A8. Aoyama, N.; Imai, H.; Kurosawa, T.; Fukuda, N.; Moriguchi, M.; Nishinari, M.; Nishii, M.; Kono, K.; Soma, K.; Izumi, T. Therapeutic strategy using extracorporeal life support, including appropriate indication, management, limitation and timing of switch to ventricular assist device in patients with acute myocardial infarction. Journal of artificial organs: the official journal of the Japanese Society for Artificial Organs 2014, 17, 33-41, doi:10.1007/s10047-013-0735-z. 
A9. Asaumi, Y.; Yasuda, S.; Morii, I.; Kakuchi, H.; Otsuka, Y.; Kawamura, A.; Sasako, Y.; Nakatani, T.; Nonogi, H.; Miyazaki, S. Favourable clinical outcome in patients with cardiogenic shock due to fulminant myocarditis supported by percutaneous extracorporeal membrane oxygenation. European heart journal 2005, 26, 21852192, doi:10.1093/eurheartj/ehi411.

A10. Aso, S.; Matsui, H.; Fushimi, K.; Yasunaga, H. The Effect of Intraaortic Balloon Pumping Under Venoarterial Extracorporeal Membrane Oxygenation on Mortality of Cardiogenic Patients: An Analysis Using a Nationwide Inpatient Database. Critical care medicine 2016, 44, 1974-1979, doi:10.1097/CCM.0000000000001828.

A11. Aziz, T.A.; Singh, G.; Popjes, E.; Stephenson, E.; Mulvey, S.; Pae, W.; El-Banayosy, A. Initial experience with CentriMag extracorporal membrane oxygenation for support of critically ill patients with refractory cardiogenic shock. The Journal of heart and lung transplantation: the official publication of the International Society for Heart Transplantation 2010, 29, 66-71, doi:10.1016/j.healun.2009.08.025.

A12. Beiras-Fernandez, A.; Deutsch, M.A.; Kainzinger, S.; Kaczmarek, I.; Sodian, R.; Ueberfuhr, P.; Meiser, B.; Schmoeckel, M.; Reichart, B.; Brenner, P. Extracorporeal membrane oxygenation in 108 patients with low cardiac output - a single-center experience. The International journal of artificial organs $2011,34,365-$ 373, doi:10.5301/IJAO.2011.7727.

A13. Beurtheret, S.; Mordant, P.; Paoletti, X.; Marijon, E.; Celermajer, D.S.; Leger, P.; Pavie, A.; Combes, A.; Leprince, P. Emergency circulatory support in refractory cardiogenic shock patients in remote institutions: a pilot study (the cardiac-RESCUE program). European heart journal 2013, 34, 112-120, doi:10.1093/eurheartj/ehs081.

A14. Biancari, F.; Dalen, M.; Perrotti, A.; Fiore, A.; Reichart, D.; Khodabandeh, S.; Gulbins, H.; Zipfel, S.; Al Shakaki, M.; Welp, H., et al. Venoarterial extracorporeal membrane oxygenation after coronary artery bypass grafting: Results of a multicenter study. International journal of cardiology $2017,241,109-114$, doi:10.1016/j.jijcard.2017.03.120.

A15. Brechot, N.; Mastroianni, C.; Schmidt, M.; Santi, F.; Lebreton, G.; Hoareau, A.M.; Luyt, C.E.; Chommeloux, J.; Rigolet, M.; Lebbah, S., et al. Retrieval of severe acute respiratory failure patients on 
extracorporeal membrane oxygenation: Any impact on their outcomes? The Journal of thoracic and cardiovascular surgery 2018, 155, 1621-1629 e1622, doi:10.1016/j.jtcvs.2017.10.084.

A16. Carroll, B.J.; Shah, R.V.; Murthy, V.; McCullough, S.A.; Reza, N.; Thomas, S.S.; Song, T.H.; NewtonCheh, C.H.; Camuso, J.M.; MacGillivray, T., et al. Clinical Features and outcomes in adults with cardiogenic shock supported by extracorporeal membrane oxygenation. The American journal of cardiology 2015, 116, 1624-1630, doi:10.1016/j.amjcard.2015.08.030.

A17. Chen, Y.S.; Yu, H.Y.; Huang, S.C.; Chiu, K.M.; Lin, T.Y.; Lai, L.P.; Lin, F.Y.; Wang, S.S.; Chu, S.H.; Ko, W.J. Experience and result of extracorporeal membrane oxygenation in treating fulminant myocarditis with shock: what mechanical support should be considered first? The Journal of heart and lung transplantation: the official publication of the International Society for Heart Transplantation 2005, 24, 81-87, doi:10.1016/j.healun.2003.09.038.

A18. Chen, J.S.; Ko, W.J.; Yu, H.Y.; Lai, L.P.; Huang, S.C.; Chi, N.H.; Tsai, C.H.; Wang, S.S.; Lin, F.Y.; Chen, Y.S. Analysis of the outcome for patients experiencing myocardial infarction and cardiopulmonary resuscitation refractory to conventional therapies necessitating extracorporeal life support rescue. Critical care medicine 2006, 34, 950-957, doi:10.1097/01.CCM.0000206103.35460.1F.

A19. Chen, K.; Hou, J.; Tang, H.; Hu, S. Concurrent Implantation of Intra-Aortic Balloon Pump and Extracorporeal Membrane Oxygenation Improved Survival of Patients With Postcardiotomy Cardiogenic Shock. Artificial organs 2019, 43, 142-149, doi:10.1111/aor.13317.

A20. Cho, S.; Lee, W.; Lim, S.H.; Kang, T.S. Relationship between Clinical Outcomes and Cardiopulmonary Resuscitation Time in Patients with Acute Myocardial Infarction Treated by Extracorporeal Membrane Oxygenation-Assisted Primary Percutaneous Coronary Intervention. Korean circulation journal 2018, 48, 705-715, doi:10.4070/kcj.2018.0121.

A21. Choi, K.H.; Yang, J.H.; Park, T.K.; Lee, J.M.; Song, Y.B.; Hahn, J.Y.; Choi, S.H.; Choi, J.H.; Cho, Y.H.; Sung, K., et al. Risk Prediction Model of In-hospital Mortality in Patients With Myocardial Infarction Treated With Venoarterial Extracorporeal Membrane Oxygenation. Revista espanola de cardiologia 2019, 72, 724731, doi:10.1016/j.rec.2018.06.010. 
A22. Chung, E.S.; Lim, C.; Lee, H.Y.; Choi, J.H.; Lee, J.S.; Park, K.H. Results of Extracorporeal Membrane Oxygenation (ECMO) Support before Coronary Reperfusion in Cardiogenic Shock with Acute Myocardial Infarction. The Korean journal of thoracic and cardiovascular surgery 2011, 44, 273-278, doi:10.5090/kjtcs.2011.44.4.273.

A23. Czobor, P.; Venturini, J.M.; Parikh, K.S.; Retzer, E.M.; Friant, J.; Jeevanandam, V.; Russo, M.J.; Uriel, N.; Paul, J.D.; Blair, J.E., et al. Sequential Organ Failure Assessment Score at Presentation Predicts Survival in Patients Treated With Percutaneous Veno-Arterial Extracorporeal Membrane Oxygenation. The Journal of invasive cardiology 2016, 28, 133-138.

A24. Elsharkawy, H.A.; Li, L.; Esa, W.A.; Sessler, D.I.; Bashour, C.A. Outcome in patients who require venoarterial extracorporeal membrane oxygenation support after cardiac surgery. Journal of cardiothoracic and vascular anesthesia 2010, 24, 946-951, doi:10.1053/j.jvca.2010.03.020.

A25. Formica, F.; Avalli, L.; Colagrande, L.; Ferro, O.; Greco, G.; Maggioni, E.; Paolini, G. Extracorporeal membrane oxygenation to support adult patients with cardiac failure: predictive factors of 30-day mortality. Interactive cardiovascular and thoracic surgery 2010, 10, 721-726, doi:10.1510/icvts.2009.220335.

A26. Gass, A.; Palaniswamy, C.; Aronow, W.S.; Kolte, D.; Khera, S.; Ahmad, H.; Cuomo, L.J.; Timmermans, R.; Cohen, M.; Tang, G.H., et al. Peripheral venoarterial extracorporeal membrane oxygenation in combination with intra-aortic balloon counterpulsation in patients with cardiovascular compromise. Cardiology 2014, 129, 137-143, doi:10.1159/000365138.

A27. Guihaire, J.; Dang Van, S.; Rouze, S.; Rosier, S.; Roisne, A.; Langanay, T.; Corbineau, H.; Verhoye, J.P.; Flecher, E. Clinical outcomes in patients after extracorporeal membrane oxygenation support for postcardiotomy cardiogenic shock: a single-centre experience of 92 cases. Interactive cardiovascular and thoracic surgery 2017, 25, 363-369, doi:10.1093/icvts/ivx155.

A28. Hei, F.; Lou, S.; Li, J.; Yu, K.; Liu, J.; Feng, Z.; Zhao, J.; Hu, S.; Xu, J.; Chang, Q., et al. Five-year results of 121 consecutive patients treated with extracorporeal membrane oxygenation at Fu Wai Hospital. Artificial organs 2011, 35, 572-578, doi:10.1111/j.1525-1594.2010.01151.x. 
A29. Kagawa, E.; Dote, K.; Kato, M.; Sasaki, S.; Nakano, Y.; Kajikawa, M.; Higashi, A.; Itakura, K.; Sera, A.; Inoue, I., et al. Should we emergently revascularize occluded coronaries for cardiac arrest?: rapid-response extracorporeal membrane oxygenation and intra-arrest percutaneous coronary intervention. Circulation 2012, 126, 1605-1613, doi:10.1161/CIRCULATIONAHA.111.067538.

A30. Kim, D.K.; Seo, G.W.; Song, P.S.; Kim, K.H.; Kim, D.I.; Jin, H.Y.; Jang, J.S.; Yoon, H.J.; Nam, C.W. Impact of concomitant use of intra-aortic balloon pump during percutaneous cardiopulmonary support in patients with cardiogenic shock complicating acute myocardial infarction. Eurointervention (EuroPCR Abstracts and Poster 2014), Poster text.

A31. Lee, J.J.; Han, S.J.; Kim, H.S.; Hong, K.S.; Choi, H.H.; Park, K.T.; Seo, J.Y.; Lee, T.H.; Kim, H.C.; Kim, S., et al. Out-of-hospital cardiac arrest patients treated with cardiopulmonary resuscitation using extracorporeal membrane oxygenation: focus on survival rate and neurologic outcome. Scandinavian journal of trauma, resuscitation and emergency medicine 2016, 24, 74, doi:10.1186/s13049-016-0266-8.

A32. Lee, W.; Kim, Y.; Choi, H.; Kim, H.; Lee, S.; Lee, H.; Chee, H.; Kim, J.; Hwang, J.; Lee, S., et al. Advanced Age as a Predictor of Survival and Weaning in Venoarterial Extracorporeal Oxygenation: A Retrospective Observational Study. BioMed research international 2017, 2017, 3505784, doi:10.1155/2017/3505784.

A33. Li, C.L.; Wang, H.; Jia, M.; Ma, N.; Meng, X.; Hou, X.T. The early dynamic behavior of lactate is linked to mortality in postcardiotomy patients with extracorporeal membrane oxygenation support: A retrospective observational study. The Journal of thoracic and cardiovascular surgery 2015, 149, 1445-1450, doi:10.1016/j.jtcvs.2014.11.052.

A34. Lin, L.Y.; Liao, C.W.; Wang, C.H.; Chi, N.H.; Yu, H.Y.; Chou, N.K.; Hwang, J.J.; Lin, J.L.; Chiang, F.T.; Chen, Y.S. Effects of Additional Intra-aortic Balloon Counter-Pulsation Therapy to Cardiogenic Shock Patients Supported by Extra-corporeal Membranous Oxygenation. Scientific reports 2016, 6, 23838, doi:10.1038/srep23838.

A35. Lorusso, R.; Centofanti, P.; Gelsomino, S.; Barili, F.; Di Mauro, M.; Orlando, P.; Botta, L.; Milazzo, F.; Actis Dato, G.; Casabona, R., et al. Venoarterial Extracorporeal Membrane Oxygenation for Acute Fulminant 
Myocarditis in Adult Patients: A 5-Year Multi-Institutional Experience. The Annals of thoracic surgery 2016, 101, 919-926, doi:10.1016/j.athoracsur.2015.08.014.

A36. Luo, X.J.; Wang, W.; Hu, S.S.; Sun, H.S.; Gao, H.W.; Long, C.; Song, Y.H.; Xu, J.P. Extracorporeal membrane oxygenation for treatment of cardiac failure in adult patients. Interactive cardiovascular and thoracic surgery 2009, 9, 296-300, doi:10.1510/icvts.2008.197681.

A37. Mikus, E.; Tripodi, A.; Calvi, S.; Giglio, M.D.; Cavallucci, A.; Lamarra, M. CentriMag venoarterial extracorporeal membrane oxygenation support as treatment for patients with refractory postcardiotomy cardiogenic shock. ASAIO journal 2013, 59, 18-23, doi:10.1097/MAT.0b013e3182768b68.

A38. Muller, G.; Flecher, E.; Lebreton, G.; Luyt, C.E.; Trouillet, J.L.; Brechot, N.; Schmidt, M.; Mastroianni, C.; Chastre, J.; Leprince, P., et al. The ENCOURAGE mortality risk score and analysis of long-term outcomes after VA-ECMO for acute myocardial infarction with cardiogenic shock. Intensive care medicine 2016, 42, 370-378, doi:10.1007/s00134-016-4223-9.

A39. Nakamura, T.; Ishida, K.; Taniguchi, Y.; Nakagawa, T.; Seguchi, M.; Wada, H.; Sugawara, Y.; Funayama, H.; Mitsuhashi, T.; Momomura, S. Prognosis of patients with fulminant myocarditis managed by peripheral venoarterial extracorporeal membranous oxygenation support: a retrospective single-center study. Journal of intensive care 2015, 3, 5, doi:10.1186/s40560-014-0069-9.

A40. Negi, S.I.; Sokolovic, M.; Koifman, E.; Kiramijyan, S.; Torguson, R.; Lindsay, J.; Ben-Dor, I.; Suddath, W.; Pichard, A.; Satler, L., et al. Contemporary Use of Veno-Arterial Extracorporeal Membrane Oxygenation for Refractory Cardiogenic Shock in Acute Coronary Syndrome. The Journal of invasive cardiology 2016, $28,52-57$.

A41. Overtchouk, P.; Pascal, J.; Lebreton, G.; Hulot, J.S.; Luyt, C.E.; Combes, A.; Kerneis, M.; Silvain, J.; Barthelemy, O.; Leprince, P., et al. Outcome after revascularisation of acute myocardial infarction with cardiogenic shock on extracorporeal life support. Eurolntervention: journal of EuroPCR in collaboration with the Working Group on Interventional Cardiology of the European Society of Cardiology 2018, 13, e2160e2168, doi:10.4244/EIJ-D-17-01014. 
A42. Papadopoulos, N.; Marinos, S.; El-Sayed Ahmad, A.; Keller, H.; Meybohm, P.; Zacharowski, K.; Moritz, A.; Zierer, A. Risk factors associated with adverse outcome following extracorporeal life support: analysis from 360 consecutive patients. Perfusion 2015, 30, 284-290, doi:10.1177/0267659114542458.

A43. Pappalardo, F.; Schulte, C.; Pieri, M.; Schrage, B.; Contri, R.; Soeffker, G.; Greco, T.; Lembo, R.; Mullerleile, K.; Colombo, A., et al. Concomitant implantation of Impella((R)) on top of veno-arterial extracorporeal membrane oxygenation may improve survival of patients with cardiogenic shock. European journal of heart failure 2017, 19, 404-412, doi:10.1002/ejhf.668.

A44. Park, T.K.; Yang, J.H.; Choi, S.H.; Song, Y.B.; Hahn, J.Y.; Choi, J.H.; Sung, K.; Lee, Y.T.; Gwon, H.C.; Lee, S.H. Clinical outcomes of patients with acute myocardial infarction complicated by severe refractory cardiogenic shock assisted with percutaneous cardiopulmonary support. Yonsei medical journal 2014, 55, 920-927, doi:10.3349/ymj.2014.55.4.920.

A45. Patel, S.M.; Lipinski, J.; Al-Kindi, S.G.; Patel, T.; Saric, P.; Li, J.; Nadeem, F.; Ladas, T.; Alaiti, A.; Phillips, A., et al. Simultaneous Venoarterial Extracorporeal Membrane Oxygenation and Percutaneous Left Ventricular Decompression Therapy with Impella Is Associated with Improved Outcomes in Refractory Cardiogenic Shock. ASAIO journal 2019, 65, 21-28, doi:10.1097/MAT.0000000000000767.

A46. Pokersnik, J.A.; Buda, T.; Bashour, C.A.; Gonzalez-Stawinski, G.V. Have changes in ECMO technology impacted outcomes in adult patients developing postcardiotomy cardiogenic shock? Journal of cardiac surgery 2012, 27, 246-252, doi:10.1111/j.1540-8191.2011.01409.x.

A47. Poptsov, V.; Spirina, E.; Dogonasheva, A.; Zolotova, E. Five years' experience with a peripheral venoarterial ECMO for mechanical bridge to heart transplantation. Journal of thoracic disease 2019,11 , S889S901, doi:10.21037/jtd.2019.02.55.???

A48. Raffa, G.M.; Gelsomino, S.; Sluijpers, N.; Meani, P.; Alenizy, K.; Natour, E.; Bidar, E.; Johnson, D.M.; Makhoul, M.; Heuts, S., et al. In-hospital outcome of post-cardiotomy extracorporeal life support in adult patients: the 2007-2017 Maastricht experience. Critical care and resuscitation: journal of the Australasian Academy of Critical Care Medicine 2017, 19, 53-61. 
A49. Rastan, A.J.; Dege, A.; Mohr, M.; Doll, N.; Falk, V.; Walther, T.; Mohr, F.W. Early and late outcomes of 517 consecutive adult patients treated with extracorporeal membrane oxygenation for refractory postcardiotomy cardiogenic shock. The Journal of thoracic and cardiovascular surgery 2010, 139, 302-311, 311 e301, doi:10.1016/j.jtcvs.2009.10.043.

A50. Ro, S.K.; Kim, J.B.; Jung, S.H.; Choo, S.J.; Chung, C.H.; Lee, J.W. Extracorporeal life support for cardiogenic shock: influence of concomitant intra-aortic balloon counterpulsation. European journal of cardio-thoracic surgery: official journal of the European Association for Cardio-thoracic Surgery 2014, 46, 186-192; discussion 192, doi:10.1093/ejcts/ezu005.

A51. Russo, C.F.; Cannata, A.; Lanfranconi, M.; Bruschi, G.; Milazzo, F.; Paino, R.; Martinelli, L. Veno-arterial extracorporeal membrane oxygenation using Levitronix centrifugal pump as bridge to decision for refractory cardiogenic shock. The Journal of thoracic and cardiovascular surgery 2010, 140, 1416-1421, doi:10.1016/j.jtcvs.2010.07.083.

A52. Sakamoto, S.; Taniguchi, N.; Nakajima, S.; Takahashi, A. Extracorporeal life support for cardiogenic shock or cardiac arrest due to acute coronary syndrome. The Annals of thoracic surgery 2012, 94, 1-7, doi:10.1016/j.athoracsur.2012.01.032.

A53. Santise, G.; Panarello, G.; Ruperto, C.; Turrisi, M.; Pilato, G.; Giunta, A.; Sciacca, S.; Pilato, M. Extracorporeal membrane oxygenation for graft failure after heart transplantation: a multidisciplinary approach to maximize weaning rate. The International journal of artificial organs $2014,37,706-714$, doi:10.5301/ijao.5000353.

A54. Shinn, S.H.; Lee, Y.T.; Sung, K.; Min, S.; Kim, W.S.; Park, P.W.; Ha, Y.K. Efficacy of emergent percutaneous cardiopulmonary support in cardiac or respiratory failure: fight or flight? Interactive cardiovascular and thoracic surgery 2009, 9, 269-273, doi:10.1510/icvts.2008.194860.

A55. Schmack, B.; Seppelt, P.; Weymann, A.; Alt, C.; Farag, M.; Arif, R.; Doesch, A.O.; Raake, P.W.; Kallenbach, K.; Mansur, A., et al. Extracorporeal life support with left ventricular decompression-improved survival in severe cardiogenic shock: results from a retrospective study. PeerJ 2017, 5, e3813, doi:10.7717/peerj.3813. 
A56. Slottosch, I.; Liakopoulos, O.; Kuhn, E.; Deppe, A.C.; Scherner, M.; Madershahian, N.; Choi, Y.H.; Wahlers, T. Outcomes after peripheral extracorporeal membrane oxygenation therapy for postcardiotomy cardiogenic shock: a single-center experience. The Journal of surgical research 2013, 181, e47-55, doi:10.1016/j.jss.2012.07.030.

A57. Slottosch, I.; Liakopoulos, O.; Kuhn, E.; Scherner, M.; Deppe, A.C.; Sabashnikov, A.; Mader, N.; Choi, Y.H.; Wippermann, J.; Wahlers, T. Lactate and lactate clearance as valuable tool to evaluate ECMO therapy in cardiogenic shock. Journal of critical care 2017, 42, 35-41, doi:10.1016/j.jcrc.2017.06.022.

A58. Smedira, N.G.; Moazami, N.; Golding, C.M.; McCarthy, P.M.; Apperson-Hansen, C.; Blackstone, E.H.; Cosgrove, D.M., 3rd. Clinical experience with 202 adults receiving extracorporeal membrane oxygenation for cardiac failure: survival at five years. The Journal of thoracic and cardiovascular surgery $2001,122,92-$ 102, doi:10.1067/mtc.2001.114351.

A59. Tepper, S.; Garcia, M.B.; Fischer, I.; Ahmed, A.; Khan, A.; Balsara, K.R.; Masood, M.F.; Itoh, A. Clinical Outcomes and Reduced Pulmonary Artery Pressure With Intra-Aortic Balloon Pump During Central Extracorporeal Life Support. ASAIO journal 2019, 65, 173-179, doi:10.1097/MAT.0000000000000788.

A60. Unosawa, S.; Sezai, A.; Hata, M.; Nakata, K.; Yoshitake, I.; Wakui, S.; Kimura, H.; Takahashi, K.; Hata, H.; Shiono, M. Long-term outcomes of patients undergoing extracorporeal membrane oxygenation for refractory postcardiotomy cardiogenic shock. Surgery today 2013, 43, 264-270, doi:10.1007/s00595-0120322-6.

A61. van den Brink, F.S.; Magan, A.D.; Noordzij, P.G.; Zivelonghi, C.; Agostoni, P.; Eefting, F.D.; Ten Berg, J.M.; Suttorp, M.J.; Rensing, B.R.; van Kuijk, J.P., et al. Veno-arterial extracorporeal membrane oxygenation in addition to primary $\mathrm{PCI}$ in patients presenting with ST-elevation myocardial infarction. Netherlands heart journal: monthly journal of the Netherlands Society of Cardiology and the Netherlands Heart Foundation 2018, 26, 76-84, doi:10.1007/s12471-017-1068-y.

A62. Wang, J.G.; Han, J.; Jia, Y.X.; Zeng, W.; Hou, X.T.; Meng, X. Outcome of veno-arterial extracorporeal membrane oxygenation for patients undergoing valvular surgery. PloS one 2013, 8, e63924, doi:10.1371/journal.pone.0063924. 
A63. Weber, C.; Deppe, A.C.; Sabashnikov, A.; Slottosch, I.; Kuhn, E.; Eghbalzadeh, K.; Scherner, M.; Choi, Y.H.; Madershahian, N.; Wahlers, T. Left ventricular thrombus formation in patients undergoing femoral veno-arterial extracorporeal membrane oxygenation. Perfusion 2018, 33, 283-288, doi:10.1177/0267659117745369.

A64. Wu, M.Y.; Lee, M.Y.; Lin, C.C.; Chang, Y.S.; Tsai, F.C.; Lin, P.J. Resuscitation of non-postcardiotomy cardiogenic shock or cardiac arrest with extracorporeal life support: the role of bridging to intervention. Resuscitation 2012, 83, 976-981, doi:10.1016/j.resuscitation.2012.01.010.

A65. Xu, J.; Leung, D.; Rajaratnam, R.; Mussap, C.; French, J.; Juergens, C.; Parr, M.; Lo, S.; Contemporary Practice of Veno-Arterial Extracorporeal Membrane Oxygenation (VA-ECMO) at a Single Non-Transplant Centre: Survival Prediction Scores, Indications and Outcomes. 2016; 25(Supplement 2): S171, doi:10.1016/j.hlc.2016.06.402

A66. Zhao, Y.; Xing, J.; Du, Z.; Liu, F.; Jia, M.; Hou, X. Extracorporeal cardiopulmonary resuscitation for adult patients who underwent post-cardiac surgery. European journal of medical research 2015, 20, 83, doi:10.1186/s40001-015-0179-4.

A67. Zhong, Z.; Jiang, C.; Yang, F.; Hao, X.; Xing, J.; Wang, H.; Hou, X. Veno-Arterial Extracorporeal Membrane Oxygenation Support in Patients Undergoing Aortic Surgery. Artificial organs 2017, 41, 11131120, doi:10.1111/aor.12951. 


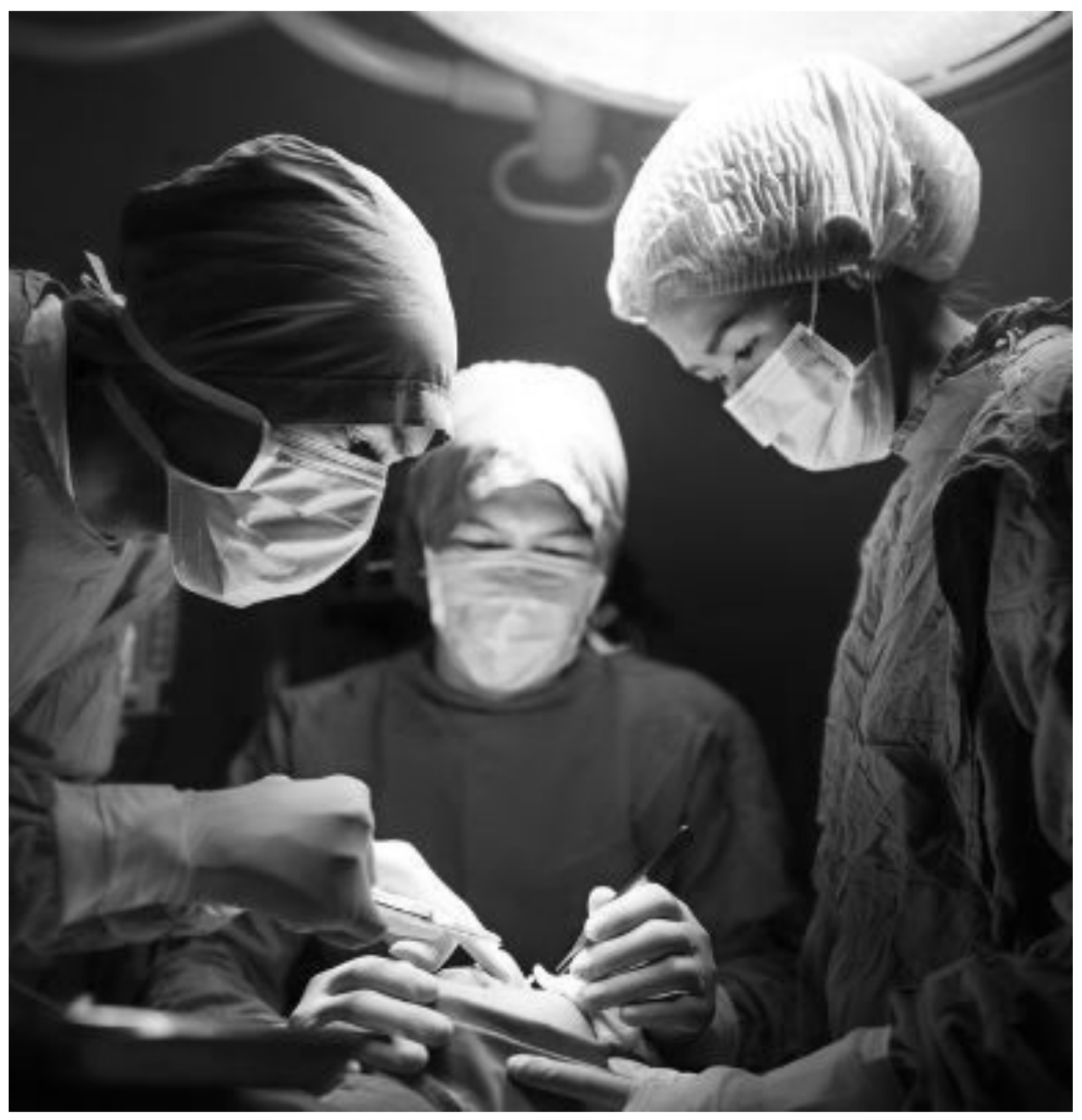




\section{CHAPTER 4}

BASELINE SURGICAL STATUS AND SHORT-TERM MORTALITY AFTER EXTRACORPOREAL MEMBRANE OXYGENATION FOR POST-CARDIOTOMY SHOCK: A META-ANALYSIS.

Kowalewski M, Raffa G, Zielinski K, Meani P, Alanazi M, Gilbers M, Heuts S, Natour E, Bidar E, Schreurs R, Delnoij T, Driessen R, Sels JW, van de Poll M, Roekaerts P, Maessen J, Suwalski P, Lorusso R. 
Objective: While reported mortality rates on post-cardiotomy extracorporeal membrane oxygenation (ECMO) vary from center to center, impact of baseline surgical status (elective/ urgent/ emergency/ salvage) on mortality is still unknown.

Methods: A systematic search was performed according to PRISMA statement using PubMed/Medline databases until March 2018 using the keywords "postcardiotomy", "cardiogenic shock", "extracorporeal membrane oxygenation", "extracorporeal life support". Relevant articles were scrutinized and included in the meta-analysis only if reporting in-hospital/30-day mortality and baseline surgical status. The correlations between mortality and percentage of elective/urgent/emergency cases were investigated. Inference analysis of baseline status and on-ECMO complications was conducted as well.

Results: Twenty-two studies (conducted between 1993-2017) enrolling N=2,235 post-cardiotomy ECMO patients were found. Patients were mostly of non-emergency status (65.2\%). Overall in-hospital/30-day mortality Event Rate (95\% Confidence Intervals) was 66.7\% (63.3-69.9\%). There were no differences in in-hospital/30day mortality with respect to baseline surgical status in the subgroup analysis (test for subgroup differences; $p=0.406$ ). Similarly, no differences between mortality in studies enrolling $<50$ vs $\geq 50 \%$ of emergency/salvage cases was found: respective event rates were $66.9 \%(63.1-70.4 \%)$ vs $64.4 \%(57.3-70.8 \%) ; p=0.525$. Yet, there was a significant positive association between increasing percentage of emergency/salvage cases and rates of: neurological complications $(p<0.001)$, limb complications $(p<0.001)$ and bleeding $(p=0.051)$. Incidence of brain death $(p=0.099)$ and sepsis $(p=0.134)$ was increased as well.

Conclusion: Other factors than baseline surgical status may, to a higher degree, influence the mortality in patients treated with ECMO for post-cardiotomy cardiogenic shock. Baseline status, however, strongly influences the complication occurrence while on ECMO.

\section{Introduction}

Extracorporeal membrane oxygenation (ECMO) is increasingly used in case of acute cardiac and lung compromise refractory to conventional treatment, when temporary support may allow the dysfunctional organs to recover, or to provide a "bridge-to-decision" approach for more advanced treatment [1-5]. The inherent 
features of ECMO in terms of quick availability, relative ease of application, and improved as well as reliable performance have made it more and more attractive, particularly in post-cardiotomy (PC) setting. Postcardiotomy ECMO has been shown to be the most frequent indication for ECMO implant in the United States until 2011 [3]; indeed, recent data from the Registry of the Extracorporeal Life Support Organization (ELSO), which includes almost 90.000 ECMO cases including both adults and children, have confirmed the substantial rise in PC-ECMO use along the time, with a remarkable increase during the last 2-3 years [5]. Unfortunately, the exponential increase in cases in the last years has paralleled a lack of substantial progress [6] or even a progressive worsening with regards to in-hospital patient outcome [5]. Despite a wide series of published experiences in ECMO, reports specifically addressing PC-ECMO are limited. These studies often include different surgical scenarios and baseline patients' surgical status (e.g. elective, urgent, emergency and salvage), making the conclusions even harder to draw. Aim of the current meta-analysis was to demonstrate whether baseline pre-ECMO surgical status has any influence on postoperative mortality and complications for PCECMO.

\section{Material and methods}

\section{Data sources and search strategy}

This systematic review and meta-analysis was performed in accordance with the Preferred Reporting Items for Systematic Reviews and Meta-Analyses (PRISMA) statement [7]. The PRISMA checklist is available as Appendix Table 1. Relevant studies to be included were searched until published in March 31st 2018, through

PubMed, EMBASE, CINAHL, the Web of Science, the Cochrane Register of Controlled Clinical Trials (CENTRAL) and Google Scholar. The search term was: "extracorporeal membrane oxygenation" and "extracorporeal life support". No language restrictions were imposed. References of original articles were reviewed manually and cross-checked for relevant reports.

\section{Selection criteria and quality assessment}


Studies were included if they met all of the following criteria: 1) study reporting baseline surgical status for at least 1 group of interest e.g. elective, urgent, emergency or salvage surgery; 2) studies assessing mortality after ECMO instituted for PC refractory cardiogenic shock; 3) study reporting institutional outcomes that for ECMO indication combined PC and non-PC cardiogenic shock, but PC comprised $>70 \%$ of cases; 4 ) studies combining non-PC and PC cardiogenic shock patients but reporting mortality outcome separately for the latter. Studies were only excluded if: 1) paediatric and congenital heart surgery-related studies or mixed paediatric-adult populations; 2) animal studies; 3) conducted in the setting of veno-venous ECMO for respiratory distress following heart surgery; and 4) studies not reporting survival/mortality rates. Reviews and case reports were not considered.

Two independent reviewers (G.M.R and K.Z.) selected the studies for inclusion, extracted studies, as well as patient characteristics of interest and relevant outcomes. Two authors (G.M.R., and K.Z.,) independently assessed the trials' eligibility and risk of bias. Risk of bias at the individual study level was assessed using the ROBINS-I tool (Risk of Bias in Not-randomized Studies-of Interventions) [8]. Any divergences were resolved by two other authors (M.K. and R.L.) and quantified using the approach of Cohen's kappa [9].

\section{Endpoint selection}

The primary endpoint was in-hospital/30-day mortality. In-hospital mortality was preferred over 30-day mortality. The latter was pooled only in in-hospital rates were not available. Secondary endpoints were in-hospital neurological complications, limb complications, bleeding or reoperation for bleeding, sepsis and acute kidney injury (AKI) with/without continuous veno-venous hemofiltration (CVVH). Neurological complications encompassed cerebrovascular events, strokes, transient ischemic attacks etc. Separate analysis of brain death was conducted as well. Outcome definitions were the ones adopted by the investigators of the included studies.

\section{Statistical analysis}

Statistical analyses were performed in Comprehensive Meta-Analysis, v. 2 (Biostat, 
Englewood, NJ). The results are expressed as pooled untransformed proportions (e.g. event rates (\%) and means with their 95\% confidence intervals $(\mathrm{Cl})$. Heterogeneity across studies was evaluated using the $\mathrm{I} 2$ test. To control for the anticipated heterogeneity among observational studies, absolute values and means were pooled using random effects models. Studies were stratified a priori based on the baseline surgical status: elective vs urgent vs emergency vs salvage; the interaction coefficient ( $Q$-value) is provided for the respective comparisons along with Pinteraction. Whenever a single study reported median values and interquartile ranges instead of mean SD, the latter were approximated as described by Wan et al [10]. Additionally, we investigated if baseline surgical status had influence on mortality by means of meta-regression analyses [11]. Sensitivity analyses were performed by excluding from analyses single studies, one at a time, and repeating the calculations. Additionally, to best account for discrepancies across single studies, as a sensitivity analysis, all outcomes were analysed as stratified by emergency vs non-emergency baseline status; for this purpose, elective and urgent cases were pooled in non-emergency stratum; reported salvage cases or those undergoing cardiopulmonary resuscitation preoperatively were added to emergencies instead. Publication bias was assessed 1) by visual approach plotting log event rate against standard error in the funnel plot; and 2) by linear regression approach [12].

\section{Results}

Initial search process yielded 22,609 records; of these, 183 abstracts were retrieved for scrutiny based on the item's title. Following detailed assessment, 58 studies met all but 1 st inclusion criteria and entered qualitative analyses. Of those, 22 (2,235 patients) [supplementary references 1-22] reported baseline surgical status and were included in the meta-analysis. The PRISMA flow chart is available as Figure 1. 

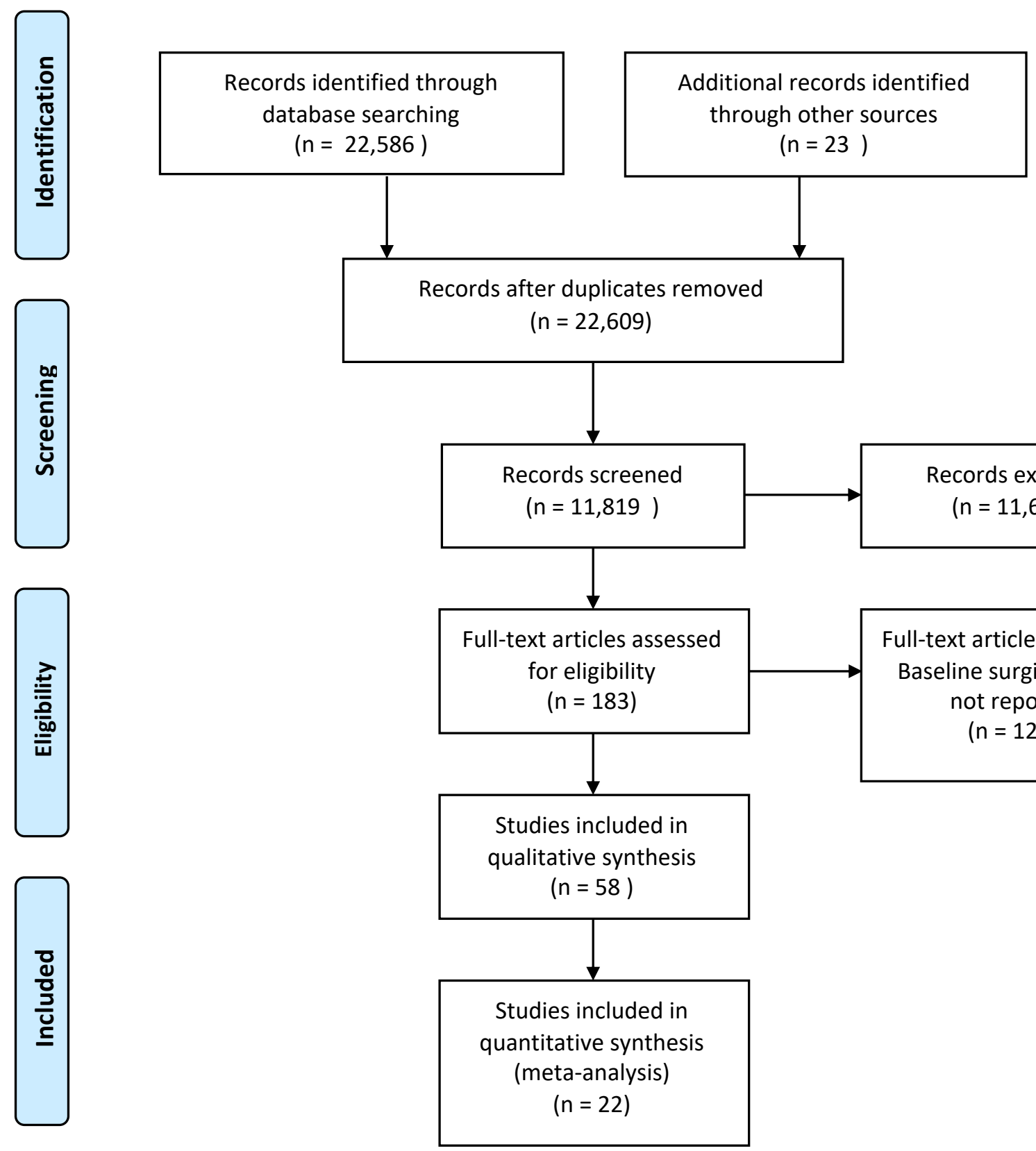

Records excluded $(n=11,636)$

Figure 1. PRISMA Flow Chart

Detailed characteristics of included studies as well as patients' baseline and surgical data are available in Table 1.

Table 1. Study baseline characteristics

\begin{tabular}{|c|c|c|c|c|c|c|c|c|c|c|}
\hline \multirow{2}{*}{$\begin{array}{l}\text { Study (year) } \\
\text { [reference] }\end{array}$} & \multirow{2}{*}{$\begin{array}{l}\mathrm{N} \text { of } \\
\mathrm{PCS} \\
\text { patients }\end{array}$} & \multirow{2}{*}{$\begin{array}{c}\text { Baseline status } \\
\text { (elective/urgent/ } \\
\text { emergency/salvage) }\end{array}$} & \multirow{2}{*}{ Age } & \multirow{2}{*}{$\begin{array}{l}\text { Male } \\
(\%)\end{array}$} & \multicolumn{4}{|c|}{ Surgery type } & \multirow{2}{*}{$\begin{array}{l}\text { ECMO } \\
\text { duration }\end{array}$} & \multirow{2}{*}{$\begin{array}{l}\text { Weaning } \\
\text { rates (\%) }\end{array}$} \\
\hline & & & & & CABG & Valve & Combined & Other & & \\
\hline $\begin{array}{l}\text { Beckmann } 2017 \\
\text { [e1] }\end{array}$ & 8 & NR/NR/3/NR & $\begin{array}{c}50.1 \pm \\
15.8\end{array}$ & 62.5 & 0 & 4 & 1 & 3 & $\begin{array}{c}12.0 \pm 5.9 \\
\text { days }\end{array}$ & 87.5 \\
\hline $\begin{array}{l}\text { Biancari } 2017 \\
\text { [e2] }\end{array}$ & 148 & $19 / 34 / 80 / 15$ & $\begin{array}{c}65.4 \pm \\
9.4\end{array}$ & 78.4 & 148 & 0 & 0 & 0 & $\begin{array}{c}6.4 \pm 5.6 \\
\text { days }\end{array}$ & 48.6 \\
\hline Doll N 2003 [e3] & 95 & $21 / 64 / 10 / 0$ & $\begin{array}{c}59.8 \pm \\
13.3\end{array}$ & 69.5 & 63 & 18 & 8 & 6 & $\begin{array}{c}2.8 \pm 2.1 \\
\text { days }\end{array}$ & 47.4 \\
\hline
\end{tabular}




\begin{tabular}{|c|c|c|c|c|c|c|c|c|c|c|}
\hline $\begin{array}{l}\text { Elsharkawy } \\
2010 \text { [e4] }\end{array}$ & 233 & NR/NR/84/NR & NR & 67.4 & & & & & NR & NR \\
\hline $\begin{array}{l}\text { Guihaire } 2017 \\
\text { [e5] }\end{array}$ & 92 & NR/NR/33/NR & $\begin{array}{c}64.5 \\
(18-83)\end{array}$ & 59 & 12 & 64 & $31^{*}$ & 16 & 6 days & 48 \\
\hline $\begin{array}{l}\text { Khorsandi } 2016 \\
{[\mathrm{e} 6]}\end{array}$ & 16 & $9 / 3 / 4 / 0$ & $\begin{array}{c}64.3 \pm \\
14.5 \\
\end{array}$ & 73.3 & 3 & 4 & 5 & 3 & $\begin{array}{c}5.5 \pm 8.9 \\
\text { days }\end{array}$ & NR \\
\hline $\begin{array}{l}\text { lazzara } 1993 \\
{[\mathrm{e} 7]}\end{array}$ & 11 & $1 / 6 / 4 / 0$ & NR & NR & & & & & $\begin{array}{c}48(22-93) \\
\text { hours }\end{array}$ & 73 \\
\hline $\begin{array}{l}\text { Magovern } 1994 \\
\text { [e8] }\end{array}$ & 21 & $0 / 11 / 10 / 0$ & $\begin{array}{c}61.6 \pm \\
2.2 \\
\end{array}$ & 80.9 & 16 & 3 & 0 & 2 & $\begin{array}{c}42.1 \pm 3.9 \\
\text { hours }\end{array}$ & 76.2 \\
\hline Mikus 2013 [e9] & 14 & $6 / 2 / 6 / 0$ & $\begin{array}{c}53.1 \pm \\
14.3\end{array}$ & 64.3 & 5 & 6 & 3 & 0 & 5 days & 50 \\
\hline $\begin{array}{l}\text { Muehrcke } 1996 \\
\text { [e10] }\end{array}$ & 23 & $6 / 0 / 17 / 0$ & $\begin{array}{c}47.3 \pm \\
16.4\end{array}$ & 73.9 & 8 & 6 & 0 & 9 & $\begin{array}{c}58.4 \pm \\
35.1 \\
\text { hours }\end{array}$ & 56.5 \\
\hline $\begin{array}{l}\text { Papadopoulos } \\
2015 \text { [e11] }\end{array}$ & 360 & NR/NR/NR/50 & $62 \pm 17$ & 76.1 & 114 & 89 & 85 & 72 & $\begin{array}{l}7 \pm 1 \\
\text { days }\end{array}$ & 58.1 \\
\hline $\begin{array}{l}\text { Pokersnik } 2012 \\
\text { [e12] }\end{array}$ & 49 & NR/NR/0/0 & $65 \pm 13$ & 67.3 & & & & & $\begin{array}{c}3.8 \pm 3.4 \\
\text { days }\end{array}$ & 55.1 \\
\hline $\begin{array}{l}\text { Pontailler } 2017 \\
\text { [e13] }\end{array}$ & 127 & NR/NR/49/NR & $\begin{array}{c}75.7 \pm \\
4.7^{\star *}\end{array}$ & $61.3^{* *}$ & 42 & 36 & 18 & 18 & $\begin{array}{c}5.6 \pm 4.3 \\
\text { days }^{* *}\end{array}$ & $41.1^{* *}$ \\
\hline Raffa 2017 [e14] & 86 & NR/NR/33/NR & $\begin{array}{l}65 \pm \\
11.2\end{array}$ & 65.1 & 19 & 14 & 29 & 24 & 5 days & 49 \\
\hline $\begin{array}{l}\text { Rastan } 2010 \\
\text { [e15] }\end{array}$ & 517 & $159 / 122 / 205 / 31$ & $\begin{array}{c}63.5 \pm \\
11.2\end{array}$ & 71.5 & 193 & 96 & 72 & 156 & $\begin{array}{c}3.28 \pm \\
2.85 \text { days }\end{array}$ & 63.3 \\
\hline $\begin{array}{l}\text { Santarpino } 2015 \\
\text { [e16] }\end{array}$ & 20 & 0/0/0/20 & $\begin{array}{c}62.8 \pm \\
8.8 \\
\end{array}$ & 80 & 20 & 0 & 0 & 0 & $\begin{array}{c}107 \pm 99 \\
\text { hours }\end{array}$ & NR \\
\hline $\begin{array}{l}\text { Saxena } 2015 \\
\text { [e17] }\end{array}$ & 45 & $35 / 6 / 4 / 0$ & $\begin{array}{l}76.8 \pm \\
4.6\end{array}$ & 68.9 & & & & & $\begin{array}{c}103.8 \pm \\
74.3 \\
\text { hours }\end{array}$ & 53.3 \\
\hline $\begin{array}{l}\text { Slottosch } 2012 \\
{[\mathrm{e} 18]^{\star * *}}\end{array}$ & 77 & NR/NR/29/NR & $60 \pm 13$ & 76.6 & 43 & 10 & 11 & 13 & $\begin{array}{c}79 \pm 57 \\
\text { hours }\end{array}$ & 62.3 \\
\hline $\begin{array}{l}\text { Slottosch } 2017 \\
\text { [e19] }\end{array}$ & 100 & $\mathrm{NR} / \mathrm{NR} / 37 / 0$ & $58 \pm 15^{*}$ & 76.3 & 45 & 19 & 24 & 12 & $\begin{array}{l}117 \pm 78 \\
\text { hours }\end{array}$ & $43.2^{\star *}$ \\
\hline $\begin{array}{l}\text { Unosawa } 2012 \\
\text { [e20] }\end{array}$ & 47 & NR/NR/22/NR & $\begin{array}{c}64.4 \pm \\
12.5\end{array}$ & 74.4 & 19 & 8 & 6 & 14 & $\begin{array}{c}63.5 \pm \\
61.5 \\
\text { hours }\end{array}$ & 61.7 \\
\hline Wu 2010 [e21] & 110 & NR/NR/31/NR & $60 \pm 14$ & 70.9 & 31 & 42 & 19 & 18 & $\begin{array}{c}143 \pm 112 \\
\text { hours }\end{array}$ & 60.9 \\
\hline $\begin{array}{l}\text { Zhong } 2017 \\
\text { [e22] }\end{array}$ & 36 & NR/NR/9/NR & $\begin{array}{c}50.4 \pm \\
12.2\end{array}$ & 91.7 & & & & & $\begin{array}{c}77.5 \pm \\
34.5 \\
\text { hours }\end{array}$ & 66.7 \\
\hline
\end{tabular}

* Multiple valve repair or valvular surgery combined with CABG; potential overlap.

${ }^{* *}$ Reported for entire study population including non-PCS patients

*** Possible 2-year study period overlap.

Publication bias analysis along with reasons for bias risk increase is available as Table 2.

Table 2. ROBINS-I tool bias assessment.

\begin{tabular}{|c|c|c|c|c|c|c|c|c|c|}
\hline Study & $\begin{array}{l}\text { Bias due } \\
\text { to } \\
\text { confoundi } \\
\text { ng }\end{array}$ & $\begin{array}{l}\text { Bias in } \\
\text { selection } \\
\text { of } \\
\text { participan } \\
\text { ts into the } \\
\text { study }\end{array}$ & $\begin{array}{l}\text { Bias in } \\
\text { measureme } \\
\text { nt of } \\
\text { intervention } \\
\mathrm{s}\end{array}$ & $\begin{array}{l}\text { Bias due to } \\
\text { departures } \\
\text { from } \\
\text { intended } \\
\text { interventio } \\
\text { ns }\end{array}$ & $\begin{array}{l}\text { Bias } \\
\text { due to } \\
\text { missing } \\
\text { data* }\end{array}$ & $\begin{array}{l}\text { Bias in } \\
\text { measureme } \\
\text { nt of } \\
\text { outcomes* }\end{array}$ & $\begin{array}{l}\text { Bias in } \\
\text { selectio } \\
n \text { of } \\
\text { reported } \\
\text { result* }\end{array}$ & $\begin{array}{l}\text { Overall } \\
\text { bias }\end{array}$ & $\begin{array}{l}\text { Cohen' } \\
\text { s } \\
\text { Kappa }\end{array}$ \\
\hline $\begin{array}{l}\text { Beckmann } \\
2017 \text { [13] }\end{array}$ & Critical & Critical & Serious & NA & Low & Moderate & Moderate & Critical & $71.4 \%$ \\
\hline
\end{tabular}




\begin{tabular}{|c|c|c|c|c|c|c|c|c|c|}
\hline $\begin{array}{l}\text { Biancari } \\
2017 \text { [14] }\end{array}$ & Critical & Low & Serious & NA & Low & Low & Low & Low & $85.7 \%$ \\
\hline $\begin{array}{l}\text { Doll N } 2003 \\
\text { [15] }\end{array}$ & Critical & Low & Low & NA & $\begin{array}{l}\text { Moderat } \\
\mathrm{e}\end{array}$ & Low & Low & Low & $71.4 \%$ \\
\hline $\begin{array}{l}\text { Elsharkawy } \\
2010 \text { [16] }\end{array}$ & Critical & Low & Low & NA & Low & Moderate & $\begin{array}{l}\text { Moderat } \\
\mathrm{e}\end{array}$ & Low & $85.7 \%$ \\
\hline $\begin{array}{l}\text { Guihaire } \\
2017 \text { [17] }\end{array}$ & Critical & Serious & Low & NA & Low & Moderate & $\begin{array}{l}\text { Moderat } \\
\mathrm{e}\end{array}$ & $\begin{array}{l}\text { Moderat } \\
\mathrm{e}\end{array}$ & $85.7 \%$ \\
\hline $\begin{array}{l}\text { Khorsandi } \\
2016 \text { [18] }\end{array}$ & Critical & Low & Serious & NA & Low & Low & Low & Low & $71.4 \%$ \\
\hline $\begin{array}{l}\text { lazzara } \\
1993 \text { [19] }\end{array}$ & Critical & Low & Serious & NA & $\begin{array}{l}\text { Moderat } \\
\mathrm{e}\end{array}$ & Critical & $\begin{array}{l}\text { Moderat } \\
\mathrm{e}\end{array}$ & $\begin{array}{l}\text { Moderat } \\
\mathrm{e}\end{array}$ & $71.4 \%$ \\
\hline $\begin{array}{l}\text { Magovern } \\
1994 \text { [20] }\end{array}$ & Critical & Low & Serious & NA & $\begin{array}{l}\text { Moderat } \\
\mathrm{e}\end{array}$ & Moderate & Critical & $\begin{array}{l}\text { Moderat } \\
\mathrm{e}\end{array}$ & $71.4 \%$ \\
\hline $\begin{array}{l}\text { Mikus } 2013 \\
{[21]}\end{array}$ & Critical & Low & Low & NA & Low & Moderate & $\begin{array}{l}\text { Moderat } \\
\mathrm{e}\end{array}$ & Low & $85.7 \%$ \\
\hline $\begin{array}{l}\text { Muehrcke } \\
1996 \text { [22] }\end{array}$ & Critical & Moderate & Critical & NA & Serious & Low & Low & $\begin{array}{l}\text { Moderat } \\
\mathrm{e}\end{array}$ & $85.7 \%$ \\
\hline $\begin{array}{l}\text { Papadopoul } \\
\text { os } 2015 \text { [23] }\end{array}$ & Critical & Low & Low & NA & Low & Moderate & $\begin{array}{l}\text { Moderat } \\
\mathrm{e}\end{array}$ & Low & $85.7 \%$ \\
\hline $\begin{array}{l}\text { Pokersnik } \\
2012 \text { [24] }\end{array}$ & Critical & Serious & Critical & NA & Low & Moderate & $\begin{array}{l}\text { Moderat } \\
\mathrm{e}\end{array}$ & Critical & $71.4 \%$ \\
\hline $\begin{array}{l}\text { Pontailler } \\
2017 \text { [25] }\end{array}$ & Critical & Low & Serious & NA & Serious & Critical & Critical & Critical & $71.4 \%$ \\
\hline $\begin{array}{l}\text { Raffa } 2017 \\
{[26]}\end{array}$ & Critical & Low & Serious & NA & Low & Moderate & Low & Low & $85.7 \%$ \\
\hline $\begin{array}{l}\text { Rastan } 2010 \\
{[27]}\end{array}$ & Critical & Low & Low & NA & Low & Moderate & $\begin{array}{l}\text { Moderat } \\
\mathrm{e}\end{array}$ & Low & $85.7 \%$ \\
\hline $\begin{array}{l}\text { Santarpino } \\
2015 \text { [28] }\end{array}$ & Critical & Low & Low & NA & $\begin{array}{l}\text { Moderat } \\
\mathrm{e}\end{array}$ & Low & Low & Low & $71.4 \%$ \\
\hline $\begin{array}{l}\text { Saxena } \\
2015 \text { [29] }\end{array}$ & Critical & Low & Low & NA & Low & Moderate & $\begin{array}{l}\text { Moderat } \\
\mathrm{e}\end{array}$ & Low & $71.4 \%$ \\
\hline $\begin{array}{l}\text { Slottosch } \\
2012 \text { [30] }\end{array}$ & Critical & Low & Low & NA & Low & Low & $\begin{array}{l}\text { Moderat } \\
\mathrm{e}\end{array}$ & Low & $100 \%$ \\
\hline $\begin{array}{l}\text { Slottosch } \\
2017 \text { [31] }\end{array}$ & Critical & Low & Low & NA & $\begin{array}{l}\text { Moderat } \\
\mathrm{e}\end{array}$ & Moderate & $\begin{array}{l}\text { Moderat } \\
\mathrm{e}\end{array}$ & $\begin{array}{l}\text { Moderat } \\
\mathrm{e}\end{array}$ & $71.4 \%$ \\
\hline $\begin{array}{l}\text { Unosawa } \\
2012 \text { [32] }\end{array}$ & Critical & Low & Low & NA & Low & Moderate & $\begin{array}{l}\text { Moderat } \\
\mathrm{e}\end{array}$ & Low & $57.1 \%$ \\
\hline $\begin{array}{l}\text { Wu } 2010 \\
{[33]}\end{array}$ & Critical & Low & Critical & NA & Low & Low & Low & Low & $57.1 \%$ \\
\hline $\begin{array}{l}\text { Zhong } 2017 \\
\text { [34] }\end{array}$ & Critical & Critical & Low & NA & Low & Serious & $\begin{array}{l}\text { Moderat } \\
\mathrm{e}\end{array}$ & Critical & $71.4 \%$ \\
\hline
\end{tabular}

*When multiple outcomes were reported for a study, the highest level of bias at the outcome level is reported in the table. Bias reported for comparison of peripheral vs central extracorporeal circulation and not for a study in general.

Studies were judged to be moderate to severe risk of bias as none previously compared directly outcomes of patients in different surgical baseline status; no signs of small/big study effect was seen on visual inspection of funnel plot for primary endpoint (Figure 2) yet marked asymmetry was present later confirmed by linear regression approach in Egger's test: $p=0.023$ 
Funnel Plot of Standard Error by Logit event rate

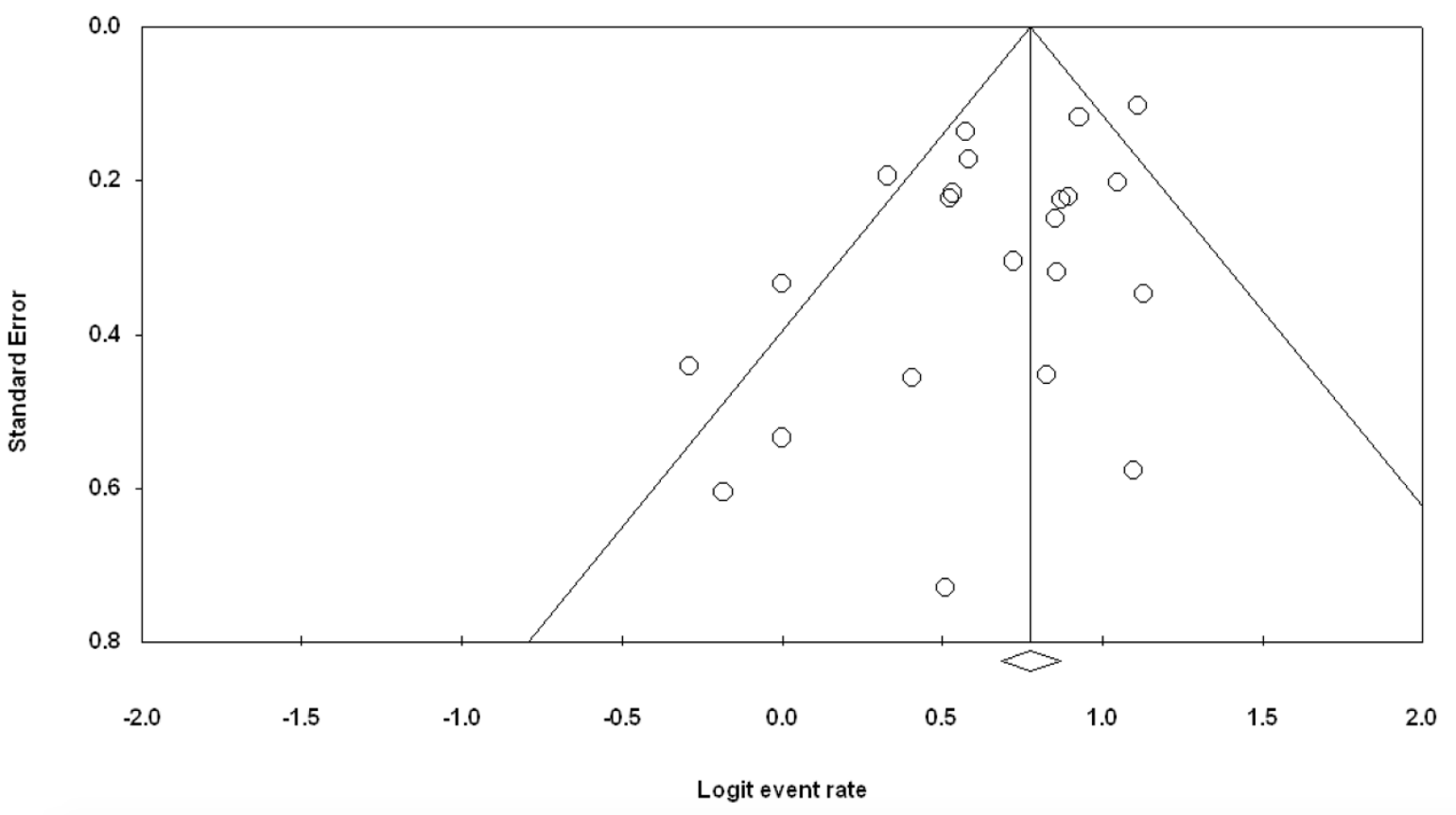

Figure 2. Publication bias

\section{Mortality}

Twenty-two studies contributed data for analysis of 30-day/in-hospital mortality; overall, 1,537 of 2,235 patients died during investigated follow-up which translated to estimated event rate of $66.7 \%(63.3-69.9 \%)$ in random effects model (Figure 3A). In a meta-regression there was no sign that percentage of emergency/salvage cases has had any influence on the estimate: ßcoef= -0.343 ; Pslope= 0.406 (Figure 3B and Figure 3C).
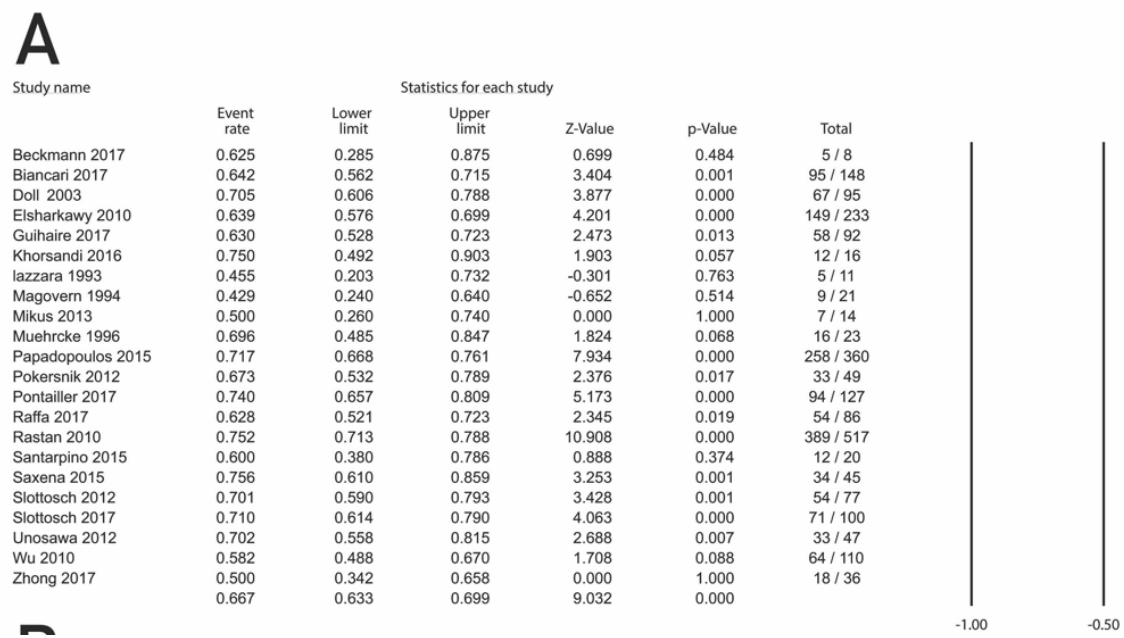

Event rate and $95 \% \mathrm{Cl}$
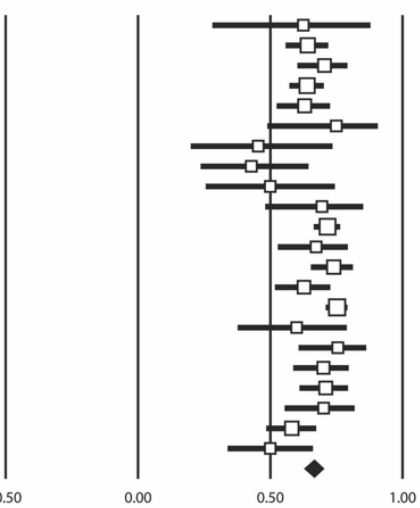
B

Regression of Percentage (\%) of emergency/salvage cases on Logit event rate
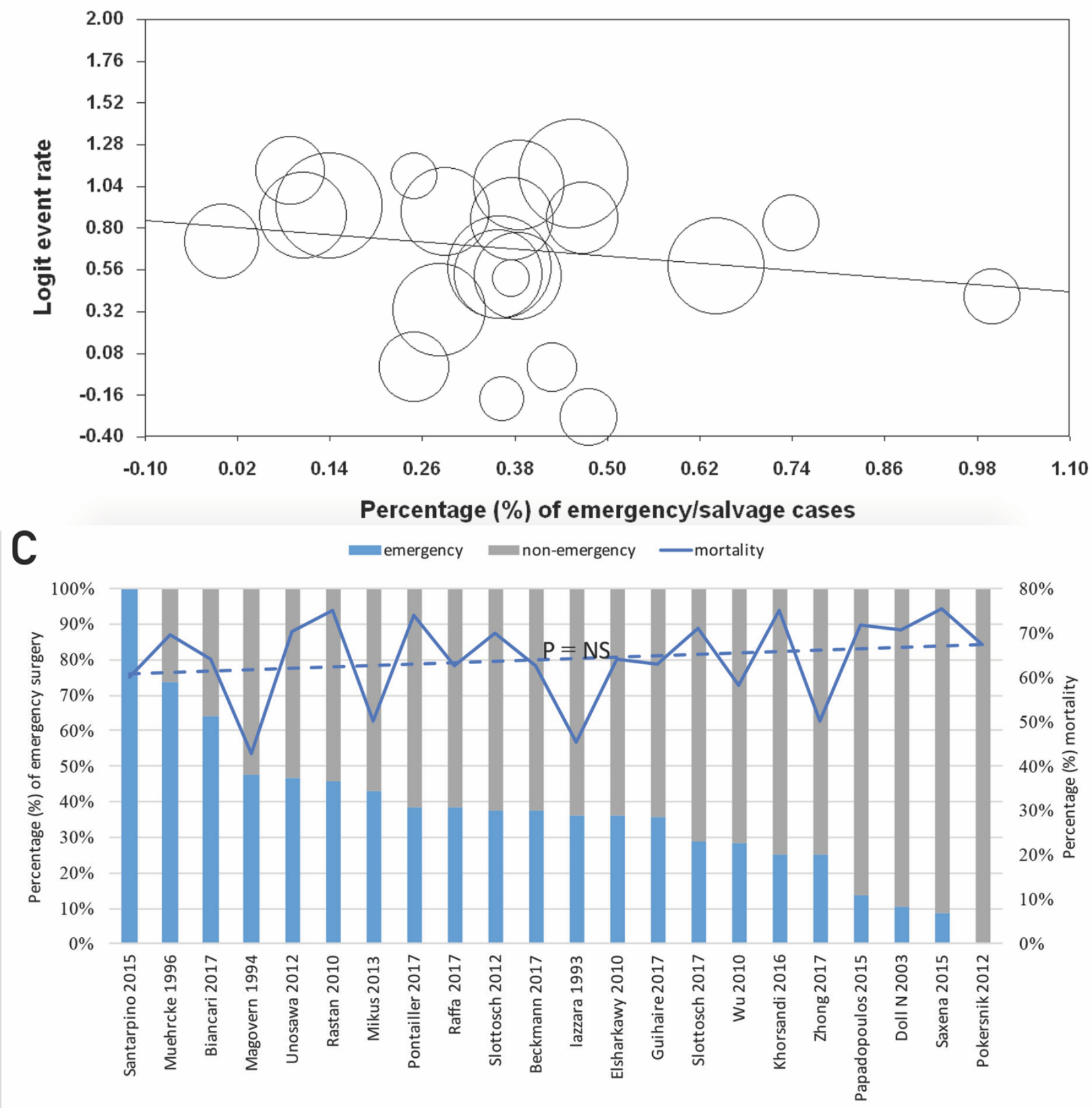

Figure 1. Overall mortality analysis following ECMO institution (A); Meta-regression analysis of overall mortality plotted against increasing percentage of emergency/salvage cases (B); Summary analysis of mortality vs percentage of emergency/salvage cases (C). HTx, heart transplantation; VAD, ventricle assist device.

Nor evidence on any differences between mortality in studies enrolling $<50$ vs $\geq 50 \%$ of emergency/salvage cases was found: respective event rates were $66.9 \%$ (63.1-70.4\%) vs 64.4 (57.3-70.8\%); $p=0.525$ (Figure 4). 


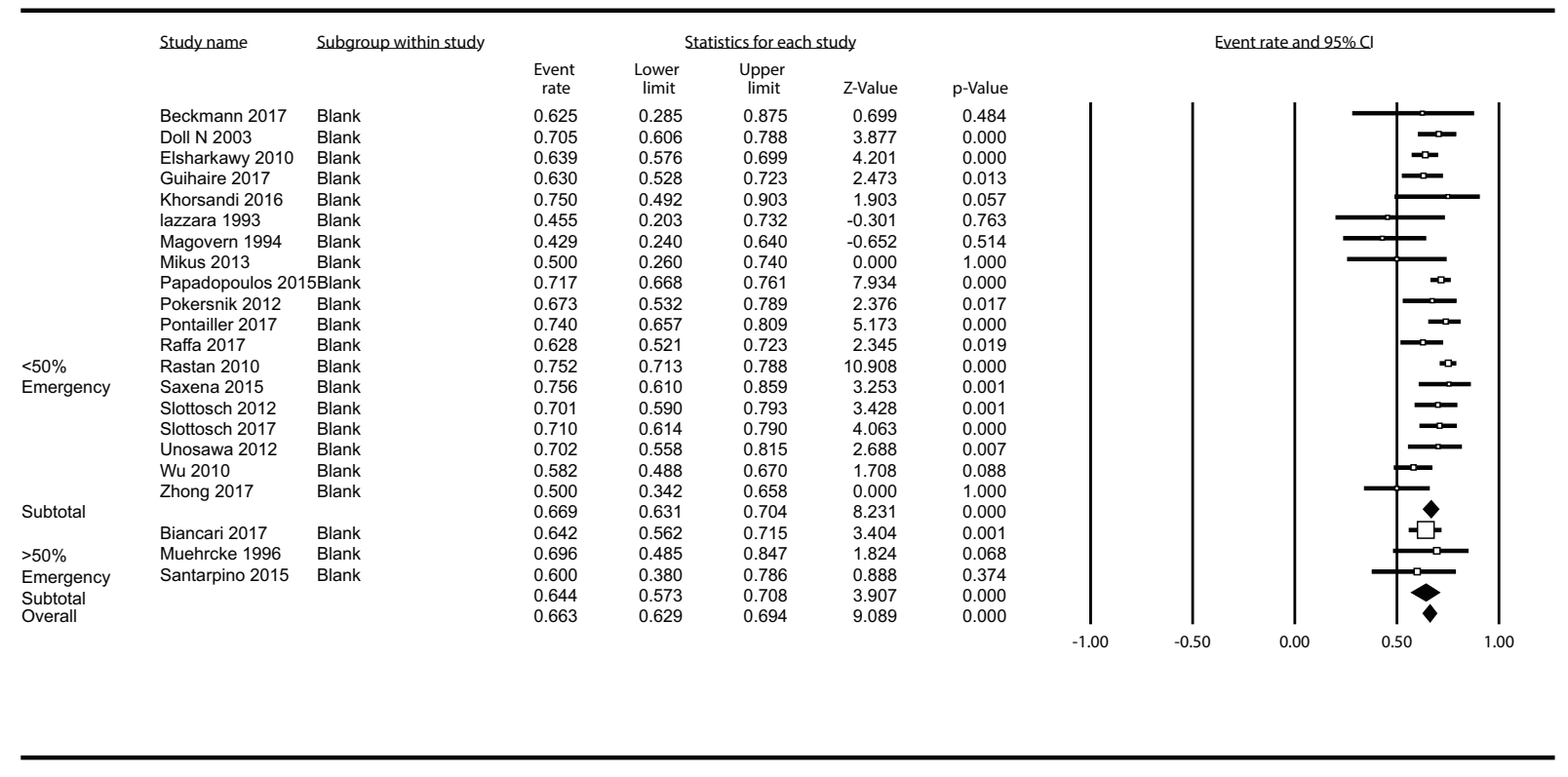

Figure 4. Sensitivity analysis $<50 \%$ emergency vs $>50 \%$ emergency cases

Whenever available, single study estimates for respective subgroups (elective vs urgent vs emergency vs salvage) were extracted. Accordingly, there was again no difference in mortality rates across these patients' strata $(P=0.398)$ : pooled mortality was $65.1 \%(59.2-70.6 \%)$ in emergency subgroup, followed by $70.9 \%(54.6-83.2 \%)$ in elective stratum. There was $73.8 \%(55.3-86.5 \%)$ mortality after ECMO in urgent surgeries and 79.4\% (59.3-91.1\%) mortality in baseline salvage cases (Figure 5).

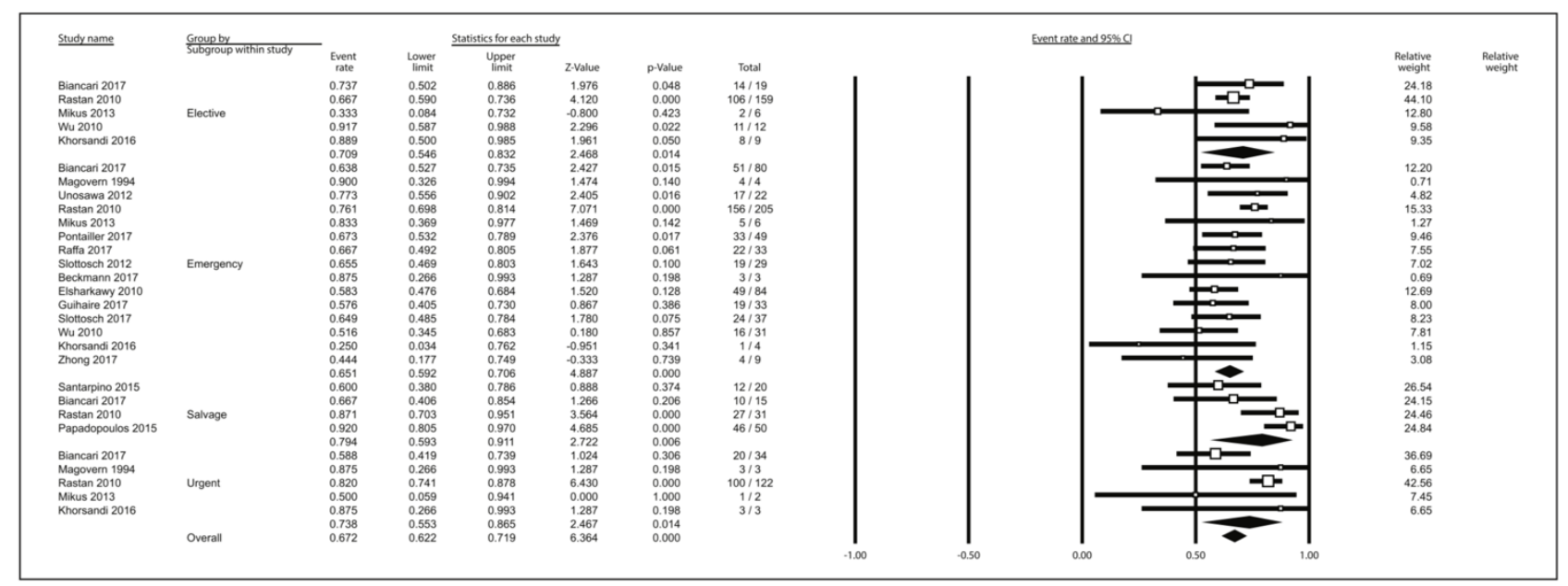

Figure 5. Analysis of mortality stratified according to number of cases in each baseline surgical status subgroup.

Detailed interaction-P values for between single subgroups comparisons are displayed in Figure 6. 


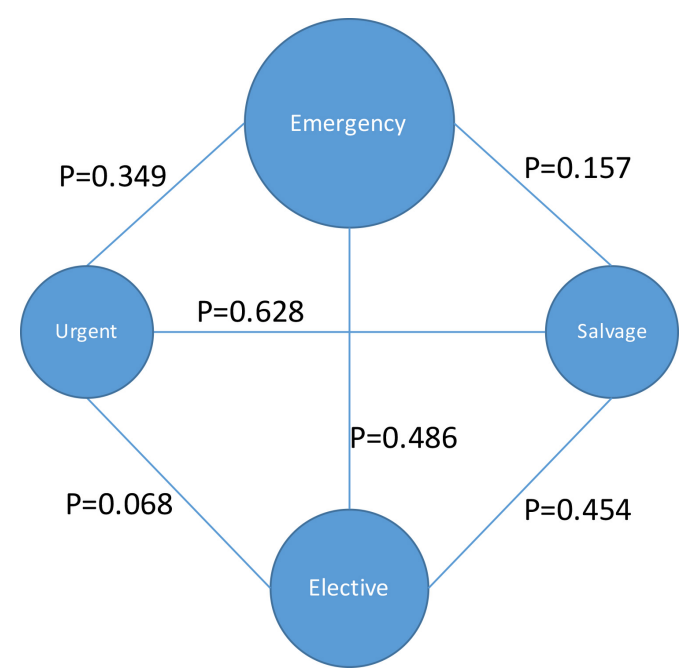

Figure 6. Network of interactions between the subgroups.

\section{Complications while on ECMO}

Table 3 lists complications occurring in the included studies and also transfusion statistics. In a meta-regression, there was a significant positive association between increasing percentage of emergency/salvage cases across single included studies and rates of complications: among them, neurological complications $(p<0.001)$ (Figure 7), limb complications $(p<0.001)$ (Figure 8$)$ and bleeding $(p=0.051)$ (Figure 9), were strongly associated with increasing percentage of emergency/salvage surgeries. Non-significant associations, albeit signals of increased incidence, were found for brain death $(\mathrm{p}=0.099)$ (Figure 10) and sepsis $(\mathrm{p}=0.134)$ (Figure 11).

\section{Regression of Percentage (\%) of emergency/salvage cases on Logit event rate}

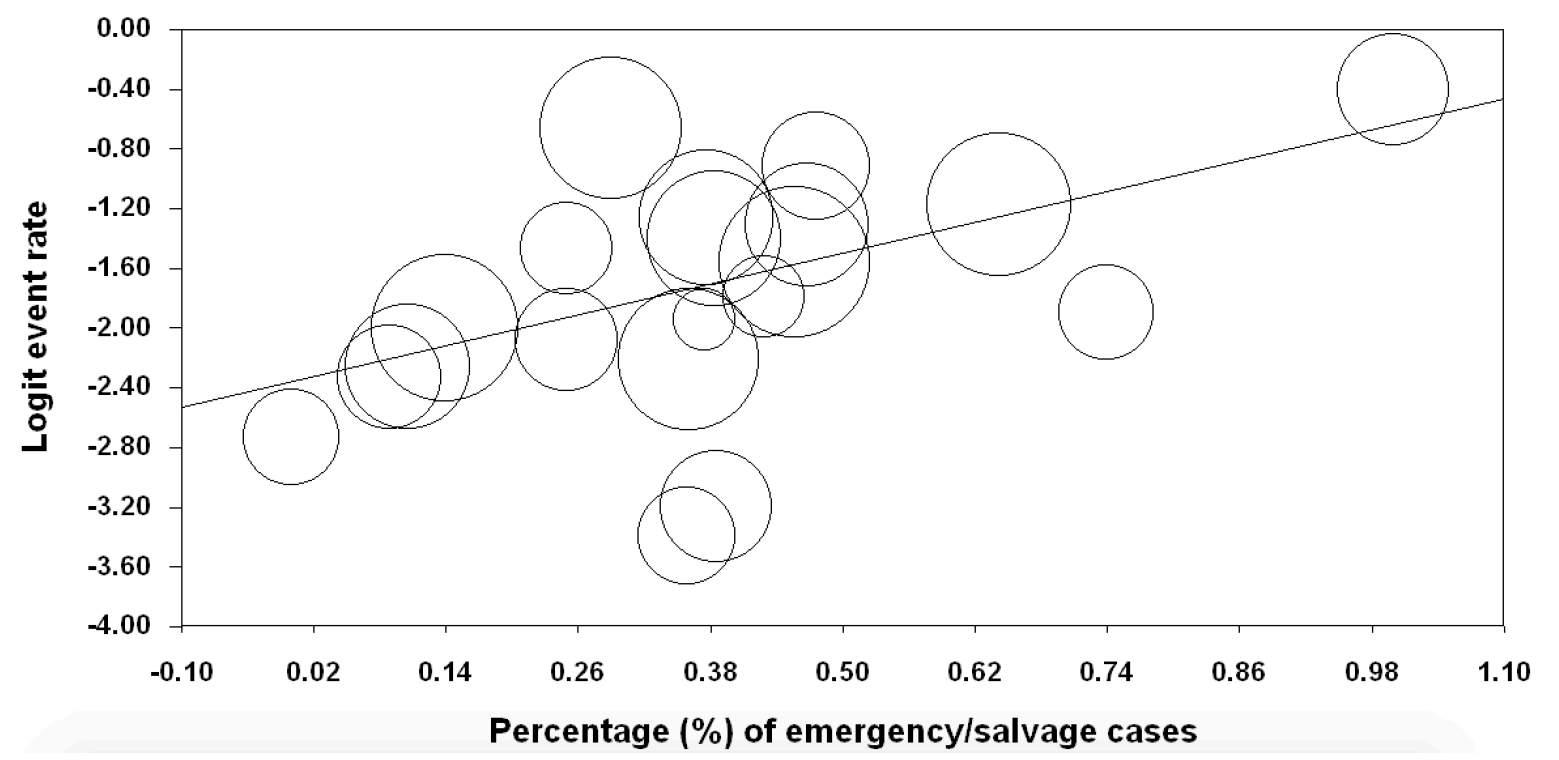

Figure 7. Neurologic complications 
Table 3. Complications

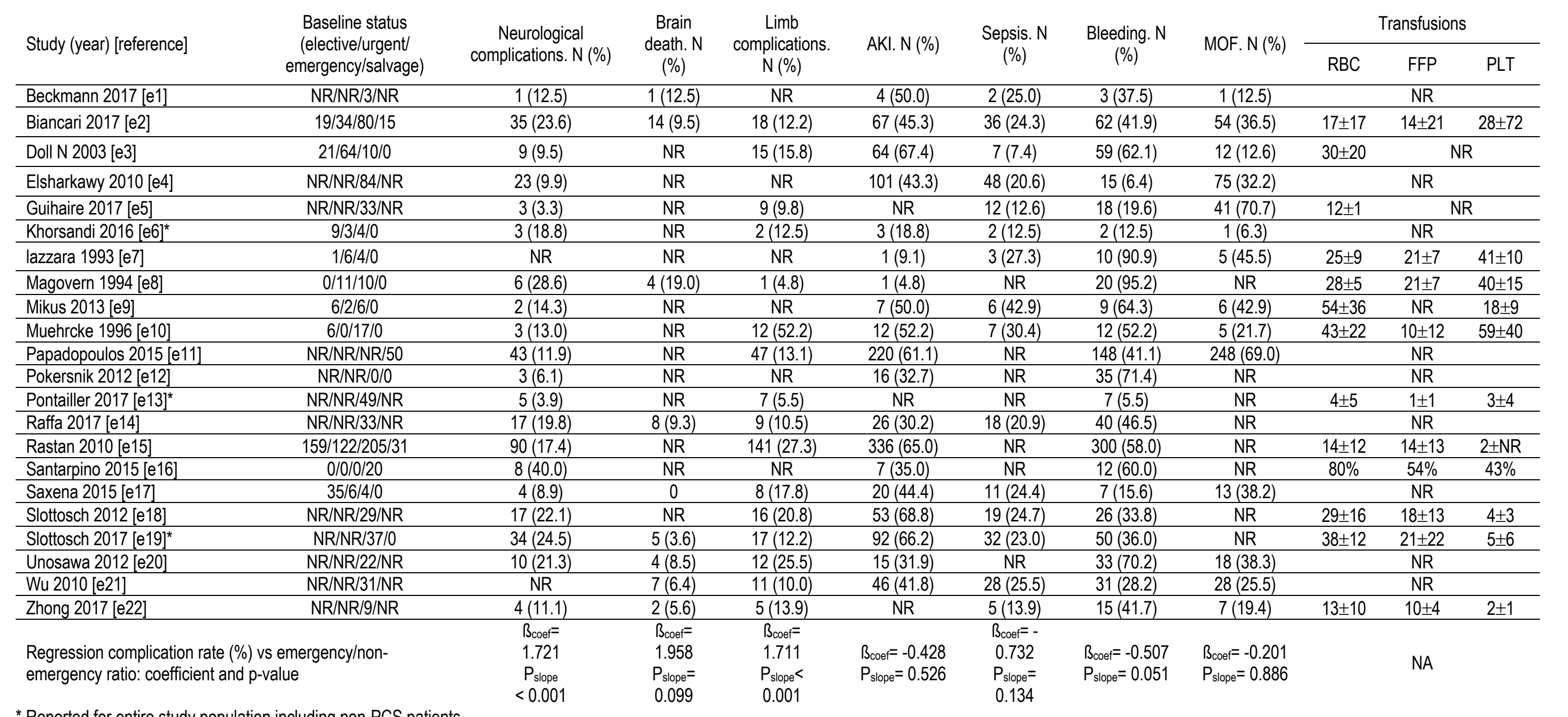

AKI, acute kidney injury; RBC, redo blood cells; FFP, fresh frozen plasma; PLT, platelets; MOF, multi-organ failure; NR, not reported. 
Regression of Percentage (\%) of emergency/salvage cases on Logit event rate

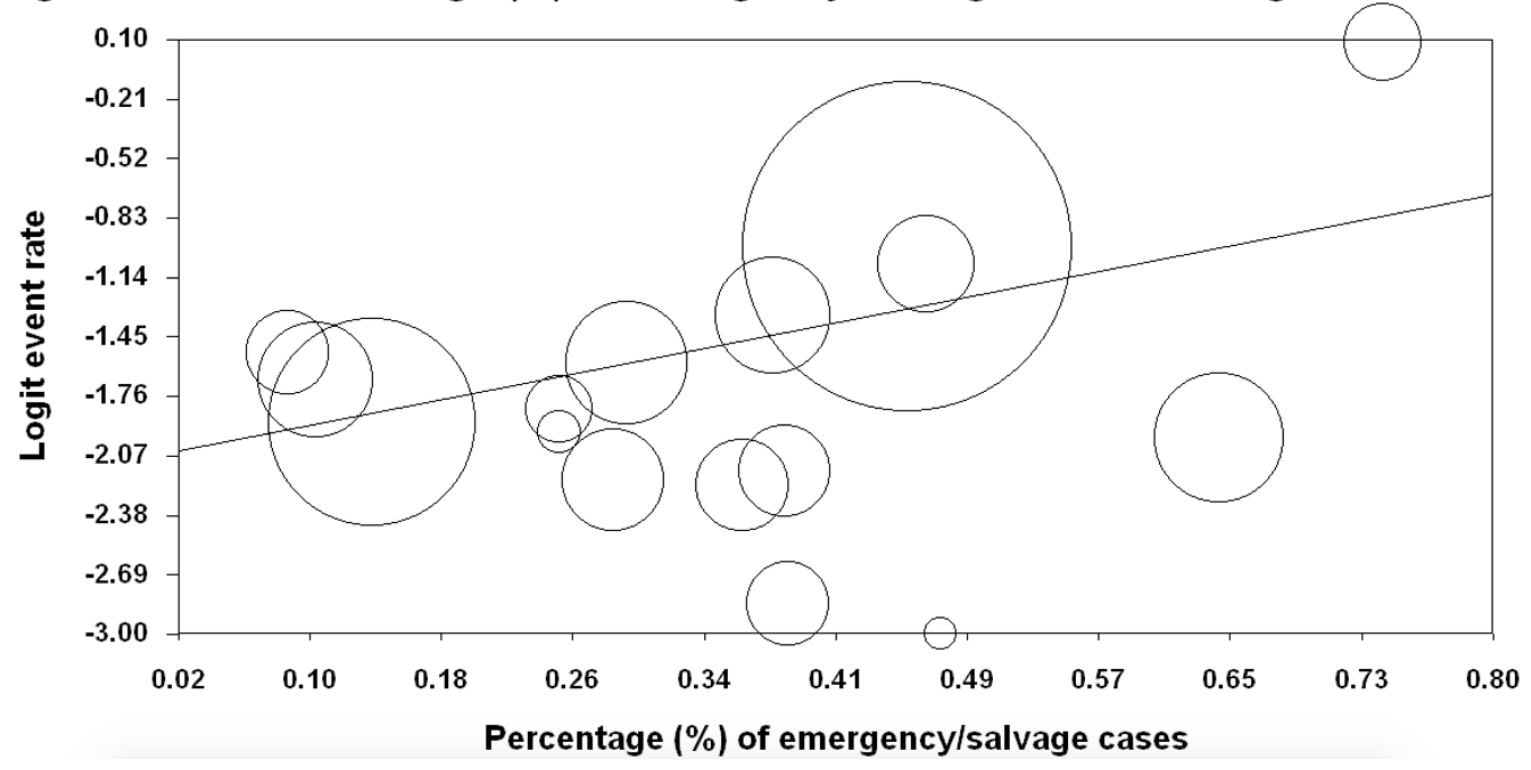

Figure 8. Limb complications

Regression of Percentage (\%) of emergency/salvage cases on Logit event rate

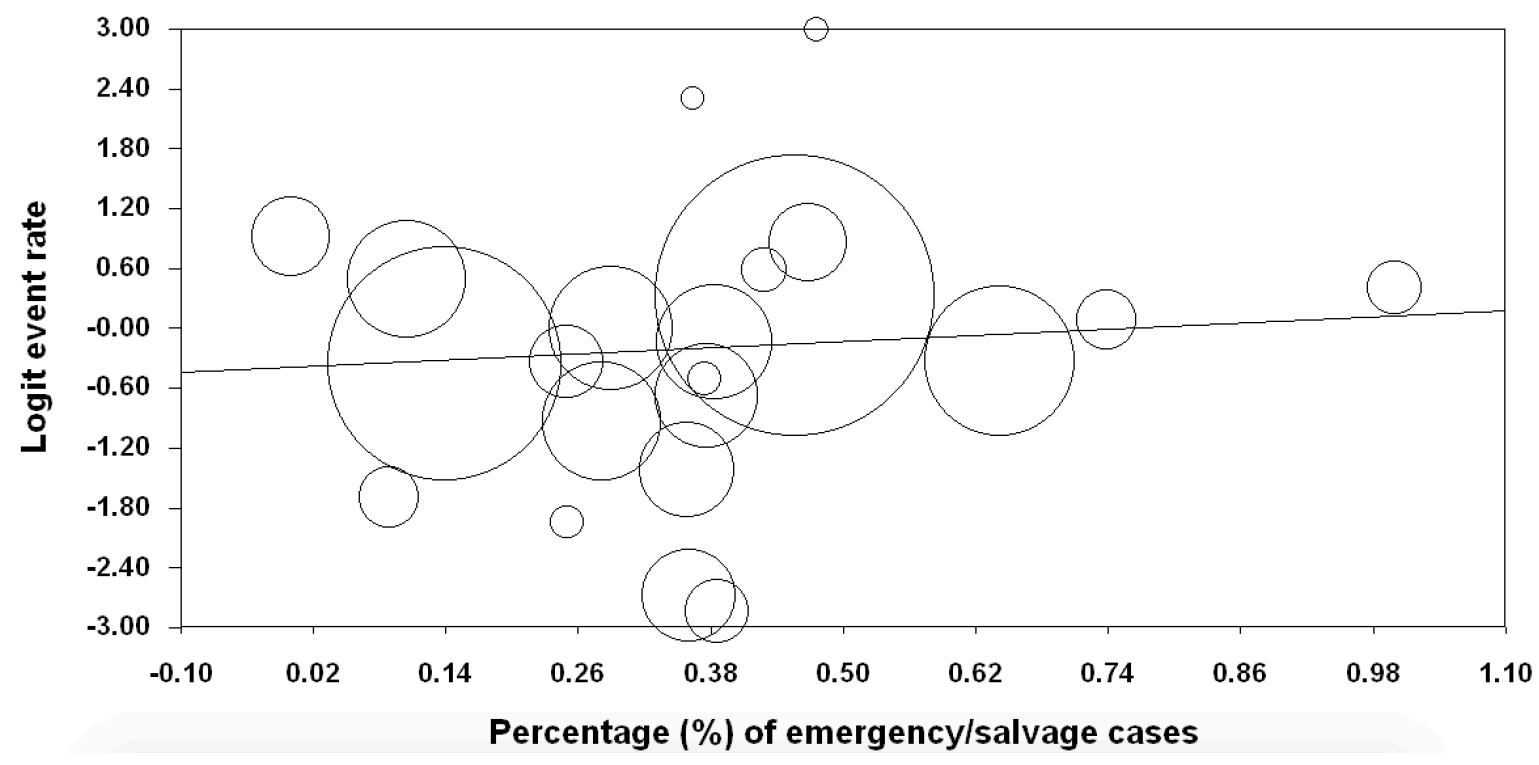

Figure 9. Bleeding 
Regression of Percentage (\%) of emergency/salvage cases on Logit event rate

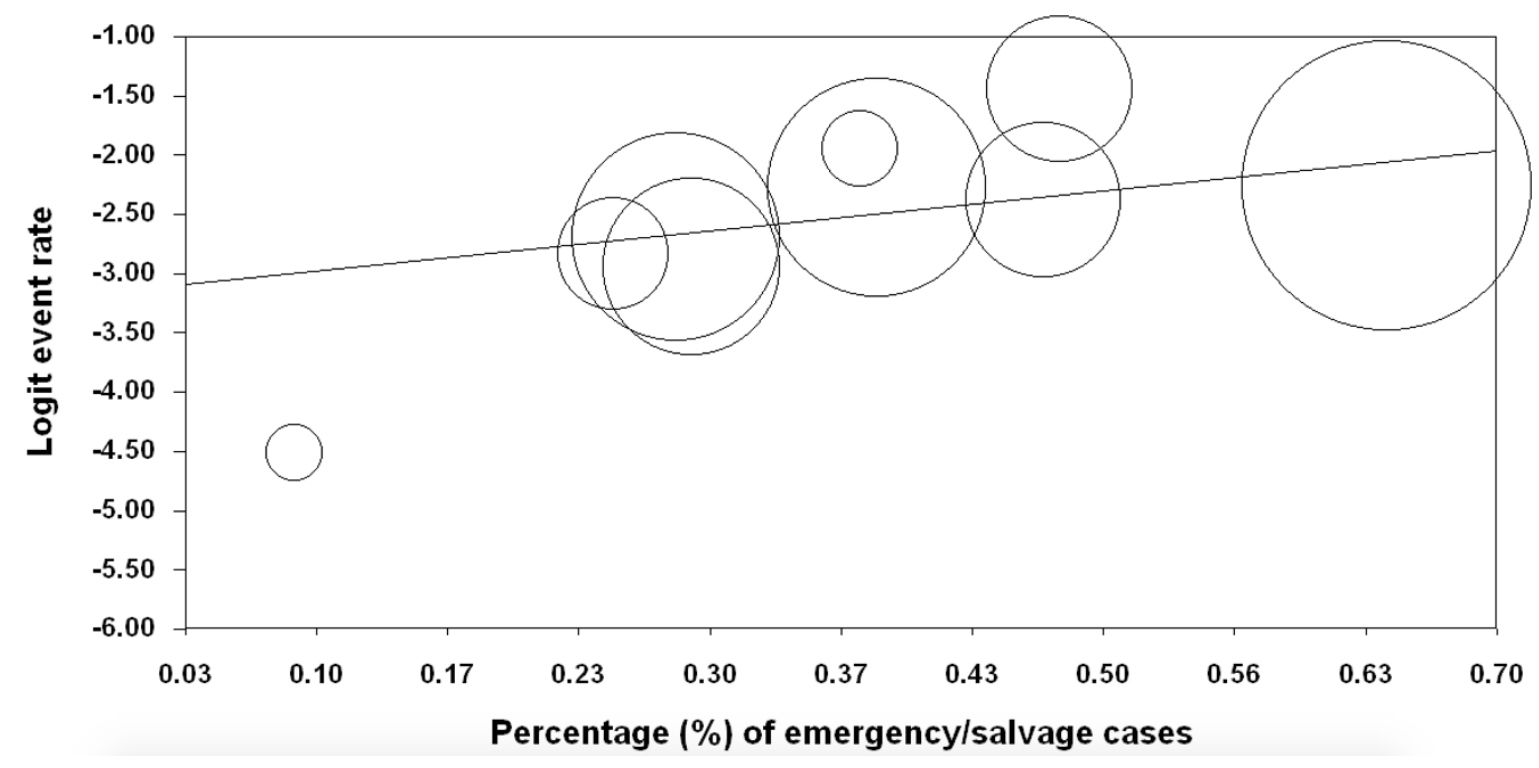

Figure 10. Brain death

Regression of Percentage (\%) of emergency/salvage cases on Logit event rate

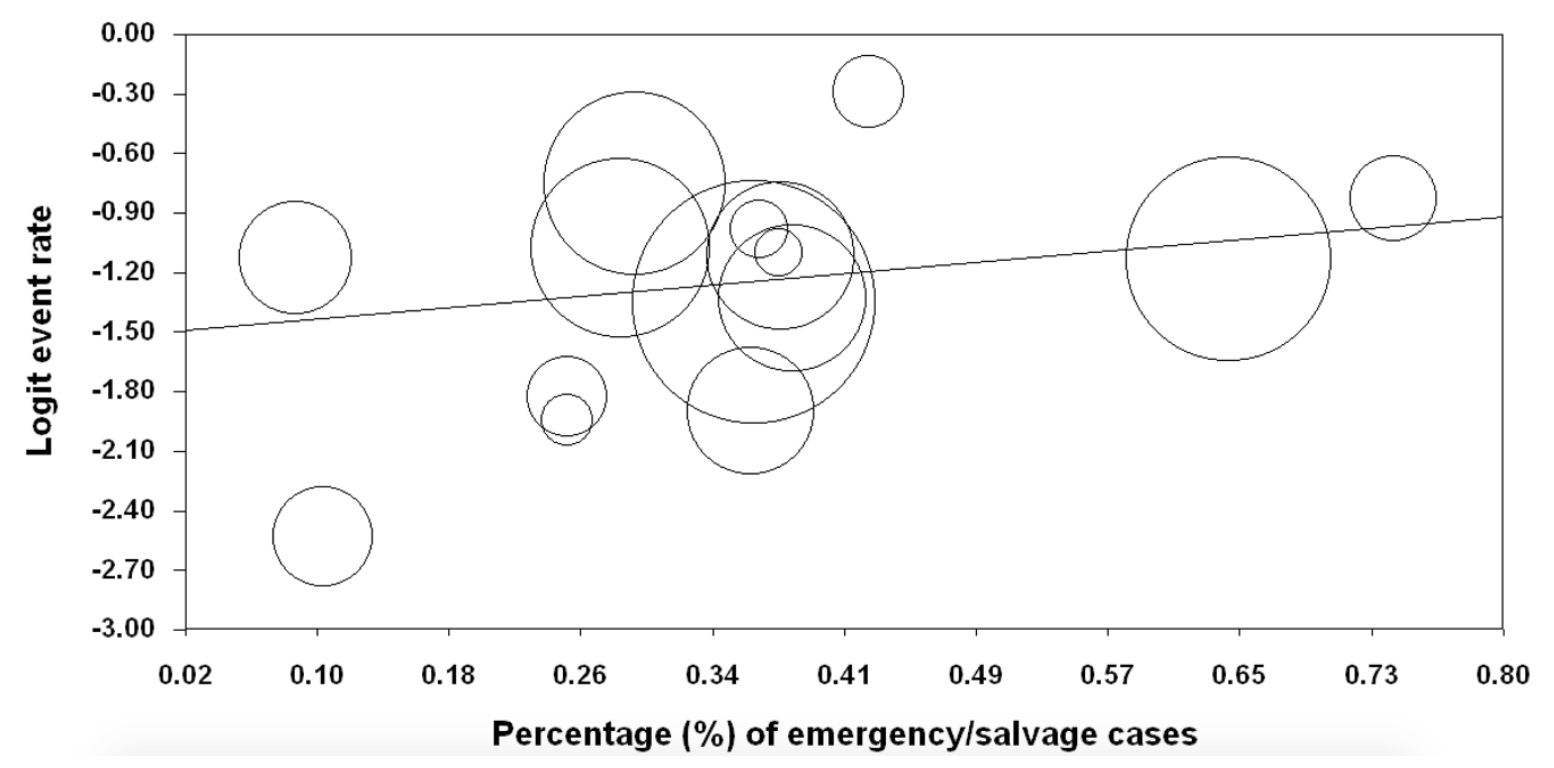

Figure 11. Sepsis

\section{Sensitivity analyses}

In an analysis performed by deleting single studies, one at a time and repeating the calculations, no evidence was found that single study has influenced the overall estimate (cumulative analysis - Figure 12). Similarly, after exclusion of studies reporting results for both post-cardiotomy and non-PC indications for ECMO, neither direction nor magnitude of the estimates was altered. 


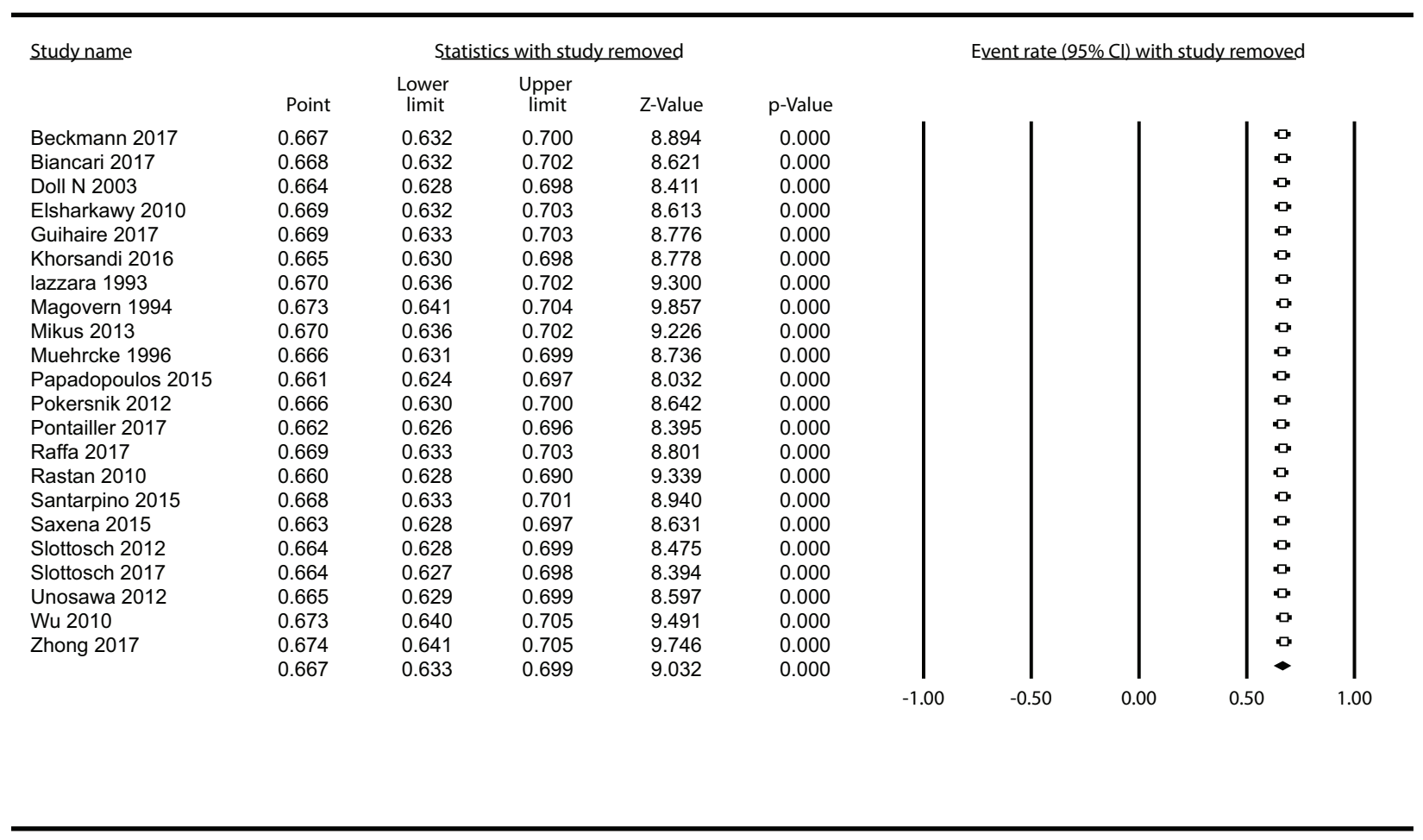

Figure 12. Cumulative analysis.

\section{Discussion}

Use of ECMO, as one of increasing varieties of mechanical circulatory support strategies, has gained worldwide recognition in the treatment of cardiopulmonary failure and its use has dramatically increased over last 20 years [6]. Veno-Arterial (V-A) ECMO has being increasingly used for PC shock that 1) often precludes weaning from CPB while in the operating room, 2) onset of refractory single-ventricle or biventricular failure in the operating room after CPB or in the perioperative phase in ICU, or 3) as salvage procedure in the presence of cardiac arrest while in the operating room or ICU after surgery. The reported definition of PC shock also includes the use of a mechanical circulatory support at any point during the initial hospital stay [13]. Patients with PC shock are typically characterised by high pre-operative serum creatinine levels, previous MI, presence of left-main disease, LV dysfunction, history of coronary artery disease, redo operations and unstable clinical status [14]. Despite plethora of applications, relative ease of handling, and technical advancements in cannulation techniques [15], improved outcomes are still hard to come by with still unsatisfactory mortality rates. Indeed, a trend toward worse survival rates, reaching a disappointing $15 \%$ of in-hospital survival in the most recent series, has been recently described through an analysis of the Extracorporeal Life Support Organization registry [5]. 
Cardiac surgical patients usually present with substantial pre-ECMO comorbidities and more advanced age [16]. All these factors, individually or in association, may influence the capability of the myocardium to recover or hamper favorable body response to prolonged extracorporeal mechanical assistance [17]. Another obvious factor potentially influencing the prognosis after implantation of ECMO in the setting of PC cardiogenic shock used to patients' baseline status and urgency of index cardiovascular procedure [13]. Surprisingly, in the current meta-analysis we were not able to demonstrate that with increasing percentage of emergency high risk interventions, the in-hospital mortality rates were any higher. Conversely, the principal finding of the current meta-analysis is the strikingly similar rates of in-hospital mortality between patients at opposite baseline surgical status (e.g. elective vs salvage cases: $71 \%$ vs $59 \%$ mortality). This, in turn, implies that ECMO implantation in an otherwise elective case yet complicated by cardiogenic shock dramatically increases the mortality risk, in our analysis well beyond the mortality threshold for ECMO salvage cases. These results, in practice, reflect the findings of the previous single reports that however did not address this issue directly. Santarpino et al. [18] reports a registry of 11 European Centres in which 85 patients underwent salvage CABG: 20 of those required V-A ECMO in early postoperative period, and $8(40 \%)$ survived to discharge. On the other hand, Saxena et al. [19] reports a series of 45 mainly valvular surgery ( $80 \%$ elective cases) patients treated with ECMO: 11 patients only were discharged accounting for $24 \%$ survival rate. Lastly, in a study by Biancari et al. [20], mortality among elective cardiac surgery patients reached $74 \%(14 / 19)$ as compared $66 \%(10 / 15)$ in salvage setting. Current meta-analysis as well did not demonstrate that higher mortality rates were associated with emergency/salvage cases throughout included series. In contrast, these were strongly associated with complication rates. Indeed, in the analysis, more neurologic and limb complications as well as more bleeding were seen in the emergency/ salvage scenarios. While excess of bleeding complications can easily be explained by different coagulation profiles of emergency/salvage coronary patients that indeed constituted more than $40 \%$ of entire analysis population (e.g. failed $\mathrm{PCI}$, prior GP IIB/IIA administration, high thrombotic burden requiring additional heparin for ECMO run etc.), increased rates of neurologic complications is presumably a multifactorial entity with preECMO illness severity and treatments, ECMO management, and post-ECMO events all contributing to cerebral injury in these patients. Loss of cerebral autoregulation during severe arterial hypertension or hypotension, 
thromboembolic events, haemorrhage related to anticoagulation use, cerebral vasospasm, and secondary brain injury from reactive tissue oedema around an area of focal cerebral insult have all been implicated in the genesis of brain injury in V-A ECMO patients. Although neurologic injury during V-A ECMO remains poorly defined in adult cohorts [21-24], prior investigations comprehensively report neurologic complications occurrence in 6-17\% in adults supported with V-A ECMO for PC cardiorespiratory failure $[21,25,26]$. Yet, post-mortem examination in adults supported with V-A ECMO has shown that neurologic injury may be clinically undetected in $23-50 \%$ of cases [27,28]. In a multi-center study of V-A ECMO instituted in 3,005 patients [30], neurologic complications occurred in $15.1 \%$ and included brain death in $7.9 \%$, cerebral infarction in $3.6 \%$, seizures in $1.8 \%$ and cerebral haemorrhage in $1.8 \%$ respectively. These events had a significant impact on hospital mortality with survival rate being $11 \%$ for those with neurologic deficits, as compared with $57 \%$ among those without $(p<0.001)$. In the current analysis, unexpectedly, we did not observe that higher burden of neurologic complications translated to higher mortality: in fact, Santarpino et al. [18] reports overall $60 \%$ mortality and $40 \%$ neurologic complications while Guihaire et al. [29] had lowest neurologic complications incidence (3.3\%) yet reported mortality reached $63 \%$. In line with the current analysis are the findings from the ELSO registry [30] pointing to neurologic complications being most common in patients supported with ECMO during CPR that in our analysis was proxy for salvage cases. Cerebral hypo- perfusion, hypoxia, and post-resuscitation reperfusion injury are frequently observed after CPR, and can result in irreversible brain injury $[21,25, \mathrm{e} 23]$.

Limb complications incidence ranged from 5.5 to $52.2 \%$ in the current series; finding attributable to heterogeneous definition of limb complication that in some studies was defined as ischemia requiring amputation, and in others fasciotomy, or groin infections. Said that, all these complications derive from continuous ischemia to the cannulated limb; large arterial cannulas can be more difficult to place during emergency settings or vascular complications (dissection or other kind of vascular damage) and may be associated with increased incidence of limb ischemia due to distal vessel occlusion or hypoperfusion [e24]. There is some evidence in the literature that smaller arterial cannulas (15 Fr) may result in adequate cardiac support as well; as assessed through hemodynamic and laboratory parameters with a significant decrease in bleeding at the cannulation site [e25]. In the current study, principally due to lack of reported data we could not 
address the role of distal perfusion cannula in reducing the incidence of distal leg ischemia. Neither whether cannulation technique and/or cannula sizes influenced the results in surgical subgroups strata. Indirectly however this was assessed in a recent meta-analysis by Raffa et al. [15] that compared peripheral vs central cannulation for ECMO institution and found the estimated benefit of peripheral setting for endpoints of bleeding $(p=0.01)$, continuous veno-venous hemofiltration $(p=0.03)$ and transfusions $(p<0.001)$ unrelated to baseline patients' status.

\section{Limitations}

Certain limitations to the current meta-analysis must be acknowledged. Firstly, data were pooled from observational case series with all underlying biases and limitations; for many reasons, among them lack of any adjustments done in single studies, we could not account for differences between patients' risk profiles, treatments received, baseline characteristics and underlying conditions. Secondly, studies are compared on a "study" and not on -patient level", therefore any conclusions regarding individualized treatments and benefits from ECMO for individual patient have to be drawn with caution. Thirdly, as for any single-arm comparisons, this meta-analysis does not compare outcomes of ECMO institution at different baseline surgical risk scenarios directly; conversely this analysis was designed to give indirect insight to differences between subgroups and to assess whether these differences were meaningful from a statistical standpoint. It must be as well acknowledged that several studies reported emergency percentages alone and did not report salvage, elective and urgent cases distribution; these for liability purpose, were therefore not included in the detailed analyses (Figure 2). On the other hand, both subgroup analyses and meta-regressions performed, represent most conservative approach for outcomes comparison, and because calculated in random effects model, accounting for between study variations, the results are robust and justified.

\section{Conclusions:}

Other factors than baseline surgical status may, to a higher degree, influence the mortality in patients treated with ECMO for PC cardiogenic shock. Baseline status, however, strongly influences the complications while on ECMO which, anyhow, apparently did not impact ultimate 30-day/in-hospital outcome. 


\section{References:}

1. Stretch R, Sauer CM, Yuh DD et al. National trends in the utilization of short-term mechanical circulatory support. J Am Coll Cardiol 2014;64:1407-15

2. McCarthy FH, McDermott KM, Kini V, et al. Trends in U.S. extracorporeal membrane oxygenation use and outcome: 2002-2012. Sem Thorac Surg 2015;27:81-88

3. Sauer CM, Yuh DD, Bonde P. Extracorporeal membrane oxygenation use increased $433 \%$ in adults in the United States from 2006 to 2011. ASAIO J 2015:61:31-36

4. Maxwell BG, Powers AJ, Sheikh AY et al. Resource use trends in extracorporeal membrane oxygenation in adults: an analysis of the Nationwide Inpatient Sample 1998-2009. J Thorac Cardiovasc Surg 2014;148;416-21 5. Whitman GJR. Extracorporeal membrane oxygenation for the treatment of postcardiotomy shock. J Thorac Cardiovasc Surg 2016;153:95-101

6. Fukuhara S, Takeda K, Garan A et al. Contemporary mechanical circulatory support therapy for postcardiotomy shock. Gen Thorac Cardiovasc Surg 2016;64:183-91

7. Liberati A, Altman DG, Tetzlaff J, et al. The prisma statement for reporting systematic reviews and metaanalyses of studies that evaluate healthcare interventions: Explanation and elaboration. BMJ. 2009;339:b2700 8. Sterne JA, Hernan MA, Reeves BC, et al. Robins-i: A tool for assessing risk of bias in non-randomised studies of interventions. BMJ. 2016;355:i4919

9. Blackman NJ, Koval JJ. Interval estimation for Cohen's kappa as a measure of agreement. Stat Med. 2000;19:723-41.

10. Wan X, Wang W, Liu J et al. Estimating the sample mean and standard deviation from the sample size, median, range and/or interquartile range. BMC Med Res Methodol 2014; 14:135.

11. Stijnen T, Hamza TH, Ozdemir P. Random effects meta-analysis of event outcome in the framework of the generalized linear mixed model with applications in sparse data. Stat Med. 2010;29:3046-67.

12. Sterne JA, Sutton AJ, loannidis JP, et al. Recommendations for examining and interpreting funnel plot asymmetry in meta-analyses of randomised controlled trials. BMJ. 2011;343:d4002. 
13. Hill JD, O'Brien TG, Murray JJ, et al. Prolonged extracorporeal oxygenation for acute post-traumatic respiratory failure (shock-lung syndrome). Use of the Bramson membrane lung. N Engl J Med. 1972;286:629634

14. Smedira NG, Blackstone EH. Postcardiotomy mechanical support: Risk factors and outcomes. Ann Thorac Surg. 2001;71:S60-66; discussion S82-65

15. Raffa GM, Kowalewski M, Brodie D et al. Meta-analysis of peripheral or central ecmo in postcardiotomy and non-postcardiotomy shock. Ann Thorac Surg. 2018

16. Lorusso R, Gelsomino S, Parise $O$ et al. Venoarterial extracorporeal membrane oxygenation for refractory cardiogenic shock in the elderly patients: Trends in application and outcome from the extracorporeal life support organization (ELSO) registry. Ann Thorac Surg. 2017;104:62-69

17. Di Mauro M, Lorusso R. Time is your best friend, but it soon becomes your worst enemy: The conflict of venoarterial extracorporeal membrane oxygenation in cardiac surgery. J Thorac Cardiovasc Surg. $2018 ; 155: 2477-2478$

18. Santarpino G, Ruggieri VG, Mariscalco G et al. Outcome in patients having salvage coronary artery bypass grafting. Am J Cardiol. 2015;116:1193-1198

19. Saxena P, Neal J, Joyce LD et al. membrane oxygenation support in postcardiotomy elderly patients: The mayo clinic experience. Ann Thorac Surg. 2015;99:2053-2060

20. Biancari F, Dalen M, Perrotti A et al. Venoarterial extracorporeal membrane oxygenation after coronary artery bypass grafting: Results of a multicenter study. Int J Cardiol. 2017;241:109-114

21. Wu MY, Lin PJ, Lee MY, et al. Using extracorporeal life support to resuscitate adult postcardiotomy cardiogenic shock: Treatment strategies and predictors of short-term and midterm survival. Resuscitation. 2010;81:1111-1116

22. Zangrillo A, Landoni G, Biondi-Zoccai G, et al. A meta-analysis of complications and mortality of extracorporeal membrane oxygenation. Crit Care Resusc. 2013;15:172-178

23. Hei F, Lou S, Li J, et al. Five-year results of 121 consecutive patients treated with extracorporeal membrane oxygenation at fu wai hospital. Artif Organs. 2011;35:572-578 
24. Chen YS, Lin JW, Yu HY, et al. Cardiopulmonary resuscitation with assisted extracorporeal life-support versus conventional cardiopulmonary resuscitation in adults with in-hospital cardiac arrest: An observational study and propensity analysis. Lancet. 2008;372:554-561

25. Rastan AJ, Dege A, Mohr M et al. Early and late outcomes of 517 consecutive adult patients treated with extracorporeal membrane oxygenation for refractory postcardiotomy cardiogenic shock. J Thorac Cardiovasc Surg. 2010;139:302-311, 311 e301

26. Ko WJ, Lin CY, Chen RJ et al. Extracorporeal membrane oxygenation support for adult postcardiotomy cardiogenic shock. Ann Thorac Surg. 2002;73:538-545

27. Rastan AJ, Lachmann N, Walther T, et al. Autopsy findings in patients on postcardiotomy extracorporeal membrane oxygenation (ecmo). Int J Artif Organs. 2006;29:1121-1131

28. Mehta A, Ibsen LM. Neurologic complications and neurodevelopmental outcome with extracorporeal life support. World J Crit Care Med. 2013;2:40-47

29. Guihaire J, Dang Van S, Rouze S et al. Clinical outcomes in patients after extracorporeal membrane oxygenation support for post-cardiotomy cardiogenic shock: A single-centre experience of 92 cases. Interact Cardiovasc Thorac Surg. 2017;25:363-369

30. Lorusso R, Barili F, Mauro MD et al. In-hospital neurologic complications in adult patients undergoing venoarterial extracorporeal membrane oxygenation: Results from the extracorporeal life support organization registry. Crit Care Med. 2016;44:e964-972

\section{References to included studies}

1. Beckmann E, Ismail I, Cebotari S, Busse A, Martens A, Shrestha M, Kuhn C, Haverich A, Fegbeutel C. Right-sided heart failure and extracorporeal life support in patients undergoing pericardiectomy for constrictive pericarditis: A risk factor analysis for adverse outcome. Thorac Cardiovasc Surg. 2017;65:662-670

2. Biancari F, Dalen M, Perrotti A, Fiore A, Reichart D, Khodabandeh S, Gulbins H, Zipfel S, Al Shakaki M, Welp H, Vezzani A, Gherli T, Lommi J, Juvonen T, Svenarud P, Chocron S, Verhoye JP, Bounader K, Gatti G, Gabrielli M, Saccocci M, Kinnunen EM, Onorati F, Santarpino G, Alkhamees K, Ruggieri VG, Dell'Aquila AM. Venoarterial 
extracorporeal membrane oxygenation after coronary artery bypass grafting: Results of a multicenter study. Int $\mathrm{J}$ Cardiol. 2017;241:109-114

3. Doll N, Fabricius A, Borger MA, Bucerius J, Doll S, Kramer K, Ullmann C, Schmitt DV, Walther T, Falk V, Mohr FW. Temporary extracorporeal membrane oxygenation in patients with refractory postoperative cardiogenic shock--a single center experience. J Card Surg. 2003;18:512-518

4. Elsharkawy HA, Li L, Esa WA, Sessler DI, Bashour CA. Outcome in patients who require venoarterial extracorporeal membrane oxygenation support after cardiac surgery. J Cardiothorac Vasc Anesth. 2010;24:946-951

5. Guihaire J, Dang Van S, Rouze S, Rosier S, Roisne A, Langanay T, Corbineau H, Verhoye JP, Flecher E. Clinical outcomes in patients after extracorporeal membrane oxygenation support for post-cardiotomy cardiogenic shock: A single-centre experience of 92 cases. Interact Cardiovasc Thorac Surg. 2017;25:363-369

6. Khorsandi M, Shaikhrezai K, Prasad S, Pessotto R, Walker W, Berg G, Zamvar V. Advanced mechanical circulatory support for post-cardiotomy cardiogenic shock: A 20 -year outcome analysis in a non-transplant unit. J Cardiothorac Surg. 2016;11:29

7. Lazzara RR, Magovern JA, Benckart DH, Maher TD, Jr., Sakert T, Magovern GJ, Jr. Extracorporeal membrane oxygenation for adult post cardiotomy cardiogenic shock using a heparin bonded system. ASAIO J. 1993;39:M444447

8. Magovern GJ, Jr., Magovern JA, Benckart DH, Lazzara RR, Sakert T, Maher TD, Jr., Clark RE. Extracorporeal membrane oxygenation: Preliminary results in patients with postcardiotomy cardiogenic shock. Ann Thorac Surg. 1994;57:1462-1468; discussion 1469-1471

9. Mikus E, Tripodi A, Calvi S, Giglio MD, Cavallucci A, Lamarra M. Centrimag venoarterial extracorporeal membrane oxygenation support as treatment for patients with refractory postcardiotomy cardiogenic shock. ASAIO J. 2013;59:18-23

10. Muehrcke DD, McCarthy PM, Stewart RW, Foster RC, Ogella DA, Borsh JA, Cosgrove DM, 3rd. Extracorporeal membrane oxygenation for postcardiotomy cardiogenic shock. Ann Thorac Surg. 1996;61:684-691

11. Papadopoulos N, Marinos S, El-Sayed Ahmad A, Keller H, Meybohm P, Zacharowski K, Moritz A, Zierer A. Risk factors associated with adverse outcome following extracorporeal life support: Analysis from 360 consecutive 
patients. Perfusion. 2015;30:284-290

12. Pokersnik JA, Buda T, Bashour CA, Gonzalez-Stawinski GV. Have changes in ecmo technology impacted outcomes in adult patients developing postcardiotomy cardiogenic shock? J Card Surg. 2012;27:246-252

13. Pontailler M, Demondion P, Lebreton G, Golmard JL, Leprince P. Experience with extracorporeal life support for cardiogenic shock in the older population more than 70 years of age. ASAIO J. 2017;63:279-284

14. Raffa GM, Gelsomino S, Sluijpers N, Meani P, Alenizy K, Natour E, Bidar E, Johnson DM, Makhoul M, Heuts S, Lozekoot P, Kats S, Schreurs R, Delnoij T, Montalti A, Sels JW, Poll MV, Roekaerts P, Maessen J, Lorusso R. Inhospital outcome of post-cardiotomy extracorporeal life support in adult patients: The 2007-2017 maastricht experience. Crit Care Resusc. 2017;19:53-61

15. Rastan AJ, Dege A, Mohr M, Doll N, Falk V, Walther T, Mohr FW. Early and late outcomes of 517 consecutive adult patients treated with extracorporeal membrane oxygenation for refractory postcardiotomy cardiogenic shock. J Thorac Cardiovasc Surg. 2010;139:302-311, 311 e301

16. Santarpino G, Ruggieri VG, Mariscalco G, Bounader K, Beghi C, Fischlein T, Onorati F, Faggian G, Gatti G, Pappalardo A, De Feo M, Bancone C, Perrotti A, Chocron S, Dalen M, Svenarud P, Rubino AS, Mignosa C, Gherli R, Musumeci F, Dell'Aquila AM, Kinnunen EM, Biancari F. Outcome in patients having salvage coronary artery bypass grafting. Am J Cardiol. 2015;116:1193-1198

17. Saxena P, Neal J, Joyce LD, Greason KL, Schaff HV, Guru P, Shi WY, Burkhart H, Li Z, Oliver WC, Pike RB, Haile DT, Schears GJ. Extracorporeal membrane oxygenation support in postcardiotomy elderly patients: The mayo clinic experience. Ann Thorac Surg. 2015;99:2053-2060

18. Slottosch I, Liakopoulos O, Kuhn E, Deppe AC, Scherner M, Madershahian N, Choi YH, Wahlers T. Outcomes after peripheral extracorporeal membrane oxygenation therapy for postcardiotomy cardiogenic shock: A single-center experience. J Surg Res. 2013;181:e47-55

19. Slottosch I, Liakopoulos O, Kuhn E, Scherner M, Deppe AC, Sabashnikov A, Mader N, Choi YH, Wippermann J, Wahlers T. Lactate and lactate clearance as valuable tool to evaluate ecmo therapy in cardiogenic shock. J Crit Care. 2017;42:35-41

20. Unosawa S, Sezai A, Hata M, Nakata K, Yoshitake I, Wakui S, Kimura H, Takahashi K, Hata H, Shiono M. Long- 
term outcomes of patients undergoing extracorporeal membrane oxygenation for refractory postcardiotomy cardiogenic shock. Surg Today. 2013;43:264-270

21. Wu MY, Lin PJ, Lee MY, Tsai FC, Chu JJ, Chang YS, Haung YK, Liu KS. Using extracorporeal life support to resuscitate adult postcardiotomy cardiogenic shock: Treatment strategies and predictors of short-term and midterm survival. Resuscitation. 2010;81:1111-1116

22. Zhong Z, Jiang C, Yang F, Hao X, Xing J, Wang H, Hou X. Veno-arterial extracorporeal membrane oxygenation support in patients undergoing aortic surgery. Artif Organs. 2017;41:1113-1120

23. Hervey-Jumper SL, Annich GM, Yancon AR et al. Neurological complications of extracorporeal membrane oxygenation in children. J Neurosurg Pediatr. 2011;7:338-344

24. Jayaraman AL, Cormican $\mathrm{D}$, Shah $\mathrm{P}$, et al. Cannulation strategies in adult veno-arterial and veno-venous extracorporeal membrane oxygenation: Techniques, limitations, and special considerations. Ann Card Anaesth. 2017;20:S11-S18

25. Takayama H, Landes E, Truby L et al. Feasibility of smaller arterial cannulas in venoarterial extracorporeal membrane oxygenation. J Thorac Cardiovasc Surg. 2015;149:1428-1433 


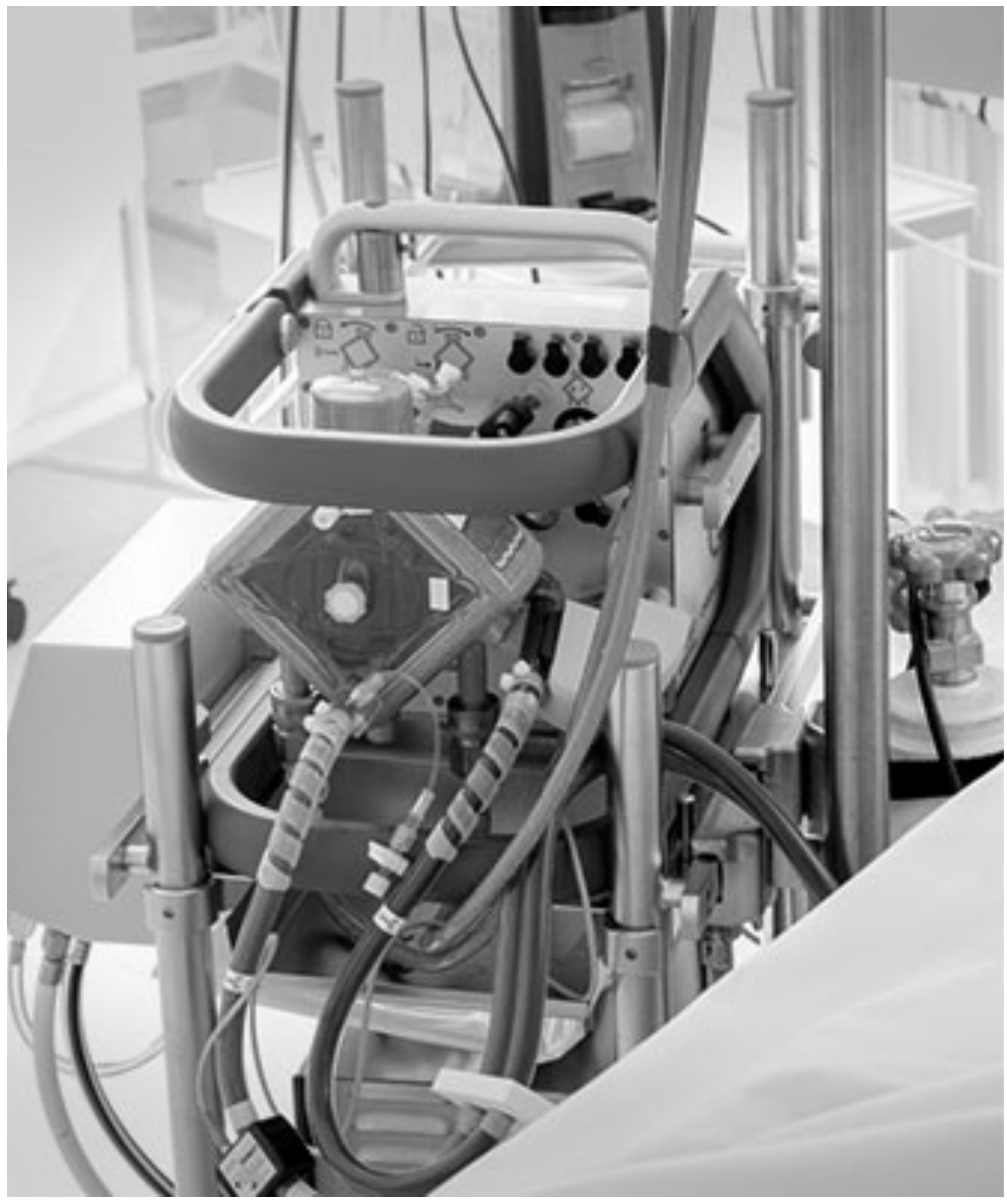


CHAPTER 5

VENO-ARTERIAL EXTRACORPOREAL MEMBRANE OXYGENATION FOR POST-CARDIOTOMY SHOCK

Kowalewski M, Zieliński K, Brodie D, MacLaren G, Whitman G, Raffa GM, Boeken U, Shekar K, Chen YS, Bermudez C, D'Alessandro, Hou X, Haft J, Belohlavek J, Suwalski P, Alexander P, Barbaro R, Gaudino M, Di Mauro M, Maessen J, Lorusso $R$

Critical Care Medicine 2021 (accepted for print) 


\section{Aims}

Use of veno-arterial (V-A) extracorporeal membrane oxygenation (ECMO) for post-cardiotomy cardiogenic shock (PCS) has increased worldwide recently. The aim was to report on trends in use of V-A ECMO for PCS.

\section{Methods and Results}

We analysed data from the Extracorporeal Life Support Organization (ELSO) registry regarding outcomes of VA ECMO for PCS in adult patients from 1995 through 2018. The analyses examined trends in use, patient profiles, and in-hospital outcomes including complications. Predictors of in-hospital mortality were assessed by multivariate logistic regression. During the study period, 8,053 patients submitted to V-A ECMO for PCS were found in the ELSO Registry. There was a significant trend toward more ECMO use in recent years (coef.: 0.009; $p<0.001)$. Mean age was $56.3 \pm 14.9$ years and significantly increased over time (coef.: $0.513 ; p<0.001)$. Most commonly, V-A ECMO was instituted after coronary artery bypass surgery (CABG) $(26.8 \%)$ and valvular surgery (25.6\%), followed by heart transplantation (20.7\%). Overall, successful ECMO weaning occurred in 4,520 cases (56.1\%), and survival to hospital discharge was achieved in $41.4 \%$ of cases. In-hospital mortality rates remained constant over time (coef.: $-8.775 ; p=0.682$ ). Kidney injury $(36.8 \%)$, surgical site bleeding $(27.2 \%)$, cardiac arrhythmias (16.3\%), sepsis (11.4\%), metabolic disorders (12.9\%) and neurologic complications (4.3\%), were the most common adverse events. Reduced complication rates were observed in recent years (coef.: -0.009 ; $p=0.003)$. Higher mortality was observed after CABG (53.8\%), combined CABG with valve $(59.0 \%)$, and vascular aortic $(66.3 \%)$ procedures than other indications. Better survival rates were observed in heart transplantation recipients. Age, central cannulation and occurrence of complications while on ECMO were independently associated with poorer prognosis.

\section{Conclusions}

Analysis of adult patients supported on V-A ECMO for PCS reported to the ELSO registry demonstrated significantly increased use from 1995 through 2018. Mortality rates remained relatively constant over time despite a decrease in complications, in the setting of supporting older, higher risk patients. 


\section{Introduction}

Veno-arterial extracorporeal membrane oxygenation (V-A ECMO) represents a well-established life-saving procedure for refractory acute cardiac or cardiorespiratory insufficiency [1,2]. Its use in the setting of postcardiotomy cardiogenic shock (PCS) has increased in recent years, despite high associated mortality [3,4]. Severity of the patients' underlying disease together with extracorporeal circulation predisposes to complications, which combine to negatively impact survival. Indeed, recent reports have shown that V-A ECMO has increased exponentially for the treatment of PCS, yet survival rates to discharge have decreased [5]. Potential explanations for this include wider access to ECMO devices, expanded inclusion criteria, as well as offering ECMO as a last resort to patients who would have otherwise died due to postoperative complications.

Indeed, V-A ECMO for PCS has represented the main indication for ECMO use in many institutions and differs from other applications of ECMO in several respects. Patients managed with PCS V-A ECMO have different complexity of underlying diseases, severity of comorbidities, indication and type of surgical procedures, modality of access and timing of implantation, and complication types and rates, when compared with other indications for ECMO [6,7]. Limited experience in these procedures, particularly in centers without well-established ECMO programs, may impact patient outcomes. Together, these factors influence ECMO management and outcomes in PCS patients and make this particular indication at high risk for unfavorable results.

Due to the increased use, complex patient management and resource intensity of PCS-related ECMO, careful evaluation of patient attributes, complication rates and in-hospital outcomes across a large accumulated experience, should meaningfully inform the role of ECMO in this setting. Furthermore, trends in these outcomes assessed over the past 3 decades may also provide insights that could improve results, or suggest areas of focus for prospective research and clinical practice change to yield the greatest impact on patient outcomes. We utilized a robust patient registry reflecting the initial efforts at PCS V-A ECMO to the present day, focusing on patient characteristics and outcomes.

\section{Methods}


The ELSO registry is a voluntary registry with more than 420 centers worldwide contributing data, including information on pre-ECMO implant patient profile, use, complications, and in-hospital outcomes in adults and children undergoing temporary ECMO support $[5,8]$. Information present in the ELSO registry from January 1 , 1995, through December 31, 2018 was analyzed. Data were collected using a standardized data reporting sheet, including patient demographics, pre-ECMO diagnoses and comorbidities, hemodynamic and laboratory information prior to and during ECMO, perioperative complications, and survival to hospital discharge. Patient diagnoses were reported using the International Classification of Diseases, $9^{\text {th }}$ and $10^{\text {th }}$ Edition codes. In this registry, indications for ECMO support are categorized as "cardiac," "respiratory," or "extracorporeal cardiopulmonary resuscitation" (ECPR).

\section{Study Population}

Data on patients more than 18 years old undergoing a single run V-A ECMO for refractory PCS were extracted. Indications for ECMO consisted of intra-operative failure to wean from cardiopulmonary bypass (CPB) due to right, left or biventricular failure, and post-operative refractory cardiogenic shock or cardiac arrest during the hospitalisation after the surgical procedure. Patients with pre-operative ECMO were excluded from the analysis, as were subsequent ECMO runs in patients undergoing more than one ECMO run. IRB approval was waived due to the retrospective design of the study and anonymous patient records in the registry. Informed consent was obtained as per regulations in the participating centers.

\section{Main Goals and Definitions}

We aimed to describe the trends of V-A ECMO for PCS, including perioperative morbidity as well as mortality, specifically attempting to identify factors associated with in-hospital mortality. All complications were categorized using ELSO registry complication codes and included the following: 1) limb complications, 2) central nervous system complications, 3) bleeding complications, 4) kidney injury, and 5) sepsis. These categories were then further subdivided, as appropriate. We declared post-operative: cardiopulmonary resuscitation, cardiac tamponade, disseminated intravascular coagulation, gastrointestinal bleeding, mediastinal bleeding, cultureproven sepsis, limb amputation or fasciotomy for ischemia, pump or oxygenator failure, severe hemolysis, brain 
death, diffuse brain ischemia or hemorrhage, pulmonary hemorrhage and renal replacement therapy as major complications.

\section{Statistical analysis}

We compared in-hospital survivors and non-survivors and used the Shapiro-Wilk test for testing of normality of continuous variables. All variables were analyzed with descriptive and frequency analysis. Variables with missing data in more than $5 \%$ of the patients were excluded from analysis. The $x 2$ and Fisher exact tests were used to compare group differences for categorical variables. Continuous variables were analyzed using the MannWhitney $U$ test and were reported as means with standard deviations (SDs) or as medians with interquartile ranges (IQRs). Complications occurring in both groups are reported as number (\%) with corresponding odds ratios $(\mathrm{OR})$ and $95 \%$ confidence intervals $(95 \% \mathrm{Cls}) . p<0.05$ was considered a significant difference between the groups. The Storey-Tibshirani multiple testing correction was used [9]. Variables that achieved $p<0.2$ in the univariate analysis were examined by using multivariate analysis with forward stepwise logistic regression to evaluate independent risk factors for hospital mortality. The performance of the multivariate model in predicting mortality was assessed by calculating a c-statistic for discrimination and by the Hosmer-Lemeshow goodness-of-fit statistics for calibration. Missing data were addressed with artificial neural networks up to $5 \%$. All statistical tests were performed in STATA MP version 13.0 software (StataCorp, College Station, TX).

\section{Results}

During the study period, 8,053 patients received V-A ECMO for PCS. Figure 1 demonstrates the trend in the number of patients initiated on V-A ECMO for PCS from the ELSO database with corresponding annual mortality rates. While there was a significant increase in the number of ECMO for PCS cases in recent years (coef.: $0.009 ; p<0.001$ ), the mortality rate did not change significantly over time (coef.: $-8.775 ; p=0.682$ ) (Figure 1 ). The mean age was $56.3 \pm 14.9$ years (range, 18-86 years); patient distribution across age strata was evenly maintained. Yet, a significant trend (coef.: $0.444 ; p<0.001)$, for increasing average age was observed (Figure 2). 


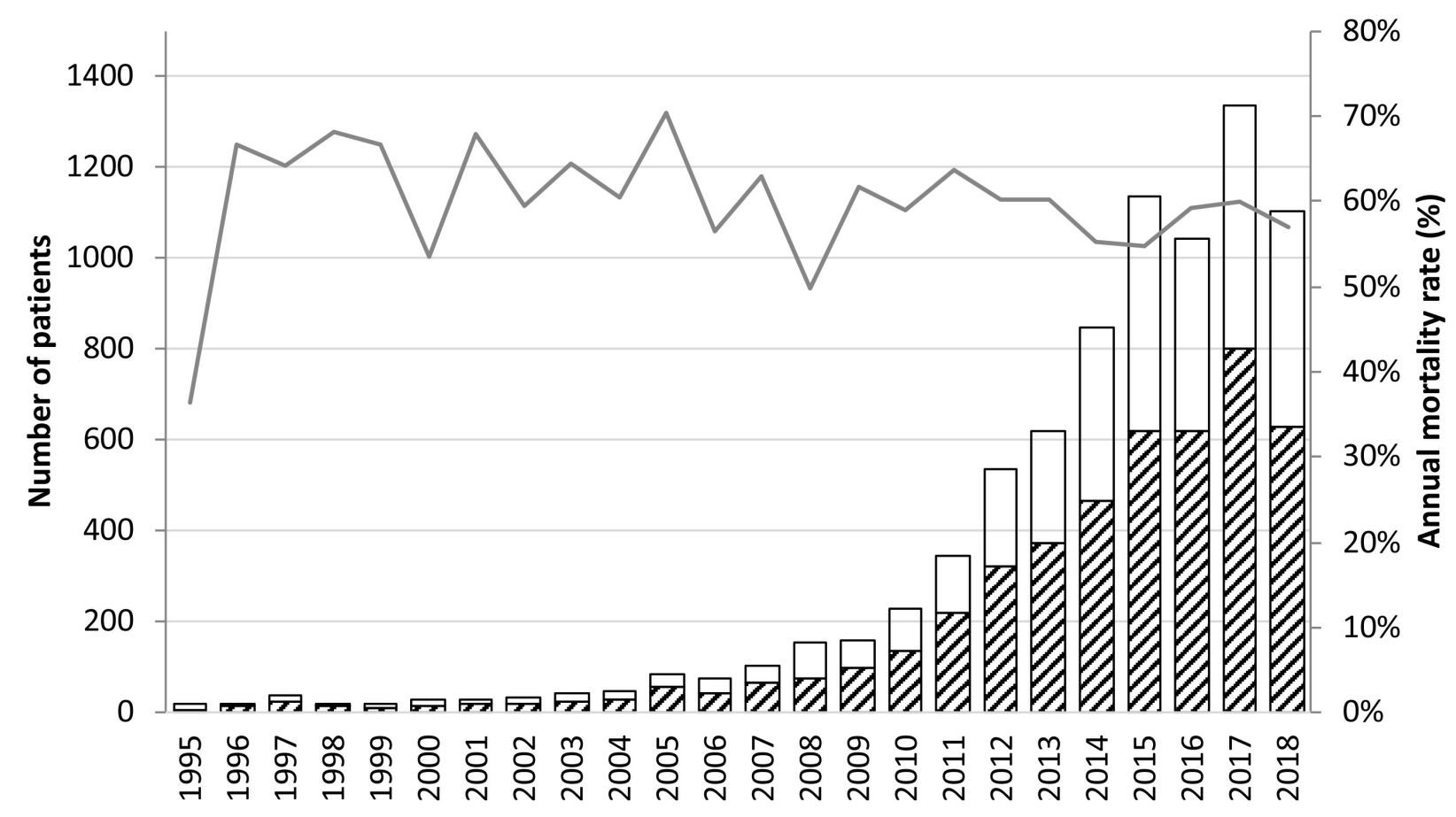

ZZIn-hospital non-survivors $\square$ In-hospital survivors -Annual mortality rate

Figure 1. Annual trend in the number of patients undergoing V-A ECMO and in-hospital mortality.

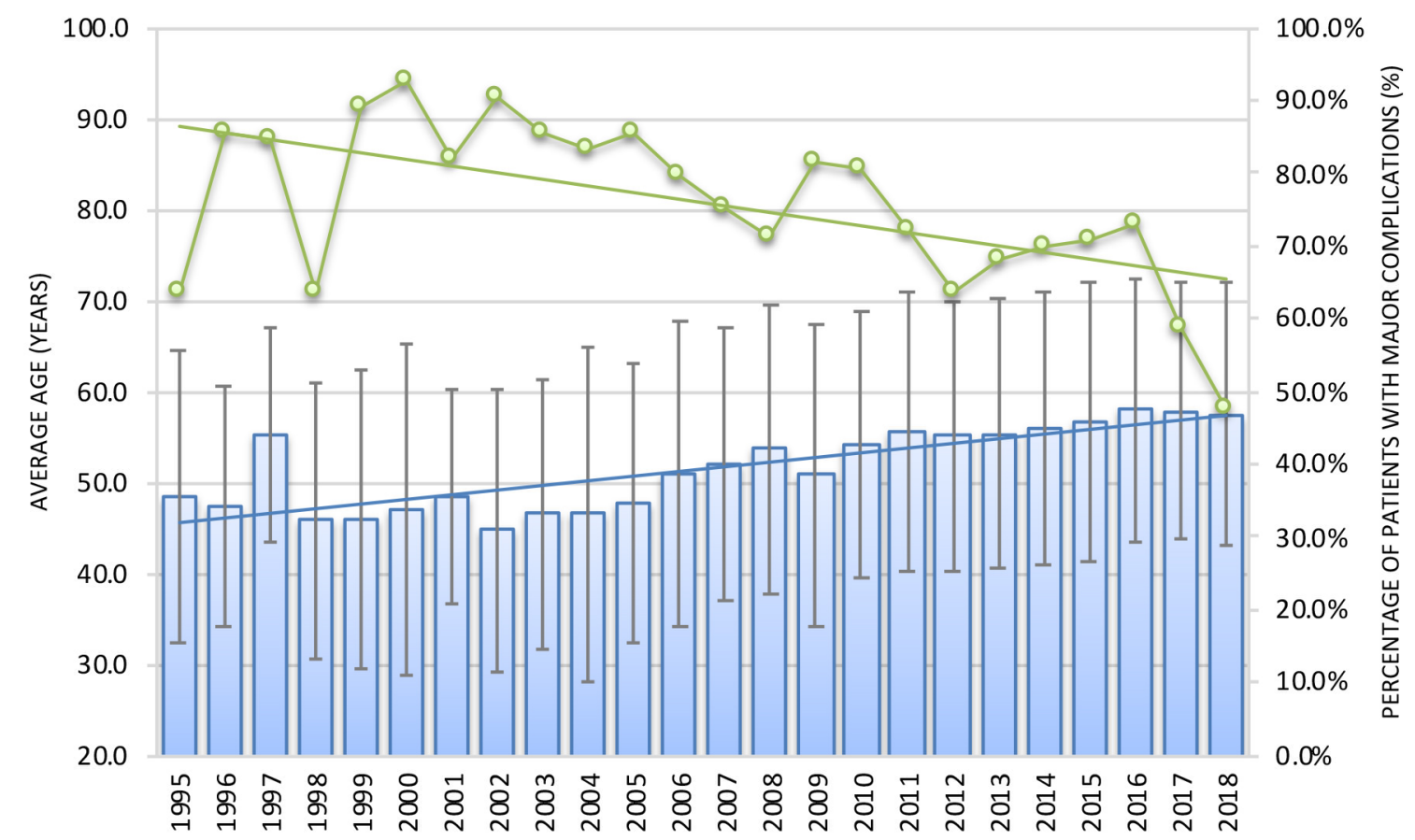

Figure 2. Trends in average age and major complications during ECMO: cardiopulmonary resuscitation, cardiac tamponade, disseminated intravascular coagulation, gastrointestinal bleeding, mediastinal bleeding, culture-proven sepsis, limb amputation or fasciotomy for ischemia, pump or oxygenator failure, severe hemolysis, brain death, diffuse brain ischemia or hemorrhage, pulmonary hemorrhage and renal replacement therapy. ECMO, extracorporeal membrane oxygenation; SD, standard deviation. 
All pre-operative patient characteristics and details about cardiac disease are shown in Table 1.

Table 1. Patient characteristics

\begin{tabular}{|c|c|c|c|c|}
\hline Variable & Total $(n=8,053)$ & $\begin{array}{l}\text { In-hospital } \\
\text { survivors } \\
(n=3,337)\end{array}$ & $\begin{array}{c}\text { In-hospital non- } \\
\text { survivors } \\
(n=4,716)\end{array}$ & $p$-value \\
\hline \multicolumn{5}{|l|}{ Mean age, years } \\
\hline $18-38$ & $1,169(14.5)$ & 638 (54.6) & $531(45.4)$ & \multirow{5}{*}{$<0.001$} \\
\hline $39-52$ & $1,691(21.0)$ & $778(46.0)$ & $913(54.0)$ & \\
\hline $53-62$ & $2,194(27.2)$ & 917 (41.8) & $1,277(58.2)$ & \\
\hline $63-70$ & $1,583(19.7)$ & 555 (35.1) & $1,028(64.9)$ & \\
\hline$>=71$ & $1,416(17.6)$ & 449 (31.7) & 967 (68.3) & \\
\hline \multicolumn{5}{|l|}{ Gender } \\
\hline Male & $5,411(67.2)$ & 2,339 (43.2) & $3,072(56.8)$ & \multirow{2}{*}{$<0.001$} \\
\hline Female & $2,641(32.8)$ & $997(37.8)$ & $1,644(62.2)$ & \\
\hline \multicolumn{5}{|l|}{ Race } \\
\hline White & $4,797(59.6)$ & $1,973(41.1)$ & $2,824(58.9)$ & \multirow{5}{*}{0.039} \\
\hline Black & $667(8.3)$ & $298(44.7)$ & 369 (55.3) & \\
\hline Asian & $1,335(16.6)$ & $580(43.4)$ & $75556.6)$ & \\
\hline Hispanic & $403(5.0)$ & $148(36.7)$ & 255 (63.3) & \\
\hline Other & $850(10.6)$ & $337(39.6)$ & $513(60.4)$ & \\
\hline Diabetes melitus & $718(8.9)$ & $273(38.0)$ & $445(62.0)$ & 0.028 \\
\hline Dyslipidemia & $495(6.1)$ & $168(33.9)$ & $327(66.1)$ & $<0.001$ \\
\hline Chronic obstructive pulmonary disease & $107(1.3)$ & $37(34.6)$ & $70(65.4)$ & 0.088 \\
\hline Obstructive sleep apnea & $143(1.8)$ & $46(32.2)$ & $97(67.8)$ & 0.014 \\
\hline Chronic kidney disease & $476(5.9)$ & $158(33.2)$ & $318(66.8)$ & $<0.001$ \\
\hline Atrial fibrillation & $706(8.8)$ & $309(43.8)$ & $397(56.2)$ & 0.101 \\
\hline STEMI $^{*}$ & $460(5.7)$ & $189(41.1)$ & $271(58.9)$ & 0.459 \\
\hline Pulmonary hypertension & $338(4.2)$ & $127(37.6)$ & $211(62.4)$ & 0.341 \\
\hline Previous heart surgery & $339(4.2)$ & $147(43.4)$ & $192(56.6)$ & 0.247 \\
\hline Bacterial endocarditis & $163(2.0)$ & $78(47.9)$ & $85(52.1)$ & 0.055 \\
\hline Cancer diagnosis & $104(1.3)$ & $33(31.7)$ & $71(68.3)$ & 0.026 \\
\hline
\end{tabular}

STEMI, ST-segment elevation myocardial infarction

Most commonly, patients were managed on ECMO for PCS after coronary artery bypass surgery (CABG) $(26.8 \%)$ and valvular surgery $(25.6 \%)$, followed by heart transplantation $(20.7 \%)$, combination surgeries, such as CABG with valve (13.4\%), and ventricular assist devices (8.5\%).

ECMO implantation and weaning details are shown in Table 2. Table 2 also lists blood gases and hemodynamic variables at ECMO implantation and 24-hours following implantation. The most frequent indication for V-A ECMO in this cohort was failure to wean from cardiopulmonary bypass. Most ECMO access was achieved by peripheral cannulation $(53.5 \%)$ followed by central cannulation (46.5\%); the combination of central arterial and peripheral venous cannulation were pooled as central cannulation strategies. Concomitant intra-aortic balloon pumps (IABP) were used in $31.8 \%$ of the patients. 
Table 2. Pre-ECMO information and support details

\begin{tabular}{|c|c|c|c|c|}
\hline Variable & Total $(n=8,053)$ & $\begin{array}{l}\text { In-hospital } \\
\text { survivors } \\
(n=3,337)\end{array}$ & $\begin{array}{c}\text { In-hospital non- } \\
\text { survivors } \\
(n=4,716)\end{array}$ & $p$-value \\
\hline \multicolumn{5}{|l|}{ Pre-ECMO suport } \\
\hline IABP & $2,563(31.8)$ & $1,031(40.2)$ & $1,532(59.8)$ & 0.070 \\
\hline CPB & $3,757(46.7)$ & $1,487(39.6)$ & $2,270(60.4)$ & 0.001 \\
\hline Nitric oxide & $899(11.2)$ & $372(41.4)$ & $527(58.6)$ & 0.502 \\
\hline Pacemaker & $840(10.4)$ & $293(34.9)$ & $547(65.1)$ & $<0.001$ \\
\hline Inotropes & $3,882(48.2)$ & $1,496(38.5)$ & $2,386(61.5)$ & $<0.001$ \\
\hline LVAD & $537(6.7)$ & $236(43.9)$ & $301(56.1)$ & 0.119 \\
\hline \multicolumn{5}{|l|}{ Pre-ECMO arterial blood gases } \\
\hline $\mathrm{pH}$ & $7.3 \pm 0.1$ & $7.31 \pm 0.13$ & $7.28 \pm 0.15$ & $<0.001$ \\
\hline $\mathrm{PCO}_{2}(\mathrm{mmHg})$ & $42.5 \pm 20.2$ & $41.9 \pm 19.4$ & $42.9 \pm 20.7$ & 0.078 \\
\hline Oxygen partial pressure $(\mathrm{mmHg})$ & $170.5 \pm 135.2$ & $173.7 \pm 136.7$ & $168.2 \pm 134.1$ & 0.123 \\
\hline Bicarbonate levels $\mathrm{mEq} / \mathrm{L}$ & $20.5 \pm 5.8$ & $21.2 \pm 5.6$ & $20 \pm 5.9$ & $<0.001$ \\
\hline $\mathrm{SaO}_{2}(\%)$ & $92.8 \pm 12.1$ & $93.6 \pm 10.7$ & $92.2 \pm 13.1$ & $<0.001$ \\
\hline \multicolumn{5}{|l|}{ Ventilator settings (pre-ECMO) } \\
\hline Respiratory rate $(/ \mathrm{min})$ & $16.1 \pm 6.2$ & $15.8 \pm 6.0$ & $16.4 \pm 6.4$ & 0.003 \\
\hline $\mathrm{FiO}_{2}(\%)$ & $81.62 \pm 23.44$ & $81 \pm 23.8$ & $82.1 \pm 23.2$ & 0.107 \\
\hline $\mathrm{PIP}\left(\mathrm{cm} \mathrm{H}_{2} \mathrm{O}\right)$ & $25.86 \pm 8.27$ & $24.7 \pm 8$ & $26.7 \pm 8.4$ & $<0.001$ \\
\hline PEEP $\left(\mathrm{cm} \mathrm{H}_{2} \mathrm{O}\right)$ & $7 \pm 4.2$ & $6.8 \pm 3.6$ & $7.2 \pm 4.6$ & 0.002 \\
\hline Mean AP & $15.9 \pm 11.6$ & $15.5 \pm 11.8$ & $16.2 \pm 11.5$ & 0.135 \\
\hline \multicolumn{5}{|l|}{ Ventilator settings (24 hours) } \\
\hline Respiratory rate (/min) & $12.5 \pm 4.6$ & $12.2 \pm 3.9$ & $12.7 \pm 5$ & $<0.001$ \\
\hline $\mathrm{FiO}_{2}(\%)$ & $50.1 \pm 18.9$ & $48.6 \pm 17.4$ & $51.4 \pm 20$ & $<0.001$ \\
\hline $\mathrm{PIP}\left(\mathrm{cm} \mathrm{H}_{2} \mathrm{O}\right)$ & $24 \pm 6.5$ & $22.8 \pm 5.7$ & $24.8 \pm 6.9$ & $<0.001$ \\
\hline PEEP $\left(\mathrm{cm} \mathrm{H}_{2} \mathrm{O}\right)$ & $7.5 \pm 3.4$ & $7.4 \pm 3.3$ & $7.6 \pm 3.4$ & 0.032 \\
\hline Mean AP & $14.3 \pm 12.1$ & $14.1 \pm 12.5$ & $14.5 \pm 11.8$ & 0.344 \\
\hline \multicolumn{5}{|l|}{ Pre-ECMO hemodynamics } \\
\hline $\mathrm{SBP}(\mathrm{mmHg})$ & $81.6 \pm 26.5$ & $83.4 \pm 24.9$ & $80.2 \pm 27.6$ & $<0.001$ \\
\hline $\mathrm{DBP}(\mathrm{mmHg})$ & $50.0 \pm 17.0$ & $51.8 \pm 15.9$ & $48.6 \pm 17.6$ & $<0.001$ \\
\hline Mean arterial pressure $(\mathrm{mmHg})$ & $60.3 \pm 18.5$ & $62.6 \pm 17.3$ & $58.6 \pm 19.2$ & $<0.001$ \\
\hline Venous oxygen saturation (\%) & $60.5 \pm 17.3$ & $60.8 \pm 17.1$ & $60.3 \pm 17.5$ & 0.597 \\
\hline \multicolumn{5}{|l|}{ Hours on ECMO } \\
\hline Mean (hours) & $140.9 \pm 158.2$ & $134.9 \pm 143.7$ & $145.1 \pm 167.7$ & 0.003 \\
\hline $0-41$ & $1,654(20.5)$ & $488(29.5)$ & $1,166(70.5)$ & \multirow{4}{*}{$<0.001$} \\
\hline $42-88$ & $1,831(22.7)$ & $872(47.6)$ & $959(52.4)$ & \\
\hline $89-161$ & $2,270(28.2)$ & $1,111(48.9)$ & $1,159(51.1)$ & \\
\hline$>161$ & $2,297(28.5)$ & $865(37.7)$ & $1,432(62.3)$ & \\
\hline \multicolumn{5}{|l|}{ Cannulation } \\
\hline Peripheral & $4,307(53.5)$ & $1,942(45.1)$ & $2,365(54.9)$ & \multirow{2}{*}{$<0.001$} \\
\hline Central & $3,745(46.5)$ & $1,394(37.2)$ & $2,351(62.8)$ & \\
\hline
\end{tabular}

ECMO, extracorporeal membrane oxygenation; IABP, intra-aortic balloon pump; CPB, cardiopulmonary bypass; LVAD, left ventricle assist device; $\mathrm{PCO}_{2}$, partial pressure of carbon dioxide; $\mathrm{SaO}_{2}$, oxygen saturation; $\mathrm{FiO}_{2}$, fraction of inspired oxygen; $\mathrm{PiP}$, peak inspiratory pressure; PEEP, positive end-expiratory pressure; AP, airway pressure; SBP, systolic blood pressure; DBP, diastolic blood pressure.

Patients were maintained on ECLS for a median duration of $140.9 \pm 158.2$ hours, with $134.9 \pm 143.7$ hours for inhospital survivors, and $145.1 \pm 167.7$ hours for non-survivors ( $p=0.003$ ). Overall, successful ECMO weaning was possible in 4,520 cases (56.1\%). However, survival to hospital discharge was achieved in $41.4 \%$ of cases. 
The use of PCS-ECMO was associated with numerous complications (Table 3).

Table 3. Complications during ECMO

\begin{tabular}{|c|c|c|c|c|}
\hline Complications* & Total $(n=8,053)$ & $\begin{array}{l}\text { In-hospital } \\
\text { survivors } \\
(n=3,337)\end{array}$ & $\begin{array}{l}\text { In-hospital non- } \\
\text { survivors } \\
(\mathrm{n}=4,716) \\
\end{array}$ & $p$-value \\
\hline \multicolumn{5}{|l|}{ Limb complications } \\
\hline Ischemia & $312(3.9)$ & $88(28.2)$ & $224(71.8)$ & $<0.001$ \\
\hline Limb compartment syndrome & $106(1.3)$ & $24(22.6)$ & $82(77.4)$ & $<0.001$ \\
\hline Fasciotomy $^{\star *}$ & $143(1.8)$ & $37(25.9)$ & $106(74.1)$ & $<0.001$ \\
\hline Amputation ${ }^{* *}$ & $44(0.5)$ & $22(50.0)$ & $22(50.0)$ & 0.158 \\
\hline \multicolumn{5}{|l|}{ Hematologic/bleeding } \\
\hline $\mathrm{DIC}^{* *}$ & $238(3.0)$ & $42(17.6)$ & $196(82.4)$ & $<0.001$ \\
\hline Hemolysis** & $382(4.7)$ & $109(28.5)$ & $273(71.5)$ & $<0.001$ \\
\hline Surgical site bleeding & $2,187(27.2)$ & $733(33.5)$ & $1,454(66.5)$ & $<0.001$ \\
\hline Cannulation site bleeding & $130(1.6)$ & $38(29.2)$ & $92(70.8)$ & 0.003 \\
\hline Cardiac tamponade $e^{* *}$ & $653(8.1)$ & $220(33.7)$ & $433(66.3)$ & $<0.001$ \\
\hline GI bleeding** & $322(4.0)$ & 79 (24.5) & $243(75.5)$ & $<0.001$ \\
\hline \multicolumn{5}{|l|}{ Neurologic } \\
\hline $\begin{array}{l}\text { Diffuse ischemia** confirmed by } \\
\text { US/CT/MRI }\end{array}$ & $7(0.1)$ & $1(14.3)$ & $6(85.7)$ & 0.141 \\
\hline $\begin{array}{l}\text { Hemorrhage }{ }^{* *} \text { confirmed by } \\
\text { US/CT/MRI }\end{array}$ & $129(1.6)$ & $13(10.1)$ & $116(89.9)$ & $<0.001$ \\
\hline Infarction confirmed by US/CT/MRI & $350(4.3)$ & $83(23.7)$ & $267(76.3)$ & $<0.001$ \\
\hline $\begin{array}{l}\text { Intra/extra parenchymal } \\
\text { Hemorrhage** confirmed by } \\
\text { US/CT/MRI }\end{array}$ & $19(0.2)$ & & $19(100.0)$ & $<0.001$ \\
\hline $\begin{array}{l}\text { Intraventricular hemorrhage }{ }^{* *} \\
\text { confirmed by US/CT/MRI }\end{array}$ & $7(0.1)$ & & $7(100.0)$ & 0.024 \\
\hline Neurosurgical intervention performed & $1(0.0)$ & & $1(100.0)$ & 0.586 \\
\hline Seizures: confirmed by EEG & $38(0.5)$ & $9(23.7)$ & $29(76.3)$ & 0.017 \\
\hline Seizures: clinically determined & $98(1.2)$ & $26(26.5)$ & $72(73.5)$ & 0.001 \\
\hline Brain death ${ }^{\star *}$ & $239(3.0)$ & & $239(100.0)$ & $<0.001$ \\
\hline \multicolumn{5}{|l|}{ Sepsis } \\
\hline Culture-proven infection** & $918(11.4)$ & $349(38.0)$ & $569(62.0)$ & 0.014 \\
\hline \multicolumn{5}{|l|}{ Kidey failure } \\
\hline $\mathrm{sCr} 1.5-3$ & $1,834(22.8)$ & $661(36.0)$ & $1,173(64.0)$ & $<0.001$ \\
\hline $\mathrm{sCr}>3$ & $857(10.6)$ & $234(27.3)$ & $623(72.7)$ & $<0.001$ \\
\hline $\mathrm{CRRT}^{* *}$ & $2,965(36.8)$ & $816(27.5)$ & $2,149(72.5)$ & $<0.001$ \\
\hline \multicolumn{5}{|l|}{ Cardiovascular } \\
\hline Cardiac arrhythmia & $1,311(16.3)$ & $438(33.4)$ & $873(66.6)$ & $<0.001$ \\
\hline CPR required $^{* *}$ & $253(3.1)$ & $42(16.6)$ & $211(83.4)$ & $<0.001$ \\
\hline Hypertension requiring vasodilators & $271(3.4)$ & $137(50.6)$ & $134(49.4)$ & 0.001 \\
\hline Inotropes on ECMO & $3,859(47.9)$ & $1,471(38.1)$ & $2,388(61.9)$ & $<0.001$ \\
\hline \multicolumn{5}{|l|}{ Metabolic } \\
\hline Glucose $<40$ & $125(1.6)$ & $4(3.2)$ & $121(96.8)$ & $<0.001$ \\
\hline Glucose $>240$ & $950(11.8)$ & $407(42.8)$ & $543(57.2)$ & 0.183 \\
\hline Hyperbilirubinemia & $1,040(12.9)$ & $275(26.4)$ & $765(73.6)$ & $<0.001$ \\
\hline $\mathrm{pH}<7.20$ & $692(8.6)$ & $117(16.9)$ & $575(83.1)$ & $<0.001$ \\
\hline $\mathrm{pH}>7.60$ & $279(3.5)$ & $134(48.0)$ & $145(52.0)$ & 0.014 \\
\hline \multicolumn{5}{|l|}{ Pulmonary } \\
\hline Pulmonary hemorrhage ${ }^{* *}$ & $210(2.6)$ & $56(26.7)$ & $154(73.3)$ & $<0.001$ \\
\hline
\end{tabular}

${ }^{*}$ Complications with their pertinent definitions are listed in the supplement

${ }^{* *}$ Declared as major complications 
DIC, disseminated intravascular coagulation; $\mathrm{GI}$, gastrointestinal; US, ultrasound; $\mathrm{CT}$, computed tomography; MRI, magnetic resonance imaging; $\mathrm{EEG}$, electroencephalogram; $\mathrm{SCr}$, serum creatinine; $\mathrm{CRRT}$, continuous renal replacement therapy; $\mathrm{CPR}$, cardiopulmonary resuscitation; ECMO, extracorporeal membrane oxygenation.

Notwithstanding, the number of patients with major complications decreased in recent years (coef.: -0.009 ; $p=0.003$; Figure 2). Overall, surgical site bleeding, sepsis, cardiac arrhythmias, kidney injury with or without the need for renal replacement therapy, metabolic disorders and neurologic complications were the most common.

When stratified by the type of primary surgery, a higher mortality was observed after CABG $(53.8 \%)$, combined CABG with valve (59.0\%), and vascular aortic (66.3\%) procedures than other indications. (Figure 3).

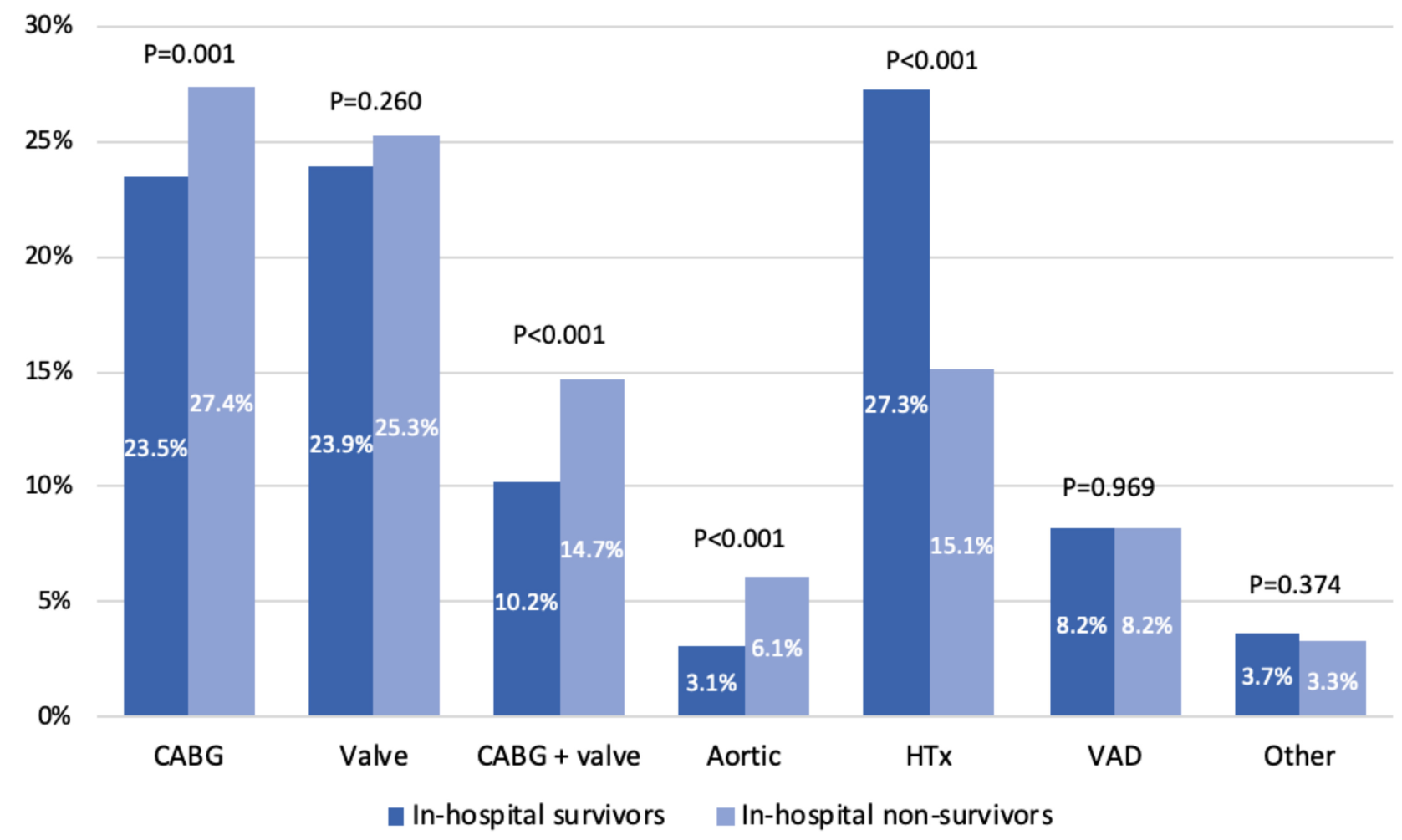

Figure 3. Analysis of in-hospital mortality stratified by the type of primary surgery. CABG, coronary artery bypass grafting; HTx, heart transplantation; VAD, ventricle assist device.

Conversely, survival rates among patients requiring V-A ECMO following heart transplantation were nearly twice as high as non-survival accounting for a crude rate of $64.4 \%$. Multivariate logistic regression analysis demonstrated that older age was significantly associated with in-hospital mortality (Table 4). 
Table 4. Multivariate predictors of death at discharge (binary logistic regression)

\begin{tabular}{lllll} 
Variable & OR & Lower Cl & Upper Cl & P-value \\
\hline Age & 1.020 & 1.017 & 1.024 & $<0.001$ \\
\hline Weight & 1.005 & 1.003 & 1.007 & $<0.001$ \\
\hline Gender (male) & 0.681 & 0.610 & 0.761 & $<0.001$ \\
\hline Peripheral cannulation & 0.729 & 0.660 & 0.806 & $<0.001$ \\
\hline Arrhythmias & 1.151 & 1.002 & 1.320 & 0.046 \\
\hline DIC & 2.534 & 1.767 & 3.635 & $<0.001$ \\
\hline GI bleeding & 1.650 & 1.254 & 2.173 & $<0.001$ \\
\hline Hemolysis & 1.335 & 1.043 & 1.706 & 0.022 \\
\hline Surgical site bleeding & 1.308 & 1.167 & 1.465 & $<0.001$ \\
\hline Limb ischemia & 1.657 & 1.260 & 2.180 & $<0.001$ \\
\hline Hypoglycemia (<40mg/dL) & 13.327 & 4.833 & 36.750 & $<0.001$ \\
\hline Pulmonary hemorrhage & 1.695 & 1.217 & 2.359 & 0.002 \\
\hline sCr $>3$ & 1.430 & 1.199 & 1.706 & $<0.001$ \\
\hline CRRT & 2.289 & 2.052 & 2.554 & $<0.001$ \\
\hline Bicarbonate & 1.361 & 1.188 & 1.560 & $<0.001$ \\
\hline Dobutamine & 0.859 & 0.752 & 0.982 & 0.026 \\
\hline Levosimendan & 3.292 & 1.185 & 9.147 & 0.022 \\
\hline Vasopressors & 1.106 & 1.003 & 1.220 & 0.044 \\
\hline CABG & 1.170 & 1.040 & 1.317 & 0.009 \\
\hline Heart transplantion & 0.626 & 0.539 & 0.727 & $<0.001$ \\
\hline Aortic surgery & 1.363 & 1.083 & 1.715 & 0.008
\end{tabular}

$\mathrm{OR}$, odds ratio; $\mathrm{Cl}$, confidence interval; $\mathrm{DIC}$, disseminated intravascular coagulation; $\mathrm{Gl}$, gastrointestinal; sCr, serum creatinine; CRRT, continuous renal replacement therapy; $C A B G$, coronary artery bypass grafting.

In particular, of 1,416 patients over 70 years of age, $68.3 \%$ (967) did not survive to discharge $(p<0.001$; Table 1). Additionally, malignant arrhythmias, cardiac tamponade, disseminated intravascular coagulation, gastrointestinal bleeding, hemolysis, and surgical complications, were all associated with worse prognosis. Interestingly, peripheral cannulation was shown in the multivariate model to be associated with lower inhospital mortality (Table 4 and Figure 4) and lower rates of surgical site bleeding complications (Figure 5). Hosmer-Lemeshow of the constructed multivariate model with $p=0.678$ with a c-statistic of $0.703(95 \% \mathrm{Cl}$, $0.692-0.715)$.

\section{Discussion}

\section{Change in trends of V-A ECMO use}

The use of temporary mechanical circulatory support including V-A ECMO is increasing but is often used as a last resort for patients who might otherwise die $[3,4]$. In United States, PCS and shock complicating ST-elevation myocardial infarction (MI) were the two most frequent indications for V-A ECMO implantation until 2012 [10]. 
The European and American Societies of Cardiology guideline recommendations assigned ECMO the class recommendation Ilb, level of evidence $C$, for the management of cardiogenic shock in STEMI [11].

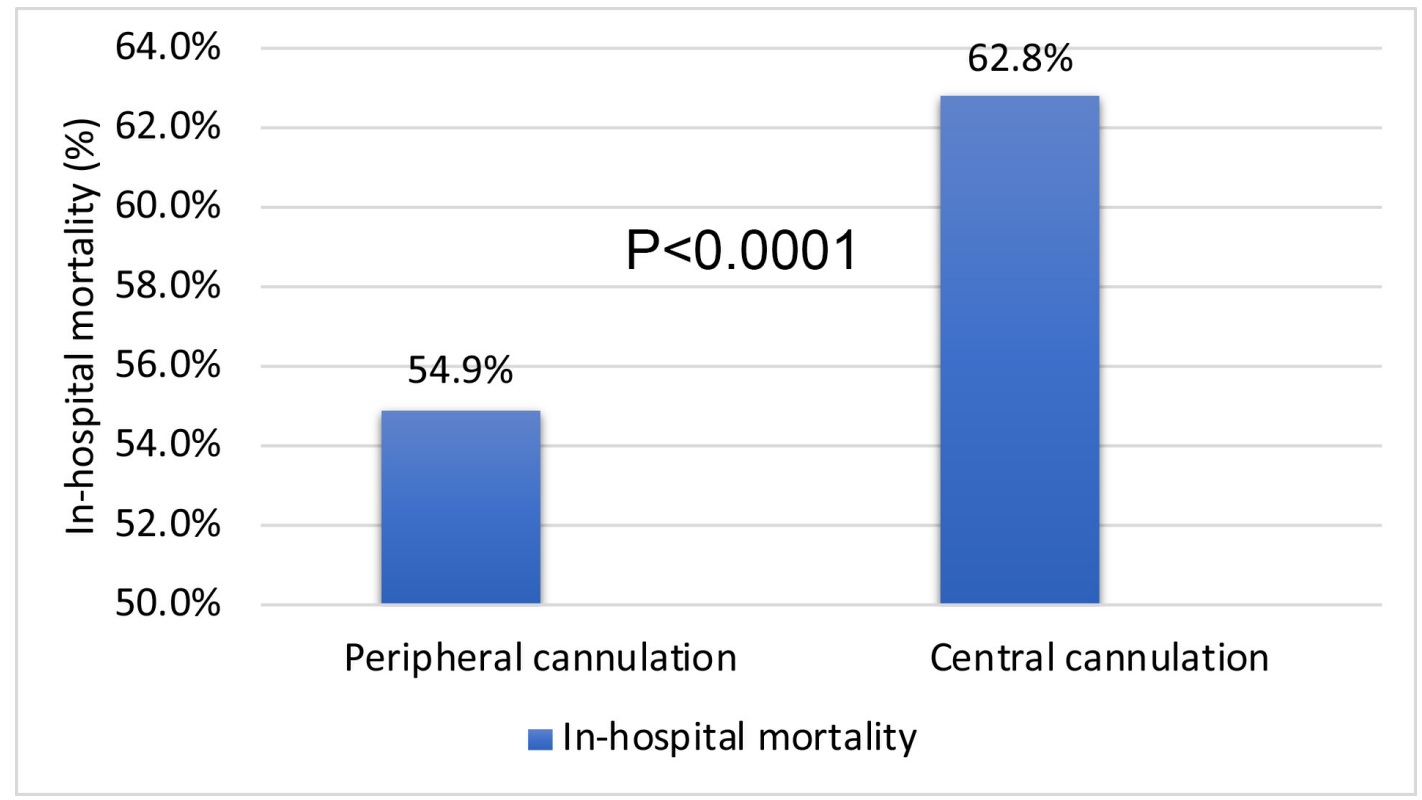

Figure 4. Analysis of trends in institution of V-A ECMO via peripheral cannulation and annual mortality rates.

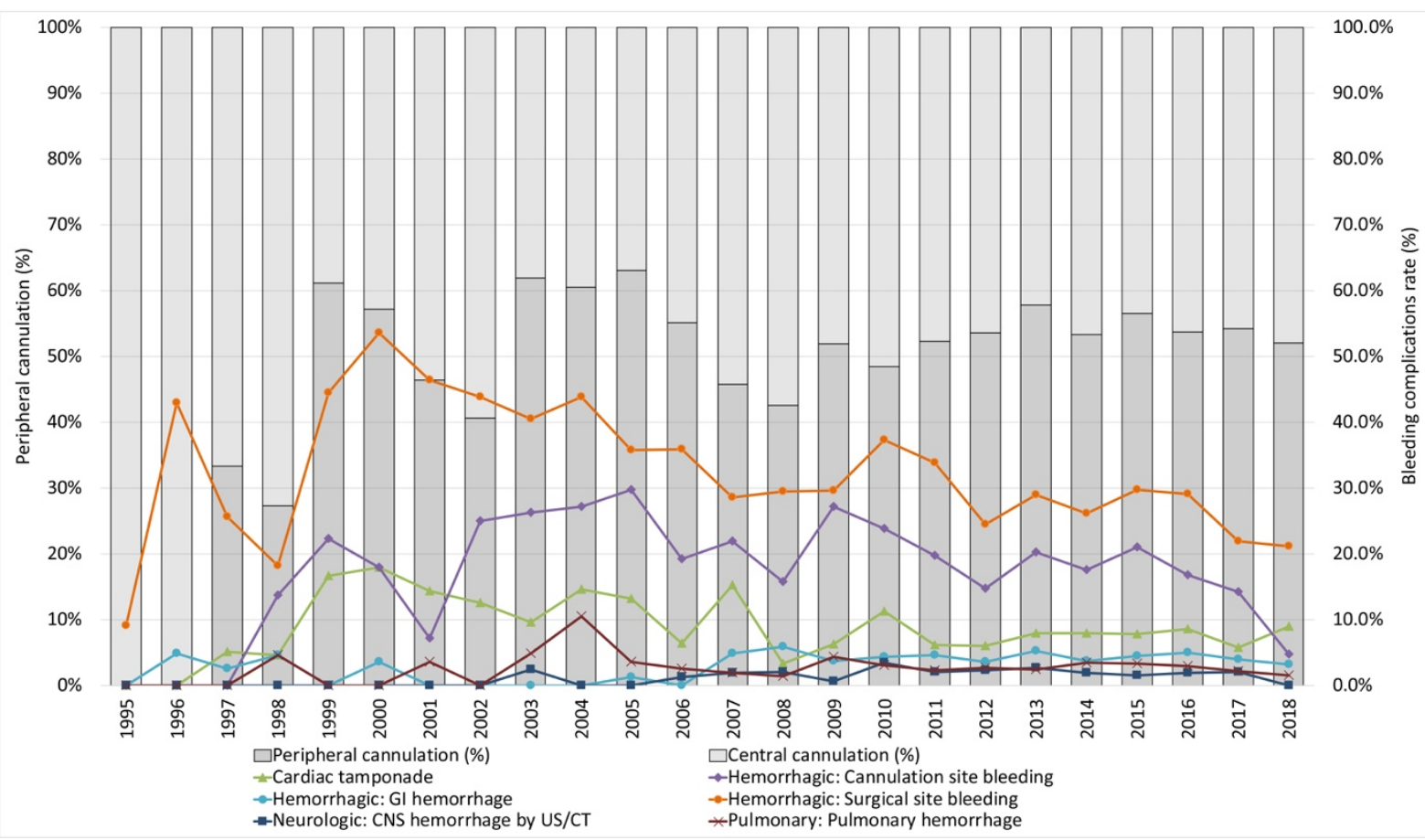

Figure 5. Analysis of trends in institution of V-A ECMO via peripheral cannulation and rates of bleeding complications 
Despite the above, and also growing worldwide utilization and experience, in-hospital ECMO outcomes have not shown substantial improvement $[6,10]$. Little is still known of who benefits most from ECMO, not to mention the cost-effectiveness of such a resource-intense therapy [4]. The inherent features of ECMO in terms of quick availability, relative ease of application in expert centers and reliability, have made it an attractive option, particularly in the post-cardiotomy setting $[1,2]$. In contrast, although the use of implantable or para-corporeal ventricular assist devices (VAD), either uni- or biventricular, has been applied in these circumstances, their complexity, lack of associated lung support, cost, and limited availability, have hampered their wider application, making V-A ECMO the most frequent temporary mechanical circulatory support in these circumstances [12].

Numerous publications have shown ECMO-related short- and medium-term outcomes [2,3]. However, specific reports about post-cardiotomy ECMO in acquired and congenital cardiac surgery patients, have been limited and usually report single center results only [13-15]. The characteristics of ECMO implantation (patient profiles, surgical access or location of implantation, timing of application, and duration of support), complications, and outcomes in the post-cardiotomy ECMO setting are different than in other applications of ECMO [16-21].

\section{Change in patients risk profile}

In addition, cardiac surgical patients are often characterized by substantial pre-ECMO comorbidities and more advanced age than in other ECMO populations [22,23]. Each of these factors, either individually or collectively, may influence the capability of the myocardium to recover from prolonged extracorporeal mechanical assistance. In some patients, the mechanical support does not facilitate improved cardiac function or organ integrity, and clinicians may therefore be forced to bridge the patient toward more advanced treatments, such as heart transplantation or long-term ventricular assist devices (VADs). The insights from important recently available studies are that prolonging V-A ECMO duration is associated with an increased mortality at early and later stages [24]. In fact, lack of cardiac function improvement within 7 days post-operatively may indicate reduced likelihood of recovery and prolonged support might favour the occurrence of complications with ominous prognosis. Notably, a trend towards worsened survival rates, reaching a low of $15 \%$ in 2016 was recently reported in another analysis of the ELSO registry, including both adult and pediatric patients [6]. Similarly, the largest report to date 
on MCS use after cardiac surgery demonstrated a steadily increasing trend in non-intra-aortic balloon pump mechanical circulatory support use. However, the mortality rates were higher in recent years [4]. According to Flecher et al, [25] who included post-cardiotomy patients in their analysis, worse outcomes among postcardiotomy ECMO patients was clearly demonstrated. Although this may be due, at least in part, to more widespread application of this technology to higher risk patients, this underlines the high complexity of PCSECMO patients.

\section{Change in mortality}

Our study demonstrates a trend toward an increasing number of ECMO procedures in recent years (coef.: 0.009; $p<0.001$ ), yet no signs of increased mortality rates over time (coef.: $-8.775 ; p=0.682$ ) were observed when looking only at the adult population. In the largest study to date assessing in-hospital and long-term survival after ECMO for PCS [14], overall successful weaning from ECMO was possible for $63.3 \%$ of the patients, but more than $50 \%$ of the weaned patients died during their hospital stay, with in-hospital survival was therefore limited to $25 \%$. This findings was comparable to results of smaller series of patients with PCS undergoing ECMO for which early survival rates of between $16 \%$ and $41 \%$ have been reported $[26,27]$. In line with previous reports, in the current analysis, overall successful ECMO weaning was possible in 4,520 cases $(56.1 \%)$, yet survival to hospital discharge was achieved in $41.4 \%$ of cases. The trend suggesting overall unchanging mortality over time might be surprising in the face of improvements in intensive care unit management, more advanced ECMO circuit components and novel technologies, as well as increased experience. On the other hand, these improvements may not directly translate to mortality reduction if they are being offset by the application of V-A ECMO for PCS in older and sicker patients. This hypothesis is supported by our finding that nearly two-thirds of patients included in the ELSO registry could be successfully weaned from ECMO despite increases in risk scores, patient age, and the complexity of the cardiac procedures.

\section{Change in survival prediction}


Prediction of post-cardiotomy ECMO weaning and survival has been addressed by numerous investigators [1,2,24-27]. Pre-implantation and intra-operative factors, as well as post-ECMO events and the patient's physiologic response to circulatory support, all play a critical role. Among pre-ECMO factors, ECPR, that is, ECMO institution during a cardiac arrest, was a strong negative predictor in several series [28-33]. Nevertheless, some investigators found that neither the occurrence of cardiopulmonary resuscitation nor the time spent in resuscitation had a significant effect on survival. The current analysis, which employed logistic regression to search for mortality predictors, demonstrated that age, duration of support, $\mathrm{pH}$, and ventilation parameters, were all significantly associated with poor prognosis. Additionally, so were malignant arrhythmias, cardiac tamponade, disseminated intravascular coagulation, gastrointestinal bleeding, hemolysis and surgical complications. The impact of patient age on survival requires a distinct discussion in the context of post-cardiotomy ECMO, as many patients eligible for such support are elderly. Narotsky et al. [34], in an analysis of patients older than 65, all with refractory cardiopulmonary failure supported by ECMO, found survival to discharge and at one year, to be $30 \%$. When the analysis was adjusted for confounders, however, age turned out not to be statistically significant as a predictor for in-hospital death, although a trend for increased risk was present. In this analysis of the ELSO registry, of 1,416 patients over age $70,68.3 \%$ (967) did not survive to discharge $(p<0.001)$.

\section{Benefits of peripheral access}

Interestingly, the current report is the first to demonstrate the protective effect of peripheral cannulation for ECMO on survival. Patients undergoing ECMO for PCS had over $25 \%$ higher odds of survival compared to their centrally cannulated counterparts. This finding is partially in accordance with one recent meta-analysis [20] that analyzed 1,691 patients for direct comparison of peripheral and central cannulation in PCS and non-PCS patients. While all-cause mortality was unaltered with either technique, the risk of serious complications, that is bleeding, continuous veno-venous hemofiltration, and blood product transfusion, was significantly lower with the peripheral cannulation strategy. With a nearly five-fold higher number of patients in the current single report and focusing exclusively on PCS, the finding of significantly lower mortality rates with peripheral cannulation appears to be a robust finding. 


\section{Limitations}

We analysed data from the ELSO Registry, an international collaboration with more than 400 contributing centers. The size of the dataset and inclusion of all PCS-ECMO criteria support the concept that generalizable conclusions may be inferred. The current analysis is, however, limited by the inherent shortcomings of registry data. Gathered data are of retrospective nature; selection criteria, V-A ECMO protocols, patient management and also skills, education and centers' ECMO experience and volume could not be accounted for in the analysis. The registry collects in-hospital data only, therefore long-term follow-up data and in particular survival and neurological sequelae were not available. The registry does not collect data on surgical and procedural characteristics other than the type of surgery. Whether the surgery was elective or emergent, the duration of cross-clamp and cardiopulmonary bypass, episodes of hypotension or arrhythmias during the surgery, could all impact the postoperative course. Finally, the current ELSO definitions were implemented recently and older data did not adhere to strict data definitions. Since mechanical circulatory support was earlier demonstrated to reduce the mortality rates in PCS to $50 \%$ (58.6\% in the current series), equipoise to conduct a randomized trial in this setting would be lacking. In absence of randomized evidence, the current analysis represents the largest to date for heart surgery patients requiring postoperative V-A ECMO.

\section{Conclusions}

Analysis of patients managed on V-A ECMO for PCS reported to the ELSO registry demonstrated significantly increased use from 1995 through 2018. Mortality rates remained relatively constant over time despite a decrease in complications, in the setting of supporting older, higher risk patients. Further studies are needed to elucidate factors that might optimize patient selection and improve the outcomes of this very complex cohort of ECMO patients. 


\section{References}

1. Abrams D, Combes A, Brodie D. Extracorporeal membrane oxygenation in cardiopulmonary disease in adults. J Am Coll Cardiol. 2014;63:2769-2778

2. Lorusso R, Raffa GM, Alenizy K, Sluijpers N, Makhoul M, Brodie D, McMullan M, Wang IW, Meani P, MacLaren G, Kowalewski M, Dalton H, Barbaro R, Hou X, Cavarocchi N, Chen YS, Thiagarajan R, Alexander P, Alsoufi B, Bermudez CA, Shah AS, Haft J, D'Alessandro DA, Boeken U, Whitman GJR. Structured review of post-cardiotomy extracorporeal membrane oxygenation: Part 1-adult patients. J Heart Lung Transplant. 2019;38:1125-1143

3. Vallabhajosyula S, Arora S, Sakhuja A, Lahewala S, Kumar V, Shantha GPS, Egbe AC, Stulak JM, Gersh BJ, Gulati R, Rihal CS, Prasad A, Deshmukh AJ. Trends, predictors, and outcomes of temporary mechanical circulatory support for postcardiac surgery cardiogenic shock. Am J Cardiol. 2019;123:489497

4. Stretch R, Sauer CM, Yuh DD, Bonde P. National trends in the utilization of short-term mechanical circulatory support: incidence, outcomes, and cost analysis. J Am Coll Cardiol. 2014;64:1407-15.

5. Thiagarajan RR, Barbaro RP, Rycus PT, McMullan DM, Conrad SA, Fortenberry JD, Paden ML, centers Em. Extracorporeal life support organization registry international report 2016. ASAIO J. 2017;63:60-67

6. Nasr VG, Raman L, Barbaro RP, Guner Y, Tonna J, Ramanathan K, Pappalardo F, Thiagarajan RR, Alexander PMA, Committee ERSO. Highlights from the extracorporeal life support organization registry: 2006-2017. ASAIO J. 2019;65:537-544

7. Lorusso R, Vizzardi E, Johnson DM, Mariscalco G, Sciatti E, Maessen J, Bidar E, Gelsomino S. Cardiac surgery in adult patients with remitted or active malignancies: A review of preoperative screening, surgical management and short- and long-term postoperative results. Eur $\mathrm{J}$ Cardiothorac Surg. 2018;54:10-18

8. Lorusso R, Gelsomino S, Parise O, Mendiratta P, Prodhan P, Rycus P, MacLaren G, Brogan TV, Chen YS, Maessen J, Hou X, Thiagarajan RR. Venoarterial extracorporeal membrane oxygenation for 
refractory cardiogenic shock in the elderly patients: Trends in application and outcome from the extracorporeal life support organization (elso) registry. Ann Thorac Surg. 2017;104:62-69

9. Storey JD. A direct approach to false discovery rates. J R Stat Soc Ser B. 2002;64:479-498.

10. McCarthy FH, McDermott KM, Kini V, Gutsche JT, Wald JW, Xie D, Szeto WY, Bermudez CA, Atluri P, Acker MA, Desai ND. Trends in u.S. Extracorporeal membrane oxygenation use and outcomes: 20022012. Semin Thorac Cardiovasc Surg. 2015;27:81-88

11. Ibanez B, James S, Agewall S, Antunes MJ, Bucciarelli-Ducci C, Bueno H, Caforio ALP, Crea F, Goudevenos JA, Halvorsen S, Hindricks G, Kastrati A, Lenzen MJ, Prescott E, Roffi M, Valgimigli M, Varenhorst C, Vranckx P, Widimsky P, Group ESCSD. 2017 esc guidelines for the management of acute myocardial infarction in patients presenting with st-segment elevation: The task force for the management of acute myocardial infarction in patients presenting with st-segment elevation of the european society of cardiology (esc). Eur Heart J. 2018;39:119-177

12. Hernandez AF, Grab JD, Gammie JS, O'Brien SM, Hammill BG, Rogers JG, Camacho MT, Dullum MK, Ferguson TB, Peterson ED. A decade of short-term outcomes in post cardiac surgery ventricular assist device implantation: Data from the society of thoracic surgeons' national cardiac database. Circulation. 2007; $116: 606-612$

13. Whitman GJ. Extracorporeal membrane oxygenation for the treatment of postcardiotomy shock. $J$ Thorac Cardiovasc Surg. 2017;153:95-101

14. Rastan AJ, Dege A, Mohr M, Doll N, Falk V, Walther T, Mohr FW. Early and late outcomes of 517 consecutive adult patients treated with extracorporeal membrane oxygenation for refractory postcardiotomy cardiogenic shock. J Thorac Cardiovasc Surg. 2010;139:302-311, 311 e301

15. Ranney DN, Benrashid E, Meza JM, Keenan JE, Bonadonna DK, Bartz R, Milano CA, Hartwig MG, Haney JC, Schroder JN, Daneshmand MA. Central cannulation as a viable alternative to peripheral cannulation in extracorporeal membrane oxygenation. Semin Thorac Cardiovasc Surg. 2017;29:188195 
16. Kowalewski M, Raffa G, Zielinski K, Meani P, Alanazi M, Gilbers M, Heuts S, Natour E, Bidar E, Schreurs R, Delnoij T, Driessen R, Sels JW, van de Poll M, Roekaerts P, Maessen J, Suwalski P, Lorusso R. Baseline surgical status and short-term mortality after extracorporeal membrane oxygenation for postcardiotomy shock: A meta-analysis. Perfusion. 2019:267659119865122

17. Meani P, Matteucci M, Jiritano F, Fina D, Panzeri F, Raffa GM, Kowalewski M, Morici N, Viola G, Sacco A, Oliva F, Alyousif A, Heuts S, Gilbers M, Schreurs R, Maessen J, Lorusso R. Long-term survival and major outcomes in post-cardiotomy extracorporeal membrane oxygenation for adult patients in cardiogenic shock. Ann Cardiothorac Surg. 2019;8:116-122

18. Lo Coco V, Lorusso R, Raffa GM, Malvindi PG, Pilato M, Martucci G, Arcadipane A, Zielinski K, Suwalski $\mathrm{P}$, Kowalewski M. Clinical complications during veno-arterial extracorporeal membrane oxigenation in post-cardiotomy and non post-cardiotomy shock: Still the achille's heel. J Thorac Dis. 2018;10:69937004

19. Raffa GM, Kowalewski M, Meani P, Follis F, Martucci G, Arcadipane A, Pilato M, Maessen J, Lorusso R, Group EiTI. In-hospital outcomes after emergency or prophylactic veno-arterial extracorporeal membrane oxygenation during transcatheter aortic valve implantation: A comprehensive review of the literature. Perfusion. 2019;34:354-363

20. Raffa GM, Kowalewski M, Brodie D, Ogino M, Whitman G, Meani P, Pilato M, Arcadipane A, Delnoij T, Natour E, Gelsomino S, Maessen J, Lorusso R. Meta-analysis of peripheral or central extracorporeal membrane oxygenation in postcardiotomy and non-postcardiotomy shock. Ann Thorac Surg. $2019 ; 107: 311-321$

21. Raffa GM, Gelsomino S, Sluijpers N, Meani P, Alenizy K, Natour E, Bidar E, Johnson DM, Makhoul M, Heuts S, Lozekoot P, Kats S, Schreurs R, Delnoij T, Montalti A, Sels JW, Poll MV, Roekaerts P, Maessen J, Lorusso R. In-hospital outcome of post-cardiotomy extracorporeal life support in adult patients: The 2007-2017 maastricht experience. Crit Care Resusc. 2017;19:53-61

22. Lawler PR, Silver DA, Scirica BM, Couper GS, Weinhouse GL, Camp PC, Jr. Extracorporeal membrane oxygenation in adults with cardiogenic shock. Circulation. 2015;131:676-680 
23. Wu MY, Lin PJ, Lee MY, Tsai FC, Chu JJ, Chang YS, Haung YK, Liu KS. Using extracorporeal life support to resuscitate adult postcardiotomy cardiogenic shock: Treatment strategies and predictors of short-term and midterm survival. Resuscitation. 2010;81:1111-1116

24. Smith M, Vukomanovic A, Brodie D, Thiagarajan R, Rycus P, Buscher H. Duration of veno-arterial extracorporeal life support (VA ECMO) and outcome: an analysis of the Extracorporeal Life Support Organization (ELSO) registry. Crit Care. 2017;21:45.

25. Flecher E, Anselmi A, Corbineau H, Langanay T, Verhoye JP, Felix C, Leurent G, Le Tulzo Y, Malledant $\mathrm{Y}$, Leguerrier A. Current aspects of extracorporeal membrane oxygenation in a tertiary referral centre: Determinants of survival at follow-up. Eur J Cardiothorac Surg. 2014;46:665-671; discussion 671

26. Smith C, Bellomo R, Raman JS, Matalanis G, Rosalion A, Buckmaster J, Hart G, Silvester W, Gutteridge GA, Smith B, Doolan L, Buxton BF. An extracorporeal membrane oxygenation-based approach to cardiogenic shock in an older population. Ann Thorac Surg. 2001;71:1421-1427

27. Fiser SM, Tribble CG, Kaza AK, Long SM, Zacour RK, Kern JA, Kron IL. When to discontinue extracorporeal membrane oxygenation for postcardiotomy support. Ann Thorac Surg. 2001;71:210-4.

28. Pontailler M, Demondion P, Lebreton G, Golmard JL, Leprince P. Experience with Extracorporeal Life Support for Cardiogenic Shock in the Older Population more than 70 Years of Age. ASAIO J. 2017;63:279-284.

29. Sertic F, Diagne D, Rame E, Wald J, Richards T, Chavez L, Na S, Jason H, Patrick W, Habertheuer A, Gutsche J, Vallabhajosyula P, Desai N, Atluri P, Acker MA, Bermudez C. Short-term outcomes and predictors of in-hospital mortality with the use of veno-arterial extracorporeal membrane oxygenation in the elderly patients with refractory cardiogenic shock. J Cardiovasc Surg (Torino). 2019;60:636-638

30. Mendiratta P, Tang X, Collins RT 2nd, Rycus P, Brogan TV, Prodhan P. Extracorporeal membrane oxygenation for respiratory failure in the elderly: a review of the Extracorporeal Life Support Organization registry. ASAIO J. 2014;60:385-90.

31. Biancari F, Saeed D, Fiore A, Dalen M, Ruggieri VG, Jonsson K, Gatti G, Zipfel S, Dell'Aquila AM, Chocron S, Bounader K, Amr G, Settembre N, Palve K, Loforte A, Gabrielli M, Livi U, Lechiancole A, 
Pol M, Netuka I, Spadaccio C, Pettinari M, De Keyzer D, Reichart D, Ragnarsson S, Alkhamees K, Lichtenberg A, Fux T, El Dean Z, Fiorentino M, Mariscalco G, Jeppsson A, Welp H, Perrotti A. Postcardiotomy venoarterial extracorporeal membrane oxygenation in patients aged 70 years or older. Ann Thorac Surg. 2019;108:1257-1264

32. Saxena P, Neal J, Joyce LD, Greason KL, Schaff HV, Guru P, Shi WY, Burkhart H, Li Z, Oliver WC, Pike RB, Haile DT, Schears GJ. Extracorporeal membrane oxygenation support in postcardiotomy elderly patients: The mayo clinic experience. Ann Thorac Surg. 2015;99:2053-2060

33. Lee SN, Jo MS, Yoo KD. Impact of age on extracorporeal membrane oxygenation survival of patients with cardiac failure. Clin Interv Aging. 2017;12:1347-1353.

34. Narotsky DL, Mosca MS, Mochari-Greenberger H, Beck J, Liao M, Mongero L, Bacchetta M. Short-term and longer-term survival after veno-arterial extracorporeal membrane oxygenation in an adult patient population: Does older age matter? Perfusion. 2016;31:366-375 


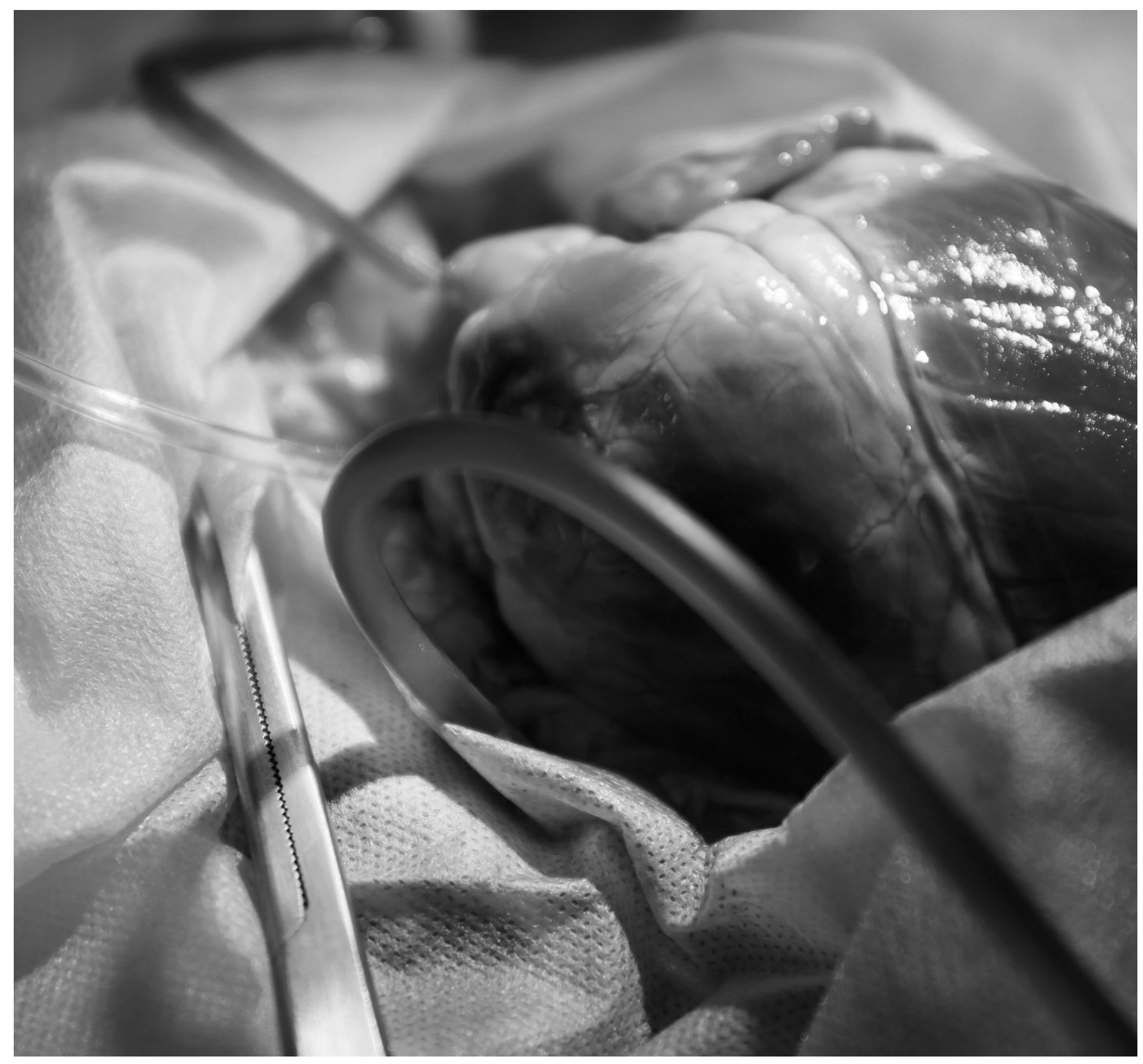


CHAPTER 6

THE IMPACT OF CENTRE'S HEART TRANSPLANT STATUS AND VOLUME ON IN-HOSPITAL OUTCOMES FOLLOWING EXTRACORPOREAL MEMBRANE OXYGENATION FOR REFRACTORY POST-CARDIOTOMY CARDIOGENIC SHOCK: A META-ANALYSIS

Kowalewski M, Raffa GM, Zieliński K, Pilato M, Alanazi M, Gilbers M, Heuts S, Natour E, Bidar E, Schreurs R, Delnoij T, Driessen R, Sels JW, van de Poll M, Roekaerts P, Meani P, Suwalski P, Lorusso R.

BMC Cardiovasc Disord. 2020;20:10

Presented as a poster at EuroELSO Conference in Prague 23-26 May 2018; EuroELSO 2018 Abstracts.

(2018). Perfusion, 33(1_suppl), 87-220.doi:10.1177/0267659118767502 
Background: Postcardiotomy cardiogenic shock (PCS) that is refractory to inotropic support remains a major concern in cardiac surgery and is almost universally fatal unless treated with mechanical support. While reported mortality rates on ECMO vary from center to center, aim of the current report is assess if the outcomes differ between centres according to volume and heart transplantation status.

Methods: A systematic search was performed according to PRISMA statement using PubMed/Medline databases between 2010 and 2018. Relevant articles were scrutinized and included in the meta-analysis only if reporting in-hospital/30-day mortality and heart transplantation status of the centre. Paediatric and congenital heart surgery-related studies along with those conducted in the setting of veno-venous ECMO for respiratory distress syndrome were excluded. Differences were assessed by means of subgroup meta-analysis and metaregression.

Results: Fifty-four studies enrolling N=4,421 ECMO patients were included. Of those, 6 series were performed in non-HTx centres (204 pts;4.6\%). Overall 30-day survival (95\% Confidence Intervals) was 35.3\% (32.5-38.2\%) and did not statistically differ between non-HTx: 33.3\% (26.8-40.4\%) and HTx centres: $35.7 \%$ (32.7-38.8\%); $P_{\text {interaction }}=0.531$. There was no impact of centre volume on survival as well: $\beta_{\text {coef }}=0.0006 ; P=0.833$. No statistical differences were seen between HTx and non-HTx with respect to ECMO duration, limb complications, reoperations for bleeding, kidney injury and sepsis. There were however significantly less neurological complications in the HTx as compared to non-HTx centres: $11.9 \%$ vs $19.5 \%$ respectively; $\mathrm{P}=0.009$; an inverse relationship was seen for neurologic complications in centres performing more ECMOs annually $ß_{\text {coef }}=-0.0066$; $P=0.031$. Weaning rates and bridging to $H T x$ and/or VADs were higher in HTx facilities.

Conclusions: There was no apparent difference in survival after ECMO implantation for refractory PCS according to centre's ECMO volume and transplantation status. Potentially different risk profiles of patients in these centres must be taken account for before definite conclusions are drawn. 


\section{Background}

Extracorporeal Membrane Oxygenation (ECMO) use is increasing; yet, it still does represent a resourceconsuming modality of treatment and, in majority of cases, is seen as a last resort for patients who, otherwise, would inevitably die [1-5]. Postcardiotomy- and ST-elevation myocardial infarction (MI) complicating- cardiogenic shock (CS) were two most frequent indications for VA-ECMO implantation in the United States until 2011 [3-5]. Despite growing worldwide utilization and experience in mechanical circulatory support (MCS), in particular, inhospital outcomes while on ECMO have not shown substantial progress [6]. While little is still known on who benefits most from ECMO support which is a long and advanced therapy [7], European Society of Cardiology guidelines cautiously assigned ECMO class of recommendation Ilb, level of evidence $\mathrm{C}$ for the management of cardiogenic shock in STEMI [8].

Unlike STEMIs, cardiac surgical patients are usually characterized by substantial pre-ECMO comorbidities and more advanced age [9]. All these factors, individually or in association, may inhibit the potential of myocardium to recover after the surgery and/or hamper favorable body response to prolonged MCS. Indeed, in some patients, prolonged MCS does not lead to improved cardiac function or organ integrity; clinicians are therefore forced to bridge the patient; since bridge to recovery is no longer an option, more advanced treatments, such as heart transplantation (HTx) or long-lasting ventricular assist devices (VADs) remain. Not all heart surgery centres perform HTx, and not all of them perform VADs.

We therefore, undertook systematic review and meta-analysis to assess to which extent do the in-hospital outcomes differ across PCS-ECMO recipients in heart transplantation- as compared to non-transplant units to which could be attributed to readability of ECMO teams and potentially shorter bridging times in HTX/VAD units. To assess the impact of possible differences in experience between centres, we analyzed how the in-hospital outcomes are affected by centre's volume and annual ECMO institution rates.

\section{Methods}

\section{Data sources and search strategy}


This systematic review and meta-analysis was performed in accordance with the Preferred Reporting Items for Systematic Reviews and meta-analyses (PRISMA) statement [10]. The PRISMA checklist is available as Appendix. To best reflect current clinical practice, relevant studies to be included were searched for between year 2000 until March 31st 2018, through PubMed, EMBASE, CINAHL, the Web of Science, the Cochrane Register of Controlled Clinical Trials (CENTRAL) and Google Scholar. Abstracts were eligible for detailed assessment if available online and reporting outcomes of interest. The search term was: "extracorporeal membrane oxygenation" and "extracorporeal life support". No language restrictions were imposed. References of original articles were reviewed manually and cross-checked for other relevant reports.

\section{Selection criteria and quality assessment}

Studies were included if they met all of the following criteria: 1) human study; 2) studies assessing survival after ECMO instituted for postcardiotomy refractory cardiogenic shock; 3) study reporting institutional outcomes that for ECMO indication combined postcardiotomy and non-postcardiotomy cardiogenic shock but reporting outcomes of interest separately for the groups. Studies were excluded if: 1) paediatric and congenital heart surgery-related studies; 2) animal studies; 3) conducted in the setting of veno-venous ECMO for respiratory distress syndrome; and 4) studies not reporting survival/mortality rates. Studies were only eligible if reporting the transplant status of the centre; whenever this was not retrievable from the individual study, institutional website was searched for information regarding range of procedures performed. Lack of clear indication whether the centre performs heart transplantation led to exclusion of the study. Similarly, registries incorporating multiple centres but not reporting the status for single facilities were not considered. Reviews and case reports were not considered.

Two independent reviewers (P.M. and K.Z.) selected the studies for inclusion, extracted studies, as well as patient characteristics of interest and relevant outcomes. Two authors (P.M. and K.Z.) independently assessed the trials' eligibility and risk of bias. Risk of bias at the individual study level was assessed using the ROBINS-I tool (Risk of Bias in Not-randomized Studies-of Interventions) [11]. Any divergences were resolved by a third reviewer (R.L.) and quantified using the approach of Cohen's kappa [12]. 


\section{Endpoint selection}

The primary endpoint was in-hospital survival. Secondary endpoints were in-hospital cerebrovascular events (CVE), limb complications, bleeding or reoperation for bleeding, sepsis and acute kidney failure with or without continuous veno-venous hemofiltration (CVVH). Bridging to VAD and/or HTx was analysed as well. Outcome definitions were the ones adopted by the investigators of the included studies.

\section{Statistical analysis}

Statistical analyses were performed in Comprehensive Meta-Analysis, v. 2 (Biostat,

Englewood, NJ). The results are expressed as pooled untransformed proportions (e.g. event rates (\%) and means with their $95 \%$ confidence intervals $(\mathrm{Cl})$. Heterogeneity across studies was evaluated using the $\mathrm{I}^{2}$ test. Where available, we digitised Kaplan-Meier curves using Engauge Digitizer 9.5 (Mark Mitchell, Torrance, CA) and reconstructed time-to-event data using the algorithm specified by Guyot et al. [13]. To control for the anticipated heterogeneity among observational studies, absolute values and means were pooled using random effects models. Studies were stratified a priori based on the centre status (HTx vs non-HTx performing centre); the interaction coefficient (Q-value) is provided for the comparison HTx vs non-HTx along with respective

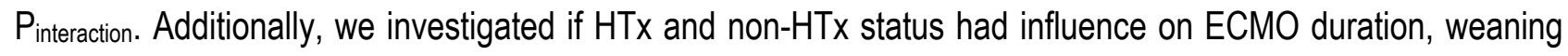
rates, bridging to HTX/VAD rates; and further if ECMO duration and weaning rates in these centres correlated with bridging to HTx/VAD by means of meta-regression analyses [14]. Similarly meta-regression approach was used to determine whether annual ECMO institution rate for centre reporting such, affects the survival and remaining in-hospital outcomes. Annual ECMO institution rate was calculated by dividing number of study subjects by study duration period. Sensitivity analyses were performed by excluding from analyses single studies, one at a time, and repeating the calculations. Subgroup analyses were performed for survival endpoint by dividing the studies into distinctive strata (by mean and median annual ECMO institution rate as well as in tertiles and quartiles) and reporting respective $\mathrm{P}_{\text {interaction }}$ for between subgroup comparison. Publication bias was assessed 1) by visual approach plotting log event rate against standard error in the funnel plot; and 2) by linear regression approach [15]. 


\section{Results}

Initial search process yielded 22,609 records; of these, 183 abstracts were retrieved for scrutiny based on the item's title. Registries were excluded since they incorporated both HTx and non-HTx centres [16-18]. Following detailed assessment, 54 studies ( $\mathrm{N}=4,421$ patients) [list of references to included studies] met inclusion criteria and entered quantitative analyses. PRISMA flow chart is available as Figure 1.

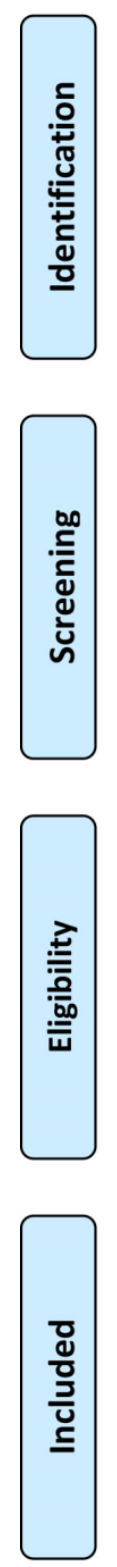

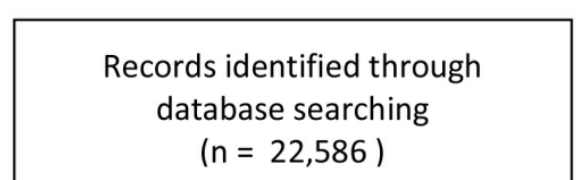

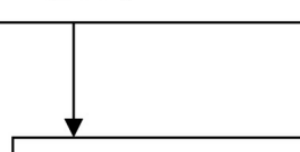

Records after duplicates removed ( $n=22,609$ )

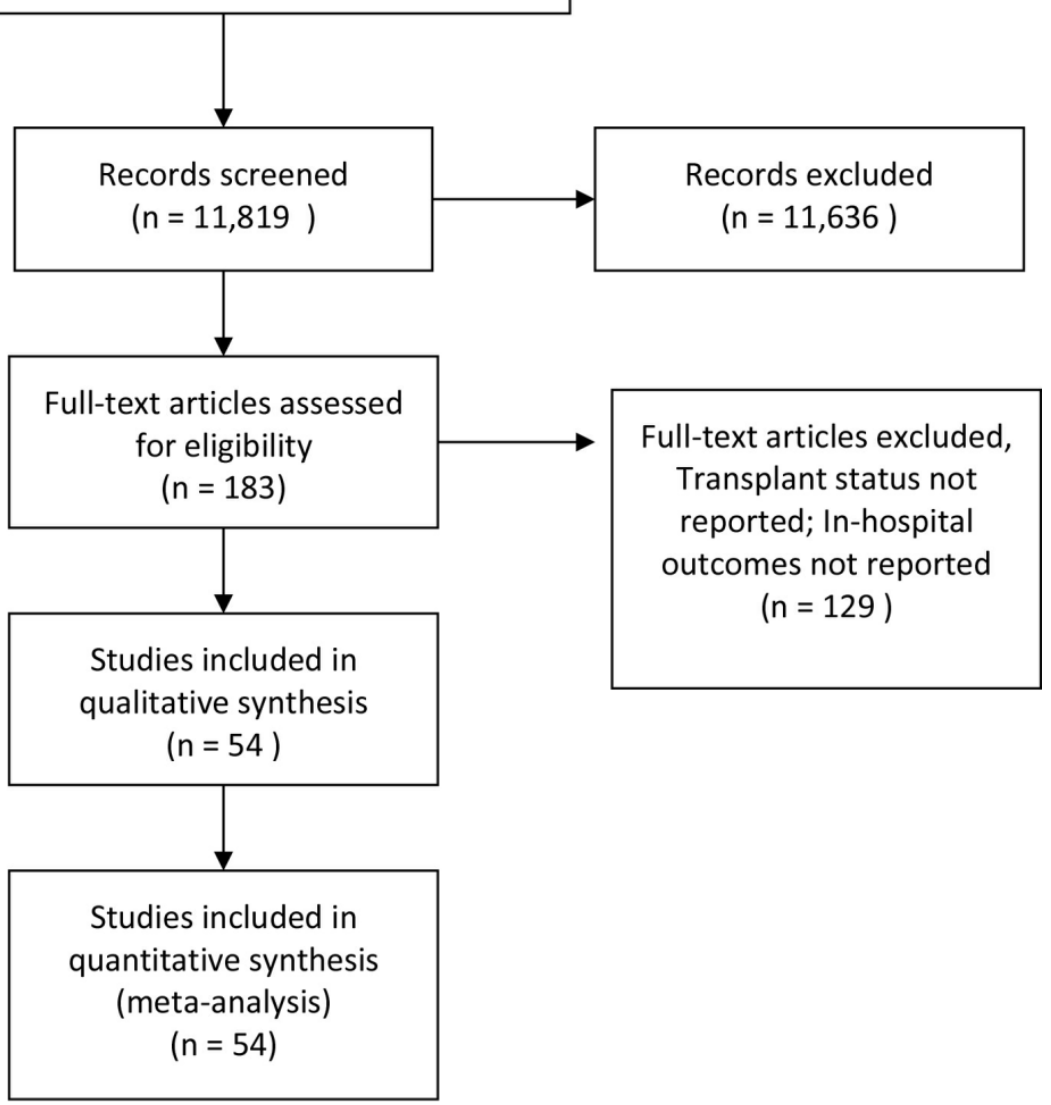

Figure 1. PRISMA Flow-chart.

Included studies were divided into HTx vs non-HTx centres subgroups: 48 studies including 4,217 (95.4\%) patients were conducted in $\mathrm{HTx}$ - whereas 6 studies $(\mathrm{N}=204)$ in non- $\mathrm{HTx}$ centres. Prevalence of ECMO ranged 
from $0.26 \%$ [70] to $3.35 \%$ [28]. Patients receiving ECMO at HTx centres were significantly younger than their non-HTx counterparts $57.2 \pm 1.6$ vs $64.2 \pm 1.6 \mathrm{P}<0.001$. CABG was most frequent procedure in both $\mathrm{HTx}$ and non-HTx centres $33.7 \%$ and $30.9 \%$ followed by valvular $(25.1 \%$ and $21.1 \%)$ and combined surgeries $(16.5 \%$ and $26.5 \%$ ). Detailed characteristics of included studies as well as patients' baseline and surgical data are available in Table 1. Publication bias analysis along with reasons for bias risk increase is available as Table 2; studies were judged to be moderate to severe risk of bias as none previously compared directly HTx vs nonHTx centre performance; no signs of asymmetry were seen on visual inspection of funnel plot for primary endpoint (Figure 2).

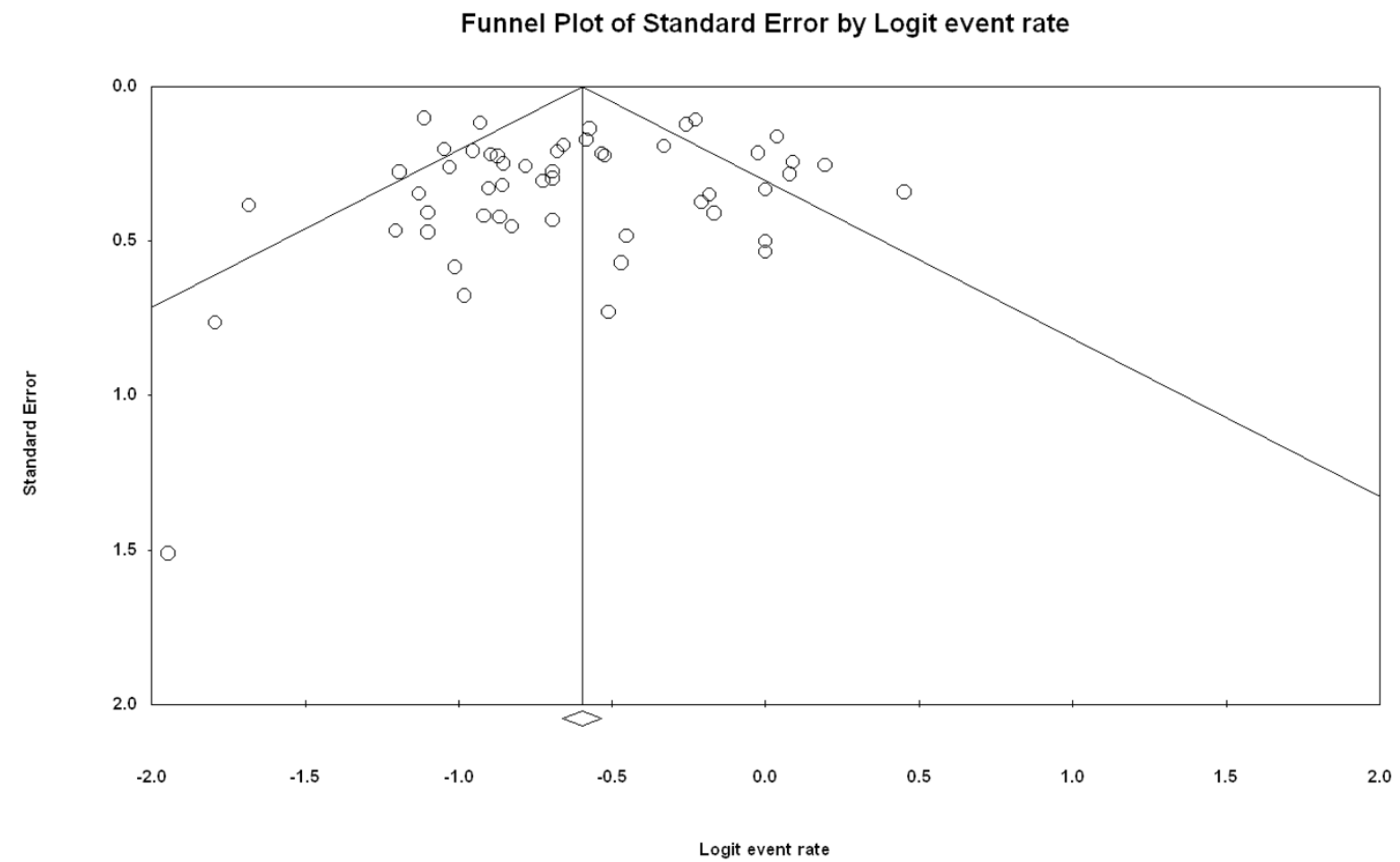

Figure 2. Funnel plot for publication bias analysis.

\section{ECMO strategy}

In the studies that reported procedural details, ECMO was established during the initial cardiac surgery in $42.7 \%$ of cases because of circulatory instability during or immediately after weaning from cardiopulmonary bypass. ECMO was initiated in the OR in $56.5 \%$ of patients $(50.1-62.7 \%)$, followed by ICU, cardiac catheterization laboratory, telemetry floor and emergency department. There was no significant difference in the rate of 
placement of ECMO in the OR in non-HTx - as compared to HTx centres with respective rates of $64.5 \%$ (52.9$74.6 \%$ ) vs $53.2 \%$ (45.6-60.7\%); $P=0.108$. Peripheral cannulation was preferred approach $(69.0 \%)$ for ECMO institution. Median ECMO duration in the entire series was 5 days (IQR: 3.3-6.0); without apparent differences between HTx (mean weighted average= 4.92 days) vs non-HTx- (5.04 days) centres. The details of procedural characteristics are available as Table 3. Successful weaning from ECMO was most often defined as decannulation after $>48$ hours. Overall, estimated $55.3 \%$ patients were weaned from ECMO with the weaning rates ranging from $31.4-100 \%$ in the entire series. No difference was noted regarding weaning rates between HTx vs non-HTx centres (56.6\% vs $50.4 \%$; $P=0.118)$.

\section{Survival and complications while on ECMO}

Reported causes of death were divided into "while on-ECMO" and "after weaning" and are available in Table 4. Fifty-three studies (4,367 patients) contributed to the analysis of survival: Overall, 1,527 patients survived to hospital discharge which translated to estimated overall survival of $35.3 \%$ (32.5-38.2\%). There was no difference between $\mathrm{HTx}-(35.7 \%$ [32.7-38.8\%]) and non-HTx centres $(33.3 \%$ [26.8-40.4\%]) $\mathrm{p}=0.531$ in random effects model. Figure 3. In meta-regression, there was no impact of centre volume on survival: $ß_{\text {coef }}=0.0006 ; P=0.833$ (Figure 4). Limb complications incidence was reported in 30 studies (2,766 pts). Overall, 424 patients (13.0\% [10.5-16.0\%]) had limb complications; Figure 5; in the analysis stratified by centre status there was no difference between HTx - (13.0\% [10.4-16.1\%] and non-HTx centres (13.35 [6.4-26.1\%] P=0.919). In meta-regression, there was no impact of centre volume on incidence of limb complications: $ß_{\text {coef }}=0.0043 ; P=0.342$ (Figure 6). There were significantly less neurological complications in the HTx as compared to non-HTx centres: overall 385 patients (33 studies) experienced neurological complications (14.1\% [11.8-16.8\%]) Figure 7; among those 88 brain deaths (7.9\% [5.6-11.0\%] occurred. Figure 8. Neurologic complications in non-HTx centres followed in $19.5 \%(14.5-25.8 \%)$ as compared to $11.9 \%(9.5-14.8 \%)$ in $\mathrm{HTx}$ centres; $\mathrm{P}=0.009$. In meta-regression, less neurologic complications and brain deaths were seen in centres with higher annual ECMO institution rate: $ß_{\text {coef }}=$ $-0.0066 ; P=0.031$ (Figure 9) and $\beta_{\text {coef }}=-0.0515 ; P=0.071$ (Figure 10) respectively for neurologic complications and brain deaths 
Table 1. Study characteristics.

\begin{tabular}{|c|c|c|c|c|c|c|c|c|c|c|c|c|c|c|}
\hline \multirow[t]{2}{*}{ Study } & \multirow{2}{*}{$\begin{array}{l}\text { Study } \\
\text { time } \\
\text { frames }\end{array}$} & \multirow{2}{*}{$\begin{array}{l}\text { Prevalence } \\
(\%)\end{array}$} & \multirow{2}{*}{$\begin{array}{l}\mathrm{N} . \\
\text { of } \\
\text { pts }\end{array}$} & \multirow{2}{*}{$\begin{array}{l}\text { Age } \\
\text { (years) }\end{array}$} & \multirow{2}{*}{$\begin{array}{l}\text { Male } \\
(\%)\end{array}$} & \multirow{2}{*}{$\begin{array}{l}\text { LVEF } \\
(\%)\end{array}$} & \multirow{2}{*}{$\begin{array}{l}\text { Baseline } \\
\mathrm{sCr} \\
(\mathrm{mg} / \mathrm{dL})\end{array}$} & \multirow{2}{*}{$\begin{array}{l}\text { Status elective/ } \\
\text { urgent/ } \\
\text { emergency/ } \\
\text { salvage }(\mathrm{n})\end{array}$} & \multicolumn{4}{|c|}{ Surgery $(\mathrm{n})$} & \multirow[b]{2}{*}{ CPB } & \multirow[b]{2}{*}{$\begin{array}{l}\text { X- } \\
\text { clamp }\end{array}$} \\
\hline & & & & & & & & & CABG & Valve & Combined & Other & & \\
\hline \multicolumn{15}{|l|}{ HTx/VAD centres } \\
\hline $\begin{array}{l}\text { Acheampong } \\
2016\end{array}$ & $\begin{array}{l}2001- \\
2013\end{array}$ & 1.06 & 24 & $\begin{array}{l}41 \text { (IQR: } \\
22-75)\end{array}$ & 58.3 & $\begin{array}{l}47 \\
(10- \\
66)\end{array}$ & NR & NR & 0 & 14 & 3 & 7 & NR & NR \\
\hline Bakhtiary 2008 & $\begin{array}{l}2003- \\
2006 \\
\end{array}$ & 0.78 & 45 & $60.1 \pm 13.6$ & 77.8 & $\begin{array}{l}25.8 \\
\pm 10 \\
\end{array}$ & NR & NR & 20 & 2 & 11 & 12 & NR & NR \\
\hline $\begin{array}{l}\text { Beckmann } \\
2017\end{array}$ & $\begin{array}{l}1997- \\
2011\end{array}$ & NR & 8 & $50.1 \pm 15.8$ & 62.5 & NR & NR & NR/NR/3/NR & 0 & 4 & 1 & 3 & NR & NR \\
\hline $\begin{array}{l}\text { Beiras- } \\
\text { Fernandez } \\
2011 \\
\end{array}$ & $\begin{array}{l}1996- \\
2006\end{array}$ & NR & 73 & $49.3 \pm 18.0$ & 64.4 & NR & $1.8 \pm 1.1$ & NR & 14 & 13 & 6 & 40 & 254.3 & 110.9 \\
\hline Biancari 2017 & $\begin{array}{l}2005- \\
2016\end{array}$ & 0.60 & 148 & $65.4 \pm 9.4$ & 78.4 & NR & NR & 19/34/80/15 & 148 & 0 & 0 & 0 & 146 & 68 \\
\hline Burrell 2015 & $\begin{array}{l}2007- \\
2013\end{array}$ & NR & 54 & $\begin{array}{l}48 \text { (IQR: } \\
34-58)\end{array}$ & 68.5 & NR & $\begin{array}{l}1.2(0.9- \\
1.6)\end{array}$ & NR & & & NR & & NR & NR \\
\hline Carroll 2015 & $\begin{array}{l}2009- \\
2014\end{array}$ & NR & 26 & $\begin{array}{l}56 \text { (IQR: } \\
41-65)^{*}\end{array}$ & $69.1^{*}$ & $\begin{array}{l}30 \\
(17- \\
57)^{*}\end{array}$ & $\mathrm{NR}$ & NR & & & NR & & NR & NR \\
\hline Chen 2011* & $\begin{array}{l}2002- \\
2008 \\
\end{array}$ & NR & 60 & $47 \pm 2$ & 60.8 & NR & $1.3 \pm 0.1$ & NR & & & NR & & NR & NR \\
\hline Combes 2008 & $\begin{array}{l}2003- \\
2006\end{array}$ & NR & 16 & $46 \pm 16^{*}$ & $56.8^{*}$ & NR & NR & NR & & & NR & & NR & NR \\
\hline $\begin{array}{l}\text { Distelmeier } \\
2016\end{array}$ & $\begin{array}{l}2003- \\
2014\end{array}$ & 3.35 & 354 & $\begin{array}{l}65 \text { (IQR: } \\
55-73)\end{array}$ & 68.6 & NR & $\begin{array}{l}1.3(1.1- \\
1.8)\end{array}$ & NR & 48 & 110 & 84 & 111 & NR & NR \\
\hline Doll 2003 & $\begin{array}{l}1997- \\
2000 \\
\end{array}$ & 1.20 & 95 & $59.8 \pm 13.3$ & 69.5 & $\begin{array}{l}46 \pm \\
17.4 \\
\end{array}$ & $\mathrm{NR}$ & $21 / 64 / 10 / 0$ & 63 & 18 & 8 & 6 & NR & NR \\
\hline $\begin{array}{l}\text { Elsharkawy } \\
2010\end{array}$ & $\begin{array}{l}1995- \\
2005 \\
\end{array}$ & 0.58 & 233 & NR & 67.4 & NR & NR & NR/NR/84/NR & & & NR & & NR & NR \\
\hline Fiser 2001 & $\begin{array}{l}1993- \\
2000 \\
\end{array}$ & 0.91 & 51 & $61.0 \pm 1.7$ & 56.9 & NR & NR & NR & 34 & 5 & 5 & 7 & 172.3 & 68.6 \\
\hline Guihaire 2017 & $\begin{array}{l}2005- \\
2014\end{array}$ & 0.70 & 92 & $64.5(18-83)$ & 59 & $\begin{array}{l}47.2 \\
\pm \\
17.4 \\
\end{array}$ & $\begin{array}{l}1.16 \pm \\
0.58\end{array}$ & NR/NR/33/NR & 12 & 64 & $31^{* *}$ & 16 & 173.3 & 109.5 \\
\hline
\end{tabular}




\begin{tabular}{|c|c|c|c|c|c|c|c|c|c|c|c|c|c|c|}
\hline Hsu 2009 & $\begin{array}{l}2002- \\
2006\end{array}$ & 2.89 & 51 & $63.0 \pm 15.7$ & 70.6 & $\begin{array}{l}40.1 \\
\pm \\
17.9\end{array}$ & NR & NR & 27 & 11 & 7 & 6 & 188 & 32 \\
\hline Kanji 2010* & $\begin{array}{l}2002- \\
2006\end{array}$ & NR & 50 & 49.36 & 72 & 23.0 & NR & NR & & & NR & & NR & NR \\
\hline Ko 2002 & $\begin{array}{l}\text { 1994- } \\
2000\end{array}$ & 2.61 & 76 & $56.8 \pm 15.9$ & 63.2 & NR & NR & NR & 37 & 14 & 6 & 19 & NR & NR \\
\hline Lamarche 2010 & $\begin{array}{l}2000- \\
2008\end{array}$ & 0.30 & 24 & $54.6 \pm 21$ & 63 & $\begin{array}{l}20 \pm \\
25\end{array}$ & NR & NR & & & NR & & NR & NR \\
\hline Li 2015 & $\begin{array}{l}2011- \\
2012 \\
\end{array}$ & 0.91 & 123 & $56.2 \pm 11.8$ & 65.9 & $\begin{array}{l}54.6 \\
\pm 13.6 \\
\end{array}$ & NR & NR & 44 & 40 & 15 & 24 & NR & NR \\
\hline Liden 2009 & $\begin{array}{l}2000- \\
2007\end{array}$ & NR & 33 & $52.4 \pm 12.7$ & 93.9 & NR & NR & NR & 10 & 0 & 0 & 23 & NR & NR \\
\hline Liu 2009 & $\begin{array}{l}2002- \\
2005\end{array}$ & 0.58 & 14 & $55.7 \pm 15.4$ & 50 & $\begin{array}{l}52.9 \\
\pm \\
21.4\end{array}$ & $1.3 \pm 1.1$ & NR & 1 & 7 & 2 & 4 & 247 & 132 \\
\hline Loforte 2014 & $\begin{array}{l}2006- \\
2012\end{array}$ & 1.27 & 155 & $\begin{array}{l}58.2(23- \\
84)^{*}\end{array}$ & $65.8^{*}$ & $\begin{array}{l}48.2 \\
(33- \\
75)^{*}\end{array}$ & NR & NR & 28 & 43 & 32 & 52 & 214.5 & NR \\
\hline Luo 2009 & $\begin{array}{l}2005- \\
2008\end{array}$ & NR & 36 & 49.7 & 72.2 & NR & NR & NR & 15 & 8 & 0 & 13 & NR & NR \\
\hline Mazzeffi 2016 & $\begin{array}{l}2010- \\
2015\end{array}$ & 0.42 & 23 & $57 \pm 15$ & 60.9 & $\begin{array}{l}50 \\
(40- \\
55) \\
\end{array}$ & $\begin{array}{l}1.2(0.9- \\
2.0)\end{array}$ & NR & 7 & 6 & 0 & 10 & 160 & NR \\
\hline Meyer 2009 & $\begin{array}{l}2007- \\
2007\end{array}$ & 1.23 & 18 & $50 \pm 15$ & 72.2 & $\mathrm{NR}$ & NR & NR & 5 & 2 & 0 & 10 & 237 & NR \\
\hline Musial 2017 & $\begin{array}{l}2009- \\
2016\end{array}$ & NR & 27 & $45 \pm 16$ & 70.4 & $\begin{array}{l}33.1 \\
\pm \\
22.3 \\
\end{array}$ & NR & NR & 0 & 16 & 0 & 11 & NR & NR \\
\hline $\begin{array}{l}\text { Papadopoulos } \\
2015\end{array}$ & $\begin{array}{l}2001- \\
2013 \\
\end{array}$ & NR & 360 & $62 \pm 17$ & 76.1 & 35 & NR & NR/NR/NR/50 & 114 & 89 & 85 & 72 & 160 & 71 \\
\hline Park 2014 & $\begin{array}{l}2005- \\
2012\end{array}$ & NR & 115 & $61.7 \pm 13.4$ & 48.7 & $\begin{array}{l}57.1 \\
\pm \\
14.3 \\
\end{array}$ & NR & NR & 25 & 31 & 33 & 26 & 232.4 & 104.7 \\
\hline Peigh 2015 & $\begin{array}{l}2010- \\
2014 \\
\end{array}$ & NR & 13 & $48 \pm 14^{*}$ & $64.4^{*}$ & NR & $\begin{array}{l}1.5 \pm \\
0.8^{*}\end{array}$ & NR & & & NR & & NR & NR \\
\hline Pokersnik 2012 & $\begin{array}{l}2005- \\
2010\end{array}$ & NR & 49 & $65 \pm 13$ & 67.3 & NR & NR & NR/NR/0/0 & & & NR & & 239 & 110 \\
\hline
\end{tabular}




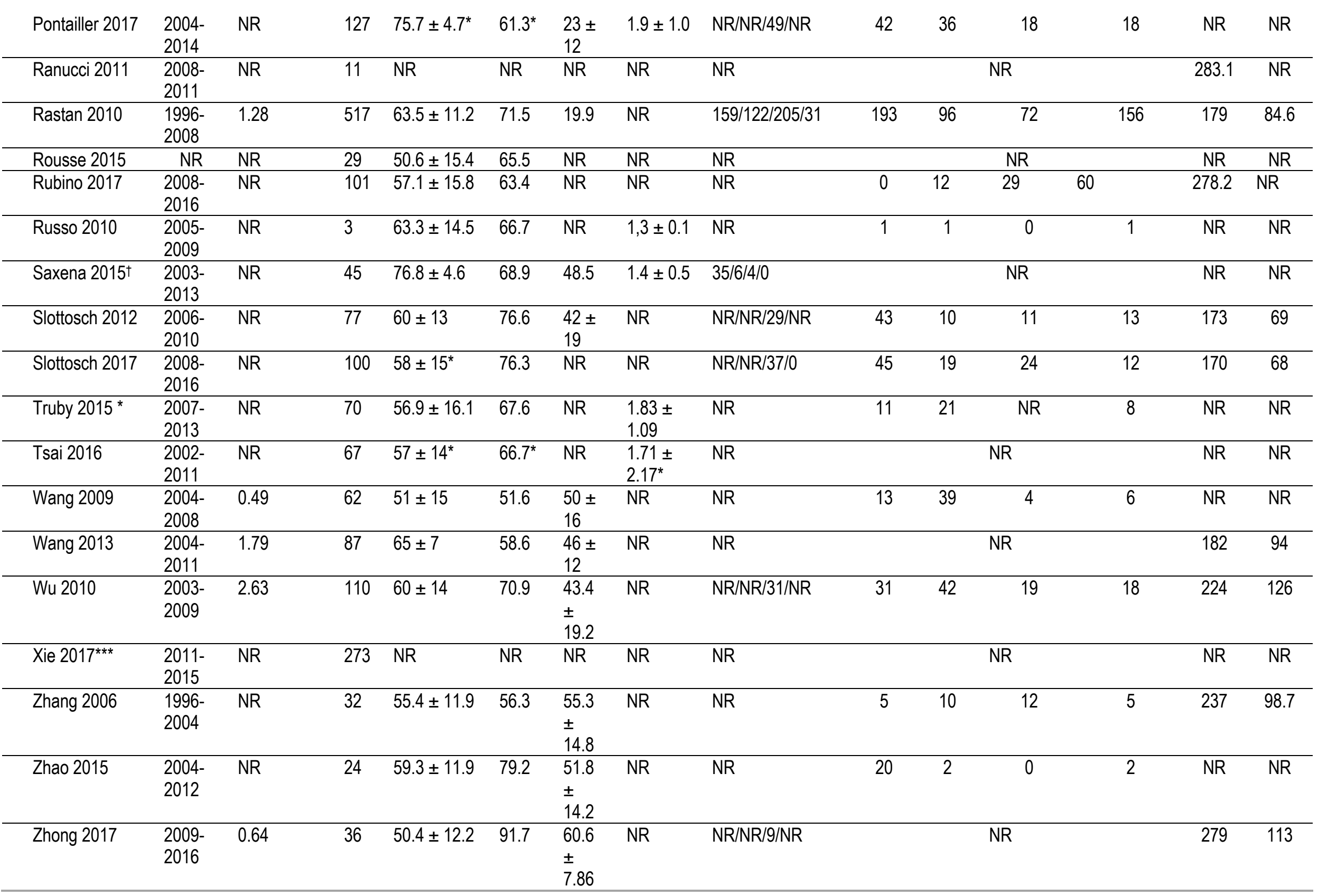


Non-HTx/VAD centres

\begin{tabular}{|c|c|c|c|c|c|c|c|c|c|c|c|c|c|c|}
\hline $\begin{array}{l}\text { Ariyaratnam } \\
2014\end{array}$ & $\begin{array}{l}2003- \\
2013\end{array}$ & NR & 14 & $65.6 \pm 10.5$ & 57.1 & NR & NR & NR & 0 & 0 & 11 & 3 & 205.6 & 109.6 \\
\hline Deschka 2013 & $\begin{array}{l}2008- \\
2011\end{array}$ & NR & 28 & $66.6 \pm 5.3$ & 92.9 & $\begin{array}{l}37.2 \\
\pm \\
13.0\end{array}$ & NR & NR & 17 & 11 & 0 & 0 & NR & NR \\
\hline Khorsandi 2016 & $\begin{array}{l}1995- \\
2015\end{array}$ & NR & 15 & $64.3 \pm 14.5$ & 73.3 & NR & NR & $9 / 3 / 4 / 0$ & 3 & 4 & 5 & 3 & NR & NR \\
\hline Mikus 2013 & $\begin{array}{l}2007- \\
2011\end{array}$ & 0.26 & 14 & $53.1 \pm 14.3$ & 64.3 & $\begin{array}{l}46.1 \\
\pm \\
13.9\end{array}$ & NR & $6 / 2 / 6 / 0$ & 5 & 6 & 3 & 0 & 240.5 & 98.4 \\
\hline Raffa 2017 & $\begin{array}{l}2007- \\
2017\end{array}$ & NR & 86 & $65 \pm 11.2$ & 65.1 & NR & NR & NR/NR/33/NR & 19 & 14 & 29 & 24 & 197 & 104 \\
\hline Unosawa 2012 & $\begin{array}{l}1992- \\
2007\end{array}$ & NR & 47 & $64.4 \pm 12.5$ & 74.4 & $\begin{array}{l}47.8 \\
\pm \\
19.1\end{array}$ & NR & NR/NR/22/NR & 19 & 8 & 6 & 14 & 217 & 81.2 \\
\hline
\end{tabular}

${ }^{\text {* }}$ Reported for entire study population including non-PCS patients

${ }^{* *}$ Multiple valve repair or valvular surgery combined with CABG; potential overlap.

${ }^{* * *}$ Article in Chinese - data from English abstract

†One patient had transfemoral transcatheter aortic valve replacement.

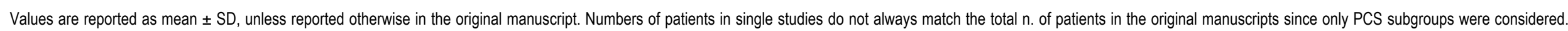
Slottosch 2012 and Slottosch 2017 are studies from the same group; first [Appendix reference 39] describes ECMO support after surgery for acquired heart disease from 2006 to 2010, the second [Appendix reference 40] reports all patients receiving

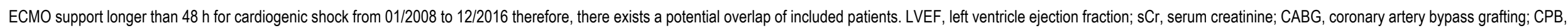
cardiopulmonary bypass; IQR, interquartile range; NR, not reported. 
Table 2. ROBINS-I tool bias assessment.

\begin{tabular}{|c|c|c|c|c|c|c|c|c|c|}
\hline Study & $\begin{array}{l}\text { Bias due } \\
\text { to } \\
\text { confoundi } \\
\text { ng }\end{array}$ & $\begin{array}{l}\text { Bias in } \\
\text { selection } \\
\text { of } \\
\text { participan } \\
\text { ts into the } \\
\text { study }\end{array}$ & $\begin{array}{l}\text { Bias in } \\
\text { measureme } \\
\text { nt of } \\
\text { intervention } \\
\mathrm{s}\end{array}$ & $\begin{array}{l}\text { Bias due to } \\
\text { departures } \\
\text { from } \\
\text { intended } \\
\text { interventio } \\
\text { ns }\end{array}$ & $\begin{array}{l}\text { Bias } \\
\text { due to } \\
\text { missing } \\
\text { data* }^{*}\end{array}$ & $\begin{array}{l}\text { Bias in } \\
\text { measureme } \\
\text { nt of } \\
\text { outcomes* }\end{array}$ & $\begin{array}{l}\text { Bias in } \\
\text { selectio } \\
n \text { of } \\
\text { reported } \\
\text { result* }^{*}\end{array}$ & $\begin{array}{l}\text { Overall } \\
\text { bias }\end{array}$ & $\begin{array}{l}\text { Cohen' } \\
\text { S } \\
\text { Kappa }\end{array}$ \\
\hline $\begin{array}{l}\text { Acheampong } \\
2016 \text { [19] }\end{array}$ & Critical & Critical & Serious & NA & Moderate & Moderate & Moderate & Moderate & 0.57 \\
\hline $\begin{array}{l}\text { Bakhtiary } \\
2008 \text { [20] }\end{array}$ & Critical & Low & Serious & NA & $\begin{array}{l}\text { Moderat } \\
\mathrm{e}\end{array}$ & Low & Low & Low & 0.71 \\
\hline $\begin{array}{l}\text { Beckmann } \\
2017 \text { [21] }\end{array}$ & Critical & Critical & Serious & NA & Low & Moderate & Moderate & Critical & 0.71 \\
\hline $\begin{array}{l}\text { Beiras- } \\
\text { Fernandez } \\
2011 \text { [22] }\end{array}$ & Critical & Low & Low & NA & Low & Critical & Critical & Critical & 0.71 \\
\hline $\begin{array}{l}\text { Biancari } \\
2017 \text { [23] }\end{array}$ & Critical & Low & Serious & NA & Low & Low & Low & Low & 0.86 \\
\hline $\begin{array}{l}\text { Burrell } \\
2015[24]\end{array}$ & Critical & Critical & Low & NA & $\begin{array}{l}\text { Moderat } \\
\mathrm{e}\end{array}$ & Moderate & $\begin{array}{l}\text { Moderat } \\
\mathrm{e}\end{array}$ & $\begin{array}{l}\text { Moderat } \\
\mathrm{e}\end{array}$ & 0.86 \\
\hline $\begin{array}{l}\text { Carroll } \\
2015 \text { [25] }\end{array}$ & Critical & Low & Moderate & NA & Serious & Critical & Serious & Critical & 0.57 \\
\hline $\begin{array}{l}\text { Chen } \\
2011 \text { [26] }\end{array}$ & Critical & Critical & Critical & NA & Serious & Critical & Critical & Critical & 0.86 \\
\hline $\begin{array}{l}\text { Combes } \\
2008 \text { [27] }\end{array}$ & Critical & Low & Low & NA & Serious & Critical & Critical & Critical & 0.86 \\
\hline $\begin{array}{l}\text { Distelmeier } \\
2016[28,29]\end{array}$ & Critical & Low & Low & NA & $\begin{array}{l}\text { Moderat } \\
\mathrm{e}\end{array}$ & Critical & Serious & Critical & 0.86 \\
\hline $\begin{array}{l}\text { Doll } \\
2003 \text { [30] }\end{array}$ & Critical & Low & Low & NA & $\begin{array}{l}\text { Moderat } \\
\mathrm{e}\end{array}$ & Low & Low & Low & 0.71 \\
\hline $\begin{array}{l}\text { Elsharkawy } \\
2010 \text { [31] } \\
\end{array}$ & Critical & Low & Low & NA & Low & Moderate & $\begin{array}{l}\text { Moderat } \\
\mathrm{e}\end{array}$ & Low & 0.71 \\
\hline $\begin{array}{l}\text { Fiser } \\
2001 \text { [32] }\end{array}$ & Critical & Low & Critical & NA & $\begin{array}{l}\text { Moderat } \\
\mathrm{e}\end{array}$ & Moderate & $\begin{array}{l}\text { Moderat } \\
\mathrm{e}\end{array}$ & $\begin{array}{l}\text { Moderat } \\
\mathrm{e}\end{array}$ & 0.86 \\
\hline $\begin{array}{l}\text { Guihaire } \\
2017 \text { [33] }\end{array}$ & Critical & Serious & Low & NA & Low & Moderate & $\begin{array}{l}\text { Moderat } \\
\mathrm{e}\end{array}$ & $\begin{array}{l}\text { Moderat } \\
\mathrm{e}\end{array}$ & 0.86 \\
\hline $\begin{array}{l}\text { Hsu } \\
2009 \text { [34] }\end{array}$ & Critical & Low & Low & NA & $\begin{array}{l}\text { Moderat } \\
\mathrm{e}\end{array}$ & Moderate & $\begin{array}{l}\text { Moderat } \\
\mathrm{e}\end{array}$ & $\begin{array}{l}\text { Moderat } \\
\mathrm{e}\end{array}$ & 0.86 \\
\hline $\begin{array}{l}\text { Kanji } \\
2010 \text { [35] }\end{array}$ & Critical & Low & Serious & NA & Serious & Moderate & $\begin{array}{l}\text { Moderat } \\
\mathrm{e}\end{array}$ & Serious & 1 \\
\hline $\begin{array}{l}\text { Ko } \\
2002 \text { [36] }\end{array}$ & Critical & Low & Critical & NA & Low & Moderate & $\begin{array}{l}\text { Moderat } \\
\mathrm{e}\end{array}$ & Critical & 0.86 \\
\hline $\begin{array}{l}\text { Lamarche } \\
2010 \text { [37] }\end{array}$ & Critical & Low & Moderate & NA & $\begin{array}{l}\text { Moderat } \\
\mathrm{e}\end{array}$ & Moderate & $\begin{array}{l}\text { Moderat } \\
\mathrm{e}\end{array}$ & $\begin{array}{l}\text { Moderat } \\
\mathrm{e}\end{array}$ & 0.57 \\
\hline $\begin{array}{l}\text { Li } \\
2015 \text { [38] }\end{array}$ & Critical & Low & Low & NA & Low & Moderate & $\begin{array}{l}\text { Moderat } \\
\mathrm{e}\end{array}$ & Low & 0.86 \\
\hline $\begin{array}{l}\text { Liden } \\
2009 \text { [39] }\end{array}$ & Critical & Moderate & Critical & NA & $\begin{array}{l}\text { Moderat } \\
\mathrm{e}\end{array}$ & Moderate & $\begin{array}{l}\text { Moderat } \\
\mathrm{e}\end{array}$ & $\begin{array}{l}\text { Moderat } \\
\mathrm{e}\end{array}$ & 0.57 \\
\hline $\begin{array}{l}\text { Liu } \\
2009 \text { [40] }\end{array}$ & Critical & Critical & Moderate & NA & Low & Moderate & $\begin{array}{l}\text { Moderat } \\
\mathrm{e}\end{array}$ & $\begin{array}{l}\text { Moderat } \\
\mathrm{e}\end{array}$ & 0.71 \\
\hline $\begin{array}{l}\text { Loforte } \\
2014 \text { [41] }\end{array}$ & Critical & Low & Critical & NA & $\begin{array}{l}\text { Moderat } \\
\mathrm{e}\end{array}$ & Moderate & Low & Critical & 0.71 \\
\hline $\begin{array}{l}\text { Luo } \\
2009 \text { [42] }\end{array}$ & Critical & Low & Low & NA & $\begin{array}{l}\text { Moderat } \\
\text { e }\end{array}$ & Moderate & Low & Low & 1 \\
\hline $\begin{array}{l}\text { Mazeffi } \\
2016 \text { [43] }\end{array}$ & Critical & Low & Moderate & NA & Low & Moderate & $\begin{array}{l}\text { Moderat } \\
\mathrm{e}\end{array}$ & $\begin{array}{l}\text { Moderat } \\
\mathrm{e}\end{array}$ & 1 \\
\hline
\end{tabular}




\begin{tabular}{|c|c|c|c|c|c|c|c|c|c|}
\hline $\begin{array}{l}\text { Meyer } \\
2009 \text { [44] }\end{array}$ & Critical & Low & Low & NA & $\begin{array}{l}\text { Moderat } \\
\mathrm{e}\end{array}$ & Moderate & $\begin{array}{l}\text { Moderat } \\
\mathrm{e}\end{array}$ & $\begin{array}{l}\text { Moderat } \\
\mathrm{e}\end{array}$ & 0.86 \\
\hline $\begin{array}{l}\text { Musial } \\
2017 \text { [45] }\end{array}$ & Critical & Low & Critical & NA & Low & Serious & $\begin{array}{l}\text { Moderat } \\
\mathrm{e}\end{array}$ & Critical & 0.71 \\
\hline $\begin{array}{l}\text { Papadopoul } \\
\text { os } \\
2015 \text { [46] }\end{array}$ & Critical & Low & Low & NA & Low & Moderate & $\begin{array}{l}\text { Moderat } \\
\mathrm{e}\end{array}$ & Low & 0.86 \\
\hline $\begin{array}{l}\text { Park } \\
2014 \text { [47] }\end{array}$ & Critical & Moderate & Low & NA & Low & Moderate & $\begin{array}{l}\text { Moderat } \\
\mathrm{e}\end{array}$ & $\begin{array}{l}\text { Moderat } \\
\mathrm{e}\end{array}$ & 0.86 \\
\hline $\begin{array}{l}\text { Peigh } \\
2015 \text { [48] }\end{array}$ & Critical & Low & Critical & NA & Serious & Critical & Critical & Critical & 0.57 \\
\hline $\begin{array}{l}\text { Pokersnik } \\
2012 \text { [49] }\end{array}$ & Critical & Serious & Critical & NA & Low & Moderate & $\begin{array}{l}\text { Moderat } \\
\mathrm{e}\end{array}$ & Critical & 0.71 \\
\hline $\begin{array}{l}\text { Pontailler } \\
2017 \text { [50] }\end{array}$ & Critical & Low & Serious & NA & Serious & Critical & Critical & Critical & 0.86 \\
\hline $\begin{array}{l}\text { Ranucci } \\
2011 \text { [51] }\end{array}$ & Critical & Critical & Critical & NA & Critical & Critical & Critical & Critical & 0.86 \\
\hline $\begin{array}{l}\text { Rastan } \\
2010 \text { [52] }\end{array}$ & Critical & Low & Low & NA & Low & Moderate & $\begin{array}{l}\text { Moderat } \\
\mathrm{e}\end{array}$ & Low & 0.71 \\
\hline $\begin{array}{l}\text { Rousse } \\
2015 \text { [53] }\end{array}$ & Critical & Low & Serious & NA & $\begin{array}{l}\text { Moderat } \\
\mathrm{e}\end{array}$ & Critical & Serious & Critical & 0.71 \\
\hline $\begin{array}{l}\text { Rubino } \\
2017 \text { [54] }\end{array}$ & Critical & Low & Critical & NA & Low & Moderate & $\begin{array}{l}\text { Moderat } \\
\mathrm{e}\end{array}$ & Critical & 0.71 \\
\hline $\begin{array}{l}\text { Russo } \\
2010 \text { [55] }\end{array}$ & Critical & Low & Low & NA & Low & Critical & Serious & Low & 0.71 \\
\hline $\begin{array}{l}\text { Saxena } \\
2015 \text { [9] }\end{array}$ & Critical & Low & Low & NA & Low & Moderate & $\begin{array}{l}\text { Moderat } \\
\mathrm{e}\end{array}$ & Low & 0.86 \\
\hline $\begin{array}{l}\text { Slottosch } \\
2012 \text { [56] }\end{array}$ & Critical & Low & Low & NA & Low & Low & $\begin{array}{l}\text { Moderat } \\
\mathrm{e}\end{array}$ & Low & 0.86 \\
\hline $\begin{array}{l}\text { Slottosch } \\
2017 \text { [57] }\end{array}$ & Critical & Low & Low & NA & $\begin{array}{l}\text { Moderat } \\
\mathrm{e}\end{array}$ & Moderate & $\begin{array}{l}\text { Moderat } \\
\mathrm{e}\end{array}$ & $\begin{array}{l}\text { Moderat } \\
\mathrm{e}\end{array}$ & 0.86 \\
\hline $\begin{array}{l}\text { Truby } \\
2015 \text { [58] }\end{array}$ & Critical & Low & Serious & NA & $\begin{array}{l}\text { Moderat } \\
\mathrm{e}\end{array}$ & Critical & Serious & Critical & 0.86 \\
\hline $\begin{array}{l}\text { Tsai } \\
2016 \text { [59] }\end{array}$ & Critical & Critical & Critical & NA & Serious & Critical & Critical & Critical & 0.57 \\
\hline $\begin{array}{l}\text { Wang } \\
2009 \text { [60] }\end{array}$ & Critical & Low & Low & NA & $\begin{array}{l}\text { Moderat } \\
\mathrm{e}\end{array}$ & Low & $\begin{array}{l}\text { Moderat } \\
\mathrm{e}\end{array}$ & Low & 0.71 \\
\hline $\begin{array}{l}\text { Wang } \\
2013 \text { [61] }\end{array}$ & Critical & Critical & Low & NA & Low & Low & $\begin{array}{l}\text { Moderat } \\
\mathrm{e}\end{array}$ & Low & 0.86 \\
\hline $\begin{array}{l}\text { Wu } \\
2010 \text { [62] }\end{array}$ & Critical & Low & Critical & NA & Low & Low & Low & Low & 1 \\
\hline $\begin{array}{l}\text { Xie } \\
2017 \text { [63] }\end{array}$ & Critical & Low & Critical & NA & Critical & Critical & Critical & Critical & 0.86 \\
\hline $\begin{array}{l}\text { Zhang } \\
2006 \text { [64] }\end{array}$ & Critical & Low & Critical & NA & Low & Serious & $\begin{array}{l}\text { Moderat } \\
\mathrm{e}\end{array}$ & Critical & 0.86 \\
\hline $\begin{array}{l}\text { Zhao } \\
2015 \text { [65] }\end{array}$ & Critical & Critical & Critical & NA & Low & Moderate & $\begin{array}{l}\text { Moderat } \\
\mathrm{e}\end{array}$ & & 0.71 \\
\hline $\begin{array}{l}\text { Zhong } \\
2017 \text { [66] }\end{array}$ & Critical & Critical & Low & NA & Low & Serious & $\begin{array}{l}\text { Moderat } \\
\mathrm{e}\end{array}$ & Critical & 0.57 \\
\hline $\begin{array}{l}\text { Ariyaratnam } \\
2014 \text { [67] }\end{array}$ & Critical & Low & Critical & NA & Low & Critical & Serious & Critical & 1 \\
\hline $\begin{array}{l}\text { Deschka } \\
2013 \text { [68] }\end{array}$ & Critical & Low & Serious & NA & $\begin{array}{l}\text { Moderat } \\
\mathrm{e}\end{array}$ & Low & Low & Low & 0.86 \\
\hline $\begin{array}{l}\text { Khorsandi } \\
2016[69]\end{array}$ & Critical & Low & Serious & NA & Low & Low & Low & Low & 0.86 \\
\hline
\end{tabular}




\begin{tabular}{|c|c|c|c|c|c|c|c|c|c|}
\hline $\begin{array}{l}\text { Mikus } \\
2013 \text { [70] }\end{array}$ & Critical & Low & Low & NA & Low & Moderate & $\begin{array}{l}\text { Moderat } \\
\mathrm{e}\end{array}$ & Low & 0.71 \\
\hline $\begin{array}{l}\text { Raffa } \\
2017 \text { [71] }\end{array}$ & Critical & Low & Serious & NA & Low & Moderate & Low & Low & 0.71 \\
\hline $\begin{array}{l}\text { Unosawa } \\
2012 \text { [72] }\end{array}$ & Critical & Low & Low & NA & Low & Moderate & $\begin{array}{l}\text { Moderat } \\
\mathrm{e}\end{array}$ & Low & 0.86 \\
\hline
\end{tabular}

*When multiple outcomes were reported for a study, the highest level of bias at the outcome level is reported in the table.

Table 3. Procedural characteristics

\begin{tabular}{|c|c|c|c|c|c|c|c|c|c|c|}
\hline \multirow[t]{2}{*}{ Study } & \multirow{2}{*}{ 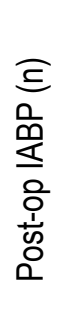 } & \multirow{2}{*}{ 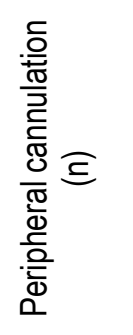 } & \multirow{2}{*}{ 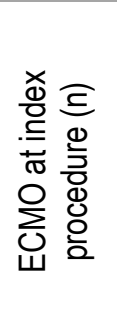 } & \multirow{2}{*}{ 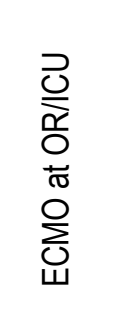 } & \multirow{2}{*}{ 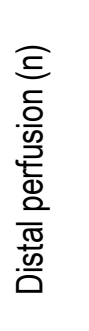 } & \multirow[b]{2}{*}{ 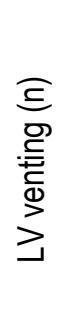 } & \multicolumn{4}{|c|}{ ECMO } \\
\hline & & & & & & & 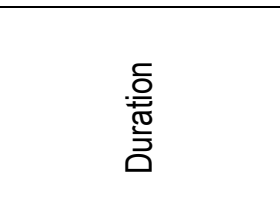 & 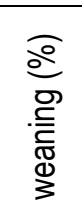 & $\begin{array}{l}\stackrel{0}{0} \\
\text { 옹 } \\
\text { 음 } \\
\text { 是 }\end{array}$ & 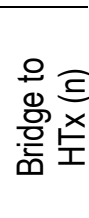 \\
\hline \multicolumn{11}{|l|}{ HTx/VAD centres } \\
\hline $\begin{array}{l}\text { Acheampong } \\
2016\end{array}$ & 14 & NR & NR & $20 / 4$ & NR & NR & $8.4(0.8-35.4)$ days & 75.0 & 1 & 0 \\
\hline $\begin{array}{l}\text { Bakhtiary } \\
2008\end{array}$ & 30 & 37 & NR & $30 / 15$ & $\mathrm{NR}$ & $\mathrm{NR}$ & $6.4 \pm 4.5$ days & 55.6 & 5 & 2 \\
\hline $\begin{array}{l}\text { Beckmann } \\
2017\end{array}$ & NR & 8 & NR & NR & 8 & NR & $12.0 \pm 5.9$ days & 87.5 & 1 & 0 \\
\hline $\begin{array}{l}\text { Beiras- } \\
\text { Fernandez } \\
2011\end{array}$ & 36 & NR & NR & NR & NR & NR & $4.4 \pm 4.0$ days & NR & NR & NR \\
\hline Biancari 2017 & 47 & 89 & 76 & NR & 66 & 5 & $6.4 \pm 5.6$ days & 48.6 & 6 & 0 \\
\hline Burrell 2015 & NR & NR & NR & NR & NR & NR & 7 (IQR: 5-8) days & 100 & NR & NR \\
\hline Carroll 2015 & 13 & 92 & NR & $61 / 31^{* *}$ & NR & NR & $\begin{array}{c}94 \text { (IQR: 43-172) } \\
\text { hours }\end{array}$ & 69 & 29 & 2 \\
\hline Chen 2011* & NR & NR & NR & NR & NR & NR & $133 \pm 12$ hours & 54.9 & NR & NR \\
\hline Combes 2008 & NR & NR & NR & NR & NR & NR & NR & NR & NR & NR \\
\hline $\begin{array}{l}\text { Distelmeier } \\
2016 / 2017\end{array}$ & 44 & 347 & $\mathrm{NR}$ & NR & NR & NR & 4 (IQR: 2-7) days & $\mathrm{NR}$ & 4 & 3 \\
\hline Doll 2003 & 95 & 26 & NR & $70 / 25$ & NR & NR & $2.8 \pm 2.1$ days & 47.4 & 8 & $3 \dagger$ \\
\hline $\begin{array}{l}\text { Elsharkawy } \\
2010\end{array}$ & 22 & 77 & NR & NR & NR & NR & $\mathrm{NR}$ & NR & 28 & 25 \\
\hline Fiser 2001 & NR & NR & NR & $22 / 29$ & NR & NR & 67.5 hours & 31.4 & NR & NR \\
\hline Guihaire 2017 & 25 & 78 & 43 & $80 / 12$ & NR & 13 & 6 days & 48 & 2 & 2 \\
\hline Hsu 2009 & 51 & 51 & NR & $\mathrm{NR}$ & $\mathrm{NR}$ & $\mathrm{NR}$ & $7.5 \pm 6.7$ days & 52.9 & 0 & 3 \\
\hline Kanji 2010 & 36 & 22 & NR & NR & NR & NR & $\begin{array}{c}2.5 \text { (IQR: 1.0-4.8) } \\
\text { days }\end{array}$ & NR & NR & 23 \\
\hline Ko 2002 & 54 & 61 & 39 & $23 / 30$ & 20 & NR & $\mathrm{NR}$ & 60.5 & 2 & 2 \\
\hline $\begin{array}{l}\text { Lamarche } \\
2010\end{array}$ & NR & 8 & NR & $16 / 8$ & NR & NR & $48 \pm 65.5$ hours & 58.3 & 3 & 3 \\
\hline Li 2015 & 73 & 123 & 61 & NR & 123 & NR & 4.3 days & 56.1 & NR & NR \\
\hline Liden 2009 & 14 & NR & NR & NR & NR & NR & $5.5 \pm 4.9$ days & NR & 2 & 2 \\
\hline Liu 2009 & 10 & 14 & 9 & NR & NR & NR & $71 \pm 52$ hours & 64.3 & NR & NR \\
\hline Loforte 2014 & 155 & 79 & NR & NR & NR & NR & $9.56(2-43)$ days & 56.8 & 1 & 4 \\
\hline Luo 2009 & 11 & NR & NR & $15 / 30$ & NR & 0 & 131.6 hours & 66.7 & NR & 2 \\
\hline Mazeffi 2016 & 3 & 9 & 3 & $\mathrm{NR}$ & NR & 0 & 3 (IQR: $1-8$ ) days & 100 & 2 & NR \\
\hline Meyer 2009 & NR & 18 & NR & NR & 18 & NR & $4 \pm 4$ days & 66.7 & NR & NR \\
\hline
\end{tabular}




\begin{tabular}{|c|c|c|c|c|c|c|c|c|c|c|}
\hline Musial 2017 & NR & 27 & 27 & NR & NR & NR & 8.89 days & NR & NR & NR \\
\hline $\begin{array}{l}\text { Papadopoulos } \\
2015\end{array}$ & NR & 324 & NR & NR & $\mathrm{NR}$ & NR & $7 \pm 1$ days & 58.1 & 6 & 2 \\
\hline Park 2014 & NR & 115 & 41 & NR & 115 & NR & $71.3(0.5-713)$ hours & 40.8 & NR & 2 \\
\hline Peigh 2015 & NR & NR & $\mathrm{NR}$ & NR & NR & NR & $9.2 \pm 6.1$ days & NR & NR & NR \\
\hline $\begin{array}{l}\text { Pokersnik } \\
2012\end{array}$ & 29 & 32 & NR & NR & 32 & NR & $3.8 \pm 3.4$ days & 55.1 & 2 & 0 \\
\hline $\begin{array}{l}\text { Pontailler } \\
2017\end{array}$ & NR & NR & NR & NR & NR & NR & $5.6 \pm 4.3$ days $^{*}$ & $41.1^{*}$ & NR & NR \\
\hline Ranucci 2011 & NR & 0 & 9/2 & NR & NR & NR & $122.1 \pm 80.5$ hours & 63.6 & NR & NR \\
\hline Rastan 2010 & 383 & 203 & $\mathrm{NR}$ & NR & 121 & NR & $3.28 \pm 2.85$ days & 63.3 & 15 & 5 \\
\hline Rousse 2015 & 5 & 25 & $\mathrm{NR}$ & NR & 29 & 29 & $8(1-86)$ days & 50.0 & 7 & 13 \\
\hline Rubino 2017 & NR & NR & 63 & NR & NR & NR & 5 (IQR: 3-8) days & 57.4 & 3 & 3 \\
\hline Russo 2010 & 3 & 1 & $\mathrm{NR}$ & NR & NR & NR & $7.0 \pm 5.2$ days & 66.7 & 0 & 1 \\
\hline Saxena $2015^{\dagger}$ & NR & 15 & $\mathrm{NR}$ & NR & NR & $\mathrm{NR}$ & $103.8 \pm 74.3$ hours & 53.3 & NR & $\mathrm{NR}$ \\
\hline $\begin{array}{l}\text { Slottosch } \\
2012\end{array}$ & 72 & 77 & 34 & $34 / 43$ & 77 & $\overline{N R}$ & $79 \pm 57$ hours & 62.3 & $\overline{N R}$ & $\overline{N R}$ \\
\hline $\begin{array}{l}\text { Slottosch } \\
2017\end{array}$ & 83 & 72 & 40 & NR & NR & NR & $117 \pm 78$ hours & $43.2^{*}$ & NR & NR \\
\hline Truby 2015 & NR & 45 & NR & $71 / 108$ & 9 & NR & $\begin{array}{c}3.58 \text { (IQR: } 1.6-5.9) \\
\text { days }\end{array}$ & NR & 52 & NR \\
\hline Tsai 2016 & $\mathrm{NR}$ & NR & $\mathrm{NR}$ & $\mathrm{NR}$ & $\mathrm{NR}$ & $\mathrm{NR}$ & $7 \pm 5$ days ${ }^{*}$ & $70.5^{\star}$ & NR & NR \\
\hline Wang 2009 & 19 & NR & NR & $36 / 26$ & NR & 0 & $61 \pm 37$ hours & 64.5 & NR & NR \\
\hline Wang 2013 & 41 & NR & 37 & $37 / 50$ & 37 & NR & $61 \pm 37$ hours & 58.6 & NR & NR \\
\hline Wu 2010 & NR & NR & $\mathrm{NR}$ & $98 / 12$ & NR & NR & $143 \pm 112$ hours & 60.9 & 2 & 0 \\
\hline Xie $2017^{* * *}$ & NR & NR & $\mathrm{NR}$ & NR & NR & NR & NR & 64.8 & NR & NR \\
\hline Zhang 2006 & 10 & 19 & $\mathrm{NR}$ & NR & NR & NR & $2.7 \pm 1.7$ days & 43.8 & NR & NR \\
\hline Zhao 2015 & 16 & 23 & 9 & $\mathrm{NR}$ & $\mathrm{NR}$ & NR & $115.23 \pm 70.17$ hours & 66.7 & $1^{* *}$ & NR \\
\hline Zhong 2017 & 9 & 29 & 24 & $24 / 12$ & NR & $\mathrm{NR}$ & $77.5 \pm 34.5$ hours & 66.7 & $\mathrm{NR}$ & NR \\
\hline \multicolumn{11}{|c|}{ Non-HTx/VAD centres } \\
\hline $\begin{array}{l}\text { Ariyaratnam } \\
2014\end{array}$ & NR & 0 & NR & NR & NR & NR & $5.6 \pm 3.4$ days & 50.0 & NR & NR \\
\hline Deschka 2013 & 25 & $0^{* \star *}$ & NR & NR & NR & NR & $8.7 \pm 3.9$ days & 42.9 & NR & NR \\
\hline $\begin{array}{l}\text { Khorsandi } \\
2016\end{array}$ & NR & 5 & $\mathrm{NR}$ & NR & NR & NR & $5.5 \pm 8.9$ days & NR & NR & NR \\
\hline Mikus 2013 & 13 & 6 & 12 & NR & 14 & 14 & 5 days & 50 & 0 & 0 \\
\hline Raffa 2017 & 23 & 30 & 48 & $48 / 38$ & $\mathrm{NR}$ & $\mathrm{NR}$ & 5 days & 49 & $\mathrm{NR}$ & $\mathrm{NR}$ \\
\hline $\begin{array}{l}\text { Unosawa } \\
2012\end{array}$ & 39 & 32 & 33 & $33 / 14$ & NR & NR & $63.5 \pm 61.5$ hours & 61.7 & 0 & 0 \\
\hline
\end{tabular}

* Reported for entire study population including non-PCS patients

** $24(23 \%)$ in the cardiac catheterization laboratory, $16(16 \%)$ at the bedside, and $1(1 \%)$ in the emergency department

${ }^{* * *}$ Central cannulation cohort alone; peripheral venous cannulation in 28 patients

†VAD and subsequent heart transplantation

Values are reported as mean $\pm S D$, unless reported otherwise in the original manuscript. $H T x$, heart transplantation; VAD, ventricular assist device; IQR, interquartile range; NR, not reported.

Numbers of patients in single studies do not always match the total $\mathrm{n}$. of patients in the original manuscripts since only PCS subgroups were considered. 
Table 4. Reported causes of in-hospital/30-day death

\begin{tabular}{|c|c|c|}
\hline Study & On ECMO only & After weaning/in-hospital/30-day death \\
\hline \multicolumn{3}{|l|}{ HTx/VAD centres } \\
\hline $\begin{array}{l}\text { Acheampong } \\
2016\end{array}$ & NR & $\begin{array}{l}1 \text { sepsis, } 1 \text { massive bleeding, } 2 \text { pulmonary; remaining: } \\
\text { multiorgan failure or cardiac related }\end{array}$ \\
\hline Bakhtiary 2008 & 18 persistent heart failure & 12 multiorgan failure \\
\hline $\begin{array}{l}\text { Beckmann } \\
2017\end{array}$ & 1 sepsis & $\begin{array}{l}1 \text { biventricular failure, } 1 \text { low cardiac output, } 1 \text { cerebral } \\
\text { haemorrhage, } 1 \text { multiorgan failure }\end{array}$ \\
\hline $\begin{array}{l}\text { Beiras- } \\
\text { Fernandez } \\
2011\end{array}$ & $\begin{array}{l}\text { refractory ventricular failure } 40.6 \% \text {, } \\
\text { bleeding } 23.2 \% \text {, isolated persistent } \\
\text { low cardiac output } 21.7 \% \text {, } \\
\text { thromboembolism } 8.7 \% \text {, allograft } \\
\text { failure } 5.8 \%\end{array}$ & 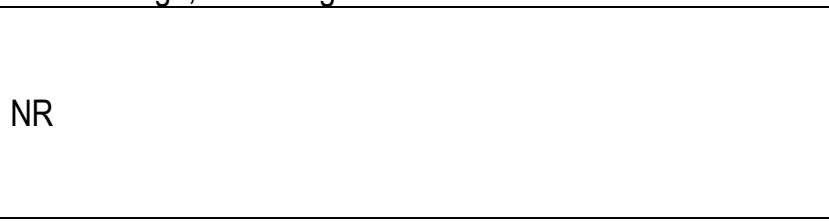 \\
\hline Biancari 2017 & $\mathrm{NR}$ & NR \\
\hline Burrell 2015 & NR & $\mathrm{NR}$ \\
\hline Carroll 2015 & NR & $\begin{array}{l}\text { multiorgan failure in } 52 \text { patients, neurologic injury in } 9 \\
\text { patients, bleeding in } 7 \text { patients, hypoxemic respiratory failure } \\
\text { in } 2 \text { patients, and other etiologies in the remaining } 5 \text { patients }\end{array}$ \\
\hline Chen $2011^{*}$ & NR & $\mathrm{NR}$ \\
\hline Combes 2008 & $\begin{array}{l}\text { mainly due to refractory multiorgan } \\
\text { failure with } 14 \text { within } 24 \text { hrs of onset }\end{array}$ & NR \\
\hline $\begin{array}{l}\text { Distelmeier } \\
\text { 2016/2017 }\end{array}$ & ( & NR \\
\hline Doll 2003 & NR & $\begin{array}{l}\text { refractory myocardial failure in } 71 \% \text {, multisystem organ failure } \\
\text { in } 13 \% \text {, sepsis in } 7 \% \text {, and other causes in } 9 \%\end{array}$ \\
\hline $\begin{array}{l}\text { Elsharkawy } \\
2010\end{array}$ & NR & e \\
\hline Fiser 2001 & $\begin{array}{l}27 \text { cardiac failures, } 12 \text { strokes, } 3 \\
\text { multisystem organ failures, } 1 \\
\text { respiratory insufficiency }\end{array}$ & NR \\
\hline Guihaire 2017 & $\mathrm{NR}$ & NR \\
\hline Hsu 2009 & $\mathrm{NR}$ & main causes were pulmonary infections \\
\hline Kanji 2010 & NR & NR \\
\hline Ko 2002 & $\begin{array}{l}16 \text { multiple organ failure, } 5 \\
\text { uncontrolled bleedings, } 3 \text { brain } \\
\text { deaths, } 2 \text { circulatory shocks, } 1 \\
\text { refractory ventricular arrhythmia, } 1 \\
\text { myocardial infarction, } 1 \text { acute } \\
\text { rejection, } 1 \text { graft failure }\end{array}$ & $\begin{array}{l}17 \text { multiple organ failure, } 3 \text { persistent heart failure, } 1 \\
\text { ventricular fibrillation }\end{array}$ \\
\hline $\begin{array}{l}\text { Lamarche } \\
2010\end{array}$ & $\mathrm{NR}$ & NR \\
\hline Li 2015 & NR & NR \\
\hline Liden 2009 & $\begin{array}{l}8 \text { multiorgan failure, } 6 \text { poor cardiac } \\
\text { function, } 1 \text { brain damage, } 1 \\
\text { retroperitoneal bleeding, } 1 \text { fungal } \\
\text { sepsis, } 1 \text { vasoplegia, } 1 \text { unknown }\end{array}$ & NR \\
\hline Liu 2009 & NR & $\begin{array}{l}4 \text { haemodynamic unstable, } 1 \text { multiorgan failure, } 1 \text { sepsis, } 1 \\
\text { other }\end{array}$ \\
\hline Loforte 2014 & $\begin{array}{l}\text { mostly associated with sepsis and } \\
\text { brain death }\end{array}$ & 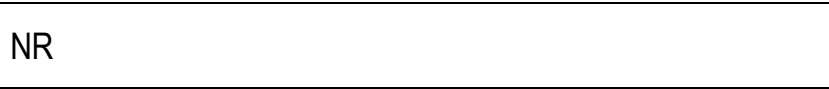 \\
\hline Luo 2009 & $\begin{array}{l}6 \text { persistent heart failure without } \\
\text { improvement, } 4 \text { multiorgan failure } \\
\text { and others }\end{array}$ & 5 sepsis and other \\
\hline Mazeffi 2016 & 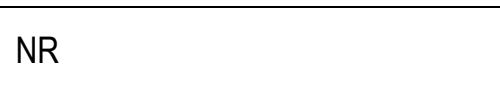 & $\begin{array}{l}7 \text { multiple organ failure, } 4 \text { brain injury, } 3 \text { sepsis, } 1 \\
\text { hemorrhage, } 1 \text { repeat arrest }\end{array}$ \\
\hline
\end{tabular}




\begin{tabular}{|c|c|c|}
\hline Meyer 2009 & NR & $\begin{array}{l}5 \text { multiorgan failure, } 4 \text { non-recoverable myocardial failure, } 3 \\
\text { sepsis, } 1 \text { intracerebral bleeding }\end{array}$ \\
\hline Musial 2017 & NR & NR \\
\hline $\begin{array}{l}\text { Papadopoulos } \\
2015\end{array}$ & NR & the main cause of death was sepsis $(69 \%)$ \\
\hline Park 2014 & NR & $\begin{array}{l}6 \text { multiorgan failure, } 3 \text { profound cardiac failure, } 2 \text { sepsis, } 2 \\
\text { pan-peritonitis, } 2 \text { aortic ruptures, } 1 \text { intracerebral } \\
\text { haemorrhage, } 1 \text { gastrointestinal bleeding }\end{array}$ \\
\hline Peigh 2015 & $\begin{array}{l}8 \text { anoxic brain injuries, } 8 \text { strokes, } 3 \\
\text { irreversible cardiac dysfunctions, } 3 \\
\text { sepsis, } 2 \text { irreversible lung diseases, } 1 \\
\text { abdominal compartment syndrome } \\
\text { with hepatorenal syndrome, } 1 \text { failure } \\
\text { to control bleeding }\end{array}$ & $\begin{array}{l}5 \text { sepsis, } 4 \text { neurologic injuries, } 2 \text { acute myocardial infraction } \\
\text { because of stent thrombosis, } 1 \text { family's withdrawal because } \\
\text { of failure to thrive, and one case of each of the following: } \\
\text { pulseless electric activity after internal defibrillator placement, } \\
\text { persistent loss of cardiac activity despite biventricular assist } \\
\text { device placement, acute failure of left ventricular assist } \\
\text { device placement with persistent low flow and malperfusion, } \\
\text { nonresectable cardiac metastasis (adenocarcinoma), and } \\
\text { severe coagulopathy and multiple bleeding }\end{array}$ \\
\hline $\begin{array}{l}\text { Pokersnik } \\
2012\end{array}$ & NR & 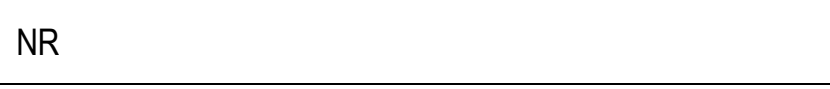 \\
\hline Pontailler 2017 & multiorgan failure for all patients & NR \\
\hline Ranucci 2011 & $\mathrm{NR}$ & $\mathrm{NR}$ \\
\hline Rastan 2010 & $\mathrm{NR}$ & the main reason for death was cardiac \\
\hline Rousse 2015 & $\begin{array}{l}21 \text { multiple organ failures, } 12 \text { intra- } \\
\text { abdominal bleeding, } 4 \text { strokes, } 3 \text { non- } \\
\text { beating hearts, } 7 \text { haemorrhage or } \\
\text { sepsis, } 2 \text { mesenteric ischemias (for } \\
\text { entire study population of } 124 \\
\text { patients) }\end{array}$ & 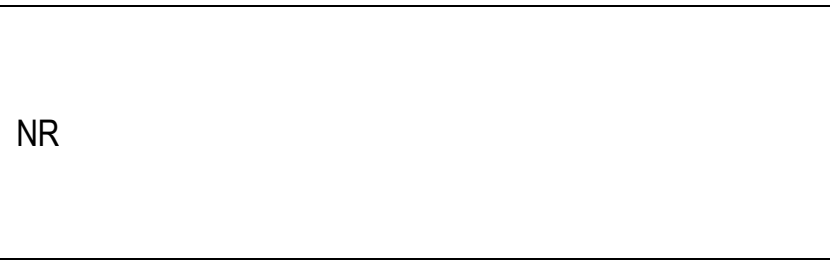 \\
\hline Rubino 2017 & NR & causes of death were mostly related to cardiac disease \\
\hline Russo 2010 & NR & $\begin{array}{l}6 \text { multiorgan failures, } 1 \text { pulmonary artery thrombosis, } 1 \\
\text { thoracic bleeding }\end{array}$ \\
\hline Saxena $2015^{\dagger}$ & NR & 30 cardiac causes, 13 multiorgan failures, 6 septicemias \\
\hline Slottosch 2012 & NR & $\begin{array}{l}\text { cardiac causes }(50.9 \%) \text {, sepsis }(29.1 \%) \text {, cerebrovascular } \\
\text { complications }(1.8 \%) \text {, bleeding }(10.9 \%) \text {, gastrointestinal } \\
\text { complications }(7.3 \%)\end{array}$ \\
\hline Slottosch 2017 & NR & $\begin{array}{l}60 \text { cardiac deaths, } 22 \text { sepsis, } 6 \text { mesenterial ischemias, } 5 \\
\text { cerebral deaths, } 5 \text { untreatable bleedings and } 4 \text { others (for } \\
\text { entire cohort of } 139 \text { patients) }\end{array}$ \\
\hline Truby 2015 & NR & NR \\
\hline Tsai 2016 & NR & NR \\
\hline Wang 2009 & $\begin{array}{l}11 \text { persistent heart failures, } 7 \text { sepsis } \\
\text { with consecutive multiorgan failure, } 2 \\
\text { cerebral infarction and bleeding, } 2 \\
\text { disseminated intravascular } \\
\text { coagulation }\end{array}$ & main cause was sepsis with consecutive multiorgan failure \\
\hline Wang 2013 & $\begin{array}{l}22 \text { persistent heart failure without any } \\
\text { improvement in cardiac function, } 10 \\
\text { sepsis, } 3 \text { disseminated intravascular } \\
\text { coagulation, } 1 \text { cerebral infarction and } \\
\text { bleeding }\end{array}$ & sepsis with consecutive multiorgan failure for all weaned \\
\hline Wu 2010 & NR & $\begin{array}{l}8 \text { excessive mediastinal bleeding, } 15 \text { profound cardiac failure, } \\
6 \text { severe brain damage, } 3 \text { bowel infarction, } 2 \text { massive air } \\
\text { embolism, } 28 \text { sepsis with multiple organ failure }\end{array}$ \\
\hline Xie $2017^{* * *}$ & NR & $\mathrm{NR}$ \\
\hline Zhang 2006 & NR & NR \\
\hline Zhao 2015 & NR & $\begin{array}{l}\text { the main cause of mortality was multiple system organ failure } \\
(50.0 \%)\end{array}$ \\
\hline
\end{tabular}



heart failures, 3 disseminated intravascular coagulation, 2 cerebral infarction

\begin{tabular}{|c|c|c|}
\hline \multicolumn{3}{|c|}{ Non-HTx/VAD centres } \\
\hline $\begin{array}{l}\text { Ariyaratnam } \\
2014\end{array}$ & NR & NR \\
\hline Deschka 2013 & NR & NR \\
\hline $\begin{array}{l}\text { Khorsandi } \\
2016\end{array}$ & NR & $\begin{array}{l}6 \text { biventricular failures, } 2 \text { septic shocks, } 1 \text { major } \\
\text { cardiovascular incident, } 1 \text { major haemorrhage, } 1 \text { respiratory } \\
\text { failure, } 1 \text { multiorgan failure }\end{array}$ \\
\hline Mikus 2013 & multiple organ failure for all & $\mathrm{NR}$ \\
\hline Raffa 2017 & NR & $\begin{array}{l}\text { the main reason for death was a cardiac event, followed by } \\
\text { multiorgan failure and neurological complications }\end{array}$ \\
\hline Unosawa 2012 & $\begin{array}{l}7 \text { intractable heart failure, } 5 \\
\text { multiorgan failure, } 4 \text { brain death, } 2 \\
\text { severe coagulopathic bleeding }\end{array}$ & $\begin{array}{l}8 \text { multiorgan failures, } 2 \text { heart failures, } 2 \text { cardiac ruptures, } 2 \\
\text { brain deaths, } 1 \text { pneumonia }\end{array}$ \\
\hline
\end{tabular}

\begin{tabular}{|c|c|c|c|c|c|c|c|c|c|}
\hline 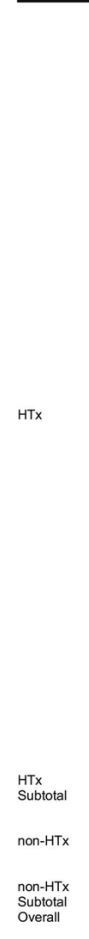 & 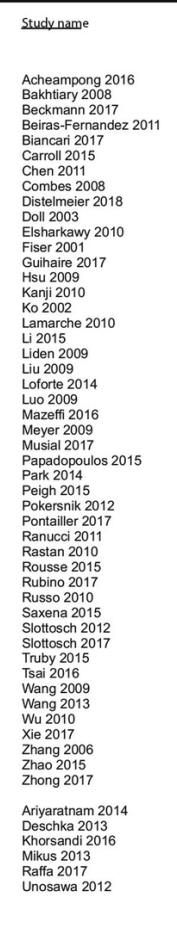 & 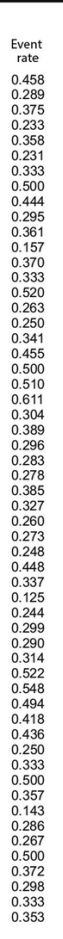 & 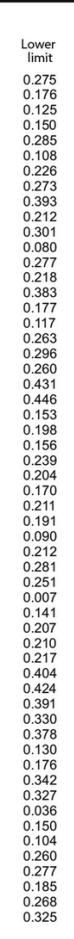 & 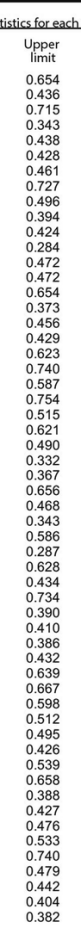 & 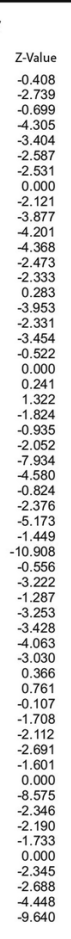 & 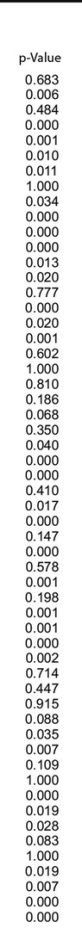 & 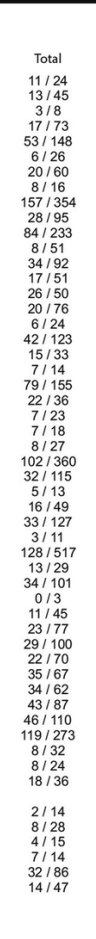 & 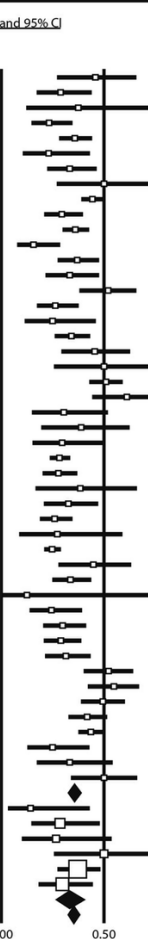 & 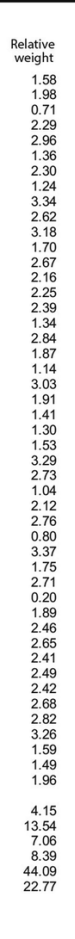 \\
\hline
\end{tabular}

Figure 3. Analysis of survival after following ECMO institution in HTx/VAD vs non-HTX/VAD centres. Squares represent point estimates of single studies; horizontal lines are respective $95 \%$ confidence intervals. Diamonds are indicative of subtotal and total pooled estimate. HTx, heart transplantation; VAD, ventricle assist device. 


\section{Regression of ECMO per year on Logit event rate}

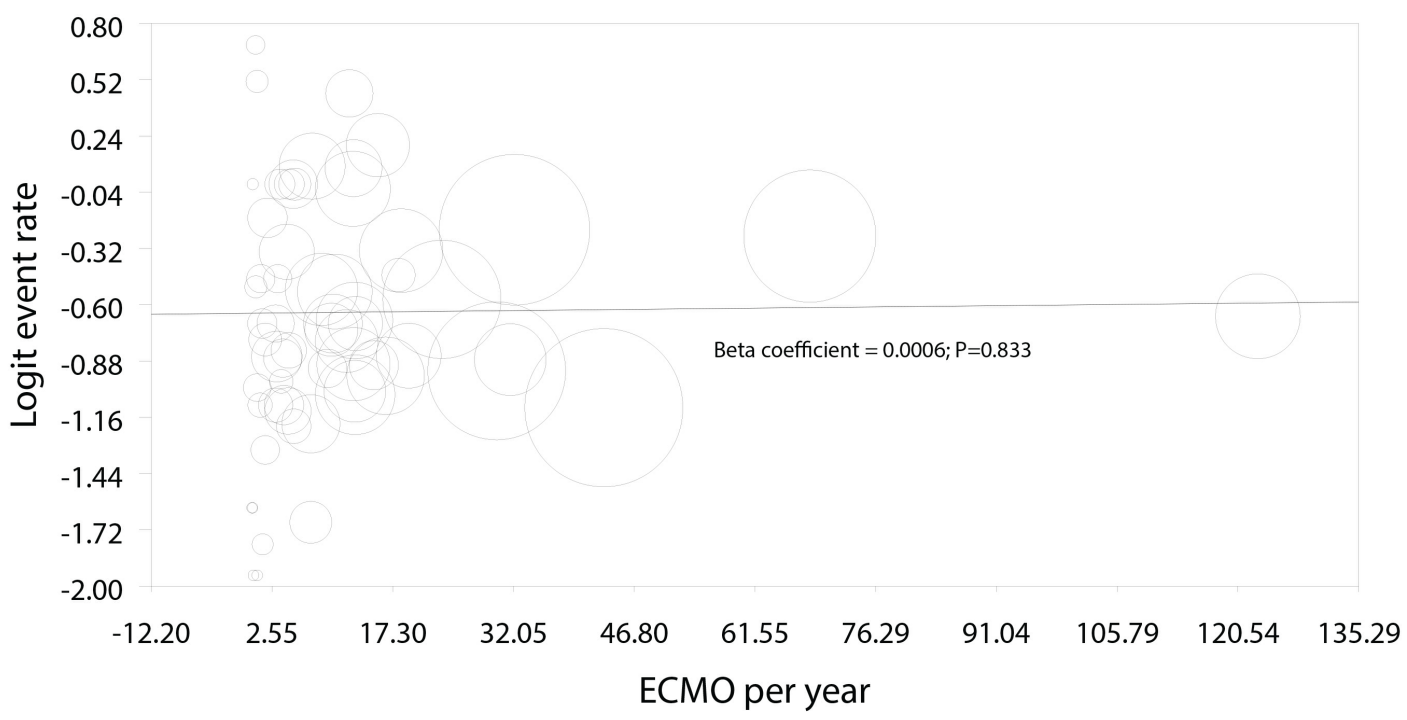

Figure 4. Meta-regression analysis of number of ECMOs per year on logit survival rate.

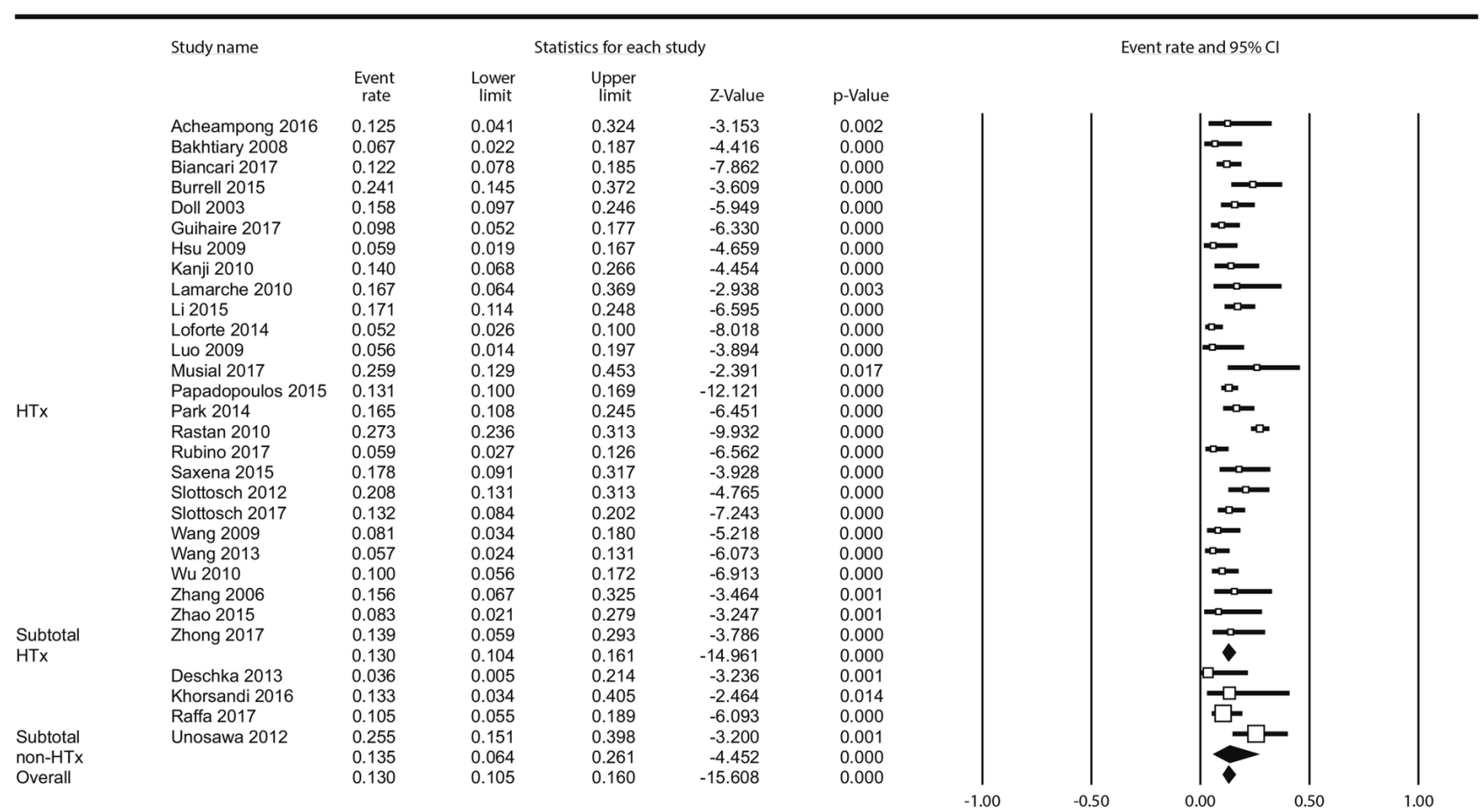

Figure 5. Analysis of limb complications following ECMO institution in HTx/VAD vs non-HTx/NAD centres. 


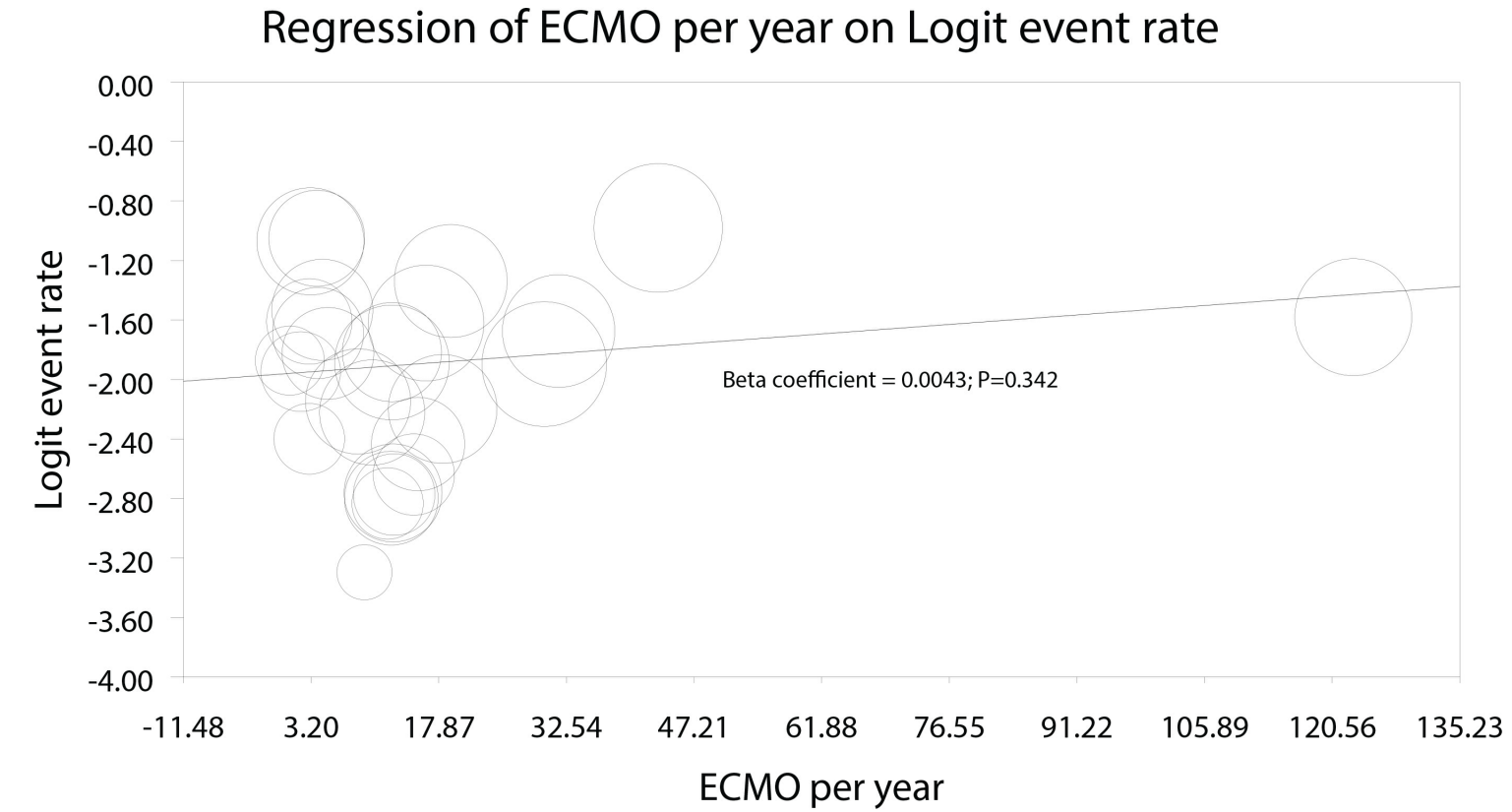

Figure 6. Meta-regression analysis of number of ECMOs per year on logit limb complications event rate.

\begin{tabular}{|c|c|c|c|c|c|c|c|c|c|c|c|}
\hline & Study name & & & ics for eac & & & & & te and $95 \% \mathrm{Cl}$ & & \\
\hline & & $\begin{array}{c}\text { Event } \\
\text { rate }\end{array}$ & $\begin{array}{c}\text { Lower } \\
\text { limit }\end{array}$ & $\begin{array}{c}\text { Upper } \\
\text { limit }\end{array}$ & Z-Value & $\mathrm{p}$-Value & & & & & \\
\hline & $\begin{array}{l}\text { Acheampong } 2016 \\
\text { Bakhtiary } 2008\end{array}$ & $\begin{array}{l}0.125 \\
0.089\end{array}$ & $\begin{array}{l}0.041 \\
0.034\end{array}$ & 0.324 & $\begin{array}{r}-3.153 \\
-4.443\end{array}$ & 0.002 & & & $=$ & & \\
\hline & $\begin{array}{l}\text { Bakhtiary } 2008 \\
\text { Beckmann } 2017\end{array}$ & $\begin{array}{l}0.089 \\
0.125\end{array}$ & $\begin{array}{l}0.034 \\
0.017\end{array}$ & $\begin{array}{l}0.214 \\
0.537\end{array}$ & $\begin{array}{r}-4.443 \\
-1.820\end{array}$ & $\begin{array}{l}0.000 \\
0.069\end{array}$ & & & $=$ & & \\
\hline & $\begin{array}{l}\text { Beckmann } 2017 \\
\text { Biancari } 2017\end{array}$ & 0.236 & 0.175 & 0.312 & $\begin{array}{l}-1.820 \\
-6.059\end{array}$ & $\begin{array}{l}0.069 \\
0.000\end{array}$ & & & $\infty$ & & \\
\hline & $\begin{array}{l}\text { Burrell } 2015 \\
\text { D }\end{array}$ & 0.037 & 0.009 & 0.136 & $\begin{array}{l}-4.522 \\
-6443\end{array}$ & 0.000 & & & $=$ & & \\
\hline & $\begin{array}{l}\text { Doll } 2003 \\
\text { Elsharkawy } 2010\end{array}$ & $\begin{array}{l}0.005 \\
0.099\end{array}$ & $\begin{array}{l}0.050 \\
0.066\end{array}$ & $\begin{array}{l}0.172 \\
0.144\end{array}$ & $\begin{array}{r}-6.443 \\
-10.069\end{array}$ & 0.000 & & & $\infty$ & & \\
\hline & Fiser 2001 & 0.235 & 0.139 & 0.370 & $\begin{array}{l}-10.069 \\
-3.570\end{array}$ & $\begin{array}{l}0.000 \\
0.000\end{array}$ & & & & & \\
\hline & Guihaire 2017 & 0.033 & 0.011 & 0.096 & -5.775 & 0.000 & & & $=$ & & \\
\hline & $\begin{array}{l}\text { Hsu } 2009 \\
\text { Kanii } 2010\end{array}$ & 0.059 & 0.019 & 0.167 & -4.659 & 0.000 & & & $=$ & & \\
\hline & $\begin{array}{l}\text { Kanji } 2010 \\
\text { Ko 2002 }\end{array}$ & 0.100 & 0.042 & 0.219 & $\begin{array}{l}-4.661 \\
-5.18\end{array}$ & 0.000 & & & $\infty$ & & \\
\hline & $\begin{array}{l}\text { Ko } 2002 \\
\text { Lamarche } 2010\end{array}$ & $\begin{array}{l}0.039 \\
0.020\end{array}$ & $\begin{array}{l}0.013 \\
0.001\end{array}$ & $\begin{array}{l}0.115 \\
0.251\end{array}$ & $\begin{array}{l}-5.418 \\
-2.724\end{array}$ & 0.000 & & & $=$ & & \\
\hline$H T x$ & Li 2015 & 0.041 & 0.017 & 0.094 & $\begin{array}{l}-2.724 \\
-6.924\end{array}$ & $\begin{array}{l}0.006 \\
0.000\end{array}$ & & & - & & \\
\hline & Liu 2009 & 0.071 & 0.010 & 0.370 & -2.472 & 0.013 & & & & & \\
\hline & Luo 2009 & 0.083 & 0.027 & 0.229 & -3.976 & 0.000 & & & $\infty$ & & \\
\hline & Mazeffi 2016 & 0.174 & 0.067 & 0.382 & -2.832 & 0.005 & & & & & \\
\hline & Papadopoulos 2015 & 0.119 & 0.090 & 0.157 & -12.293 & 0.000 & & & $\infty$ & & \\
\hline & Pokersnik 2012 & 0.061 & 0.020 & 0.173 & -4.582 & 0.000 & & & & & \\
\hline & Rastan 2010 & 0.174 & 0.144 & 0.209 & -13.424 & 0.000 & & & $\infty$ & & \\
\hline & Rubino 2017 & 0.139 & 0.084 & 0.221 & -6.344 & 0.000 & & & $=$ & & \\
\hline & $\begin{array}{l}\text { Saxena } 2015 \\
\end{array}$ & 0.089 & 0.034 & 0.214 & -4.443 & 0.000 & & & 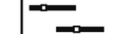 & & \\
\hline & $\begin{array}{l}\text { Slottosch } 2012 \\
\text { Slottosch } 2017\end{array}$ & $\begin{array}{l}0.221 \\
0.264\end{array}$ & $\begin{array}{l}0.142 \\
0.195\end{array}$ & $\begin{array}{l}0.327 \\
0.346\end{array}$ & $\begin{array}{r}-4.590 \\
-5142\end{array}$ & 0.000 & & & & & \\
\hline & Wang 2009 & $\begin{array}{l}0.264 \\
0.129\end{array}$ & 0.066 & $\begin{array}{l}0.346 \\
0.237\end{array}$ & $\begin{array}{l}-5.142 \\
-5.041\end{array}$ & $\begin{array}{l}0.000 \\
0.000\end{array}$ & & & - & & \\
\hline & Wang 2013 & 0.069 & 0.031 & 0.145 & -6.151 & 0.000 & & & $\infty$ & & \\
\hline & Zhao 2015 & 0.375 & 0.208 & 0.578 & -1.212 & 0.226 & & & & & \\
\hline $\begin{array}{l}\text { Subtotal } \\
\text { HTX }\end{array}$ & Zhong 2017 & 0.111 & 0.042 & 0.261 & -3.921 & 0.000 & & & - & & \\
\hline HTX & Deschka 2013 & $\begin{array}{l}0.119 \\
0.179\end{array}$ & $\begin{array}{l}0.095 \\
0.076\end{array}$ & 0.148 & $\begin{array}{l}-15.467 \\
-3093\end{array}$ & 0.000 & & & \pm & & \\
\hline & $\begin{array}{l}\text { Deschka a } 2013 \\
\text { Khorsandi } 2016\end{array}$ & 0.200 & $\begin{array}{l}0.066 \\
0.066\end{array}$ & $\begin{array}{l}0.364 \\
0.470\end{array}$ & $\begin{array}{r}-3.093 \\
-2.148\end{array}$ & $\begin{array}{l}0.002 \\
0.032\end{array}$ & & & $\longrightarrow$ & & \\
\hline non-HTx & Mikus 2013 & 0.143 & 0.036 & 0.427 & -2.346 & 0.019 & & & & & \\
\hline & Raffa 2017 & 0.198 & 0.127 & 0.295 & -5.174 & 0.000 & & & $=$ & & \\
\hline $\begin{array}{l}\text { Subtotal } \\
\text { non-HTx }\end{array}$ & Unosawa 2012 & 0.213 & 0.118 & 0.352 & -3.671 & 0.000 & & & & & \\
\hline $\begin{array}{l}\text { non-HTX } \\
\text { Overall }\end{array}$ & & $\begin{array}{l}0.195 \\
0.141\end{array}$ & $\begin{array}{l}0.145 \\
0.118\end{array}$ & $\begin{array}{l}0.258 \\
0.168\end{array}$ & $\begin{array}{r}-7.716 \\
-17087\end{array}$ & $\begin{array}{l}0.000 \\
0.000\end{array}$ & & & & & \\
\hline & & & & & & & -1.00 & -0.50 & 0.00 & 0.50 & 1.00 \\
\hline
\end{tabular}

Figure 7. Analysis of neurologic complications following ECMO institution in HTX/VAD vs non-HTX/VAD centres. 


\begin{tabular}{|c|c|c|c|c|c|c|c|c|c|c|c|}
\hline & \multirow[t]{2}{*}{$\underline{\text { Study name }}$} & \multicolumn{5}{|c|}{ Statistics for each study } & \multicolumn{5}{|c|}{ Event rate and $95 \% \mathrm{Cl}$} \\
\hline & & $\begin{array}{l}\text { Event } \\
\text { rate }\end{array}$ & $\begin{array}{l}\text { Lower } \\
\text { limit }\end{array}$ & $\begin{array}{c}\text { Upper } \\
\text { limit }\end{array}$ & Z-Value & $\mathrm{p}$-Value & & & & & \\
\hline & Acheampong 2016 & 0.042 & 0.006 & 0.244 & -3.069 & 0.002 & & & & & \\
\hline & Beckmann 2017 & 0.125 & 0.017 & 0.537 & -1.820 & 0.069 & & & & & \\
\hline & Biancari 2017 & 0.095 & 0.057 & 0.153 & -8.042 & 0.000 & & & 0 & & \\
\hline & Fiser 2001 & 0.235 & 0.139 & 0.370 & -3.570 & 0.000 & & & & & \\
\hline & Ko 2002 & 0.039 & 0.013 & 0.115 & -5.418 & 0.000 & & & - & & \\
\hline & Liden 2009 & 0.030 & 0.004 & 0.186 & -3.413 & 0.001 & & & & & \\
\hline \multirow[t]{9}{*}{ HTx } & Loforte 2014 & 0.161 & 0.111 & 0.228 & -7.549 & 0.000 & & & & & \\
\hline & Mazeffi 2016 & 0.130 & 0.043 & 0.335 & -3.064 & 0.002 & & & & & \\
\hline & Meyer 2009 & 0.056 & 0.008 & 0.307 & -2.753 & 0.006 & & & & & \\
\hline & Park 2014 & 0.009 & 0.001 & 0.059 & -4.716 & 0.000 & & & $=$ & & \\
\hline & Saxena 2015 & 0.011 & 0.001 & 0.151 & -3.172 & 0.002 & & & & & \\
\hline & Wang 2013 & 0.011 & 0.002 & 0.077 & -4.429 & 0.000 & & & 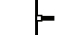 & & \\
\hline & Wu 2010 & 0.064 & 0.031 & 0.127 & -6.884 & 0.000 & & & 0 & & \\
\hline & Zhang 2006 & 0.063 & 0.016 & 0.218 & -3.708 & 0.000 & & & & & \\
\hline & Zhao 2015 & 0.083 & 0.021 & 0.279 & -3.247 & 0.001 & & & & & \\
\hline Subtotal & Zhong 2017 & 0.056 & 0.014 & 0.197 & -3.894 & 0.000 & & & & & \\
\hline \multirow{2}{*}{ HTx } & & 0.072 & 0.047 & 0.110 & -10.764 & 0.000 & & & 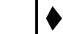 & & \\
\hline & Raffa 2017 & 0.093 & 0.047 & 0.175 & -6.134 & 0.000 & & & $\square$ & & \\
\hline Subtotal & Unosawa 2012 & 0.085 & 0.032 & 0.206 & -4.543 & 0.000 & & & $\square$ & & \\
\hline non-HTx & & 0.090 & 0.052 & 0.152 & -7.632 & 0.000 & & & & & \\
\hline \multirow[t]{2}{*}{ Overall } & & 0.079 & 0.056 & 0.110 & -13.180 & 0.000 & & & 10 & & \\
\hline & & & & & & & -1.00 & -0.50 & 0.00 & 0.50 & 1.00 \\
\hline
\end{tabular}

Figure 8. Analysis of brain death following ECMO institution in HTx/VAD vs non-HTx/VAD centres. Squares represent point estimates of single studies; horizontal lines are respective $95 \%$ confidence intervals. Diamonds are indicative of subtotal and total pooled estimate.

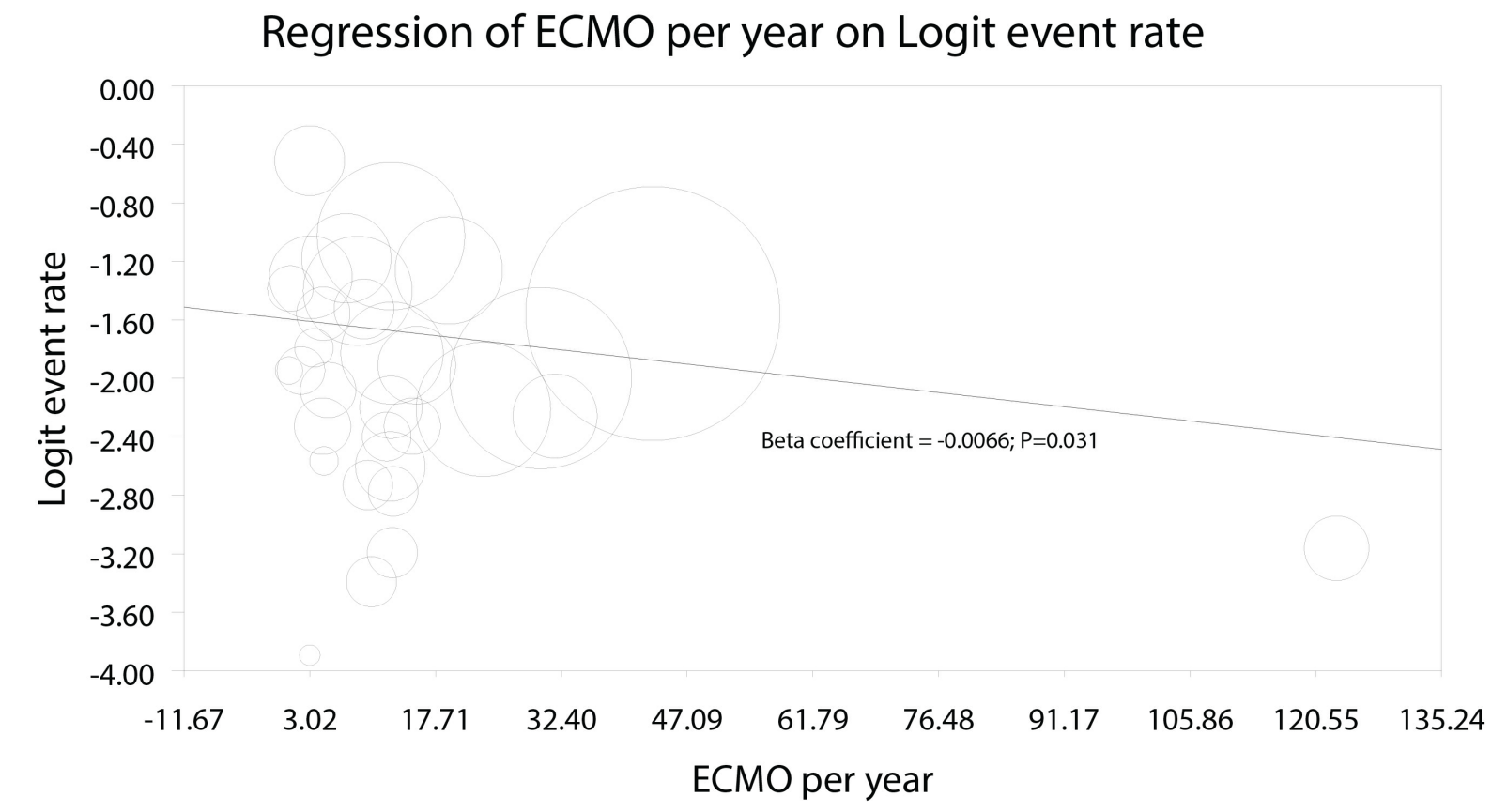

Figure 9. Meta-regression analysis of number of ECMOs per year on logit neurologic complications event rate. 


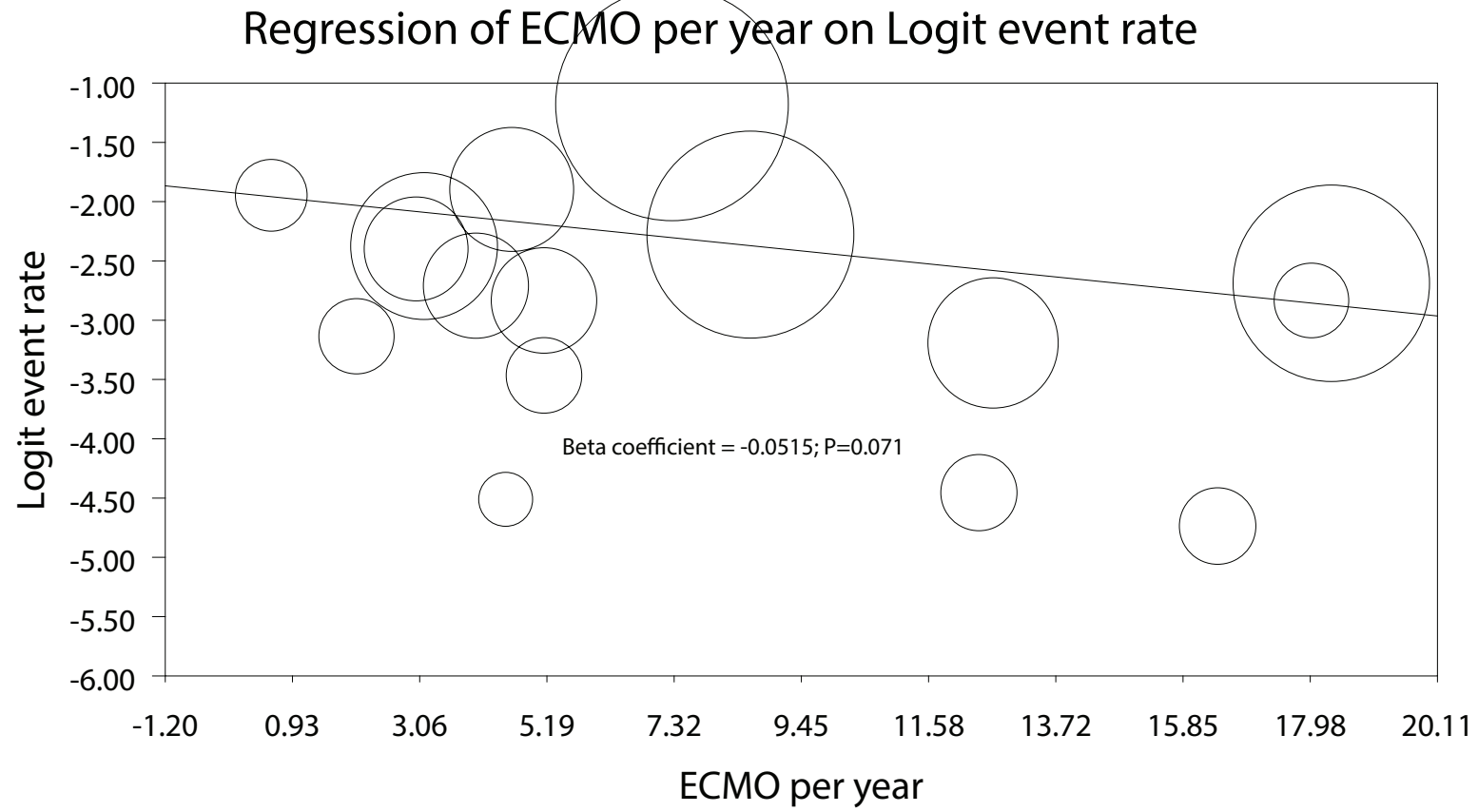

Figure 10. Meta-regression analysis of number of ECMOs per year on logit brain death event rate

Thirty-three studies enrolling 2,832 patients reported reoperations for bleeding; these were necessary in 1,232 cases $(41.2 \%$ [35.6-47.1\%]) in the entire series without statistical differences between $\mathrm{HTx}$ : $39.5 \%$ (33.6-45.8\%); and non-HTx centres: $52.6 \%$ (36.6-68.0\%); $\mathrm{P}=0.139$. Figure 11. In meta-regression, there was no impact of centre volume on incidence of reoperation for bleeding: $\beta_{\text {coef }}=-0.0012 ; P=0.489$ (Figure 12). Sepsis has complicated 385 ECMO cases $20.7 \%$ (17.0-24.9\%) but there were again no differences between HTx - (19.5\% [15.5-24.1\%]) and non-HTx centres (25.2\% [16.9-36.0\%]); $\mathrm{P}=0.259$ in the meta-analysis (Figure 13) nor in metaregression of centre's volume impact (Figure 14) $\left(\beta_{\text {coef }}=-0.0040 ; P=0.692\right)$. In the analysis of AKI with or without CVVH (Table 5 lists AKI definitions across included studies) less AKIs in non-HTx centres were seen but the difference was not significant $(p=0.220)$ Figure 15: Total incidence of AKI was $47.3 \%(41.5-53.1 \%)-1,513$ reported cases; in non-HTx centres AKI estimated rate was 38.7\% (25.5-53.7\%) as compared to 48.8\% (42.555.1\%) as observed in HTx centres; no effect of centre's annual ECMO institution rate on AKI incidence was demonstrated in meta-regression ( $\left.ß_{\text {coef }}=-0.0012 ; P=0.488\right)$ Figure 16. 


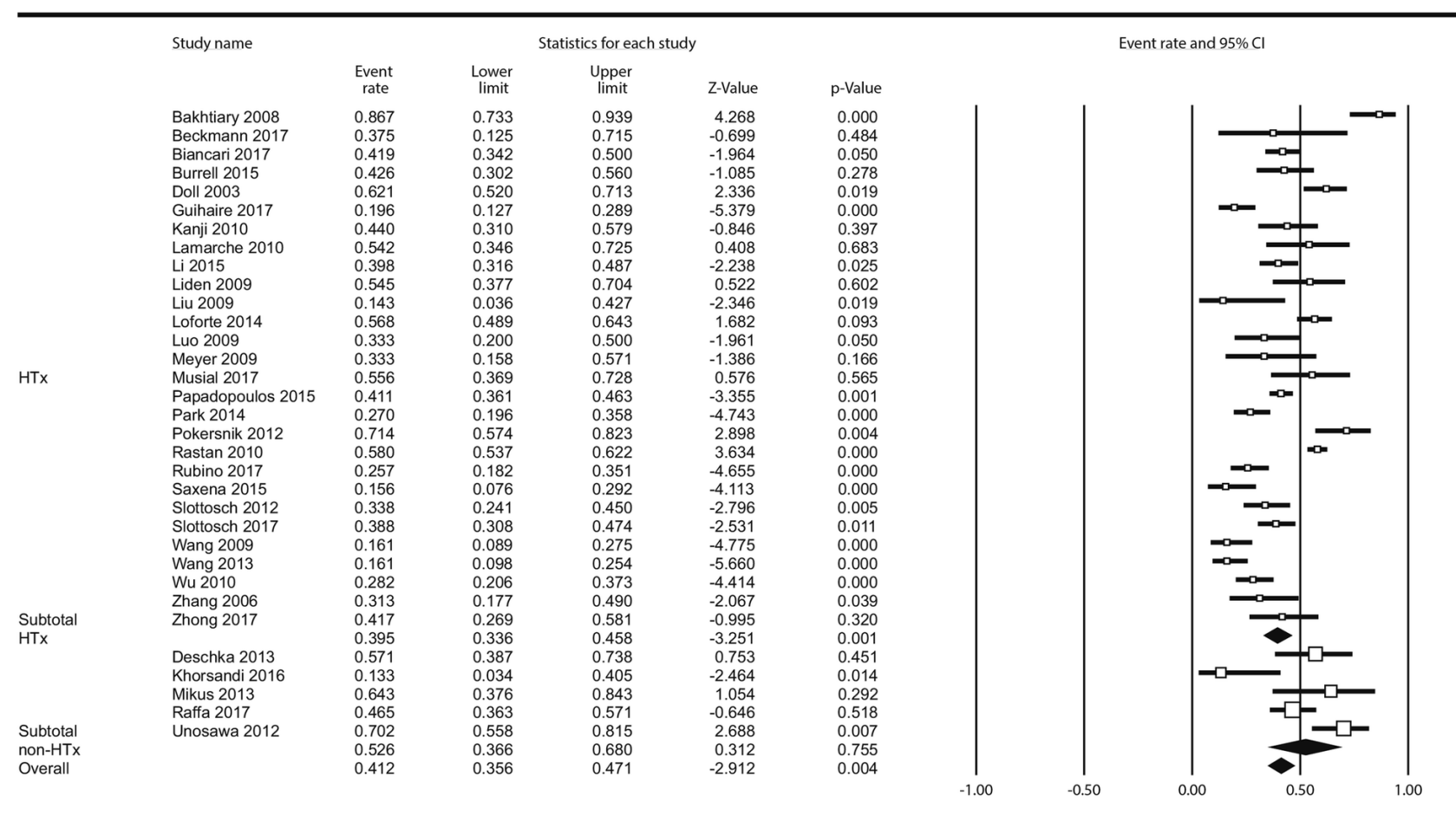

Figure 11. Analysis of reoperations for bleeding following ECMO institution in HTx/VAD vs non-HTx/VAD centres.

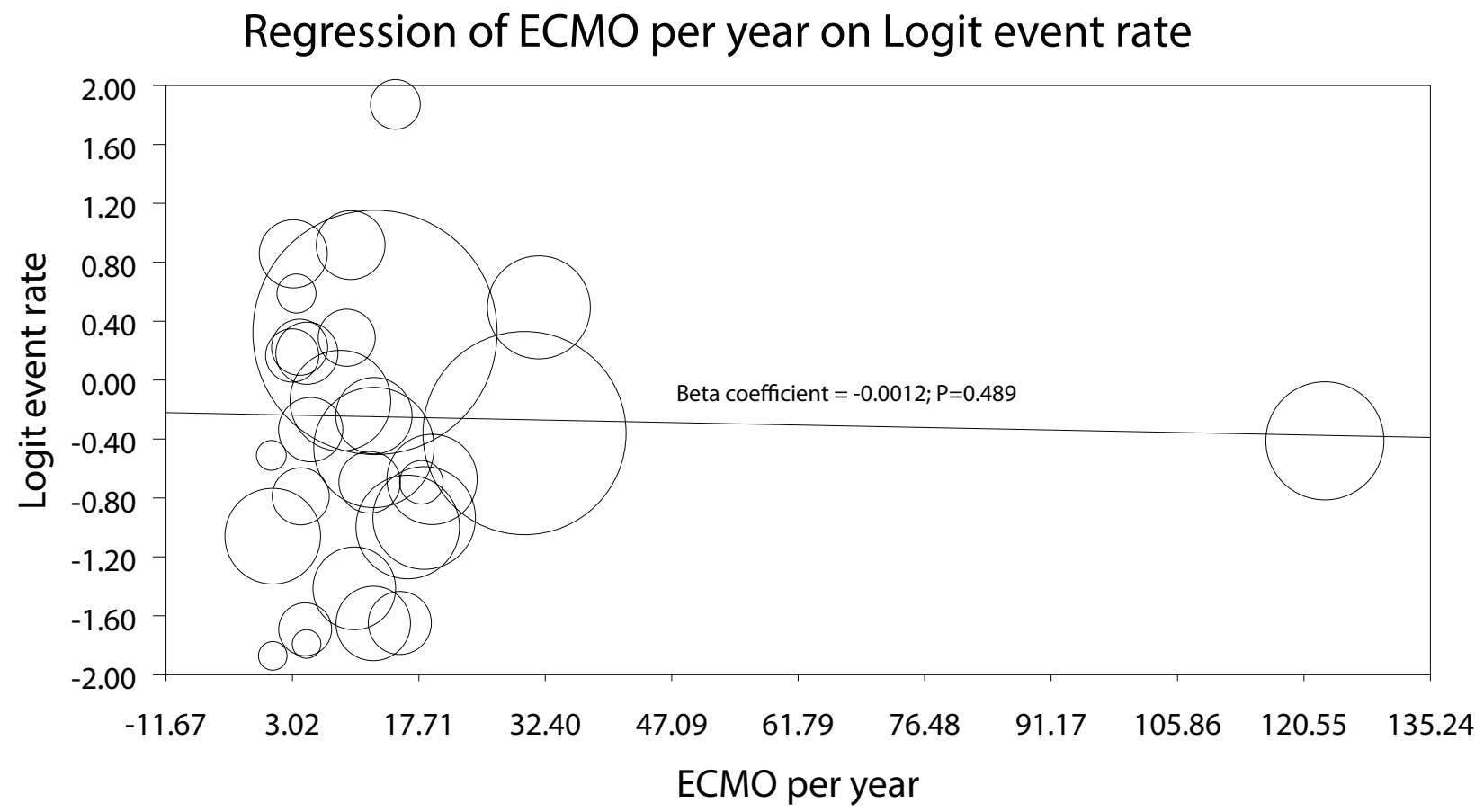

Figure 12. Meta-regression analysis of number of ECMOs per year on logit reoperations for bleeding event rate. 


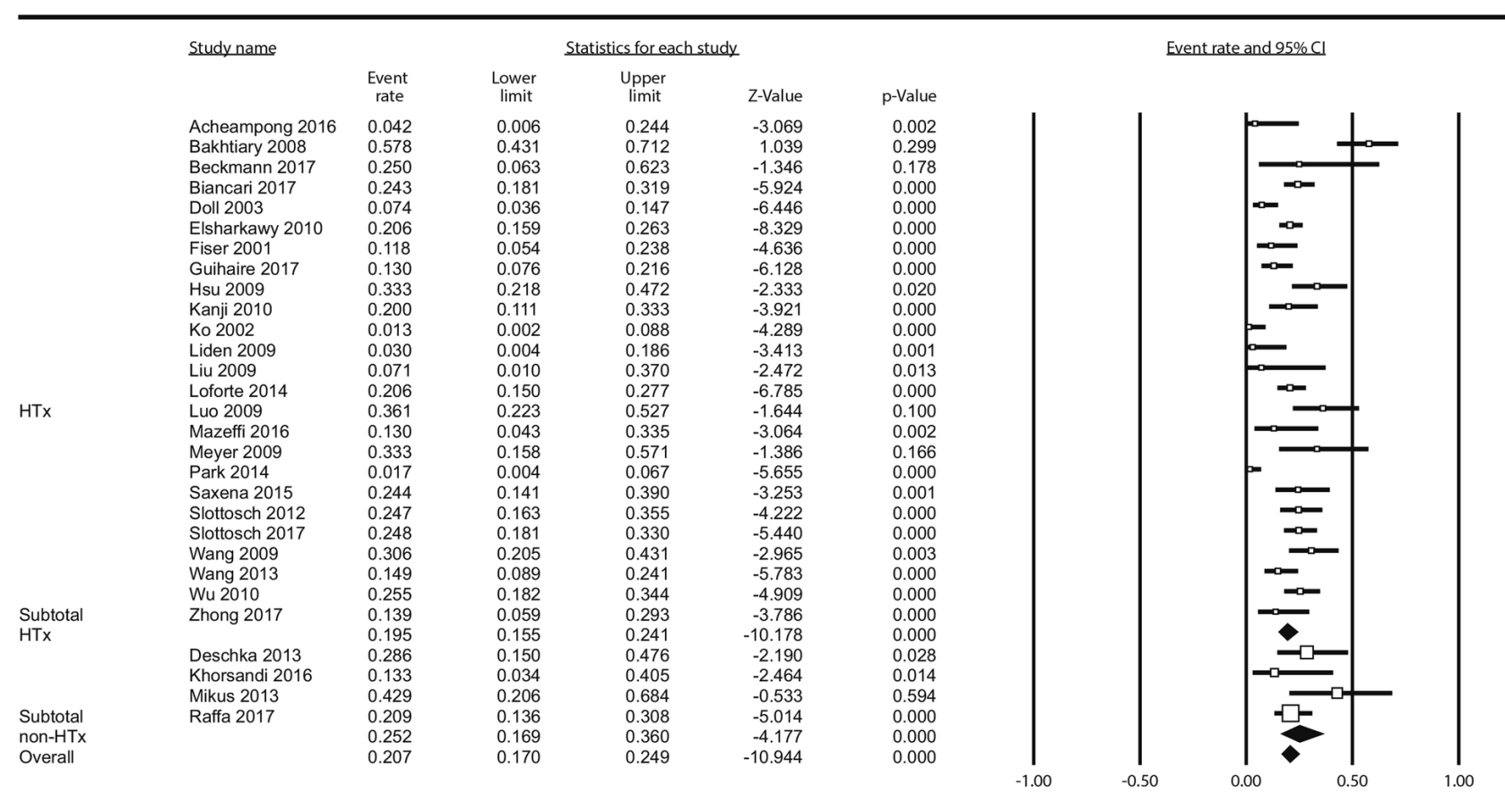

Figure 13. Analysis of sepsis following ECMO institution in HTx/VAD vs non-HTx/NAD centres.

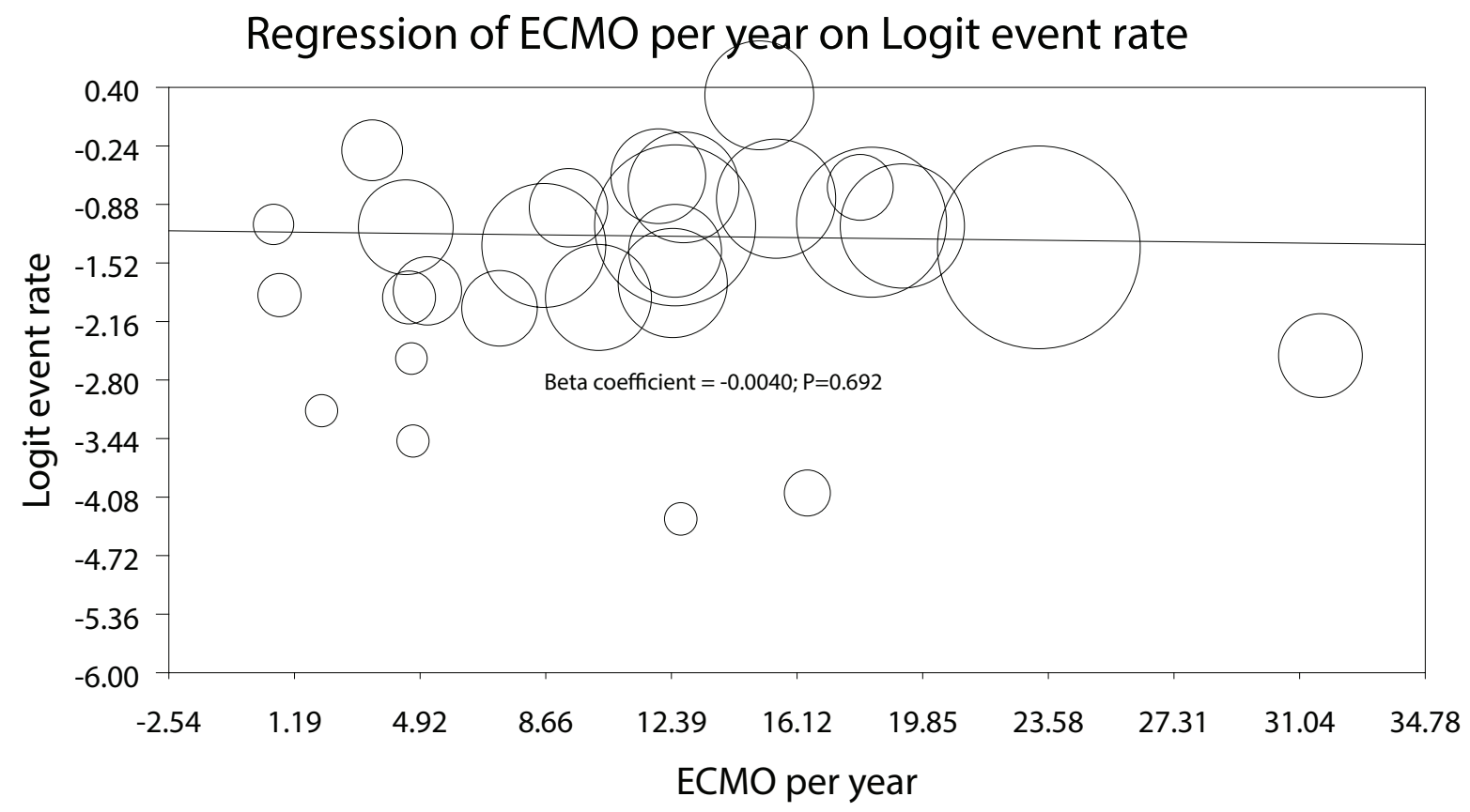

Figure 14. Meta-regression analysis of number of ECMOs per year on logit sepsis event rate.

Table 5. AKI definitions

Study

AKI definition

HTx/VAD centres

Acheampong $2016 \quad$ Renal insufficiency requiring hemodialysis

Bakhtiary $2008 \quad$ Renal failure requiring continuous venovenous hemofiltration 
Beckmann 2017

Beiras-Fernandez 2011

Biancari 2017

Burrell 2015

Carroll 2015

Chen 2011*

Combes 2008

Distelmeier 2016/2017

Doll 2003

Elsharkawy 2010

Fiser 2001

Guihaire 2017

Hsu 2009

Kanji 2010

Ko 2002

Lamarche 2010

Li 2015

Liden 2009

Liu 2009

Loforte 2014

Luo 2009

Mazeffi 2016

Meyer 2009

Musial 2017

Papadopoulos 2015

Park 2014

Peigh 2015

Pokersnik 2012

\begin{tabular}{ll} 
& \\
\hline Pontailler 2017 & N \\
\hline Ranucci 2011 & N \\
\hline Rastan 2010 & N \\
\hline Rousse 2015 & R \\
\hline Rubino 2017 & N \\
\hline Russo 2010 \\
\hline Saxena 2015 \\
\hline Slottosch 2012
\end{tabular}

\section{Slottosch 2017}

Truby 2015

Tsai 2016

Wang 2009

Wang 2013

\begin{tabular}{ll} 
Wu 2010 & R \\
Xie 2017 & N/A* \\
\hline Zhang 2006 & N/A \\
\hline Zhao 2015 & $\mathrm{H}$ \\
\hline Zhong 2017 & $\mathrm{N} / A$ \\
\hline Non-HTx/VAD centres &
\end{tabular}

$\mathrm{N} / \mathrm{A}$

N/A

Renal replacement therapy

$\mathrm{N} / \mathrm{A}$

$\mathrm{N} / \mathrm{A}$

$\mathrm{N} / \mathrm{A}$

$\mathrm{N} / \mathrm{A}$

$\mathrm{N} / \mathrm{A}$

Renal failure requiring hemofiltration

Acute renal failure requiring dialysis

Renal failure requiring dialysis

$\mathrm{N} / \mathrm{A}$

Renal failure requiring continuous venovenous hemofiltration

$\mathrm{N} / \mathrm{A}$

Acute renal failure requiring dialysis

$\mathrm{N} / \mathrm{A}$

Postoperative continuous renal replacement therapy

Postoperative dialysis

Acute renal failure requiring hemodialysis

Continuous veno-venous hemofiltration on ECMO

Acute renal failure treated by continuous renal replacement therapy

Acute renal failure requiring renal replacement therapy

Renal failure requiring hemodialysis

Acute renal failure requiring continuous renal replacement therapy

Acute renal failure requiring continuous venovenous hemofiltration

$\mathrm{N} / \mathrm{A}$

$\mathrm{N} / \mathrm{A}$

An increase in serum creatinine to $>2.0$, and two times the most recent preoperative creatinine level or a new requirement for dialysis postoperatively

N/A

$\mathrm{N} / \mathrm{A}$

$\mathrm{N} / \mathrm{A}$

N/A

Renal impairment requiring continuous veno-venous hemofiltration

N/A

$\mathrm{N} / \mathrm{A}$

Oliguria (less than $0.5 \mathrm{~mL} / \mathrm{kg} / \mathrm{h}$ ) and a doubling of postoperative creatinine values with the need for hemodialysis

Oliguria ( $<0.5 \mathrm{ml} / \mathrm{kg} / \mathrm{h})$ and a doubling of postoperative creatinine values with need for hemodialysis

$\mathrm{N} / \mathrm{A}$

$\mathrm{N} / \mathrm{A}$

Renal failure requiring continuous venovenous hemofiltration

PCS-related renal failure requiring continuous venovenous hemofiltration (e.g. renal replacement therapy)

Renal failure requiring continuous arteriovenous hemofiltration

$\mathrm{N} / \mathrm{A}$

$\mathrm{N} / \mathrm{A}$

Hemodialysis on ECMO

$\mathrm{N} / \mathrm{A}$

Ariyaratnam $2014 \quad$ N/A

Deschka 2013

Khorsandi 2016

Mikus 2013

Raffa 2017

Acute renal failure requiring continuous veno-venous hemodiafiltration

Renal failure requiring renal replacement therapy

Renal failure requiring continuous venovenous hemofiltration

$\mathrm{N} / \mathrm{A}$ 


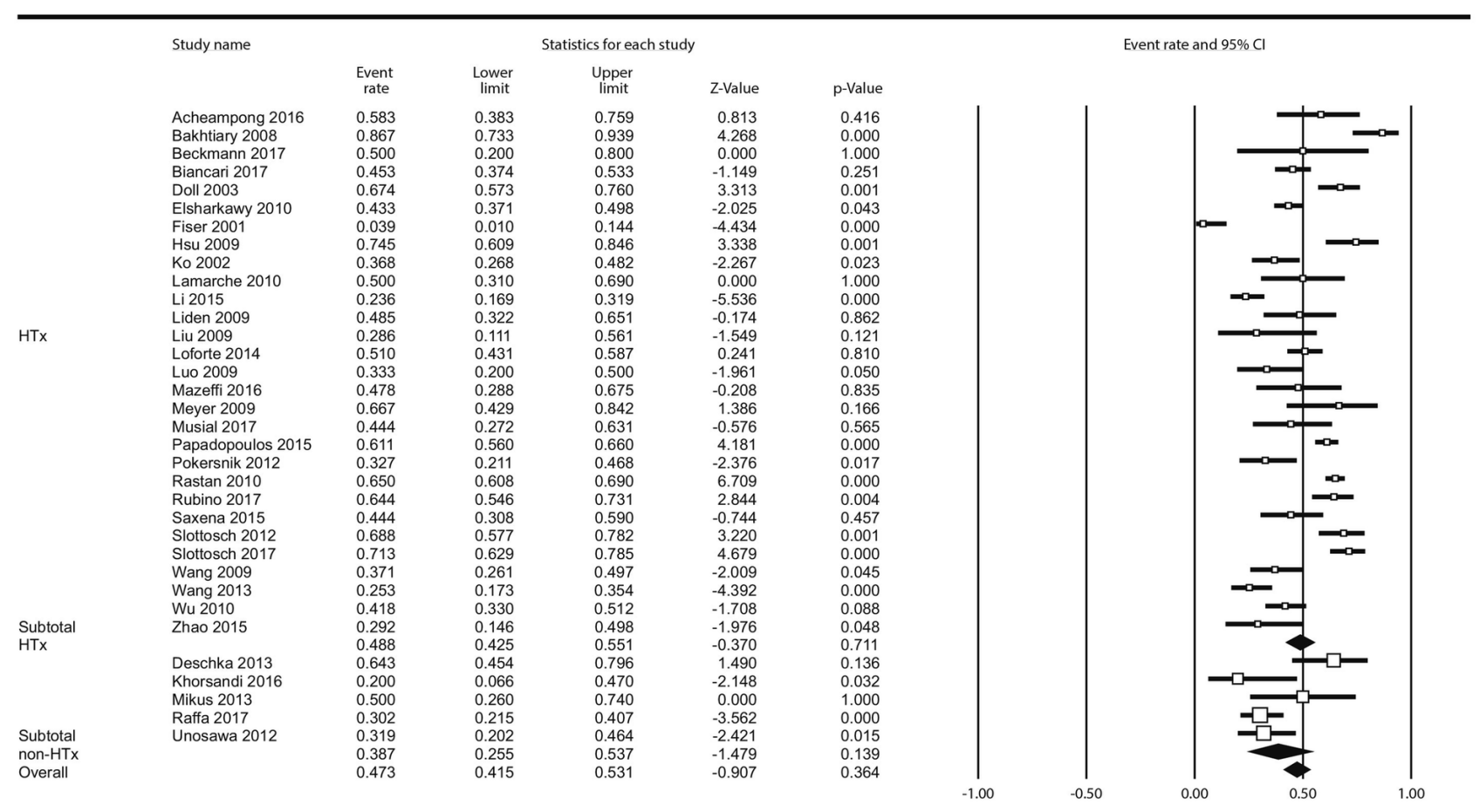

Figure 15. Analysis of acute kidney injury following ECMO institution in HTXNVAD vs non-HTX/VAD centres.

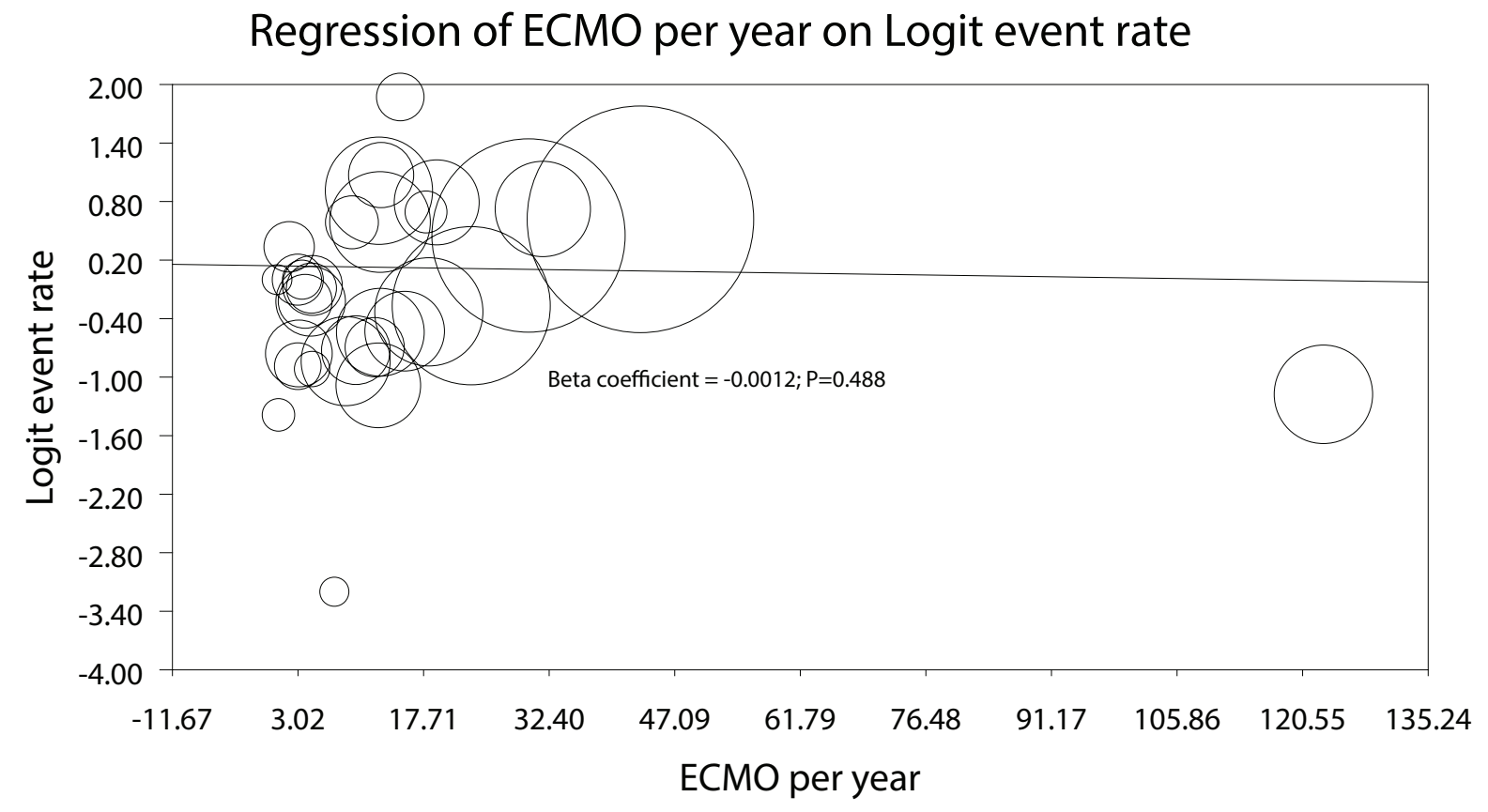

Figure 16. Meta-regression analysis of number of ECMOs per year on logit acute kidney injury event rate. 


\section{ECMO as bridging therapy}

Eighty-six (estimated rate 3.5\% [1.8-6.6\%]) patients were bridged to heart transplantation. Of those, all were bridged to $\mathrm{HTx}$ in $\mathrm{HTx}$ centres. Off note, one reported patient died on ECMO after transfer from non-Htx centre to the referral hub centre while waiting for heart transplantation [70]. ECMO bridging to short- or long-term VAD ensued in 99 patients (4.3\% [2.8-6.5\%]); there were again no instance of reported bridging to VADs in non-HTx centres.

\section{Additional analyses:}

In several conducted meta-regressions, no impact of centre status on survival ( $\beta_{\text {coef }}=0.1418 ; P_{\text {slope }}=0.555$ ) or ECMO duration ( $\beta_{\text {coof }}=0.0052 ; P_{\text {slope }}=0.833$ ) could be demonstrated. Centre status positively, yet nonsignificantly, correlated with higher weaning rates ( $\beta_{\text {coef }}=0.2651 ; P_{\text {slope }}=0.601$ ). Figure 17 and 18 summarize subgroup analyses performed for survival rates as divided by annual number of ECMOs performed. In sensitivity analysis for survival performed deleting single studies, one at a time, and repeating the calculations, no single study effect was seen changing neither direction nor the magnitude of the estimates.

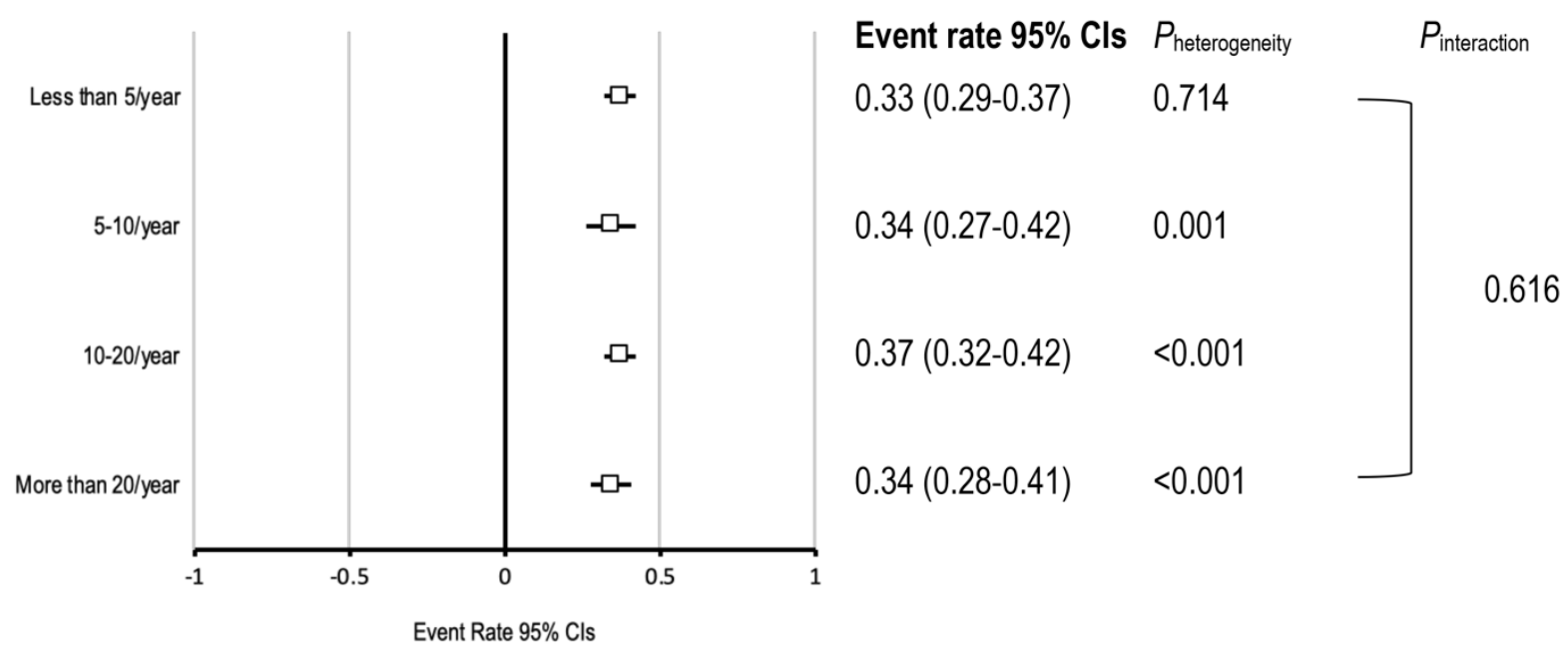

Figure 17. Subgroup analysis to assess impact of centre volume on survival: arbitrary thresholds. 


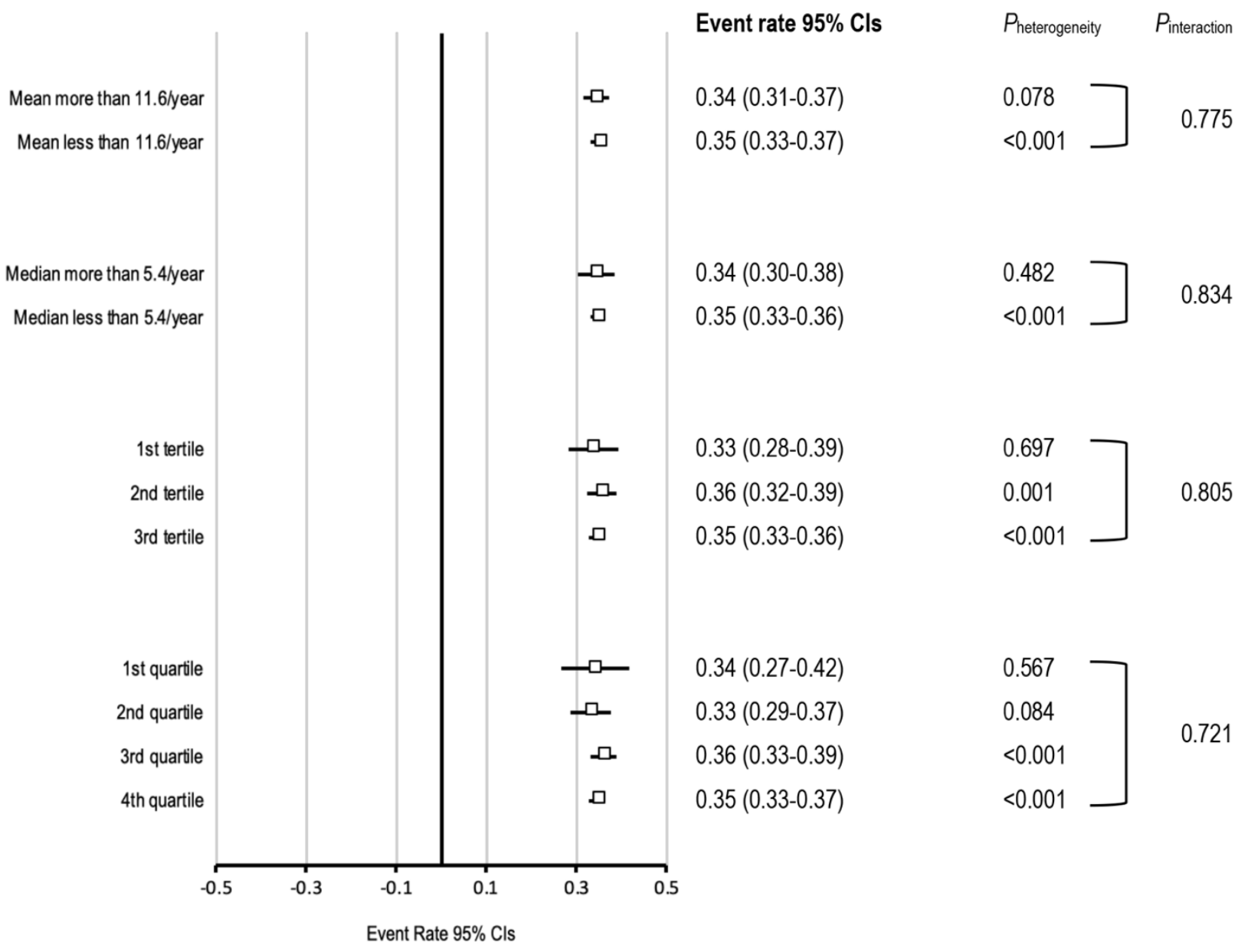

Figure 18. Subgroup analysis to assess impact of centre volume on survival: thresholds divided by mean and median number of ECMOs per year and divided in tertiles and quartiles.

\section{Discussion}

The current meta-analysis represents the first attempt to compare, although in indirect fashion, in-hospital outcomes of patients supported with VA-ECMO for refractory PCS between HTx and non-HTx centres. This research was aimed to investigate further factors other than the well-known patients' clinical status and procedure type that may affect the final outcome in PCS-ECMO patient. The care center with experience in dealing with acute and chronic end stage heart failure with expertise and prompt resources availability (medium and long term mechanical circulatory support and heart transplantation) as factor potentially affecting this outcome was the primary hypothesis of our study. 
VA-ECMO is increasingly used for cardiorespiratory support in patients affected by refractory cardiogenic shock or cardiac arrest after cardiac surgery. [2] Despite that growing worldwide utilization and experience, ECMO inhospital outcomes have not shown substantial progress. Conversely, a trend towards worse survival rates, reaching a disappointing $15 \%$ has been recently reported in another analysis of the Extracorporeal Life Support Organization registry [2]. Patients undergoing heart surgery usually present with substantial pre-ECMO comorbidities, more advanced age and above all different stages of developed heart failure. All these factors, individually or in association influence the capability of the myocardium to recover after the surgery and thus preclude favorable body response to prolonged MCS. Unfortunately, in a considerable proportion of patients, the MCS regardless of its duration, does not prompt to improved cardiac function or organ integrity; in turn, clinicians are forced to bridging the patient to more advanced treatments, such as HTx or VADs. The insights from important recently available study by Distelmeier [20] are that prolonging of VA-ECMO duration is associated with a disproportionate mortality at early and later stages. In fact, lack of cardiac function improvement within 7 days post-op. was indicative of futile support in the analysis. Consequently, this leads to conclusion that perhaps HTx or VADs in such ECMO-supported patients should be used much sooner, just in time to prevent life-threatening complications

Such hypothesis led to conception of the current study which is the first to compare, although in indirect fashion, the outcomes between $\mathrm{HTx}$ and non-HTx performing centres in patients undergoing ECMO treatment for refractory PCS. The first consideration come from the study population of this meta-analysis: The majority of patients $(4,217$ out of 4,421$)$ and number of reports (48 out of 54) come from HTx centres which might suggest that 1) cardiac surgery population in HTx performing centres are of an increased risk for developing PCS, therefore higher operative risk burden in a first place; 2) ECMO represents a tool more routinely used for the treatment of refractory PCS in the HTx units; 3) there exists an unexplained underreporting from non-HTx centres of patients undergoing ECMO treatment and their perioperative outcomes. Regardless, our main findings were that among patients with PCS no differences in 30 day/in-hospital mortality were observed between heart transplantation centres as compared to non-transplant units. This was also confirmed in a subgroup analysis. While neutral, this finding implies similar mortality rates among patients operated on in HTx and long-term 
assistance facilities as compared to patients operated in non-transplant units, given their respective potentially higher and lower baseline risk.

Second, there was no difference between the centres type with respect to limb complications, reoperation for bleeding, sepsis and acute renal injury with or without dialysis, yet neurological complications occurred less frequently in HTx centres. Neurologic complications are presumably a multifactorial entity with pre-ECMO illness severity and treatments, ECMO management, and post-ECMO events all contributing to CNS injury rates in these patients. Loss of cerebral autoregulation during severe arterial hypertension or hypotension, thromboembolic events, haemorrhage related to anticoagulation use, cerebral vasospasm, and secondary brain injury from reactive tissue oedema around an area of focal CNS injury have all been implicated in the genesis of brain injury in VA-ECMO patients. Although neurologic injury during VA-ECMO remains poorly defined in adult cohorts [16,21-23], prior investigations comprehensively report neurologic complications occurrence in 6-17\% in adults supported with VA-ECMO for postcardiotomy cardiorespiratory failure $[21,24,25]$. What seems even more illustrative, postmortem examination in adults supported with VA-ECMO has shown that neurologic injury may be clinically undetected in $23-50 \%$ of cases $[26,27]$. In the current analysis, we saw neurologic complications more frequent in non-HTx centres. While this could not be accounted for in that type of analyses, the "over-delay" to ECMO commencement in the institutions with lower experience with circulatory support systems (be that ECMO or VADs) may have played a role in the excess of strokes in this population.

Finally, patients on ECMO bridged to HTx or mechanical circulatory support are reported only in the HTx units. Single patients in non-HTx institutions died while waiting for referral to HTx hub after the decision to transplant was met. From the technical standpoint, is noteworthy to underline that the were no differences in the ECMO duration between the two centres, yet notice must be made of statistical trend for the different ECMO location placement and weaning rate; that is, ECMO was instituted in the OR more frequently in non-HTx centres but again since delay to ECMO was seldom reported, we cannot address the issue whether this might had affected patient outcome. On the other hand, this may further suggest an easier applicability of ECMO in locations other than OR in HTx-centres with possibly prompt ECMO team availability as compared to the non-HTx units. 


\section{Limitations}

Current meta-analysis is based on observational, one-arm comparisons and because of that is more prone to confounding as compared to head-to-head comparisons. On the other hand, no RCT exist regarding analyzed topic and presumably will not be organized due to ethical issues. One limitation of the study may be underrepresentation of patients treated in non-HTx institutions. Random effect meta-analysis and inverse variance analysis was used to account for that fact. These methods appoint random weights also in a subgroup analysis which could overcome discrepancies between population sizes. There was no standard definition for secondary endpoints or risk of bias of the included studies. Conducting detailed subgroup analyses was precluded by not sufficient data on timing and location of implantation, type, status and duration of surgical procedure likewise other baseline characteristic.

\section{Conclusions}

There was no apparent difference in survival after ECMO implantation for refractory PCS between centres which perform heart transplantations and those which do not. Potentially different risk profiles of patients in these centres must be taken account for before definite conclusions are drawn.

\section{References:}

1. Lawler PR, Silver DA, Scirica BM, Couper GS, Weinhouse GL, Camp PC, Jr. Extracorporeal membrane oxygenation in adults with cardiogenic shock. Circulation 2015;131:676-680.

2. Whitman GJ. Extracorporeal membrane oxygenation for the treatment of postcardiotomy shock. J Thorac Cardiovasc Surg. 2017;153:95-101

3. Stretch R, Sauer CM, Yuh DD, Bonde P. National trends in the utilization of short-term mechanical circulatory support: Incidence, outcomes, and cost analysis. J Am Coll Cardiol 2014;64:1407-1415 
4. McCarthy FH, McDermott KM, Kini V, Gutsche JT, Wald JW, Xie D et al. Trends in U.S. Extracorporeal membrane oxygenation use and outcomes: 2002-2012. Semin Thorac Cardiovasc Surg. 2015;27:8188

5. Karagiannidis C, Brodie D, Strassmann S, Stoelben E, Philipp A, Bein T et al. Extracorporeal membrane oxygenation: Evolving epidemiology and mortality. Intensive Care Med. 2016;42:889-896

6. Maxwell BG, Powers AJ, Sheikh AY, Lee PH, Lobato RL, Wong JK. Resource use trends in extracorporeal membrane oxygenation in adults: An analysis of the nationwide inpatient sample 19982009. J Thorac Cardiovasc Surg 2014;148:416-421.

7. Monaco F, Belletti A, Bove T, Landoni G, Zangrillo A. Extracorporeal membrane oxygenation: Beyond cardiac surgery and intensive care unit: Unconventional uses and future perspectives. J Cardiothorac Vasc Anesth. 2018;32:1955-1970

8. Ibanez B, James S, Agewall S, Antunes MJ, Bucciarelli-Ducci C, Bueno H et al. 2017 ESC guidelines for the management of acute myocardial infarction in patients presenting with st-segment elevation: The task force for the management of acute myocardial infarction in patients presenting with st-segment elevation of the european society of cardiology (esc). Eur Heart J. 2018;39:119-177

9. Saxena P, Neal J, Joyce LD, Greason KL, Schaff HV, Guru P et al. Extracorporeal membrane oxygenation support in postcardiotomy elderly patients: The mayo clinic experience. Ann Thorac Surg. 2015;99:2053-2060

10. Liberati A, Altman DG, Tetzlaff J, Mulrow C, Gotzsche PC, loannidis JP et al. The PRISMA statement for reporting systematic reviews and meta-analyses of studies that evaluate healthcare interventions: Explanation and elaboration. BMJ. 2009;339:b2700

11. Sterne JA, Hernan MA, Reeves BC, Savovic J, Berkman ND, Viswanathan M et al. Robins-I: A tool for assessing risk of bias in non-randomised studies of interventions. BMJ. 2016;355:i4919

12. Blackman NJ, Koval JJ. Interval estimation for Cohen's kappa as a measure of agreement. Stat Med. 2000;19:723-41. 
13. Guyot P, Ades AE, Ouwens MJ, Welton NJ. Enhanced secondary analysis of survival data: Reconstructing the data from published kaplan-meier survival curves. BMC Med Res Methodol. $2012 ; 12: 9$

14. Stijnen T, Hamza TH, Ozdemir P. Random effects meta-analysis of event outcome in the framework of the generalized linear mixed model with applications in sparse data. Stat Med. 2010;29:3046-67.

15. Sterne JA, Sutton AJ, loannidis JP, Terrin N, Jones DR, Lau J, et al. Recommendations for examining and interpreting funnel plot asymmetry in meta-analyses of randomised controlled trials. BMJ. 2011;343:d4002.

16. Chen SW, Tsai FC, Lin YS, Chang CH, Chen DY, Chou AH et al. Long-term outcomes of extracorporeal membrane oxygenation support for postcardiotomy shock. J Thorac Cardiovasc Surg. 2017;154:469477 e462

17. Santarpino G, Ruggieri VG, Mariscalco G, Bounader K, Beghi C, Fischlein T et al. Outcome in patients having salvage coronary artery bypass grafting. Am J Cardiol. 2015;116:1193-1198

18. Lorusso R, Gelsomino S, Parise O, Mendiratta P, Prodhan P, Rycus P et al. Venoarterial extracorporeal membrane oxygenation for refractory cardiogenic shock in the elderly patients: Trends in application and outcome from the extracorporeal life support organization (ELSO) registry. Ann Thorac Surg. $2017 ; 104: 62-69$

19. Di Mauro M, Lorusso R. Time is your best friend, but it soon becomes your worst enemy: The conflict of venoarterial extracorporeal membrane oxygenation in cardiac surgery. J Thorac Cardiovasc Surg. $2018 ; 155: 2477-2478$

20. Distelmaier K, Wiedemann D, Binder C, Haberl T, Zimpfer D, Heinz G, Koinig H, Felli A, Steinlechner B, Niessner A, Laufer G, Lang IM, Goliasch G. Duration of extracorporeal membrane oxygenation support and survival in cardiovascular surgery patients. J Thorac Cardiovasc Surg. 2018;155:2471-2476

21. Wu MY, Lin PJ, Lee MY, Tsai FC, Chu JJ, Chang YS et al. Using extracorporeal life support to resuscitate adult postcardiotomy cardiogenic shock: Treatment strategies and predictors of short-term and midterm survival. Resuscitation. 2010;81:1111-1116 
22. Zangrillo A, Landoni G, Biondi-Zoccai G, Greco M, Greco T, Frati G et al. A meta-analysis of complications and mortality of extracorporeal membrane oxygenation. Crit Care Resusc. 2013;15:172178

23. Hei F, Lou S, Li J, Yu K, Liu J, Feng Z et al. Five-year results of 121 consecutive patients treated with extracorporeal membrane oxygenation at fu wai hospital. Artif Organs. 2011;35:572-578

24. Rastan AJ, Dege A, Mohr M, Doll N, Falk V, Walther T et al. Early and late outcomes of 517 consecutive adult patients treated with extracorporeal membrane oxygenation for refractory postcardiotomy cardiogenic shock. J Thorac Cardiovasc Surg. 2010;139:302-311, 311 e301

25. Ko WJ, Lin CY, Chen RJ, Wang SS, Lin FY, Chen YS. Extracorporeal membrane oxygenation support for adult postcardiotomy cardiogenic shock. Ann Thorac Surg. 2002;73:538-545

26. Rastan AJ, Lachmann N, Walther T, Doll N, Gradistanac T, Gommert JF et al. Autopsy findings in patients on postcardiotomy extracorporeal membrane oxygenation (ecmo). Int $\mathrm{J}$ Artif Organs. 2006;29:1121-1131

27. Mehta A, Ibsen LM. Neurologic complications and neurodevelopmental outcome with extracorporeal life support. World J Crit Care Med. 2013;2:40-47

\section{References to included studies:}

1. Acheampong B, Johnson JN, Stulak JM, Dearani JA, Kushwaha SS, Daly RC, Haile DT, Schears GJ. Postcardiotomy ecmo support after high-risk operations in adult congenital heart disease. Congenit Heart Dis. 2016;11:751-755 1.

2. Bakhtiary F, Keller H, Dogan S, Dzemali O, Oezaslan F, Meininger D, Ackermann H, Zwissler B, Kleine P, Moritz A. Venoarterial extracorporeal membrane oxygenation for treatment of cardiogenic shock: Clinical experiences in 45 adult patients. J Thorac Cardiovasc Surg. 2008;135:382-388

3. Beckmann E, Ismail I, Cebotari S, Busse A, Martens A, Shrestha M, Kuhn C, Haverich A, Fegbeutel C. Right-sided heart failure and extracorporeal life support in patients undergoing pericardiectomy for 
constrictive pericarditis: A risk factor analysis for adverse outcome. Thorac Cardiovasc Surg. $2017 ; 65: 662-670$

4. Beiras-Fernandez A, Deutsch MA, Kainzinger S, Kaczmarek I, Sodian R, Ueberfuhr P, Meiser B, Schmoeckel M, Reichart B, Brenner P. Extracorporeal membrane oxygenation in 108 patients with low cardiac output - a single-center experience. Int J Artif Organs. 2011;34:365-373

5. Biancari F, Dalen M, Perrotti A, Fiore A, Reichart D, Khodabandeh S, Gulbins H, Zipfel S, Al Shakaki M, Welp H, Vezzani A, Gherli T, Lommi J, Juvonen T, Svenarud P, Chocron S, Verhoye JP, Bounader K, Gatti G, Gabrielli M, Saccocci M, Kinnunen EM, Onorati F, Santarpino G, Alkhamees K, Ruggieri VG, Dell'Aquila AM. Venoarterial extracorporeal membrane oxygenation after coronary artery bypass grafting: Results of a multicenter study. Int J Cardiol. 2017;241:109-114

6. Burrell AJ, Pellegrino VA, Wolfe R, Wong WK, Cooper DJ, Kaye DM, Pilcher DV. Long-term survival of adults with cardiogenic shock after venoarterial extracorporeal membrane oxygenation. J Crit Care. 2015;30:949-956

7. Carroll BJ, Shah RV, Murthy V, McCullough SA, Reza N, Thomas SS, Song TH, Newton-Cheh CH, Camuso JM, MacGillivray T, Sundt TM, Semigran MJ, Lewis GD, Baker JN, Garcia JP. Clinical features and outcomes in adults with cardiogenic shock supported by extracorporeal membrane oxygenation. Am J Cardiol. 2015;116:1624-1630

8. Chen YC, Tsai FC, Chang $\mathrm{CH}$, Lin $\mathrm{CY}$, Jenq CC, Juan KC, Hsu HH, Chang MY, Tian YC, Hung CC, Fang JT, Yang CW. Prognosis of patients on extracorporeal membrane oxygenation: The impact of acute kidney injury on mortality. Ann Thorac Surg. 2011;91:137-142

9. Combes A, Leprince P, Luyt CE, Bonnet N, Trouillet JL, Leger P, Pavie A, Chastre J. Outcomes and long-term quality-of-life of patients supported by extracorporeal membrane oxygenation for refractory cardiogenic shock. Crit Care Med. 2008;36:1404-1411

10. Distelmaier K, Wiedemann D, Binder C, Haberl T, Zimpfer D, Heinz G, Koinig H, Felli A, Steinlechner B, Niessner A, Laufer G, Lang IM, Goliasch G. Duration of extracorporeal membrane oxygenation support and survival in cardiovascular surgery patients. J Thorac Cardiovasc Surg. 2017 
11. Distelmaier K, Schrutka L, Binder C, Steinlechner B, Heinz G, Lang IM, Ristl R, Maurer G, Koinig H, Wiedemann D, Rutzler K, Niessner A, Goliasch G. Cardiac arrest does not affect survival in postoperative cardiovascular surgery patients undergoing extracorporeal membrane oxygenation. Resuscitation. 2016;104:24-27

12. Doll N, Fabricius A, Borger MA, Bucerius J, Doll S, Kramer K, Ullmann C, Schmitt DV, Walther T, Falk V, Mohr FW. Temporary extracorporeal membrane oxygenation in patients with refractory postoperative cardiogenic shock--a single center experience. J Card Surg. 2003;18:512-518

13. Elsharkawy HA, Li L, Esa WA, Sessler DI, Bashour CA. Outcome in patients who require venoarterial extracorporeal membrane oxygenation support after cardiac surgery. J Cardiothorac Vasc Anesth. 2010;24:946-951

14. Fiser SM, Tribble CG, Kaza AK, Long SM, Zacour RK, Kern JA, Kron IL. When to discontinue extracorporeal membrane oxygenation for postcardiotomy support. Ann Thorac Surg. 2001;71:210-214

15. Guihaire J, Dang Van S, Rouze S, Rosier S, Roisne A, Langanay T, Corbineau H, Verhoye JP, Flecher E. Clinical outcomes in patients after extracorporeal membrane oxygenation support for post-cardiotomy cardiogenic shock: A single-centre experience of 92 cases. Interact Cardiovasc Thorac Surg. 2017;25:363-369

16. Hsu PS, Chen JL, Hong GJ, Tsai YT, Lin CY, Lee CY, Chen YG, Tsai CS. Extracorporeal membrane oxygenation for refractory cardiogenic shock after cardiac surgery: Predictors of early mortality and outcome from 51 adult patients. Eur J Cardiothorac Surg. 2010;37:328-333

17. Kanji HD, Schulze CJ, Oreopoulos A, Lehr EJ, Wang W, MacArthur RM. Peripheral versus central cannulation for extracorporeal membrane oxygenation: A comparison of limb ischemia and transfusion requirements. Thorac Cardiovasc Surg. 2010;58:459-462

18. Ko WJ, Lin CY, Chen RJ, Wang SS, Lin FY, Chen YS. Extracorporeal membrane oxygenation support for adult postcardiotomy cardiogenic shock. Ann Thorac Surg. 2002;73:538-545 
19. Lamarche $\mathrm{Y}$, Chow B, Bedard A, Johal N, Kaan A, Humphries KH, Cheung A. Thromboembolic events in patients on extracorporeal membrane oxygenation without anticoagulation. Innovations (Phila). 2010;5:424-429

20. Li CL, Wang H, Jia M, Ma N, Meng X, Hou XT. The early dynamic behavior of lactate is linked to mortality in postcardiotomy patients with extracorporeal membrane oxygenation support: A retrospective observational study. J Thorac Cardiovasc Surg. 2015;149:1445-1450

21. Liden H, Wiklund L, Haraldsson A, Berglin E, Hultman J, Dellgren G. Temporary circulatory support with extra corporeal membrane oxygenation in adults with refractory cardiogenic shock. Scand Cardiovasc J. 2009;43:226-232

22. Liu KS, Tsai FC, Huang YK, Wu MY, Chang YS, Chu JJ, Lin PJ. Extracorporeal life support: A simple and effective weapon for postcardiotomy right ventricular failure. Artif Organs. 2009;33:504-508

23. Loforte A, Marinelli G, Musumeci F, Folesani G, Pilato E, Martin Suarez S, Montalto A, Lilla Della Monica P, Grigioni F, Frascaroli G, Menichetti A, Di Bartolomeo R, Arpesella G. Extracorporeal membrane oxygenation support in refractory cardiogenic shock: Treatment strategies and analysis of risk factors. Artif Organs. 2014;38:E129-141

24. Luo XJ, Wang W, Hu SS, Sun HS, Gao HW, Long C, Song YH, Xu JP. Extracorporeal membrane oxygenation for treatment of cardiac failure in adult patients. Interact Cardiovasc Thorac Surg. 2009;9:296-300

25. Mazzeffi MA, Sanchez PG, Herr D, Krause E, Evans CF, Rector R, McCormick B, Pham S, Taylor B, Griffith B, Kon ZN. Outcomes of extracorporeal cardiopulmonary resuscitation for refractory cardiac arrest in adult cardiac surgery patients. J Thorac Cardiovasc Surg. 2016;152:1133-1139

26. Meyer AL, Strueber M, Tomaszek S, Goerler A, Simon AR, Haverich A, Fischer S. Temporary cardiac support with a mini-circuit system consisting of a centrifugal pump and a membrane ventilator. Interact Cardiovasc Thorac Surg. 2009;9:780-783 
27. Musial R, Ochonska K, Proc A, Stolinski J, Plicner D, Kapelak B, Drwila R. Veno-arterial extracorporeal membrane oxygenation as cardiogenic shock therapy support in adult patients after heart surgery. Kardiochir Torakochirurgia Pol. 2017;14:32-36

28. Papadopoulos N, Marinos S, El-Sayed Ahmad A, Keller H, Meybohm P, Zacharowski K, Moritz A, Zierer A. Risk factors associated with adverse outcome following extracorporeal life support: Analysis from 360 consecutive patients. Perfusion. 2015;30:284-290

29. Park SJ, Kim SP, Kim JB, Jung SH, Choo SJ, Chung CH, Lee JW. Blood lactate level during extracorporeal life support as a surrogate marker for survival. J Thorac Cardiovasc Surg. 2014;148:714720

30. Peigh G, Cavarocchi N, Keith SW, Hirose H. Simple new risk score model for adult cardiac extracorporeal membrane oxygenation: Simple cardiac ecmo score. J Surg Res. 2015;198:273-279

31. Pokersnik JA, Buda T, Bashour CA, Gonzalez-Stawinski GV. Have changes in ecmo technology impacted outcomes in adult patients developing postcardiotomy cardiogenic shock? J Card Surg. $2012 ; 27: 246-252$

32. Pontailler M, Demondion P, Lebreton G, Golmard JL, Leprince P. Experience with extracorporeal life support for cardiogenic shock in the older population more than 70 years of age. ASAIO J. 2017;63:279284

33. Ranucci M, Ballotta A, Kandil H, Isgro G, Carlucci C, Baryshnikova E, Pistuddi V, Surgical, Clinical Outcome Research G. Bivalirudin-based versus conventional heparin anticoagulation for postcardiotomy extracorporeal membrane oxygenation. Crit Care. 2011;15:R275

34. Rastan AJ, Dege A, Mohr M, Doll N, Falk V, Walther T, Mohr FW. Early and late outcomes of 517 consecutive adult patients treated with extracorporeal membrane oxygenation for refractory postcardiotomy cardiogenic shock. J Thorac Cardiovasc Surg. 2010;139:302-311, 311 e301

35. Rousse N, Juthier F, Pincon C, Hysi I, Banfi C, Robin E, Fayad G, Jegou B, Prat A, Vincentelli A. Ecmo as a bridge to decision: Recovery, vad, or heart transplantation? Int J Cardiol. 2015;187:620-627 
36. Rubino A, Costanzo D, Stanszus D, Valchanov K, Jenkins D, Sertic F, Fowles JA, Vuylsteke A. Central veno-arterial extracorporeal membrane oxygenation (c-va-ecmo) after cardiothoracic surgery: A singlecenter experience. J Cardiothorac Vasc Anesth. 2017

37. Russo CF, Cannata A, Lanfranconi M, Bruschi G, Milazzo F, Paino R, Martinelli L. Veno-arterial extracorporeal membrane oxygenation using levitronix centrifugal pump as bridge to decision for refractory cardiogenic shock. J Thorac Cardiovasc Surg. 2010;140:1416-1421

38. Saxena P, Neal J, Joyce LD, Greason KL, Schaff HV, Guru P, Shi WY, Burkhart H, Li Z, Oliver WC, Pike RB, Haile DT, Schears GJ. Extracorporeal membrane oxygenation support in postcardiotomy elderly patients: The mayo clinic experience. Ann Thorac Surg. 2015;99:2053-2060

39. Slottosch I, Liakopoulos O, Kuhn E, Deppe AC, Scherner M, Madershahian N, Choi YH, Wahlers T. Outcomes after peripheral extracorporeal membrane oxygenation therapy for postcardiotomy cardiogenic shock: A single-center experience. J Surg Res. 2013;181:e47-55

40. Slottosch I, Liakopoulos O, Kuhn E, Scherner M, Deppe AC, Sabashnikov A, Mader N, Choi YH, Wippermann J, Wahlers T. Lactate and lactate clearance as valuable tool to evaluate ecmo therapy in cardiogenic shock. J Crit Care. 2017;42:35-41

41. Truby L, Mundy L, Kalesan B, Kirtane A, Colombo PC, Takeda K, Fukuhara S, Naka Y, Takayama H. Contemporary outcomes of venoarterial extracorporeal membrane oxygenation for refractory cardiogenic shock at a large tertiary care center. ASAIO J. 2015;61:403-409

42. Tsai TY, Tsai FC, Fan PC, Chang CH, Lin CY, Chang WW, Lee SY, Hsu HH, Tian YC, Fang JT, Yang CW, Chen YC. Application of the age, creatinine, and left ventricular ejection fraction score for patients on extracorporeal membrane oxygenation. Artif Organs. 2017;41:146-152

43. Wang J, Han J, Jia Y, Zeng W, Shi J, Hou X, Meng X. Early and intermediate results of rescue extracorporeal membrane oxygenation in adult cardiogenic shock. Ann Thorac Surg. 2009;88:18971903

44. Wang JG, Han J, Jia YX, Zeng W, Hou XT, Meng X. Outcome of veno-arterial extracorporeal membrane oxygenation for patients undergoing valvular surgery. PLoS One. 2013;8:e63924 
45. Wu MY, Lin PJ, Lee MY, Tsai FC, Chu JJ, Chang YS, Haung YK, Liu KS. Using extracorporeal life support to resuscitate adult postcardiotomy cardiogenic shock: Treatment strategies and predictors of short-term and midterm survival. Resuscitation. 2010;81:1111-1116

46. Xie HX, Yang F, Jiang CJ, Wang JH, Hou DB, Wang JG, Wang H, Hou XT. [predictors of in-hospital mortality in adult postcardiotomy cardiacgenic shock patients successfully weaned from venoarterial extracorporeal membrane oxygenation]. Zhonghua Yi Xue Za Zhi. 2017;97:929-933

47. Zhang R, Kofidis T, Kamiya H, Shrestha M, Tessmann R, Haverich A, Klima U. Creatine kinase isoenzyme mb relative index as predictor of mortality on extracorporeal membrane oxygenation support for postcardiotomy cardiogenic shock in adult patients. Eur J Cardiothorac Surg. 2006;30:617-620

48. Zhao Y, Xing J, Du Z, Liu F, Jia M, Hou X. Extracorporeal cardiopulmonary resuscitation for adult patients who underwent post-cardiac surgery. Eur J Med Res. 2015;20:83

49. Zhong Z, Jiang C, Yang F, Hao X, Xing J, Wang H, Hou X. Veno-arterial extracorporeal membrane oxygenation support in patients undergoing aortic surgery. Artif Organs. 2017;41:1113-1120

50. Ariyaratnam P, McLean LA, Cale AR, Loubani M. Extra-corporeal membrane oxygenation for the postcardiotomy patient. Heart Fail Rev. 2014;19:717-725

51. Deschka H, Machner M, El Dsoki S, Alken A, Wimmer-Greinecker G. Central closed chest implantation of extracorporeal membrane oxygenation to prevent limb ischemia. Int J Artif Organs. 2013;36:687-692

52. Khorsandi M, Shaikhrezai K, Prasad S, Pessotto R, Walker W, Berg G, Zamvar V. Advanced mechanical circulatory support for post-cardiotomy cardiogenic shock: A 20-year outcome analysis in a nontransplant unit. J Cardiothorac Surg. 2016;11:29

53. Mikus E, Tripodi A, Calvi S, Giglio MD, Cavallucci A, Lamarra M. Centrimag venoarterial extracorporeal membrane oxygenation support as treatment for patients with refractory postcardiotomy cardiogenic shock. ASAIO J. 2013;59:18-23

54. Raffa GM, Gelsomino S, Sluijpers N, Meani P, Alenizy K, Natour E, Bidar E, Johnson DM, Makhoul M, Heuts S, Lozekoot P, Kats S, Schreurs R, Delnoij T, Montalti A, Sels JW, Poll MV, Roekaerts P, 
Maessen J, Lorusso R. In-hospital outcome of post-cardiotomy extracorporeal life support in adult patients: The 2007-2017 maastricht experience. Crit Care Resusc. 2017;19:53-61

55. Unosawa S, Sezai A, Hata M, Nakata K, Yoshitake I, Wakui S, Kimura H, Takahashi K, Hata H, Shiono M. Long-term outcomes of patients undergoing extracorporeal membrane oxygenation for refractory postcardiotomy cardiogenic shock. Surg Today. 2013;43:264-270 
57.

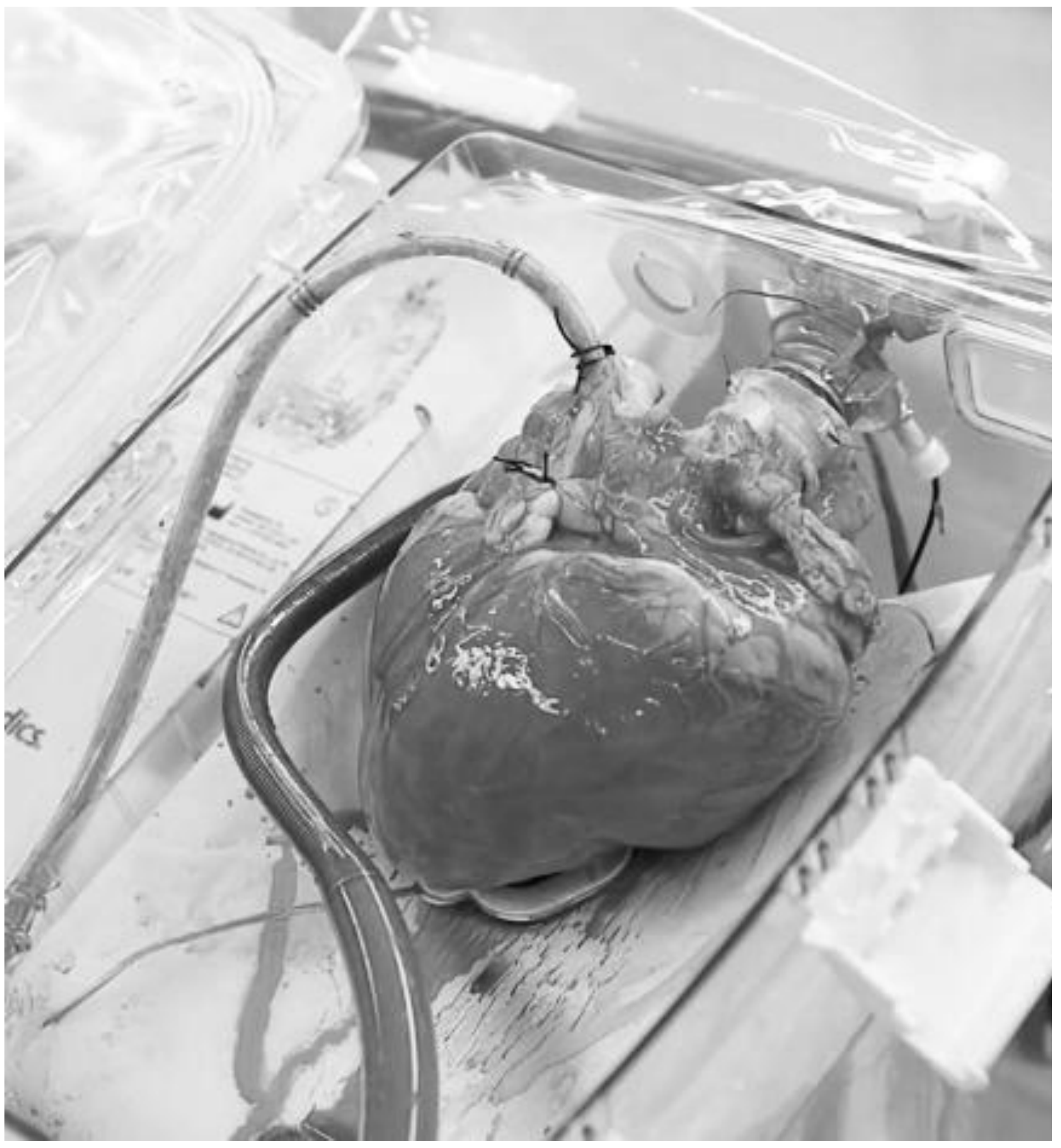


CHAPTER 7

CARDIOGENIC SHOCK AND VENO-ARTERIAL ECLS IN HEART TRANSPLANTATION/VAD CENTRES AS COMPARED TO NON-TRANSPLANT/VAD UNITS. META-ANALYSIS.

Kowalewski M*, Zieliński $K^{\star}$, Gozdek M, Raffa GM, Pilato M, Alanazi M, Gilbers M, Heuts S, Natour E, Bidar E, Schreurs R, Delnoij T, Driessen R, Sels JW, van de Poll M, Roekaerts P, Meani P, Pasierski M, Suwalski P, Lorusso $R$.

ESC: Heart Failure 2020 (accepted, ahead of print), 
Objectives: Since reported mortality on veno-arterial (V-A) extracorporeal life support (ECLS) substantially vary between centers, aim of the current analysis was to assess the outcomes between units performing heart transplantation and/or implanting ventricular assist device (HTx/VAD) versus non-HTx/VAD units in patients undergoing V-A ECLS for cardiogenic shock.

Methods: Systematic search according to PRISMA was performed using PubMed/Medline databases between 2010 and 2019. Articles reporting in-hospital/30-day mortality and centre's HTx/VAD status were included. Inhospital outcomes and long-term survival were analysed in subgroup meta-analysis.

Results: 174 studies enrolling $N=13,308$ patients were included with 20 series performed in non-HTX/VAD centres (1,016 patients, 7.8\%). Majority of patients underwent V-A ECLS for postcardiotomy shock (44.2\%) and acute myocardial infarction (20.7\%). Estimated overall in-hospital mortality was 57.2\% (54.9-59.4\%). Mortality rates were higher in non-HTx/VAD (65.5\% [59.8-70.8\%]) as compared to HTx/VAD centres (55.8\% [53.358.2\%]); $P<0.001$. Estimated late survival was $61.8 \%(55.7-67.9 \%)$ without differences between non-HTx/VAD and HTx/VAD centres: $66.5 \%$ (30.3-1.02\%) vs 61.7\% (55.5-67.8\%), respectively ( $p=0.797)$. No differences were seen with respect to ECLS duration, limb complications, reoperations for bleeding, kidney injury and sepsis. Yet, weaning rates were higher in HTx/VAD vs non-HTx/VAD centres $58.7 \%(56.2-61.1 \%)$ vs $48.9 \%$ (42.0-55.9\%): $p=0.010$. Estimated rate of bridge to heart transplant was $6.6 \%(5.2-8.3 \%)$ with numerical, yet not statistically significant difference between non-HTxNAD (2.7\% [0.8-8.3\%]) as compared to HTx/VAD (6.7\% [5.3-8.6\%]) $(p=0.131)$.

Conclusions: Survival after V-A ECLS differed according to centre's HTX/VAD status. Potentially different risk profiles of patients must be taken account for before definite conclusions are drawn.

\section{Introduction}

Despite advances in revascularization strategies, operative techniques and management, as well as heart failure therapy, cardiogenic shock (CS), regardless whether resulting from acute, chronic or end-stage heart condition, 
continues to be associated with significant morbidity and mortality [1]. Nowadays, veno-arterial (V-A) extracorporeal life support (ECLS) is widely recognized as an efficient and easy to implant mechanical support system (MCS), providing efficient, both hemodynamic and respiratory support. It safeguards end-organ perfusion during the shock state, thereby, serves as a bridge to recovery of cardiac function, heart transplantation (HTx) or more durable ventricle assist device (VAD) $[2,3,4,5]$. Despite that, V-A ECLS still represents a resource-consuming modality and mostly last resort of treatment. In most cases, centres' protocols and resources limit ECLS implementation to highest risk patients which are least likely to benefit from such therapies $[4,6,7,8,9]$. Since CS arises from a plethora of underlying impaired cardiovascular and since conducting a randomized controlled trial in this peculiar setting would raise ethical questions, V-A ECLS's optimal implementation and management in patients with CS has not been well studied or defined. Despite growing worldwide utilization and experience in MCS, outcomes of patients undergoing V-A ECLS, in particular inhospital mortality, have not shown substantial progress $[4,10]$. Interestingly, they are fairly different from centre to centre suggesting that variations in practice patterns in management of cardiogenic shock endure and may play a role in driving the above differences $[11,39]$. These might include different schemes of timing of cardiogenic shock recognition, tailored escalation to mechanical circulatory support, centralization of care and hemodynamic monitoring. We hypothesized that readability of well-experienced ECLS teams and potentially shorter bridging times in HTx/VAD units may contribute to improved results. Therefore, we undertook a systematic review and meta-analysis to assess to which extent do the in-hospital and remote outcomes differ across patients in cardiogenic shock and receiving V-A ECLS treatment in HTX/VAD as compared to nonHTx/VAD facilities.

\section{Methods}

\section{Data sources and search strategy}

This systematic review and meta-analysis was performed in accordance with the Preferred Reporting Items for Systematic Reviews and meta-analyses (PRISMA) statement [12]. Relevant studies to be included were searched for until November 30th 2019, through PubMed, EMBASE, CINAHL, the Web of Science, the Cochrane 
Register of Controlled Clinical Trials (CENTRAL) and Google Scholar. Abstracts were eligible for detailed assessment if available online and reporting outcomes of interest. The search term was: "extracorporeal membrane oxygenation", "extracorporeal life support" and "cardiogenic shock". No language restrictions were imposed. References of original articles were reviewed manually and cross-checked for other relevant reports.

\section{Selection criteria and quality assessment}

Studies were included if they met all of the following criteria: 1) human study; 2) studies assessing survival after ECLS instituted for refractory CS regardless of underlying conditions; 3 ) studies conducted in the setting of V-A ECLS or studies conducted in combined setting of veno-arterial and veno-venous (V-V) ECLS, but reporting at least one of the outcomes of interest for the former group. Studies were only excluded if: 1) paediatric and congenital heart surgery-related studies; 2) animal studies; 3) conducted entirely in the setting of V-V ECLS regardless of underlying conditions; and 4) studies not reporting survival/mortality rates. Studies were only eligible if reporting the transplant status of the centre; whenever this was not retrievable from the individual study, institutional website was searched for information regarding range of procedures performed. Lack of clear indication whether the centre performs heart transplantation led to exclusion of the study. Similarly, registries incorporating multiple centres but not reporting the status for single facilities were not considered. Studies reporting in both paediatric and adult population were considered only if pertinent data was available for adult subset or in case paediatric population was $<15 \%$ of the study. Mixed V-A ECLS configurations were also eligible such as standard V-A ECLS, veno-veno-arterial (V-VA) and/or veno-arterial-venous (V-AV) setting. Studies conducted in centres performing VAD only were pooled with those performing HTx and VADs. Reviews and case reports were not considered.

Two independent reviewers (G.M.R and K.Z.) selected the studies for inclusion, extracted studies, as well as patient characteristics of interest and relevant outcomes. Two authors (G.M.R. and K.Z.) independently assessed the trials' eligibility and risk of bias. Risk of bias at the individual study level was assessed using the ROBINS-I tool (Risk of Bias in Not-randomized Studies-of Interventions) [13]. Any divergences were resolved by a third reviewer (M.K.) and quantified using the approach of Cohen's kappa [14]. 


\section{Endpoint selection}

The primary endpoint was in-hospital mortality. Secondary endpoints were in-hospital neurologic complications, limb complications, bleeding, sepsis and acute kidney failure with or without continuous veno-venous hemofiltration (CVVH). Bridging to VAD and/or HTx was analysed as well. Neurological complications encompassed cerebrovascular events, strokes, transient ischemic attacks and other ischemic and haemorrhagic brain complications. A separate analysis of brain death was also conducted. Long-term survival was assessed at longest "out-of" hospital follow-up available. Outcome definitions were the ones adopted by the investigators of the included studies.

\section{Statistical analysis}

Statistical analyses were performed in Comprehensive Meta-Analysis, v. 2 (Biostat, Englewood, NJ). The results are expressed as pooled untransformed proportions (e.g. event rates (\%) and means with their $95 \%$ confidence intervals $(\mathrm{Cl})$. Heterogeneity across studies was evaluated using the $\mathrm{l}^{2}$ test. Whenever a single study reported median values and interquartile ranges instead of mean $\pm S D$, the latter were approximated as described by Wan et al [15]. Where available, we digitised Kaplan-Meier curves using Engauge Digitizer 9.5 (Mark Mitchell, Torrance, CA) and reconstructed time-to-event data using the algorithm specified by Guyot et al [16]. To control for the anticipated heterogeneity among observational studies, absolute values and means were pooled using random effects models. Studies were stratified a priori based on the centre status (non-HTx/VAD vs HTx/VAD performing centre); the interaction coefficient (Q-value) is provided for the comparison non-HTx/VAD vs HTx/VAD along with respective $P_{\text {interaction. Additionally, we investigated if non-HTx/VAD and HTx/VAD status had }}$ influence on ECLS duration, weaning rates, bridging to HTx/VAD rates; and further if ECLS duration and weaning rates in these centres correlated with bridging to HTXNAD by means of meta-regression analyses [17]. For the analysis of long-term survival study-level data were analyzed according to the original report for which outcome data were available. To account for potential differences in study's duration of follow-up, rate ratios (RRs) with $95 \% \mathrm{Cl}$ derived from an analysis with adjusted models by person-years, a measure incorporating study duration, were used as summary statistics. Sensitivity analyses were performed by excluding from analyses single 
studies, one at a time, and repeating the calculations for primary endpoint. Publication bias was assessed 1) by visual approach plotting log event rate against standard error in the funnel plot [18]; and 2) by linear regression approach [egger's regression]

\section{Results}

\section{Study characteristics}

Initial search process yielded 48,226 records; of these, 761 abstracts were retrieved for scrutiny based on the item's title. Registries were excluded since they incorporated both non-HTx/VAD and HTx/VAD centres. Following detailed assessment, 174 studies $(\mathrm{N}=13,038)$ [references to included studies] met inclusion criteria and entered quantitative analyses (Figure 1). Included studies were divided into non-HTx/VAD vs HTx/VAD centres subgroups: 154 studies including 12,022 (92.2\%) patients were conducted in HTx whereas 20 studies $(1,016$ patients [7.8\%]) in non-HTxNAD centres. Prevalence of ECLS ranged from $0.26 \%$ [190] to $22.6 \%$ [55].

Studies were mostly conducted in the setting of postcardiotomy CS (44.2\%) and acute myocardial infarction (20.7\%) followed by other indications. Distribution of patients across range of indications for V-A ECLS is detailed in Figure 2.

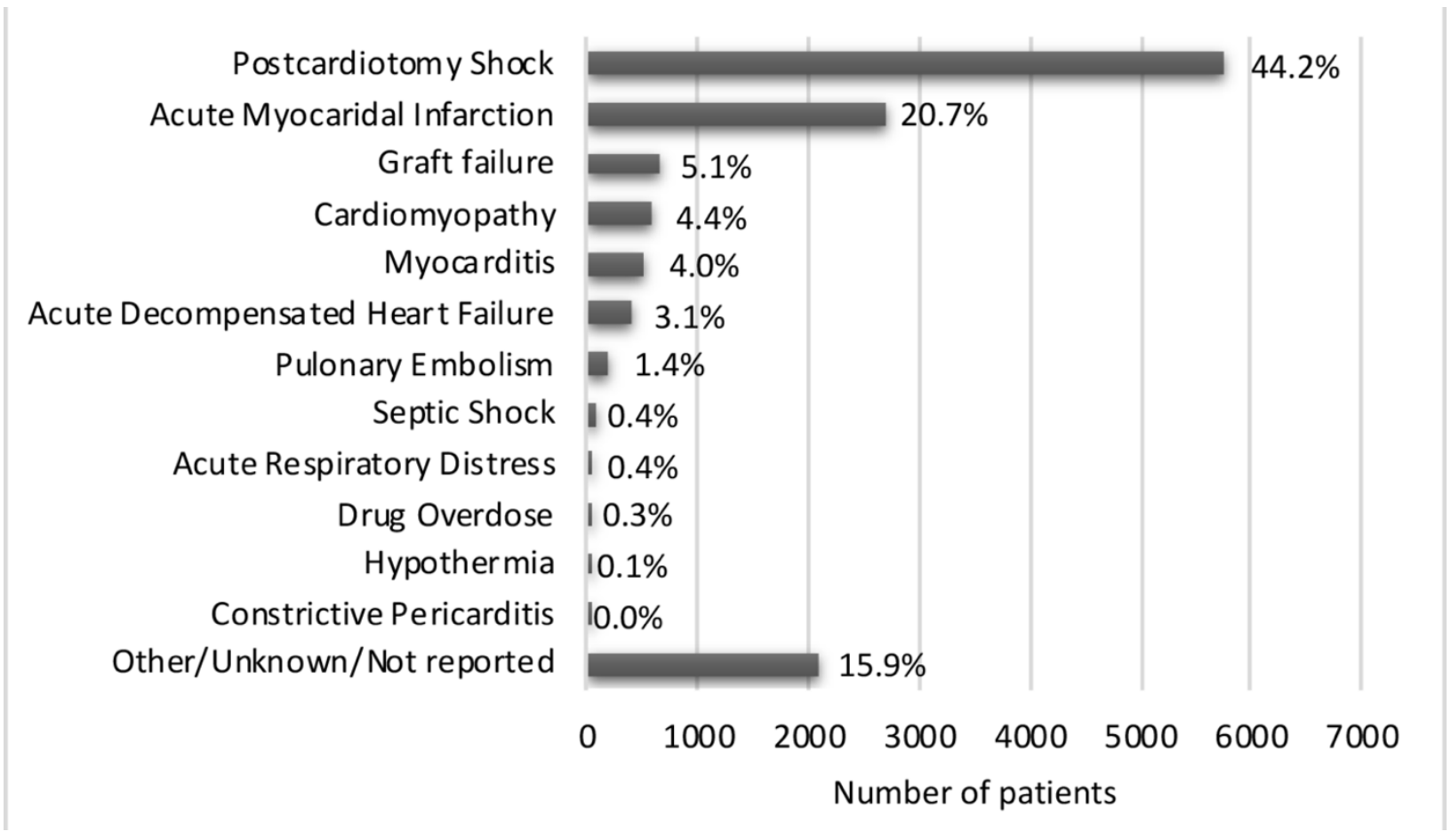

Figure 2. Distribution of patients across range of indications for veno-arterial extracorporeal membrane oxygenation. 

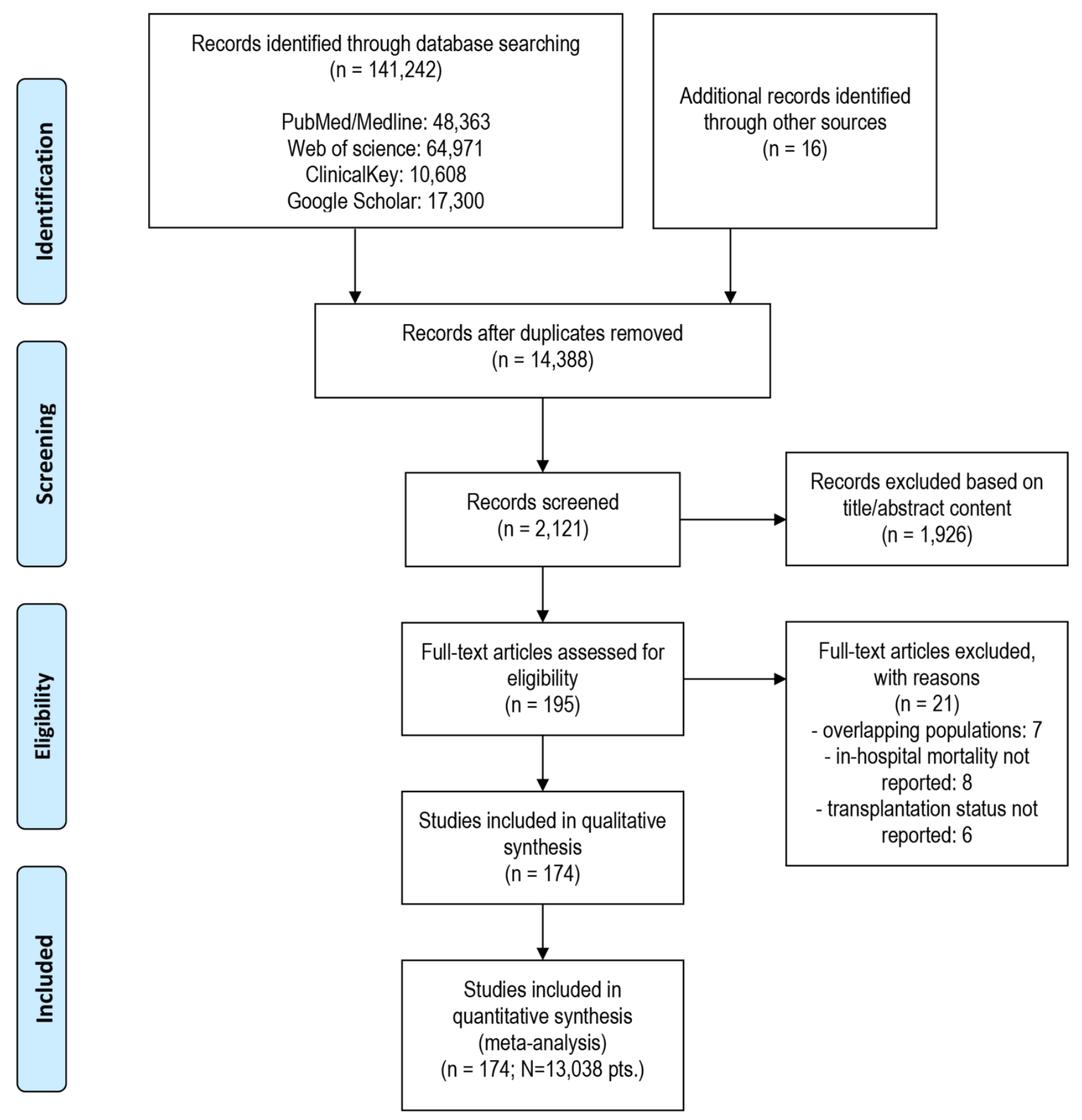

Figure 1. Study selection process according to PRISMA guidelines.

Detailed characteristics of included studies as well as patients' baseline and surgical data are available as

Table 1 and Table 2. Publication bias analysis along with reasons for bias risk increase is available as Table 3. 
Table 1. Study characteristics.

\begin{tabular}{|c|c|c|c|c|c|}
\hline Study & $\begin{array}{c}\text { Prevalence } \\
(\%)\end{array}$ & $\begin{array}{l}\text { N. of } \\
\text { pts }\end{array}$ & $\begin{array}{c}\text { Age } \\
\text { (years) }\end{array}$ & $(\%)$ & PCS \\
\hline \multicolumn{6}{|l|}{ HTx/NAD centres } \\
\hline Acheampong 2016 & 1.06 & 24 & 41 (IQR: 22-75) & 58.3 & 100 \\
\hline Akin S 2019 & NR & 103 & $49.0 \pm 16.0$ & 54 & 48 \\
\hline Ariza-Sole A 2015 & NR & 29 & NR & 72 & 0 \\
\hline Arpesella 2008 & 5.85 & 11 & $49.4 \pm 13.9$ & 72.7 & 100 \\
\hline Asaumi Y 2005 & NR & 27 & $35.6 \pm 16.5$ & 70.4 & 0 \\
\hline Aubin H 2016 & NR & 115 & $56 \pm 15$ & 74 & 0 \\
\hline Avalli 2012 & NR & 42 & 58 & 73.8 & 19 \\
\hline Aziz TA 2010 & NR & 10 & $45 \pm 18$ & 50 & 40 \\
\hline Bakhtiary 2008 & 0.78 & 45 & $60.1 \pm 13.6$ & 77.8 & 96 \\
\hline Barth 2011 & NR & 242 & NR & NR & 13 \\
\hline Beckmann 2017 & NR & 8 & $50.1 \pm 15.8$ & 62.5 & 38 \\
\hline Bednarczyk 2014 & NR & 32 & $55 \pm 11$ & 66 & 0 \\
\hline Beiras-Fernandez 2011 & NR & 73 & $49.3 \pm 18.0$ & 64.4 & 74 \\
\hline Bermudez 2011 & NR & 33 & 55 & 81 & 0 \\
\hline Bermudez 2011 (2) & NR & 9 & 48 & 88 & 0 \\
\hline Beurtheret 2013 & NR & 87 & $46 \pm 15$ & 68 & 0 \\
\hline Biancari 2017 & 0.6 & 148 & $65.4 \pm 9.4$ & 78.4 & 100 \\
\hline Boulate D 2013 & NR & 55 & 51.2 & 80 & 0 \\
\hline Cakici 2016 & NR & 148 & $56.6 \pm 12$ & 66.9 & 30 \\
\hline Carroll 2015 & NR & 123 & $47 \pm 2$ & 69.1 & 21 \\
\hline Centofanti 2017 & NR & 24 & $46.0 \pm 14.41$ & 54.2 & 17 \\
\hline Chamogeorgakis 2013 & NR & 308 & $57.2 \pm 14.9$ & 64 & 56 \\
\hline Chen 2011 & NR & 102 & $47 \pm 2$ & 60.8 & 59 \\
\hline Chen YS 1999 & NR & 2 & $27 \pm 2.8$ & 50 & 0 \\
\hline Chen YS 2005 & NR & 10 & $35 \pm 16.1$ & NR & 0 \\
\hline Cho YH 2015 & NR & 25 & $41.3 \pm 17.2$ & 72 & 16 \\
\hline Choi D-H 2016 & NR & 10 & $57.7 \pm 6.2$ & 70 & NR \\
\hline Chong SZ 2018 & NR & 35 & $40.6 \pm 14.8$ & 51.4 & 0 \\
\hline Chung SY 2012 & NR & 134 & $51.8 \pm 20.5$ & 77.6 & 23 \\
\hline Colafranceshi 2008 & NR & 11 & $63.5 \pm 12$ & 45.5 & 18 \\
\hline Combes 2008 & NR & 81 & $46 \pm 16$ & 56.8 & 32 \\
\hline Czobor 2016 & NR & 25 & NR & 20 & NR \\
\hline D'Alessandro 2010 & 22.6 & 91 & $47 \pm 17$ & 80.2 & 100 \\
\hline de Waha 2017 & NR & 100 & 61 (IQR: 50-71) & 72 & 0 \\
\hline
\end{tabular}

Etiology of cardiogenic shock (\%)

\begin{tabular}{|c|c|c|}
\hline AMI & myocarditis & cardiomyopathy \\
\hline 0 & 0 & 0 \\
\hline 24 & 0 & 24 \\
\hline 48 & 17 & 28 \\
\hline 0 & 0 & 0 \\
\hline 0 & 100 & 0 \\
\hline 39 & 3 & 18 \\
\hline 50 & 0 & 7 \\
\hline 10 & 0 & 10 \\
\hline 0 & 0 & 0 \\
\hline 0 & 0 & 0 \\
\hline 0 & 0 & 0 \\
\hline 75 & 3 & 0 \\
\hline 0 & 0 & 0 \\
\hline 100 & 0 & 0 \\
\hline 0 & 0 & 100 \\
\hline 46 & 16 & 28 \\
\hline 0 & 0 & 0 \\
\hline 44 & 7 & 35 \\
\hline 14 & 2 & 0 \\
\hline 28 & 12 & 0 \\
\hline 42 & 25 & 17 \\
\hline 18 & 0 & 14 \\
\hline 4 & 18 & 0 \\
\hline 0 & 100 & 0 \\
\hline 0 & 100 & 0 \\
\hline 0 & 8 & 32 \\
\hline NR & NR & NR \\
\hline 0 & 100 & 0 \\
\hline 40 & 19 & 4 \\
\hline 0 & 0 & 0 \\
\hline 20 & 20 & 22 \\
\hline NR & NR & NR \\
\hline 0 & 0 & 0 \\
\hline 60 & 0 & 27 \\
\hline
\end{tabular}


de Waha S 2016

Delmas 2017

Demondion 2013

den Uil 2017

Diez-Villanueva P 2014

Dini CS 2015

Distelmaier 2016/2017

Dobrilovic N 2019

Doll 2003

Durinka JB 2014

Elsharkawy 2010

Esper 2015

Fiser 2001

Flécher 2014

Formica F 2010

Fux 2017

Fux T 2018 PCS

Fux T 2018

Garcia-Gigorro 2017

Guenther 2014

Guenther 2015

Guenther SPW 2018

Guihaire 2017

Hei 2011

Hoefer D 2006

Hou LS 2013

Huang M 2019

Hryniewicz K 2016

Hsu 2009

Huang S.C. 2006

Idelchik GM 2008

Jaamaa-Holmberg S 2018

Jaski 2010

Jo 2011

Kanji 2010

Ko 2002

Koerner MW 2019

Lamarche 2010

Lazzara RR 1993

\begin{tabular}{|c|c|c|c|c|}
\hline NR & 83 & 61 (IQR: 50-72) & 73.5 & 0 \\
\hline NR & 82 & 54 (IQR: 51-57) & 64.7 & 24 \\
\hline NR & 77 & $56.1 \pm 0.7$ & 75.3 & 0 \\
\hline NR & 132 & $47 \pm 16$ & 55 & 25 \\
\hline NR & 4 & $54.5 \pm 7.4$ & 75 & 0 \\
\hline NR & 14 & $52.1 \pm 13.3$ & 64.3 & 0 \\
\hline 3.35 & 354 & 65 (IQR: 55-73) & 68.6 & 100 \\
\hline NR & 12 & $56(39-77)$ & 41.7 & 0 \\
\hline 1.2 & 95 & $59.8 \pm 13.3$ & 69.5 & 100 \\
\hline NR & 17 & $45 \pm 11.5$ & 70.6 & 0 \\
\hline 0.58 & 233 & NR & 67.4 & 100 \\
\hline NR & 18 & $60 \pm 11.7$ & 72.2 & 0 \\
\hline 0.91 & 51 & $61.0 \pm 1.7$ & 56.9 & 100 \\
\hline NR & 259 & $54 \pm 15$ & 69 & 42 \\
\hline NR & 42 & $64.3 \pm 11.3$ & 66.7 & 60 \\
\hline NR & 181 & 58 (IQR: 47-66) & 75 & 58 \\
\hline NR & 105 & 62 (IQR: 52-68) & 76 & 100 \\
\hline NR & 76 & 52 (IQR: 37-60) & 74 & 0 \\
\hline NR & 46 & $48 \pm 15$ & 61 & 33 \\
\hline NR & 41 & $52 \pm 13$ & 85.4 & 0 \\
\hline NR & 87 & $54 \pm 13$ & 84 & 0 \\
\hline NR & 10 & $36 \pm 16$ & 60 & 20 \\
\hline 0.7 & 92 & $64.5(18-83)$ & 59 & 100 \\
\hline NR & 68 & $49.2 \pm 13.3$ & 76.5 & 90 \\
\hline NR & 131 & $48.8 \pm 14.7$ & 67 & 47 \\
\hline NR & 54 & NR & NR & NR \\
\hline NR & 127 & NR & NR & 0 \\
\hline NR & 37 & $61 \pm 12$ & 76 & 14 \\
\hline 2.89 & 51 & $63.0 \pm 15.7$ & 70.6 & 100 \\
\hline NR & 31 & $51.3 \pm 15.1$ & 74.2 & 26 \\
\hline NR & 18 & $47.9 \pm 16.5$ & 83.3 & 0 \\
\hline NR & 133 & 53 (IQR 18) & 69.9 & 47 \\
\hline NR & 150 & $57 \pm 17$ & 68.7 & 4 \\
\hline NR & 83 & $58.1 \pm 17.3$ & 63.9 & 0 \\
\hline NR & 50 & 49.36 & 72 & 88 \\
\hline 2.61 & 76 & $56.8 \pm 15.9$ & 63.2 & 100 \\
\hline NR & 184 & $55 \pm 15$ & 71 & 24 \\
\hline NR & 32 & $52.5 \pm 21$ & 63 & 100 \\
\hline $\mathrm{NR}$ & 11 & $63+8$ & 727 & 100 \\
\hline
\end{tabular}

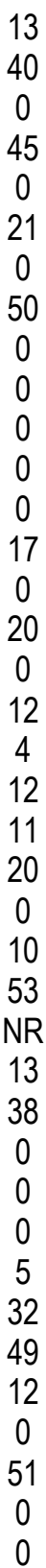


Le Guen 2011

Le Pennec-Prigent S 2017

Leprince 2005

Li 2015

Liao X 2017

Liden 2009

Liu 2009

Loforte 2014

Luo 2009

Maekawa K 2013

Maggio 2007

Magovern GJ 1994

Mair P 1996

Marasco 2010

Massetti 2005

Mateen 2011

Matsumoto 2018

Mazeffi 2016

Meyer 2009

Mohite 2015

Mojoli 2013

Moraca 2012

Morshuis M 2019

Mozami N 2005

Muehrcke 1996

Muller 2016

Musial 2017

Nakamura T 2015

Negi 2016

Noon GP 1999

Pabst 2018

Pagani 2000

Pages 2009

Papadopoulos 2015

Park 2014

Peigh 2015

Pineton de Chambrun M 2016

Pokersnik 2012

Pontailler 2017

\begin{tabular}{|c|c|c|c|c|}
\hline NR & 51 & $42 \pm 15$ & 90 & 0 \\
\hline NR & 26 & $52.4 \pm 9.2$ & 88.5 & 0 \\
\hline 11.9 & 14 & $36 \pm 15$ & 78.6 & 100 \\
\hline 0.91 & 123 & $56.2 \pm 11.8$ & 65.9 & 100 \\
\hline NR & 33 & $33 \pm 19$ & 48.5 & 0 \\
\hline NR & 52 & $49.8 \pm 15.1$ & 84.6 & 63 \\
\hline 0.58 & 14 & $55.7 \pm 15.4$ & 50 & 100 \\
\hline NR & 228 & $58.3 \pm 10$ & 68 & 68 \\
\hline NR & 45 & $49.0 \pm 14.1$ & 75.6 & 80 \\
\hline NR & 24 & 57 (IQR: 48-63) & 79.2 & NR \\
\hline NR & 19 & $41.8 \pm 13.7$ & 47.4 & 0 \\
\hline NR & 21 & $56 \pm 2.2$ & 71.4 & 100 \\
\hline NR & 7 & $51 \pm 11.5$ & 71.4 & 14 \\
\hline 16.3 & 39 & $49.5 \pm 12.5$ & 76.9 & 100 \\
\hline NR & 40 & $42 \pm 15$ & 57.5 & 10 \\
\hline NR & 87 & 54 & 60 & 84 \\
\hline NR & 37 & 42.4 & 56.8 & 0 \\
\hline 0.42 & 23 & $57 \pm 15$ & 60.9 & 100 \\
\hline 1.23 & 18 & $50 \pm 15$ & 72.2 & 100 \\
\hline NR & 68 & NR & NR & 0 \\
\hline NR & 23 & 54 (IQR: 45-61) & 78.3 & 0 \\
\hline NR & 26 & 54 & 69.2 & 0 \\
\hline NR & 134 & $53 \pm 13$ & 73 & NR \\
\hline NR & 38 & NR & NR & NR \\
\hline 0.38 & 23 & $47.3 \pm 16.4$ & 73.9 & 100 \\
\hline NR & 138 & 55 (IQR: 46-63) & 79.7 & 0 \\
\hline NR & 27 & $45 \pm 16$ & 70.4 & 100 \\
\hline NR & 22 & $46.2 \pm 14.8$ & 45.5 & 0 \\
\hline NR & 15 & $57 \pm 13$ & 60 & 0 \\
\hline NR & 141 & 61.6 & 79.4 & 100 \\
\hline NR & 61 & $62.2 \pm 9.8$ & 77 & 0 \\
\hline NR & 14 & $45 \pm 9$ & 78.6 & 0 \\
\hline NR & 6 & $40 \pm 4$ & 50 & 0 \\
\hline NR & 360 & $62 \pm 17$ & 76.1 & 100 \\
\hline NR & 152 & $60.3 \pm 16.1$ & 61.2 & 100 \\
\hline NR & 73 & $48 \pm 14$ & 64.4 & 21 \\
\hline NR & 94 & $50.8 \pm 11.5$ & 75.5 & 0 \\
\hline NR & 49 & $65 \pm 13$ & 67.3 & 100 \\
\hline NR & 163 & $75.7 \pm 4.7$ & 61.3 & 78 \\
\hline
\end{tabular}

0
0
0
0
0
0
17
0
12
0
$N R$
0
0
29
0
40
0
0
0
0
0
0
65
62
$N R$
$N R$
0
100
0
0
0
0
0
0
0
0
0
0
0
0
0
0


Pozzi M 2019 PCS

Pozzi M 2019 AMI

Ranucci 2011

Rastan 2010

Reedy JE 1990

Rousse 2015

Rubino 2017

Russo 2010

Saeed 2014

Salna 2018

Saxena 2015†

Scherer 2009

Schmack 2017

Schmidt 2012

Schwarz 2003

Sheu JJ 2010

Shibilsky 2017

Shin 2011

Slottosch 2012

Slottosch 2017

Smedira 2001

Tang GHL 2013

Tarzia 2015

Truby 2015

Tsai 2016

Tsai TY 2019

Vanzetto G 2009

Villavicencio 2017

Wang 2009

Wang 2013

Wang Y 2019

Wester T 2014

Wu 2010

Wu 2012

Wu MY 2013

Xie 2017

Yeh 2018

Yost 2018

Yu K 2011

$\begin{array}{lccccc}\text { NR } & 90 & 57.5 \pm 15.0 & 62 & 100 & 0 \\ \text { NR } & 56 & 56.7 \pm 9.7 & 89.3 & 0 & 100 \\ \text { NR } & 11 & \text { NR } & \text { NR } & 100 & 0 \\ 1.28 & 517 & 63.5 \pm 11.2 & 71.5 & 100 & 0 \\ \text { NR } & 38 & 49.4 & 78.9 & 3 & 32 \\ \text { NR } & 98 & 42.8 & 60.2 & 42 & 17 \\ \text { NR } & 101 & 57.1 \pm 15.8 & 63.4 & 100 & 0 \\ \text { NR } & 14 & 47.8 \pm 16.8 & 71.4 & 29 & 21 \\ \text { NR } & 37 & 62.6 \pm 13.5 & 56.8 & 68 & 0 \\ \text { NR } & 355 & 59(I Q R: 48-68) & 68.2 & 44 & 30 \\ \text { NR } & 45 & 76.8 \pm 4.6 & 68.9 & 100 & 0 \\ \text { NR } & 5 & 47 \pm 11 & 80 & 0 & 0 \\ \text { NR } & 48 & 49.7 \pm 19.5 & 47.9 & 0 & 13 \\ \text { NR } & 220 & 49 \pm 16 & 66.8 & 35 & 19 \\ \text { NR } & 46 & 47.8 \pm 19.7 & 76.1 & 0 & 24 \\ \text { NR } & 46 & N R & N R & 0 & 100 \\ \text { NR } & 15 & 46.1 \pm 13 & N R & 0 & 33 \\ \text { NR } & 85 & 59.9 \pm 15.3 & 62.4 & 0 & 45 \\ \text { NR } & 77 & 60 \pm 13 & 76.6 & 100 & 0 \\ \text { NR } & 139 & 58 \pm 15 & 76.3 & 72 & 14 \\ \text { NR } & 202 & 55 \pm 14 & 71.8 & 56 & 16 \\ \text { NR } & 21 & 61 \pm 14 & 66.7 & 0 & 100 \\ \text { NR } & 64 & 50 \pm 16 & 81.3 & 0 & 58 \\ \text { NR } & 179 & 56.9 \pm 16.1 & 67.6 & 49 & 26 \\ \text { NR } & 105 & 57 \pm 14 & 66.7 & 64 & 19 \\ \text { NR } & 23 & 57(I Q R 19) & 82.6 & 57 & 26 \\ \text { NR } & 100 & 54 \pm 17 & 69 & 0 & 46 \\ \text { NR } & 28 & 42 \pm 13 & 82.1 & 7 & 0 \\ 0.49 & 62 & 51 \pm 15 & 51.6 & 100 & 0 \\ 1.79 & 87 & 65 \pm 7 & 58.6 & 100 & 0 \\ \text { NR } & 7 & 43.1 \pm 9.3 & 71.4 & 100 & 0 \\ \text { NR } & 8 & 59 & 75 & 50 & 25 \\ 2.63 & 110 & 60 \pm 14 & 70.9 & 100 & 0 \\ \text { NR } & 60 & 49 & 66.7 & 2 & 43 \\ \text { NR } & 35 & 67 & 77.1 & 0 & 100 \\ \text { NR } & 273 & N R & N R & 100 & 0 \\ \text { NR } & 99 & 76.4 \pm 6.4 & 77.8 & \text { NR } & 0 \\ \text { NR } & 107 & 53.1 \pm 14.9 & 59.8 & 19 & 42 \\ \text { NR } & 120 & 29.3 \pm 25 & 66.9 & 12 & 0\end{array}$




\begin{tabular}{|c|c|c|c|c|c|c|c|c|c|}
\hline Zhang 2006 & NR & 32 & $55.4 \pm 11.9$ & 56.3 & 100 & 0 & 0 & 0 & 0 \\
\hline Zhao 2015 & NR & 24 & $59.3 \pm 11.9$ & 79.2 & 100 & 0 & 0 & 0 & 0 \\
\hline Zhong 2017 & 0.64 & 36 & $50.4 \pm 12.2$ & 91.7 & 100 & 0 & 0 & 0 & 0 \\
\hline \multicolumn{10}{|l|}{ Non-HTx/VAD centres } \\
\hline Ariyaratnam 2014 & NR & 14 & $65.6 \pm 10.5$ & 57.1 & 100 & 0 & 0 & 0 & 0 \\
\hline Belle L 2012 & NR & 51 & $51.1 \pm 15.5$ & 74.5 & 0 & 33 & 6 & 14 & 47 \\
\hline Deschka 2013 & NR & 28 & $66.6 \pm 5.3$ & 92.9 & 100 & 0 & 0 & 0 & 0 \\
\hline Junqueira N 2015 & NR & 7 & 62 & 85.7 & 100 & 0 & 0 & 0 & 0 \\
\hline Khorsandi 2016 & NR & 15 & $64.3 \pm 14.5$ & 73 & 100 & 0 & 0 & 0 & 0 \\
\hline Kim 2018 & NR & 38 & $56.7 \pm 14.7$ & 68.4 & 0 & 0 & 26 & 0 & 74 \\
\hline Kuroki N 2015 & NR & 217 & $58.9 \pm 15.0$ & 82.9 & 2 & 58 & 5 & 0 & 35 \\
\hline Lee HS 2019 & NR & 135 & $59.4 \pm 16.5$ & 69.9 & 0 & 53 & 0 & 0 & 47 \\
\hline Lee SN 2017 & NR & 95 & $62.1 \pm 8.7$ & 62.1 & 5 & 52 & 8 & 0 & 35 \\
\hline Lin 2016 & NR & 17 & NR & NR & 0 & 0 & 0 & 0 & 100 \\
\hline Liu 2011 & NR & 11 & $55.9 \pm 7.6$ & 81.8 & 0 & 100 & 0 & 0 & 0 \\
\hline Mégarbane 2011 & NR & 66 & 46 (IQR: 39-55) & 77.3 & 0 & 39 & 3 & 8 & 50 \\
\hline Mikus 2013 & 0.26 & 14 & $53.1 \pm 14.3$ & 64.3 & 100 & 0 & 0 & 0 & 0 \\
\hline Raffa 2017 & NR & 86 & $65 \pm 11.2$ & 65.1 & 100 & 0 & 0 & 0 & 0 \\
\hline Rigamonti F 2016 & NR & 29 & NR & 86.2 & 0 & 100 & 0 & 0 & 0 \\
\hline Sakamoto 2012 & NR & 98 & $72 \pm 12$ & 66.3 & 2 & 98 & 0 & 0 & 0 \\
\hline Smith 2001 & NR & 17 & 69 & 76 & 94 & 0 & 0 & 6 & 0 \\
\hline Sun 2018 & NR & 22 & 53 (IQR:40-64) & 77 & 0 & 0 & 5 & 0 & 95 \\
\hline Unosawa 2012 & NR & 47 & $64.4 \pm 12.5$ & 74.4 & 100 & 0 & 0 & 0 & 0 \\
\hline Zhu RQ 2016 & NR & 10 & NR & 60 & 0 & 40 & 50 & 0 & 10 \\
\hline
\end{tabular}

HTx, heart transplantation; VAD, ventricle assist device; PCS, postcardiotomy shock, AMI, acute myocardial infarction; NR, not reported 
Table 2. Procedural characteristics.

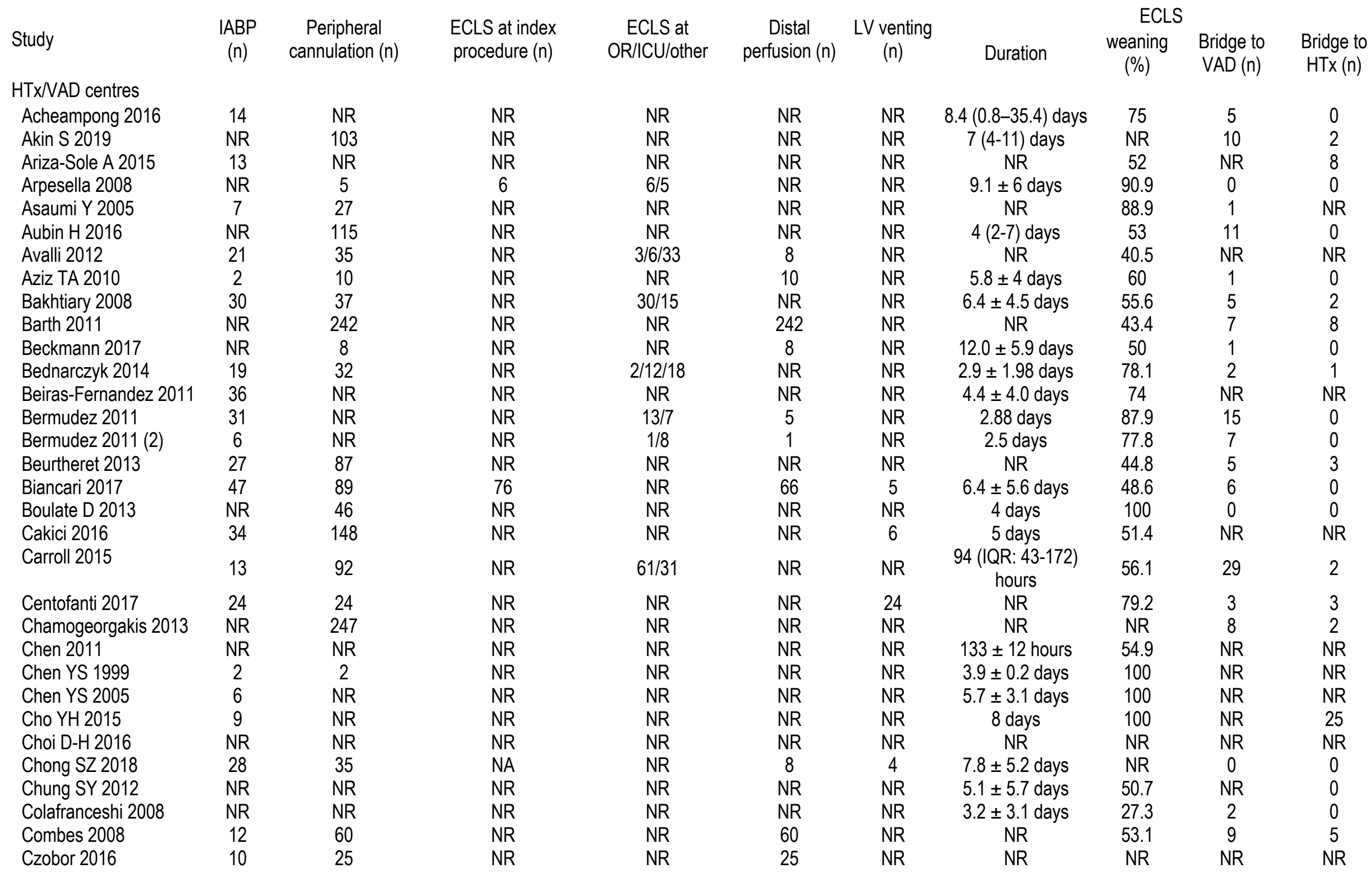




\begin{tabular}{lcc} 
D'Alessandro 2010 & NR & 33 \\
de Waha 2017 & NR & 100 \\
de Waha S 2016 & 19 & 83 \\
Delmas 2017 & 12 & 82 \\
Demondion 2013 & 43 & 59 \\
den Uil 2017 & 37 & 130 \\
Diez-Villanueva P 2014 & 4 & 4 \\
Dini CS 2015 & 13 & 14 \\
Distelmaier 2016/2017 & 44 & 347 \\
Dobrilovic N 2017 & 1 & NR \\
Doll 2003 & 95 & 26 \\
Durinka JB 2014 & 0 & 17 \\
Elsharkawy 2010 & 22 & 77 \\
Esper 2015 & 3 & 18 \\
& NR & NR \\
Fiser 2001 & NR & 238 \\
Flécher 2014 & 29 & 27 \\
Formica F 2010 & NR & NR \\
Fux 2017 & 5 & 80 \\
Fux T 2018 PCS & 18 & NR \\
Fux T 2018 & NR & 39 \\
Garcia-Gigorro 2017 & 23 & 41 \\
Guenther 2014 & NR & 43 \\
Guenther 2015 & 12 & 96 \\
Guenther SPW 2018 & 5 & 8 \\
Guihaire 2017 & 25 & 78 \\
Hei 2011 & 11 & 67 \\
Hoefer D 2006 & 0 & 131 \\
Hou LS 2013 & NR & NR \\
Huang M 2019 & NR & NR \\
Hryniewicz K 2016 & 20 & 37 \\
Hsu 2009 & 51 & 51 \\
Huang S.C. 2006 & 27 & 31 \\
Idelchik GM 2008 & 17 & 18 \\
Jaamaa-Holmberg S & 36 & 94 \\
2018 & & \\
Jaski 2010 & & \\
Jo 2011 & & \\
\hline
\end{tabular}

\begin{tabular}{|c|c|c|}
\hline NR & NR & 33 \\
\hline NR & NR & 100 \\
\hline NR & NR & 83 \\
\hline NR & NR & NR \\
\hline NR & $20 / 27 / 30$ & NR \\
\hline NR & NR & 127 \\
\hline NR & NR & NR \\
\hline NR & $1 / 5 / 8$ & 14 \\
\hline NR & NR & NR \\
\hline 12 & NR & NR \\
\hline NR & $70 / 25$ & NR \\
\hline NR & NR & 17 \\
\hline NR & NR & NR \\
\hline NR & NR & NR \\
\hline NR & $22 / 29$ & NR \\
\hline NR & $150 / 109$ & 238 \\
\hline NR & $21 / 10 / 11$ & 10 \\
\hline NR & NR & NR \\
\hline NR & $51 / \mathrm{NR} / \mathrm{NR}$ & 72 \\
\hline NR & $47 / 18 / 11$ & NR \\
\hline NR & NR & NR \\
\hline NR & NR & 41 \\
\hline NR & NR & 96 \\
\hline NR & NR & NR \\
\hline 43 & $80 / 12$ & NR \\
\hline NR & $29 / 39$ & NR \\
\hline NR & NR & 131 \\
\hline NR & NR & NR \\
\hline NR & NR & NR \\
\hline NR & 8/NR/29 & 37 \\
\hline NR & NR & NR \\
\hline NR & NR & NR \\
\hline NR & NR/NR/18 & NR \\
\hline NR & NR & NR \\
\hline NR & NR/76/74 & NR \\
\hline NR & NR & 83 \\
\hline
\end{tabular}

\begin{tabular}{|c|c|c|c|c|}
\hline 19 & $7 \pm 4$ days & 60.4 & 2 & 1 \\
\hline NR & 5 (IQR: 3-8) days & 56 & NR & NR \\
\hline NR & 6 (IGR:4-8) days & 56.6 & 1 & 3 \\
\hline NR & $\mathrm{NR}$ & 42.7 & 3 & 5 \\
\hline NR & $9.8 \pm 7.1$ days & 48.1 & 13 & 5 \\
\hline 2 & 6 (IQR: 3-9) & 65.2 & 11 & 4 \\
\hline NR & $5 \pm 2.6$ days & 100 & 1 & 0 \\
\hline NR & $5.8 \pm 5.5$ & NR & NR & 1 \\
\hline NR & 4 (IQR: 2-7) days & NR & 4 & 3 \\
\hline NR & 200 (113-379) hours & NR & 5 & 0 \\
\hline NR & $2.8 \pm 2.1$ days & 47.4 & 8 & 0 \\
\hline NR & $12.1 \pm 7.9$ days & 12.9 & 17 & 0 \\
\hline NR & NR & NR & 28 & 25 \\
\hline NR & $\begin{array}{c}3.2 \text { (IQR: 2-4.75) } \\
\text { days }\end{array}$ & NR & 4 & NR \\
\hline NR & 67.5 hours & 31.4 & NR & NR \\
\hline 20 & $7 \pm 6$ days & 59.1 & 7 & 15 \\
\hline NR & $7.9 \pm 5.3$ days & 69 & NR & NR \\
\hline NR & 7 (IQR: 3-13) days & 54.1 & 7 & 11 \\
\hline NR & 7 (IQR: 3-14) days & 51 & 1 & 1 \\
\hline NR & 5 (IQR: 2-11) days & 37 & 3 & 10 \\
\hline NR & 17 (8-29) days & 67.4 & NR & 14 \\
\hline NR & $5.2 \pm 3.7$ days & 41.5 & 3 & 1 \\
\hline 1 & $4.7 \pm 3.2$ days & 62.1 & 9 & 1 \\
\hline 8 & $753 \pm 777$ hours & 60 & 3 & 1 \\
\hline 13 & 6 days & 47.8 & 2 & 2 \\
\hline NR & $4.8 \pm 2.8$ days & 76.5 & NR & 8 \\
\hline NR & $2.9 \pm 1.9$ days & 60.3 & 28 & 5 \\
\hline NR & 1 day & 57.4 & NR & NR \\
\hline NR & NR & 58 & 9 & NR \\
\hline NR & 4 (IQR: 3-5) days & 70.3 & 4 & 1 \\
\hline NR & $7.5 \pm 6.7$ days & 52.9 & 0 & 3 \\
\hline NR & NR & 64.5 & 8 & 1 \\
\hline NR & $4.2 \pm 2.5$ days & 77.8 & 14 & NR \\
\hline NR & 6 (IQR 7) days & 50 & 15 & 17 \\
\hline NR & NR & 46 & 7 & 0 \\
\hline NR & 1.75 days & 57.8 & NR & 7 \\
\hline
\end{tabular}




\begin{tabular}{|c|c|c|}
\hline Kanji 2010 & 36 & 22 \\
\hline Ko 2002 & 54 & \\
\hline Koerner MW 2019 & NR & NR \\
\hline Lamarche 2010 & NR & 15 \\
\hline Lazzara RR 1993 & 11 & 1 \\
\hline Le Guen 2011 & NR & 51 \\
\hline $\begin{array}{l}\text { Le Pennec-Prigent S } \\
2017\end{array}$ & NR & 26 \\
\hline Leprince 2005 & NR & 13 \\
\hline Li 2015 & 73 & 123 \\
\hline Liao X 2017 & 5 & NR \\
\hline Liden 2009 & 18 & NR \\
\hline Liu 2009 & 10 & 14 \\
\hline Loforte 2014 & 228 & 126 \\
\hline Luo 2009 & 11 & 40 \\
\hline Maekawa K 2013 & 9 & NR \\
\hline Maggio 2007 & NR & NR \\
\hline Magovern GJ 1994 & 19 & 5 \\
\hline Mair P 1996 & 1 & 7 \\
\hline Marasco 2010 & 9 & 16 \\
\hline Massetti 2005 & 2 & 40 \\
\hline Mateen 2011 & NR & NR \\
\hline Matsumoto 2018 & 28 & 37 \\
\hline Mazeffi 2016 & 3 & 9 \\
\hline Meyer 2009 & NR & 18 \\
\hline Mohite 2015 & NR & NR \\
\hline Mojoli 2013 & 13 & 23 \\
\hline Moraca 2012 & 21 & 26 \\
\hline Morshuis M 2019 & NR & NR \\
\hline Mozami N 2005 & NR & NR \\
\hline Muehrcke 1996 & 17 & 17 \\
\hline Muller 2016 & 96 & NR \\
\hline Musial 2017 & NR & 27 \\
\hline Nakamura T 2015 & 21 & 22 \\
\hline Negi 2016 & 9 & 15 \\
\hline Noon GP 1999 & NR & 97 \\
\hline Pabst 2018 & 38 & 61 \\
\hline Pagani 2000 & 9 & 14 \\
\hline
\end{tabular}

\begin{tabular}{|c|c|c|}
\hline NR & NR & NR \\
\hline 39 & $23 / 30$ & 20 \\
\hline NR & NR & NR \\
\hline NR & $24 / 8$ & NR \\
\hline NR & $6 / 5$ & NR \\
\hline NR & NR & 51 \\
\hline NR & NR & 26 \\
\hline 6 & $6 / 8$ & 13 \\
\hline 61 & NR & 123 \\
\hline NR & NR & NR \\
\hline NR & NR & NR \\
\hline 9 & NR & NR \\
\hline NR & $202 / 26$ & 83 \\
\hline NR & $15 / 30$ & 40 \\
\hline NR & NR & NR \\
\hline NR & NR & 2 \\
\hline 12 & NR & NR \\
\hline 0 & $0 / 6 / 1$ & NR \\
\hline NR & NR & 16 \\
\hline NR & $16 / 11 / 13$ & NR \\
\hline NR & NR & NR \\
\hline NR & NR & 3 \\
\hline 3 & NR & NR \\
\hline NR & NR & 18 \\
\hline NR & NR & NR \\
\hline NR & NR & NR \\
\hline NR & NR & NR \\
\hline NR & NR & NR \\
\hline NR & NR & NR \\
\hline NR & $15 / 8$ & 0 \\
\hline NR & NR & NR \\
\hline 27 & NR & NR \\
\hline NR & NR & 22 \\
\hline NR & NR & NR \\
\hline 114 & $114 / 27$ & NR \\
\hline 6 & NR & 61 \\
\hline NR & NR & 1 \\
\hline
\end{tabular}

NR
NR
NR
NR
NR
NR
NR
NR
NR
NR
NR
NR
NR
0
NR
NR
NR
NR
NR
NR
NR
NR
0
NR
NR
NR
NR
NR
NR
NR
NR
NR
NR
NR
NR
NR
NR

\begin{tabular}{|c|c|c|c|}
\hline $\begin{array}{c}2.5 \text { (IQR: 1.0-4.8) } \\
\text { days }\end{array}$ & NR & 0 & 23 \\
\hline NR & 28.9 & 2 & 2 \\
\hline $7.8 \pm 7.9$ days & 51.6 & 12 & NR \\
\hline $46.25 \pm 61$ hours & 78.1 & 6 & 3 \\
\hline 2 days & 72.7 & NR & NR \\
\hline NR & NR & NR & NR \\
\hline $7.1 \pm 6.3$ days & 50 & 1 & 1 \\
\hline $5 \pm 2.5$ days & 78.6 & 1 & 1 \\
\hline 4.3 days & 56.1 & NR & NR \\
\hline 3 days & NR & NR & NR \\
\hline $7.7 \pm 11.4$ days & 50 & 2 & 2 \\
\hline $71 \pm 52$ hours & 64.3 & NR & 1 \\
\hline $10.9 \pm 9.7$ days & 63.2 & 6 & 31 \\
\hline $5.3 \pm 4.3$ days & 60 & NR & 5 \\
\hline 49 (IQR: 43-66) min & NR & NR & NR \\
\hline $4.6 \pm 4.3$ days & NR & NR & NR \\
\hline $41.8 \pm 7.4 \mathrm{~min}$ & 76.2 & NR & NR \\
\hline NR & 57.1 & NR & 1 \\
\hline $6.78 \pm 2.64$ days & 87.2 & 3 & NR \\
\hline $105 \pm 44 \min$ & 15 & 9 & 2 \\
\hline 3.8 days & NR & NR & NR \\
\hline NR & 83.8 & 9 & 0 \\
\hline 3 (IQR: 1-8) days & 60.9 & 2 & NR \\
\hline $4 \pm 4$ days & 66.7 & NR & NR \\
\hline NR & 60.3 & NR & NR \\
\hline 3 (IQR: 2-14) days & 43.5 & NR & 6 \\
\hline 3 days & 84.6 & 9 & 1 \\
\hline NR & 44 & 29 & 0 \\
\hline NR & NR & NR & NR \\
\hline $58.4+35.1 \mathrm{~h}$ & 56.5 & 4 & 0 \\
\hline 7 (IQR: 4-10) days & 35.5 & 18 & 13 \\
\hline 8.89 days & NR & NR & NR \\
\hline $7.5 \pm 1.1$ days & NR & 1 & 0 \\
\hline 1.9 days & 53.3 & 1 & NR \\
\hline 3.8 days & 31.2 & NR & NR \\
\hline 6.6 days & 60.7 & 8 & 2 \\
\hline $6 \pm 5$ days & 57.1 & 7 & 0 \\
\hline
\end{tabular}




\begin{tabular}{|c|c|c|}
\hline Pages 2009 & 1 & 6 \\
\hline Papadopoulos 2015 & NR & 324 \\
\hline Park 2014 & NR & 152 \\
\hline Peigh 2015 & NR & NR \\
\hline $\begin{array}{l}\text { Pineton de Chambrun M } \\
2016\end{array}$ & 47 & 94 \\
\hline Pokersnik 2012 & 29 & 32 \\
\hline Pontailler 2017 & 55 & 136 \\
\hline Pozzi M 2019PCS & 9 & 54 \\
\hline Pozzi M 2019AMI & 46 & 54 \\
\hline Ranucci 2011 & NR & 0 \\
\hline Rastan 2010 & 383 & 203 \\
\hline Reedy JE 1990 & 25 & NR \\
\hline Rousse 2015 & 13 & 78 \\
\hline Rubino 2017 & NR & NR \\
\hline Russo 2010 & 12 & 8 \\
\hline Saeed 2014 & NR & 25 \\
\hline Salna 2018 & NR & 305 \\
\hline Saxena 2015† & NR & 15 \\
\hline Scherer 2009 & 1 & 5 \\
\hline Schmack 2017 & 17 & 10 \\
\hline Schmidt 2012 & NR & NR \\
\hline Schwarz 2003 & NR & 46 \\
\hline Sheu JJ 2010 & 46 & 46 \\
\hline Shibilsky 2017 & NR & 15 \\
\hline Shin 2011 & NR & 85 \\
\hline Slottosch 2012 & 72 & 77 \\
\hline Slottosch 2017 & 104 & 110 \\
\hline Smedira 2001 & 115 & 153 \\
\hline Tang GHL 2013 & NR & 21 \\
\hline Tarzia 2015 & 25 & 63 \\
\hline Truby 2015 & 57 & 134 \\
\hline Tsai 2016 & NR & NR \\
\hline Tsai TY 2019 & 18 & NR \\
\hline Vanzetto G 2009 & 30 & 93 \\
\hline Villavicencio 2017 & 8 & 0 \\
\hline Wang 2009 & 19 & NR \\
\hline Wang 2013 & 41 & NR \\
\hline
\end{tabular}

\begin{tabular}{|c|c|c|c|c|c|c|c|}
\hline NR & $4 / 2$ & 6 & NR & $13 \pm 4$ days & 100 & 1 & 0 \\
\hline NR & NR & NR & NR & $7 \pm 1$ days & 58.1 & 6 & 0 \\
\hline 41 & $11 / 76 / 65$ & 152 & NR & $67.3 \pm 107.4$ hours & 44.1 & NR & 3 \\
\hline NR & NR & NR & NR & $9.2 \pm 6.1$ days & 64.4 & NR & NR \\
\hline NR & NR & 94 & NR & 4 (IQR: 2-6) days & 35.1 & 4 & 2 \\
\hline NR & NR & 32 & NR & $3.8 \pm 3.4$ days & 55.1 & 2 & NR \\
\hline NR & NR & 136 & NR & $5.6 \pm 4.3$ days & 41.1 & NR & NR \\
\hline 63 & $63 / 27 / 0$ & NR & NR & $6.4 \pm 6.3$ days & 50 & 0 & 0 \\
\hline NR & NR & NR & NR & $8.1 \pm 14.3$ days & 50 & 5 & 4 \\
\hline NR & NR & NR & NR & $122.1 \pm 80.5$ hours & 63.6 & NR & NR \\
\hline NR & NR & 121 & NR & $3.28 \pm 2.85$ days & 63.4 & 15 & 5 \\
\hline NR & NR & NR & NR & 1.2 days & 0 & 0 & 0 \\
\hline NR & NR & 78 & NR & 4.5 days & 50 & 7 & 13 \\
\hline 63 & NR & NR & NR & 5 (IQR: 3-8) days & 57.4 & 3 & 3 \\
\hline NR & NR/5/NR & 8 & 1 & $11.5 \pm 8.2$ days & 78.6 & 2 & 2 \\
\hline NR & NR & 25 & NR & $5.9 \pm 4.2$ & NR & 4 & NR \\
\hline NR & NR & NR & NR & 4 (IQR: 1-6) days & 72.4 & NR & NR \\
\hline NR & NR & NR & NR & $103.8 \pm 74.3$ hours & 53.3 & NR & NR \\
\hline NR & NR & 5 & NR & $8 \pm 4$ days & 100 & 5 & 0 \\
\hline NR & NR & NR & 20 & $6.10 \pm 3.81$ days & NR & 14 & 5 \\
\hline NR & $106 / 65 / 49$ & NR & NR & 13.4 days & NR & NR & NR \\
\hline 0 & NR & NR & NR & $1.7 \pm 1.5$ days & 60.9 & NR & 6 \\
\hline NR & NR & 3 & NR & NR & 78.3 & NR & 1 \\
\hline NR & NR & 15 & NR & $7.5 \pm 2.6$ days & 100 & 15 & 0 \\
\hline NR & NR & NR & NR & $42.1 \pm 25.7 \mathrm{~min}$ & NR & NR & 2 \\
\hline 34 & $34 / 43$ & 77 & NR & $79 \pm 57$ hours & 62.3 & NR & NR \\
\hline NR & NR/59/NR & 110 & NR & $113 \pm 74$ hours & 63.3 & 15 & NR \\
\hline NR & NR & NR & NR & NR & 58.9 & 42 & 6 \\
\hline NR & 14/NR/7 & NR & NR & $9.0 \pm 7.5$ days & 76.2 & 2 & 0 \\
\hline NR & $33 / 31$ & NR & NR & 7 days & 85.9 & 23 & 12 \\
\hline NR & $71 / 108$ & 9 & NR & $\begin{array}{c}3.58 \text { (IQR: } 1.6-5.9) \\
\text { days }\end{array}$ & NR & 52 & NR \\
\hline NR & NR & NR & NR & $7 \pm 5$ days & 70.5 & NR & NR \\
\hline NR & $0 / 23 / 0$ & NR & NR & 5 (IQR 5) days & NR & NR & NR \\
\hline NR & NR & NR & NR & $2.38 \pm 2.8$ days & 33 & NR & NR \\
\hline NR & $28 / 0$ & NR & NR & 40 days & 71.4 & NR & 18 \\
\hline NR & $36 / 26$ & NR & 0 & $61 \pm 37$ hours & 64.5 & NR & NR \\
\hline 37 & $37 / 50$ & 37 & NR & $61 \pm 37$ hours & 58.6 & NR & NR \\
\hline
\end{tabular}




\begin{tabular}{|c|c|c|c|c|c|c|c|c|c|c|}
\hline Wang Y 2019 & NR & NR & 6 & $6 / 1 / 0$ & NR & NR & $244.5 \pm 57.8$ hours & 100 & 0 & 0 \\
\hline Wester T 2014 & 6 & 7 & NR & NR & NR & NR & $5.1 \pm 2.8$ days & 62.5 & NR & NR \\
\hline Wu 2010 & NR & NR & NR & $98 / 12$ & NR & NR & $143 \pm 112$ hours & 60.9 & 2 & 0 \\
\hline Wu 2012 & 44 & NR & NR & $1 / 25 / 34$ & NR & NR & NR & 63.3 & NR & NR \\
\hline Wu MY 2013 & NR & NR & NR & NR & NR & NR & 3 days & 62.9 & NR & 16 \\
\hline Xie $2017^{* * *}$ & NR & NR & NR & NR & NR & NR & NR & NR & NR & NR \\
\hline Yeh 2018 & NR & 99 & NR & NR & 99 & NR & $5.2 \pm 5.2$ days & 28.3 & NR & NR \\
\hline Yost 2018 & NR & NR & 5 & NR & NR & NR & 14 days & NR & NR & NR \\
\hline Yu K 2011 & 12 & 78 & NR & NR & NR & NR & $5.7 \pm 4.8$ days & NR & NR & NR \\
\hline Zhang 2006 & 10 & 19 & NR & NR & NR & NR & $2.7 \pm 1.7$ days & 43.8 & NR & NR \\
\hline Zhao 2015 & 16 & 23 & 9 & NR & NR & NR & $115.2 \pm 70.2$ hours & 66.7 & 1 & NR \\
\hline Zhong 2017 & 9 & 29 & 24 & $24 / 12$ & NR & NR & $77.5 \pm 34.5$ hours & 66.7 & NR & NR \\
\hline \multicolumn{11}{|c|}{ Non-HTx/VAD centres } \\
\hline Ariyaratnam 2014 & NR & 0 & NR & NR & NR & NR & $5.6 \pm 3.4$ days & 50 & NR & NR \\
\hline Belle L 2012 & 5 & 51 & NR & $0 / 8 / 43$ & 4 & NR & NR & 33.3 & 1 & 0 \\
\hline Deschka 2013 & 25 & 0 & NR & NR & NR & NR & $8.7 \pm 3.9$ days & 42.9 & NR & NR \\
\hline Junqueira N 2015 & 6 & 7 & 5 & $5 / 2 / 0$ & NR & NR & 5.4 days & 57.1 & NR & NR \\
\hline Khorsandi 2016 & NR & 5 & NR & NR & NR & NR & $5.5 \pm 8.9$ days & 40 & NR & NR \\
\hline Kim 2018 & NR & NR & NR & NR & NR & NR & $9.0 \pm 7.6$ days & 55.3 & NR & NR \\
\hline Kuroki N 2015 & 146 & 217 & NR & NR & NR & NR & $3.2 \pm 3.3$ days & 39.2 & NR & NR \\
\hline Lee HS 2019 & 22 & NR & NR & NR & NR & NR & $99.6 \pm 103.2$ hours & 39.3 & NR & NR \\
\hline Lee SN 2017 & NR & NR & NR & NR & NR & NR & $7.6 \pm 6.9$ days & 42.1 & NR & NR \\
\hline Lin 2016 & NR & NR & NR & NR & NR & NR & NR & NR & NR & NR \\
\hline Liu 2011 & 11 & 11 & NR & $0 / 2 / 9$ & NR & NR & $80.2 \pm 62.7$ hours & 63.6 & NR & NR \\
\hline Mégarbane 2011 & NR & 66 & NR & $0 / 66$ & 66 & NR & 8 (IQR: 3-26) hours & 1.5 & NR & 1 \\
\hline Mikus 2013 & 13 & 6 & 12 & NR & 14 & 14 & 5 days & 50 & NR & 0 \\
\hline Raffa 2017 & 23 & 30 & 48 & $48 / 38$ & NR & NR & 5 days & 48.8 & NR & NR \\
\hline Rigamonti F 2016 & NR & NR & NR & NR & 20 & NR & NR & NR & NR & NR \\
\hline Sakamoto 2012 & 94 & 98 & NR & NR/NR/98 & NR & NR & $2.9 \pm 2.6$ days & 55.1 & 0 & 0 \\
\hline \multirow{2}{*}{$\begin{array}{l}\text { Smith } 2001 \\
\text { Sun } 2018\end{array}$} & 14 & 11 & NR & NR & NR & 0 & \multirow{2}{*}{$\begin{array}{c}3.6 \text { days } \\
2.2 \text { (IQR: } 1.78-4.55) \\
\text { days }\end{array}$} & 64.7 & NR & $N R$ \\
\hline & 9 & 22 & NR & $7 / 2 / 13$ & 5 & NR & & 81.8 & 6 & 0 \\
\hline Unosawa 2012 & 39 & 32 & 33 & $33 / 14$ & NR & NR & $63.5 \pm 61.5$ hours & 61.7 & 0 & 0 \\
\hline Zhu RQ 2016 & 3 & NR & NR & NR & NR & NR & NR & 90 & NR & NR \\
\hline
\end{tabular}

HTx, heart transplantation; VAD, ventricle assist device; ECLS, extracorporeal life support; LV, left ventricle 
Table 3. ROBINS-I tool bias assessment.

\begin{tabular}{|c|c|c|c|c|c|c|c|c|c|}
\hline Study & $\begin{array}{l}\text { Bias due to } \\
\text { confounding }\end{array}$ & $\begin{array}{l}\text { Bias in selection } \\
\text { of participants into } \\
\text { the study }\end{array}$ & $\begin{array}{l}\text { Bias in } \\
\text { measurement of } \\
\text { interventions }\end{array}$ & $\begin{array}{l}\text { Bias due to } \\
\text { departures from } \\
\text { intended } \\
\text { interventions }\end{array}$ & $\begin{array}{l}\text { Bias due to } \\
\text { missing } \\
\text { data* }^{*}\end{array}$ & $\begin{array}{l}\text { Bias in } \\
\text { measurement of } \\
\text { outcomes* }\end{array}$ & $\begin{array}{l}\text { Bias in } \\
\text { selection of } \\
\text { reported } \\
\text { result* }^{*}\end{array}$ & $\begin{array}{l}\text { Overall } \\
\text { bias }\end{array}$ & $\begin{array}{l}\text { Cohen's } \\
\text { Kappa }\end{array}$ \\
\hline Akin S 2019 & Critical & Low & Low & NA & Low & Serious & Moderate & Moderate & 0.86 \\
\hline Ariza-Sole 2015 & Critical & Low & Critical & NA & Serious & Critical & Critical & Critical & 0.86 \\
\hline Asaumi 2005 & Critical & Serious & Critical & NA & Moderate & Serious & Serious & Serious & 0.71 \\
\hline Aubin 2016 & Critical & Moderate & Moderate & NA & Low & Low & Low & Low & 0.86 \\
\hline Avalli 2012 & Critical & Moderate & Low & NA & Moderate & Serious & Serious & Serious & 0.71 \\
\hline Aziz 2010 & Critical & Low & Low & NA & Low & Low & Low & Low & 0.86 \\
\hline Bednarczyk 2014 & Critical & Moderate & Low & NA & Low & Low & Low & Low & 0.86 \\
\hline $\begin{array}{l}\text { Beiras-Fernandez } \\
2011\end{array}$ & Critical & Low & Low & NA & Serious & Critical & Critical & Critical & 0.71 \\
\hline Bermudez 2011 & Critical & Serious & Low & NA & Serious & Low & Low & Low & 0.86 \\
\hline $\begin{array}{l}\text { Bermudez } 2011 \\
\text { (2) }\end{array}$ & Critical & Serious & Low & NA & Serious & Low & Low & Low & 0.86 \\
\hline Beurtheret 2013 & Critical & Low & Serious & NA & Low & Low & Low & Low & 0.86 \\
\hline Biancari 2017 & Critical & Serious & Serious & NA & Low & Low & Low & Low & 0.86 \\
\hline
\end{tabular}




\begin{tabular}{|c|c|c|c|c|c|c|c|c|c|}
\hline Boulate 2013 & Critical & Critical & Critical & NA & Moderate & Serious & Serious & Critical & 0.71 \\
\hline Cakici 2016 & Critical & Low & Low & NA & Moderate & Low & Low & Low & 0.86 \\
\hline Carroll 2015 & Critical & Low & Moderate & NA & Low & Critical & Moderate & Critical & 0.57 \\
\hline Centofanti 2017 & Critical & Moderate & Serious & NA & Moderate & Moderate & Moderate & Moderate & 0.86 \\
\hline $\begin{array}{l}\text { Chamogeorgakis } \\
2013\end{array}$ & Critical & Low & Critical & NA & Moderate & Moderate & Moderate & Moderate & 0.86 \\
\hline Chen 2011 & Critical & Critical & Critical & NA & Serious & Critical & Critical & Critical & 0.86 \\
\hline Chen 1999 & Critical & Serious & Critical & NA & Low & Serious & Serious & Serious & 0.86 \\
\hline Chen 2005 & Critical & Serious & Low & NA & Critical & Serious & Serious & Serious & 0.86 \\
\hline Cho 2015 & Critical & Moderate & Critical & NA & Moderate & Serious & Serious & Critical & 0.86 \\
\hline Choi 2016 & Critical & Moderate & Low & NA & Moderate & Critical & Critical & Critical & 0.86 \\
\hline Chong SZ 2018 & Critical & Low & Low & NA & Low & Serious & Moderate & Moderate & 0.71 \\
\hline Chung 2012 & Critical & Low & Low & NA & Moderate & Moderate & Moderate & Moderate & 0.86 \\
\hline Colafranceshi 2008 & Critical & Low & Serious & NA & Moderate & Moderate & Moderate & Moderate & 0.86 \\
\hline Combes 2008 & Critical & Low & Low & NA & Low & Critical & Moderate & Low & 0.86 \\
\hline Czobor 2016 & Critical & Low & Low & NA & Critical & Serious & Serious & Critical & 0.86 \\
\hline D'Alessandro 2010 & Critical & Serious & Serious & NA & Moderate & Serious & Serious & Serious & 0.71 \\
\hline de Waha 2017 & Critical & Serious & Low & NA & Moderate & Serious & Serious & Serious & 0.86 \\
\hline de Waha S 2016 & Critical & Low & Low & NA & Low & Low & Low & Low & 0.86 \\
\hline Delmas 2017 & Critical & Low & Low & NA & Moderate & Low & Low & Low & 0.86 \\
\hline Demondion 2013 & Critical & Serious & Serious & NA & Moderate & Moderate & Moderate & Moderate & 0.71 \\
\hline den Uil 2017 & Critical & Low & Low & NA & Moderate & Moderate & Moderate & Moderate & 0.86 \\
\hline
\end{tabular}




\begin{tabular}{|c|c|c|c|c|c|c|c|c|c|}
\hline $\begin{array}{l}\text { Diez-Villanueva } \\
2014\end{array}$ & Critical & Serious & Critical & NA & Low & Moderate & Moderate & Critical & 0.86 \\
\hline Dini 2015 & Critical & Low & Low & NA & Low & Moderate & Moderate & Low & 0.86 \\
\hline $\begin{array}{l}\text { Distelmaier } \\
\text { 2016/2017 }\end{array}$ & Critical & Low & Low & NA & Moderate & Critical & Serious & Critical & 0.86 \\
\hline Dobrilovic N 2017 & Critical & Low & Low & NA & Low & Serious & Moderate & Moderate & 0.86 \\
\hline Doll 2003 & Critical & Serious & Low & NA & Moderate & Low & Low & Low & 0.71 \\
\hline Durinka 2014 & Critical & Critical & Serious & NA & Moderate & Moderate & Moderate & Moderate & 0.71 \\
\hline Elsharkawy 2010 & Critical & Serious & Low & NA & Critical & Moderate & Moderate & Critical & 0.71 \\
\hline Esper 2015 & Critical & Serious & Critical & NA & Moderate & Moderate & Moderate & Moderate & 0.86 \\
\hline Fiser 2001 & Critical & Low & Critical & NA & Serious & Moderate & Moderate & Critical & 0.86 \\
\hline Flécher 2014 & Critical & Low & Low & NA & Moderate & Serious & Serious & Serious & 0.71 \\
\hline Formica 2010 & Critical & Moderate & Serious & NA & Moderate & Moderate & Moderate & Moderate & 0.86 \\
\hline Fux 2017 & Critical & Low & Serious & NA & Serious & Serious & Serious & Serious & 0.86 \\
\hline Fux T 2018 PCS & Critical & Low & Low & NA & Low & Serious & Low & Moderate & 0.86 \\
\hline Fux T 2018 & Critical & Low & Low & NA & Low & Serious & Low & Moderate & 0.71 \\
\hline $\begin{array}{l}\text { Garcia-Gigorro } \\
2017\end{array}$ & Critical & Low & Low & NA & Low & Moderate & Moderate & Low & 0.86 \\
\hline Guenther 2014 & Critical & Low & Serious & NA & Low & Low & Low & Low & 0.86 \\
\hline Guenther 2015 & Critical & Moderate & Serious & NA & Moderate & Low & Low & Moderate & 0.86 \\
\hline $\begin{array}{l}\text { Guenther SPW } \\
2018\end{array}$ & Critical & Low & Low & NA & Low & Serious & Low & Moderate & 0.71 \\
\hline Guihaire 2017 & Critical & Serious & Low & NA & Low & Moderate & Low & Low & 0.86 \\
\hline Hei 2011 & Critical & Low & Low & NA & Low & Low & Low & Low & 0.86 \\
\hline
\end{tabular}




\begin{tabular}{|c|c|c|c|c|c|c|c|c|c|}
\hline Hoefer 2006 & Critical & Low & Critical & NA & Moderate & Moderate & Moderate & Moderate & 0.86 \\
\hline Hou 2013 & Critical & Moderate & Low & NA & Critical & Serious & Serious & Critical & 0.57 \\
\hline Huang M 2019 & Critical & Low & Low & NA & Low & Serious & Serious & Moderate & 0.86 \\
\hline Hryniewicz 2016 & Critical & Low & Critical & NA & Moderate & Moderate & Moderate & Moderate & 0.86 \\
\hline Hsu 2009 & Critical & Low & Low & NA & Moderate & Moderate & Low & Low & 0.86 \\
\hline Huang 2006 & Critical & Moderate & Low & NA & Low & Serious & Serious & Serious & 0.86 \\
\hline Idelchik 2008 & Critical & Critical & Low & NA & Moderate & Serious & Serious & Critical & 0.71 \\
\hline $\begin{array}{l}\text { Jaamaa-Holmberg } \\
\text { S } 2018\end{array}$ & Critical & Low & Low & NA & Low & Serious & Moderate & Moderate & 0.86 \\
\hline Jaski 2010 & Critical & Low & Critical & NA & Moderate & Serious & Serious & Critical & 0.86 \\
\hline Jo 2011 & Critical & Moderate & Serious & NA & Low & Moderate & Moderate & Moderate & 0.86 \\
\hline Kanji 2010 & Critical & Low & Serious & NA & Moderate & Moderate & Low & Moderate & 1 \\
\hline Ko 2002 & Critical & Low & Critical & NA & Low & Moderate & Moderate & Critical & 0.86 \\
\hline Koerner MM 2019 & Critical & Low & Low & NA & Low & Serious & Serious & Moderate & 0.86 \\
\hline Lamarche 2010 & Critical & Serious & Moderate & NA & Moderate & Moderate & Low & Moderate & 0.71 \\
\hline Lazzara 1993 & Critical & Serious & Moderate & NA & Moderate & Moderate & Moderate & Moderate & 0.86 \\
\hline Le Guen 2011 & Critical & Moderate & Moderate & NA & Moderate & Serious & Serious & Moderate & 0.86 \\
\hline $\begin{array}{l}\text { Le Pennec-Prigent } \\
2017\end{array}$ & Critical & Moderate & Low & NA & Low & Moderate & Moderate & Moderate & 0.86 \\
\hline Leprince 2005 & Critical & Serious & Moderate & NA & Moderate & Serious & Serious & Serious & 0.57 \\
\hline Li 2015 & Critical & Low & Low & NA & Low & Moderate & Low & Low & 0.86 \\
\hline Liao 2017 & Critical & Serious & Low & NA & Serious & Moderate & Moderate & Serious & 0.86 \\
\hline Liden 2009 & Critical & Moderate & Critical & NA & Serious & Moderate & Low & Critical & 0.57 \\
\hline
\end{tabular}




\begin{tabular}{|c|c|c|c|c|c|c|c|c|c|}
\hline Liu 2009 & Critical & Critical & Moderate & NA & Low & Moderate & Low & Critical & 0.71 \\
\hline Loforte 2014 & Critical & Low & Critical & NA & Low & Moderate & Low & Low & 0.71 \\
\hline Luo 2009 & Critical & Low & Low & NA & Low & Moderate & Low & Low & 1 \\
\hline Maekawa 2013 & Critical & Moderate & Critical & NA & Serious & Critical & Critical & Critical & 0.71 \\
\hline Maggio 2007 & Critical & Serious & Low & NA & Serious & Critical & Critical & Critical & 0.86 \\
\hline Magovern 1994 & Critical & Serious & Serious & NA & Moderate & Serious & Serious & Serious & 0.86 \\
\hline Mair 1996 & Critical & Low & Moderate & NA & Low & Moderate & Moderate & Moderate & 0.86 \\
\hline Marasco 2010 & Critical & Serious & Low & NA & Moderate & Low & Low & Low & 0.86 \\
\hline Massetti 2005 & Critical & Low & Serious & NA & Moderate & Low & Low & Low & 0.71 \\
\hline Mateen 2011 & Critical & Serious & Critical & NA & Serious & Serious & Serious & Serious & 0.86 \\
\hline Matsumoto 2018 & Critical & Serious & Serious & NA & Low & Moderate & Moderate & Serious & 0.86 \\
\hline Mazeffi 2016 & Critical & Low & Moderate & NA & Moderate & Moderate & Moderate & Moderate & 1 \\
\hline Meyer 2009 & Critical & Low & Low & NA & Moderate & Moderate & Moderate & Moderate & 0.71 \\
\hline Mohite 2015 & Critical & Low & Critical & NA & Critical & Critical & Critical & Critical & 1 \\
\hline Mojoli 2013 & Critical & Low & Low & NA & Low & Low & Low & Low & 0.86 \\
\hline Moraca 2012 & Critical & Low & Low & NA & Moderate & Moderate & Moderate & Moderate & 0.86 \\
\hline Morshuis M 2019 & Critical & Low & Low & NA & Low & Serious & Serious & Moderate & 0.86 \\
\hline Mozami 2005 & Critical & Moderate & Moderate & NA & Serious & Serious & Serious & Serious & 0.86 \\
\hline Muehrcke 1996 & Critical & Serious & Critical & NA & Low & Low & Low & Low & 0.86 \\
\hline Muller 2016 & Critical & Serious & Low & NA & Serious & Moderate & Moderate & Serious & 0.86 \\
\hline Musial 2017 & Critical & Low & Critical & NA & Low & Serious & Moderate & Critical & 0.71 \\
\hline Nakamura 2015 & Critical & Serious & Serious & NA & Low & Moderate & Moderate & Serious & 0.57 \\
\hline
\end{tabular}




\begin{tabular}{|c|c|c|c|c|c|c|c|c|c|}
\hline Negi 2016 & Critical & Serious & Low & NA & Low & Low & Low & Low & 0.86 \\
\hline Noon 1999 & Critical & Serious & Serious & NA & Moderate & Moderate & Moderate & Moderate & 0.86 \\
\hline Pabst 2018 & Critical & Serious & Critical & NA & Moderate & Moderate & Moderate & Moderate & 0.71 \\
\hline Pagani 2000 & Critical & Critical & Low & NA & Moderate & Serious & Serious & Critical & 0.86 \\
\hline Pages 2009 & Critical & Serious & Critical & NA & Moderate & Serious & Serious & Serious & 0.86 \\
\hline $\begin{array}{l}\text { Papadopoulos } \\
2015\end{array}$ & Critical & Low & Low & NA & Moderate & Moderate & Low & Low & 0.86 \\
\hline Park 2014 & Critical & Moderate & Low & NA & Low & Moderate & Moderate & Moderate & 0.86 \\
\hline Peigh 2015 & Critical & Low & Critical & NA & Serious & Critical & Serious & Critical & 0.57 \\
\hline $\begin{array}{l}\text { Pineton de } \\
\text { Chambrun M } 2016\end{array}$ & Critical & Low & Low & NA & Low & Moderate & Moderate & Low & 0.86 \\
\hline Pokersnik 2012 & Critical & Serious & Critical & NA & Low & Moderate & Moderate & Critical & 0.71 \\
\hline Pontailler 2017 & Critical & Low & Serious & NA & Low & Critical & Serious & Critical & 0.86 \\
\hline Pozzi M 2019 PCS & Critical & Low & Low & NA & Low & Serious & Low & Moderate & 0.86 \\
\hline Pozzi M 2019 AMI & Critical & Low & Low & NA & Low & Serious & Moderate & Moderate & 0.71 \\
\hline Ranucci 2011 & Critical & Critical & Critical & NA & Critical & Critical & Critical & Critical & 0.86 \\
\hline Rastan 2010 & Critical & Low & Low & NA & Low & Moderate & Low & Low & 0.71 \\
\hline Reedy 1990 & Critical & Moderate & Moderate & NA & Serious & Serious & Serious & Serious & 0.86 \\
\hline Rousse 2015 & Critical & Low & Serious & NA & Moderate & Critical & Moderate & Critical & 0.71 \\
\hline Rubino 2017 & Critical & Low & Critical & NA & Serious & Moderate & Low & Critical & 0.71 \\
\hline Russo 2010 & Critical & Low & Low & NA & Low & Critical & Serious & Low & 0.71 \\
\hline Saeed 2014 & Critical & Critical & Critical & NA & Moderate & Moderate & Moderate & Critical & 0.86 \\
\hline Salna 2018 & Critical & Moderate & Low & NA & Moderate & Critical & Critical & Critical & 0.86 \\
\hline
\end{tabular}




\begin{tabular}{|c|c|c|c|c|c|c|c|c|c|}
\hline Saxena 2015 & Critical & Serious & Low & NA & Low & Moderate & Low & Low & 0.86 \\
\hline Scherer 2009 & Critical & Critical & Critical & NA & Moderate & Moderate & Moderate & Critical & 0.86 \\
\hline Schmack 2017 & Critical & Low & Low & NA & Moderate & Serious & Serious & Serious & 0.71 \\
\hline Schmidt 2012 & Critical & Critical & Low & NA & Serious & Critical & Critical & Critical & 0.86 \\
\hline Schwarz 2003 & Critical & Moderate & Serious & NA & Moderate & Moderate & Moderate & Moderate & 0.86 \\
\hline Sheu 2010 & Critical & Serious & Low & NA & Critical & Moderate & Moderate & Critical & 0.86 \\
\hline Shibilsky 2017 & Critical & Critical & Critical & NA & Low & Serious & Serious & Critical & 0.71 \\
\hline Shin 2011 & Critical & Moderate & Low & NA & Moderate & Serious & Serious & Serious & 0.71 \\
\hline Slottosch 2012 & Critical & Low & Low & NA & Low & Low & Low & Low & 0.86 \\
\hline Slottosch 2017 & Critical & Low & Low & NA & Low & Moderate & Low & Low & 0.86 \\
\hline Smedira 2001 & Critical & Low & Critical & NA & Moderate & Low & Low & Low & 0.71 \\
\hline Tang 2013 & Critical & Serious & Serious & NA & Moderate & Low & Low & Serious & 0.57 \\
\hline Tarzia 2015 & Critical & Serious & Low & NA & Moderate & Low & Low & Low & 0.86 \\
\hline Truby 2015 & Critical & Low & Serious & NA & Low & Critical & Moderate & Critical & 0.86 \\
\hline Tsai 2016 & Critical & Critical & Critical & NA & Serious & Critical & Critical & Critical & 0.57 \\
\hline Tsai TY 2019 & Critical & Low & Low & NA & Low & Serious & Serious & Moderate & 0.71 \\
\hline Vanzetto 2009 & Critical & Low & Moderate & NA & Moderate & Serious & Serious & Serious & 0.86 \\
\hline Villavicencio 2017 & Critical & Serious & Low & NA & Moderate & Low & Low & Low & 0.86 \\
\hline Wang 2009 & Critical & Low & Low & NA & Serious & Low & Low & Low & 0.71 \\
\hline Wang 2013 & Critical & Critical & Low & NA & Serious & Low & Low & Low & 0.86 \\
\hline Wang Y 2019 & Critical & Low & Low & NA & Low & Serious & Serious & Moderate & 0.71 \\
\hline Wester 2014 & Critical & Serious & Critical & NA & Moderate & Serious & Serious & Serious & 0.71 \\
\hline
\end{tabular}




\begin{tabular}{|c|c|c|c|c|c|c|c|c|c|}
\hline Wu 2010 & Critical & Low & Critical & NA & Serious & Low & Low & Low & 1 \\
\hline Wu 2012 & Critical & Serious & Low & NA & Serious & Moderate & Moderate & Serious & 0.86 \\
\hline Wu MY 2013 & Critical & Serious & Low & NA & Serious & Moderate & Moderate & Serious & 0.86 \\
\hline Xie 2017 & Critical & Serious & Critical & NA & Critical & Critical & Critical & Critical & 0.86 \\
\hline Yeh 2018 & Critical & Critical & Serious & NA & Low & Critical & Critical & Critical & 0.86 \\
\hline Yost 2018 & Critical & Low & Critical & NA & Serious & Critical & Critical & Critical & 0.71 \\
\hline Yu 2011 & Critical & Low & Critical & NA & Moderate & Low & Low & Low & 0.71 \\
\hline Zhang 2006 & Critical & Serious & Critical & NA & Low & Serious & Moderate & Critical & 0.86 \\
\hline Zhao 2015 & Critical & Critical & Critical & NA & Low & Moderate & Moderate & Critical & 0.71 \\
\hline Zhong 2017 & Critical & Critical & Low & NA & Low & Serious & Moderate & Critical & 0.57 \\
\hline Ariyaratnam 2014 & Critical & Serious & Critical & NA & Low & Critical & Critical & Critical & 1 \\
\hline Belle 2012 & Critical & Low & Low & NA & Moderate & Low & Low & Low & 0.86 \\
\hline Deschka 2013 & Critical & Serious & Serious & NA & Moderate & Low & Low & Serious & 0.86 \\
\hline Junqueira 2015 & Critical & Serious & Serious & NA & Moderate & Moderate & Moderate & Moderate & 0.71 \\
\hline Khorsandi 2016 & Critical & Serious & Serious & NA & Low & Low & Low & Low & 0.86 \\
\hline Kim 2018 & Critical & Serious & Critical & NA & Serious & Critical & Critical & Critical & 0.86 \\
\hline Kuroki 2015 & Critical & Moderate & Serious & NA & Moderate & Serious & Serious & Serious & 0.86 \\
\hline Lee HS 2019 & Critical & Low & Low & NA & Low & Serious & Moderate & Moderate & 0.86 \\
\hline Lee 2017 & Critical & Low & Low & NA & Serious & Serious & Serious & Serious & 0.71 \\
\hline Lin 2016 & Critical & Serious & Critical & NA & Critical & Critical & Critical & Critical & 0.86 \\
\hline Liu 2011 & Critical & Serious & Serious & NA & Moderate & Moderate & Moderate & Moderate & 0.86 \\
\hline Mégarbane 2011 & Critical & Moderate & Serious & NA & Moderate & Moderate & Moderate & Moderate & 0.86 \\
\hline
\end{tabular}




\begin{tabular}{|c|c|c|c|c|c|c|c|c|c|}
\hline Mikus 2013 & Critical & Serious & Low & NA & Low & Moderate & Low & Low & 0.71 \\
\hline Raffa 2017 & Critical & Serious & Serious & NA & Low & Low & Low & Low & 0.71 \\
\hline Rigamonti 2016 & Critical & Serious & Low & NA & Critical & Critical & Critical & Critical & 0.86 \\
\hline Sakamoto 2012 & Critical & Serious & Low & NA & Low & Moderate & Moderate & Moderate & 0.86 \\
\hline Smith 2001 & Critical & Low & Low & NA & Low & Moderate & Moderate & Low & 0.71 \\
\hline Sun 2018 & Critical & Serious & Serious & NA & Moderate & Low & Low & Serious & 0.86 \\
\hline Unosawa 2012 & Critical & Serious & Low & NA & Low & Moderate & Low & Low & 0.86 \\
\hline Zhu 2016 & Critical & Low & Moderate & NA & Low & Serious & Serious & Serious & 0.71 \\
\hline
\end{tabular}

*When multiple outcomes were reported for a study, the highest level of bias at the outcome level is reported in the table. Bias re ported for comparison of peripheral vs central extracorporeal circulation and not for a study in general. 
Studies were judged to be moderate to severe risk of bias as none previously compared directly non-HTx/VAD vs HTx/VAD centres performance; no signs of small/big study effect was seen on visual inspection of funnel plot for primary endpoint (Figure 3).

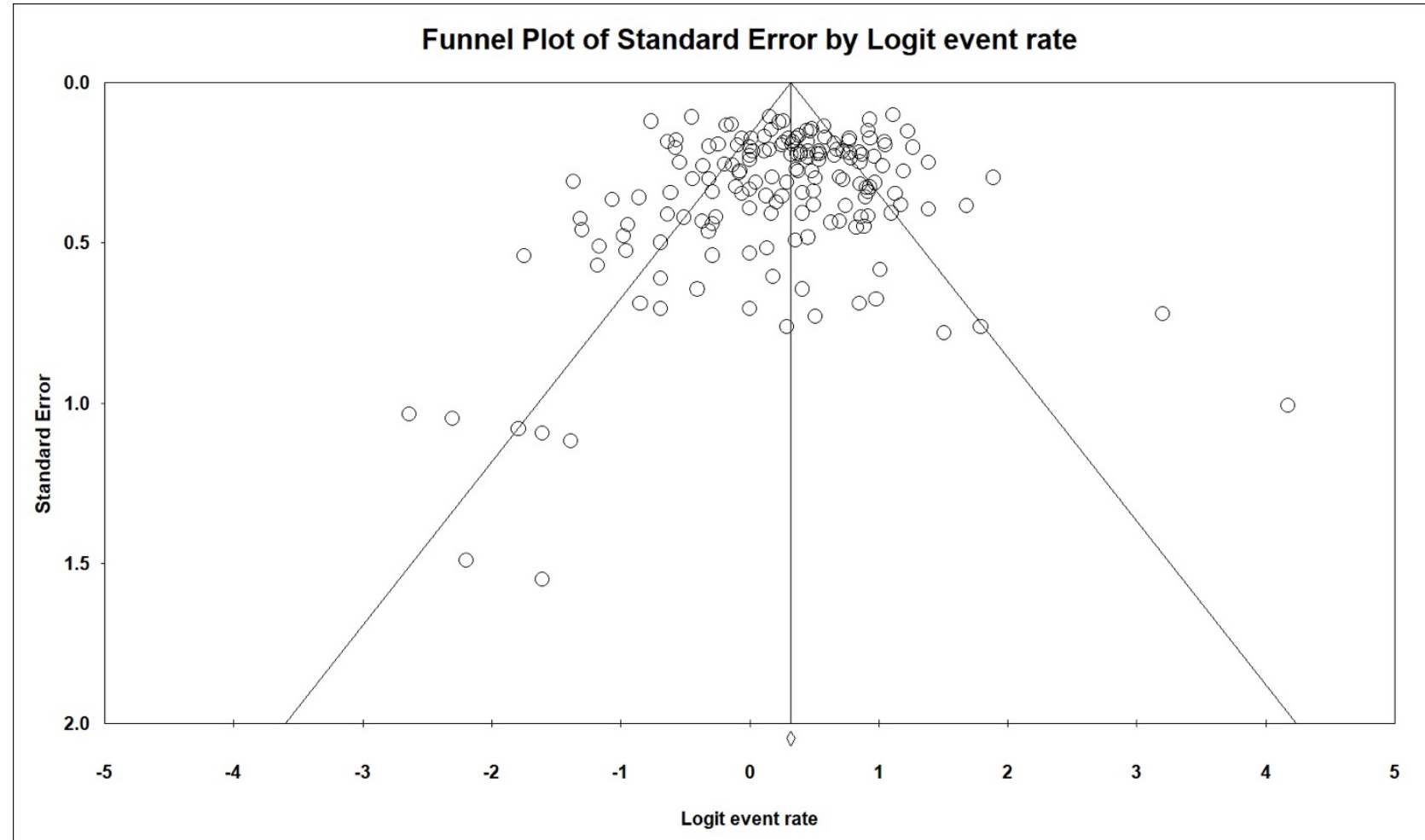

FIGURE 3. Funnel-plot of primary endpoint.

\section{ECLS strategy}

ECLS was initiated in the operating room in $43.0 \%$ of patients $(36.5-49.8 \%)$, followed by intensive care unit, cardiac catheterization laboratory, telemetry floor and emergency department without statistical differences between HTx/VAD - as compared to non-HTx/VAD centres: $43.6 \%(36.8-50.7 \%)$ and $37.3 \%(19.2-59.8 \%)$, respectively $(p=0.589)$. Median ECLS duration in the entire series was 6.11 days again without apparent differences between HTx/VAD (mean weighted average = 5.95 days) vs non-HTx/VAD (4.77 days) centres $(p=0.204)$. Successful weaning from ECLS was most often defined as decannulation after $>48$ hours. Overall, estimated $57.5 \%$ (55.2-59.9\%) patients were weaned from ECLS with the weaning rates ranging from 0 to $100 \%$ in the entire series. These rates were significantly higher in HTx/VAD vs non-HTx/VAD centres 58.7\% (56.2$61.1 \%)$ vs $48.9 \%(42.0-55.9 \%): p=0.010$. 


\section{Survival and complications following ECLS institution}

Analysis of in-hospital mortality, complications, rate of bridge to VAD/HTx and remote survival following V-A ECLS institution in non-HTx/VAD vs HTx/VAD centres are shown in Figure 4.

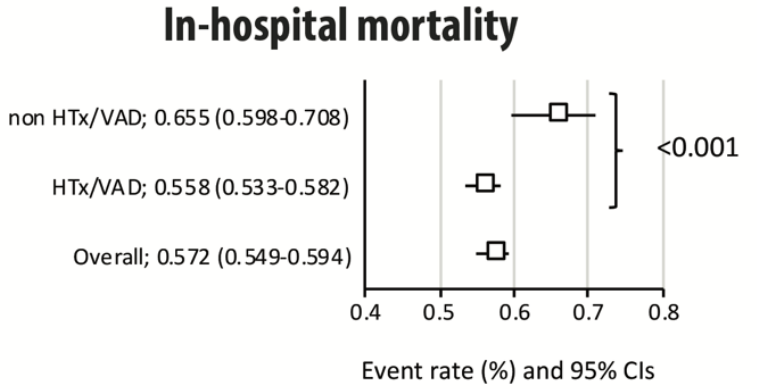

Long-term survival

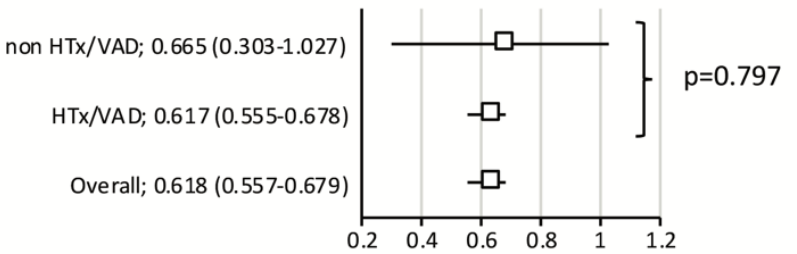

Rates per person-year (\%) and 95\% Cls

\section{Limb complications}

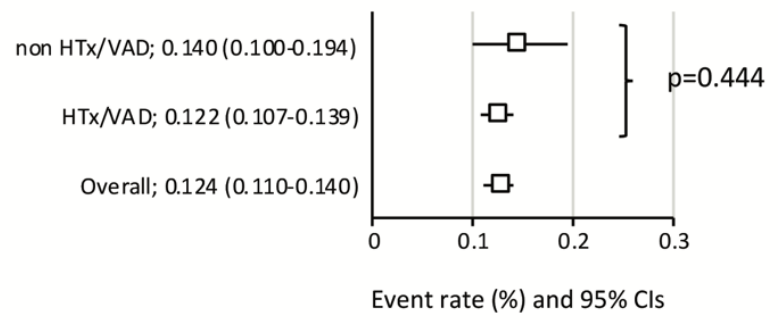

\section{Neurological complications}

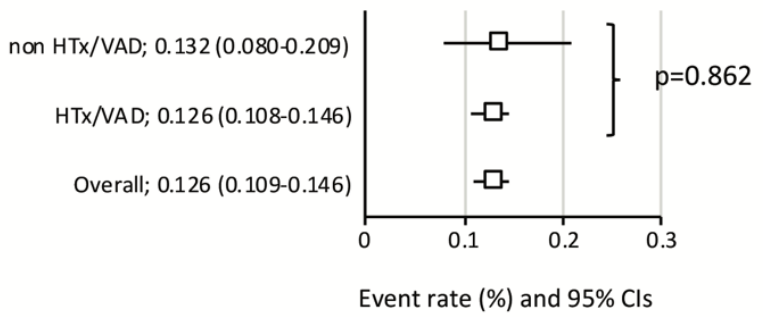

Brain death

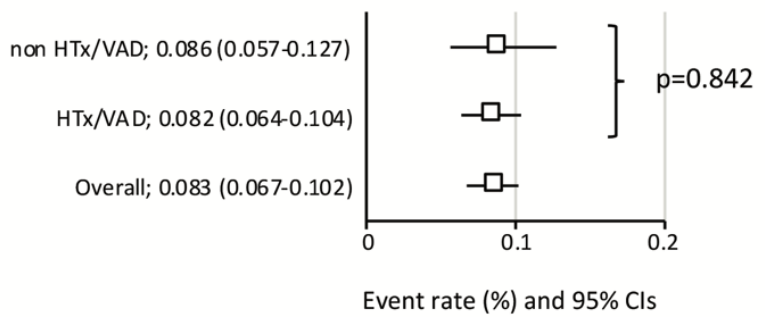

\section{Major bleeding requiring intervention}

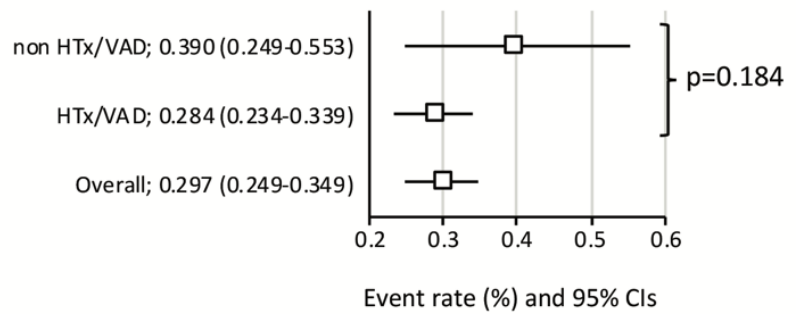

Sepsis

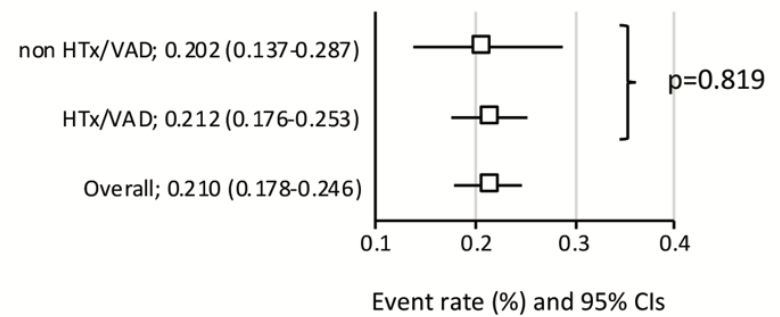

Acute Kidney Injury

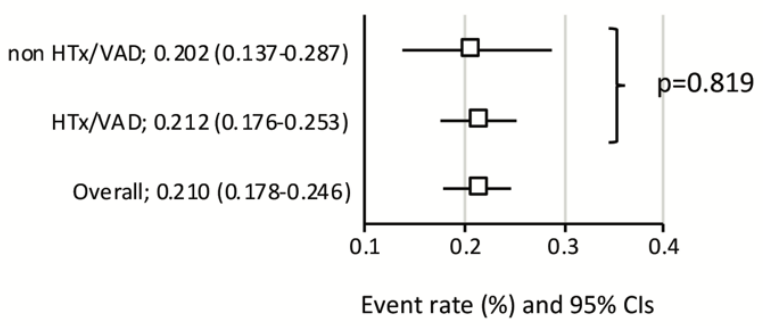

Bridging to HTX

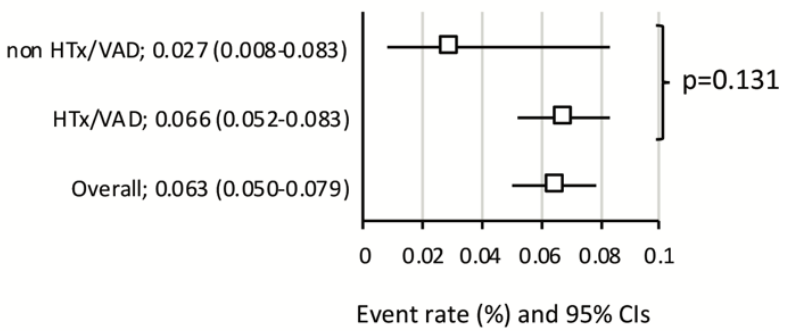

Bridging to VAD

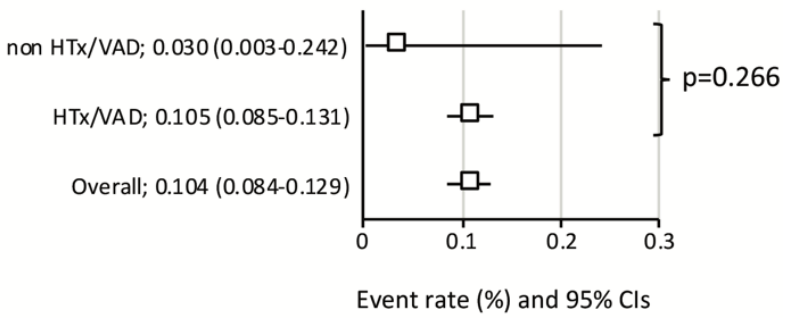


Figure 4. Analysis of in-hospital mortality, complications, bridge to VAD/HTx and remote survival following V-A ECLS institution in non-HTx/VAD vs HTx/VAD centres. Squares represent point estimates of pooled studies; horizontal lines are respective $95 \%$ confidence intervals. HTx, heart transplantation; VAD, ventricle assist device.
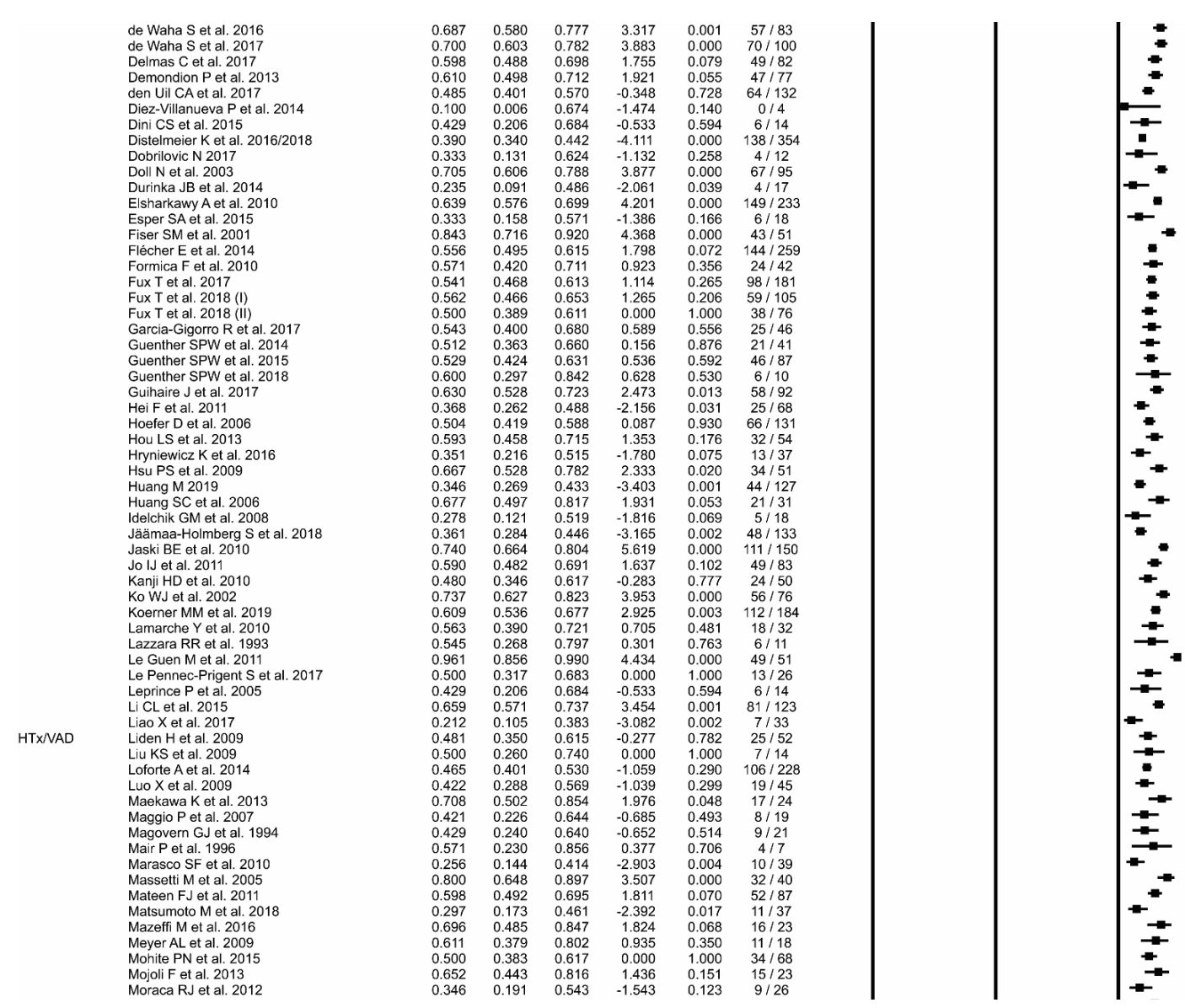

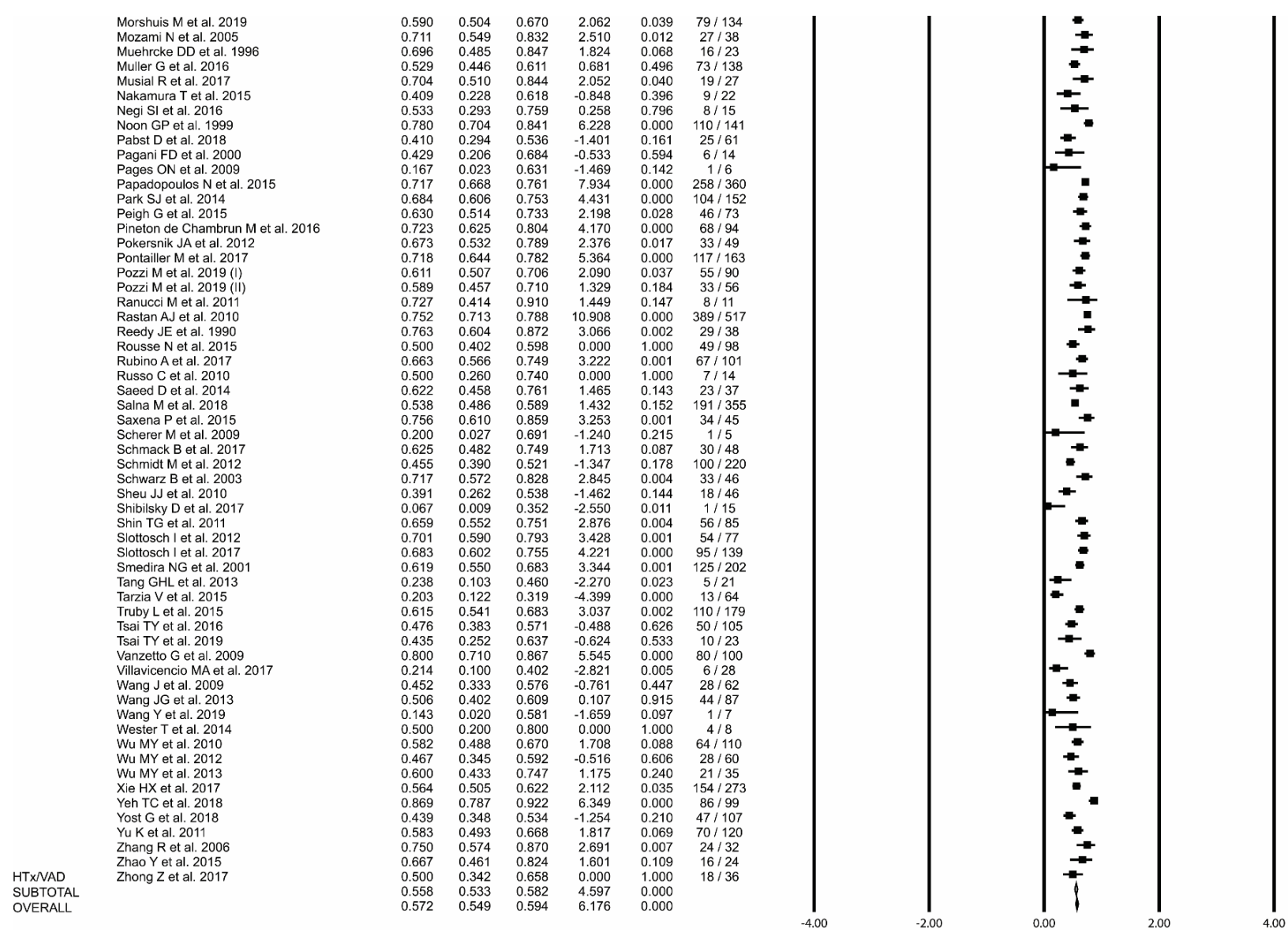

FIGURE 5. In-hospital mortality rates in non-HTx/VAD as compared to HTx/VAD centres.

Eighty-eight studies (5,824 person years) were included in the analysis of long-term survival; overall estimated late survival was $61.8 \%$ (55.7-67.9\%) without significant differences between non-HTx/VAD as compared to HTxNAD centres: $66.5 \%(30.3-1.02 \%)$ vs $61.7 \%(55.5-67.8 \%)$, respectively $(p=0.797)$. The detailed estimated rates are reported as Figure 6. HTx/VAD (12.2\% [10.7-13.9\%]) and non-HTx/VAD centres (14.0 [10.0-19.4\%]) $(p=0.444)$. Ninety-seven studies enrolling an overall of 7,040 patients contributed to the analysis of neurologic complications; 980 patients experienced neurological complications (12.6\% [10.9-14.6\%]); among those 298 brain deaths (8.3\% [6.7-10.2\%]; 56 studies; 3,756 patients) occurred. No marked differences were seen between the rates of neurologic complications and brain deaths in non-HTx/VAD centres as compared to HTx/VAD centres: $13.2 \%(8.0-20.9 \%)$ vs $12.6 \%(10.8-14.6 \%), p=0.862$ and $8.6 \%(5.7-12.7 \%)$ vs $8.2 \%(6.4-10.4 \%)$; $p=0.842$ for neurologic complications and brain deaths, respectively. No further differences were seen between non-HTx/VAD centres as compared to HTx/VAD centres respectively in the analyses of 1) major bleeding requiring intervention (39.0\% [24.9-55.3\%] vs 28.4\% [23.4-33.9\%]; $p=0.184) ; 2)$ sepsis $(20.2 \%$ [13.8-28.7\%] vs 
21.2\% [17.6-25.3\%]; $p=0.819) ;$ and 3) acute kidney injury (36.4\% [25.9-48.4\%] vs 42.8\% [39.1-46.5\%]; $p=0.312$ ).

Detailed analyses of individual studies are available as Figures 7-12.

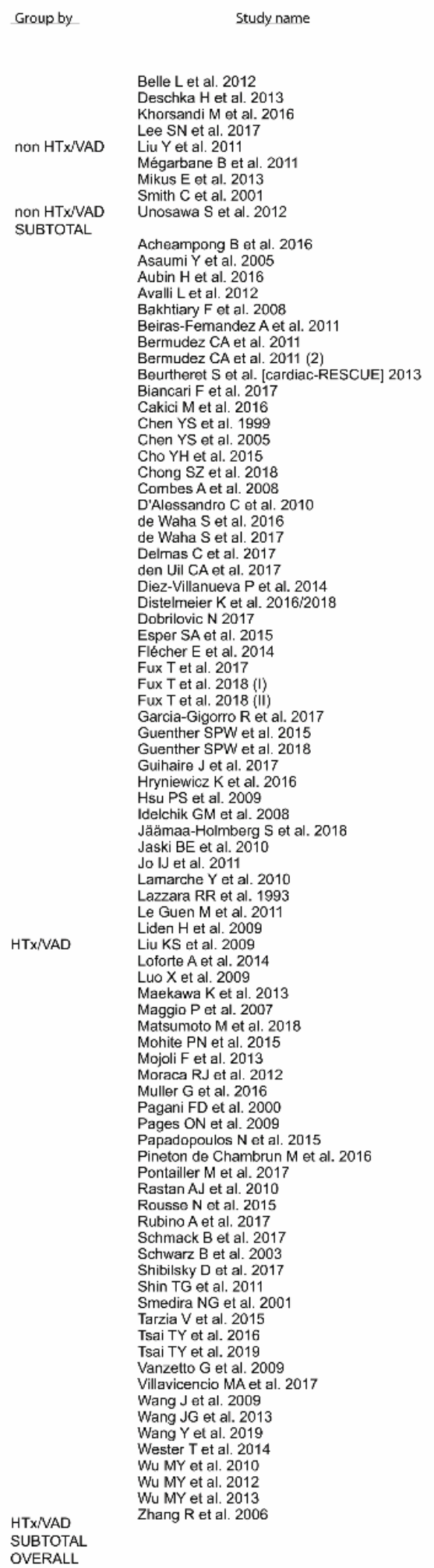

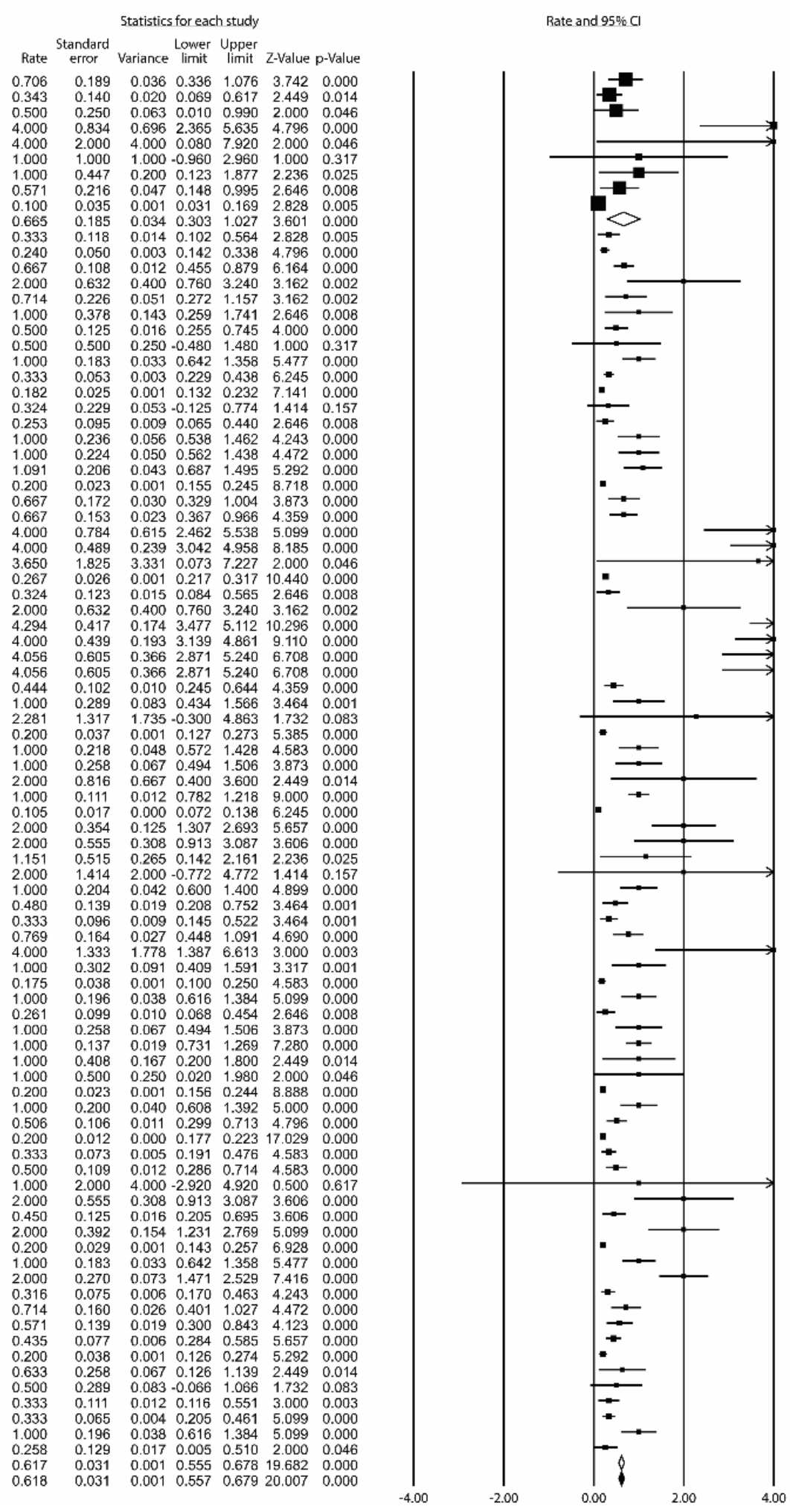

FIGURE 6. Estimated long-term survival in non-HTx/VAD as compared to HTX/VAD centres. 


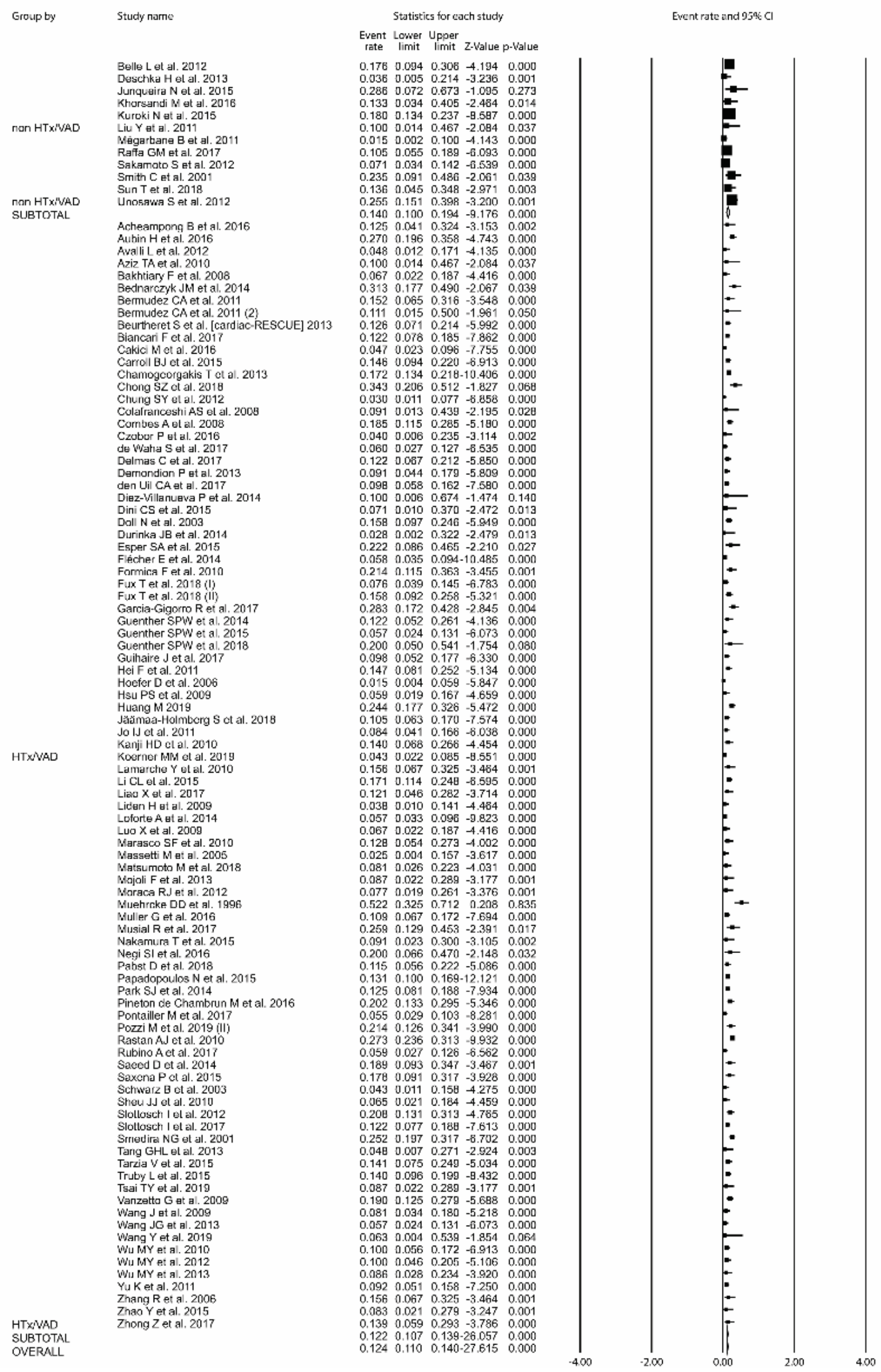

FIGURE 7. Limb complications incidence in non-HTX/VAD as compared to HTX/VAD centres. 


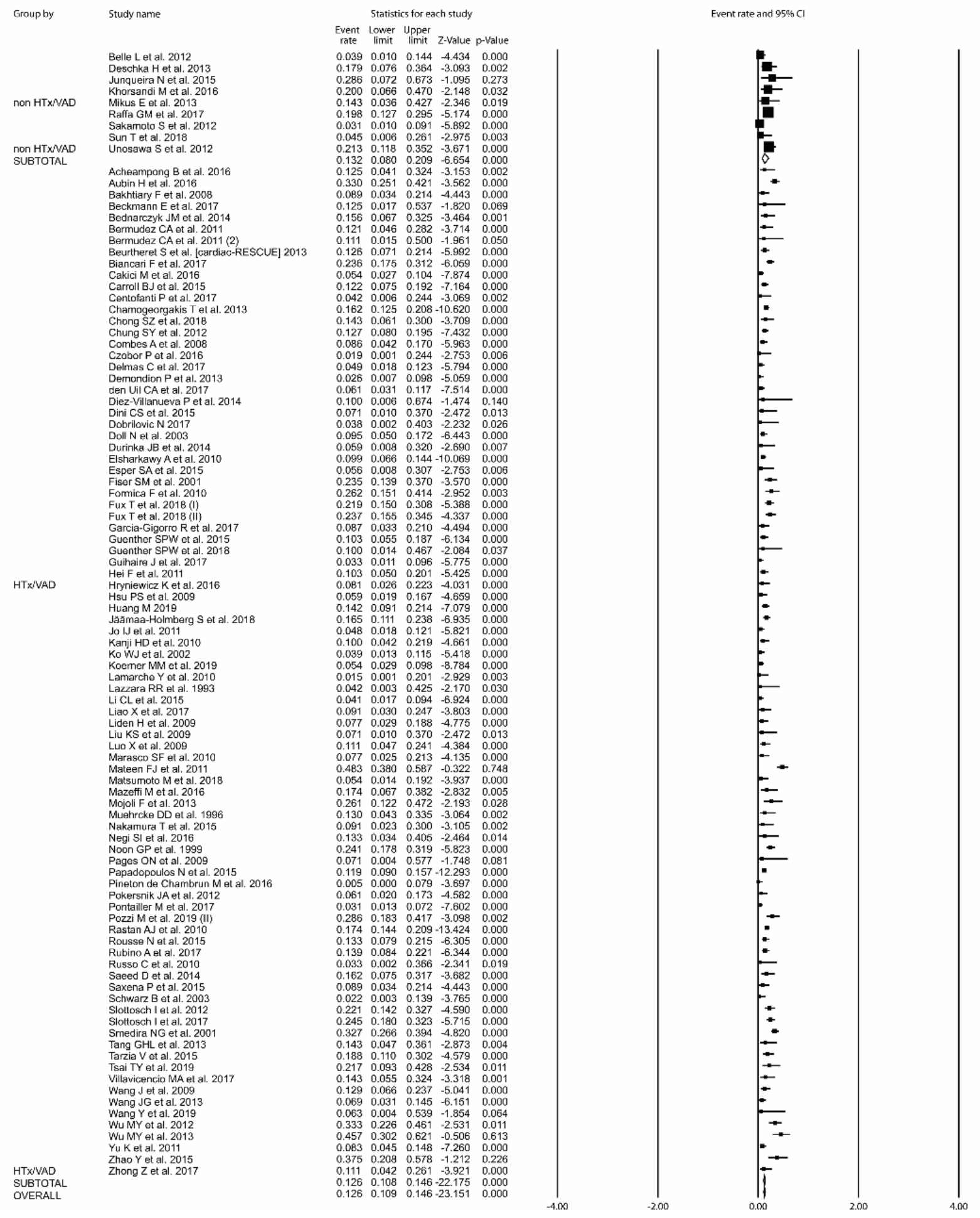

FIGURE 8. Neurologic complications incidence in non-HTx/VAD as compared to HTx/VAD centres. 
Limb complications incidence was reported in 102 studies (8,157 pts). Overall, 1,075 patients (12.4\% [11.0-

$14.0 \%]$ ) had limb complications; in the analysis stratified by centre status there was no difference between

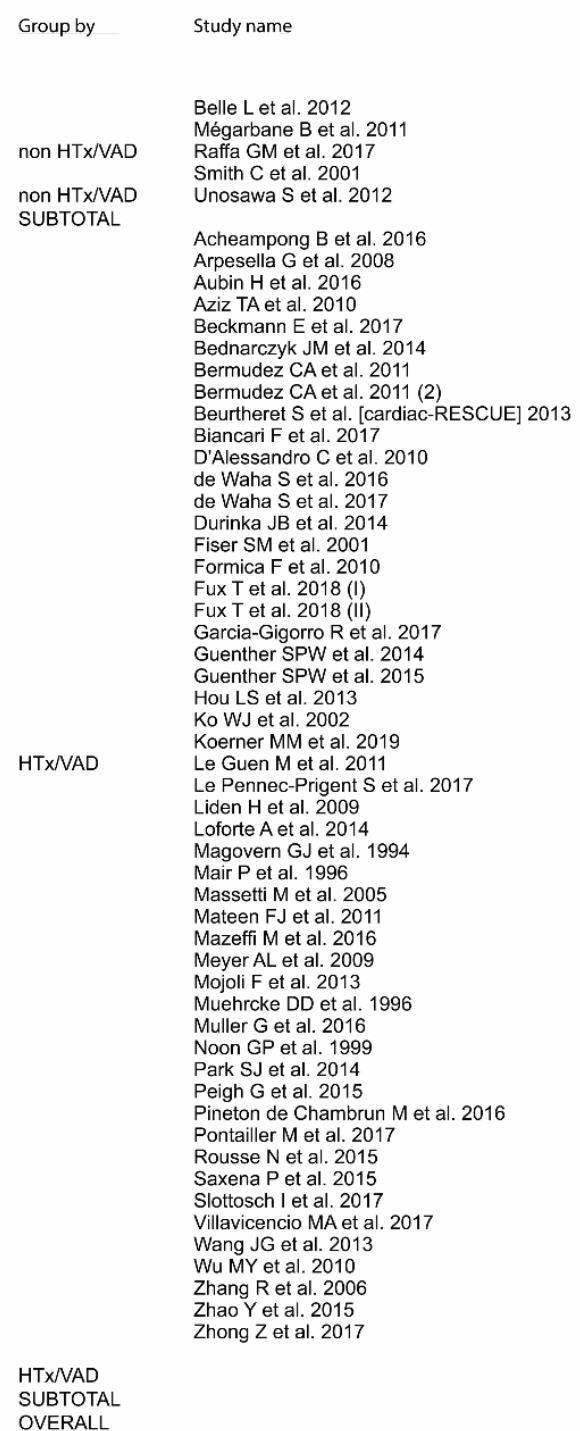

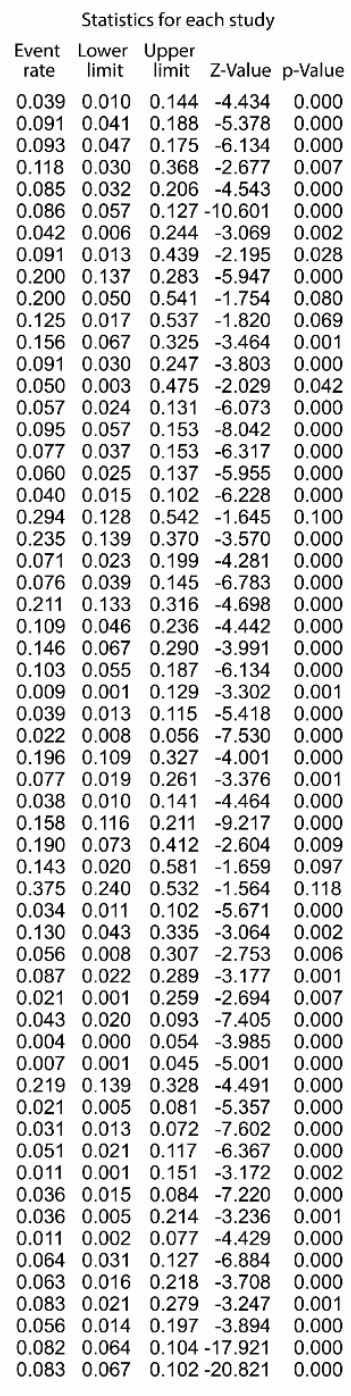

FIGURE 9. Brain death incidence in non-HTX/VAD as compared to HTX/VAD centres. 


\begin{tabular}{|c|c|}
\hline \multirow{6}{*}{ non $\mathrm{HT} x / \mathrm{VAD}$} & Belle L et al. 2012 \\
\hline & $\begin{array}{l}\text { Deschka H et al. } 2013 \\
\text { (angueira }\end{array}$ \\
\hline & Khorsandi M et al. 2016 \\
\hline & Mikus $\mathrm{E}$ et al. 2013 \\
\hline & Raffa GM et al. 2017 \\
\hline & Smith C et al. 2001 \\
\hline \multirow{31}{*}{$\begin{array}{l}\text { non } \mathrm{HTX} / \mathrm{NAD} \\
\text { SUBTOTAL }\end{array}$} & Unosawa S et al. 2012 \\
\hline & Aziz TA et al. 2010 \\
\hline & Bakhtiary F et al. 2008 \\
\hline & Beckmann E et al. 2017 \\
\hline & Bednarczyk JM et al. 2014 \\
\hline & $\begin{array}{l}\text { Beurtheret S et al. [cardiac-RESCUE] } 2013 \\
\text { Biancari F et al. } 2017\end{array}$ \\
\hline & Cakici M et al. 2016 \\
\hline & Centofanti P et al. 2017 \\
\hline & Delmas C et al. 2017 \\
\hline & Doll $\mathrm{N}$ et al. 2003 \\
\hline & Esper SA et al. 2015 \\
\hline & Fux T et al. 2018 (I) \\
\hline & Guenther SPW et al. 2014 \\
\hline & Guenther SPW et al. 2015 \\
\hline & Guihaire J et al. 2017 \\
\hline & $\begin{array}{l}\text { Hei F et al. } 2011 \\
\text { Hoefer D et al. } 2006\end{array}$ \\
\hline & Hryniewicz K et al. 2016 \\
\hline & Kanji HD et al. 2010 \\
\hline & Lamarche Y et al. 2010 \\
\hline & $\begin{array}{l}\text { Le Pennec-Prigent S et al. } 2017 \\
\text { Li CL et al. } 2015\end{array}$ \\
\hline & Liden H et al. 2009 \\
\hline & Liu KS et al. 2009 \\
\hline & Loforte A et al. 2014 \\
\hline & Luo X et al. 2009 \\
\hline & Mair $\mathrm{P}$ et al. 1996 \\
\hline & Marasco SF et al. 2010 \\
\hline & Massetti M et al. 2005 \\
\hline & Meyer AL et al. 2009 \\
\hline & Mojoli F et al. 2013 \\
\hline & Muehrcke DD et al. 1996 \\
\hline & Musial R et al. 2017 \\
\hline \multirow[t]{18}{*}{ HTX/NAD } & Negi SI et al. 2016 \\
\hline & Pabst D et al. 2018 \\
\hline & Papadopoulos N et al. 2015 \\
\hline & Pokersnik JA et al. 2012 \\
\hline & Rastan AJ et al. 2010 \\
\hline & Rubino A et al. 2017 \\
\hline & Saeed D et al. 2014 \\
\hline & Saxena P et al. 2015 \\
\hline & Scherer M et al. 2009 \\
\hline & Sheu JJ et al. 2010 \\
\hline & $\begin{array}{l}\text { Slottosch I et al. } 2012 \\
\text { Tsaa TY et al } 2019\end{array}$ \\
\hline & Villavicencio MA et al. 2017 \\
\hline & Wang J et al. 2009 \\
\hline & Wang JG et al. 2013 \\
\hline & Wang Y et al. 2019 \\
\hline & Wu MY et al. 2010 \\
\hline & Yu K et al. 2011 \\
\hline & Zhang R et al. 2006 \\
\hline $\begin{array}{l}\text { HTXNAD } \\
\text { SUBTOTA }\end{array}$ & Zhong Z et al. 2017 \\
\hline $\begin{array}{l}\text { SUBTOTAL } \\
\text { OVERALL }\end{array}$ & \\
\hline
\end{tabular}

Event Lower Upper

$\begin{array}{lllll}0.098 & 0.041 & 0.215 & -4.713 & 0.000\end{array}$ $\begin{array}{lllll}0.571 & 0.387 & 0.738 & 0.753 & 0.451\end{array}$ $\begin{array}{llllll}0.133 & 0.034 & 0.405 & -2.464 & 0.7014\end{array}$ $\begin{array}{llllll}0.133 & 0.034 & 0.405 & -2.464 & 0.014 \\ 0.643 & 0.376 & 0.843 & 1.054 & 0.292\end{array}$ $\begin{array}{llllll}0.465 & 0.363 & 0.571 & -0.646 & 0.518\end{array}$ $\begin{array}{llllll}0.353 & 0.168 & 0.596 & -1.194 & 0.232\end{array}$ $\begin{array}{llllll}0.227 & 0.098 & 0.444 & -2.405 & 0.016\end{array}$ $\begin{array}{lllll}0.702 & 0.558 & 0.815 & 2.688 & 0.007\end{array}$ $\begin{array}{llllll}0.390 & 0.249 & 0.553 & -1.332 & 0.183\end{array}$ $\begin{array}{llllll}0.045 & 0.003 & 0.448 & -2.103 & 0.035\end{array}$ $\begin{array}{llllll}0.867 & 0.733 & 0.939 & 4.268 & 0.000\end{array}$ $\begin{array}{llllll}0.375 & 0.125 & 0.715 & -0.699 & 0.484\end{array}$ $\begin{array}{llllll}0.183 & 0.087 & 0.359 & -3.238 & 0.001\end{array}$ $\begin{array}{llllll}0.419 & 0.342 & 0.500 & -1.964 & 0.0050\end{array}$ $\begin{array}{lllll}0.128 & 0.083 & 0.193 & -7.795 & 0.000\end{array}$ $\begin{array}{llllll}0.083 & 0.021 & 0.279 & -3.247 & 0.001\end{array}$ $\begin{array}{llllll}0.049 & 0.018 & 0.123 & -5.794 & 0.000\end{array}$ $\begin{array}{llllll}0.621 & 0.520 & 0.713 & 2.336 & 0.019\end{array}$ $\begin{array}{llllll}0.026 & 0.002 & 0.310 & -2.519 & 0.012\end{array}$ $\begin{array}{llllll}0.648 & 0.552 & 0.733 & 2.979 & 0.003\end{array}$ $\begin{array}{llllll}0.049 & 0.012 & 0.175 & -4.097 & 0.000\end{array}$ $\begin{array}{llllll}0.046 & 0.017 & 0.116 & -5.924 & 0.000\end{array}$ $\begin{array}{llllll}0.324 & 0.127 & 0.289 & -5.379 & 0.000\end{array}$ $\begin{array}{llllll}0.099 & 0.058 & 0.163 & -7.548 & 0.000\end{array}$ $\begin{array}{llllll}0.0135 & 0.058 & 0.163 & -7.548 & 0.000\end{array}$ $\begin{array}{llllll}0.440 & 0.310 & 0.579 & -0.846 & 0.397\end{array}$ $\begin{array}{llllll}0.438 & 0.279 & 0.610 & -0.705 & 0.481\end{array}$ $\begin{array}{lllll}0.192 & 0.082 & 0.387 & -2.884 & 0.004\end{array}$ $\begin{array}{lllll}0.398 & 0.316 & 0.487 & -2.238 & 0.025\end{array}$ $\begin{array}{llllll}0.519 & 0.385 & 0.650 & 0.277 & 0.782\end{array}$ $\begin{array}{llllll}0.143 & 0.036 & 0.427 & -2.346 & 0.019\end{array}$ $\begin{array}{lllll}0.548 & 0.483 & 0.612 & 1.455 & 0.146\end{array}$ $\begin{array}{llllll}0.267 & 0.158 & 0.413 & -3.001 & 0.003\end{array}$ $\begin{array}{llllll}0.385 & 0.247 & 0.544 & -1.428 & 0.153\end{array}$ $\begin{array}{llllll}0.125 & 0.053 & 0.267 & -4.070 & 0.000\end{array}$ $\begin{array}{llllll}0.333 & 0.158 & 0.571 & -1.386 & 0.166\end{array}$ $\begin{array}{llllll}0.130 & 0.043 & 0.335 & -3.064 & 0.002\end{array}$ $\begin{array}{llllll}0.522 & 0.325 & 0.712 & 0.208 & 0.835\end{array}$ $\begin{array}{lllll}0.556 & 0.369 & 0.728 & 0.576 & 0.565\end{array}$ $\begin{array}{llllll}0.267 & 0.104 & 0.533 & -1.733 & 0.083\end{array}$ $\begin{array}{llllll}0.016 & 0.002 & 0.107 & -4.061 & 0.000\end{array}$ $\begin{array}{lllll}0.411 & 0.361 & 0.463 & -3.355 & 0.001\end{array}$ $\begin{array}{lllll}0.714 & 0.574 & 0.823 & 2.898 & 0.004\end{array}$ $\begin{array}{llllll}0.580 & 0.537 & 0.622 & 3.634 & 0.000\end{array}$ $\begin{array}{llllll}0.622 & 0.458 & 0.761 & 1.465 & 0.143\end{array}$ $\begin{array}{lllllll}0.156 & 0.076 & 0.292 & -4.113 & 0.143\end{array}$ $\begin{array}{llllll}0.400 & 0.100 & 0.800 & -0.444 & 0.657\end{array}$ $\begin{array}{llllll}0.022 & 0.003 & 0.139 & -3.765 & 0.000\end{array}$ $\begin{array}{llllll}0.338 & 0.241 & 0.450 & -2.796 & 0.005\end{array}$ $\begin{array}{lllll}0.217 & 0.093 & 0.428 & -2.534 & 0.011\end{array}$ $\begin{array}{llllll}0.357 & 0.204 & 0.546 & -1.490 & 0.136\end{array}$ $\begin{array}{llllll}0.161 & 0.089 & 0.275 & -4.775 & 0.000\end{array}$ $\begin{array}{llllll}0.161 & 0.098 & 0.254 & -5.660 & 0.000\end{array}$ $\begin{array}{lllllll}0.286 & 0.072 & 0.673 & -1.095 & 0.273\end{array}$ $\begin{array}{llllll}0.317 & 0.240 & 0.3705 & -3.414 & 0.000\end{array}$ $\begin{array}{llllll}0.531 & 0.361 & 0.694 & 0.353 & 0.724\end{array}$ $\begin{array}{llllll}0.517 & 0.369 & 0.581 & -0.995 & 0.724\end{array}$ $0.284 \quad 0.234 \quad 0.339-7.048 \quad 0.000$ $\begin{array}{lllll}0.297 & 0.249 & 0.349 & -7.048 & 0.000\end{array}$

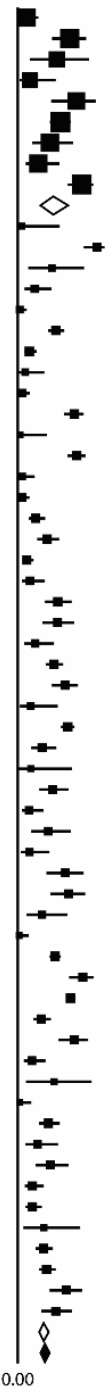

FIGURE 10. Major bleeding requiring intervention incidence in non-HTx/VAD as compared to HTx/VAD centres. 


\begin{tabular}{|c|c|}
\hline Group by & Study name \\
\hline non $\mathrm{HT} \times / \mathrm{VAD}$ & $\begin{array}{l}\text { Belle L et al. } 2012 \\
\text { Deschka H et al. } 2013 \\
\text { Khorsandi M et al. } 2016 \\
\text { Liu Y et al. } 2011 \\
\text { Mikus E et al. } 2013 \\
\text { Raffa GM et al. } 2017\end{array}$ \\
\hline $\begin{array}{l}\text { non } H T X / V A D \\
\text { SUBTOTAL }\end{array}$ & 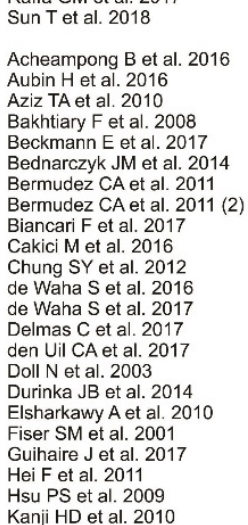 \\
\hline HTX/VAD & $\begin{array}{l}\text { Ko WJ et al. } 2002 \\
\text { Lazzara RR et al. } 1993 \\
\text { Li CL et al. } 2015 \\
\text { Liao X et al. } 2017 \\
\text { Liden H et al. } 2009 \\
\text { Liu KS et al. } 2009 \\
\text { Loforte A et al. } 2014 \\
\text { Luo X et al. } 2009 \\
\text { Marasco SF et al. } 2010 \\
\text { Massetti M et al. } 2005 \\
\text { Mazeffi M et al. } 2016 \\
\text { Meyer AL et al. } 2009 \\
\text { Mojoli F et al. } 2013 \\
\text { Muehrcke DD et al. } 1996 \\
\text { Noon GP et al. } 1999 \\
\text { Saxena P et al. } 2015 \\
\text { Scherer M et al. } 2009 \\
\text { Slottosch I et al. } 2012 \\
\text { Slottosch I et al. } 2017 \\
\text { Smedira NG et al. } 2001 \\
\text { Tang GHL et al. } 2013 \\
\text { Tarzia V et al. } 2015 \\
\text { Villavicencio MA et al. } 2017 \\
\text { Wang J et al. } 2009 \\
\text { Wang JG et al. } 2013 \\
\text { Wu MY et al. } 2010 \\
\text { Yu K et al. } 2011 \\
\text { Zhong Z et al. } 2017 \\
\text { Koerner MM et al. } 2019 \\
\text { Fux T et al. } 2018 \text { (I) }\end{array}$ \\
\hline $\begin{array}{l}\text { HTXNAD } \\
\text { SUBTOTAL }\end{array}$ & Fux T et al. 2018 (II) \\
\hline
\end{tabular}
Event Lower Upper $\begin{array}{lllll}0.137 & 0.067 & 0.261 & -4.518 & 0.000\end{array}$ $\begin{array}{lllll}0.286 & 0.150 & 0.476 & -2.190 & 0.028\end{array}$ $\begin{array}{lllll}0.133 & 0.034 & 0.405 & -2.464 & 0.014\end{array}$ $\begin{array}{lllll}0.100 & 0.014 & 0.467 & -2.084 & 0.037\end{array}$ $\begin{array}{llllll}0.429 & 0.206 & 0.684 & -0.533 & 0.594 \\ 0.209 & 0.136 & 0.308 & -5.014 & 0.000\end{array}$ $\begin{array}{llllll}0.091 & 0.023 & 0.300 & -3.105 & 0.002\end{array}$ $\begin{array}{llllll}0.0202 & 0.138 & 0.287 & -5.829 & 0.000\end{array}$ $\begin{array}{llllll}0.042 & 0.006 & 0.244 & -3.069 & 0.002\end{array}$ $\begin{array}{llllll}0.148 & 0.094 & 0.225 & -6.667 & 0.000\end{array}$ $\begin{array}{llllll}0.200 & 0.050 & 0.541 & -1.754 & 0.080\end{array}$ $\begin{array}{lllll}0.578 & 0.431 & 0.712 & 1.039 & 0.299\end{array}$ $\begin{array}{lllll}0.250 & 0.063 & 0.623 & -1.346 & 0.178\end{array}$ $\begin{array}{llllll}0.281 & 0.153 & 0.458 & -2.386 & 0.017\end{array}$ $\begin{array}{lllll}0.242 & 0.126 & 0.415 & -2.805 & 0.005\end{array}$ $\begin{array}{llllll}0.333 & 0.111 & 0.667 & -0.980 & 0.327\end{array}$ $\begin{array}{lllll}0.243 & 0.181 & 0.319 & -5.924 & 0.000\end{array}$ $\begin{array}{llllll}0.896 & 0.831 & 0.937 & 7.607 & 0.000\end{array}$ $\begin{array}{llllll}0.193 & 0.122 & 0.292 & -5.147 & 0.000\end{array}$ $\begin{array}{lllll}0.130 & 0.077 & 0.211 & -6.393 & 0.000\end{array}$ $\begin{array}{lllll}0.171 & 0.104 & 0.268 & -5.385 & 0.000\end{array}$ $\begin{array}{llllll}0.083 & 0.047 & 0.144 & -7.614 & 0.000\end{array}$ $\begin{array}{llllll}0.074 & 0.036 & 0.147 & -6.446 & 0.000\end{array}$ $\begin{array}{llllll}0.176 & 0.058 & 0.427 & -2.421 & 0.015\end{array}$ $\begin{array}{llllll}0.206 & 0.159 & 0.263 & -8.329 & 0.000\end{array}$ $\begin{array}{lllll}0.118 & 0.054 & 0.238 & -4.636 & 0.000 \\ 0.130 & 0.076 & 0.216 & -6.128 & 0.000\end{array}$ $\begin{array}{lllll}0.130 & 0.076 & 0.216 & -6.128 & 0.000\end{array}$ $\begin{array}{llllll}0.333 & 0.218 & 0.472 & -2333 & 0.020\end{array}$ $\begin{array}{llllll}0.200 & 0.111 & 0.333 & -3.921 & 0.000\end{array}$ $\begin{array}{lllll}0.013 & 0.002 & 0.088 & -4.289 & 0.000\end{array}$ $\begin{array}{lllll}0.273 & 0.090 & 0.586 & -1.449 & 0.147\end{array}$ $\begin{array}{llllll}0.130 & 0.081 & 0.202 & -7.089 & 0.000\end{array}$ $\begin{array}{lllll}0.212 & 0.105 & 0.383 & -3.082 & 0.002\end{array}$ $\begin{array}{llllll}0.019 & 0.003 & 0.124 & -3.894 & 0.000 \\ 0.071 & 0.010 & 0.370 & -2.472 & 0.013\end{array}$ $\begin{array}{llllll}0.071 & 0.010 & 0.370 & -2.472 & 0.013\end{array}$ $\begin{array}{llllll}0.189 & 0.143 & 0.245 & -8.619 & 0.000 \\ 0.378 & 0.249 & 0.526 & -1.623 & 0.105\end{array}$ $\begin{array}{llllll}0.378 & 0.249 & 0.526 & -1.623 & 0.105\end{array}$ $\begin{array}{llllll}0.025 & 0.004 & 0.157 & -3.617 & 0.000\end{array}$ $\begin{array}{lllll}0.130 & 0.043 & 0.335 & -3.064 & 0.002\end{array}$ $\begin{array}{llllll}0.333 & 0.158 & 0.571 & -1.386 & 0.166\end{array}$ $\begin{array}{lllll}0.348 & 0.184 & 0.557 & -1.436 & 0.151\end{array}$ $\begin{array}{llllll}0.217 & 0.093 & 0.428 & -2.534 & 0.011\end{array}$ $\begin{array}{llllll}0.191 & 0.135 & 0.265 & -6.730 & 0.000\end{array}$ $\begin{array}{llllll}0.244 & 0.141 & 0.390 & -3.253 & 0.001\end{array}$ $\begin{array}{llllll}0.200 & 0.027 & 0.691 & -1.240 & 0.215\end{array}$ $\begin{array}{llllll}0.247 & 0.163 & 0.355 & -4.222 & 0.000\end{array}$ $\begin{array}{llllll}0.490 & 0.422 & 0.559 & -0.281 & 0.778\end{array}$ $\begin{array}{llllll}0.143 & 0.047 & 0.361 & -2.873 & 0.004\end{array}$ $\begin{array}{llllll}0.141 & 0.075 & 0.249 & -5.034 & 0.000\end{array}$ $\begin{array}{llllll}0.179 & 0.076 & 0.364 & -3.093 & 0.002\end{array}$ $\begin{array}{lllll}0.306 & 0.205 & 0.431 & -2.965 & 0.003\end{array}$ $\begin{array}{lllll}0.149 & 0.089 & 0.241 & -5.783 & 0.000\end{array}$ $\begin{array}{llllll}0.255 & 0.182 & 0.344 & -4.909 & 0.000\end{array}$ $\begin{array}{lllllll}0.133 & 0.083 & 0.207 & -6.970 & 0.000\end{array}$ $\begin{array}{lllll}0.139 & 0.059 & 0.293 & -3.786 & 0.000\end{array}$ $\begin{array}{lllll}0.185 & 0.135 & 0.247 & -7.814 & 0.000\end{array}$ $\begin{array}{lllll}0.229 & 0.158 & 0.318 & -5.234 & 0.000 \\ 0.329 & 0.233 & 0.442 & -2.20 & 0.003\end{array}$

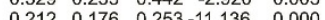
$\begin{array}{llll}0.210 & 0.178 & 0.246-12.567 & 0.000\end{array}$
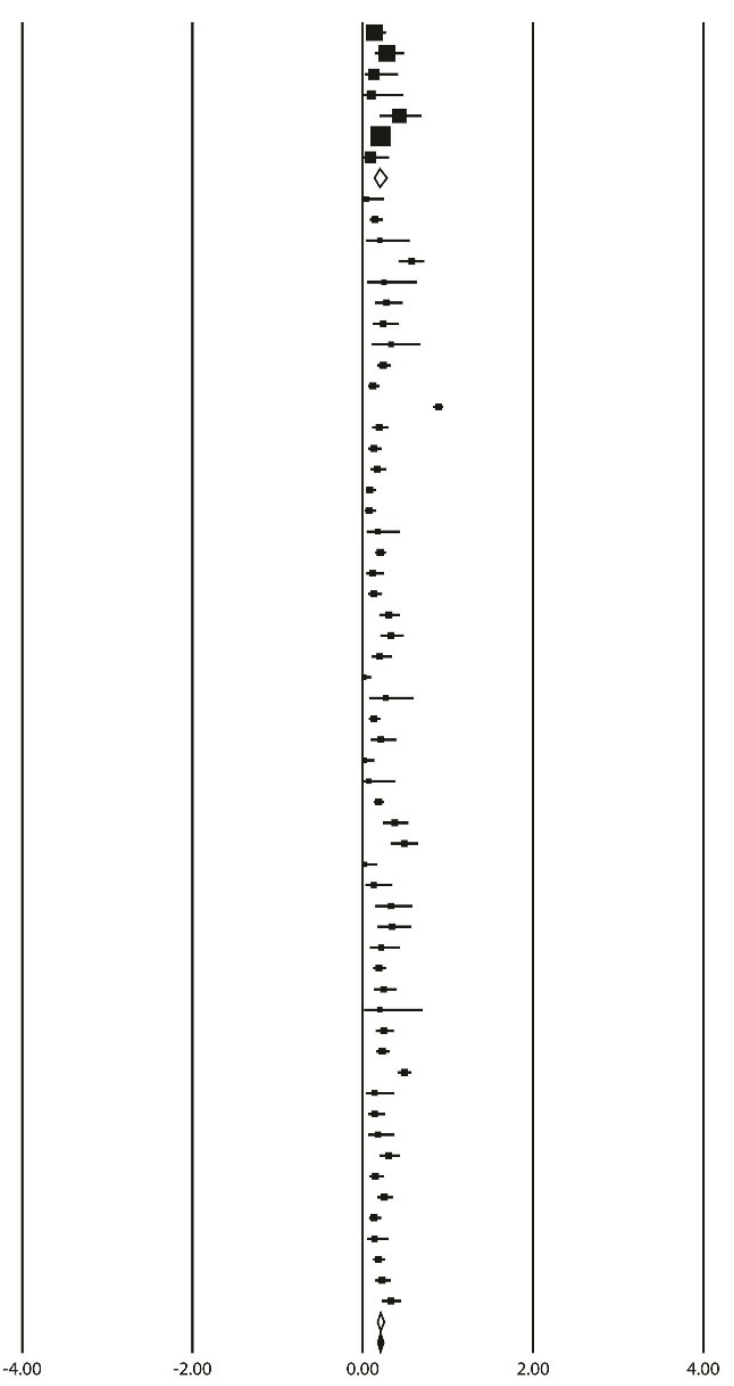

FIGURE 11. Sepsis incidence in non-HTXNAD as compared to HTx/VAD centres. 


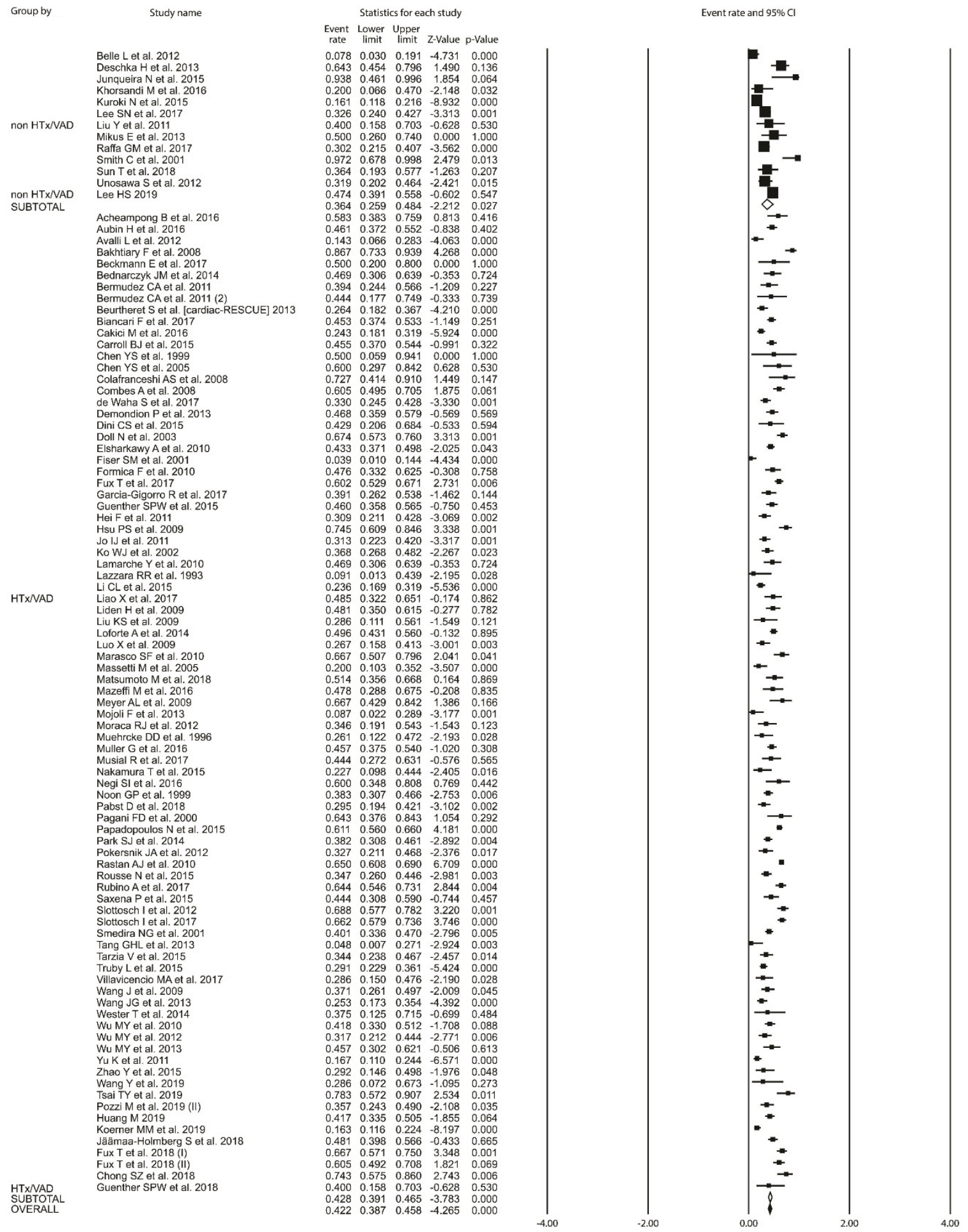

FIGURE 12. Acute kidney injury incidence in non-HTx/VAD as compared to HTx/VAD centres.

\section{ECLS as bridging therapy}

Data regarding ECLS bridge to HTx was available from 97 studies that included 7,857 patients; in an overall analysis, 474 patients underwent $\mathrm{HTx}$ which translated to an estimated rate of $6.3 \%(5.0-7.9 \%)$; there was numerical, yet not statistically significant difference between non-HTx/VAD (2.7\% [0.8-8.3\%]) as compared to 
HTxNAD (6.6\% [5.2-8.3\%]) favoring the latter $(p=0.131)$; Figure 3. Similarly, there were no marked differences between non-HTx/VAD centres as compared to HTx/VAD centres with respect to ECLS bridge to VAD: across 94 studies (7,873 patients), 754 underwent bridging to VAD: 10.4\% (8.4-12.9\%); again, only numerical difference was observed between non-HTx/VAD (3.0\% [0.3-24.2\%]) and HTx/VAD (10.5\% [8.5-13.1\%]); p=0.266; Figure 4.

\section{Additional analyses}

In several conducted meta-regressions counter-opposing logER of in-hospital mortality and percentage of patients undergoing ECLS therapy for different indications, there was higher mortality with increasing (\%) postcardiotomy ECLSs; $0.4214(0.1843-0.6587) ; p<0.001$, which was maintained in the subgroup of only HTx/VAD centres (0.4652 [0.2108-0.7197]; $p<0.001$. Figure 13.

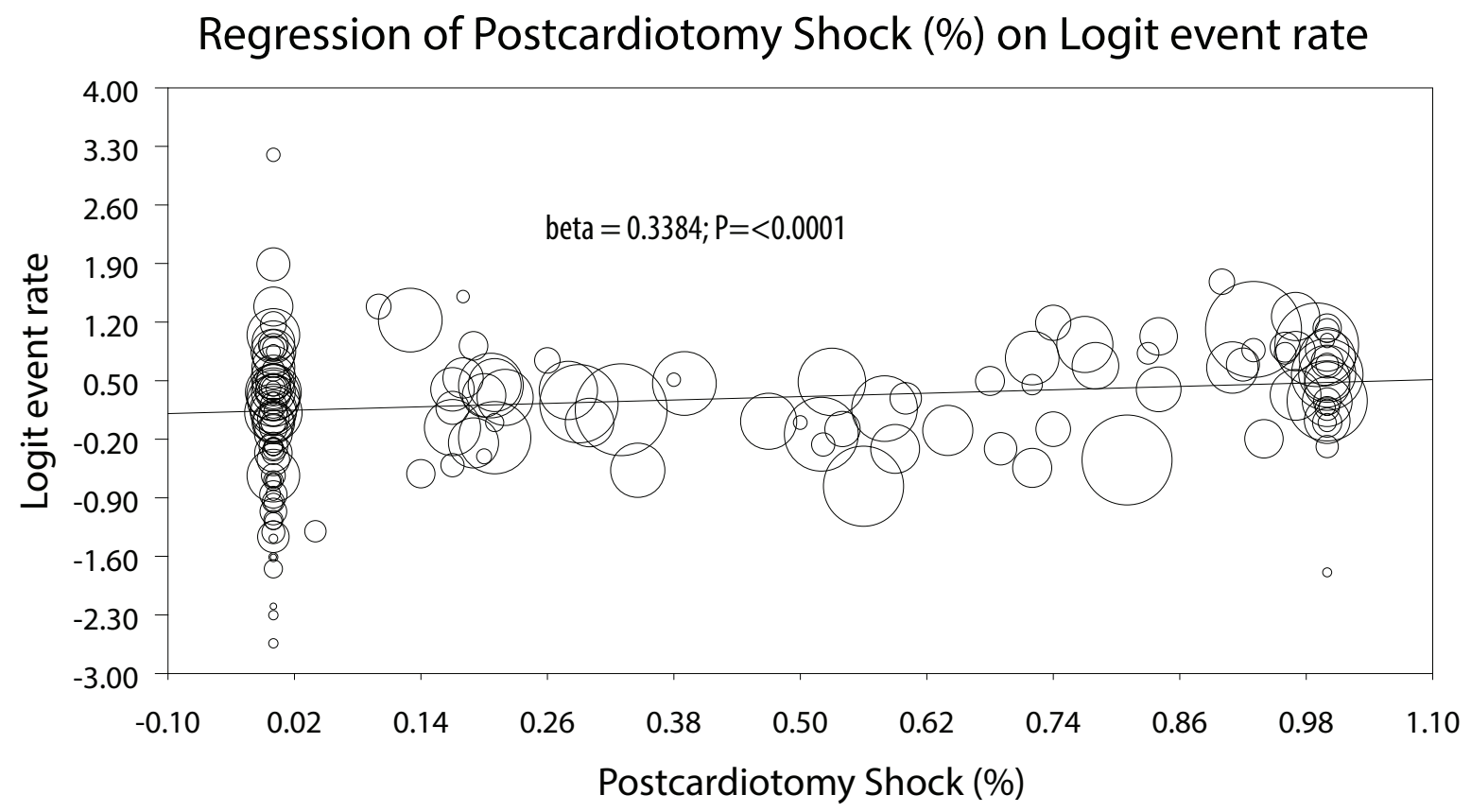

FIGURE 13. Meta-regression analysis: in-hospital mortality vs postcardiotomy shock (\%).

Conversely, lower rates of mortality were observed with increasing (\%) of ECLSs for 1) acute myocardial infarction $(-0.3765[-0.7324-\{-0.0206\}] ; p=0.0381)$; Figure $14 ; 2)$ graft failure $(-0.8846[-1.5415-\{-0.2277\}]$; $p=0.0083)$ Figure 15; 3$)$ acute decompensated heart failure $(-1.7919[-3.2789-\{-0.3049\}] ; p=0.0181)$; Figure 16; 
4) myocarditis (-1.5322 [-2.0919-\{-0.9726\}]; $p<0.001)$; Figure 17; and 5) cardiomyopathy $(-1.1074[-1.7685-\{-$ 0.4462\}]; $p=0.0010) ;$ Figure 18; without differences between between non-HTx- as compared to HTx/VAD centres.

\section{Regression of AMI (\%) on Logit event rate}

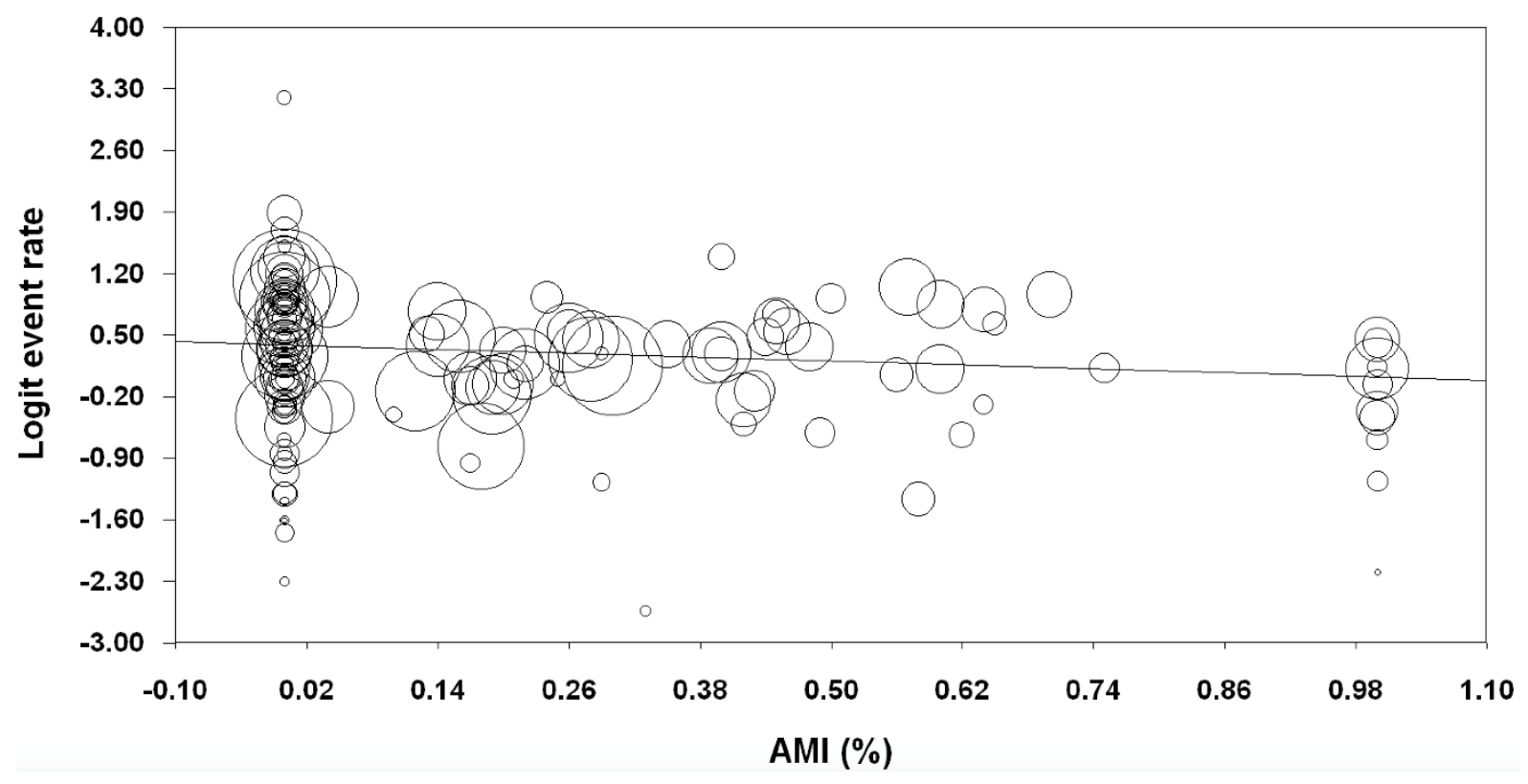

FIGURE 14. Meta-regression analysis: in-hospital mortality vs acute myocardial infarction (\%).

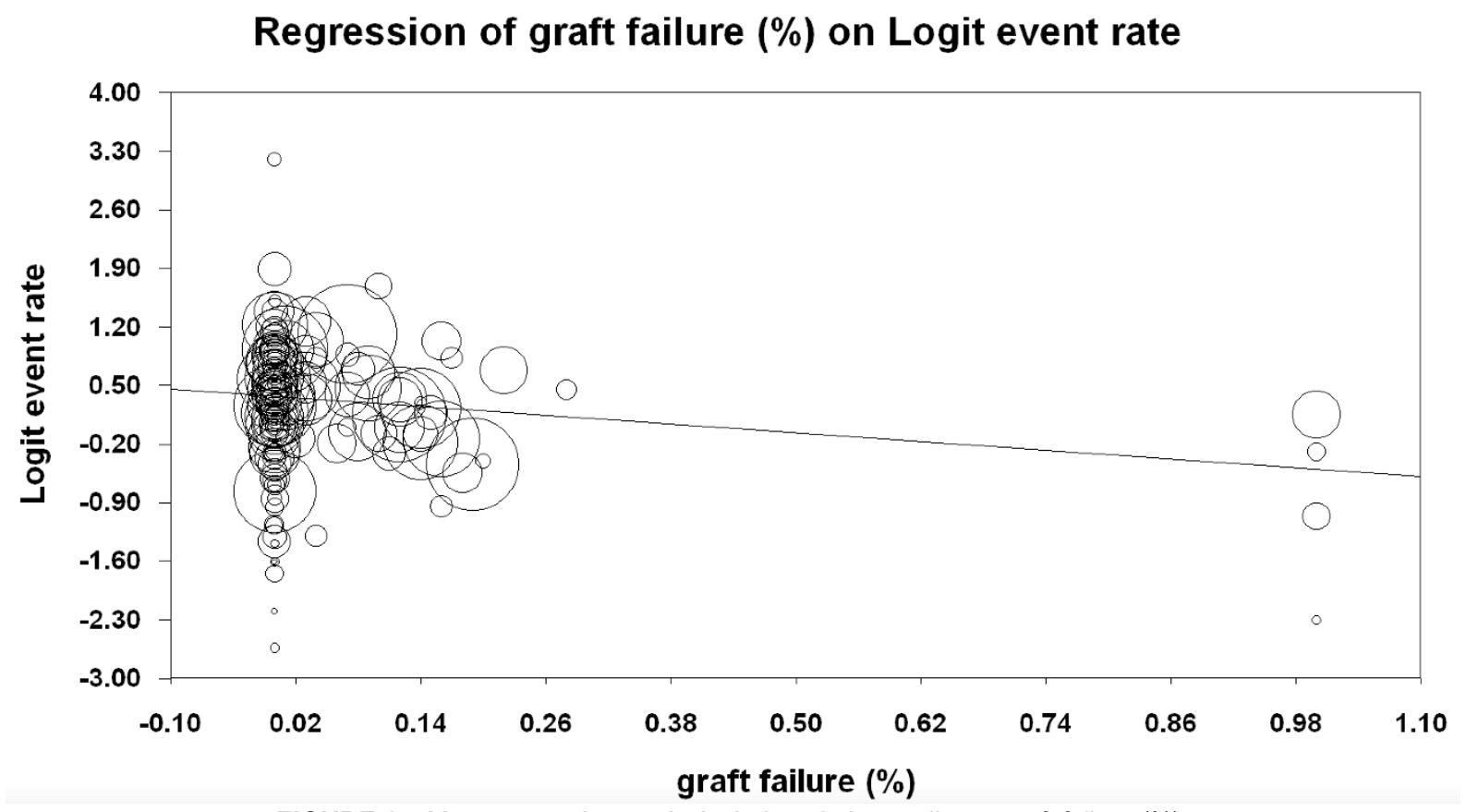

FIGURE 15. Meta-regression analysis: in-hospital mortality vs graft failure (\%). 


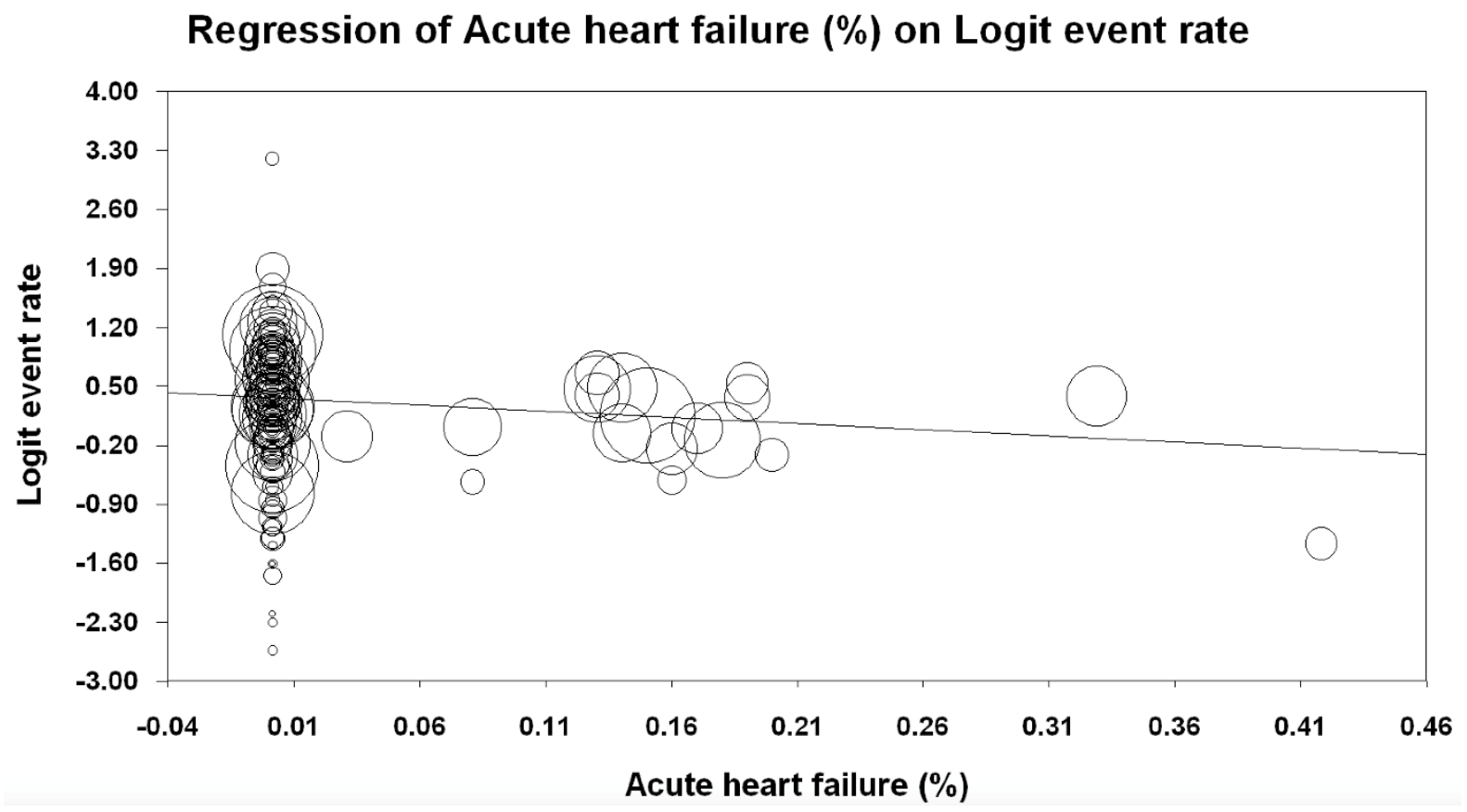

FIGURE 16. Meta-regression analysis: in-hospital mortality vs acute decompensated heart failure (\%).

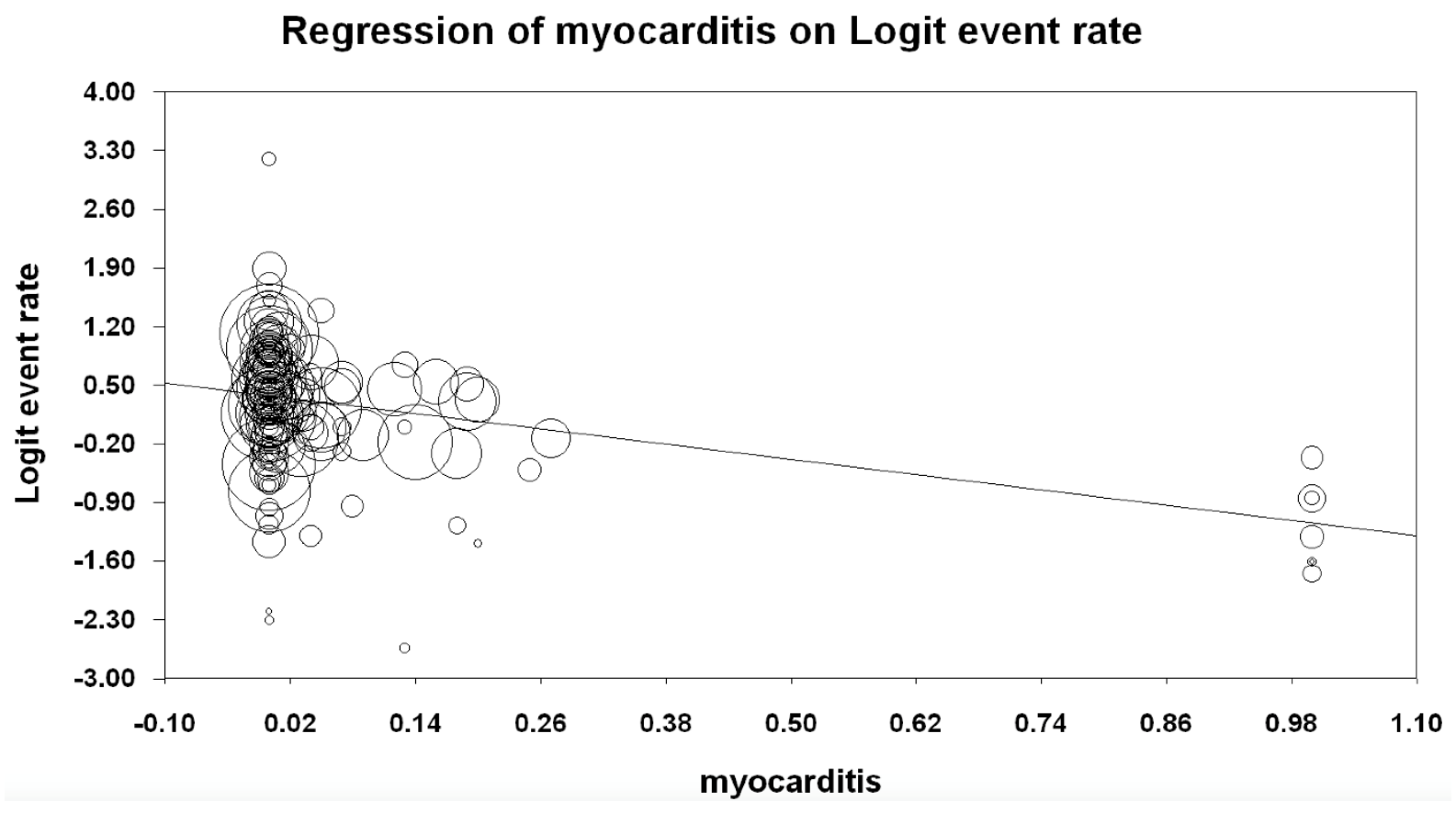

FIGURE 17. Meta-regression analysis: in-hospital mortality vs myocarditis (\%). 


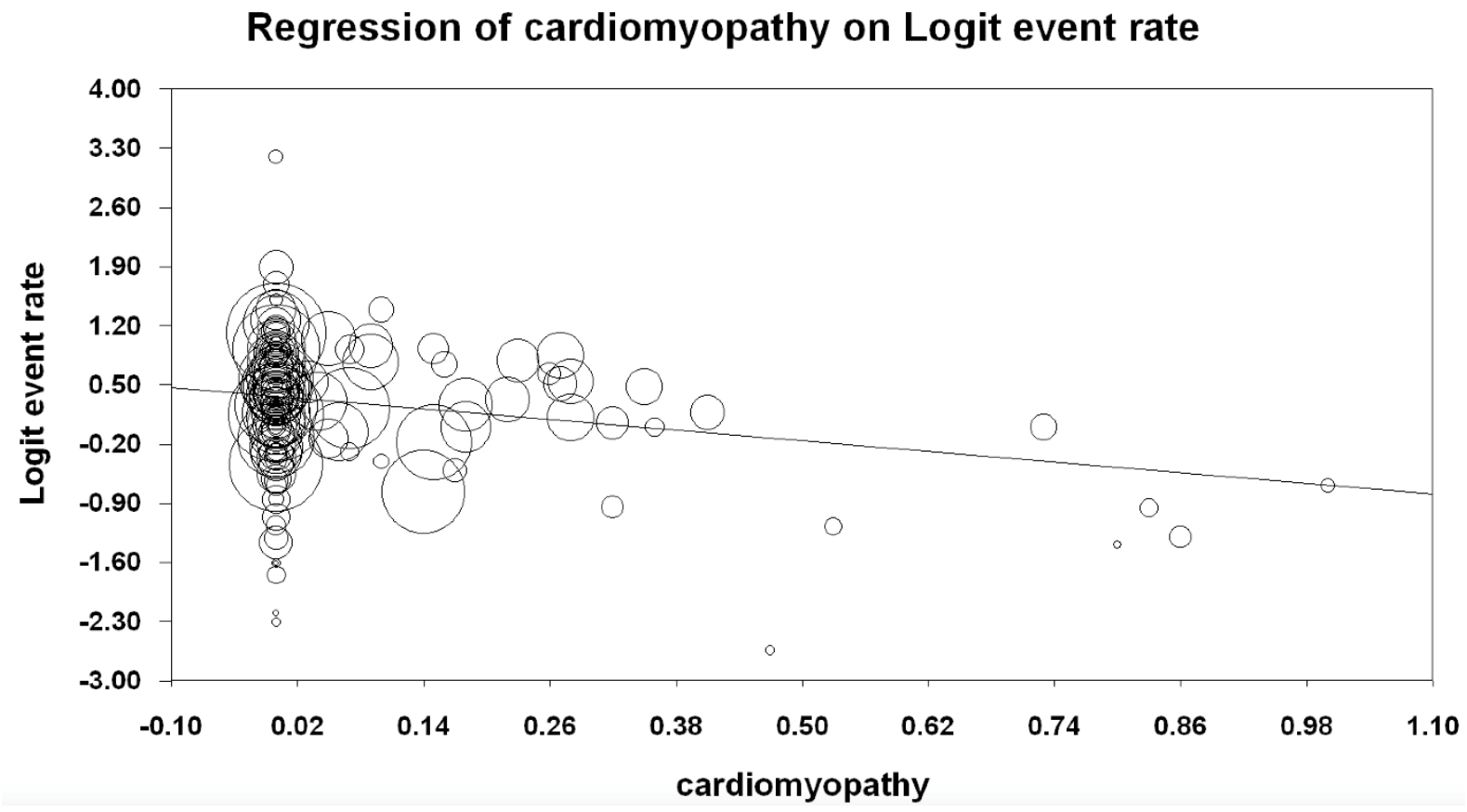

FIGURE 18. Meta-regression analysis: in-hospital mortality vs cardiomyopathy (\%).

In sensitivity analysis for mortality performed deleting single studies, one at a time, and repeating the calculations, no single study effect was seen changing neither direction nor the magnitude of the estimates. Additionally we repeated the calculations for the comparison non-HTx/VAD vs HTx/VAD centres after excluding studies 1) judged to be at critical risk of bias; $65.8 \%(59.8-71.1 \%)$ vs $56.2(53.7-58.6 \%) ; p=0.001$; and those enrolling 2) <50 patients: $70.9 \%(64.8-76.3 \%)$ vs $58.9(55.9-61.8 \%)$; $p=0.001 ; 3)<100$ patients: $72.4 \%$ (67.5$76.8 \%$ ) vs $58.0 \%$ (54.0-62.0\%); $p<0.001$; only to prove maintenance of the effect.

\section{Discussion}

The current meta-analysis represents the first attempt to compare, although in indirect fashion not only inhospital but also remote outcomes of patients supported with V-A ECLS for refractory cardiogenic shock between HTx/VAD and non-HTx/VAD performing centres. The main findings are as follows: 1) in an overall analysis, in-hospital mortality regardless of the underlying cause of cardiogenic shock remained high and was estimated at: $57.2 \%$ (54.9-59.4\%); 2) in-hospital mortality rates were significantly higher in non-HTx/VAD (65.5\% [59.8-70.8\%]) as compared to HTxNAD centres (55.8\% [53.3-58.2\%]); $P<0.001 ; 3)$ in the overall analysis, 
estimated late survival was $61.8 \%(55.7-67.9 \%)$ without significant differences between non-HTx/VAD as compared to HTx/VAD centres; 4) no differences were found between centres with respect to ECLS complications; 5) numerically, more patients were bridged to HTx and VADs in the centres that perform these procedures but the differences were not statistically significant; 6) postcardiotomy cardiogenic shock yielded higher in-hospital mortality irrespective of centre status; increasing percentage of patients treated with V-A ECLS for CS of other etiology correlated with lower mortality rates.

In the lack of randomised controlled trials in the area of V-A ECLS best evidence comes from meta-analyses of observational studies which questioned factors associated with survival including unloading of left ventricle [19], peripheral cannulation [20] or baseline surgical status in postcardiotomy setting [21]. Prolonging of V-A ECLS duration after 7 days was associated with a disproportionate increase in mortality $[22,63]$. Consequently, this led to hypothesis of the present meta-analysis that potentially shorter bridging times in HTx/VAD units due to readability of well-experienced ECLS teams experienced in dealing with both acute, chronic and end-stage heart failure also with prompt resources availability (medium- and long-term mechanical circulatory support and heart transplantation) might prevent life-threatening complications and contribute to better results.

The majority of reports came from HTX/VAD centres. 154 out of 174 studies included were conducted in HTx/VAD units and as a result $92.2 \%$ of reported patients were treated there. This is similar to findings from analysis focused exclusively on postcardiotomy patients [23]. Overrepresentation of reports on V-A ECLS from HTx/VAD centres seem to apply to different etiologies of CS. Hypotheses explaining this notion might include higher disease burden and subsequent risk of patients treated in HTx/VAD centres, higher preference for ECLS use in the treatment of refrectory CS in this centres, or unexplained underreporting from non-HTx centres.

The main finding of present analysis is that 30 day/in-hospital weaning and survival rates were significantly lower in non-HTx/VAD as compared to HTx/VAD centres. This is in contrast to results of analysis focusing exclusively on postcardiotomy patients where no differences were observed [23]. Different risk profiles of postcardiotomy and non-postcardiotomy patients must be taken to account. V-A ECLS after adult cardiac surgery had been associated with higher risk of in-hospital mortality compared with other indications $[42,159]$. Its exponential 
increase in use in this setting has not been paralleled by improved results [4]. The current meta-analysis demonstrates that postcardiotomy yielded higher in-hospital mortality irrespective of centre status. Indeed, in the mixed etiology population overall 30-day survival was $42.8 \%$ (40.6-45.1\%) and in the postcardiotomy setting it was estimated at 35.3\% (32.5-38.2\%) [23]. Negative prognostic effect of postcardiotomy on survival may be explained by the impact of the underlying cardiac disease with its accompanying risk factors as well as the extent of the surgical procedure and its potential complications. In acute settings such as postcardiotomy shock V-A ECLS is mainly instituted as a temporizing measure and a bridge to recovery rather than bridge to ventricular assist device or heart transplantation which are, indeed, more frequent therapeutic options in chronic heart failure patients $[3,4,158]$. In fact, in the overall analysis, estimated rates of HTx and bridging to VAD were $6.3 \%$ $(5.0-7.9 \%)$ and $10.4 \%(8.4-12.9 \%)$, respectively. On the other hand, in the postcardiotomy setting respective estimated rates were $3.5 \%[1.8-6.6 \%]$ and $4.3 \%[2.8-6.5 \%][23]$.

Despite difference in short-term outcomes, estimated late survival $(5,824$ person years) was similar. In the study of Smedira et al. survival after being bridged from ECLS to a VAD/HTx versus after being weaned from ECLS without a bridge was $67 \%$ versus $52 \%$ at 30 days and 5 -year survival was similar ( $44 \%$ and $40 \%$, respectively) [156]. The profit from potentially shorter bridging times in HTx/VAD units might be more apparent in the early period of intensive treatment characterised by high risk of mortality. Failure to wean from V-A ECLS support or chronic heart disease and thus need for bridging to more durable VAD or HTx might be associated with patient's high disease burden and thus effect of such procedure in the long-term might be less evident.

What could be responsible for observed differences in mortality remain inconclusive. There was no statistically significant difference in rates of $H T x$ and bridging to VAD between non-HTx/VAD as compared to HTx/VAD centres, however numerically higher in the latter. Also, there was no statistical difference between HTx/VAD (mean weighted average $=5.95$ days) vs non-HTx centres (4.77 days) in the median ECLS duration. Unexpected, yet complex finding, we could not demonstrate any difference in complication rates between HTx/VAD and non-HTx/VAD centres, in contrast to previous meta-analysis focusing on postcardiotomy CS alone, which found neurological complications occurred less frequently in HTx centres. On one hand, distinct 
shock protocols, designated, well-trained response teams, daily monitoring, neurovascular assessment, endorgan perfusion and hemodynamics assessment, daily evaluation for weaning vs escalation of support could be responsible at least in part for the overall low number of complications and, in particular, in HTx/VAD centres. On the other, significantly shorter time needed and spent on ECLS in non-HTx/VAD centres is a proxy for overall lower risk profiles in these patients, thus lower baseline risk for complications.

\section{Limitations}

Current meta-analysis is based on observational, one-arm comparisons and because of that is more prone to confounding as compared to head-to-head comparisons. On the other hand, no randomized controlled trial exist regarding analyzed topic and presumably will not be organized due to ethical issues. One limitation of the study may be underrepresentation of patients treated in non-HTx/VAD institutions. Random effect meta-analysis and inverse variance analysis was used to account for that fact. These methods appoint random weights also in a subgroup analysis which could overcome discrepancies between population sizes. There was no standard definition for secondary endpoints or risk of bias of the included studies. Conducting detailed subgroup analyses was precluded by not sufficient data on timing and location of implantation, exact device type, cannulation strategies, LV unloading techniques if any, status and duration of surgical procedure in case of postcardiotomy shock and likewise other baseline characteristic.

\section{Conclusions}

There was an apparent difference in weaning rates and survival after V-A ECLS implantation for refractory cardiogenic shock between centres which perform heart transplantations and/or implant ventricular assist device and those which do not in favor of transplant centres. Potentially different risk profiles of patients in these facilities must be taken account for before definite conclusions are drawn.

\section{References}


1. Harjola VP, Lassus J, Sionis A, et al. Clinical picture and risk prediction of short-term mortality in cardiogenic shock. Eur J Heart Fail. 2015;17:501-9.

2. Werdan K, Gielen S, Ebelt H, Hochman JS. Mechanical circulatory support in cardiogenic shock. Eur Heart J. 2014;35:156-67.

3. Lorusso R, Raffa GM, Alenizy K, et al. Structured review of post-cardiotomy extracorporeal membrane oxygenation: part 1-Adult patients. J Heart Lung Transplant. 2019;38:1125-1143.

4. Whitman GJ. Extracorporeal membrane oxygenation for the treatment of postcardiotomy shock. J Thorac Cardiovasc Surg. 2017;153:95-101.

5. Lorusso R, Gelsomino S, Parise O, et al. Venoarterial extracorporeal membrane oxygenation for refractory cardiogenic shock in the elderly patients: Trends in application and outcome from the extracorporeal life support organization (elso) registry. Ann Thorac Surg. 2017;104:62-69

6. Lawler PR, Silver DA, Scirica BM, Couper GS, Weinhouse GL, Camp PC, Jr. Extracorporeal membrane oxygenation in adults with cardiogenic shock. Circulation 2015;131:676-680.

7. Stretch R, Sauer CM, Yuh DD, Bonde P. National trends in the utilization of short-term mechanical circulatory support: Incidence, outcomes, and cost analysis. Journal of the American College of Cardiology 2014;64:14071415.

8. McCarthy FH, McDermott KM, Kini V et al. Trends in u.S. Extracorporeal membrane oxygenation use and outcomes: 2002-2012. Seminars in thoracic and cardiovascular surgery 2015;27:81-88.

9. Karagiannidis C, Brodie D, Strassmann S, et al. Extracorporeal membrane oxygenation: evolving epidemiology and mortality. Intensive Care Med. 2016;42:889-896.

10. Maxwell BG, Powers AJ, Sheikh AY, Lee PH, Lobato RL, Wong JK. Resource use trends in extracorporeal membrane oxygenation in adults: An analysis of the nationwide inpatient sample 1998-2009. The Journal of thoracic and cardiovascular surgery 2014;148:416-421. 
11. Barbaro RP, Odetola FO, Kidwell KM, et al. Association of hospital-level volume of extracorporeal membrane oxygenation cases and mortality. Analysis of the extracorporeal life support organization registry. Am J Respir Crit Care Med. 2015;191:894-901.

12. Liberati A, Altman DG, Tetzlaff J, et al. The prisma statement for reporting systematic reviews and metaanalyses of studies that evaluate healthcare interventions: Explanation and elaboration. BMJ. 2009;339:b2700

13. Sterne JA, Hernan MA, Reeves BC, et al. Robins-i: A tool for assessing risk of bias in non-randomised studies of interventions. BMJ. 2016;355:i4919

14. Blackman NJ, Koval JJ. Interval estimation for Cohen's kappa as a measure of agreement. Stat Med. 2000;19:723-41.

15. Wan X, Wang W, Liu J, Tong T. Estimating the sample mean and standard deviation from the sample size, median, range and/or interquartile range. BMC Med Res Methodol. 2014;14:135.

16. Guyot P, Ades AE, Ouwens MJ, Welton NJ. Enhanced secondary analysis of survival data: Reconstructing the data from published kaplan-meier survival curves. BMC Med Res Methodol. 2012;12:9

17. Stijnen T, Hamza TH, Ozdemir P. Random effects meta-analysis of event outcome in the framework of the generalized linear mixed model with applications in sparse data. Stat Med. 2010;29:3046-67.

18. Sterne JA, Sutton AJ, loannidis JP, et al. Recommendations for examining and interpreting funnel plot asymmetry in meta-analyses of randomised controlled trials. BMJ. 2011;343:d4002.

19. Russo JJ, Aleksova N, Pitcher I, et al. Left Ventricular Unloading During Extracorporeal Membrane Oxygenation in Patients With Cardiogenic Shock. J Am Coll Cardiol. 2019;73:654-662.

20. Raffa GM, Kowalewski M, Brodie D, et al. Meta-Analysis of Peripheral or Central Extracorporeal Membrane Oxygenation in Postcardiotomy and Non-Postcardiotomy Shock. Ann Thorac Surg. 2019;107:311321. 
21. Kowalewski M, Raffa G, Zieliński K, et al. Baseline surgical status and short-term mortality after extracorporeal membrane oxygenation for post-cardiotomy shock: a meta-analysis. Perfusion. 2019:267659119865122.

22. Tsyganenko D, Gromann TW, Schoenrath F, et al. Predictors of mid-term outcomes in patients undergoing implantation of a ventricular assist device directly after extracorporeal life support. Eur J Cardiothorac Surg. 2019;55:773-779.

23. Kowalewski M, Raffa GM, Zieliński K, et al. The impact of Centre's heart transplant status and volume on in-hospital outcomes following extracorporeal membrane oxygenation for refractory post-cardiotomy cardiogenic shock: a meta-analysis. BMC Cardiovasc Disord. 2020;20:10.

References to included studies

24. Acheampong B, Johnson JN, Stulak JM, Dearani JA, Kushwaha SS, Daly RC, Haile DT, Schears GJ. Postcardiotomy ecmo support after high-risk operations in adult congenital heart disease. Congenit Heart Dis. 2016;11:751-755 1.

25. Akin S, Caliskan K, Soliman O, Muslem R, Guven G, van Thiel RJ, Struijs A, Gommers D, Zijlstra F, Bakker J, Dos Reis Miranda D. A novel mortality risk score predicting intensive care mortality in cardiogenic shock patients treated with veno-arterial extracorporeal membrane oxygenation. J Crit Care. 2020;55:35-41.

26. Ariza-Solé A, Sánchez-Salado JC, Lorente V, González-Costello J, Sbraga F, Cequier Á. Learning curve and prognosis in patients with refractory cardiogenic shock receiving ECMO ventricular support. Med Intensiva. 2015;39:523-5.

27. Arpesella G, Loforte A, Mikus E, Mikus PM. Extracorporeal membrane oxygenation for primary allograft failure. Transplant Proc. 2008;40:3596-7.

28. Asaumi Y, Yasuda S, Morii I, Kakuchi H, Otsuka Y, Kawamura A, Sasako Y, Nakatani T, Nonogi H, Miyazaki S. Favourable clinical outcome in patients with cardiogenic shock due to fulminant myocarditis supported by percutaneous extracorporeal membrane oxygenation. Eur Heart J. 2005;26:2185-92. 
29. Aubin H, Petrov G, Dalyanoglu H, Saeed D, Akhyari P, Paprotny G, Richter M, Westenfeld R, Schelzig H, Kelm M, Kindgen-Milles D, Lichtenberg A, Albert A. A Suprainstitutional Network for Remote Extracorporeal Life Support: A Retrospective Cohort Study. JACC Heart Fail. 2016;4:698-708.

30. Avalli L, Maggioni E, Formica F, Redaelli G, Migliari M, Scanziani M, Celotti S, Coppo A, Caruso R, Ristagno G, Fumagalli R. Favourable survival of in-hospital compared to out-of-hospital refractory cardiac arrest patients treated with extracorporeal membrane oxygenation: an Italian tertiary care centre experience. Resuscitation. 2012;83:579-83.

31. Aziz TA, Singh G, Popjes E, Stephenson E, Mulvey S, Pae W, El-Banayosy A. Initial experience with CentriMag extracorporal membrane oxygenation for support of critically ill patients with refractory cardiogenic shock. J Heart Lung Transplant. 2010;29:66-71.

32. Bakhtiary F, Keller H, Dogan S, Dzemali O, Oezaslan F, Meininger D, Ackermann H, Zwissler B, Kleine P, Moritz A. Venoarterial extracorporeal membrane oxygenation for treatment of cardiogenic shock: Clinical experiences in 45 adult patients. J Thorac Cardiovasc Surg. 2008;135:382-388

33. Barth E, Durand M, Heylbroeck C, Rossi-Blancher M, Boignard A, Vanzetto G, Albaladejo P, Chavanon O. Extracorporeal life support as a bridge to high-urgency heart transplantation. Clin Transplant. 2012;26:484-8.

34. Beckmann E, Ismail I, Cebotari S, Busse A, Martens A, Shrestha M, Kuhn C, Haverich A, Fegbeutel C. Right-sided heart failure and extracorporeal life support in patients undergoing pericardiectomy for constrictive pericarditis: A risk factor analysis for adverse outcome. Thorac Cardiovasc Surg. 2017;65:662-670

35. Bednarczyk JM, White CW, Ducas RA, Golian M, Nepomuceno R, Hiebert B, Bueddefeld D, Manji RA, Singal RK, Hussain F, Freed DH. Resuscitative extracorporeal membrane oxygenation for in hospital cardiac arrest: a Canadian observational experience. Resuscitation. 2014;85:1713-9.

36. Beiras-Fernandez A, Deutsch MA, Kainzinger S, Kaczmarek I, Sodian R, Ueberfuhr P, Meiser B, Schmoeckel M, Reichart B, Brenner P. Extracorporeal membrane oxygenation in 108 patients with low cardiac output - a single-center experience. Int J Artif Organs. 2011;34:365-373 
37. Bermudez CA, Rocha RV, Toyoda Y, Zaldonis D, Sappington PL, Mulukutla S, Marroquin OC, Toma C, Bhama JK, Kormos RL. Extracorporeal membrane oxygenation for advanced refractory shock in acute and chronic cardiomyopathy. Ann Thorac Surg. 2011;92:2125-31.

38. Beurtheret S, Mordant P, Paoletti X, Marijon E, Celermajer DS, Léger P, Pavie A, Combes A, Leprince P. Emergency circulatory support in refractory cardiogenic shock patients in remote institutions: a pilot study (the cardiac-RESCUE program). Eur Heart J. 2013;34:112-20.

39. Biancari F, Dalen M, Perrotti A, Fiore A, Reichart D, Khodabandeh S, Gulbins H, Zipfel S, Al Shakaki M, Welp H, Vezzani A, Gherli T, Lommi J, Juvonen T, Svenarud P, Chocron S, Verhoye JP, Bounader K, Gatti G, Gabrielli M, Saccocci M, Kinnunen EM, Onorati F, Santarpino G, Alkhamees K, Ruggieri VG, Dell'Aquila AM. Venoarterial extracorporeal membrane oxygenation after coronary artery bypass grafting: Results of a multicenter study. Int J Cardiol. 2017;241:109-114

40. Boulate D, Luyt CE, Pozzi M, Niculescu M, Combes A, Leprince P, Kirsch M. Acute lung injury after mechanical circulatory support implantation in patients on extracorporeal life support: an unrecognized problem. Eur J Cardiothorac Surg. 2013;44:544-9; discussion 549-50.

41. Cakici M, Ozcinar E, Baran C, Bermede AO, Sarıcaoglu MC, Inan MB, Durdu MS, Aral A, Sirlak M, Akar AR. A retrospective cohort analysis of percutaneous versus side-graft perfusion techniques for veno-arterial extracorporeal membrane oxygenation in patients with refractory cardiogenic shock. Perfusion. 2017;32:363371.

42. Carroll BJ, Shah RV, Murthy V, McCullough SA, Reza N, Thomas SS, Song TH, Newton-Cheh CH, Camuso JM, MacGillivray T, Sundt TM, Semigran MJ, Lewis GD, Baker JN, Garcia JP. Clinical features and outcomes in adults with cardiogenic shock supported by extracorporeal membrane oxygenation. Am J Cardiol. 2015;116:1624-1630 
43. Centofanti P, Attisani M, La Torre M, Ricci D, Boffini M, Baronetto A, Simonato E, Clerici A, Rinaldi M. Left Ventricular Unloading during Peripheral Extracorporeal Membrane Oxygenator Support: A Bridge To Life In Profound Cardiogenic Shock. J Extra Corpor Technol. 2017;49:201-205.

44. Chamogeorgakis T, Lima B, Shafii AE, Nagpal D, Pokersnik JA, Navia JL, Mason D, Gonzalez-Stawinski GV. Outcomes of axillary artery side graft cannulation for extracorporeal membrane oxygenation. J Thorac Cardiovasc Surg. 2013;145:1088-1092.

45. Chen YC, Tsai FC, Chang CH, Lin CY, Jenq CC, Juan KC, Hsu HH, Chang MY, Tian YC, Hung CC, Fang JT, Yang CW. Prognosis of patients on extracorporeal membrane oxygenation: The impact of acute kidney injury on mortality. Ann Thorac Surg. 2011;91:137-142

46. Chen YS, Wang MJ, Chou NK, Han YY, Chiu IS, Lin FY, Chu SH, Ko WJ. Rescue for acute myocarditis with shock by extracorporeal membrane oxygenation. Ann Thorac Surg. 1999;68:2220-4.

47. Chen YS, Yu HY, Huang SC, Chiu KM, Lin TY, Lai LP, Lin FY, Wang SS, Chu SH, Ko WJ. Experience and result of extracorporeal membrane oxygenation in treating fulminant myocarditis with shock: what mechanical support should be considered first? J Heart Lung Transplant. 2005;24:81-7.

48. Cho YH, Yang JH, Sung K, Jeong DS, Park PW, Kim WS, Lee YT, Jeon ES. Extracorporeal life support as a bridge to heart transplantation: importance of organ failure in recipient selection. ASAIO J. 2015;61:139-43.

49. Choi DH, Kim YJ, Ryoo SM, Sohn CH, Ahn S, Seo DW, Lim JY, Kim WY. Extracorporeal cardiopulmonary resuscitation among patients with out-of-hospital cardiac arrest. Clin Exp Emerg Med. 2016;3:132-138.

50. Chong SZ, Fang CY, Fang HY, Chen HC, Chen CJ, Yang CH, Hang CL, Yip HK, Wu CJ, Lee WC. Associations with the In-Hospital Survival Following Extracorporeal Membrane Oxygenation in Adult Acute Fulminant Myocarditis. J Clin Med. 2018;7.

51. Chung SY, Sheu JJ, Lin YJ, Sun CK, Chang LT, Chen YL, Tsai TH, Chen CJ, Yang CH, Hang CL, Leu S, Wu CJ, Lee FY, Yip HK. Outcome of patients with profound cardiogenic shock after cardiopulmonary 
resuscitation and prompt extracorporeal membrane oxygenation support. A single-center observational study. Circ J. 2012;76:1385-92.

52. Colafranceschi AS, Monteiro AJ, Canale LS, Campos LA, Montera MW, Silva PR, Fernandes MR, Pinto Ade A, Molas SM, Mesquita ET. Adult extracorporeal life support: a failed or forgotten concept? Arq Bras Cardiol. 2008;91:34-41.

53. Combes A, Leprince P, Luyt CE, Bonnet N, Trouillet JL, Leger P, Pavie A, Chastre J. Outcomes and longterm quality-of-life of patients supported by extracorporeal membrane oxygenation for refractory cardiogenic shock. Crit Care Med. 2008;36:1404-1411

54. Czobor P, Venturini JM, Parikh KS, Retzer EM, Friant J, Jeevanandam V, Russo MJ, Uriel N, Paul JD, Blair JE, Nathan S, Shah AP. Sequential Organ Failure Assessment Score at Presentation Predicts Survival in Patients Treated With Percutaneous Veno-Arterial Extracorporeal Membrane Oxygenation. J Invasive Cardiol. 2016;28:133-8.

55. D'Alessandro C, Aubert S, Golmard JL, Praschker BL, Luyt CE, Pavie A, Gandjbakhch I, Leprince P. Extra-corporeal membrane oxygenation temporary support for early graft failure after cardiac transplantation. Eur J Cardiothorac Surg. 2010;37:343-9.

56. de Waha S, Graf T, Desch S, Fuernau G, Eitel I, Pöss J, Jobs A, Stiermaier T, Ledwoch J, Wiedau A, Lurz P, Schuler G, Thiele H. Outcome of elderly undergoing extracorporeal life support in refractory cardiogenic shock. Clin Res Cardiol. 2017;106:379-385.

57. de Waha S, Fuernau G, Desch S, Eitel I, Wiedau A, Lurz P, Schuler G, Thiele H. Long-term prognosis after extracorporeal life support in refractory cardiogenic shock: results from a real-world cohort. Eurolntervention. 2016;11:1363-71.

58. Delmas C, Conil JM, Sztajnic S, Georges B, Biendel C, Dambrin C, Galinier M, Minville V, Fourcade O, Silva S, Marcheix B. Early Prediction of 3-month Survival of Patients in Refractory Cardiogenic Shock and Cardiac Arrest on Extracorporeal Life Support. Indian J Crit Care Med. 2017;21:138-145. 
59. Demondion P, Fournel L, Golmard JL, Niculescu M, Pavie A, Leprince P. Predictors of 30-day mortality and outcome in cases of myocardial infarction with cardiogenic shock treated by extracorporeal life support. Eur J Cardiothorac Surg. 2014;45:47-54.

60. den Uil CA, Jewbali LS, Heeren MJ, Constantinescu AA, Van Mieghem NM, Reis Miranda DD. Isolated left ventricular failure is a predictor of poor outcome in patients receiving veno-arterial extracorporeal membrane oxygenation. Eur J Heart Fail. 2017;19 Suppl 2:104-109.

61. Díez-Villanueva P, Sousa I, Núñez A, Díez F, Elízaga J, Fernández-Avilés F. Early treatment of refractory cardiogenic shock with percutaneous veno-arterial ECMO implanted in the cardiac catheterization laboratory. Rev Esp Cardiol (Engl Ed). 2014;67:1059-61.

62. Dini CS, Lazzeri C, Chiostri M, Gensini GF, Valente S. A local network for extracorporeal membrane oxygenation in refractory cardiogenic shock. Acute Card Care. 2015;17:49-54.

63. Distelmaier K, Wiedemann D, Binder C, Haberl T, Zimpfer D, Heinz G, Koinig H, Felli A, Steinlechner B, Niessner A, Laufer G, Lang IM, Goliasch G. Duration of extracorporeal membrane oxygenation support and survival in cardiovascular surgery patients. J Thorac Cardiovasc Surg. 2017

64. Distelmaier K, Schrutka L, Binder C, Steinlechner B, Heinz G, Lang IM, Ristl R, Maurer G, Koinig H, Wiedemann D, Rutzler K, Niessner A, Goliasch G. Cardiac arrest does not affect survival in post-operative cardiovascular surgery patients undergoing extracorporeal membrane oxygenation. Resuscitation. 2016;104:24-27

65. Dobrilovic N, Lateef O, Michalak L, Delibasic M, Raman J. Extracorporeal Membrane Oxygenation Bridges Inoperable Patients to Definitive Cardiac Operation. ASAIO J. 2019;65:43-48.

66. Doll N, Fabricius A, Borger MA, Bucerius J, Doll S, Kramer K, Ullmann C, Schmitt DV, Walther T, Falk V, Mohr FW. Temporary extracorporeal membrane oxygenation in patients with refractory postoperative cardiogenic shock--a single center experience. J Card Surg. 2003;18:512-518 
67. Durinka JB, Bogar LJ, Hirose H, Brehm C, Koerner MM, Pae WE, El-Banayosy A, Stephenson ER, Cavarocchi NC. End-organ recovery is key to success for extracorporeal membrane oxygenation as a bridge to implantable left ventricular assist device. ASAIO J. 2014;60:189-92.

68. Elsharkawy HA, Li L, Esa WA, Sessler DI, Bashour CA. Outcome in patients who require venoarterial extracorporeal membrane oxygenation support after cardiac surgery. J Cardiothorac Vasc Anesth. 2010;24:946-951

69. Esper SA, Bermudez C, Dueweke EJ, Kormos R, Subramaniam K, Mulukutla S, Sappington P, Waters J, Khandhar SJ. Extracorporeal membrane oxygenation support in acute coronary syndromes complicated by cardiogenic shock. Catheter Cardiovasc Interv. 2015;86 Suppl 1:S45-50.

70. Fiser SM, Tribble CG, Kaza AK, Long SM, Zacour RK, Kern JA, Kron IL. When to discontinue extracorporeal membrane oxygenation for postcardiotomy support. Ann Thorac Surg. 2001;71:210-214

71. Flécher E, Anselmi A, Corbineau H, Langanay T, Verhoye JP, Félix C, Leurent G, Le Tulzo Y, Malledant $Y$, Leguerrier A. Current aspects of extracorporeal membrane oxygenation in a tertiary referral centre: determinants of survival at follow-up. Eur J Cardiothorac Surg. 2014;46:665-71; discussion 671.

72. Formica F, Avalli L, Colagrande L, Ferro O, Greco G, Maggioni E, Paolini G. Extracorporeal membrane oxygenation to support adult patients with cardiac failure: predictive factors of 30-day mortality. Interact Cardiovasc Thorac Surg. 2010;10:721-6.

73. Fux T, Holm M, Corbascio M, van der Linden J, Lund LH. Pre-Implant Outcome Predictors in Patients With Refractory Cardiogenic Shock Supported With VA-ECMO. J Am Coll Cardiol. 2017;70:2094-2096.

74. Fux T, Holm M, Corbascio M, Lund LH, van der Linden J. Venoarterial extracorporeal membrane oxygenation for postcardiotomy shock: Risk factors for mortality. J Thorac Cardiovasc Surg. 2018;156:18941902.e3.

75. Fux T, Holm M, Corbascio M, Lund LH, van der Linden J. VA-ECMO Support in Nonsurgical Patients With Refractory Cardiogenic Shock: Pre-Implant Outcome Predictors. Artif Organs. 2019;43:132-141. 
76. García-Gigorro R, Renes-Carreño E, Pérez-Vela JL, Marín-Mateos H, Gutiérrez J, Corrés-Peiretti MA, Delgado JF, Pérez-de la Sota E, Cortina-Romero JM, Montejo-González JC. Mechanical support with venoarterial extracorporeal membrane oxygenation (ECMO-VA): Short-term and long-term prognosis after a successful weaning. Med Intensiva. 2017;41:513-522.

77. Guenther S, Theiss HD, Fischer M, Sattler S, Peterss S, Born F, Pichlmaier M, Massberg S, Hagl C, Khaladj N. Percutaneous extracorporeal life support for patients in therapy refractory cardiogenic shock: initial results of an interdisciplinary team. Interact Cardiovasc Thorac Surg. 2014;18:283-91.

78. Guenther SP, Brunner S, Born F, Fischer M, Schramm R, Pichlmaier M, Massberg S, Hagl C, Khaladj N. When all else fails: extracorporeal life support in therapy-refractory cardiogenic shock. Eur J Cardiothorac Surg. 2016;49:802-9.

79. Guenther SP, Shudo Y, Hiesinger W, Banerjee D. Prolonged veno-arterial extracorporeal life support for cardiac failure. Int J Artif Organs. 2018;41:437-444.

80. Guihaire J, Dang Van S, Rouze S, Rosier S, Roisne A, Langanay T, Corbineau H, Verhoye JP, Flecher E. Clinical outcomes in patients after extracorporeal membrane oxygenation support for post-cardiotomy cardiogenic shock: A single-centre experience of 92 cases. Interact Cardiovasc Thorac Surg. 2017;25:363-369 81. Hei F, Lou S, Li J, Yu K, Liu J, Feng Z, Zhao J, Hu S, Xu J, Chang Q, Liu Y, Wang X, Liu P, Long C. Fiveyear results of 121 consecutive patients treated with extracorporeal membrane oxygenation at Fu Wai Hospital. Artif Organs. 2011;35:572-8.

82. Hoefer D, Ruttmann E, Poelzl G, Kilo J, Hoermann C, Margreiter R, Laufer G, Antretter H. Outcome evaluation of the bridge-to-bridge concept in patients with cardiogenic shock. Ann Thorac Surg. 2006;82:2833.

83. Hou LS, Xie G, Li JW, Jiang CH, Yuan Y, Li BF, Jiang HM, Ning Y, Wu GS, Zheng WH, Zhao SB. Clinical application of extracorporeal membrane oxygenation for treatment of adult refractory cardiogenic shock. Zhonghua Xin Xue Guan Bing Za Zhi. 2013;41:590-3. 
84. Huang M, Ong BH, Hoo AEE, Gao F, Chao VTT, Lim CH, Tan TE, Sin KYK. Prognostic Factors for Survival After Extracorporeal Membrane Oxygenation for Cardiogenic Shock. ASAIO J. 2020;66:141-145.

85. Hryniewicz K, Sandoval Y, Samara M, Bennett M, Cabuay B, Chavez IJ, Seatter S, Eckman P, Zimbwa P, Dunn A, Sun B. Percutaneous Venoarterial Extracorporeal Membrane Oxygenation for Refractory Cardiogenic Shock Is Associated with Improved Short- and Long-Term Survival. ASAIO J. 2016;62:397-402.

86. Hsu PS, Chen JL, Hong GJ, Tsai YT, Lin CY, Lee CY, Chen YG, Tsai CS. Extracorporeal membrane oxygenation for refractory cardiogenic shock after cardiac surgery: Predictors of early mortality and outcome from 51 adult patients. Eur J Cardiothorac Surg. 2010;37:328-333

87. Huang SC, Chen YS, Chi NH, Hsu J, Wang CH, Yu HY, Chou NK, Ko WJ, Wang SS, Lin FY. Out-of-center extracorporeal membrane oxygenation for adult cardiogenic shock patients. Artif Organs. 2006;30:24-8.

88. Idelchik GM, Simpson L, Civitello AB, Loyalka P, Gregoric ID, Delgado R 3rd, Kar B. Use of the percutaneous left ventricular assist device in patients with severe refractory cardiogenic shock as a bridge to long-term left ventricular assist device implantation. J Heart Lung Transplant. 2008;27:106-11.

89. Jäämaa-Holmberg S, Salmela B, Suojaranta R, Jokinen JJ, Lemström KB, Lommi J. Extracorporeal membrane oxygenation for refractory cardiogenic shock: patient survival and health-related quality of life. Eur J Cardiothorac Surg. 2019;55:780-787.

90. Jaski BE, Ortiz B, Alla KR, Smith SC Jr, Glaser D, Walsh C, Chillcott S, Stahovich M, Adamson R, Dembitsky W. A 20-year experience with urgent percutaneous cardiopulmonary bypass for salvage of potential survivors of refractory cardiovascular collapse. J Thorac Cardiovasc Surg. 2010;139:753-7.e1-2.

91. Jo IJ, Shin TG, Sim MS, Song HG, Jeong YK, Song YB, Hahn JY, Choi SH, Gwon HC, Jeon ES, Kim WS, Lee YT, Sung K, Choi JH. Outcome of in-hospital adult cardiopulmonary resuscitation assisted with portable auto-priming percutaneous cardiopulmonary support. Int J Cardiol. 2011;151:12-7. 
92. Kanji HD, Schulze CJ, Oreopoulos A, Lehr EJ, Wang W, MacArthur RM. Peripheral versus central cannulation for extracorporeal membrane oxygenation: A comparison of limb ischemia and transfusion requirements. Thorac Cardiovasc Surg. 2010;58:459-462

93. Ko WJ, Lin CY, Chen RJ, Wang SS, Lin FY, Chen YS. Extracorporeal membrane oxygenation support for adult postcardiotomy cardiogenic shock. Ann Thorac Surg. 2002;73:538-545

94. Koerner MM, Harper MD, Gordon CK, Horstmanshof D, Long JW, Sasevich MJ, Neel JD, El Banayosy A. Adult cardiac veno-arterial extracorporeal life support (VA-ECMO): prevention and management of acute complications. Ann Cardiothorac Surg. 2019;8:66-75.

95. Lamarche Y, Chow B, Bedard A, Johal N, Kaan A, Humphries KH, Cheung A. Thromboembolic events in patients on extracorporeal membrane oxygenation without anticoagulation. Innovations (Phila). 2010;5:424429

96. Lazzara RR, Magovern JA, Benckart DH, Maher TD Jr, Sakert T, Magovern GJ Jr. Extracorporeal membrane oxygenation for adult post cardiotomy cardiogenic shock using a heparin bonded system. ASAIO J. 1993;39:M444-7.

97. Le Guen M, Nicolas-Robin A, Carreira S, Raux M, Leprince P, Riou B, Langeron O. Extracorporeal life support following out-of-hospital refractory cardiac arrest. Crit Care. 2011;15:[7]9.

98. Le Pennec-Prigent S, Flecher E, Auffret V, Leurent G, Daubert JC, Leclercq C, Mabo P, Verhoye JP, Martins RP. Effectiveness of Extracorporeal Life Support for Patients With Cardiogenic Shock Due To Intractable Arrhythmic Storm. Crit Care Med. 2017;45:e281-e289.

99. Leprince P, Aubert S, Bonnet N, Rama A, Léger P, Bors V, Levasseur JP, Szefner J, Vaissier E, Pavie A, Gandjbakhch I. Peripheral extracorporeal membrane oxygenation (ECMO) in patients with posttransplant cardiac graft failure. Transplant Proc. 2005;37:2879-80. 
100. Li CL, Wang H, Jia M, Ma N, Meng X, Hou XT. The early dynamic behavior of lactate is linked to mortality in postcardiotomy patients with extracorporeal membrane oxygenation support: A retrospective observational study. J Thorac Cardiovasc Surg. 2015;149:1445-1450

101. Liao X, Li B, Cheng Z. Extracorporeal membrane oxygenation in adult patients with acute fulminant myocarditis : Clinical outcomes and risk factor analysis. Herz. 2018;43:728-732.

102. Liden H, Wiklund L, Haraldsson A, Berglin E, Hultman J, Dellgren G. Temporary circulatory support with extra corporeal membrane oxygenation in adults with refractory cardiogenic shock. Scand Cardiovasc J. $2009 ; 43: 226-232$

103. Liu KS, Tsai FC, Huang YK, Wu MY, Chang YS, Chu JJ, Lin PJ. Extracorporeal life support: A simple and effective weapon for postcardiotomy right ventricular failure. Artif Organs. 2009;33:504-508

104. Loforte A, Marinelli G, Musumeci F, Folesani G, Pilato E, Martin Suarez S, Montalto A, Lilla Della Monica P, Grigioni F, Frascaroli G, Menichetti A, Di Bartolomeo R, Arpesella G. Extracorporeal membrane oxygenation support in refractory cardiogenic shock: Treatment strategies and analysis of risk factors. Artif Organs. 2014;38:E129-141

105. Luo XJ, Wang W, Hu SS, Sun HS, Gao HW, Long C, Song YH, Xu JP. Extracorporeal membrane oxygenation for treatment of cardiac failure in adult patients. Interact Cardiovasc Thorac Surg. 2009;9:296-300 106. Maekawa K, Tanno K, Hase M, Mori K, Asai Y. Extracorporeal cardiopulmonary resuscitation for patients with out-of-hospital cardiac arrest of cardiac origin: a propensity-matched study and predictor analysis. Crit Care Med. 2013;41:1186-96.

107. Maggio P, Hemmila M, Haft J, Bartlett R. Extracorporeal life support for massive pulmonary embolism. J Trauma. 2007;62:570-6.

108. Magovern GJ Jr, Magovern JA, Benckart DH, Lazzara RR, Sakert T, Maher TD Jr, Clark RE. Extracorporeal membrane oxygenation: preliminary results in patients with postcardiotomy cardiogenic shock. Ann Thorac Surg. 1994;57:1462-8; discussion 1469-71. 
109. Mair P, Hoermann C, Moertl M, Bonatti J, Falbesoner C, Balogh D. Percutaneous venoarterial extracorporeal membrane oxygenation for emergency mechanical circulatory support. Resuscitation. 1996;33:29-34.

110. Marasco SF, Vale M, Pellegrino V, Preovolos A, Leet A, Kras A, Schulberg E, Bergin P, Esmore DS. Extracorporeal membrane oxygenation in primary graft failure after heart transplantation. Ann Thorac Surg. 2010;90:1541-6.

111. Massetti M, Tasle M, Le Page O, Deredec R, Babatasi G, Buklas D, Thuaudet S, Charbonneau P, Hamon M, Grollier G, Gerard JL, Khayat A. Back from irreversibility: extracorporeal life support for prolonged cardiac arrest. Ann Thorac Surg. 2005;79:178-83; discussion 183-4.

112. Mateen FJ, Muralidharan R, Shinohara RT, Parisi JE, Schears GJ, Wijdicks EF. Neurological injury in adults treated with extracorporeal membrane oxygenation. Arch Neurol. 2011;68:1543-9.

113. Matsumoto M, Asaumi Y, Nakamura Y, Nakatani T, Nagai T, Kanaya T, Kawakami S, Honda S, Kataoka Y, Nakajima S, Seguchi O, Yanase M, Nishimura K, Miyamoto Y, Kusano K, Anzai T, Noguchi T, Fujita T, Kobayashi J, Ishibashi-Ueda H, Shimokawa H, Yasuda S. Clinical determinants of successful weaning from extracorporeal membrane oxygenation in patients with fulminant myocarditis. ESC Heart Fail. 2018;5:675-684.

114. Mazzeffi MA, Sanchez PG, Herr D, Krause E, Evans CF, Rector R, McCormick B, Pham S, Taylor B, Griffith B, Kon ZN. Outcomes of extracorporeal cardiopulmonary resuscitation for refractory cardiac arrest in adult cardiac surgery patients. J Thorac Cardiovasc Surg. 2016;152:1133-1139

115. Meyer AL, Strueber M, Tomaszek S, Goerler A, Simon AR, Haverich A, Fischer S. Temporary cardiac support with a mini-circuit system consisting of a centrifugal pump and a membrane ventilator. Interact Cardiovasc Thorac Surg. 2009:9:780-783

116. Mohite PN, Kaul S, Sabashnikov A, Rashid N, Fatullayev J, Zych B, Popov AF, Maunz O, Patil NP, Garcia-Saez D, DeRobertis F, Bahrami T, Amrani M, Banner NR, Simon AR. Extracorporeal life support in 
patients with refractory cardiogenic shock: keep them awake. Interact Cardiovasc Thorac Surg. 2015;20:75560.

117. Mojoli F, Venti A, Pellegrini C, De Ferrari GM, Ferlini M, Zanierato M, Maurelli M, lotti GA, D'Armini AM, Braschi A. Hospital survival and long term quality of life after emergency institution of venoarterial ECMO for refractory circulatory collapse. Minerva Anestesiol. 2013;79:1147-55.

118. Moraca RJ, Wanamaker KM, Bailey SH, McGregor WE, Murali S, Benza R, Sokos G, Magovern GJ Jr. Salvage peripheral extracorporeal membrane oxygenation using Cobe Revolution(®) centrifugal pump as a bridge to decision for acute refractory cardiogenic shock. J Card Surg. 2012;27:521-7.

119. Morshuis M, Bruenger F, Becker T, Kempa-Haupt A, Kizner L, Al-Khalil R, Gummert JF, Schramm R. Inter-hospital transfer of extracorporeal membrane oxygenation-assisted patients: the hub and spoke network. Ann Cardiothorac Surg. 2019;8:62-65.

120. Moazami N, Moon MR, Pasque MK, Lawton JS, Bailey MS, Damiano RJ Jr. Strategies for temporary mechanical support: contemporary experience with pulsatile and non-pulsatile support systems. Heart Surg Forum. 2005;8:E216-20.

121. Muehrcke DD, McCarthy PM, Stewart RW, Foster RC, Ogella DA, Borsh JA, Cosgrove DM 3rd. Extracorporeal membrane oxygenation for postcardiotomy cardiogenic shock. Ann Thorac Surg. 1996;61:68491.

122. Muller G, Flecher E, Lebreton G, Luyt CE, Trouillet JL, Bréchot N, Schmidt M, Mastroianni C, Chastre J, Leprince P, Anselmi A, Combes A. The ENCOURAGE mortality risk score and analysis of long-term outcomes after VA-ECMO for acute myocardial infarction with cardiogenic shock. Intensive Care Med. 2016;42:370-378. 123. Musial R, Ochonska K, Proc A, Stolinski J, Plicner D, Kapelak B, Drwila R. Veno-arterial extracorporeal membrane oxygenation as cardiogenic shock therapy support in adult patients after heart surgery. Kardiochir Torakochirurgia Pol. 2017;14:32-36 
124. Nakamura T, Ishida K, Taniguchi $Y$, Nakagawa T, Seguchi M, Wada H, Sugawara $Y$, Funayama $H$, Mitsuhashi T, Momomura S. Prognosis of patients with fulminant myocarditis managed by peripheral venoarterial extracorporeal membranous oxygenation support: a retrospective single-center study. $\mathrm{J}$ Intensive Care. 2015;3:5.

125. Negi SI, Sokolovic M, Koifman E, Kiramijyan S, Torguson R, Lindsay J, Ben-Dor I, Suddath W, Pichard A, Satler L, Waksman R. Contemporary Use of Veno-Arterial Extracorporeal Membrane Oxygenation for Refractory Cardiogenic Shock in Acute Coronary Syndrome. J Invasive Cardiol. 2016;28:52-7.

126. Noon GP, Lafuente JA, Irwin S. Acute and temporary ventricular support with BioMedicus centrifugal pump. Ann Thorac Surg. 1999;68:650-4.

127. Pabst D, Foy AJ, Peterson B, Soleimani B, Brehm CE. Predicting Survival in Patients Treated With Extracorporeal Membrane Oxygenation After Myocardial Infarction. Crit Care Med. 2018;46:e359-e363.

128. Pagani FD, Lynch W, Swaniker F, Dyke DB, Bartlett R, Koelling T, Moscucci M, Deeb GM, Bolling S, Monaghan $\mathrm{H}$, Aaronson KD. Extracorporeal life support to left ventricular assist device bridge to heart transplant: A strategy to optimize survival and resource utilization. Circulation. 1999;100(19 Suppl):II206-10. 129. Pages ON, Aubert S, Combes A, Luyt CE, Pavie A, Léger P, Gandjbakhch I, Leprince P. Paracorporeal pulsatile biventricular assist device versus extracorporal membrane oxygenation-extracorporal life support in adult fulminant myocarditis. J Thorac Cardiovasc Surg. 2009;137:194-7.

130. Papadopoulos N, Marinos S, El-Sayed Ahmad A, Keller H, Meybohm P, Zacharowski K, Moritz A, Zierer A. Risk factors associated with adverse outcome following extracorporeal life support: Analysis from 360 consecutive patients. Perfusion. 2015;30:284-290

131. Park SJ, Kim SP, Kim JB, Jung SH, Choo SJ, Chung CH, Lee JW. Blood lactate level during extracorporeal life support as a surrogate marker for survival. J Thorac Cardiovasc Surg. 2014;148:714-720

132. Peigh G, Cavarocchi N, Keith SW, Hirose H. Simple new risk score model for adult cardiac extracorporeal membrane oxygenation: Simple cardiac ecmo score. J Surg Res. 2015;198:273-279 
133. Pineton de Chambrun M, Bréchot N, Lebreton G, Schmidt M, Hekimian G, Demondion P, Trouillet JL, Leprince P, Chastre J, Combes A, Luyt CE. Venoarterial extracorporeal membrane oxygenation for refractory cardiogenic shock post-cardiac arrest. Intensive Care Med. 2016;42:1999-2007.

134. Pokersnik JA, Buda T, Bashour CA, Gonzalez-Stawinski GV. Have changes in ecmo technology impacted outcomes in adult patients developing postcardiotomy cardiogenic shock? J Card Surg. $2012 ; 27: 246-252$

135. Pontailler M, Demondion P, Lebreton G, Golmard JL, Leprince P. Experience with extracorporeal life support for cardiogenic shock in the older population more than 70 years of age. ASAIO J. 2017;63:279-284 136. Pozzi M, Flagiello M, Armoiry X, Generali T, Adamou Nouhou K, Koffel C, Schweizer R, Fellahi JL, Cuenin L, Cellier G, Green L, Derimay F, Rioufol G, Finet G, Obadia JF. Extracorporeal life support in the multidisciplinary management of cardiogenic shock complicating acute myocardial infarction. Catheter Cardiovasc Interv. 2019 Apr 29. [Epub ahead of print]

137. Pozzi M, Alvau F, Armoiry X, Grinberg D, Hugon-Vallet E, Koffel C, Portran P, Scollo G, Fellahi JL, Obadia JF. Outcomes after extracorporeal life support for postcardiotomy cardiogenic shock. J Card Surg. 2019;34:74-81.

138. Ranucci M, Ballotta A, Kandil H, Isgro G, Carlucci C, Baryshnikova E, Pistuddi V, Surgical, Clinical Outcome Research G. Bivalirudin-based versus conventional heparin anticoagulation for postcardiotomy extracorporeal membrane oxygenation. Crit Care. 2011;15:[7]75

139. Rastan AJ, Dege A, Mohr M, Doll N, Falk V, Walther T, Mohr FW. Early and late outcomes of 517 consecutive adult patients treated with extracorporeal membrane oxygenation for refractory postcardiotomy cardiogenic shock. J Thorac Cardiovasc Surg. 2010;139:302-311, 311 e301

140. Reedy JE, Swartz MT, Raithel SC, Szukalski EA, Pennington DG. Mechanical cardiopulmonary support for refractory cardiogenic shock. Heart Lung. 1990;19:514-23. 
141. Rousse N, Juthier F, Pincon C, Hysi I, Banfi C, Robin E, Fayad G, Jegou B, Prat A, Vincentelli A. Ecmo as a bridge to decision: Recovery, vad, or heart transplantation? Int J Cardiol. 2015;187:620-627

142. Rubino A, Costanzo D, Stanszus D, Valchanov K, Jenkins D, Sertic F, Fowles JA, Vuylsteke A. Central veno-arterial extracorporeal membrane oxygenation (c-va-ecmo) after cardiothoracic surgery: A single-center experience. J Cardiothorac Vasc Anesth. 2017

143. Russo CF, Cannata A, Lanfranconi M, Bruschi G, Milazzo F, Paino R, Martinelli L. Veno-arterial extracorporeal membrane oxygenation using levitronix centrifugal pump as bridge to decision for refractory cardiogenic shock. J Thorac Cardiovasc Surg. 2010;140:1416-1421

144. Saeed D, Stosik H, Islamovic M, Albert A, Kamiya H, Maxhera B, Lichtenberg A. Femoro-femoral versus atrio-aortic extracorporeal membrane oxygenation: selecting the ideal cannulation technique. Artif Organs. 2014;38:549-55.

145. Salna M, Takeda K, Kurlansky P, Ikegami H, Fan L, Han J, Stein S, Topkara V, Yuzefpolskaya M, Colombo PC, Karmpaliotis D, Naka Y, Kirtane AJ, Garan AR, Takayama H. The influence of advanced age on venous-arterial extracorporeal membrane oxygenation outcomes. Eur J Cardiothorac Surg. 2018;53:11511157.

146. Saxena P, Neal J, Joyce LD, Greason KL, Schaff HV, Guru P, Shi WY, Burkhart H, Li Z, Oliver WC, Pike RB, Haile DT, Schears GJ. Extracorporeal Membrane Oxygenation Support in Postcardiotomy Elderly Patients: The Mayo Clinic Experience. Ann Thorac Surg. 2015;99:2053-60.

147. Scherer M, Moritz A, Martens S. The use of extracorporeal membrane oxygenation in patients with therapy refractory cardiogenic shock as a bridge to implantable left ventricular assist device and perioperative right heart support. J Artif Organs. 2009;12:160-5.

148. Schmack B, Seppelt P, Weymann A, Alt C, Farag M, Arif R, Doesch AO, Raake PW, Kallenbach K, Mansur A, Popov AF, Karck M, Ruhparwar A. Extracorporeal life support with left ventricular decompressionimproved survival in severe cardiogenic shock: results from a retrospective study. PeerJ. 2017:5:e3813. 
149. Schmidt M, Bréchot N, Hariri S, Guiguet M, Luyt CE, Makri R, Leprince P, Trouillet JL, Pavie A, Chastre J, Combes A. Nosocomial infections in adult cardiogenic shock patients supported by venoarterial extracorporeal membrane oxygenation. Clin Infect Dis. 2012;55:1633-41.

150. Schwarz B, Mair P, Margreiter J, Pomaroli A, Hoermann C, Bonatti J, Lindner KH. Experience with percutaneous venoarterial cardiopulmonary bypass for emergency circulatory support. Crit Care Med. 2003;31:758-64.

151. Sheu JJ, Tsai TH, Lee FY, Fang HY, Sun CK, Leu S, Yang CH, Chen SM, Hang CL, Hsieh YK, Chen CJ, Wu CJ, Yip HK. Early extracorporeal membrane oxygenator-assisted primary percutaneous coronary intervention improved 30-day clinical outcomes in patients with ST-segment elevation myocardial infarction complicated with profound cardiogenic shock. Crit Care Med. 2010;38:1810-7.

152. Schibilsky D, Haller C, Lange B, Schibilsky B, Haeberle H, Seizer P, Gawaz M, Rosenberger P, Walker T, Schlensak C. Extracorporeal life support prior to left ventricular assist device implantation leads to improvement of the patients INTERMACS levels and outcome. PLoS One. 2017;12:e0174262.

153. Shin TG, Choi JH, Jo IJ, Sim MS, Song HG, Jeong YK, Song YB, Hahn JY, Choi SH, Gwon HC, Jeon ES, Sung K, Kim WS, Lee YT. Extracorporeal cardiopulmonary resuscitation in patients with inhospital cardiac arrest: A comparison with conventional cardiopulmonary resuscitation. Crit Care Med. 2011;39:1-7.

154. Slottosch I, Liakopoulos O, Kuhn E, Deppe AC, Scherner M, Madershahian N, Choi YH, Wahlers T. Outcomes after peripheral extracorporeal membrane oxygenation therapy for postcardiotomy cardiogenic shock: A single-center experience. J Surg Res. 2013;181:e47-55

155. Slottosch I, Liakopoulos O, Kuhn E, Scherner M, Deppe AC, Sabashnikov A, Mader N, Choi YH, Wippermann J, Wahlers T. Lactate and lactate clearance as valuable tool to evaluate ecmo therapy in cardiogenic shock. J Crit Care. 2017;42:35-41 
156. Smedira NG, Moazami N, Golding CM, McCarthy PM, Apperson-Hansen C, Blackstone EH, Cosgrove DM 3rd. Clinical experience with 202 adults receiving extracorporeal membrane oxygenation for cardiac failure: survival at five years. J Thorac Cardiovasc Surg. 2001;122:92-102.

157. Tang GH, Malekan R, Kai M, Lansman SL, Spielvogel D. Peripheral venoarterial extracorporeal membrane oxygenation improves survival in myocardial infarction with cardiogenic shock. J Thorac Cardiovasc Surg. 2013;145:e32-3.

158. Tarzia V, Bortolussi G, Bianco R, Buratto E, Bejko J, Carrozzini M, De Franceschi M, Gregori D, Fichera D, Zanella F, Bottio T, Gerosa G. Extracorporeal life support in cardiogenic shock: Impact of acute versus chronic etiology on outcome. J Thorac Cardiovasc Surg. 2015;150:333-40.

159. Truby L, Mundy L, Kalesan B, Kirtane A, Colombo PC, Takeda K, Fukuhara S, Naka Y, Takayama H. Contemporary outcomes of venoarterial extracorporeal membrane oxygenation for refractory cardiogenic shock at a large tertiary care center. ASAIO J. 2015;61:403-409

160. Tsai TY, Tsai FC, Fan PC, Chang CH, Lin CY, Chang WW, Lee SY, Hsu HH, Tian YC, Fang JT, Yang CW, Chen YC. Application of the age, creatinine, and left ventricular ejection fraction score for patients on extracorporeal membrane oxygenation. Artif Organs. 2017;41:146-152

161. Tsai TY, Tu KH, Tsai FC, Nan YY, Fan PC, Chang CH, Tian YC, Fang JT, Yang CW, Chen YC. Prognostic value of endothelial biomarkers in refractory cardiogenic shock with ECLS: a prospective monocentric study. BMC Anesthesiol. 2019;19:73.

162. Vanzetto G, Akret C, Bach V, Barone G, Durand M, Chavanon O, Hacini R, Bouvaist H, Machecourt J, Blin D. Percutaneous extracorporeal life support in acute severe hemodynamic collapses: single centre experience in 100 consecutive patients. Can J Cardiol. 2009;25:e179-86.

163. Villavicencio MA, Larraín E, Larrea R, Peralta JP, Lim JS, Rojo P, Donoso E, Gajardo F, Hurtado M, Rossel V. Bridge to transplant or recovery in cardiogenic shock in a developing country. Asian Cardiovasc Thorac Ann. 2017;25:105-112. 
164. Wang J, Han J, Jia Y, Zeng W, Shi J, Hou X, Meng X. Early and intermediate results of rescue extracorporeal membrane oxygenation in adult cardiogenic shock. Ann Thorac Surg. 2009;88:1897-1903

165. Wang JG, Han J, Jia YX, Zeng W, Hou XT, Meng X. Outcome of veno-arterial extracorporeal membrane oxygenation for patients undergoing valvular surgery. PLoS One. 2013;8:e63924

166. Wang Y, Piao H, Li B, Wang W, Huang M, Zhu Z, Li D, Wang T, Liu K. Extracorporeal Membrane Oxygenation in Stanford Type A Aortic Dissection. Int Heart J. 2019;60:845-848.

167. Wester T, Awan ZA, Kvernebo TS, Salerud G, Kvernebo K. Skin microvascular morphology and hemodynamics during treatment with veno-arterial extra-corporeal membrane oxygenation. Clin Hemorheol Microcirc. 2014;56:119-31.

168. Wu MY, Lin PJ, Lee MY, Tsai FC, Chu JJ, Chang YS, Haung YK, Liu KS. Using extracorporeal life support to resuscitate adult postcardiotomy cardiogenic shock: Treatment strategies and predictors of shortterm and midterm survival. Resuscitation. 2010;81:1111-1116

169. Wu MY, Lee MY, Lin CC, Chang YS, Tsai FC, Lin PJ. Resuscitation of non-postcardiotomy cardiogenic shock or cardiac arrest with extracorporeal life support: the role of bridging to intervention. Resuscitation. 2012;83:976-81.

170. Wu MY, Tseng YH, Chang YS, Tsai FC, Lin PJ. Using extracorporeal membrane oxygenation to rescue acute myocardial infarction with cardiopulmonary collapse: the impact of early coronary revascularization. Resuscitation. 2013;84:940-5.

171. Xie HX, Yang F, Jiang CJ, Wang JH, Hou DB, Wang JG, Wang H, Hou XT. [predictors of in-hospital mortality in adult postcardiotomy cardiacgenic shock patients successfully weaned from venoarterial extracorporeal membrane oxygenation]. Zhonghua Yi Xue Za Zhi. 2017;97:929-933

172. Yeh TC, Chang HH, Ger LP, Wang JO, Kao S, Ho ST. Clinical risk factors of extracorporeal membrane oxygenation support in older adults. PLoS One. 2018;13:e0195445. 
173. Yost G, Bhat G, Pappas $P$, Tatooles $A$. The neutrophil to lymphocyte ratio in patients supported with extracorporeal membrane oxygenation. Perfusion. 2018;33:562-567.

174. Yu K, Long C, Hei F, Li J, Liu J, Ji B, Gao G, Zhang H, Song Y, Wang W. Clinical evaluation of two different extracorporeal membrane oxygenation systems: a single center report. Artif Organs. 2011;35:733-7.

175. Zhang R, Kofidis T, Kamiya H, Shrestha M, Tessmann R, Haverich A, Klima U. Creatine kinase isoenzyme mb relative index as predictor of mortality on extracorporeal membrane oxygenation support for postcardiotomy cardiogenic shock in adult patients. Eur J Cardiothorac Surg. 2006;30:617-620

176. Zhao Y, Xing J, Du Z, Liu F, Jia M, Hou X. Extracorporeal cardiopulmonary resuscitation for adult patients who underwent post-cardiac surgery. Eur J Med Res. 2015;20:83

177. Zhong Z, Jiang C, Yang F, Hao X, Xing J, Wang H, Hou X. Veno-arterial extracorporeal membrane oxygenation support in patients undergoing aortic surgery. Artif Organs. 2017;41:1113-1120

178. Ariyaratnam P, McLean LA, Cale AR, Loubani M. Extra-corporeal membrane oxygenation for the postcardiotomy patient. Heart Fail Rev. 2014;19:717-725

179. Belle L, Mangin L, Bonnet H, Fol S, Santré C, Delavenat L, Savary D, Bougon D, Vialle E, Dompnier A, Desjoyaux E, Blin D. Emergency extracorporeal membrane oxygenation in a hospital without on-site cardiac surgical facilities. Eurolntervention. 2012;8:375-82.

180. Deschka H, Machner M, El Dsoki S, Alken A, Wimmer-Greinecker G. Central closed chest implantation of extracorporeal membrane oxygenation to prevent limb ischemia. Int J Artif Organs. 2013;36:687-692

181. Junqueira N, Côrte-Real H, Gallego J, Ferreira R, Guerra N, Carvalheiro C, Ferreira H, Sena A, Arruda R, Mendes M, Lucas Nobre A. Results of the utilization of the ECMO-VA following cardiac surgery, in the Department of Cardiothoracic Surgery of Santa Maria Hospital. Rev Port Cir Cardiotorac Vasc. 2015;22:81-87. 
182. Khorsandi M, Shaikhrezai K, Prasad S, Pessotto R, Walker W, Berg G, Zamvar V. Advanced mechanical circulatory support for post-cardiotomy cardiogenic shock: A 20-year outcome analysis in a non-transplant unit. J Cardiothorac Surg. 2016;11:29

183. Kim DW, Cho HJ, Kim GS, Song SY, Na KJ, Oh SG, Oh BS, Jeong IS. Predictive Value of Procalcitonin for Infection and Survival in Adult Cardiogenic Shock Patients Treated with Extracorporeal Membrane Oxygenation. Chonnam Med J. 2018;54:48-54.

184. Kuroki N, Abe D, Iwama T, Sugiyama K, Akashi A, Hamabe Y, Aonuma K, Sato A. Prognostic effect of estimated glomerular filtration rate in patients with cardiogenic shock or cardiac arrest undergoing percutaneous veno-arterial extracorporeal membrane oxygenation. J Cardiol. 2016;68:439-446.

185. Lee HS, Kim HS, Lee SH, Lee SA, Hwang JJ, Park JB, Kim YH, Moon HJ, Lee WS. Clinical implications of the initial SAPS II in veno-arterial extracorporeal oxygenation. J Thorac Dis. 2019;11:68-83.

186. Lee SN, Jo MS, Yoo KD. Impact of age on extracorporeal membrane oxygenation survival of patients with cardiac failure. Clin Interv Aging. 2017;12:1347-1353.

187. Lin CY, Tsai FC, Lee HA, Tseng YH. Extracorporeal membrane oxygenation support in post-traumatic cardiopulmonary failure: A 10-year single institutional experience. Medicine (Baltimore). 2017;96:e6067.

188. Liu Y, Cheng YT, Chang JC, Chao SF, Chang BS. Extracorporeal membrane oxygenation to support prolonged conventional cardiopulmonary resuscitation in adults with cardiac arrest from acute myocardial infarction at a very low-volume centre. Interact Cardiovasc Thorac Surg. 2011;12:389-93.

189. Mégarbane B, Deye N, Aout M, Malissin I, Résière D, Haouache H, Brun P, Haik W, Leprince P, Vicaut E, Baud FJ. Usefulness of routine laboratory parameters in the decision to treat refractory cardiac arrest with extracorporeal life support. Resuscitation. 2011;82:1154-61.

190. Mikus E, Tripodi A, Calvi S, Giglio MD, Cavallucci A, Lamarra M. Centrimag venoarterial extracorporeal membrane oxygenation support as treatment for patients with refractory postcardiotomy cardiogenic shock. ASAIO J. 2013;59:18-23 
191. Raffa GM, Gelsomino S, Sluijpers N, Meani P, Alenizy K, Natour E, Bidar E, Johnson DM, Makhoul M, Heuts S, Lozekoot P, Kats S, Schreurs R, Delnoij T, Montalti A, Sels JW, Poll MV, Roekaerts P, Maessen J, Lorusso R. In-hospital outcome of post-cardiotomy extracorporeal life support in adult patients: The 2007-2017 maastricht experience. Crit Care Resusc. 2017;19:53-61

192. Rigamonti F, Montecucco F, Boroli F, Rey F, Gencer B, Cikirikcioglu M, Reverdin S, Carbone F, Noble S, Roffi M, Banfi C, Giraud R. The peak of blood lactate during the first $24 \mathrm{~h}$ predicts mortality in acute coronary syndrome patients under extracorporeal membrane oxygenation. Int J Cardiol. 2016;221:741-5.

193. Sakamoto S, Taniguchi N, Nakajima S, Takahashi A. Extracorporeal life support for cardiogenic shock or cardiac arrest due to acute coronary syndrome. Ann Thorac Surg. 2012;94:1-7.

194. Smith C, Bellomo R, Raman JS, Matalanis G, Rosalion A, Buckmaster J, Hart G, Silvester W, Gutteridge GA, Smith B, Doolan L, Buxton BF. An extracorporeal membrane oxygenation-based approach to cardiogenic shock in an older population. Ann Thorac Surg. 2001;71:1421-7.

195. Sun T, Guy A, Sidhu A, Finlayson G, Grunau B, Ding L, Harle S, Dewar L, Cook R, Kanji HD. Venoarterial extracorporeal membrane oxygenation (VA-ECMO) for emergency cardiac support. J Crit Care. 2018:44:31-38.

196. Unosawa S, Sezai A, Hata M, Nakata K, Yoshitake I, Wakui S, Kimura H, Takahashi K, Hata H, Shiono M. Long-term outcomes of patients undergoing extracorporeal membrane oxygenation for refractory postcardiotomy cardiogenic shock. Surg Today. 2013;43:264-270

197. Zhu RQ, Liu CZ, Lu JH, Su YP, Wen SC, Nie GJ, Hu YZ, Zuo LE. The effect and factors associated with outcome of extracorporeal membrane oxygenation in refractory cardiogenic shock patients. Zhonghua Xin Xue Guan Bing Za Zhi. 2016;44:777-781. 


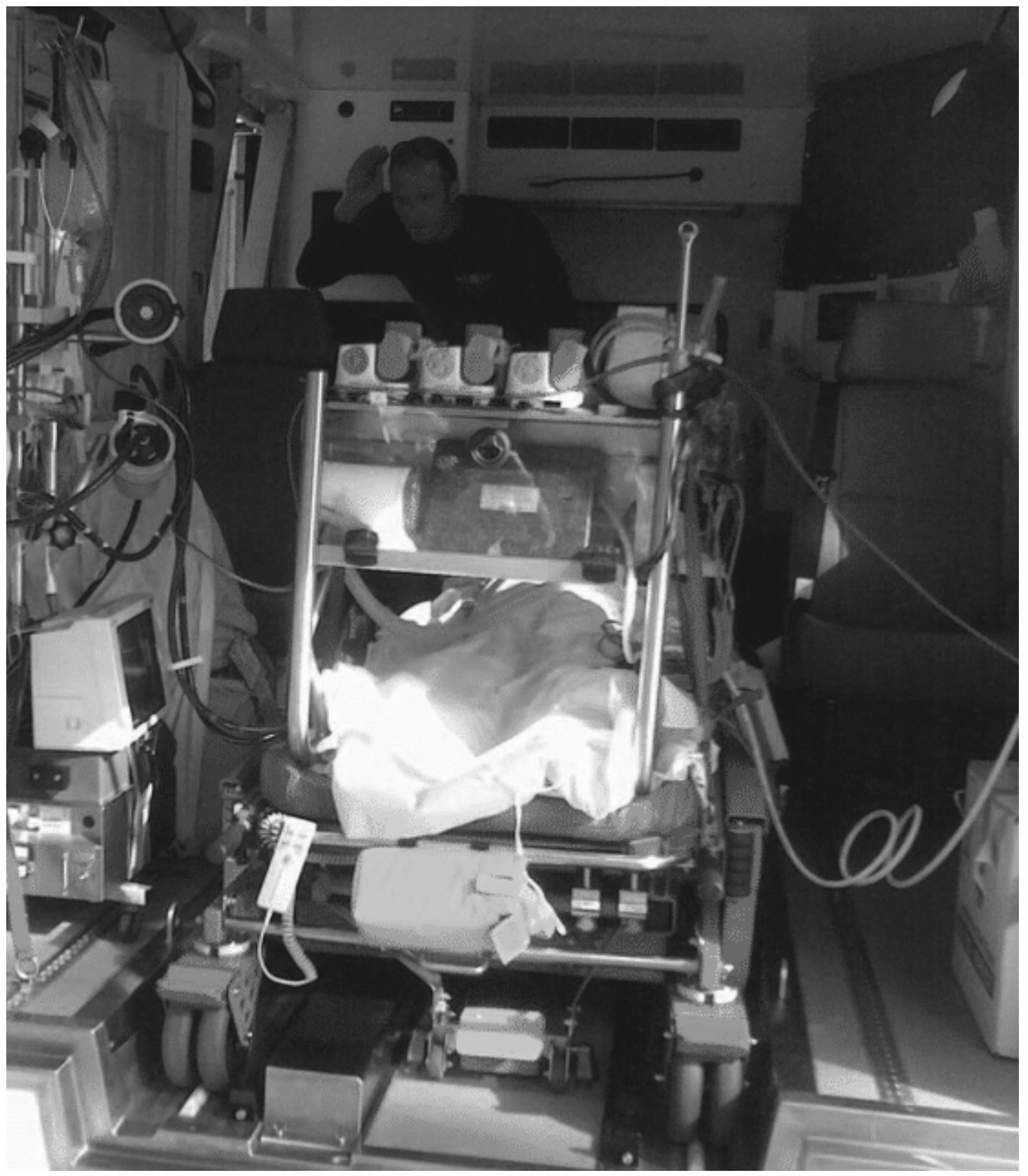


CHAPTER 8

GENERAL DISCUSSION 
ECMO-related technology has witnessed a remarkable progress in the last 20 years. More advanced, user friendly, miniaturized technology has made a wider application of such a temporary support possible with promising results. In particular interest lie several instances once viewed as absolute contraindications. Indeed, patients at prohibitive risk, who were often denied heart surgery in the first place, or those who suffererd severe post-AMI cardiogenic shock are of greatest concern, since in those very patients the safety and efficacy of MCSs may sway the balance towards survival or mortality. In the context of recent exponential increase in the use of MCS in general, it is reasonable to question in which patients is it truly beneficial, giving patients time to recover rather than simply prolonging the time to death.

With all recent advancements in technology and skillsets, overall survival for patients undergoing ECMO for post-cardiotomy cardiogenic shock is not improving which is looming large in minds of ECMO enthusiasts. While the trends in mortality have been rather stable in the past 20 years, the patient characteristics undergoing cardiac surgery have changed. Indeed, salvage of patients who otherwise would never have survived e.g. feared post bypass myocardial dysfunction is now not surprising any longer. Reoperations, advanced age, surgical urgency and poor cardiac reserve are increasingly present in candidates for cardiac surgery, which may contribute to higher risk for cardiopulmonary insufficiency after CPB weaning. Nevetheless, due to improvements in surgical techniques higher risk patients and more complex procedures can be safely performed. ECMO institution is relatively easy and can be done in both ICU and peripheral fashion; unloading techniques have evolved, all contributing to balanced life/death ratio.

Adding to the balance is the subsequent pressure on the caregiving team to institute ECMO as soon as possible to avoid intra-operative fatal outcome. As a consequence, intraoperative death is nowadays a rare event. These phenomena and new circumstances increase over-utilization of ECMO in an effort to avoid intraoperative mortality often moving the mortality events from OR to ICU. In addition, mortality after weaning from ECMO accounts for $40-50 \%$ of 30 -day deaths suggesting too early ECMO withdrawal or still high burden of complications occurring after termination of ECMO therapy. ECMO over-utilization needs to be recognized and 
managed, to maximize survival, minimizing its futile use. Obvious targets to accomplish this include, improvements in technological aspects of the circuitry, e.g the pump, oxygenator, and tubing design, more reliable anticoagulation, rational vasoactive/inotropic support, a better understanding of the most effective ways to achieve temporary cardiopulmonary support, more effective monitoring, and improving care-giver education and training.

Patient selection for ECMO poses a true challenge; what once was viewed as a last-resort therapy can now be used as prophylaxis. With ECMO in one's armamentarium complex surgical procedures may be performed in high risk patients. Among high risk patients, the elderly is a separate group of interest because these individuals have higher risk profile due to cardiovascular co-morbidity combined with frailty and polypharmacy. Despite increasing use and expertise, V-A ECMO represents an aggressive treatment in complex patients, thereby associated with high complication and mortality rates. The search for predictors for unfavorable patient outcome is, therefore, critical in an attempt to improve results, resource utilization, and decision-making in challenging conditions. While decision on whether to institute ECMO in such patients should be based on individual risk factors, elderly patients are rarely candidates for such therapy given their small chance for recovery and resistance to bridging to more durable/permanent support. Indeed, as demonstrated in chapter 2, the most frequent condition for ECMO implant in the elderly patients was non-postcardiotomy cardiogenic shock which is in line with other reports suggesting post-cardiotomy indication for V-A ECMO placement is indeed less common in older patients as compared to younger subjects. This aspect may indicate that clinicians are less inclined to consider and accept the use of temporary support due to RCS in the elderly patients than in non-surgical environment. However, we were able to identify subgroups of elderly patients reaching up to $50 \%$ survival which is comparable to their younger counterparts; lower mortality was observed in heart transplantation recipients, post-TAVR and in pulmonary embolism. On the other hand, sepsis had almost always an ominous prognosis in the elderly; higher mortality rates were also observed on ECMO following coronary artery bypass graft (CABG) combined with valve surgery. (Chapter 2) 
In chapter 3 we discussed that counterintuitively, the type of surgery, rather than urgency and patients baseline status, contributes to mortality on-ECMO. Indeed, ECMO implantation in an otherwise elective case yet complicated by cardiogenic shock dramatically increases the mortality risk well beyond the mortality threshold for ECMO salvage cases. (Chapter 3)

Complication rates on the other hand, were only associated with patients baseline status. (Chapter 3) Indeed, in this analysis, more neurologic and limb complications as well as more bleeding were seen in the emergency/ salvage scenarios. Excess of bleeding complications can easily be explained by different coagulation profiles of emergency/salvage coronary patients that indeed constituted more than $40 \%$ of the entire analysis population (e.g. failed PCI, prior GP IIB/IIIA administration, high thrombotic burden requiring additional heparin for ECMO run etc.). However, increased rates of neurologic complications is presumably a multifactorial entity with preECMO illness severity and treatments, ECMO management, and post-ECMO events all potentially contributing to cerebral injury. Loss of cerebral autoregulation during severe arterial hypertension or hypotension, thromboembolic events, haemorrhage related to anticoagulation use, cerebral vasospasm, and secondary brain injury from reactive tissue oedema around an area of focal cerebral insult may all contribute to brain injury in VA ECMO patients.

The application of V-A ECMO in patients with refractory isolated cardiac or cardiopulmonary failure is a matter of debate in adult patients; the choice between "central" access, with the direct cannulation of the right atrium and ascending aorta, and "peripheral" access, most commonly using the femoral vein and artery, is dependent on patients' characteristics and not rarely, physicians preference. (Chapter 4) This is also true for the choice between LV unloading techniques. Despite observational evidence suggesting improved outcomes with peripheral cannulation and LV unloading, employing these two approaches have not been assessed in a randomized fashion. In our analyses LV unloading was effective and safe in both PCS and non-PCS patients regardless of device.(Chapter 4) This is of particular importance given worse clinical conditions usually pertained by post-cardiotomy situation because of pre-ECMO comorbidities, impact of pre-operative cardiac illnesses and complicated surgical procedures, as well as type of complications more frequently observed in such a setting 
such as bleeding. Other etiologies might have better results. In fact, AMI patients more often have undergone prior escalation to a balloon pump or Impella $\circledR$, with eventual escalation to ECMO as compared to postcardiotomy setting. Escalation may occur due to failure of MCS, vascular complications or progression of shock with development of renal failure and rising lactate which can often result in patients lingering in shock for prolonged periods of time.

Decision to implant or continue a temporary MCS as ECMO, is often difficult and several clinicians may avoid or limit the indications for such intensive therapy to reduce resource consumption in limitedly successful procedures. From a clinical perspective, the majority of centers look at physical and neurologic status prior to the event necessitating ECMO, the severity of insult, duration/degree of shock, presence of prior arrest, and associated medical comorbidities when selecting potential candidates for ECMO therapy. The availability, therefore, of indicators for more favorable outcome might be precious and guiding clinical management, either prior or during ECMO support.

From the current studies, that include most of published evidence on the topic, it is apparent that there are differences in outcome between centres with heart failure programs and centres without such programs. Indeed, centres dealing with ECMO patients on a daily basis produce better results. In addition, they usually enroll patients at higher baseline risk, often denied cardiac surgery in other centre or transferred to a referral hub after developing complications. These observations led to the hypothesis of our meta-analyses that potentially shorter bridging times in HTx/VAD units due to readability of well-experienced ECLS teams experienced in dealing with both acute, chronic and end-stage heart failure also with prompt resources availability (medium- and long-term mechanical circulatory support and heart transplantation) might prevent life threatening complications and contribute to better results. (Chapter 5) Indeed, there seems to be a strong association between volume and outcome as well, with lower mortality and complications burden in higher volume centres. (Chapter 5)

The application of ECMO as a rescue therapy/support, in the presence of perioperative shock like in HTx or general cardiac surgery, has shown the potential benefits, but also the high rate of complications, somehow 
apparently strictly related to the extent of maladaptive body reaction, secondary to the interaction between the body and a prolonged extracorporeal circulation, but also to intrinsic potential shortcomings related to the invasiveness of the technique. The use of ECMO as a transient circulatory or respiratory, or concomitant assistance of both impaired systems, has been shown to represent an invaluable opportunity, although characterized by several drawbacks. Therefore, additional efforts aimed at minimizing the above is mandatory, such that, hopefully, in the near future, the rationale for its use will be understood and justifiable in all cases. 


\section{Valorization}

This thesis highlights the incidence, results, complications and innovative management of patients submitted to ECMO because of cardiogenic shock sfrom various etiologies. The main findings of the performed research for this thesis can be summarized as follows; careful and vigilant patient selection together with aggressive management of patient himself and ECMO circuit can lead to promising results in the most complex and dim clinical scenarios. The thesis provides relevant insights about the efficacy of ECMO in several settings, including cardiac surgery and related interventions. Indeed, the favorable results obtained in complex settings, like postcardiotomy cardiogenic shock after general cardiac surgery, confirms the efficacy of such a temporary support in case of refractory and life-threatening postcardiotomy conditions.

The focus of the analyses was not limited to postcardiotomy cardiogenic shock though; indeed, cardiogenic shock resulting from acute coronary syndromes, myocarditis, cardiomyopathies and other causes can also be managed with ECMO with encouraging outcomes.

We were able to demonstrate by means of registry big data analyses and also in meta-analytical approach, that addressing and tackling certain mortality predictors could improve the ultimate outcomes. Similarly, minimizing the invasiveness of the approach as with peripheral cannulation, employing different techniques to unload the LV and referral of patients in cardiogenic shock to experienced high volume centres, are important features of successful ECMO therapy.

\section{Patient selection}

The performed research demonstrated that proper selection of patient for the most intensive management modality can lead to better outcomes. In fact, prompt initiation of ECMO in selected patient and timely (before severe end-organ dysfunction appears) offers "appealing" survival rates. More importantly, we could show that advanced age, often considered as contraindication for ECMO or, in fact, for any MCS, should not be viewed as prohibitive or as an absolute contraindication. Factors other than age, like general condition, postcardiotomy or non-postcardiotomy shock and reversibility of the condition play more important role and should be considered first. The above information is calling, from one side, for a more focused patient selection whatever the indication; from another, an algorithm or a guideline is to be introduced, not denying MCS to the elderly subjects, as this 
may be at least as effective treatment modality in this very particular group of patients. Indeed, we have provided, for a first time, a list of variables contributing to reduced survival to be considered rather than age.

Another important finding, of the conducted research is that baseline surgical status in post-cardiotomy patients, whether elective or salvage, albeit impacts the propensity for complications, does not affect mortality rates when ECMO is initiated. This, in turn, suggests that initiation of ECMO in the postcardiotomy setting has the survival predictive function outweighing every single EuroSCORE risk stratification components and should be taken account for. What needs to be addressed in the future research is, undeniably, a risk stratification tool and a scoring system for both postcardiotomy and non-postcardiotomy setting which would combine the predictive abilities of yet available scoring systems (REMEMBER, SAFE) but validated on a broader group of patients and not limited to single indications.

\section{Advancements in ECMO management}

As already shown, the performed research confirmed that ECMO configurations do affect the outcomes of patients in cardiogenic shock. In particular, it has been shown that the access to implement such a support may also influence the patient outcome with regards to the complication types and rate with the peripheral approach. With the biggest dataset of post-cardiotomy patient series ever analyzed, peripheral cannulation was shown to be associated with improved in-hospital survival and lower complication rates which is in line also with a recent meta-analysis by our group. Additionally, several LV unloading techniques were investigated; when applied to ECMO circuit, IABP and Impella have potential to reduce mortality in both post-cardiotomy and nonpostcardiotomy shock, thereby representing an important insight for the clinical and ECMO communities. Importantly the benefit is seen also with percutaneous implantation of these devices; allowing cardiologists and intensivists for a prompt and successful application with ultrasound guidance rather than with surgical approach.

\section{ECMO experience}

Ultimately, we have also performed a set of meta-analyses based on a presumption that centres which perform VAD implantations and heart transplantations may have better outcomes in patients on MCS due to their experience in dealing with end-stage heart failure; in fact, centres in which VADs and HTXs are performed had better results in terms of complication rates in patients undergoing ECMO for postcardiotomy shock. When both 
postcardiotomy and medical applications were considered, survival was as well affected with higher in-hospital survival in more experienced centres.

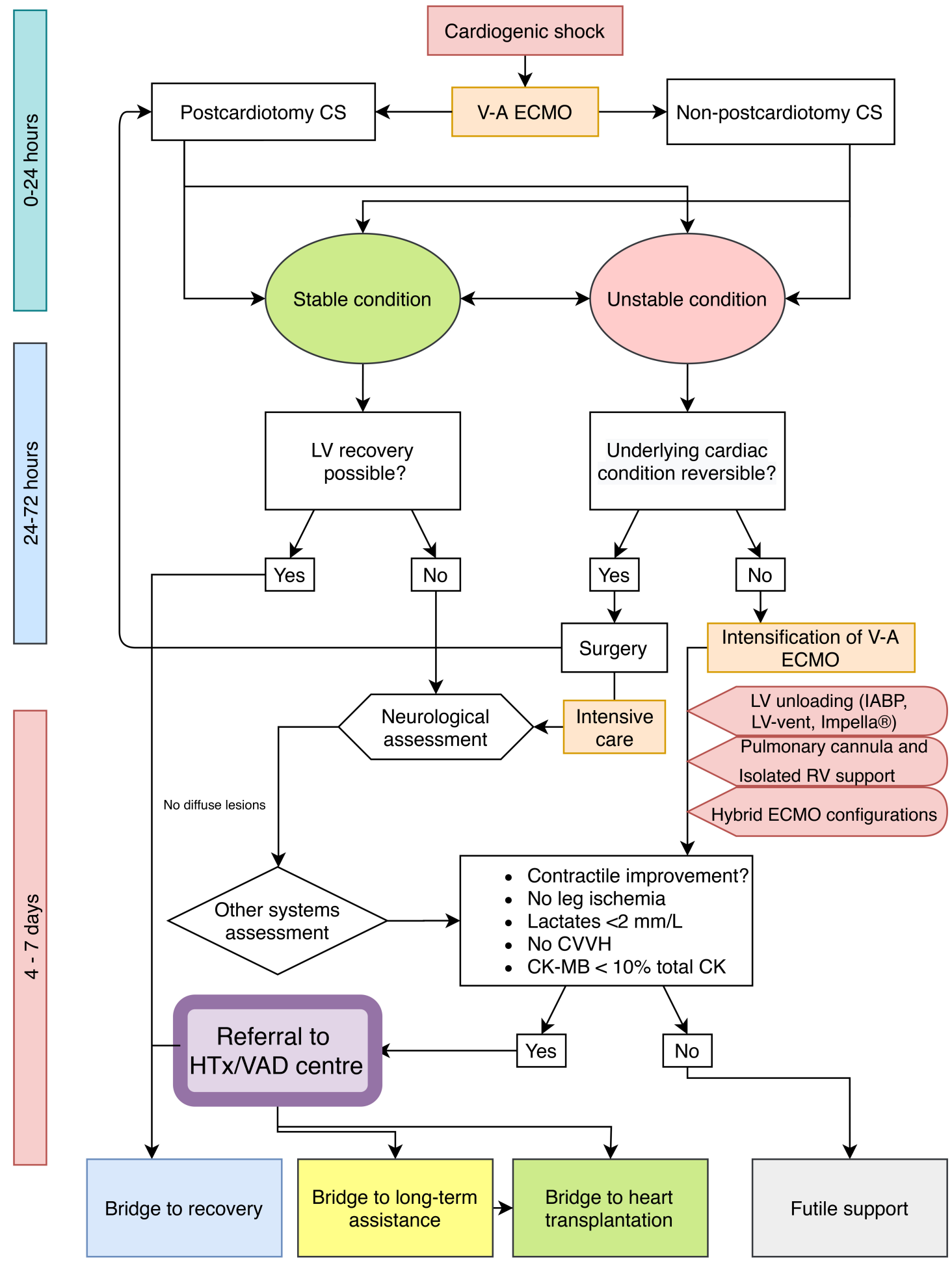

Central figure. Proposed algorithm of patient management: V-A ECMO in cardiogenic shock with respect to potential referral to HTx/VAD centre. V-A ECMO, veno-arterial extracorporeal membrane oxygenation; LV/RV, left/right ventricle; $\mathrm{CVVH}$, continuous veno-venous hemofiltration; $\mathrm{CK}-\mathrm{MB}$, creatin kinase muscle-brain isoenzyme; HTx, heart transplantation; VAD, ventricle assist device 
This means that experienced and well established ECLS program may indeed make a difference in patient outcome. With this finding, a call for appropriate personnel training and the creation of dedicated team, also in centres not performing transplant/VAD procedure, is highlighted and suggested. What is also important from clinical standpoint, is management of ECMO as a bridging therapy. It was shown that patients managed in experienced centres are more likely to be bridged to destination therapy (HTx or VAD); we have, again for a first time, proposed an algorithm taking into account ECMO duration and clinical variables in order to find a best time frame for transferring a patient from non-HTX/VAD unit to destination centre as well as to determine a best time for bridging to more advanced or longer MCS.

\section{What needs to be addressed in the future?}

The information available for ECMO has been always rather poor and limited to single-centre experiences. A tendency not to present poor outcomes is not to be missed; a thorough review, with the provision on detailed information about prevalence, in relation to the overall cardiac surgery procedural number, medical conditions, patient profiles, support modalities, complications and outcome at short or long-term are certainly precious for investigators and people involved in dealing with cardiogenic shock in such settings. 
SUMMARY 
Chapter 2. In this chapter, we analyzed the multicenter ELSO registry. 2,644 patients $\geq 70$ years (1,395 [52.8\%] 70-74 years of age, 858 [32.5\%] 75-79 years, and 391 [14.8\%] $\geq 80$ y.o.) were managed with $\mathrm{V}-\mathrm{A}$ ECMO, for refractory cardiogenic shock due to various etiologies. Overall in-hospital mortality was estimated at $68.3 \%$ $(1,807 / 2,644$ pts.) with highest crude mortality rates observed in $75-79$ y.o. subgroup (70.1\%). Complications were mostly cardiovascular and bleeding, without apparent differences between subgroups. Airway pressures, 24-hours $\mathrm{pH}$ after ECMO start, ECMO duration, and renal replacement therapy were associated with higher mortality. This study confirmed the remarkable increase of V-A ECMO use in the elderly affected by RCS. Despite in-hospital mortality remained high, we declared that V-A ECMO should still be considered in such a setting even in very elderly patients, since age itself was not linked to increased mortality, whereas several predictors may guide indication and management.

Chapter $\mathbf{3}$ is a systematic review and meta-analysis on left ventricle unloading with veno-arterial extracorporeal membrane oxygenation for cardiogenic shock. lincluded adult patients from studies published between January 2000 and March 2019. The search was conducted through numerous databases. Overall, from 62 papers, 7581 patients were included, among whom 3337 (44.0\%) received LV unloading concomitant to VA-ECMO. Overall, in-hospital mortality was $58.9 \%$ (4466/7581). A concomitant strategy of LV unloading as compared to ECMO alone was associated with $12 \%$ lower mortality risk (RR 0.88; 95\% $\mathrm{Cl} 0.82-0.93 ; p<0.0001 ; 12=40 \%$ ) and $35 \%$ higher probability of weaning from ECMO (RR 1.35; 95\% Cl 1.21-1.51; $p<0.00001 ; 12=38 \%$ ). In an analysis stratified by setting, the highest mortality risk benefit was observed in case of acute myocardial infarction: RR $0.75 ; 95 \% \mathrm{Cl} 0.68-0.83 ; \mathrm{p}<0.0001 ; 12=0 \%$. There were no apparent differences between two techniques in terms of complications. In heterogeneous populations of critically ill adults in CS and supported with VA-ECMO, the adjunct of LV unloading is associated with lower early mortality and higher rate of weaning.

Chapter 4 is an attempt to address certain mortality differences between patients undergoing ECMO for PCS; in a meta-analysis we stratified pateints based on baseline surgical status (elective/ urgent/ emergency/ salvage) and assessed its impact on short-term mortality. Twenty-two studies enrolling N=2,235 post-cardiotomy ECMO patients were found. Patients were mostly of non-emergency status (65.2\%). Overall in-hospital/30-day mortality 
was $66.7 \%$. Yet, there were no differences in in-hospital/30-day mortality with respect to baseline surgical status in the subgroup analysis. Similarly, no differences between mortality in studies enrolling $<50$ vs $\geq 50 \%$ of emergency/salvage cases was found. There was a significant positive association between increasing percentage of emergency/salvage cases and rates of: neurological complications $(p<0.001)$, limb complications $(p<0.001)$ and bleeding $(p=0.051)$. Incidence of brain death $(p=0.099)$ and sepsis $(p=0.134)$ was increased as well. We concluded that other factors than baseline surgical status may, to a higher degree, influence the mortality in patients treated with ECMO for post-cardiotomy cardiogenic shock. Baseline status, however, strongly influences the complication occurrence while on ECMO.

In Chapter 5, we again analysed data from the Extracorporeal Life Support Organization (ELSO) registry regarding outcomes of V-A ECMO for PCS in adult patients. The analyses examined trends in use, patient profiles, and in-hospital outcomes including complications. Predictors of in-hospital mortality were assessed by multivariate logistic regression. During the study period, 8,053 patients submitted to V-A ECMO for PCS were found in the ELSO Registry. There was a significant trend toward more ECMO use in recent years. Mean age was $56.3 \pm 14.9$ years and significantly increased over time. Most commonly, V-A ECMO was instituted after coronary artery bypass surgery and valvular surgery followed by heart transplantation. Overall, successful ECMO weaning occurred in 4,520 cases (56.1\%), and survival to hospital discharge was achieved in $41.4 \%$ of cases. In-hospital mortality rates remained constant over time. Kidney injury, surgical site bleeding, cardiac arrhythmias, sepsis, metabolic disorders, and neurologic complications were the most common adverse events. Higher mortality was observed after $\mathrm{CABG}$, combined $\mathrm{CABG}$ with valve and vascular aortic procedures than other indications. Better survival rates were observed in heart transplantation recipients. Age, central cannulation and occurrence of complications while on ECMO were independently associated with poorer prognosis. In conclusion, with the largest dataset ever analyzed we showed mortality rates to remained relatively constant over time despite a decrease in complications, in the setting of supporting older, higher risk patients.

Chapter 6 is a systematic review and meta-analysis of studies reporting in-hospital outcomes of V-A ECMO for PCS together with transplant status of the centre. While reported mortality rates on ECMO vary from center 
to center, aim of the current report was to assess if the outcomes differ between centres according to volume and heart transplantation status. Fifty-four studies enrolling $\mathrm{N}=4,421 \mathrm{ECMO}$ patients were included. Of those, 6 series were performed in non-HTx centres. Overall 30-day survival was $35.3 \%$ and did not statistically differ between non-HTx: $33.3 \%$ and HTx centres: $35.7 \%$. No statistical differences were seen between HTx and non-HTx with respect to ECMO duration, limb complications, reoperations for bleeding, kidney injury and sepsis. There were however significantly less neurological complications in the HTx as compared to non-HTx centres: $11.9 \%$ vs $19.5 \%$ respectively. An inverse relationship was seen for neurologic complications in centres performing more ECMOs annually. Weaning rates and bridging to HTx and/or VADs were higher in HTx facilities. We concluded that there was no apparent difference in survival after ECMO implantation for refractory PCS according to centre's ECMO volume and transplantation status; yet, potentially different risk profiles of patients in these centres must be taken account for.

Chapter 7 is a natural continuity and expanding the findings of previous analysis to non-PCS field and thus cardiogenic shock in general. The aim of the current meta-analysis was to assess the outcomes between units performing heart transplantation and/or implanting ventricular assist device (HTx/VAD) versus non-HTx/VAD units in patients undergoing V-A ECLS for cardiogenic shock. Of 174 studies enrolling $N=13,308$ patients, 20 series were performed in non-HTx/VAD centres. Majority of patients underwent V-A ECLS for postcardiotomy shock (44.2\%) and acute myocardial infarction (20.7\%). Estimated overall in-hospital mortality was $57.2 \%$ but mortality rates were higher in non-HTxNAD: $65.5 \%$ as compared to HTx/VAD centres: $55.8 \%$; $P<0.001$. No differences were seen with respect to ECLS duration, limb complications, reoperations for bleeding, kidney injury and sepsis. Weaning rates were $10 \%$ higher in HTx/VAD vs non-HTx/VAD centres. Estimated rate of bridge to heart transplant was $6.6 \%$ with numerical, yet not statistically significant difference between non-HTx/VAD as compared to HTx/VAD units. 


\section{SAMENVATTING}

Hoofdstuk 2. In dit hoofdstuk hebben we het multicenter ELSO-register geanalyseerd. 2.644 patiënten $\geq 70$ jaar (1.395 [52,8\%] 70-74 jaar, 858 [32,5\%] 75-79 jaar en 391 [14,8\%] $\geq 80$ jaar) werden behandeld met VA ECMO, voor refractaire cardiogene shock als gevolg van verschillende etiologieën. De totale mortaliteit in het ziekenhuis werd geschat op 68,3\% (1.807 / 2.644 pt.) Met de hoogste ruwe sterfteciffers waargenomen in 7579 jaar. subgroep $(70,1 \%)$. Complicaties waren meestal cardiovasculair en bloeden, zonder duidelijke verschillen tussen subgroepen. Luchtwegdruk, 24 uur pH na ECMO-start, ECMO-duur en niervervangende therapie waren geassocieerd met hogere mortaliteit. Deze studie bevestigde de opmerkelijke toename van het gebruik van V-A ECMO bij ouderen met RCS. Ondanks dat de mortaliteit in het ziekenhuis hoog bleef, verklaarden we dat V-A ECMO in een dergelijke setting nog steeds overwogen zou moeten worden, zelfs bij zeer oudere patiënten, aangezien leeftijd zelf niet gekoppeld was aan verhoogde mortaliteit, terwijl verschillende voorspellers indicatie en management kunnen sturen.

Hoofdstuk 3 is een systematische review en meta-analyse van het ontladen van de linker ventrikel met venoarteriële extracorporale membraanoxygenatie voor cardiogene shock. Ik heb volwassen patiënten opgenomen uit onderzoeken die tussen januari 2000 en maart 2019 zijn gepubliceerd. De zoekopdracht werd uitgevoerd via talrijke databases. In totaal werden van 62 papers 7581 patiënten geïncludeerd, van wie 3337 (44,0\%) LVlossing gelijktijdig met VA-ECMO kregen. De totale mortaliteit in het ziekenhuis was 58,9\% (4466/7581). Een gelijktijdige strategie van LV-lossing in vergelijking met alleen ECMO was geassocieerd met $12 \%$ lager sterfterisico (RR 0,88; 95\% BI 0,82-0,93; $p<0,0001 ; 12=40 \%$ ) en 35\% hogere kans op spenen van ECMO (RR 1,$35 ; 95 \%-B \mid 1,21-1,51 ; p<0,00001 ; 12=38 \%$ ). In een analyse gestratificeerd naar setting, werd het hoogste risico op mortaliteit waargenomen in geval van een acuut myocardinfarct: $R R$ R, $75 ; 95 \%$ BI 0,68-0,83; $p<0,0001$; $12=0 \%$. Er waren geen duidelijke verschillen tussen twee technieken in termen van complicaties. In heterogene populaties van ernstig zieke volwassenen in CS en ondersteund met VA-ECMO, wordt de toevoeging van LVlossing geassocieerd met een lagere vroege mortaliteit en een hogere mate van spenen. 
Hoofdstuk 4 is een poging om bepaalde sterfteverschillen aan te pakken tussen patiënten die ECMO voor PCS ondergaan; in een meta-analyse hebben we pateints gestratificeerd op basis van de chirurgische status van de baseline (electieve / dringende / nood / berging) en de impact ervan op de mortaliteit op korte termijn beoordeeld. Er werden 22 studies gevonden met $\mathrm{N}=2.235$ ECMO-patiënten na een cardiotomie. Patiënten hadden meestal een niet-noodstatus $(65,2 \%)$. De totale mortaliteit in het ziekenhuis / 30 dagen was $66,7 \%$. Toch waren er geen verschillen in sterfte in het ziekenhuis / 30-dagen met betrekking tot de chirurgische status bij aanvang in de subgroepanalyse. Evenzo werden geen verschillen gevonden tussen mortaliteit in onderzoeken met $<50$ versus $\geq 50 \%$ van de nood- / reddingsgevallen. Er was een significant positief verband tussen toenemend percentage nood- / reddingsgevallen en het percentage van: neurologische complicaties $(p<0,001)$, complicaties van de ledematen $(p<0,001)$ en bloeding $(p=0,051)$. De incidentie van hersendood $(p=0,099)$ en sepsis $(p=0,134)$ was ook verhoogd. We concludeerden dat andere factoren dan de baseline chirurgische status, in hogere mate, de mortaliteit kunnen beïnvloeden bij patiënten die met ECMO werden behandeld voor cardiogene shock na een cardiotomie. De baselinestatus heeft echter een sterke invloed op het optreden van complicaties tijdens ECMO.

In Hoofdstuk 5 hebben we opnieuw gegevens geanalyseerd uit het register van de Extracorporeal Life Support Organization (ELSO) met betrekking tot de uitkomsten van V-A ECMO voor PCS bij volwassen patiënten. Bij de analyses werd gekeken naar trends in gebruik, patiëntprofielen en uitkomsten in het ziekenhuis, inclusief complicaties. Voorspellers van mortaliteit in het ziekenhuis werden beoordeeld door middel van multivariate logistische regressie. Tijdens de onderzoeksperiode werden 8.053 patiënten die bij V-A ECMO voor PCS waren ingediend, aangetroffen in de ELSO-registratie. Er was de afgelopen jaren een significante trend naar meer ECMO-gebruik. De gemiddelde leeftijd was 56,3 - 14,9 jaar en nam in de loop van de tijd significant toe. Meestal werd V-A ECMO ingesteld na een bypassoperatie van de kransslagader en een hartklepoperatie gevolgd door een harttransplantatie. In totaal trad succesvolle ECMO-ontwenning op in 4.520 gevallen $(56,1 \%)$, en overleving tot ontslag uit het ziekenhuis werd bereikt in $41,4 \%$ van de gevallen. Het sterftecijfer in het ziekenhuis bleef in de loop van de tijd constant. Nierletsel, bloeding op de operatieplaats, hartritmestoornissen, sepsis, stofwisselingsstoornissen en neurologische complicaties waren de meest voorkomende bijwerkingen. Een 
hogere mortaliteit werd waargenomen na $C A B G$, gecombineerd $C A B G$ met klep- en vasculaire aorta-ingrepen dan bij andere indicaties. Er werden betere overlevingspercentages waargenomen bij ontvangers van harttransplantaties. Leeftijd, centrale canulatie en het optreden van complicaties tijdens ECMO waren onafhankelijk geassocieerd met een slechtere prognose. Concluderend, met de grootste dataset die ooit is geanalyseerd, toonden we aan dat het sterftecijfer relatief constant bleef in de tijd ondanks een afname van complicaties, in de setting van het ondersteunen van oudere patiënten met een hoger risico.

Hoofdstuk 6 is een systematische review en meta-analyse van studies die de uitkomsten van V-A ECMO voor PCS in het ziekenhuis rapporteren, samen met de transplantatiestatus van het centrum. Hoewel de gerapporteerde sterftecijfers op ECMO variëren van centrum tot centrum, was het doel van het huidige rapport om te beoordelen of de uitkomsten verschillen tussen centra op basis van volume en harttransplantatiestatus. Vierenvijftig onderzoeken met $\mathrm{N}=4.421$ ECMO-patiënten werden geïncludeerd. Daarvan werden 6 series uitgevoerd in niet-HTx-centra. De totale overleving na 30 dagen was 35,3\% en verschilde statistisch niet tussen niet-HTx: 33,3\% en HTx-centra: 35,7\%. Er werden geen statistische verschillen gezien tussen HTx en niet-HTx met betrekking tot ECMO-duur, ledemaatcomplicaties, heroperaties voor bloeding, nierletsel en sepsis. Er waren echter significant minder neurologische complicaties in de HTx in vergelijking met niet-HTx-centra: respectievelijk 11,9\% versus 19,5\%. Een omgekeerd verband werd gezien voor neurologische complicaties in centra die jaarlijks meer ECMO's uitvoeren. Speencijfers en overbrugging naar HTx en / of VAD's waren hoger in HTx-faciliteiten. We concludeerden dat er geen duidelijk verschil was in overleving na ECMO-implantatie voor refractaire PCS volgens het ECMO-volume en de transplantatiestatus van het centrum; toch moet rekening worden gehouden met mogelijk verschillende risicoprofielen van patiënten in deze centra.

Hoofdstuk 7 is een natuurlijke continuïteit en uitbreiding van de bevindingen van eerdere analyses naar nietPCS-veld en dus cardiogene shock in het algemeen. Het doel van de huidige meta-analyse was om de resultaten te beoordelen tussen eenheden die een harttransplantatie uitvoeren en / of een ventriculair hulpmiddel (HTx / VAD) implanteren versus niet-HTx / VAD-eenheden bij patiënten die V-A ECLS voor cardiogene shock ondergaan. Van de 174 onderzoeken met $\mathrm{N}=13.308$ patiënten, werden 20 series uitgevoerd in niet-HTx / VAD- 
centra. De meerderheid van de patiënten onderging V-A ECLS voor postkaartiotomieschok $(44,2 \%)$ en acuut myocardinfarct (20,7\%). De geschatte totale mortaliteit in het ziekenhuis was $57,2 \%$, maar het sterftecijfer was hoger in niet-HTx / VAD-centra: 65,5\% in vergelijking met HTx / VAD-centra: 55,8\%; P <0,001. Er werden geen verschillen gezien met betrekking tot ECLS-duur, complicaties van de ledematen, heroperaties wegens bloeding, nierletsel en sepsis. De speencijfers waren 10\% hoger in HTx / VAD-centra versus niet-HTx / VADcentra. Het geschatte aantal brug-naar-harttransplantaties was 6,6\% met een numeriek, maar niet statistisch significant verschil tussen niet-HTx / VAD-eenheden in vergelijking met HTx / VAD-eenheden. 


\section{ACKNOWLEDGEMENTS}

University of Maastricht Medical Center, leading institution in medicine, research and innovation.

Prof. Dr. R. Lorusso, promotor. Dear Professor Lorusso, I am very thankful for all the support received since our first meeting in Rome 2017. Thank you for the patience, it has been a privilege preparing my doctoral thesis under your supervision. Besides, your knowledge of Italian cuisine and People only deepens my love for this country. Hopefully, this could be the starting point to a successful collaboration.

Prof. Dr. J.G. Maessen, promotor. Dear Professor Maessen, I want to thank you for the attention you reserved to this project.

Dr Elham Bidar, co-promotor, thank you for your time in reviewing my thesis and for your valuable and constructive suggestions.

Dr. P. Suwalski, Dear Prof. Suwalski first I learned from you is that nothing is done beyond what is necessary for the patient's sake, and second the patient comes first of all especially before and after his operation. Dear Prof. Suwalski, your model and the quality of your daily commitment is an essential and constant aspect of my professional activity: dedication, perseverance and sacrifice. Thank you for continuous support.

Dr. GM. Raffa and Dr PG. Malvindi, cardiac surgeons, co-authors, dearest friends. Dear Giuseppe and PG, I'm lucky to have met you during my career. Friendship and strategy will accompany us all the way. Forza!

Staff of the Clinical Department of Cardiac Surgery in Central Clinical Hospital of Ministry of Interior and Administration in Warsaw and Cardiac Surgery Department of Univeristy Hospital $\mathrm{n} 1$ in Bydgoszcz, dear 
Colleagues, Consultants, Fellows, thank you for your continuous help and your understanding and daily interactions.

Special thanks to my wife, Magdalena who is my dearest soul and to whom I always turn to in need. You are my inspiration and drive. 


\section{ABOUT THE AUTHOR}

The author of this thesis, Mariusz Kowalewski, was born on 3 Oct 1988 in Łódź, Poland. He graduated high school in Bydgoszcz and the same year was admitted to Collegium Medicum of Nicolaus Copernicus University in Toruń at the Medical Faculty. During $3^{\text {rd }}$ year he became chair of students' cardiac surgery research society involved in students' conference and workshops organization. As an exchange student he spent 1 year in Milan, Italy (mainly in Cardiac Surgery Department, Humanitas, Milano-Rozzano under Dr Giuseppe Tarelli). This is where he met PG Malvindi and GM Raffa his future collaborators and friends beyond the surgical scope. He started residency program in cardiac surgery in Bydgoszcz University Hospital shortly after returning from Milan in 2014. He defended his PhD thesis on "Effectiveness of Gentamycin Collagen Sponge in Preventing postCABG sternal wound infections" in April 2016. Several later publications will focus on preventing other postCABG complications including stroke and bleeding. With collaboration with Drs Szwed and Słomka, he investigated the impact of different surgical techniques of off-pump CABG on the incidence of neurological events both clinically evident and silent as with biomarkers for neuronal damage. He took part in conception and design of Carbon Dioxide Surgical Field Flooding and Aortic No-touch Off-pump Coronary Artery Bypass Grafting to Reduce Neurological Injuries After Surgical Coronary Revascularization (CANON) trial. After moving to Warsaw and began collaboration with Prof Dr Piotr Suwalski, president of International Society of Minimally Invasive Cardiothoracic Surgery his particular interest switched to minimally invasive techniques in cardiac surgery and atrial fibrillation. In parallel, however, he was extending his research network to European and American centres. With a few of his friends and research partners he founded Thoracic Research Centre, a platform designed to promote research and evidence-based medicine approach in Cardiothoracic Surgery. Among a number of invited congress prelections, at one in Rome (SICCH), he met Prof Dr Roberto Lorusso who invited him to extend the area of interest to extracorporeal life support. After completion of several projects he begun the $\mathrm{PhD}$ in Maastricht University with the purpose of identifying factors determining high on-ECMO mortality in high risk individuals and complex clinical scenarios. He is married to Magdalena Kowalkowska, a gynecologist and esthetic medicine consultant, and has a son Vincent (12 months now). Surgical interests include minimally invasive aortic root and arch surgery, high risk cardiac surgery w/wo prophylactic ECMO, 
minimizing neurological complications in CABG. Research interests are epidemiological studies on efficacy and safety of heart surgery in patients with underlying atrial fibrillation. Interest not related to work include speed alpine skiing, high altitude mountaineering, ice climbing and moto racing. He is a wine and food lover. 


\section{LIST OF PUBLICATIONS}

1. Fina D, Matteucci M, Jiritano F, Meani P, Lo Coco V, Kowalewski M, Maessen J, Guazzi M, Ballotta A, Ranucci M, Lorusso R. Extracorporeal membrane oxygenation without therapeutic anticoagulation in adults: A systematic review of the current literature. Int J Artif Organs. 2020:391398820904372

2. Gozdek M, Kowalewski M, Ruchalski M, Malvindi PG, Anisimowicz L. Mortality benefit after reinforced reduction aortoplasty for dilated ascending aorta. Meta-analysis. Int J Cardiol. 2015;199:50-52

3. Gozdek M, Pawliszak W, Hagner W, Zalewski P, Kowalewski J, Paparella D, Carrel T, Anisimowicz L, Kowalewski M. Systematic review and meta-analysis of randomized controlled trials assessing safety and efficacy of posterior pericardial drainage in patients undergoing heart surgery. J Thorac Cardiovasc Surg. $2017 ; 153: 865-875$ e812

4. Gozdek M, Raffa GM, Suwalski P, Kolodziejczak M, Anisimowicz L, Kubica J, Navarese EP, Kowalewski M, group S-T. Comparative performance of transcatheter aortic valve-in-valve implantation versus conventional surgical redo aortic valve replacement in patients with degenerated aortic valve bioprostheses: Systematic review and meta-analysis. Eur J Cardiothorac Surg. 2018;53:495-504

5. Gozdek M, Ratajczak J, Arndt A, Zielinski K, Pasierski M, Matteucci M, Fina D, Jiritano F, Meani P, Raffa GM, Malvindi PG, Pilato M, Paparella D, Slomka A, Landes U, Kornowski R, Kubica J, Lorusso R, Suwalski P, Kowalewski M, Thoracic Research C. Transcatheter aortic valve replacement with lotus and sapien 3 prosthetic valves: A systematic review and meta-analysis. J Thorac Dis. 2020;12:893-906

6. Gozdek M, Zielinski K, Pasierski M, Matteucci M, Fina D, Jiritano F, Meani P, Raffa GM, Malvindi PG, Pilato M, Paparella D, Slomka A, Kubica J, Jagielak D, Lorusso R, Suwalski P, Kowalewski M. Transcatheter aortic valve replacement with self-expandable acurate neo as compared to balloon-expandable sapien 3 in patients with severe aortic stenosis: Meta-analysis of randomized and propensity-matched studies. J. Clin. Med. 2020, 9, 397. J Clin Med. 2020;9

7. Gozdek M, Zielinski K, Pasierski M, Matteucci M, Fina D, Jiritano F, Meani P, Raffa GM, Malvindi PG, Pilato M, Paparella D, Slomka A, Kubica J, Jagielak D, Lorusso R, Suwalski P, Kowalewski M. Transcatheter aortic valve replacement with self-expandable acurate neo as compared to balloon-expandable sapien 3 in 
patients with severe aortic stenosis: Meta-analysis of randomized and propensity-matched studies. J Clin Med. $2020 ; 9$

8. Kolodziejczak M, Andreotti F, Kowalewski M, Buffon A, Ciccone MM, Parati G, Scicchitano P, Uminska JM, De Servi S, Bliden KP, Kubica J, Bortone A, Crea F, Gurbel P, Navarese EP. Implantable cardioverterdefibrillators for primary prevention in patients with ischemic or nonischemic cardiomyopathy: A systematic review and meta-analysis. Ann Intern Med. 2017;167:103-111

9. Kowalewski J, Kowalewski M, Wnuk P. Early stage lung cancer with nodal involvement occult to pet-ct: Treat the image or treat the disease? J Thorac Dis. 2015;7:E615-618

10. Kowalewski M, Fina D, Slomka A, Raffa GM, Martucci G, Lo Coco V, De Piero ME, Ranucci M, Suwalski P, Lorusso R. Covid-19 and ecmo: The interplay between coagulation and inflammation-a narrative review. Crit Care. 2020;24:205

11. Kowalewski M, Gozdek M, Hagner W, Anisimowicz L. Posterior pericardial drainage by any means may improve outcomes after cardiac surgery. J Thorac Cardiovasc Surg. 2017;154:512-514

12. Kowalewski M, Gozdek M, Raffa GM, Slomka A, Zielinski K, Kubica J, Anisimowicz L, Kowalewski J, Landes U, Kornowski R, Lorusso R, Suwalski P. Transcathether aortic valve implantation with the new repositionable self-expandable medtronic evolut $r$ vs. Corevalve system: Evidence on the benefit of a metaanalytical approach. J Cardiovasc Med (Hagerstown). 2019;20:226-236

13. Kowalewski M, Gozdek M, Zielinski K, Raffa GM, Suwalski P, Lorusso R. Long-term mortality following pci with des compared with cabg for multivessel and left main disease: A meta-analysis. Kardiol Pol. 2020

14. Kowalewski M, Jasinski M, Staromlynski J, Zembala M, Widenka K, Brykczynski M, Skiba J, Zembala M, Bartus K, Hirnle T, Dziembowska I, Knapik P, Tobota Z, Maruszewski B, Suwalski P, Investigators K. Onpump vs off-pump coronary artery bypass surgery in atrial fibrillation. Analysis from the polish national registry of cardiac surgery procedures (krok). PLoS One. 2020;15:e0231950 - pozycja wymieniona w pkt 1.2.

15. Kowalewski M, Jasinski M, Staromlynski J, Zembala M, Widenka K, Zembala MO, Bartus K, Hirnle T, Dziembowska I, Knapik P, Deja M, Wierzba W, Tobota Z, Maruszewski BJ, Suwalski P. Long-term survival following surgical ablation for atrial fibrillation concomitant to isolated and combined coronary artery bypass 
surgery-analysis from the polish national registry of cardiac surgery procedures (krok). J Clin Med. 2020;9 pozycja wymieniona w pkt 1.2.

16. Kowalewski M, Malvindi PG, Suwalski P, Raffa GM, Pawliszak W, Perlinski D, Kowalkowska ME, Kowalewski J, Carrel T, Anisimowicz L. Clinical safety and effectiveness of endoaortic as compared to transthoracic clamp for small thoracotomy mitral valve surgery: Meta-analysis of observational studies. Ann Thorac Surg. 2017;103:676-686

17. Kowalewski M, Malvindi PG, Zielinski K, Martucci G, Slomka A, Suwalski P, Lorusso R, Meani P, Arcadipane A, Pilato M, Raffa GM. Left ventricle unloading with veno-arterial extracorporeal membrane oxygenation for cardiogenic shock. Systematic review and meta-analysis. J Clin Med. 2020;9

18. Kowalewski M, Pawliszak W, Kolodziejczak M, Navarese EP, Anisimowicz L. 30-day mortality reduction with miniaturized extracorporeal circulation as compared to conventional cardiopulmonary bypass for coronary revascularization. Meta-analysis of randomized controlled trials. Int J Cardiol. 2015;198:63-65

19. Kowalewski M, Pawliszak W, Malvindi PG, Bokszanski MP, Perlinski D, Raffa GM, Kowalkowska ME, Zaborowska K, Navarese EP, Kolodziejczak M, Kowalewski J, Tarelli G, Taggart DP, Anisimowicz L. Off-pump coronary artery bypass grafting improves short-term outcomes in high-risk patients compared with on-pump coronary artery bypass grafting: Meta-analysis. J Thorac Cardiovasc Surg. 2016;151:60-77 e61-58

20. Kowalewski M, Pawliszak W, Raffa GM, Malvindi PG, Kowalkowska ME, Zaborowska K, Kowalewski J, Tarelli G, Taggart DP, Anisimowicz L. Safety and efficacy of miniaturized extracorporeal circulation when compared with off-pump and conventional coronary artery bypass grafting: Evidence synthesis from a comprehensive bayesian-framework network meta-analysis of 134 randomized controlled trials involving 22778 patients. Eur J Cardiothorac Surg. 2016;49:1428-1440

21. Kowalewski M, Pawliszak W, Zaborowska K, Navarese EP, Szwed KA, Kowalkowska ME, Kowalewski J, Borkowska A, Anisimowicz L. Gentamicin-collagen sponge reduces the risk of sternal wound infections after heart surgery: Meta-analysis. J Thorac Cardiovasc Surg. 2015;149:1631-1640 e1631-1636

22. Kowalewski M, Raffa G, Zielinski K, Meani P, Alanazi M, Gilbers M, Heuts S, Natour E, Bidar E, Schreurs R, Delnoij T, Driessen R, Sels JW, van de Poll M, Roekaerts P, Maessen J, Suwalski P, Lorusso R. Baseline 
surgical status and short-term mortality after extracorporeal membrane oxygenation for post-cardiotomy shock: A meta-analysis. Perfusion. 2020;35:246-254

23. Kowalewski M, Raffa GM, Lorusso R, Anisimiowicz L, Lazar HL, Suwalski P. Vancomycin paste in sternal wound infection prophylaxis-a genuine debate or futile attempts to justify flawed study? J Thorac Cardiovasc Surg. 2018;156:1128-1130

24. Kowalewski M, Raffa GM, Szwed KA, Anisimowicz L. Meta-analysis to assess the effectiveness of topically used vancomycin in reducing sternal wound infections after cardiac surgery. J Thorac Cardiovasc Surg. 2017; 154:1320-1323 e1323

25. Kowalewski M, Raffa GM, Zielinski K, Alanazi M, Gilbers M, Heuts S, Natour E, Bidar E, Schreurs R, Delnoij T, Driessen R, Sels JW, van de Poll M, Roekaerts P, Meani P, Maessen J, Suwalski P, Lorusso R. The impact of centre's heart transplant status and volume on in-hospital outcomes following extracorporeal membrane oxygenation for refractory post-cardiotomy cardiogenic shock: A meta-analysis. BMC Cardiovasc Disord. 2020;20:10

26. Kowalewski M, Schulze V, Berti S, Waksman R, Kubica J, Kolodziejczak M, Buffon A, Suryapranata H, Gurbel PA, Kelm M, Pawliszak W, Anisimowicz L, Navarese EP. Complete revascularisation in st-elevation myocardial infarction and multivessel disease: Meta-analysis of randomised controlled trials. Heart. $2015 ; 101: 1309-1317$

27. Kowalewski M, Suwalski P, Pawliszak W, Benetti F, Raffa GM, Malvindi PG, Carrel T, Paparella D, Anisimowicz L. Risk of stroke with "no-touch" - as compared to conventional off-pump coronary artery bypass grafting. An updated meta-analysis of observational studies. Int J Cardiol. 2016;222:769-771

28. Kowalewski M, Suwalski P, Raffa GM, Slomka A, Kowalkowska ME, Szwed KA, Borkowska A, Kowalewski J, Malvindi PG, Undas A, Windyga J, Pawliszak W, Anisimowicz L, Carrel T, Paparella D, Lip GYH. Meta-analysis of uninterrupted as compared to interrupted oral anticoagulation with or without bridging in patients undergoing coronary angiography with or without percutaneous coronary intervention. Int J Cardiol. 2016;223:186-194 
29. Lo Coco V, Lorusso R, Raffa GM, Malvindi PG, Pilato M, Martucci G, Arcadipane A, Zielinski K, Suwalski P, Kowalewski M. Clinical complications during veno-arterial extracorporeal membrane oxigenation in postcardiotomy and non post-cardiotomy shock: Still the achille's heel. J Thorac Dis. 2018;10:6993-7004

30. Lorusso R, Raffa GM, Alenizy K, Sluijpers N, Makhoul M, Brodie D, McMullan M, Wang IW, Meani P, MacLaren G, Kowalewski M, Dalton H, Barbaro R, Hou X, Cavarocchi N, Chen YS, Thiagarajan R, Alexander P, Alsoufi B, Bermudez CA, Shah AS, Haft J, D'Alessandro DA, Boeken U, Whitman GJR. Structured review of post-cardiotomy extracorporeal membrane oxygenation: Part 1-adult patients. J Heart Lung Transplant. $2019 ; 38: 1125-1143$

31. Lorusso R, Raffa GM, Kowalewski M, Alenizy K, Sluijpers N, Makhoul M, Brodie D, McMullan M, Wang IW, Meani P, MacLaren G, Dalton H, Barbaro R, Hou X, Cavarocchi N, Chen YS, Thiagarajan R, Alexander P, Alsoufi B, Bermudez CA, Shah AS, Haft J, Oreto L, D'Alessandro DA, Boeken U, Whitman G. Structured review of post-cardiotomy extracorporeal membrane oxygenation: Part 2-pediatric patients. J Heart Lung Transplant. 2019;38:1144-1161

32. Malvindi PG, Mastro F, Kowalewski M, Ringold M, Margari V, Suwalski P, Speziale G, Paparella D. Durability of mitral valve bioprostheses: A meta-analysis of long-term follow-up studies. Ann Thorac Surg. 2020;109:603-611

33. Maruszewski M, Smoczynski R, Kowalewski M, Bartczak M, Witkowska A, Staromlynski J, Drobinski D, Kujawski M, Suwalski P. Pilot study of totally thoracoscopic periareolar approach for minimally invasive mitral valve surgery. Towards even less invasive? Wideochir Inne Tech Maloinwazyjne. 2019;14:326-332

34. Matteucci M, Fina D, Jiritano F, Blankesteijn WM, Raffa GM, Kowalewski M, Beghi C, Lorusso R. Corrigendum to: 'Sutured and sutureless repair of postinfarction left ventricular free-wall rupture: A systematic review' [eur j cardiothorac surg; doi:10.1093/ejcts/ezz101]. Eur J Cardiothorac Surg. 2019;56:1023

35. Matteucci M, Fina D, Jiritano F, Blankesteijn WM, Raffa GM, Kowalewski M, Beghi C, Lorusso R. Sutured and sutureless repair of postinfarction left ventricular free-wall rupture: A systematic review. Eur J Cardiothorac Surg. 2019;56:840-848 
36. Matteucci M, Kowalewski M, Fina D, Jiritano F, Meani P, Raffa GM, Aldobayyan I, Beghi C, Maessen J, Lorusso R. Extracorporeal life support for phaeochromocytoma-induced cardiogenic shock: A systematic review. Perfusion. 2020;35:20-28

37. Meani P, Matteucci M, Jiritano F, Fina D, Panzeri F, Raffa GM, Kowalewski M, Morici N, Viola G, Sacco A, Oliva F, Alyousif A, Heuts S, Gilbers M, Schreurs R, Maessen J, Lorusso R. Long-term survival and major outcomes in post-cardiotomy extracorporeal membrane oxygenation for adult patients in cardiogenic shock. Ann Cardiothorac Surg. 2019;8:116-122

38. Navarese E, Kowalewski M. Complete versus culprit-only revascularisation for st-segment elevation myocardial infarction. Heart. 2016;102:1335-1336

39. Navarese EP, Andreotti F, Kolodziejczak M, Schulze V, Wolff G, Dias S, Claessen B, Brouwer M, Tarantini G, lliceto S, Brockmeyer M, Kowalewski M, Lin Y, Eikelboom J, Musumeci G, Lee L, Lip GY, Valgimigli M, Berti S, Kelm M. Comparative efficacy and safety of anticoagulant strategies for acute coronary syndromes. Comprehensive network meta-analysis of 42 randomised trials involving 117,353 patients. Thromb Haemost. 2015;114:933-944

40. Navarese EP, Andreotti F, Schulze V, Kolodziejczak M, Buffon A, Brouwer M, Costa F, Kowalewski M, Parati G, Lip GY, Kelm M, Valgimigli M. Optimal duration of dual antiplatelet therapy after percutaneous coronary intervention with drug eluting stents: Meta-analysis of randomised controlled trials. BMJ. 2015;350:h1618

41. Navarese EP, Gurbel PA, Andreotti F, Kolodziejczak MM, Palmer SC, Dias S, Buffon A, Kubica J, Kowalewski M, Jadczyk T, Laskiewicz M, Jedrzejek M, Brockmeyer M, Airoldi F, Ruospo M, De Servi S, Wojakowski W, C OC, Strippoli GF. Prevention of contrast-induced acute kidney injury in patients undergoing cardiovascular procedures-a systematic review and network meta-analysis. PLoS One. 2017;12:e0168726

42. Navarese EP, Kowalewski M, Andreotti F, van Wely M, Camaro C, Kolodziejczak M, Gorny B, Wirianta J, Kubica J, Kelm M, de Boer MJ, Suryapranata H. Meta-analysis of time-related benefits of statin therapy in patients with acute coronary syndrome undergoing percutaneous coronary intervention. Am J Cardiol. 2014;113:1753-1764 
43. Navarese EP, Kowalewski M, Cortese B, Kandzari D, Dias S, Wojakowski W, Buffon A, Lansky A, Angelini P, Torguson R, Kubica J, Kelm M, de Boer MJ, Waksman R, Suryapranata H. Short and long-term safety and efficacy of polymer-free vs. Durable polymer drug-eluting stents. A comprehensive meta-analysis of randomized trials including 6178 patients. Atherosclerosis. 2014;233:224-231

44. Navarese EP, Kowalewski M, Kandzari D, Lansky A, Gorny B, Koltowski L, Waksman R, Berti S, Musumeci G, Limbruno U, van der Schaaf RJ, Kelm M, Kubica J, Suryapranata H. First-generation versus second-generation drug-eluting stents in current clinical practice: Updated evidence from a comprehensive meta-analysis of randomised clinical trials comprising 31379 patients. Open Heart. 2014;1:e000064

45. Navarese EP, Kowalewski M, Suryapranata H. Percutaneous coronary intervention vs medical treatment in stable angina: The never-ending story. JAMA Intern Med. 2014;174:1199-1200

46. Navarese EP, Robinson JG, Kowalewski M, Kolodziejczak M, Andreotti F, Bliden K, Tantry U, Kubica J, Raggi P, Gurbel PA. Association between baseline Idl-c level and total and cardiovascular mortality after Idl-c lowering: A systematic review and meta-analysis. JAMA. 2018;319:1566-1579

47. Navarese EP, Schulze V, Andreotti F, Kowalewski M, Kolodziejczak M, Kandzari DE, Rassaf T, Gorny B, Brockmeyer M, Meyer C, Berti S, Kubica J, Kelm M, Valgimigli M. Comprehensive meta-analysis of safety and efficacy of bivalirudin versus heparin with or without routine glycoprotein iib/iiia inhibitors in patients with acute coronary syndrome. JACC Cardiovasc Interv. 2015;8:201-213

48. Navarese EP, Tandjung K, Claessen B, Andreotti F, Kowalewski M, Kandzari DE, Kereiakes DJ, Waksman R, Mauri L, Meredith IT, Finn AV, Kim HS, Kubica J, Suryapranata H, Aprami TM, Di Pasquale G, von Birgelen C, Kedhi E. Safety and efficacy outcomes of first and second generation durable polymer drug eluting stents and biodegradable polymer biolimus eluting stents in clinical practice: Comprehensive network metaanalysis. BMJ. 2013;347:f6530

49. Navarese EP, Tarantini G, Musumeci G, Napodano M, Rossini R, Kowalewski M, Szczesniak A, Kolodziejczak M, Kubica J. Manual vs mechanical thrombectomy during pci for stemi: A comprehensive direct and adjusted indirect meta-analysis of randomized trials. Am J Cardiovasc Dis. 2013;3:146-157 
50. Obonska K, Navarese EP, Lansky A, Tarantini G, Rossini R, Kozinski M, Musumeci G, Di Pasquale G, Gorny B, Szczesniak A, Kowalewski M, Gurbel PA, Kubica J. Low-dose of oral factor xa inhibitors in patients with a recent acute coronary syndrome: A systematic review and meta-analysis of randomized trials. Atherosclerosis. 2013;229:482-488

51. Pasierski M, Zielinski K, Raffa GM, Lazar H, Lorusso R, Suwalski P, Kowalewski M. Devil is in the detailhow to critically analyze studies designed to assess effectiveness of topical antibiotics in preventing sternal wound infections? J Thorac Dis. 2019;11:S1861-S1864

52. Pawliszak W, Kowalewski M, Anisimowicz L. Off-pump versus on-pump coronary artery bypass grafting: Who benefits? J Thorac Cardiovasc Surg. 2015;150:1666-1668

53. Pawliszak W, Kowalewski M, Raffa GM, Malvindi PG, Kowalkowska ME, Szwed KA, Borkowska A, Kowalewski J, Anisimowicz L. Cerebrovascular events after no-touch off-pump coronary artery bypass grafting, conventional side-clamp off-pump coronary artery bypass, and proximal anastomotic devices: A meta-analysis. J Am Heart Assoc. 2016;5

54. Pawliszak W, Szwed K, Slomka A, Piekus-Slomka N, Szwed M, Kowalewski M, Zekanowska E, Borkowska A. Three-vessel coronary artery disease may predict changes in biochemical brain injury markers after off-pump coronary artery bypass grafting(). J Zhejiang Univ Sci B. 2018;19:735-738

55. Pawliszak W, Szwed K, Szwed M, Kowalewski M, Bielinski M, Piskunowicz M, Sukiennik A, Zaborowska $\mathrm{K}$, Anisimowicz L, Borkowska A. Predictive value of the syntax score for short-term cognitive outcomes after offpump coronary artery bypass surgery. Int J Cardiol. 2016;209:9-11

56. Raffa GM, Kowalewski M, Brodie D, Ogino M, Whitman G, Meani P, Pilato M, Arcadipane A, Delnoij T, Natour E, Gelsomino S, Maessen J, Lorusso R. Meta-analysis of peripheral or central extracorporeal membrane oxygenation in postcardiotomy and non-postcardiotomy shock. Ann Thorac Surg. 2019;107:311-321

57. Raffa GM, Kowalewski M, Malvindi PG, Bertani A, Romano G, Sciacca S, Turrisi M, Armaro A, Stringi V, Montalbano G, Mattiucci G, Follis F, Pilato M. Aortic surgery in marfan patients with severe pectus excavatum. J Cardiovasc Med (Hagerstown). 2017;18:305-310 
58. Raffa GM, Kowalewski M, Meani P, Follis F, Martucci G, Arcadipane A, Pilato M, Maessen J, Lorusso R, Group EiTI. In-hospital outcomes after emergency or prophylactic veno-arterial extracorporeal membrane oxygenation during transcatheter aortic valve implantation: A comprehensive review of the literature. Perfusion. 2019;34:354-363

59. Raffa GM, Malvindi PG, Kowalewski M, Sansone F, Menicanti L. Training in coronary artery bypass surgery: Tips and tricks of the trade. Semin Thorac Cardiovasc Surg. 2017;29:137-142

60. Slomka A, Kowalewski M, Zekanowska E, Suwalski P, Lorusso R, Eikelboom JW. Plasma levels of protein $z$ in ischemic stroke: A systematic review and meta-analysis. Thromb Haemost. 2020;120:815-822

61. Slomka A, Kowalewski M, Zekanowska E. Coronavirus disease 2019 (covid-19): A short review on hematological manifestations. Pathogens. 2020;9

62. Slomka A, Piekus A, Kowalewski M, Pawliszak W, Anisimowicz L, Zekanowska E. Assessment of the procoagulant activity of microparticles and the protein z system in patients undergoing off-pump coronary artery bypass surgery. Angiology. 2018;69:347-357

63. Suwalski P, Kowalewski M, Jasinski M, Staromlynski J, Zembala M, Widenka K, Brykczynski M, Skiba J, Zembala MO, Bartus K, Hirnle T, Dziembowska I, Deja M, Tobota Z, Maruszewski BJ. Surgical ablation for atrial fibrillation during isolated coronary artery bypass surgery. Eur J Cardiothorac Surg. 2020;57:691-700 pozycja wymieniona w pkt 1.2 .

64. Suwalski P, Kowalewski M, Jasinski M, Staromlynski J, Zembala M, Widenka K, Brykczynski M, Skiba J, Zembala MO, Bartus K, Hirnle T, Dziembowska I, Tobota Z, Maruszewski BJ, Investigators K. Survival after surgical ablation for atrial fibrillation in mitral valve surgery: Analysis from the polish national registry of cardiac surgery procedures (krok). J Thorac Cardiovasc Surg. 2018 - pozycja wymieniona w pkt 1.2.

65. Szczesniak A, Gorny B, Kowalewski M, Kolodziejczak M, Kotlarek N. Things to avoid in meta-analysis. Eur J Prev Cardiol. 2013;20:513

66. Wnuk P, Kowalewski M, Malkowski B, Bella M, Dancewicz M, Szczesny T, Blawat P, Kowalewski J. Petct derived artificial neural network can predict mediastinal lymph nodes metastases in non-small cell lung cancer patients. Preliminary report and scoring model. Q J Nucl Med Mol Imaging. 2014 
67. Zielinski K, Koltowski L, Kalinczuk L, Mintz GS, Kochman J, Witkowski A, Pregowski J, Motyl D, Lorusso R, Suwalski P, Kowalewski M. Inhospital outcomes of rotational versus orbital atherectomy during percutaneous coronary intervention: A metaanalysis. Kardiol Pol. 2019;77:846-852 


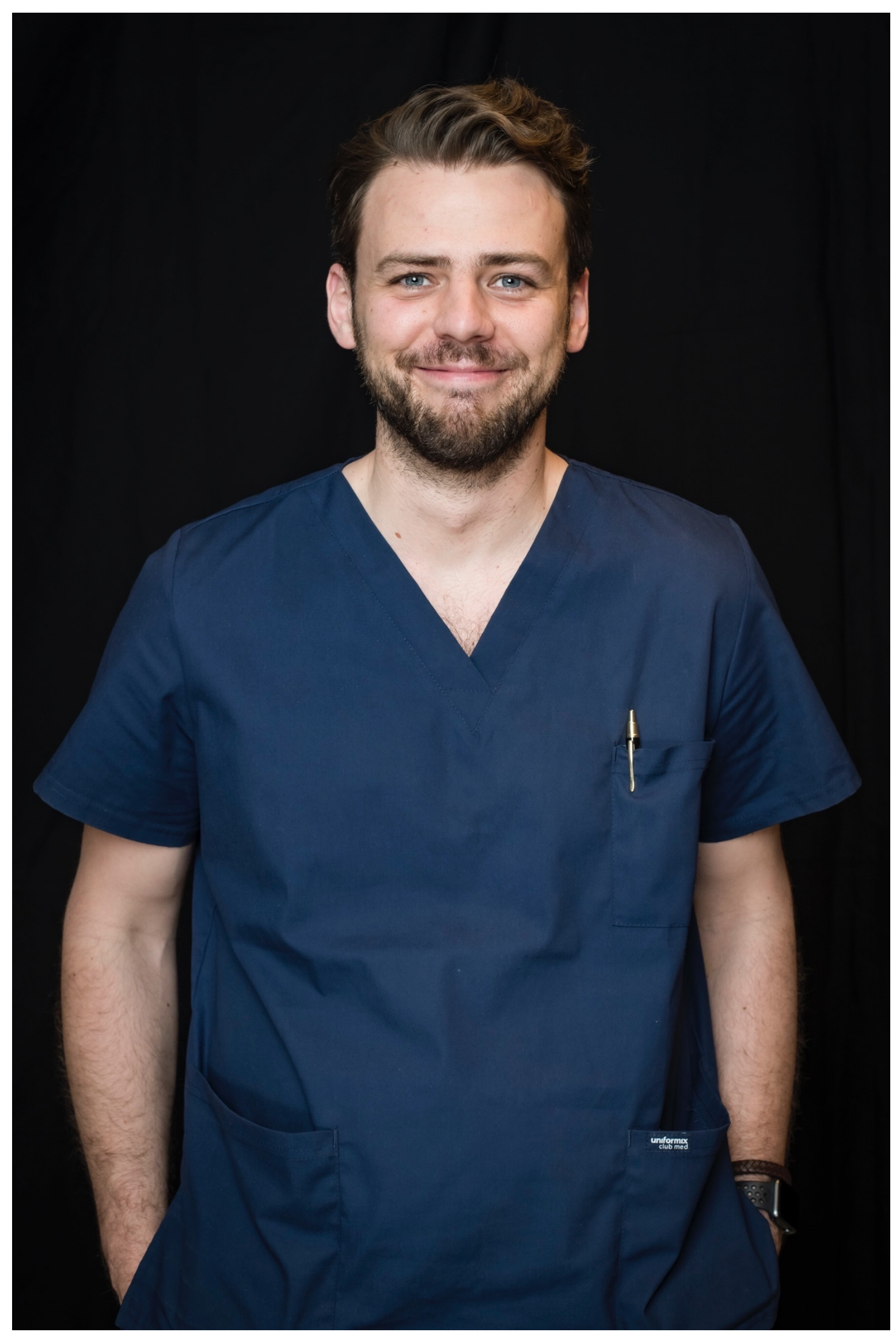


